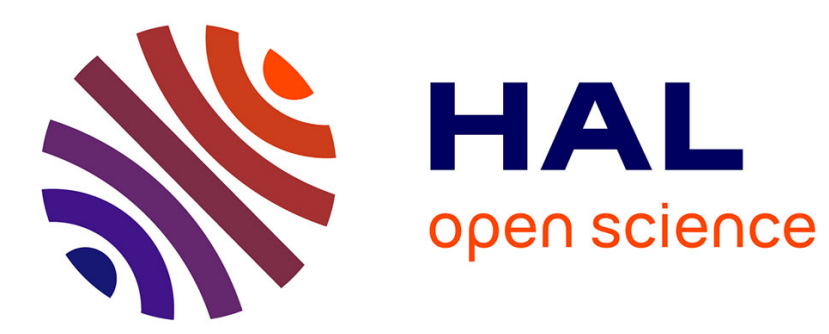

\title{
Paisajes Agrarios de Michoacán
}

Hubert Cochet, Eric Léonard, Jean Damien de Surgy

\section{To cite this version:}

Hubert Cochet, Eric Léonard, Jean Damien de Surgy. Paisajes Agrarios de Michoacán. 1988, $10.2307 / 2516470$. hal-02534545

\section{HAL Id: hal-02534545 \\ https://hal.science/hal-02534545}

Submitted on 18 Jun 2020

HAL is a multi-disciplinary open access archive for the deposit and dissemination of scientific research documents, whether they are published or not. The documents may come from teaching and research institutions in France or abroad, or from public or private research centers.
L'archive ouverte pluridisciplinaire HAL, est destinée au dépôt et à la diffusion de documents scientifiques de niveau recherche, publiés ou non, émanant des établissements d'enseignement et de recherche français ou étrangers, des laboratoires publics ou privés. 


\section{Paisajes Agrarios de Michoacán}

Book in Hispanic American Historical Review · February 1991

DOl: $10.2307 / 2516470$

\section{CITATION}

1

3 authors, including:

Hubert Cochet

AgroParisTech

112 PUBLICATIONS 720 CITATIONS

SEE PROFILE
READS

61

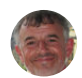

Eric Léonard

Institute of Research for Development

117 PUBLICATIONS 480 CITATIONS

SEE PROFILE

Some of the authors of this publication are also working on these related projects:

Propocid. The production of sustainable rural development policies in their contextes View project

LA PRIVATIZACIÓN DE LA PROPIEDAD SOCIAL EN MÉXICO. (I)LEGALIDAD Y (I)LEGITIMIDAD SOCIAL DE LA ENAJENACIÓN DE TIERRAS EJIDALES EN UN CONTEXTO NEOLIBERAL View project 


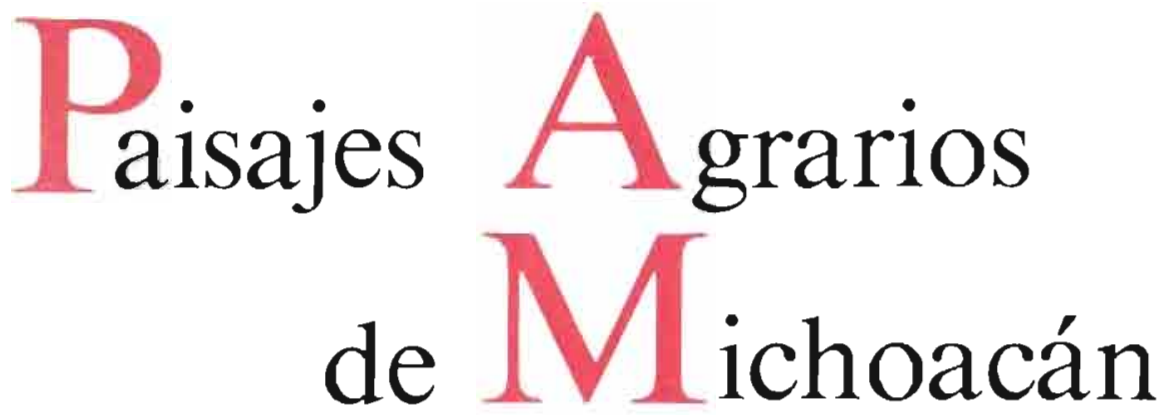

Hubert Cochet Eric Léonard Jean Damien de Surgy
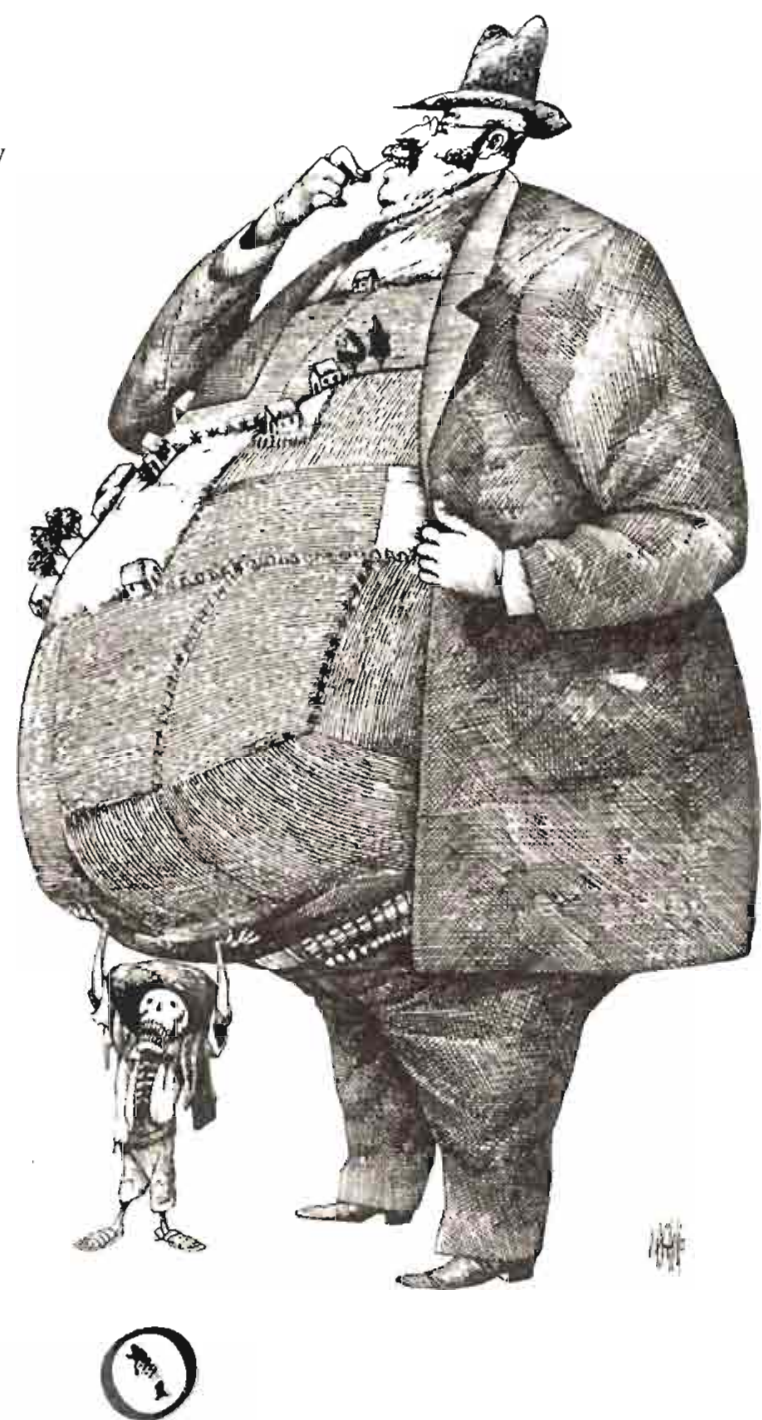

Paisajes $\mathbf{M g r a r i o s}_{\text {de }} \mathbf{M}_{\text {ichoacán }}$ 



\section{Paisajes Agrarios de $\mathbf{M}$ ichoacán}

Hubert Cochet

Eric Léonard

Jean Damien de Surgy

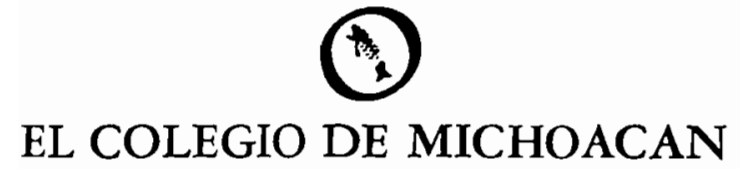


Cuidado de la edición:

Guadalupe Noriega Elío, Eric Léonard, José Luis Domínguez y Abelardo Aldama

Diseño portada: Rogelio Naranjo

- El Colegio de Michoacán, 1988

Martínez de Navarrete \# 505

Esq. Av. del Arbol

59690 Zamora, Mich.

Impreso y hecho en México

Printed and made in Mexico 

Este libro se editó en buena medida gracias a la aportación del Centre Scientifique et Tech nique de l'Ambassade de France au Mexique. 



\section{INTRODUCCION}

Las grandes transformaciones del agro mexicano ponen de relieve el carácter discriminatorio del tipo de desarrollo agropecuario que se ha seguido a lo largo de los últimos cuatro decenios.

El énfasis puesto en el fomento de la agroexportación en los años cincuenta y sesenta se tradujo en la implementación de una modernización selectiva de la agricultura. Instauró rápidamente una división del trabajo asentada en una estructura agraria dual, tanto en lo que concierne al acceso a los recursos, como a los medios de producción y a los mercados. El abasto del mercado externo conforma así el verdadero polo dinamizador de la agricultura nacional. Para los productores e intermediarios significa el acceso a rentas sumamente elevadas. Para la economía nacional, garantiza el acceso a las divisas, indispensable para alimentar la industrialización. Lógicamente, el esfuerzo productivo - inversión pública y privada, extensión espectacular de las cuencas de riego, difusión del cambio tecnológico- se canaliza en gran parte hacia el fomento de las exportaciones agropecuarias. Desde luego, esta dinámica implica cambios que distan mucho de ser uniformes u homogéneos. Las transformaciones agrícolas benefician casi exclusivamente a la agricultura capitalista o neolatifundista mejor adaptada social y económicamente a la integración de los cambios tecnológicos.

Si bien la agricultura campesina queda marginada, no deja por tanto de desempeñar un papel sumamente importante en la dinámica de acumulación. Se encierra cada vez más en sus funciones de proveedora de bienes-salario (alimentos básicos) y de reserva de mano de obra barata. Se trata de dos funciones esenciales que la agricultura campesina asume con dificultades crecientes desde principios de los años sesentas.

A raíz de la disminución de los precios de garantía, los ingresos campesinos se deterioran en forma progresiva. El crecimiento demográfico, pero también la pauperización y marginación crecientes del medio rural, alimentan flujos migratorios incontrolables hacia las ciudades y hacia los Estados Unidos. El agotamiento de la Reforma Agraria a mediados de los 
años sesenta agudiza esta evolución. La base territorial de la agricultura campesina no puede seguir expandiéndose, lo que pone en peligro la estabilidad política del país y su seguridad alimenticia.

Así, la superficie cultivada de maíz entra en 1966 en un período de estancamiento que no tarda en convertirse, a mediados de los setentas, en una notable disminución de la oferta de alimentos básicos. Esta no puede ajustarse a la expansión demográfica: desde 1970, México importa anualmente alrededor de la cuarta parte del maíz que consume. Con el agotamiento de la Reforma Agraria, se debilita también una importante base de control político del campo: los años setenta se caracterizan por una notable inestabilidad política del agro.

A lo largo de los años setentas y principios de los ochentas se da una serie de ajustes al modelo de desarrollo seguido hasta entonces.

La intervención del estado se extiende progresivamente a la agricultura de temporal. Se publican en 1972 las primeras enmiendas a la ley de Reforma Agraria destinadas a fomentar la organización de productores. El Departamento Agrario se convierte en Secretaría de Reforma Agraria, en torno a la cual se van estructurando durante un tiempo, las políticas agrarias y agrícolas. Pero el giro dado a las políticas agrícolas cobra realmente sentido a partir de 1976-1977. Se integran en la SARH, las antiguas Secretarías de Agricultura y Ganadería y de Recursos Hidraúlicos y se reestructura el crédito agrícola con la creación del BANRURAL.

Sin poner en duda la importancia de estos ajustes, es preciso recalcar que no corresponden a una redefinición del modelo de desarrollo agropecuario. Las políticas agrícolas se asientan en las mismas opciones tecnológicas, directamente inspiradas del modelo tecnológico occidental. ${ }^{1} \mathrm{Si}$ el estado brinda ahora un apoyo marcado a las áreas temporales y a la agricultura campesina, su proyecto de modernización se reduce a una difusión de la Revolución Verde en contextos que no se prestan siempre a su aplicación. Si el fomento del crédito agrícola y de la organización de los productores permite franquear un umbral importante, la intervención del estado no deja de ser sumamente discriminatoria: tiende invariablemente a canalizar sus recursos hacia los sectores sociales y las regiones cuyo "potencial de desarrollo" se juzga más elevado: campesinos acomodados, regiones más fértiles o mejor comunicadas.

Sobre todo, el papel asignado a la agricultura campesina en la división del trabajo no se cuestiona en nada. Las opciones tecnológicas que difunde el estado consolidan un movimiento de especialización que coloca a las unidades domésticas de producción en una situación cada vez más frágil. La agricultura capitalista sigue gozando de un monopolio de los mercados más

1. Basada en un consumo sistemático de insumos y medios de producción de origen industrial en sustitución de recursos locales. 
dinámicos que se extiende ahora mediante una competencia directa y desigual en relación a la agricultura campesina.

La expansión urbana y el reforzamiento de las clases medias han dado un fuerte impulso a la difusión de hábitos de consumo de tipo occidental, con un elevado contenido de alimentos de origen animal, de vegetales frescos y de alimentos industrializados. Se definen así nuevos mercados en torno a los cuales tiende a estructurarse la agricultura. Los cultivos forrajeros -especialmente el sorgo-, la avicultura y la porcicultura, las frutas y hortalizas, definen los rubros que han tenido el mayor crecimiento a lo largo de los últimos veinte años. Integran el conjunto de las especulaciones privilegiadas de los años setenta y ochenta. O sea, las actividades que se asocian a los mercados más dinámicos, que garantizan el acceso a elevadas rentas de situación ${ }^{2}$ y, en fin, delimitan el nuevo campo de acumulación de la agricultura capitalista.

El agotamiento del modelo agroexportador en el principio de los años setentas evidencia la profundidad del proceso de reestructuración de la agricultura nacional. De 1972 en adelante, la contribución del sector agropecuario a la obtención de divisas deja de ser significativa.

Esta evolución no se da únicamente a expensas de la agroexportación. El abastecimiento a los centros urbanos de productos difíciles de transportar y almacenar estimula la estructuración de redes de abasto extensas y centralizadas que imponen a los agricultores normas estrictas en cuanto a calidad, presentación y cantidades que descalifican a la agricultura campesina. Ahora bien, su expansión en el conjunto del sistema urbano se ha realizado a expensas de mercados hacia los cuales los campesinos solían realizar el producto de sus actividades agropecuarias complementarias: pequeña ganadería de solar (aves y puercos), huertos tradicionales, etc. Estas actividades permitían reducir los riesgos inherentes a la agricultura de temporal, asegurando un uso más continuo y más completo de la fuerza de trabajo familiar y de los recursos disponibles; en fin, garantizaban el acceso a ingresos monetarios nada despreciables. El decaimiento de estas actividades implica un notable estrechamiento de las bases de reproducción de la agricultura campesina ("fragilización"). Las unidades de producción tienden ahora a organizarse en torno al monocultivo del maíz y al fomento de actividades extraagrícolas. Son víctimas de un proceso de simplificación y especialización forzadas que se expresa a menudo, y como se verá luego, en una dinámica de extensificación agropecuaria.

Las nuevas relaciones mercantiles y la dinámica de difusión del cambio tecnológico han llevado consigo importantes ajustes en el tipo de desarrollo seguido en la agricultura. Han reforzado el dominio que ejercen centros de

2. Renta de situación: ganancia suplementaria obtenida gracias a la situación que tiene el productor dentro de las redes de comercialización y transportes. 
poder exteriores a la agricultura y pueden por lo tanto considerarse como verdaderas relaciones de poder. Como tales inducen profundas transformaciones estructurales del sector agropecuario.

Estas transformaciones podrían estudiarse en una perspectiva macroeconómica y sectorial. Se trataría entonces de identificar los centros de poder más significativos (el estado, las firmas que controlan el agronegocio...) para analizar luego las relaciones que fomentan con la agricultura. Este enfoque tiene la gran ventaja de proporcionar un panora ma general de la agricultura y del sentido de su evolución. Es más, el énfasis que se pondría entonces en las cadenas agroalimenticias permitiría seguir la pista que abren las relaciones de dominio. Sin embargo, un enfoque de este tipo tiene los defectos propios de todas las representaciones en exceso simplificadoras de la agricultura: no permitiría medir el impacto indirecto o inducido de las relaciones de poder ni tampoco enfatizar sus interacciones con las estructuras económicas y sociales campesinas.

Ahora bien, son precisamente estos aspectos los que queremos analizar. Si con el "desarrollo" se pretende fomentar cambios socialmente benéficos de los procesos de producción agropecuarios, es imprescindible entonces tener un conocimiento de las condiciones de existencia y de transformación (en el tiempo y en el espacio) de dichos procesos. El deseo de llevar a cabo un estudio sistemático de las mutaciones -o transformaciones estructurales- de la agricultura campesina nos indujo a adoptar un punto de vista radicalmente opuesto. El enfoque que se adoptó es ante todo pragmático. Procura, en efecto, partir de una visión dinámica de la organización de la agricultura campesina a nivel familiar y regional para llegar a entender, caso por caso, cuáles son las modalidades de integración a la economía global y cuál es el impacto de las relaciones de dominio.

\section{APUNTES TEORICOS}

Se suele considerar a la agricultura como artificialización de la naturaleza en vista a la producción de especies vegetales y animales útiles. Detrás de la simplicidad aparente de esta explicación, queda claro que la agricultura conforma un objeto de estudio sumamente complejo, ya que se encuentra en la confluencia de tres tipos de relaciones:

-Relaciones con la naturaleza. Con la producción agrícola, el hombre modifica los procesos biológicos y las cadenas alimenticias naturales creando así ecosistemas artificializados (o agrosistemas). 
-Relaciones de cooperación. La artificialización de la naturaleza es socialmente definida. En la producción de sus condiciones materiales de existencia, los hombres tienen que coordinar sus esfuerzos. Así, la producción del paisaje (ordenamiento territorial), la adquisición de conocimientos, de técnicas, el uso de medios de producción y de los recursos, implican siempre y en grados variables una cooperación efectiva (y no necesariamente igualitaria) de los productores.

-Relaciones de producción. Las que definen las condiciones de apropiación de los medios de producción y de los recursos productivos y de repartición del producto.

Podemos inferir de estas observaciones que la agricultura pertenece a la inserción de campos del conocimiento sumamente heterogéneos. Así, la artificialización de la naturaleza, presente en toda actividad agrícola, invita a poner cierto énfasis en las relaciones técnicas. A hora bien, todos los trabajos empíricos, y especialmente la investigación en agricultura comparada, evidencian que no existe ningún determinismo tecnológico. En otros términos, la organización técnica de la producción agrícola no puede desvincularse de su organización social; es un hecho contingente, histórica y socialmente definido. En este sentido, el estudio de la agricultura exige que se asocien los puntos de vista propios de la agronomía, de la historia, de la economía y de las demás ciencias sociales.

Por último, es también evidente que todos los aspectos que se acaban de presentar pueden - deben-tratarse desde escalas muy diferentes: desde el conjunto que forman las relaciones entre una planta y su entorno inmediato, hasta el planeta en su totalidad. Así, una técnica agrícola cobra su verdadero sentido al nivel de una parcela de cultivo. Pero sus modalidades de integración en la producción dependen directamente de decisiones tomadas a nivel de las unidades de producción. Estas decisiones resultan a su vez ampliamente condicionadas por la evolución de los precios de los insumos y de los productos o por las estrategias adoptadas por las firmas agroindustriales que controlan la producción de la tecnología.

Desde luego, sería totalmente ilusorio y vano pretender realizar un estudio exhaustivo y completo de la agricultura. La complejidad mis ma del objeto de estudio impone la definición de prioridades, de secuencias y la eliminación de un gran número de aspectos considerados menos pertinentes. Esta simplificación necesaria de la realidad puede realizarse según dos tipos de enfoques:

a) El enfoque analítico se asienta en una descomposición de la agricultura en "sectores" mediante recortes verticales o por disciplina. Sin entrar mucho en detalle, podría caracterizarse por el hecho de que enfatiza el estudio de los componentes y de las relaciones de cada sector y de que presta muy poca atención a los vínculos que pueden unir los diferentes sectores. Se 
trata de una opción que puede ser perfectamente justificada cuando se trata de estudiar agriculturas fuertemente integradas a la economía nacional y que se han especializado notablemente. Tal podría ser, por ejemplo, el caso de las granjas integradas, de la producción de frutas y hortalizas, de los cultivos de riego o de complejos agroindustriales. En tales casos, la organización de la agricultura está fundamentalmente determinada por su integración vertical. En cambio, cuando los agricultores no se han especializado fuertemente, cuando su integración a la economía global es todavía parcial o cuando los tejidos económicos y sociales locales juegan un papel importante en la organización de la producción, cualquier corte vertical resulta arbitrario y engañoso. Así, el fracaso de las políticas agrícolas implementadas durante los diez últimos años se puede explicar en gran parte por el hecho de que el estado proyectó una visión sectorial y vertical sobre agriculturas organizadas ante todo horizontal y territorialmente: en tales condiciones las recetas tecnológicas que difunde, difícilmente pueden integrarse en las estrategias económicas de los productores.

b) El enfoque "territorial" en términos de "sistema" ofrece una alternativa interesante en la medida en que se asienta sobre cortes horizontales. Por cierto, ya no se trata de analizar una producción en especial, ni una técnica, sino un proceso de producción. Ahora bien, veremos que los procesos de producción tienen una expresión espacial congruente a varias escalas simultáneamente. Es posible, en efecto, proceder para cada una de ellas a una jerarquización de sus componentes a partir de un análisis de los flujos que los estructuran (fertilidad, energías, productos, información) con el fin de conocer sus condiciones de reproducción y de evolución. El estudio sigue así pautas similares en cada una de las escalas contempladas, pero para llegar a conclusiones diferentes. Con el cambio de escala, los componentes que se relacionan no son los mismos y, sobre todo, el estudio persigue fines diferentes, como se verá ahora.

Se suelen considerar los siguientes niveles de análisis. La lista, desde luego, no es inmutable: ${ }^{3}$

\section{Sistema de cultivo y sistema de ganado}

En los niveles más finos, que corresponden a las escalas mayores (superiores a 1:5,000), el sistema de cultivo y el sistema de ganado definen las unidades de estudio (la parcela, el hato) en las cuales las relaciones entre los productores y la naturaleza cobran su mayor relevancia. El estudio de la organización de la producción agropecuaria en estos niveles tenderá por lo

3. Ello dependerá desde luego de los contextos estudiados. La especificidad de México frente a las agriculturas europeas (que han inspirado el método que estamos usando) nos condujo a definir la noción de "sistema social de producción". 
tanto a enfatizar el análisis de los procesos técnicos y, desde este punto de vista, la dinámica de evolución y de reproducción de los agrosistemas.

El sistema de cultivo puede definirse así como el conjunto for mado por una unidad espacial (una o varias parcelas tratadas en forma homogénea), una unidad de tiempo (o ciclo agrícola definido por la sucesión de cultivos característicos) una secuencia técnica (con los conocimientos y los medios de producción correspondientes).${ }^{4} \mathrm{El}$ tiempo, siempre presente, en los ciclos climáticos, en los procesos biológicos que el hombre trata de domesticar, en la distribución de los esfuerzos productivos o en las secuencias técnicas, ${ }^{5}$ define un marco idóneo para el estudio de las relaciones enire los componentes del sistema y su entorno. La integración de los ciclos naturales (biológicos y climáticos), de los calendarios de trabajo, de las sucesiones de cultivo y de las secuencias técnicas, definen el ciclo agrícola. Su duración puede ser muy variable, de un año (o sea el ciclo estacional completo), en el caso de un cultivo sistemático; hasta más de 15 años en el caso del maíz bajo roza, tumba y quema (dos años de cultivo seguidos de un largo pericdo de recuperarión).

Finalmente, existen varios indicadores de eficiencia del sistema de cultivo: rendimientos (físicos, en producto o energéticos) por unidad de superficies o por unidad de trabajo, etc.

De la misma manera y con propósitos similares se define al sistema de ganado como el conjunto formado por un hato, con su estructura por edades y sexo, su base forrajera eventualmente, y la secuencia técnica que caracteriza el manejo de los animales.

\section{El sistema de producción}

Los sistemas de ganado y los sistemas de cultivo constituyen los subsistemas del sistema de producción. Según Pierre George, ${ }^{6}$ éste corresponde al "balance de los cultivos y de las ganaderías practicadas y de los medios involucrados". Se define al nivel de la unidad de producción, unidad elemental de decisión y de administración de la producción agropecuaria. De ahí, que el estudio de los procesos de producción a este nivel, se orienta principalmente al conocimiento del comportamiento económico de los agricultores, o sea de los elementos que intervienen en los procesos de decisión. ¿En base a qué criterios, cómo y en vista de qué objetivos procuran

4. Según M. Sebillote: Journées du Département d'Agronomie de l'INRA. Vichy, 1982: "...une surface de terrain traitée d'une maniere homogene, des cultures avec leur ordre de succession et les itinéraires techniques qui leur sont appliqués".

5. Se habla a menudo de itinerarios técnicos.

6. Citado por Jacqueline Bonnamour, Géographie rurale, méthodes et perspectives, Masson, París, 1973. 
los agricultores optimizar el uso de los recursos y de los medios de producción a los cuales tienen acceso?

A menos de que se trate de una agricultura estrictamente especializada (lo que sería una situación excepcional en las áreas temporaleras), esta optimización no puede entenderse sin referencia a las relaciones de complementariedad, -o mejor dicho, a las sinergias -7 que unen los diferentes componentes del sistema de producción. Los sistemas de producción complejos se asientan en un aprovechamiento extenso de estas sinergias. Cada uno de ellos procura llegar a un uso combinado de los recursos, anticipado en la valorización de los otros. Alcanzan así a asentarse en una organización compleja de flujos internos de fertilidad, energía y productos. Si alguno de éstos podrían detectarse en los subsistemas, resulta obvio que sólo cobran sentido en la escala de las unidades de producción.

La asociación de plantas generadoras y consumidoras de nitrógeno por ejemplo el maíz y el frijol, una pradera sembrada de gramíneas y trébol, proporciona ilustraciones bastante triviales del aprovechamiento de estas sinergias. Podría evidenciarse también con la asociación frecuente de producciones animales y vegetales que permite valorizar sus sub-productos respectivos y obtener parte de la energía que exigen los cultivos. Asimismo, la combinación de actividades diferentes incluyendo eventualmente actividades no agrícolas, permite limitar los riesgos y acercarse a un uso continuo e integral del espacio y de la fuerza de trabajo familiar o contratada, contemplada en sus aspectos cuantitativos - número de brazos dis poniblesy cualitativos - conocimiento, habilidad, distribución por edad y sexo. Estos argumentos evidencian que las decisiones de los agricultores se basan mucho más en el resultado global de sus actividades que en el producto que pueden esperar de cada una de ellas por separado.

Las decisiones tienen que ajustarse también a una serie de limitantes. Algunas resultan de condicionantes impuestos por el medio natural (luz, precipitaciones, temperatura, etc.): su impacto suele enfatizarse en el estudio de los subsistemas. Otros en cambio, son la expresión directa de relaciones sociales. Pueden ejercer un peso que se deja sentir en forma homogénea en la totalidad de los agricultores: tal es el caso de las relaciones de precio de los productos, de los medios de producción, de los insumos y de la fuerza de trabajo. Pero otras se resienten en forma diferenciada e implican un acceso desigual a los recursos productivos: al espacio y a los medios de producción, a la información sobre mercados y tecnologías, por ejemplo, y, eventualmente, a los subsidios, al crédito y a la asistencia técnica. Este fenómeno se verifica en el hecho de que las sociedades rurales distan mucho

7. El concepto podría definirse genéricamente como la asociación de variosórganos para la producción de un trabajo. 
de ser igualitarias. Son, a menudo netamente estratificadas y los comport dmientos económicos de los agricultores son con frecuencia muy heterogéneos.

El estudio de un sistema de producción no sería completo sin que se evidenciara la coherencia que lo caracteriza. La combinación de actividades y de medios de producción sigue una racionalidad puesta en evidencia por el estudio de las estrategias económicas. ${ }^{8}$ Estas pueden definirse como la secuencia coherente de decisiones y de objetivos. Veamos algunos ejemplos:

\section{Ejemplo 1}

Un campesino minifundista tiene interés en producir él mismo todos los alimentos para asegurar las necesidades de su familia. Tenderá a valorizar sistemáticamente las sinergias procurando combinar sus recursos en tierra y su fuerza de trabajo para obtener una gran variabilidad de productos, minimizar los gastos monetarios y eliminar el riesgo de obtener una cosecha insuficiente para cubrir el consumo de su familia, aún a costa de menores rendimientos potenciales por hectárea o por unidad de trabajo.

En este caso, el campesino sembrará '-ultivos asociados (varios tipos de plantas intercaladas en la misma parcela) para tener acceso a un gran número de productos y eso en varias parcelas para disminuir el riesgo de que le haga falta uno de esos productos (sembrados cada uno en una parcela, una plaga podría devastar una de sus parcelas y privarlo así de un producto). Además tendrá la precaución de aplicar una baja densidad de siembra - pocas plantas por metro cuadrado - con el fin de disminuir la competencia entre las plantas por los nutrientes y el agua, lo que reduce aún más los riesgos de perder la cosecha en caso de lluvias escasas.

\section{Ejemplo 2}

En una región frutícola, un campesino minifundista, cuyos recursos sean parecidos al del primer ejemplo, tendrá otra estrategia si tiene acceso a un cultivo comercial remunerador. Para asegurar las necesidades alimenticias de su familia, buscará aumentar el ingreso monetario en cada una de sus parcelas (optimizar la productividad del terreno). Usará insumos externos (comprados), en la medida en que el incremento monetario obtenido con la cosecha sea superior al gasto suplementario.

\section{Ejemplo 3}

Al contrario, se trata de un productor que dispone de mucha tierra y no tiende necesariamente a aumentar la productividad por unidad de superficie (hectáreas). Buscará más bien incrementar lo más posible el ingreso por unidad de mano de obra familiar o asalariada (aumentar la productividad del

8. Sobre el mismo tema, ver el trabajo de Marc Dufumier: Sistemas de producción y desarrollo agricola en el tercer mundo. 
trabajo). Muchas veces, el desarrollo de la ganadería extensiva podrá explicarse por este tipo de racionalidad socio-económica.

\section{Ejemplo 4}

Por último, un productor que tenga mucho capital invertido en la agricultura buscará la forma más adecuada de aumentar el indice de ganancia para su capital invertido (maximizar la remuneración del capital). Alli por ejemplo, el productor puede comprar maquinaria agrícola para los trabajos que hay que llevar a cabo en épocas durante las cuales escasea la mano de obra. Mientras tanto, contratará mano de obra abundante y barata para otros trabajos (cosecha, etc.).

En todos los casos, el juego de las limitantes y la organización de la producción se expresan en una jerarquización específica de actividades. Los sistemas de producción tienden así a estructurarse en torno a ciertas actividades que juegan un papel decisivo en la reproducción de la unidad o en los objetivos que se han fijado los agricultores. Estas jerarquías suelen coincidir con categorías relativamente homogéneas de estrategias. Su conocimiento constituye por lo tanto, una base imprescindible para la elaboración de una tipología de las unidades de producción.

\section{Sistema social de producción}

Estas tipologías constituyen una herramienta necesaria para entender los procesos de producción en una escala superior, definida por la unidad socio-económica y territorial que conforma la comunidad campesina. Esta puede definirse como una combinación de unidades de producción, en la cual los diferentes productores tienen entre sí relaciones específicas (relaciones sociales de producción, familiares, de compadrazgo, etc.). Define el marco en el cual la complementariedad de los esfuerzos individuales - las relaciones de cooperación- ${ }^{2}$ y la confrontación de las estrategias familiares, llega a expresarse en la definición de una racionulidud colectiva. En esta perspectiva, el estudio de los sistemas sociules de produccioin tiende a una evaluación de esta racionalidad colectiva enfatizando las interacciones de los diferentes sistemas de producción en su relación con las modalidades de acceso a los recursos productivos. ${ }^{10}$

Aunque este nivel de análisis se descuide con frecuencia, al menos en sus dimensiones económicas, no cabe duda que los procesos de producción

9. Desde luego, no nos referimos exclusivamente a relaciones de cooperación simple, sino al hecho de que la combinación de sistemas de producción diferenciados obedece a una coherencia económica perceptible desde el punto de vista de la valorización del espacio en una escala que rebasa la unidad de producción.

10. Se entienden en una acepción amplia: espacio, medios de producción, canales de mediación y sinergia. 
cobran frecuentemente una coherencia notable en la escala que define la comunidad campesina con su base territorial." Así, en la escala del terruño -que definimos como unidad espacial socializada y coberente desde el punto de vista de su valorización agronómica- las sinergias y el carácter global y continuo del aprovechamiento de los recursos puede apreciarse en toda su plenitud.

En forma complementaria, el análisis de la confrontación de las estrategias familiares permite entender la naturaleza de las relaciones de cooperación en las cuales se asienta la organización de la producción en esta escala. Pueden evidenciarse rupturas, contradicciones, entre la organización comunitaria ${ }^{12}$ del trabajo y la apropiación individual de los recursos. Analizándolas, se lleva a evidenciar que las relaciones de cooperación con frecuencia distan mucho de ser igualitarias y que pueden desempeñar un papel decisivo en los procesos de diferenciación campesina. Es así patente que las modalidades de aprovechamiento de las sinergias dependen de la orientación de las unidades de producción y que, por lo tanto, difícilmente pueden ser las mismas para todos.

Por ejemplo, en contextos que suelen caracterizarse por una repartición sumamente desigual del ganado mayor, el libre acceso a los pastos inducidos, y eventualmente a los rastrojos, proporciona una base forrajera gratuita a los ganaderos. Esta se convierte luego, en una renta sustancial cuando los animales se venden o se alquilan. Los ganaderos sacan provecho de un trabajo no remunerado proporcionado por los agricultores, que les pone en condición de acumular más ganado, diversificar o intensificar sus actividades. En cambio, los campesinos desprovistos de tiro verán estrecharse las bases de reproducción de sus unidades de producción. Este ejemplo nos muestra que en un sistema social de producción hay cambios en ambos sentidos (hacia una acumulación creciente y hacia la descomposición gradual), por lo que se hablará de acumulación diferencial, sugiriendo que por naturaleza, el desarrollo es un proceso contradictorio y ambiguo, ya que la acumulación en ciertas unidades de producción va acompañada del deterioro de las condiciones de producción en otras.

11. Por cierto, la Reforma Agraria ha legitimizado el control corporativo que la comunidad campesina - ejido o comunidad agraria - ejerce sobre su territorio. Pero no hacen falta ni un soporte jurídico ni una base territorial claramente delimitada para que la organización de la producción tenga coherencia en una escala que rebasa las unidades de producción. Lo demuestra el trabajo que se ha realizado en la Sierra Madre del Sur (segunda parte de este libro). En el mismo sentido, Esteban Barragán (Más allá de los caminos, los rancheros de la sierra, El Colegio de Michoacán, aún no publicado) evidencia en qué grado la organización del trabajo constituye el sostén de la organización socio-económica de una región que se ha quedado al margen del reparto agrario.

12. En la medida en que está definida en el marco de la comunidad campesina. 
Lo anterior podría ilustrarse también aludiendo a las modalidades de aprovechamiento del patrimonio territorial comunitario con la asociación del cultivo del maíz y de la ganadería mayor, que se verifican en numerosas regiones de agricultura de temporal. ${ }^{13}$ En la escala del terruño, el libre acceso a los agostaderos comunales y a las tierras de cultivo en descanso da fe de la fuerza de las relaciones comunitarias: los campesinos pierden todo derecho individual sọbre sus parcelas, a menos que las hayan cercado, hasta el inicio del ciclo siguiente. Es más, estas relaciones pueden reforzarse por una reglamentación estricta que prohibe toda modificación de los calendarios agrícolas susceptible de limitar el paso de los animales. ${ }^{14}$ Sin embargo, el amparo del derecho de libre acceso al patrimonio territorial de la comunidad oculta en realidad una apropiación discriminatoria de los recursos. En efecto, la ausencia de control del crecimiento de los hatos individuales y de administración colectiva de los agostaderos implica un deterioro de las relaciones comunitarias en favor de los más pudientes. La repartición sumamente desigual de los animales y la evolución divergente de los hatos lo evidencian. Tenemos en este caso también un intercambio desigual, basado en un acaparamiento de recursos, a expensas de los intereses del conjunto de los miembros de la comunidad.

En fin, pueden encontrarse también ilustraciones de la descomposición de las relaciones comunitarias en el control que se ejerce a menudo sobre las funciones de mediación a través de las coaliciones campesinas o redes de relaciones preferenciales. El acceso al crédito - sobre todo al crédito refaccionario- a la tecnología, a las redes de comercialización, etc., suele también ser bastante desigual. Todos los estudios que se exponen a continuación lo verifican en grados variables y evidencian que el monopolio que los grupos sociales más poderosos logran tener sobre estos recursos, constituye con frecuencia el punto de partida de una acumulación diferenciada.

Más allá de estos ejemplos damos a entender que el acceso a los recursos y a la riqueza se encuentra diferenciado y jerarquizado; ello tiene como consecuencia una diferenciación marcada de los roles, de los status y, por ende, del poder económico de los diferentes actores sociales que se expresa en el reforzamiento de la división del trabajo en el seno mismo de las comunidades. Se trata desde luego - aunque sus contornos sean a menudo

13. Entendemos por patrimonio comunitario la parte no fraccionada (parcializada) del territorio: bosques, lagos y presas, agostaderos. En promedio nacional, para el sector ejidal, representa una superficie cinco o seis veces mayor que la de las tierras de labor. El tema se desarrolla en los capítulos dedicados a Aguanato y Turitzio. Véase también Thierry Linck: "Estrategias campesinas y agropolítica", Relaciones. 9, El Colegio de Michoacán, Zamora, 1982, pp. 49-96.

14. Ver por ejemplo M. Belshaw: La tierra y la gente de Huecario, F.C.E., México, 1976. 
borrosos- de la oposición clásica entre cultivadores y ganaderos pero también entre medieros, yunteros, peones, artesanos y demás, según las características propias a cada sistema social de producción.

Estos ejemplos ta mbién evidencian que todas las actividades no ejercen el mismo peso sobre la evolución del sistema social de producción. En este sentido es imprescindible asentar su estudio en una jerarquización de las actividudes adoptando como criterio el peso que puede asociárseles. ¿En qué medida las actividades dominantes definen un polo diferenciador? ¿Cómo interactúan con el acceso a los recursos productivos y el reparto del producto global? Son preguntas esenciales en torno a las cuales se ha estructurado el conjunto del trabajo. Se ha enfatizado así el impacto del desarrollo de la ganadería en Aguanuato, Turitzio y Maravatío, y su papel en proceso de colonización de la Sierra Madre del Sur, en Atapan y Nuevo Urecho se han puesto de relieve los efectos del auge frutícola.

Son también preguntas esenciales en una visión prospectiva, en apoyo a acciones de desarrollo. El conocimiento de los sistemas sociales de producción permite anticipar así los efectos del cambio tecnológico sobre la dinámica de diferenciación campesina.

\section{Sistema agrario}

En realidad, si la existencia de modalidades específicas de organización del trabajo y de acceso a los recursos productivos define el sistema social de producción como totalidad coherente, más allá del terruño, varios centros de actividades humanas participan en el desarrollo histórico de una entidad geográfica más amplia. Estos sistemas sociales de producción se encuentran ligados entre sí por múltiples relaciones, que giran en torno de la división regional del trabajo, de intercambios, de redes de comercialización, de poder, etc. La organización regional de la agricultura representa entonces un objeto de análisis a un nivel de observación todavía más amplio. Su estudio cobra tanto más interés, cuanto que influye de manera determinante en la evolución de los procesos de producción. Su acción se ejerce en dos direcciones:

-en términos de competencia y de exclusión cuando se hacen valer "ventajas relativas" en relación a la productividad del trabajo o a la adecuación de la oferta agrícola a las exigencias de las redes de comercialización. Esta relación puede comprobarse en el impacto que tiene el auge de las plantaciones frutícolas sobre la fruticultura rústica. Llega a expresarse en una división espacial del trabajo estricta que especializa regiones enteras en un pequeño número de producciones. Tal sería el caso de la producción de caña, de algodón, de trigo, de sorgo, de hortalizas, de puercos, de aves, de leche, etc.

-en térninos de complementariedad, relaciones que se dan cuando dos 
regiones, eventualmente muy distantes, cooperan en un mismo proceso de producción. Podemos encontrar un ejemplo característico en las relaciones que unen la Sierra de Coalcomán con la Huasteca. Los ganaderos de Coalcomán tienden a especializarse en la cría. Venden sus becerros en la Huasteca donde la abundancia de forraje estimula una especialización en la engorda. Otro ejemplo, en el seno del marco regional amplio, lo proporciona la asociación en el Bajío del cultivo de sorgo, de la producción industrial de aves y puercos y de actividades agroindustriales.

Además, la evolución de los sistemas sociales de producción depende generalmente del juego de factores externos. Estos inducen rupturas que modifican el equilibrio de las actividades y por ende, la organización del trabajo y las modalidades de acceso a los recursos.

Así, las políticas agropecuarias ${ }^{15}$ y la difusión del cambio tecnológico desde centros de poder exter nos ${ }^{16}$ conforman factores de cambio sumamente importantes. La organización vertical de la agricultura que difunden tiende a imponer una lógica de especialización que limita el aprovechamiento de las sinergias, tanto en la escala de los sistemas de producción como en la de los sistemas sociales de producción, contradiciendo así la racionalidad económica campesina.

Encontramos otro factor decisivo en la difusión de nuevas relaciones mercantiles: relaciones de precio y organización de los mercados. Tal y como lo hemos señalado, estos cambios remiten a la organización del aparato productivo nacional, a la evolución de las relaciones de poder entre los grandes actores económicos, a los procesos de expansión urbana y a la difusión de nuevos hábitos alimenticios. Las modalidades de expansión de las plantaciones frutícolas (véase Atapan y Nuevo Urecho) se inscriben directamente en esta dinámica. En el mismo sentido, la sobrevaloración de los productos animales en relación al maíz permite convertir en una renta el acaparamiento de los esquilmos y de los agostaderos comunitarios.

Al fin, en un espacio geográfico (región) que rebasa los límites del terruño, los sistemas sociales de producción y todos los factores que determinan su evolución pueden integrarse en un nivel macroeconómico ${ }^{17}$ regional o global ${ }^{18}$ en el cual su asociación obedece a una racionalidad específica y tiene por lo tanto cierta coherencia. En fin, están integrados en

15. En los años cuarentas, la política del rifle sanitario (erradicación de la fiebre aftosa) por ejemplo, modificó profundamente la repartición del ganado y estimuló la difusión de nuevas técnicas agrícolas (véase estudios de Maravatío y Coalcomán cap. 2 y 4).

16. Estado y empresas agroindustriales.

17. Escala en la cual la noción de circuito económico puede cobrar sentido.

18. Economís nacional o mundial, enfatizando entonces las modalidades de integración en la división internacional del trabajo. 
lo que llamaremos un sistema agrario. ${ }^{19}$

El ejemplo antes citado de dos regiones tan distantes como la Sierra de Coalcomán y la Huasteca, integradas sin embargo en un mismo sistema agrario mediante el flujo de animales flacos que abastecen la región de engorda de la Huasteca, nos lleva a rechazar la idea de una región "limitada" como espacio al nivel del cual el concepto de sistema agrario adquiere su pertinencia y logra su coherencia. De la misma manera, afirmaríamos que los flujos de migrantes que cruzan la línea fronteriza de Estados Unidos y las explotaciones agrícolas de California que contratan esa mano de obra, son elementos imprescindibles del sistema agrario.

Es por eso que su expresión territorial, la región, se proyecta, en realidad, mucho más allá de ciertos límites geográficos.

\section{El estudio dinámico de los procesos de producción}

De lo anterior podemos inferir que la evolución de los procesos de producción en un nivel dado está ligada con frecuencia a la acción de factores definidos en otros niveles. Por ejemplo, una modificación de los sistemas de cultivo tiene que integrarse, en la escala de la unidad de producción, en las estrategias campesinas y, por lo tanto, provocará cambios en el sistema de producción. Recíprocamente, el énfasis puesto en el desarrollo de alguna actividad, implica un desplazamiento del equilibrio entre las actividades en la escala de la unidad de producción, y surte efectos en cada uno de los subsistemas por medio de la reubicación de los recursos productivos y de la fuerza de trabajo. En realidad, todos los niveles están, de alguna manera, vinculados. Siguiendo el ejemplo anterior, podrían evidenciarse correspondencias entre sistema agrario, sistema social de producción, sistema de producción y sistema de cultivo.

La combinación de escalas conforma así un aspecto esencial del estudiu de los procesos de producción. Tiene que ser bastante pragmático y recurrir ampliamente a la observación. La secuencia y las prioridades en base a las cuales se organiza la combinación de los diferentes niveles de análisis, dependen en última instancia de criterios que derivan de la confrontación de los siguientes aspectos:

-los objetivos y las hipótesis preliminares que ha definido el investigador;

19. Marcel Mazoyer define el Sistema Agrario como: "modo de aprovechamiento del medio, históricamente constituido, adaptado a las condiciones bioclimáticas de un espacio dado y que corres ponde a las condiciones y necesidades sociales del momento". Systemes agricoles et développement agricole. Institut National Agronomique, ParisGrignon. Chaire d'agriculture comparée et développement agricole. Manuscrito, 1985. M. Mazoyer aplica el concepto de sistema agrario a nivel de regiones muy amplias o franjas del planeta como la Cuenca amazónica, Ja Cordillera de los Andes o la región mediterránea, etc. 
-la naturaleza de los procesos que investiga;

-su dimensión histórica.

Este último aspecto tiene mucha importancia. Desde luego porque las relaciones técnicas y las relaciones sociales se definen históricamente. Pero también, porque el conocimiento de la trayectoria histórica de los procesos de producción facilita la identificación de los polos de acumulación y de diferenciación, de los cuellos de botella, de los grupos sociales dominantes, etc., útiles para formular hipótesis.

Por ejemplo: en la región costera de Michoacán se ha puesto en evidencia una dinámica de invasión de las tierras comunales mediante el cercado de los montes por parte de ganaderos mestizos. El acontecimiento observado en el nivel del sistema social de producción invita a plantear hipótesis sobre su impacto en el nivel de los sistemas de producción: $¿$ Desplazamiento del centro de gravedad del sistema de producción hacia la ganadería, cambio de lógica interna y descuido consecutivo de la milpa? De hecho, observamos una reducción de la base territorial del cultivo de maíz bajo roza, tumba y quema y un acortamiento de 15 a 5 años del período de renuevo forestal necesario para que la parcela recobre su fertilidad y su limpieza. Esta observación nos lleva a plantear nuevas hipótesis en cuanto al patrón de cultivo a nivel del sistema de cultivo: surgimiento de nuevos cuellos de botella para la producción de maíz — baja de la fertilidad potencial del suelo, invasión de las malezas-y adaptación de las técnicas agrícolas a esas nuevas limitaciones. De hecho, se puede observar un adelanto de las fechas de siembra y un uso creciente de herbicidas, observaciones que nos invitan a plantear hipótesis sobre la modificación de los sistemas de producción: ¿Cómo se adaptaron los calendarios de trabajo? ¿Cómo se asumirá el incremento de los gastos monetarios? ¿de los riesgos?, etc. Estas a su vez invitan a plantear otras preguntas en el nivel del sistema social de producción: ¿De dónde y cómo se obtendrán los recursos monetarios, la fuerza de trabajo? ¿Cómo evolucionarán las modalidades de acceso al espacio? Por último, llegamos al nivel del sistema agrario: ¿Cómo evolucionarán las relaciones entre los ganaderos y las comunidades indígenas? La gráfica que se anexa resume los pasos que se acaban de exponer y que se explican con detalle en el capítulo $\mathrm{V}$.

Con todo, sería difícil asimilar los sistemas en sus diferentes niveles a tipos estables o duraderos de organización de la producción. Las condiciones de reproducción de los sistemas pueden así apreciarse en una doble dirección:

- hacia la evidencia de un proceso de acumulación diferenciada; -hacia el cuestionamiento eventual de las bases de reproducción de los sistemas.

La regıón costera de Michoacán proporciona una ilustración de esta doble evolución. El acaparamiento de las tierras comunales asienta la 


\section{Cuadro $\mathrm{N}^{0} 1$}

ESTUDIO DINAMICO DE LOS PROCESOS DE PRODUCCION:

CASO DE La zONA COSTERA DE MiCHOACAN

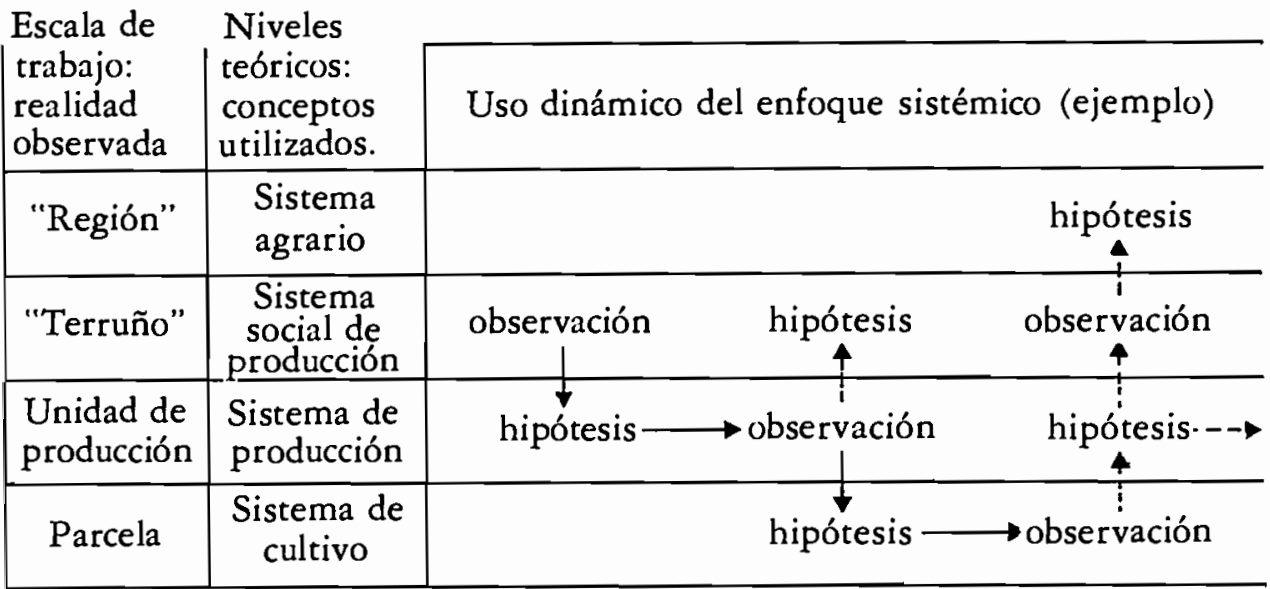

prosperidad de los ganaderos, pero implica un empobrecimiento considerable de las poblaciones nativas. Con el acortamiento del periodo de renuevo forestal, el cultivo del maíz es más costoso y arriesgado, menos productivo y atractivo. La deforestación incrementa los daños causados por la erosión, al punto de poner en peligro la reproducción de los agrosistemas. El espacio regional se encamina así hacia una especialización estricta en la ganadería bovina.

Las modalidades de aprovechamiento de los agostaderos comunales en el Bajío seco proporciona otra ilustración. En el momento en que están saturados los agostaderos, la ganadería bovina puede definirse como polo diferenciador. En una situación de sobrepastoreo, el incremento de los hatos individuales sólo puede lograrse modificando el reparto de los recursos forrajeros, o sea a expensas de otros hatos.

Se trata desde luego de una situación que les da ventaja a los grandes ganaderos: pueden integrar más fácilmente sus pérdidas eventuales y prevenirse de los riesgos comprando complementos de forrajes. Podrán acumular más ganado y diversificar o intensificar sus actividades. En cambio los dueños de pequeños hatos, se verán en la obligación de abandonar poco a poco la ganadería y en consecuencia de ajustar sus sistemas de producción, fomentando actividades poco remunerativas o extra-agrícolas. En tales condiciones, el desarrollo de la ganadería tiene todas las características de una verdadera carrera hacia el pillaje de los patrimonios comunitarios: los 
ganaderos no se responsabilizan de la preservación de sus recursos forrajeros, el sobrepastoreo es permanente y la preservación de los agostaderos no se asegura.

\section{Herramientas metodológicas}

El estudio de los procesos de producción puede iniciarse con la aplicación de encuestas ligeras o, hasta con un censo superficial. La información que se puede obtener por este medio suele ser útil para disponer de un marco de referencias cuantitativas o para formular hipótesis provisionales. Pero resulta sumamente superficial ya que:

- no puede cubrir todos los niveles de análisis;

-no abarca sistemáticamente los aspectos históricos.

Sin embargo, proporciona una base pertinente para recurrir a otras técnicas de investigación. De hecho, se ha optado siempre por poner un mayor énfasis en la calidad de la información que en la búsqueda de un estricto rigor estadístico. Se han abandonado los muestreos representativos para tratar de recoger la mayor cantidad posible de información de un número reducido de productores y tener así un conocimiento extenso y amplio de sus sistemas de producción respectivos.

Con tales lineamientos, la selección de los informantes no es una tarea sencilla. Se ha realizado considerando que era indispensable conocer una gama extensa de situaciones diferentes con el fin de tener un conocimiento, tan fino como sea posible, de los aspectos que diferencian los sistemas de producción. Desde luego, muchos de los casos no pueden considerarse representativos.

Por ejemplo, un sistema de producción que representa el $5 \%$ de los casos estudiados, puede influir de manera determinante en el sistema social de producción si este grupo de productores logra controlar una gran parte de los recursos de la comunidad.

De la misma manera, puede presentarse un campesino marginado, que a nuestro entender, sea único en su caso, pero que presente para nosotros tanto interés como el que despierta cualquier productor cuyo sistema sea representativo de la mayoría de las unidades de producción. Si estos últimos se vuelven "piedra angular" del estudio, la consideración del campesino marginal hasta podría parecernos absurda. Sin embargo, nos ayuda a comprender la problemática general al sugerirnos las siguientes preguntas: ¿Por qué ha adoptado una estrategia diferente? ¿En qué medida es una estrategia difundible? Las respuestas a estas preguntas proporcionan siempre elementos útiles para entender el sentido de la evolución del conjunto de los sistemas de producción.

La información obtenida en las entrevistas a los productores tiene que 
relativizarse. Además de las encuestas previas, se ha procurado recurrir sistemáticamente a "informantes privilegiados". En este sentido, los ancianos suelen proporcionar información sobre la historia regional y del sistema social de producción, útil para formular y ajustar hipótesis de trabajo. En esta perspectiva, ningún informante potencial merece ser despreciado, siempre y cuando se logre establecer el diálogo y se procure verificar la información obtenida.

La información estadística suele ser escasa y poco fiable; proporciona, sin embargo, útiles puntos de referencia.

Por último, la comprensión de los procesos analizados difícilmente llega a ser efectiva sin la realización de recorridos de campo. Todos los estudios de caso presentados se asientan en el estudio de:

-la situación y distribución de las parcelas;

-la presencia y disposición de los cultivos;

-los movimientos del ganado;

-las fuentes de agua;

-los flujos comerciales;

-las asambleas ejidales o de comunidad, etc.

Se trataba de recoger en cada escala de observación indicadores significativos del nivel (sistemas) considerado para lograr una localización y una jerarquización de los fenómenos observados. Estos indicadores se han confrontado luego con la información oral recabada y los datos que se han sacado de los archivos y documentos consultados: archivos de la S.R.A., fotografías aéreas, mapas, etc.

\section{ANTECEDENTES Y PUNTO DE PARTIDA}

Esta investigación es el primer punto de un acuerdo de cooperación científica franco-mexicano establecido en 1983 con El Colegio de Michoacán. De acuerdo con los términos del convenio, se elaboró un plan de investigación destinado a ahondar la problemática del desarrollo y a obtener un marco empírico y metodológico de referencia susceptible de valorizarse en el diseño e implementación de proyectos de desarrollo. Con esta doble finalidad se ha procurado elaborar un diagnóstico de las transformaciones agrícolas y agrarias en un contexto ya profundamente marcado por el énfasis que las políticas agropecuarias ponían en la producción de granos y en la agricultura campesina. Se estructuró la investigación adoptando como hipótesis inicial que el tipo de desarrollo de la economía nacional implicaba 
un deterioro, una "fragilización", de las condiciones de reproducción de la agricultura campesina (empobrecimiento de sus bases de reproducción, debilitamiento de los agrosistemas y desagregación de sus estructuras sociales a consecuencia del reforzamiento de los procesos de diferenciación).

Sobre esta base, la investigación tenía que seguir dos líneas a la vez complementarias y divergentes.

En primer lugar, siguiendo un corte horizontal, se procuró comprobar y ajustar esta hipótesis mediante el análisis de las modalidades de reproducción de la agricultura campesina en contextos geográficos e históricos diferenciados. Este constituye básicamente el objetivo que comparten los trabajos que se presentan a continuación.

En segundo lugar correspondía analizar sistemáticamente la evolución de las relaciones entre agricultura campesina y sociedad global. Con este objetivo, partiendo de la identificación de las rupturas y de los cuellos de botella, era preciso definir los factores de cambio y estudiarlos según un corte temático, siguiendo las pistas que han abierto los estudios de caso. Dos géneros de factores de cambio o relaciones de integración se han estudiado a través de las problemáticas que definen el cambio tecnológico y las políticas agropecuarias y la difusión de nuevas relaciones mercantiles. Este as pecto de la investigación se expone en una publicación separada ${ }^{20}$ que complementa a la presente.

En todo caso, es claro que los trabajos que se presentan a continuación llegan a conclusiones que invitan a matizar la hipótesis que se había adoptado al principio.

No cabe duda que todos los tipos de agricultura estudiados han reforzado sus vínculos con la economía global y los mercados urbanos, tanto para la compra de insumos y medios de producción como para la venta de sus productos o de su fuerza de trabajo. En términos globales, todos han experimentado un notable auge económico ${ }^{21}$ que dejó una profunda huella en su organización socioẹconómica. Con todo, el dualismo entre agriculturas capitalista y campesina, entre riego y temporal que, con todo acierto, podía denunciarse al final de los años sesentas, no resulta hoy en día tan claro ni tan esquemático.

Lo cierto es que los procesos de diferenciación han rebasado un umbral y adoptado nuevas modalidades. No siguen hoy en día cortes tan elementales como antaño sino, con una nitidez creciente, líneas que dividen a las sociedades campesinas mismas. El auge económico de todos los casos estudiados depende en realidad de la expansión de unas cuantas actividades

20. Thierry Linck: El campesino desposeido. El Colegio de Michoacán, en proceso de edición.

21. Utilizado como sinónimo de expansión económica (incremento del producto mercantil global) y no como desarrollo. 
productivas, alimentada ésta por rentas derivadas del acaparamiento de los recursos productivos. Este auge económico es la expresión de una dinámica de acumulación contradictoria.

La dinámica de especialización en la cual están inmersas todas las agriculturas observadas puede verificarse en todos los niveles de organización de la producción. Así, al nivel de la unidad de producción, el desarrollo privilegiado de una actividad que define el polo de acumulación y diferenciación implica, como contraparte, un retroceso o una extensificación de las demás actividades.

En la escala del terruño, la diferenciación y la especialización limitan las posibilidades de valorización de las sinergias y el aprovechamiento integral del espacio. Es más, como puede evidenciarlo la incidencia del sobrepastoreo o del agoțamiento de los suelos, la reproducción misma de los agrosistemas está con frecuencia en peligro.

Así, la "fragilización" de la agricultura campesina es una realidad. Pero no resulta de la marginalización de la agricultura campesina, sino que al contrario, proviene del hecho de que está ahora plenamente involucrada en la dinámica de cambio.

Desde luego, no se puede esperar de nuestras investigaciones, propuestas concretas en materia de alternativas de desarrollo. Sin embargo, llegamos a conclusiones que invitan a los actores económicos autorizados a poner mayor énfasis en el estudio previo de los procesos de producción. Así, sólo se puede alcanzar cierto control sobre los procesos de diferenciación definiendo las acciones de desarrollo en la escala de los sistemas sociales de producción puesto que en este nivel se definen las modalidades de acceso a los recursos productivos. En el mismo sentido, es preciso inventar opciones tecnológicas alternativas tomando como referencia las estrategias campesinas: de ello depende en gran parte la integración efectiva de los cambios tecnológicos en los sistemas de producción. En este sentido, no cabe duda que la orientación excesivamente sectorial de las políticas agropecuarias contradice tanto la racionalidad económica de los campesinos, cuyo objetivo es optimizar el aprovechamiento de las sinergias, como las exigencias de un aprovechamiento integral de los recursos, aunque refuerza efectivamente la dinámica de especialización de los productores.

\section{Las áreas estudiadas}

Se han seleccionado las áreas de estudio procurando alcanzar una cobertura tan amplia como sea posible respecto a los grandes complejos geográficos y culturales que componen el estado de Michoacán. Desde luego, los casos estudiados no pueden considerarse representativos de sus respectivos marcos regionales pero sí, sintomáticos de los problemas y de las tendencias 
que les afectan. Bajo estas reservas puede considerarse que nuestros trabajos proponen un acercamiento a la problemática de la agricultura campesina en las siguientes regiones:

1. El Bajío michoacano, al norte del Eje Neovolcánico reúne condiciones agroclimáticas intermedias (precipitaciones del orden de los $800-900 \mathrm{~mm}$ anuales con fuertes fluctuaciones). Se encuentra representado por dos estudios de caso: el primero, Aguanuato, que es un ejido temporalero que depende fundamentalmente de la asociación del cultivo de maíz y de la cría de ganado mayor. Al noroeste del estado de Michoacán, en el Valle de Maravatío, se eligió el ejido de Campo Hermoso que asocia la cría de ganado lechero con el cultivo irrigado de forraje.

2. Las franjas meridionales de la Meseta Tarasca definen una zona de transición entre las tierras frías e indígenas de la Sierra y las tierras calientes y mestizas del Valle de Tepalcatepec. Las temperaturas benignas y la calidad de los suelos han estimulado la expansión de una fruticultura intensiva cuyos efectos se estudian en Atapan (aguacate) y en Tepenahua (mango).

3. Las Tierras Calientes de Michoacán (Valles del Balsas y del Tepalcatepec) se han vuelto famosas por el cultivo del algodón y, luego, del melón, de la sandía, del sorgo y sus plantaciones. Sin embargo, of recen al margen de su distrito de riego, condiciones agroclimáticas sumamente adversas (precipitaciones escasas y muy aleatorias). Se ha estudiado el caso del ejido de Turitzio, municipio de Huetamo.

4. La Sierra Madre del Sur, con sus valles profundos y su ausencia de comunicaciones, define una región de colonización reciente y bastante desconocida aún. La organización peculiar, tomando como punto de referencia los demás estudios, de la producción agropecuaria que la caracteriza se analiza en dos regiones que cubren un espacio que abarca desde la ciudad de Coalcomán en la sierra hasta la comunidad indígena de Pómaro en la costa del Pacífico.

Nuestro propósito se limitaba a ahondar la problemática de las transformaciones recientes de la agricultura campesina, especialmente en las regiones que no fueron priorizadas en las políticas etatales. Por esta razón excluímos de antemano importantes regiones agrícolas de Michoacán como los grandes valles de riego: Valle de Zamora, Ciénaga de Chapala, Valle de Morelia y Plan de Tierra Caliente (Apatzingán). Nuestro trabajo no tiene, ni mucho menos, la pretención de constituir una especie de atlas agrario del estado de Michoacán y el plan que adoptamos no sigue una secuencia geográfica:

En los tres estudios que componen la primera parte, tratamos de evidenciar las dinámicas de diferenciación campesina al interior de los ejidos. A pesar de que abarcan regiones geográficas muy distintas (Aguanato en el bajío seco, Maravatío en el noroeste del estado y Huetamo en las tierras calientes), revelan sin embargo fuertes similitudes: en los tres casos, la 
MAPa No 1 . Ubicacion de los 7 estudios de Caso en el estado de MichoaCan

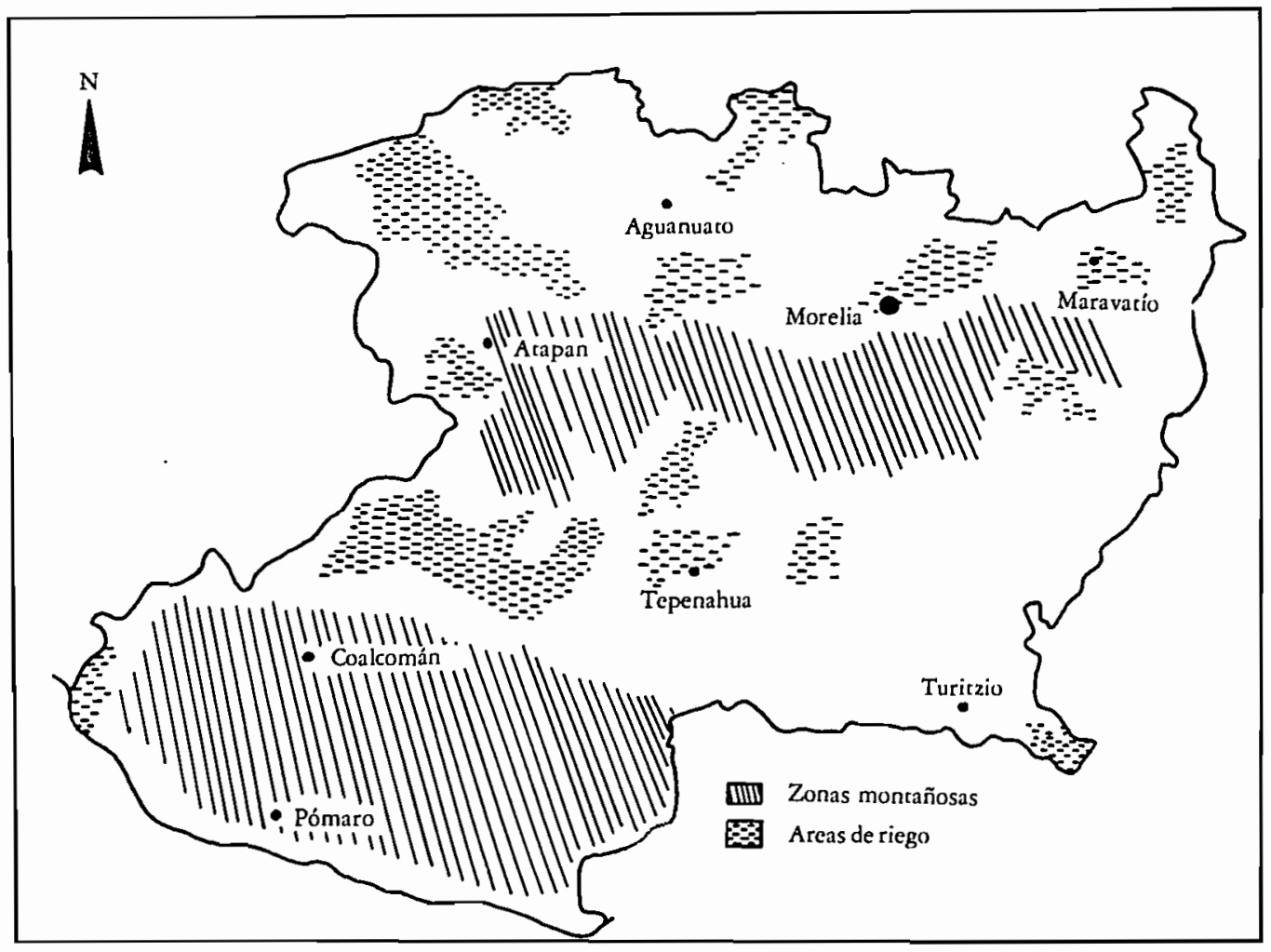


ganadería, medio histórico de acumulación de capital, se ha vuelto principal factor de diferenciación campesina, siendo los recursos comunitarios (agostaderos) aprovechados cada vez más por un reducido número de familias.

La Sierra Madre del Sur, la región más apartada y desconocida del estado, define una problemática específica que merecía un tratamiento separado (segunda parte). La expansión de la ganadería - "ganaderización"- se enmarca, en efecto, en una dinámica de colonización o mejor, de enajenación progresiva de las tierras comunales de la costa.

En la tercera parte, que abarca las franjas meridionales de la Meseta Tarasca (Atapan, Nuevo Urecho), analizamos la "respuesta" de los sistemas de producción a la introducción y al desarrollo de un cultivo específico -aguacate y mango-fuertemente relacionados con los mercados urbanos. (Cfr. mapa 1).

\section{Agradecimientos}

De acuerdo con los principios que rigen las labores académicas de El Colegio de Michoacán, el equipo de investigación ha trabajado con absoluta autonomía, por lo que se responsabiliza plenamente de sus resultados. Sin embargo, se ha trabajado en interacción constante con la comunidad científica del propio Colegio y con otras instituciones académicas del país. Los intercambios que hemos tenido con nuestros colegas y con los estudiantes de las maestrías nos han permitido ahorrar tiempo y esfuerzos en el conocimiento de la problemática del agro michoacano y han enriquecido nuestra investigación principalmente en los aspectos históricoantropológicos.

Queremos agradecer también a todos los funcionarios de la Administración Agropecuaria que con su curiosidad, amistad, discusiones y apoyo, participaron en la elaboración de este trabajo: técnicos e ingenieros de las Unidades y Distritos de Temporal de la SARH o del Gobierno del Estado. (Mención especial del M.V.Z. Carlos Naranjo Ureña).

Nuestra gratitud se dirige igualmente a Marc Dufumier (Institut National Agronomique, Paris-Grigron, Chaire d'Agriculture Comparée et de Développement Agricole) por brindarnos orientaciones, al equipo de geógrafos del IPEALT de la Université de Toulouse-Le Mirail; y a José Luis Domínguez $\mathrm{C}$. por su paciencia y maestría en la corrección de estilo.

Desde luego, agradecemos a los campesinos, protagonistas en gran parte de esta investigación.

Thierry Linck con la colaboración de Hubert Cochet

Jean Damien deSurgy

Eric Léonard 


\section{PRIMERA PARTE \\ GANADERIA Y DIFERENCIACION CAMPESINA EN EJIDOS TEMPORALEROS}





\section{INTRODUCCION}

Desde hace varios años, el ejido está en el centro de un debate ideológico, en parte inspirado por el "pensamiento neoliberal" que se ha desarrollado desde el principio de este decenio. El ejido es considerado con frecuencia como una unidad homogénea e indivisible, que funciona mal y no reacciona a la implantación de proyectos de desarrollo. Las críticas son todavía más fuertes hacia los ejidos de temporal, los cuales, al parecer, son incapaces de salir del marco tradicional de la producción y, aún dentro de este marco, incapaces de desarrollar en forma satisfactoria las fuerzas productivas, a pesar de los avances de la revolución verde, la difusión del crédito y de la maquinaria, los rendimientos no aumentan, Suele considerarse que el fraccionamiento de las dotaciones y el desarrollo del minifundismo en el seno de los ejidos es un freno mayor a la intensificación y lleva a los campesinos a esperar sin iniciativa propia la intervención del estado, aprovechando su paternalismo.

En pocas palabras, se ha llegado a pensar que la respuesta al estancamiento de la productividad de los ejidos podría ser su privatización mediante un cambio de estatuto hacia la pequeña propiedad. El costo social sería sin duda alguna muy elevado: pocos productores se quedarían y los centros urbanos podrían difícilmente absorber el flujo de expulsados. Por otro lado, los resultados económicos esperados serían hipotéticos: la supuesta superioridad de las pequeñas propiedades en la productividad nunca ha sido demostrada y la concentración de la tierra favorecería más bien las producciones extensivas.

Nuestro propósito fue considerar al ejido como movido por dinámicas internas antagónicas, producto de una diferenciación fuerte, y luego, saber si estas "carencias" del sistema ejidal se deben o no a su estructura interna.

Los tres estudios que componen esta parte muestran la necesidad de observar tanto lo que pasa dentro (a nivel de la diferenciación campesina) como alrededor del ejido, principalmente en las relaciones de producción con la pequeña propiedad, para entender sus carencias. Abarcan regiones de Michoacán muy distintas por las condiciones que ofrecen al desarrollo de la 
actividad agropecuaria (geoclimáticas, recursos ácueos, comunicación con los centros económicos y de decisión política, densidad de población, etc.). Pero revelan sin embargo fuertes similitudes:

-Una es la antigua existencia, en todas partes, de una gran variedad de producciones agrícolas (maíz, frijol, calabazà, garbanzo, trigo, cebada, caña, ajonjolí, etc.) y pecuarias (bueyes de trabajo, bovinos de carne, leche y quesos, puercos para engorda, aves de corral, etc.) característica de los sistemas de producción anteriores al reparto agrario.

-Luego, pese a las actuales tendencias hacia distintas especializaciones regionales, el desarrollo de la ganadería extensiva se revela como el principal medio de acumulación y luego un paso obligatorio hacia otras especializaciones (maíz en Aguanuato, producción lechera o cerealera en Maravatío, ganadería extensiva, más concentrada en Huetamo).

- La ganadería extensiva aparece entonces como el principal factor de una diferenciación campesina que encuentra sus raíces en las estructuras anteriores a la reforma agraria, a la creación de los ejidos, de los que se repartieron las tierras, pero no las herramientas ni los animales necesarios para su aprovechamiento. El grado de esta diferenciación va creciendo con la antigüedad del ejido.

-La intervención de la administración y las migraciones, generalizadas en Michoacán, se integran a esta dinámica como factores exteriores de la evolución. Pueden tener un papel acelerador o, por el contrario, moderador de la diferenciación. Por ejemplo, el ingreso proveniente de familiares que trabajan en EE. UU. puede ser una oportunidad para los campesinos pobres de iniciar la acumulación en ganado: Sin embargo, una acumulación previa es necesaria para pagar la migración y en casos extremos, sólo los ricos ejidatarios se aprovechan de esa posibilidad.

Los siguientes trabajos son la ilustración y el desarrollo de estos planteamientos. 


\title{
CAPITULO I \\ EMERGENCIA Y DESÁRROLLO DE UN CACIQUISMO GANADERO EN EL EJIDO DE TURITZIO
}

\author{
Eric Léonard \\ Héctor Medina Hernández
}

\section{Agradecimientos}

La Tierra Caliente del Balsas es un lugar reseco y caluroso que difícilmente se podría soportar si no fuera por la gentileza y la hospitalidad de sus habitantes. Queremos agradecer a todos los campesinos del ejido de Turitzio quienes con su paciencia y su buen humor hicieron de este trabajo algo inolvidable. Gracias a los funcionarios de la Secretaría de Programación y Presupuesto, de la Secretaría de Fomento Rural del estado de Michoacán, de la Secretaría de Agricultura y Recursos Hidráulicos que tanto nos ayudaror. Una mención especial a don Salvador Gonzáles y a toda su familia quien nos abrió su hogar en forma tan generosa.

\section{INTRODUCCION: MARCOS DE ESTUDIO}

El "fondillo del mundo"

La cuenca del Río Balsas, en el tramo que separa los estados de Guerrero y de Michoacán pertenece a esas regiones aisladas, olvidadas por los proyectos y las políticas de desarrollo. Ahí, la instalación del hombre en la región siempre ha estado limitada por su difícil acceso (véase mapa 2) y por su clima, que la convierten en una "tierra para quien no ha nacido en ella, inhabitable y para los nacidos, insufrible..." En pocas palabras es el fondillo del mundo como se complace en calificarla Luis González, ${ }^{2}$ o "el planeta de los burros" según un campesino del lugar.

1. Diego Basalenque, Historia de la provincia de San Nicolás Tolentino de Michoacán de orden de N.P.S. Agustin. Edit. Jus, México, 1963, p. 42.

2. Luis González, La Querencia. SEP, Morelia, 1982. 


\section{MaPa Ne 2. Ubicacion del ejido de Turitzio}

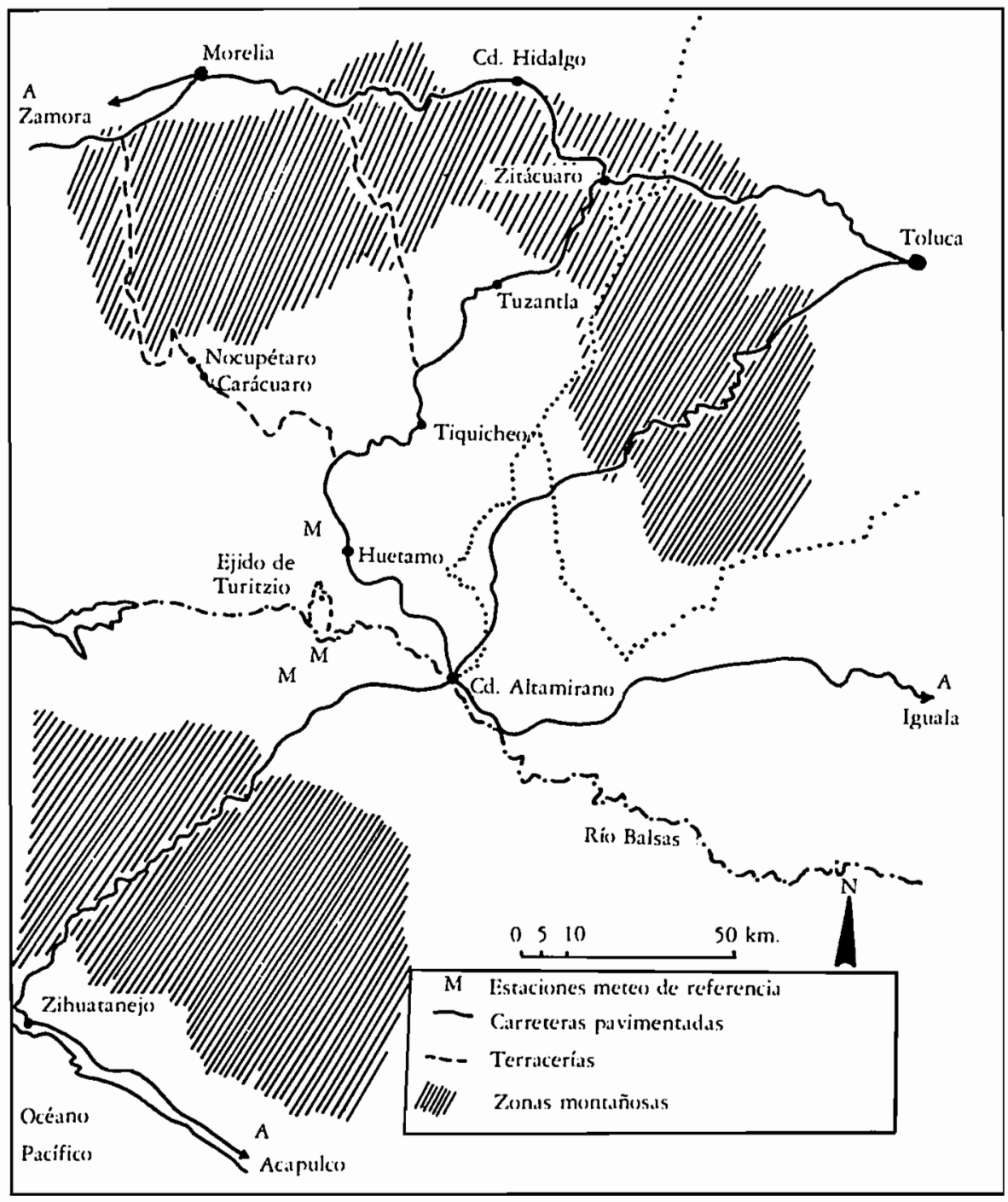

La zona nunca permitió el desarrollo de una economía agrícola floreciente y quedó al margen de las inversiones productivas, tanto en el tiempo de ĺa colonia como durante los 150 años que han seguido a la independencia. Se considera que tiene - según un vocablo tecnócrata muy 
en boga-, una "vocación ganadera"; tan importantes son las limitantes para la agricultura.

\section{Condiciones de la actividad humana}

De hecho, los recursos en tierra y más que todo en agua son muy pobres. Dominan los suelos pobres, calcáreos y muy permeables correspondientes a los regosoles y litosoles, en la clasificación FAO/UNESCO/1970, además de ser muy difíciles de mejorar. Con frecuencia son muy delgados pues los litosoles no cuentan con más de $10 \mathrm{~cm}$., de profundidad y son ineptos para un uso agrícola. Los únicos suelos de calidad aceptable - tipo Feozem- son muy vulnerables a la erosión, hasta en pendientes débiles. En las orillas del río Balsas, por ser arcillosos los suelos, se pueden presentar, además, acumulaciones de sales.

En toda esta parte, la agricultura de riego es desconocida por la mayoría de los campesinos. Excepto pequeñas áreas en el municipio de San Lucas y al lado del Balsas las actividades agrícolas quedan sometidas a las contingencias del temporal. Este se concentra en los meses de junio a octubre, cuatro meses en los que las lluvias toman un carácter torrencial y representan el $85 \%$ de las precipitaciones anuales; los tres meses de julio a octubre representan con frecuencia el $70 \%$ de las lluvias. La gráfica 1 representa los diagramas climáticos de las tres estaciones de referencia de la zona de estudio. Lo sobresaliente es la variabilidad que caracteriza tanto al principio, como al final de la temporada de lluvias. Estas se pueden hacer esperar hasta el final del mes de junio, poniendo en peligro todo el ciclo de cultivo (creación de un cuello de botella en el calendario de trabajo, levantamiento de las malezas que "tapan" las parcelas y ahogan la milpa...). Luego, el suelo logra con dificultad mantenerse húmedo más de un mes en todo el año, cosa que generalmente sucede en julio. El caracter frecuentemente torrencial de las lluvias y la naturaleza de los suelos favorecen una fuerte erosión que puede alcanzar las 50 toneladas de material por hectárea y por año. La desaparición de la cobertura vegetal en los relieves acentúa el fenómeno y se encuentran barrancas impresionantes en toda la región.

Otra característica del temporal en esta parte es el "verano" o canícula que corresponde a la disminución de las lluvias hacia fines de agosto y principios de septiembre. Este fenómeno no se manifiesta muy claramente en los datos meteorológicos, pero puede tener un efecto dramático sobre el desarrollo de los cultivos (véase gráfica 2 y en particular los diagramas correspondientes a las estaciones de Zirándaro y La Calera). Afecta mucho más al maíz, que florece en esa época -2 meses después de la siembra- si ha sido sembrado con un poco de retraso, que a los demás cultivos, ajonjolí y sorgo, mucho más resistentes. Una carencia hídrica durable en este 


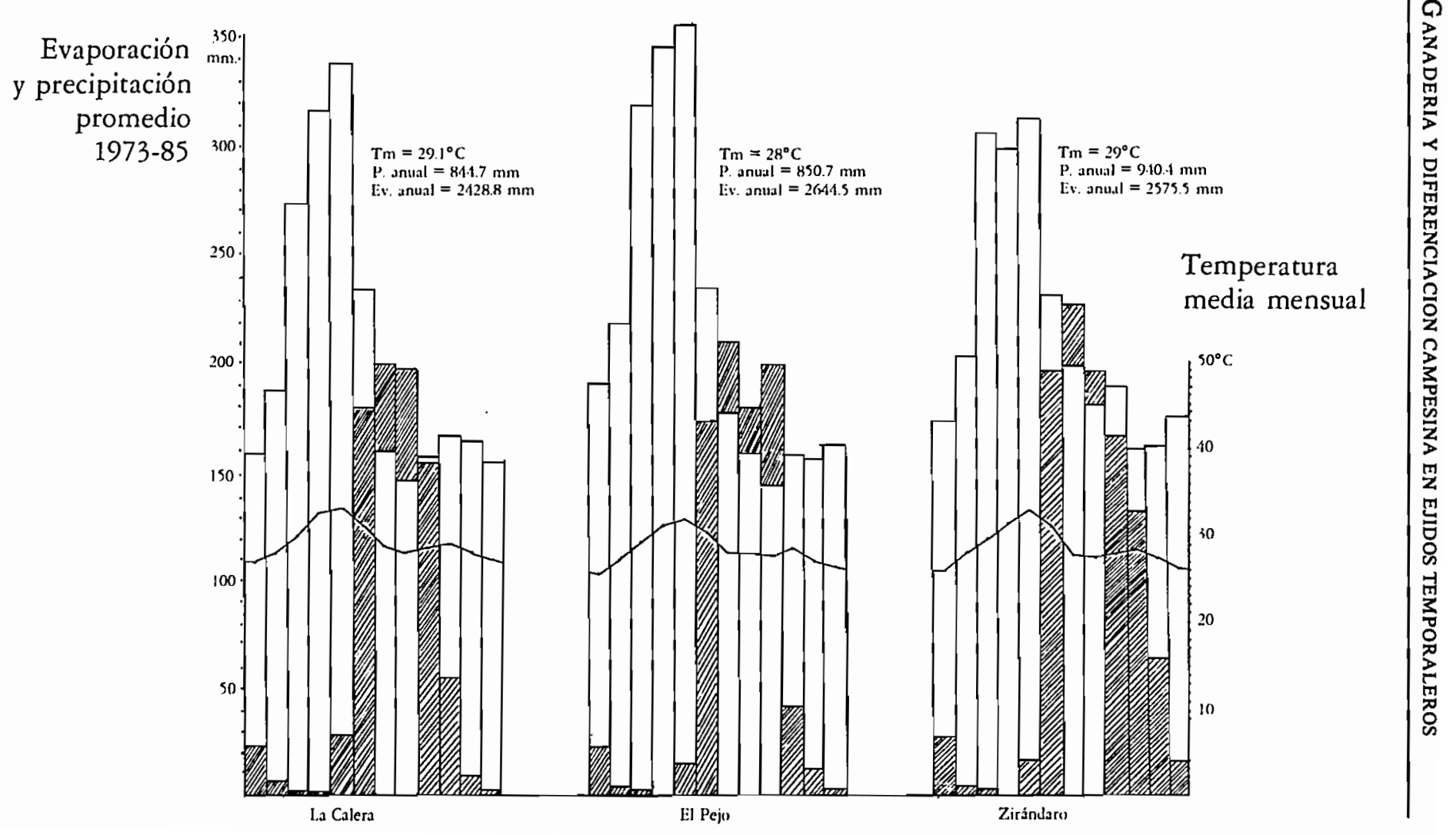


Grafica № 2: Precipitaciones - eVAPORacion en el periodo de mayores Riesgos (agoșto-septiembre)

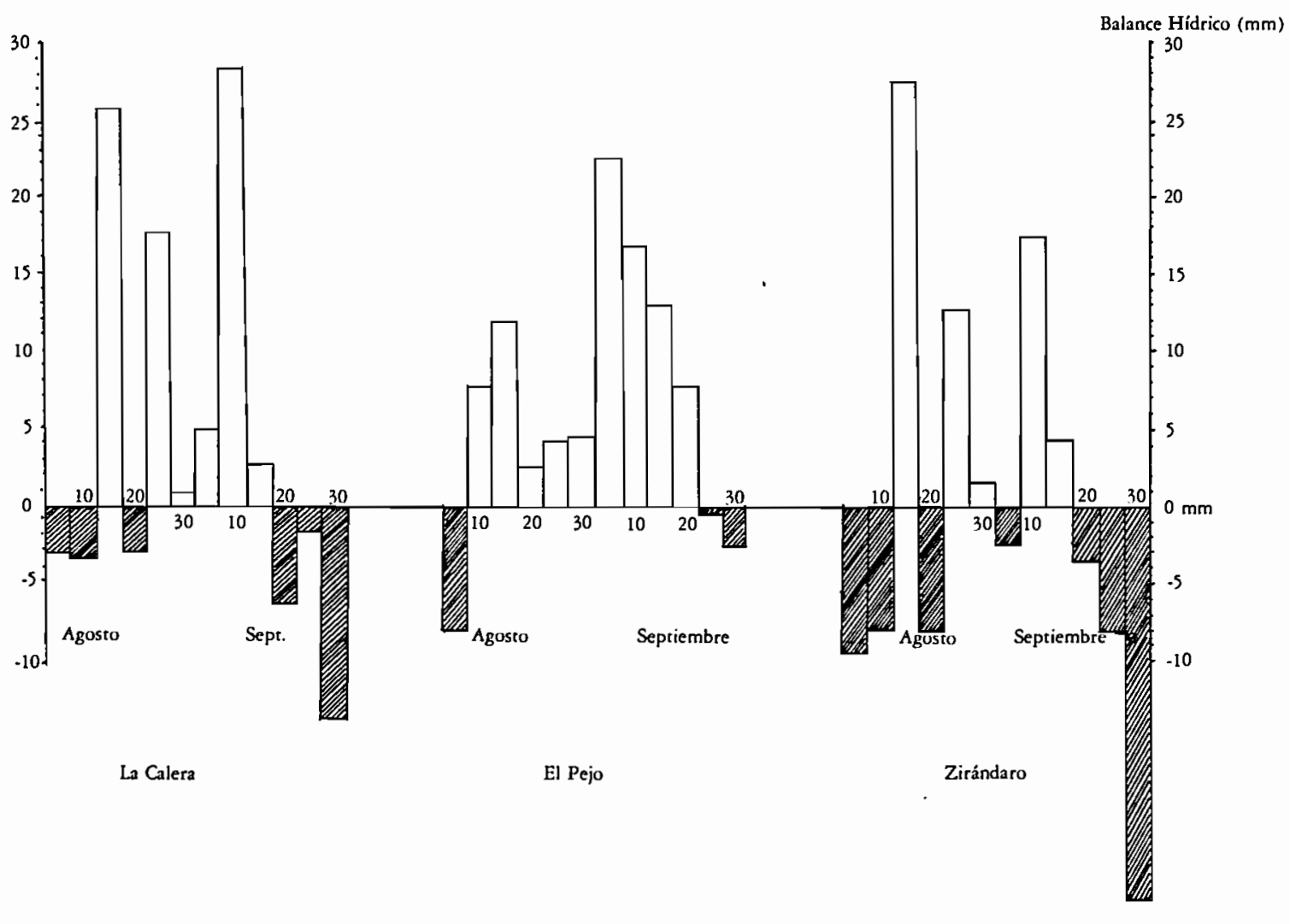


momento puede reducir en mayor proporción la cosecha.

La conjunción de estos factores contribuye a mantener baja la densidad de población, pese a la existencia del río Balsas, gran eje de comunicación de la región. En medio siglo, dicha densidad pasó de 14.4 habitantes por kilómetro cuadrado, a 24 en el municipio de Huetamo y de 14.4 a 21.6, en el de San Lucas. ${ }^{3}$ Las tasas de crecimiento demográfico quedan muy abajo del promedio estatal: 1.6 y 0.8 contra 3.6 en Michoacán entre 1970 y $1980 . .^{4}$ Las migraciones temporales son muy importantes; en el campo sorprende el número de casas nuevas que han sido construidas gracias a los dólares de los migrantes; dos veces a la semana salen de Huetamo camiones rumbo a Tijuana.

Se puede, sin embargo, preguntar cuáles han sido los efectos de la especialización regional en una zona que parece haber quedado al margen del desarrollo económico, donde los mecanismos de diferenciación campesina tal vez se expresaron con más independencia y claridad que en otras partes.

Este capítulo, lo enfocamos hacia un ejido, el de Turitzio - el segundo del municipio de Huetamo por su tamaño- situado a unos 20 kilómetros de la cabecera municipal. Ahí, la aparente prosperidad de un pueblo en expansión contrasta con la pobreza del medio ambiente. Esta prosperidad, muy selectiva como lo veremos, es el producto de fenómenos de evolución y diferenciación que nos proponemos detallar ahora.

\section{SISTEMA DE PRODUCCION ANTES DEL AGRARISMO}

\section{Rancherías y "condueñazgo"s}

A principios del siglo $\mathrm{XX}$, tres latifundios dominan el paisaje agrario del área: las "haciendas" de Charácuaro y San Bartolo, propiedades de la familia Sánchez y el "condueñazgo" de Turitzio-Comburindio en las manos de la familia Sierra-Romero.

Los testimonios con respecto a esas tres entidades son algunas veces contradictorios. Sin embargo, se puede reconstruir, en parte, la fisonomía de esos latifundios antes de la creación del ejido en 1936 (véase mapa 5).

3. Secretaría de Industria y Comercio. Dirección General de Estadísticas. Censos Generales de Población y Vivienda. 1970.

4. Secrecaría de Programación y Presupuesto, INEGI, Censos de población y vivienda 1980.

5. En términos regionales, así se reconoce a la asociación de varios propietarios con igualdad de derechos sobre un territorio compartido. 
Los ranchos de Charácuaro y San Bartolo fueron comprados a fines del siglo pasado por un negociante de ganado de Zirándaro llamado Natividad Sánchez. Más tarde, la propiedad de Aterio, situada al este de la zona que nos ocupa, vino a completar lo que fue uno de los latifundios grandes del actual municipio. Sin embargo, a nivel regional, no hubo haciendas como las que se extendían en la parte oeste de la Tierra Caliente michoacana y la cuenca del Tepalcatepec. Sólo dos entidades de más de 10,000 hectáreas existieron en el marco regional: El Devanador, con 17,546 hectáreas y San José de Gracia con sus 12,838 hectáreas $^{6}$ situadas al norte del municipio. En la cuenca del Balsas prosperaban más bien ranchos - aunque se les denominaba haciendas-de 1,000 a 2,000 hectáreas de superficie, tales como los de la familia Sánchez. Con la revolución y luego con los primeros rumores agraristas la propiedad Sánchez se dividió entre tres hijos: Aterio para Angel, San Bartolo a J.Jesús y Charácuaro a J. María. Son ellos quienes tuvieron que enfrentarse a la repartición.

Resulta difícil reconstruir con precisión la extensión de las dos "haciendas" de Charácuaro y San Bartolo. A la creación del ejido de Turitzio y sin que se pueda saber si ya habían sufrido algunas afectaciones, esas dos entidades juntaban unas 1,235 hectáreas de tierras de temporal y 2,685 hectáreas de agostaderos y pastizalez de cerril, o sea unas 3,920 hectáreas. ${ }^{7}$

Queda patente la sub-utilización del espacio, ya que no se cultivaban más que unas 130 hectáreas en San Bartolo y quizás 150 en Charácuaro, la mayor parte mediante la renta de tierras, como lo veremos. Sólo unas 50 hectáreas se cultivaban anualmente bajo control de los dueños, quienes empleaban peones que vivían durante la mayor parte del ciclo de cultivo en los ranchos.

El "condueñazgo" de Turitzio-Cumburindio constituye un caso distinto. Ese latifundio corresponde tal vez a una antigua hacienda - los archivos mencionan una hacienda de doña Francisca de Velasco en Turiceo ${ }^{8}$-que se hubiera fraccionado entre varios dueños. El acto de creación del ejido9 menciona a cuatro propietarios afectados por el mismo: las señoras Celsa Ríos, Andrea Romero, Marcelina Dávalos y el caballero Nicolás Torres. Pero ese "condueñazgo" se extendía muy al norte y al oeste del terruño del actual ejido de Turitzio, hacia las tierras de las comunidades de Cumburindio, Los Hornos, La Era... Con la llegada de persistentes rumores sobre la repartición de tierras a principios de la década de 1930, se produjo un primer

6. Enrique Cárdenas de la Peña, Tierra Caliente, porción sureste dè Michoacán. México, 1980.

7. Documento de la S.R.A., Ratificando la creación del ejido de Turitzio.

8. Ramón López Lara, El Obispado de Micboacán en el siglo XVIII. Fimax Publicistas, Morelia, 1973.

9. Documento S.R.A. op. cit. 
movimiento de división de esas propiedades mediante la venta de terrenos de 6 a 8 hectáreas a familiares de los dueños. Pero el número de esos pequeños propietarios, generalmente relegados hacia los márgenes del "condueñazgo", no parece haber rebasado las ocho personas.

De hecho, las superficies laborables a disposición de cada uno no parecen haber rebasado las 60 y 80 hectáreas. Excepto en el caso de los pequeños propietarios, la valorización de terreno se hacía mediante el empleo de arrendatarios o, muy raras veces, de medieros. No parece que se hubiera recurrido al trabajo de peones para el cultivo bajo el mando directo de los grandes "condueños". 10

La base de la prosperidad de los ranchos en toda la región era la ganadería. Según el testimonio de un agente del censo de 1930, las comunidades de Turitzio, Zicuirán y Charácuaro contaban con unas 200,30 y 40 almas, o sea, en una de las partes más pobladas de la región había una densidad de 5 habitantes por kilómetro cuadrado. Con esta densidad de población y las condiciones climáticas que caracterizan la zona, la ganadería correspondía a una mayor disminución de los riesgos y a una mayor valorización de la mano de obra disponible.

En los ranchos de San Bartolo y Charácuaro se ordeñaban cada año en la temporada de lluvias un total de 200 a 220 vacas, según testimonios de los antiguos caporales. Lo que corresponde a un rebaño de aproximadamente 1,500 reses que se suman a unos 500 equinos que mantenían esas entidades. En el "condueñazgo" de Turitzio la actividad ganadera se daba a una escala menor: el más rico de los condueños contaba con un rebaño que se acercaba probablemente a las 400 cabezas.

Esta actividad ganadera dependía en mayor grado de la capacidad que tenía un propietario para mantener su ganado en la estación seca. Era entonces necesaria una cierta extensión de cultivos para el uso forrajero de los residuos de cosecha (esquilmos). Eso se obtenía mediante una organización del trabajo a dos niveles de explotación.

\section{La organización del trabajo: arrendatarios y peones}

El primer eslabón de esa explotación era el sistema de arrendamiento por parte de los terratenientes que ocupaban superficies grandes a "gente de confianza", por lo regular miembros de la familia del mismo dueño. Los contratos eran verbales y parecían a priori, precarios. Pero todos los testimonios coinciden para subrayar que las condiciones de arrendamiento eran muy estables debido a los lazos familiares entre las dos partes, a la poca disponibilidad de mano de obra en la región y a las condiciones de vida

10. "Condueño": compañero de otro en el dominio o señorío de alguna cosa. 
-relativamente favorables en el contexto de la época- de las que se beneficiaban los arrendatarios: la movilidad de las familias de arrendatarios era muy reducida.

En el marco de esos "contratos", se dejaba al arrendatario la superficie que podía cultivar con una yunta de bueyes, sea unos 35 o 40 dobles $^{11}$ de semilla: 5 a 6 hectáreas. La renta de la tierra equivalía entonces a 5 o 6 cargas de maíz al igual que el alquiler de los animales de trabajo. El cultivo del maíz era impuesto al arrendata rio en 4 hectáreas por lo regular. Eso se explica por el nivel del pago en especie que se daba al terrateniente y por las necesidades de la familia del arrenda tario: contando con 200 a 250 kilos de grano para el abasto de una persona al año, una familia de 6 a 7 miembros necesitaba el equivalente de 1.5 toneladas de maíz para su mantenimiento y la reproducción de sus reservas de semilla. La renta de la tierra y de la fuerza de tracción representaban 1.7 toneladas, o sea se necesitaba un total de 3.2 toneladas para la reproducción del sistema. Esa suma correspondía a las 4 hectáreas con rendimientos de 0.8 toneladas por hectárea, con lo que se acercaba probablemente a lo que se podía esperar de una temporada "medio mala". Esa superficie de 4 hectáreas a sembrar de maíz corresponde entonces al límite de seguridad para la familia del arrendatario. Para el dueño de la tierra, el cultivo del maíz en una área importante era la condición de sobrevivencia de su ganado a fines de la temporada seca, cuando sólo quedan los esquilmos para forraje.

Por lo general, el arrendatario cultivaba lo que sobraba con ajonjolí. Ese cultivo se extendió en la región a fines del siglo XIX y por su resistencia y mayor adaptación a la aleatoriedad climática se impuso como principal cultivo de renta. Para el arrendatario, el cultivo del ajonjolí era la única forma de acceder a un principio de acumulación. Pero las posibilidades de comercialización eran muy reducidas y por lo común las cosechas acababan en las bodegas de los terratenientes. Sin embargo, esa acumulación previa que se podía es perar de una buena cosecha, era la condición para el acceso a la posesión de animales que permitía librarse de la renta de la fuerza de tracción. Aquí cabe mencionar diferencias notables entre las comunidades.

En el "condueñazgo" de Turitzio, la superficie puesta a disposición del arrenda tario era aproximadamente de 6 hectáreas, lo que dejaba 2 hectáreas al campesino para el cultivo de renta y la constitución de un fondo de seguridad y de acumulación. Los dueños permitían además al arrendatario poseer animales, quizás debido a los lazos familiares que les unían. $\mathrm{Al}$ revés en las "haciendas" de Charácuaro y San Bartolo, esa oportunidad no se daba a los campesinos y la limitación de la superficie en renta a 5 hectáreas por lo

11. Medida de peso que tiene equivalencias desde 1.8 hasta 2.8 kilogramos según el producto y la región: Diccionario Agropecuario de México. INCA-RURAL, México, 1982. 
regular no permitía la menor acumulación. Esa diferencia en las condiciones del arrendamiento puede explicar bastante de las evoluciones ulteriores del sistema agrario en el área.

Los animales de trabajo (bueyes) se mantenían en los agostaderos del dueño, pero quedaban a cargo del arrendatario en los períodos de trabajo así como el empleo y pago de los peones. Esas extracciones rebajaban año con año el margen de beneficio y de acumulación del arrendatario. De hecho la mayoría de los arrendatarios - sobre todo en Charácuaro y San Bartolo-se encontraban endeudados y sometidos a los terratenientes. Esas condiciones limitaban su acceso a la posesión de ganado vacuno así como las presiones de los terratenientes dueños de los agostaderos y de los esquilmos (arón ${ }^{12}$ y rastrojo se quedan en las parcelas). Sin embargo en el "condueñazgo" de Turitzio es innegable que esas condiciones de acumulación precaria fueron suficientes para permitur el acceso de una porción de la población a la posesión de unas pocas reses y de un pequeño terreno, aprovechando rumores agraristas y los lazos familiares con la oligarquía.

Dentro de ese grupo destacan los caporales que se beneficiaron con abundantes recursos. Esa minoría - los ranchos de Charácuaro y San Bartolo no contaban con más de dos caporales - recibía, en pago del cuidado del ga nado del terrateniente, toda la leche de su hato excepto el domingo en que se entregaba a los peones, así como la posibilidad de sembrar la superficie que alcanzaban a cultivar 2 a 4 yuntas (hasta 20 hectáreas). Quedaban entonces a su cargo el empleo de ayudantes, en general un ordeñador y un "becerrero" necesarios para el buen manejo del ganado. La posibilidad de poseer ganado dependía, para el caporal como para el arrendatario, de las condiciones particulares de cada latifundio.

Arrendatarios y caporales no representaron más de 35 a 40 personas en el área que nos ocupa. Por ejemplo, Charácuaro empleaba 10 de ellos, San Bartolo 9. La mayoría, quizás el $70 \%$ de la población estaba compuesta por los peones y familiares que constituían el segundo eslabón de la organización del trabajo. No hubo en esa parte peones de planta ligados con algún terrateniente; los únicos asalariados de éstos eran los caporales-vaqueros. Los peones estaban sometidos a una gran movilidad en busca de trabajo con los arrendatarios o también con los terratenientes. Al final de la cosecha salían hacia las áreas de riego de Guerrero o del Estado de México, y regresaban a fines de mayo para el ciclo de temporal. La orientación ganadera de los latifundios no permitía la sedentarización de estos trabajadores y los sueldos - 25 centavos al día en 1930 - no les dejaba ninguna perspectiva de acumulación.

En la temporada de lluvias los peones ocupaban instalaciones de los

12. Así se llama localmente a la paja del ajonjolí. 
ranchos de Charácuaro y San Bartolo o compartían las casas de los arrendatarios. Las tiendas de los terratenientes donde se vendía el excedente de grano, producto de la renta de la tierra y de los animales, permitían su mantenimiento así como un beneficio suplementario para sus dueños.

\section{Bases técnicas de los sistemas de producción}

La actividad ganadera, base de la prosperidad de los terratenientes, estaba estrechamente vinculada con las producciones agrícolas, función principal de los arrendatarios. La utilización de los esquilmos era una base del sistema forrajero del ganado que, en cambio, procuraba fuerza de tracción y renovaba la fertilidad de los terrenos de cultivo.

En la lógica del sistema de producción de los terratenientes, la producción de forrajes para permitirle al ganado pasar el periodo crítico del final de las sequías era el primer objetivo del sistema de cultivo. Los términos de los contratos de arrenda miento que obligaban a los campesinos a sembrar entre dos tercios y tres cuartos de la superficie asignada con maíz perseguían esa meta: el rastrojo de maíz representaba una cantidad de forraje muy superior al a rón del ajonjolí. Además, el maíz que no recibía un trabajo de limpieza (escardas y chapeo) tan completo como el del ajonjolí conservaba entre las matas una cantidad de malezas que contribuían a elevar el valor forrajero de los residuos de cosecha. ${ }^{13}$

Las tierras cultivadas se limitaban a las partes más húmedas del terruño, o sea unas 150 hectáreas en la "hacienda" de Charácuaro y quizá 200 en el "condueñazgo" de Turitzio. Al contrario de lo que se observa en otras regiones tratándose de agricultura de temporal, no parece que se haya utilizado el recurso de periodos de barbecho-descanso hacia el final de las rotaciones: los testigos entrevistados afirman que las parcelas se cultivaban año por año. Pese a limitaciones técnicas fuertes - las herramientas de las que disponía el arrendatario se limitaban a la "tarecua" - hierro en forma de triángulo- para los trabajos de limpieza de la milpa, al yugo y al arado de palo que no permitía barbechar (voltear la tierra e incorporar malezas y residuos de cultivo) sino abrir surcos, la permanencia del ganado en las parcelas durante una parte de la sequía parece haber permitido una renovación suficiente de la fertilidad. ${ }^{14}$

En la primera mitad del siglo, la duración de la temporada de lluvias

13. Se puede considerar que una parcela de maíz puede producir unas 1,100 unidades forrajeras (U.F. sistema Leroy) que quedan después de la cosecha: 2 toneladas de rastrojo igual a 800 U.F. 300 U.F. correspondientes a las arvenses. Mientras ese total no alcanza las 400 U.F. para el ajonjoli debido a la poca digestibilidad del arón. (1 U.F. es el equivalente energético de un kilogramo seco de cebada).

14. De hecho, la permanencia de los animales durante dos meses permite la concentración 
- de fines de mayo hasta fines de octubre según los testimonios- - permitía extender el ciclo de cultivos a más de 6 meses: desde el principio de junio hasta el mes de diciembre.

El maíz, base del sistema de producción se cultivaba asociado con el frijol judío y la calabaza. Se sembraba a principios y hasta mitad de junio, mezclado con el frijol en surcos que guardaban entre sí una distancia de 90 centímetros, contando con 3 a 4 semillas en cada hoyo. Cada 7 hoyos se agregaba una semilla de calabaza. Las densidades de siembra alcanzaban las 17000 matas de maíz y 2500 plantas de calabaza por hectárea. El frijol judío, planta voluble, se enrollaba entonces alrededor del pie de maíz. Esa práctica de asociación de cultivos (distancia relativamente importante entre matas y siembra de varias semillas - a veces de variedades distintas de una misma especie- en la misma mata) corresponden a medidas clásicas en medios difíciles para disminuir los riesgos: la incertidumbre climática fue una constante en la historia regional aunque a un grado quizás menor en la primera mitad del siglo.

El ajonjolí siempre ha sido objeto de un cultivo puro, en densidades de 30 a 35,000 matas por hectárea, o sea el doble de la del maíz. En cada mata se acostumbró desde siempre a juntar unas 20 a 25 semillas. Las características de resistencia del ajonjolí permitían seguir cultivando suelos ya agotados o bien, colonizar terrenos marginados. Sin embargo ese cultivo apareció rápidamente como un factor considerable de erosión.

Esas características de resistencia del ajonjolí a los cambios climáticos, tales como la canícula de agosto, permitió desde luego descargar y escalonar el calendario de trabajo de los campesinos, sembrando primero el maíz y luego extendiendo en el tiempo los trabajos de limpia de los cultivos, sin que haya realmente una sobrecarga de trabajo difícil de asumir.

Esos trabajos de limpia, llevados a cabo con la tarecua movilizaban en dos ocasiones una numerosa mano de obra de peones. En las parcelas de maíz, una raya con la yunta y luego, en agosto, el chapeo con machete venían a completar esas tareas. Las densidades de siembra del ajonjolí han hecho de ese cultivo el más consumidor de energía para los trabajos de escarda pero las remuneraciones propuestas para la semilla lo hacían muy atractivo para los arrendatarios: era un primer paso necesario hacia la acumulación de capital.

de unas 7 a 8 toneladas de estiércol por hectárea (contando con 6 o siete animales por hectárea); lo que equivale a llevar de 35 a 40 kilos de nitrógeno (N). 20 a 25 kilos de ácido fosfórico $\left(\mathrm{P}^{2} \mathrm{O}^{3}\right)$ y 40 a 50 kilos de potasio $\left(\mathrm{K}^{2} \mathrm{O}\right)$.

Basándose sobre rendimientos del maíz del orden de 1 a 1.5 toneladas de granos por hectárea, las exportaciones son entonces de un nivel de 40 kilos de $\mathrm{N}, 18$ kilos de $\mathrm{P}^{2} \mathrm{O}^{5} \mathrm{y}$ 42 kilos de $\mathrm{K}^{2} \mathrm{O}$, cubiertas por las aportaciones de estiércol. Sin embargo el pastoreo de los animales y el consumo del rastrojo aumenta el nivel de las extracciones de minerales... 
Los trabajos de cosechas se extendían entonces desde octubre con el corte del ajonjolí hasta los primeros días de diciembre con la cosecha del maíz. Resulta difícil llegar a una estimación de los niveles de rendimientos en aquella época. Sin embargo, se podría considerar que promedios de 450 kilos por hectárea para frijol; 400 kilos para el ajonjolí y 800 a 1,200 kilos para el maíz, son datos plausibles. Estos promedios sufrían, sin embargo, variaciones sensibles en función de la pluviometría. Las calabazas que no habían sido utilizadas por los campesinos durante las lluvias se quedaban, despues de la cosecha, a disposición de los animales.

Esos cultivos de temporal constituían por lo regular la tarea de los arrendatarios. Sin embargo los dueños de los ranchos de Charácuaro y San Bartolo acostumbraban cultivar directamente unas 50 a 60 hectáreas de maíz y ajonjolí cada año. Las rotaciones vigentes eran del tipo de maíz asociado (2 ó 3 años) y luego, ajonjolí, aunque desde esa época se haya podido observar una relegación progresiva de ese último cultivo hacia los márgenes del terruño por su fuerte adaptación y su acción erosiva.

La numerosa mano de obra desmovilizada en la temporada seca podía encontrar oportunidades de empleo con cultivos que se podían hacer en las orillas del río Balsas. Ahí, se dejaban a la disposición de los arrendatarios las playas de arena que se descubrían y donde se podían sembrar "huertas" de sandía, cebollas, chiles y hasta una pequeña parcela de maíz para la producción de elotes. Esos productos se podían vender a Zirándaro o más sencillamente al dueño, quien se encargaba de su comercialización ulterior y de sacar mayor provecho. La desocupación en esa época del año permitía consagrar gran parte del día a cargar botes de agua del río hasta la "huerta" para regar. Otro sistema de riego era el que utilizaba norias construidas en el río que llevaban el agua a una altura de 5 metros y permitían así regar pequeñas áreas. Esos sistemas de cultivo se extendían entonces a todo lo largo del río y pese a los medios que requerían como mano de obra, necesidad de apartar y proteger una área de $0.2 \mathrm{Ha}$. del ganado de los terratenientes, construcción de un mecanismo complejo de noria que una brusca variación del nivel del río se podía llevar al igual que la misma huerta, etc., permitían a una parte del campesinado mantenerse durante la "cuaresma", o temporada seca.

En el "condueñazgo" de Turitzio, a lo largo del arroyo que actualmente atraviesa el pueblo, los "condueños" acostumbraban sembrar pequeñas parcelas de caña de azúcar regadas por gravedad. Esas superficies fueron sin embargo suficientes para que funcionara durante algún tiempo en Turitzio un trapiche que tenía como objetivo abastecer de piloncillo a la comunidad de peones y arrendatarios que vivían ahí.

El sistema de ganado se integraba estrechamente y daba gran parte de su sentido al patrón de cultivos descrito. En las manos de los caporales, el 
manejo de los animales seguía modalidades inmutables, primero descansando en la explotación de los pastizales cerriles durante la temporada de lluvias, luego con la disminución del agua, la utilización del agostadero de llano más húmedo y por fin la ocupación de las parcelas de cultivo donde quedaban esquilmos. El esquema siguiente resume ese calendario forrajero:

GRAFica Ne 3

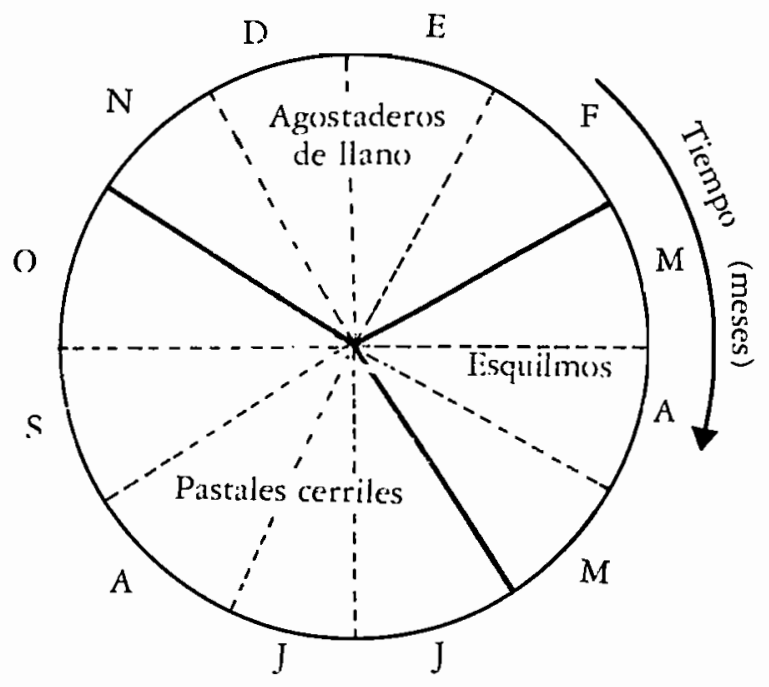

La concentración de los hatos en los últimos meses de la temporada seca en las escasas parcelas cultivadas - unas 150 hectáreas para el rancho de Charácuaro que contaba con unas 800 reses-, se hacía sin dejar de plantear varios problemas. Una carga animal podía entonces alcanzar hasta 4 "unidades animales" 15 (u.a.) por hectárea, mientras la misma carga descendía a 0.3 en la temporada de lluvias. De hecho, contando con necesidades de 4 u.f. por vaca y por día y con unas 850 u.f. disponibles en una hectárea de rastrojo de maíz, deducidos los desperdicios, esa hectárea alcanza apenas a mantener 2.5 a 3 bovinos en los tres últimos meses de la temporada seca. Ese cálculo nos demuestra que los terratenientes habían alcanzado una acumulación máxima en forma de cabezas de ganado que no se podía incrementar más sin abrir nuevos terrenos de cultivo y facilitar el acceso de los arrendatarios y peones a la tierra. Pero esa no era la tendencia en los ranchos de Charácuaro y San Bartolo donde la saturación de los recursos forrajeros era más sensible. 
Se intentaba entonces mantener al ganado el mayor tiempo posible en los agostaderos. Durante esa estancia en temporada de lluvias se encerraba a los becerros en corrales construidos en el llano, lo que permitía atraer las vacas paridas y ordeñarlas antes de que se regresaran al cerro. Ordeñador y becerrero quedaban encargados de ese manejo. La leche se cuajaba para hacer queso, lo que permitía al caporal un manejo comercial más cómodo. Debido a ese manejo extensivo, la frecuencia de los partos no alcanzaba a uno cada dos años por vaca.

Esa actividad ganadera se quedó limitada a los "condueños" y "hacendados" de Charácuaro y San Bartolo y, en un grado menor, a los pequeños propietarios que aparecieron en el curso de los años treintas y caporales a quienes se permitía tener algunas reses. Por el contrario, la cría de puercos era generalizada entre los arrendatarios y constituía la forma principal de valorización del excedente de maíz y de las calabazas. Los puercos se vendían para el consumo local en Huetamo, Zirándaro o a los matadc res de las comunidades. Sólo el pequeño ganado - puercos, chivas y eventualmente burros - estaba al alcance de esa categoría de campesinos quienes se quedaban a la merced de las decisiones de los terratenientes en cuanto al acceso a los agostaderos.

El sistema de producción vigente en la región, orientado hacia la ganadería extensiva y la producción de carne y animales de tiro, había logrado una utilización del espacio que no se podría modificar sin tocar las relaciones de poder entre terratenientes y arrendatarios en beneficio de esos últimos. El mapa 3 intenta reflejar esa utilización del espacio en función de los testimonios que se han recogido.

15. Una "unidad animal" corresponde aproximadamente a una cabeza de ganado "corriente" de $350 \mathrm{Kg}$. 
MAPA Ne 3: OcupaCION DEL ESPACIO AGROPECUARIO EN EL AREA DE ESTUDIO ANTES DEL AGRARISMO

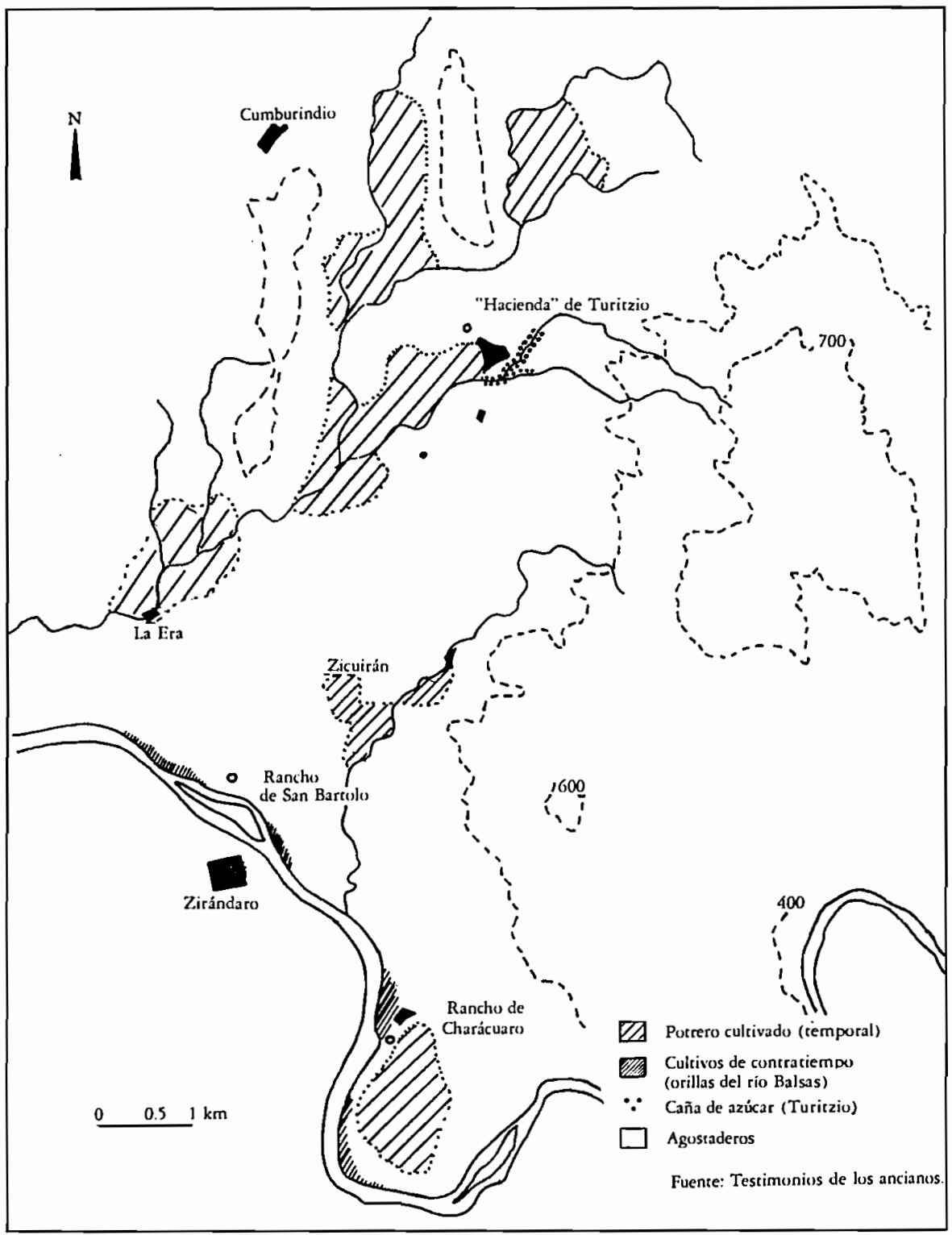




\section{Comercio e intercambios}

Los terratenientes concentraron durante mucho tiempo en sus manos las actividades comerciales. Además de las deducciones de maíz correspondientes a la renta de la tierra, compraban el ajonjolí y los excedentes de maíz a los arrendatarios, así como eventualmente los puercos que éstos criaban, sacando luego provecho de las posibilidades de almacenamiento y transporte que tenían para hacer especulaciones más lucrativas.

El ajonjolí se vendía por lo regular en Huetamo, donde funcionó un molino desde el año 1907 hasta los años sesentas - y donde operaban varias fábricas de jabón-o, se llevaba hasta Ciudad Altamirano. El maíz se cargaba en trenes de arrieros que iban hacia Churumuco o más lejos, a Zitácuaro, Morelia u otros. La vía fluvial del Balsas permitía alcanzar las vías de ferrocarril que llegaban a Guerrero, pero era más utilizada en otro sentido, es decir para vender en los ranchos las telas y productos manufacturados que traía el ferrocarril y que acababan en las tiendas de los terratenientes (véase mapa 4).

El ganado se escoltaba hacia Morelia, Toluca y México para matanza, pero también se llevaban yuntas amansadas hasta el Bajío. Como ya lo vimos, los dueños de los ranchos de Charácuaro y San Bartolo eran negociantes de ganado con relaciones en la ciudad de México.

El aislamiento de la región - solamente dos brechas pésimas la comunicaban con el norte hasta 1950 - dificultó muchísimo el desarrollo de intercambios. Sin embargo éstos empezaron a extenderse a principios de los años treintas cuando algunos "condueños" de Turitzio organizaron "atajos"16 de 25 a 30 animales para llevar el comercio de ajonjolí, maíz y puercos hacia la costa guerrerense. Regresaban con mezcal, condimentos y pieles para la industria curtidora que se vendían en Huetamo, Santa Clara del Cobre y Morelia. Ese negocio ocupaba la temporada seca en la que no había qué hacer en los ranchos y se podía emplear una mano de obra barata. El comercio con la costa se extendió a los pequeños propietarios y algunos arrendatarios "ricos" de Turitzio, pues reveló rápidamente ser la vía de acumulación más rápida: con el beneficio de una buena cosecha de ajonjolí, se podían comprar uno o dos burros, conseguir mercancía fiada con los "condueños" familiares - el lazo familiar con el rico era en la mayoría de los casos la condición para poder salir a comerciar-y luego sacar de ese comercio ganancias suficientes para la compra de ganado o de un pedacito de terreno que el "condueño" estaba dispuesto a vender. Esa oportunidad de comerciar, que dependía esencialmente de los lazos familiares del campesino, constituyó un importante factor de diferenciación en Turitzio y la posesión de burros era entonces el

16. Conjunto de animales (mulas) que se utilizaba en el traslado de mercancías. 


\section{MAPA Ne 4.}

COMERCIO E INTERCAMBIOS EN LA CUENCA DEI. BAISAS EN IOS AÑOS 1930

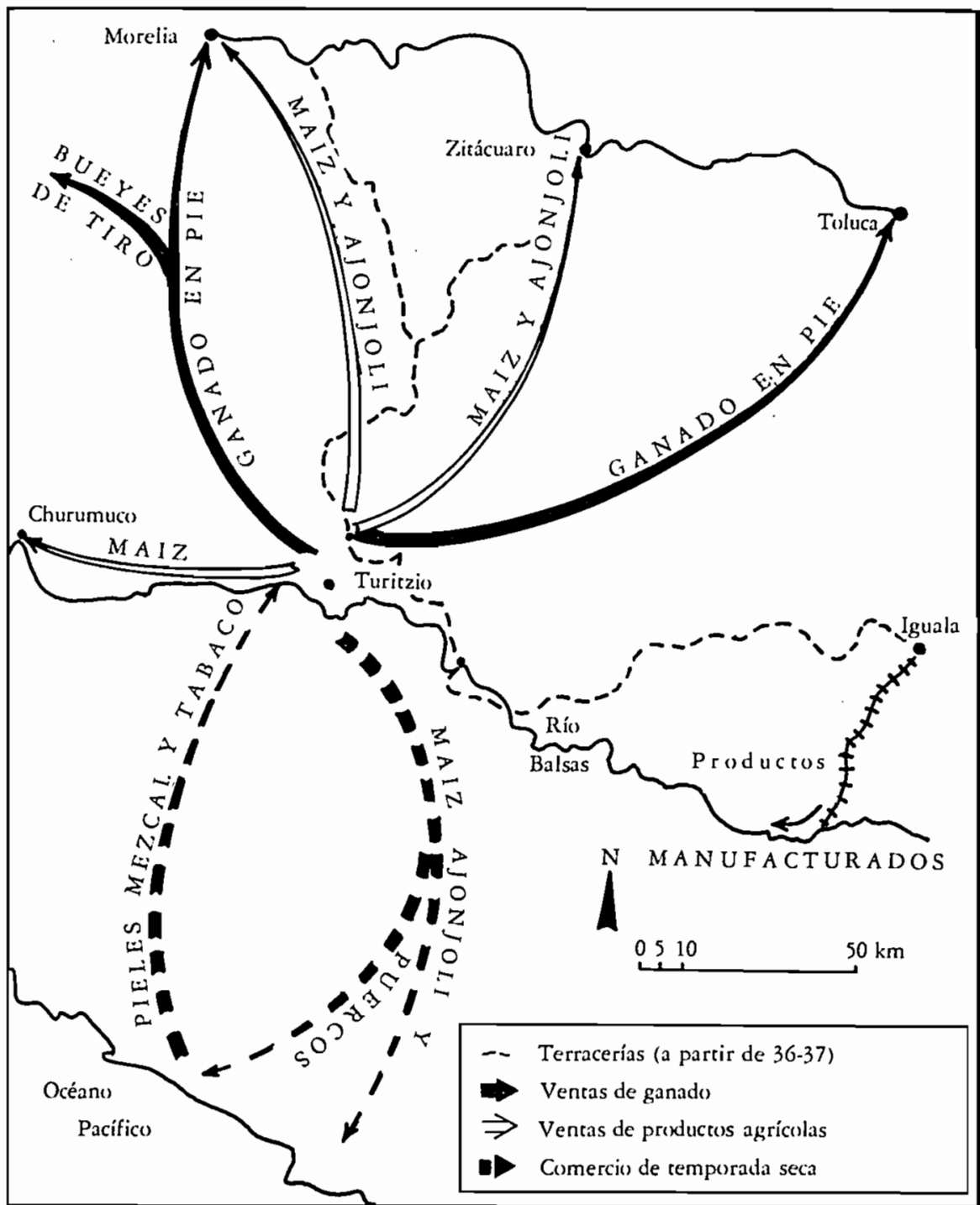


primer peldaño necesario en la acumulación.

En los ranchos de Charácuaro y San Bartolo, más aislados y donde los márgenes de acumulación de los arrenda tarios eran también más reducidos, los terratenientes impidieron el desarrollo de ese tipo de comercio: los intercambios se limitaban a la compra de la cosecha por el dueño.

\section{Conclusiones}

En 1934, cuando pareció evidente que los latifundios iban a ser afectados y que un ejido iba a reunir a las comunidades de Turitzio, Zicuirán y Charácuaro, dos categorías de campesinos podían ver ventajas en los cambios que se preparaban. Los peones que pretendían el acceso a la tierra sin tener de antemano ningún medio de producción salvo su fuerza de trabajo y los arrendatarios, que iban a librarse del saqueo operado por los terratenientes, teniendo acceso a los medios de acumulación (equinos para el comercio, agostaderos colectivos para mantener el ganado), la vía de diferenciación ya estaba trazada y la ventaja que tenían sobre los peones en el desarrollo de sus intereses era grande.

Semejante desigualdad también aparecía entre las comunidades; en Turitzio, por ejemplo, una capa de la población estaba ya comprometida con los procesos de acumulación (posesión de tierras, de ganado, participación en el comercio temporal) sin tener el temor de ser a fectada por el agrarismo, mientras que en Charácuaro los posibles beneficiarios de una repartición de las tierras no tenían ningún (o casi ningún) medio de producción.

\section{GANADEROS Y AGRICULTORES: DIFERENCIACION Y ACUMULACION EN EL EJIDO DE TURITZIO (1936-1960)}

\section{Creación del ejido y diferenciación social ${ }^{17}$}

En 1934 se aprobó la resolución de creación del ejido de Turitzio que tuvo existencia legal desde noviembre de 1936. El ejido se extiende sobre las tierras de las "haciendas" de Charácuaro (1,545 hectáreas), San Bartolo (771 hectáreas), Limón de Angandico (216 hectáreas) y del "condueñazgo" de Turitzio (2,079.5 hectáreas). El mapa 5 intenta reconstruir los linderos del

17. Sobre el mismo tema en el Bajío zamorano ver Jean Meyer, "Los 'Kulaki' del ejido (los años 30)", en Relaciones. No. 29, El Colegio de Michoacán, Zamora, Mich., 1987, p. $23-31$. 
nuevo ejido constituido alrededor de los de los antiguos latifundios. Por sus dimensiones, el ejido de Turitzio es el segundo del municipio. Las tierras de temporal representaban 1,916 hectáreas, o sea el $41.5 \%$ del total de la superficie $(4,611.5$ hectáreas), pero esa cifra no tiene gran sentido: varios terrenos considerados de temporal al ser poco accidentados tienen suelos demasiado delgados para prestarse al cultivo.

Sin embargo, en un primer momento sólo fueron distribuidas 80 parcelas que recibieron los arrendatarios, pequeños propietarios y unos 35 peones líderes del movimiento agrarista en la micro-región. Enseguida se fue ampliando el número de dotaciones hasta llegar a 173 en 1937. Por supuesto la duración del proceso tuvo influencia sobre la dimensión y la calidad de las parcelas distribuidas.

De hecho, pequeños propietarios, arrendatarios y algunos de los "condueños" pudieron instalarse en las tierras que se cultivaban antes (en términos generales, las que figuran en el mapa 3), más húmedas, más profundas y que se habían beneficiado desde luego de las aportaciones de fertilidad del ganado. Los que llegaron en último término recibieron tierras marginadas o bien, fueron mandados a las comunidades de Charácuaro y Zicuirán donde la gente los recibió con hostilidad y los confinó en parcelas de menor calidad. La presión sobre la tierra se manifestó desde un principio en Turitzio donde el tamaño de las parcelas distribuidas pasó de 8 hectáreas en un principio a $4-5$ hectáreas un año después, para los peones que habían tardado en hacer acto de solicitud o cuyo derecho había sido dejado a salvo. La situación era distinta en 'Charácuaro donde los ejidatarios disponían en un principio de dos a tres parcelas de ocho hectáreas cada una (sólo 20 personas habían sido dotadas). Pero el límite ahí era otro: los arrendatarios no disponían de ganado y la fuerza de trabajo (animales de tiro) quedaba así muy limitada.

La repartición de los otros medios de producción entre ejidatarios siguió el mismo patrón. Los dueños de los ranchos de Charácuaro y San Bartolo confinados en pequeñas propiedades de menos de 100 hectáreas, con el $90 \%$ de pastizales cerriles) y privados de la seguridad del uso de los agostaderos y de los residuos de cosecha vendieron la mayor parte de sus hatos. Algunos de los arrendatarios de Turitzio y Zicuirán pudieron aprovechar esa oportunidad para adquirir una yunta. Pero la mayor parte del ganado que integró el ejido provenía de los hatos de los "condueños", caporales y pequeños propietarios que recibieron parcela, aprovechando sus lazos familiares y su poder económico. Un ejemplo sería cuando el "condueño" más rico en Turitzio, poseedor de un hato de 400 cabezas, pagó y hospedó a los ingenieros del Departamento de Asuntos Agrarios y Colonización (DAAC) y prestó dinero a los líderes agraristas. ${ }^{18}$ En 1937 ,

18. Entrevistas con los ancianos del ejido. 
MAPA No 5 .

El eJIDO DE TURITZIO EN EL MARCO DE LOS ANTIGUOS LATIFUNDIOS

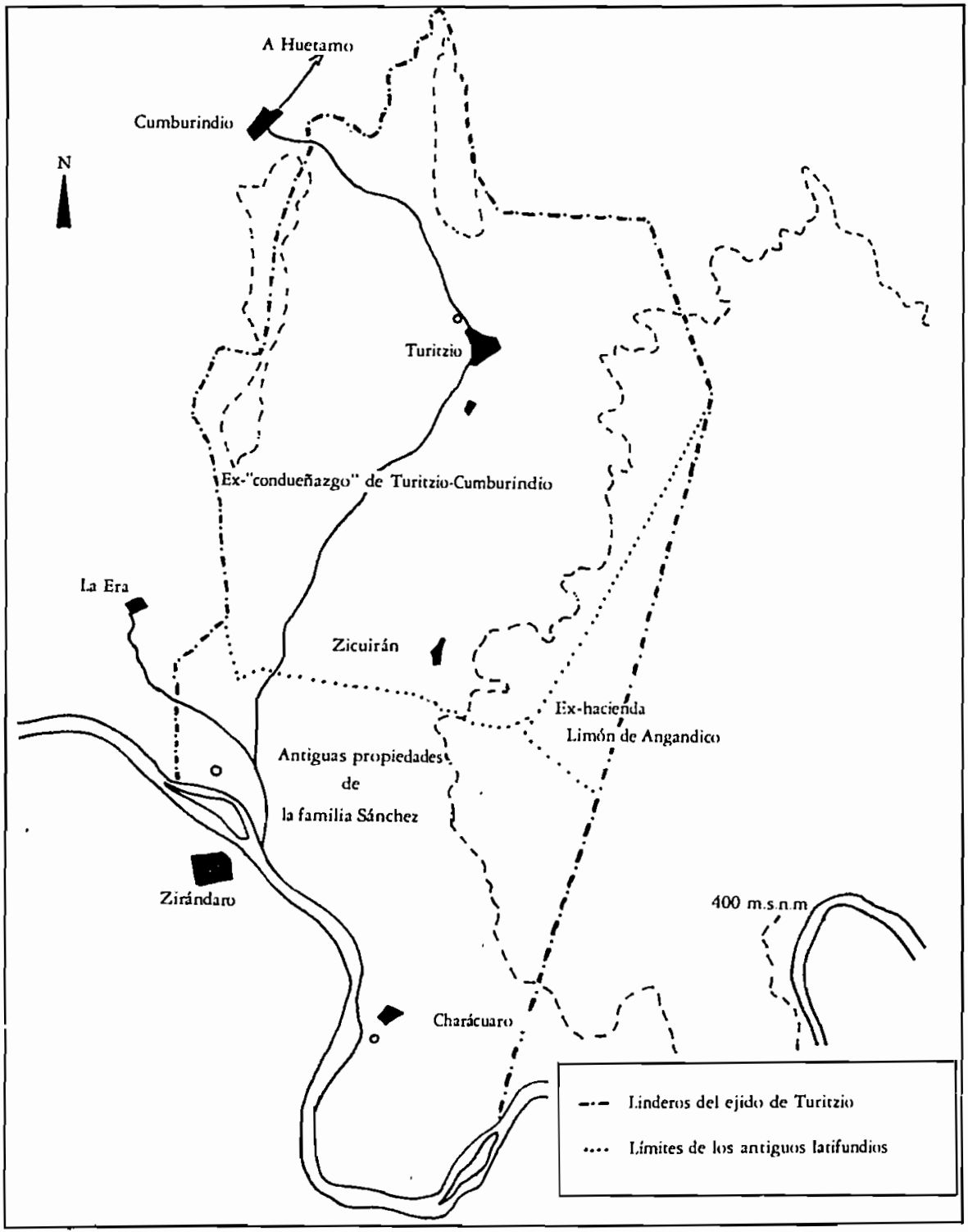


unos 20 ejidatarios concentraban el ganado vacuno del ejido así como los arados, yugos, etc. Tres o cuatro de ellos tenian más de 30 cabezas y aprovechaban sin costo alguno los agostaderos y los esquilmos agrícolas. En Charácuaro el dueño del rancho conservaba el control de los animales de tiro pese a las numerosas ventas de ganado que había hecho. Las yuntas se prestaban el tiempo de amansarlas o se rentaban antes de venderlas hacia Ario de Rosales, Morelia, etc. El hato del rancho pudo seguir aprovechando las tierras de cultivo después de la cosecha; las aportaciones de estiércol seguian siendo una necesidad para los ejidatarios.

El pueblo de Turitzio se volvió así rápidamente el "centro ganadero" del ejido mientras las demás comunidades -Charácuaro sobre todo- se quedaban semi-sujetas a los ex-terratenientes y se atrasaban en el proceso de acumulación. Con la fuerte reducción de los efectivos de los hatos en Charácuaro y San Bartolo y la "desaturación" consecuente del espacio forrajero, los ganaderos de Turitzio adquirieron un poder económico mucho más fuerte, así como perspectivas evidentes de reforzarlo más a corto plazo.

\section{Apertura de la economía campesina}

Los dos primeros decenios de existencia del ejido de Turitzio corresponden en principio - y eso es un fenómeno general a nivel de la región-a la multiplicación de los nexos con otras regiones y la integración de la economía campesina en el marco de la economía nacional. En ese proceso, la apertura de las comunicaciones con el altipla no mexicano a fines de los años treinta tuvo un papel preponderante: en 1936 y 1937 se abrieron las terracerías que unen a Huetamo con Morelia y Zitácuaro y que convirtieron a esa ciudad en el trampolín para la proyección comercial de la sierra guerrerense todavía incomunicada. En poco tiempo, los sistemas de producción campesinos que, hasta entonces, estaban orientados hacia la autosuficiencia familiar estuvieron integrados al mercado nacional. Eso se tradujo en el sensible incremento de las superficies sembradas de ajonjolí - como lo veremos más adelante - y al flujo de materias se sumaron muy rápidamente flujos de trabajo en dos formas distintas.

El desarrollo de las actividades comerciales "de cuaresma"

Ese fenómeno que había aparecido entre los arrendatarios y algunos condueños en el curso de los años treintas se generalizó a un número creciente de ejidatarios, modificándose en su forma. Con el acercamiento de la región al altiplano, los productos agrícolas - maíz y ajonjolí-, encontraron un mercado mucho más accesible que en las partes aisladas de la cuenca del Balsas (Churumuco) o de la Sierra Madre del Sur. En cambio, ahora llegaban productos manufacturados como telas, ropa, ferretería, etc., 
de los cuales se podía sacar beneficio en esas regiones, donde no llegaban ni tren ni camión.

Se fueron multiplicando entonces las salidas de los ejidatarios en la temporada seca llevando ropas y telas en burros hasta la sierra y la costa de Guerrero, en viajes que duraban un mes o más. Regresaban con chile seco, tabaco, pieles y chivos que se vendían en Ciudad Altamirano, Huetamo, Zirándaro, etc. Pese a los riesgos y asaltos frecuentes en el camino, todos los testimonios coincidieron en subrayar la rentabilidad de esas operaciones: se volvieron el medio más rápido y seguro para "hacerse de ganado" y acumular medios de producción o de comercio en el ejido.

Pero no cualquiera tenía acceso a esa próspera actividad: se necesitaba poseer un atajo de tres o cuatro burros y luego conseguir la mercancía fiada con los comerciantes de Huetamo. Ahí los lazos y relaciones familiares o los bienes personales entraban en consideración. El que no podía hacer prevalecer un pariente ganadero o un pequeño capital en ganado no tenía acceso a la mercancía. La posición de intermediario en Huetamo para la compra y venta de la ropa era, la más "jugosa": por lo menos dos de los ex-terratenientes del "condueñazgo" de Turitzio se instalaron así en Huetamo. De hecho, son en su mayoría los hijos de los antiguos "condueños" o los más ricos de los ex-arrendatarios y pequeños propietarios quienes pudieron aprovechar ese comercio. Para los ejidatarios pobres las posibilidades de acumulación seguían siendo reducidas y el solo bien que podían valorizar era su fuerza de trabajo. El reclutamiento de braceros en áreas de agricultura intensiva les daba una oportunidad.

\section{Primeras migraciones de braceros}

Con la entrada de Estados Unidos en la segunda guerra mundial y el lanzamiento del programa bracero de 1942 a 1964, algunos ejidatarios pudieron aprovechar esos contratos temporales de 3 a 6 meses que les permitieron constituir un capital en dólares. Pero el número de campesinos que salían de braceros era muy limitado: se fijaba un cupo de tres a cuatro personas por ejido que luego daba lugar a un sorteo con las oportunidades de manipulación que se pueden imaginar por parte de las autoridades. Más seguro era, para los que disponían de los recursos necesarios, ir hasta Monterrey o Sonora y aprovechar ahí los reclutamientos masivos. De tal manera que esos contratos muy rentables los aprovechaban principalmente los familiares de ejidatarios ricos.

Las salidas hacia los perímetros irrigados de la República Mexicana eran al fin y al cabo, mucho más fáciles, aunque menos rentables. Desde principios de los años cuarentas los ejida tarios comenzaron a ir hacia la zona cafetalera de Atoyac, Guerrero, o los perímetros irrigados de Apatzingán y 
trabajar parte o la totalidad de la temporada. Pero el fenómeno migratorio que cobró más importancia se hizo hacia la franja cañera del estado de Veracruz, a partir de la mitad de los años cuarentas. Con gran rapidez, los ingenios de la costa sur de Veracruz desarrollaron una red de contratación y de transporte desde la cuenca del Balsas hasta las plantaciones. Gracias a la construcción de la terracería que llegaba hasta Huetamo, los camiones fletados por los ingenios llegaban a los pueblos para llevar a los braceros hasta la zona cañera. El sistema de reclutamiento descansó entonces sobre un número limitado de "contactos" en cada ejido: los "cabos" de gente se escogían entre las autoridades políticas o económicas de las comunidades y eran por lo regular hijos de ganaderos. Estos reclutaban "su gente" (unas 100 personas) y salían con ellas, casi siempre a principios de diciembre, para el comienzo de la zafra.

Durante los seis meses que duraba la zafra, el "cabo" hacia de intermediario entre el ingenio y sus trabajadores; el ingenio le pagaba las cañas por tonelada, con el encargo de repartir el dinero entre los braceros en función de lo que cortaba cada quien. Su comisión era del orden del 30 al $40 \%$ de lo que pagaba el ingenio. Los testimonios abundan sobre las malversaciones por parte de los "cabos": trampas en el peso de la caña; robo de las indemnizaciones por accidente; del sueldo de los días de lluvia en que no se podía trabajar pero que el ingenio pagaba, etc. Cuando se sabe además que las tiendas que vendían alimentos, ropa, etc. a los braceros, pertenecían en general a los "cabos", se entiende lo jugoso que podía ser el negocio de la mano de obra en la zona cañera.

Pese a esas condiciones, el corte de caña a partir de los años cincuentas, se volvió un elemento fundamental del sistema de producción de los ejidatarios más pobres. Con la salida se aseguraba el mantenimiento de la familia durante seis meses sin tocar las reservas de maíz de la unidad de producción, lo que permitía además reducir la superficie sembrada de maíz en beneficio del ajonjolíe incrementar los ingresos monetarios de la familia. "No se ahorraba nada en el corte de caña" confiesan los braceros. Sin embargo, el beneficio para ellos era obvio. Además, la necesidad de salir a principios de diciembre limitaba sensiblemente el tiempo que se podía consagrar a la cosecha del maíz, mientras que con el ajonjoli, que se cosechaba en octubre, el problema no se planteaba. En los años cincuentas y sesentas, según los testimonios de la gente entrevistada, el ejido se vaciaba de más de la mitad de su población. Se iba a buscar a la gente hasta San Jerónimo, en la frontera con el municipio de Churumuco, distante en esa época seis horas del camino de Huetamo.

Rápidamente, los comerciantes-ganaderos siguieron el movimiento hacia el Golfo de México, llevando ropa, zapatos y hasta joyas de oro que se fabrican en Huetamo. Se podía conseguir la mercancía en Huetamo o en casas de 
negocio de la ciudad de México. El flujo de trabajadores en esa época del año amplificaba el mercado potencial. Poco a poco, con el desarrollo económico del sureste, el área de migraciones se fue ampliando hacia los estados de Tabasco, Chiapas y Campeche.

Al fin y al cabo, esa apertura de la economía campesina contribuyó a ahondar el abismo entre dos tipos de ejidatarios.

\section{Ganaderos-comerciantes y agricultores-braceros: acumulación y diferenciación}

A mediados de los años cincuentas, el comercio temporal hacia las costas del Pacífico o del A tlántico ya se había afirmado como la vía más rápida y segura de acumulación. Peroesa actividad comercial estaba estrechamente vinculada con la posesión y cría de ga nado bovino: como ya lo vimos, la acumulación previa - y aunque limitada - en forma de ganado fue una condición para el acceso a los préstamos y fianzas de mercancía, sin los cuales ese negocio hubiera quedado fuera del alcance de la mayoría de los ejidatarios. La ganadería era también, junto con la compra de un fondo de comercio en Huetamo, Turitzio o Zirándaro, la forma más común de invertir y hacer fructificar los beneficios del negocio.

Se perfiló así entre los años 1940 y 1960 una clase de ganaderoscomerciantes cuyas características, pese a orientaciones más acentuadas hacia el comercio o hacia la ganadería, afirman la homogeneidad y la convergencia de sus intereses. En el ejido de Turitzio, esa clase no contaba en 1960 con más de 20 representantes que concentraban el $90 \%$ del ganado. Todos vivían y tenían tierras en Turitzio. Zicuirán y, sobre todo, Charácuaro seguían siendo pueblos de agricultores, económicamente atrasados. En Turitzio, dos personas sintetizaban ese caciquismo ganadero y comerciante: Miguel Reyna, quien fue hasta su muerte el principal negociante y usufructurario del ejido, y Raúl Aguirre con " 500 reses, 6 mujeres y 35 hijos" quien era el ganadero más importante. Se habla todavía de ellos en términos de referencia. Esos ganaderos acostumbraban por lo regular dejar las actividades comerciales en manos de sus hijos cuando su aprendizaje estaba terminado, lo que les permitía hacerse de un capital, y luego invertirlo en el inicio de un nuevo hato. Ese ganado se podía entonces mantener, gracias a la influencia del padre, en los agostaderos y potreros del ejido y servía, cuando el hijo se quería instalar, de fondo de inversión para la compra de una dotación. En el intervalo éste podía rentar tierras a ejidatarios careciendo de fuerza de trabajo, eventualmente a cambio del préstamo de una yunta. Así pues, mediante la posesión de los animales de trabajo, los ganaderos seguían controlando el desarrollo de los sistemas de producción de los campesinos pobres. 
Para los agricultores, el éxito de los ganaderos-comerciantes había dibujado las líneas de un proceso de acumulación que no quedaba totalmente fuera de su alcance. Los antiguos peones tendian entonces a ampliar las superficies sembradas de ajonjoli en espera de una buena cosecha que les iba a permitir comprar el atajo de burros indispensable para el comercio hacia la sierra y la costa del Pacífico. El desarrollo de las migraciones de temporada seca y la desaparición de las limitaciones impuestas por los terratenientes antes de la creación del ejido provocaron el desarrollo sensible del cultivo del ajonjolí -fenómeno general a toda la región de la cuenca del Balsas- que se convirtió en el primer producto agrícola, en valor, de toda la zona. Se generalizó en las unidades de producción la rotación bi-anual maíz-ajonjolí en las tierras favorables y el cultivo puro del ajonjolí (tres años de cultivo seguidos de un año de descanso por lo regular) en las zonas marginales, de lomas a muy delgadas. Esa extensión del ajonjolí en todo el terruño del ejido tuvo una influencia cierta en el incremento de la erosión que se hizo preocupante en toda la región desde esa época. La existencia de un molino para la extracción del aceite en Huetamo permitía limitar el papel y las recaudaciones de los intermediarios.

De hecho, la gran mayoría de los ejidatarios pudo adquirir un tronco o hasta un atajo de burros que les daba autonomía para traer la leña, transportar la cosecha y eventualmente, hacer labores como rayar la milpa. El acceso al comercio temporal, seguía siendo subordinado al apoyo de algún ganadero que aceptara servir de garantía para conseguir mercancía fiada. Los ex-peones que tenían esas oportunidades eran contados.

Quedaba la posibilidad de ir ahorrando los beneficios de las cosechas de ajonjolí para comprar poco a poco bovinos, mientras la diferencia de acumulación con los ganaderos no dejaba de crecer.

Al fin y al cabo y pese a esa oportunidad que constituía para ellos el cultivo del ajonjolí, los agricultores pobres seguían padeciendo de las herencias del sistema latifundista: carencia de una fuerza de tracción que les pusiera al amparo del control de los ganaderos; tierras marginales de menor calidad que las que se cultivaban antes de la repartición y que conservaron dueños y arrendatarios; dependencia en las aportaciones de fertilizantes, de la permanencia del hato de los ganaderos; fragilidad financiera que podía llevar a endeudarse con esos mismos ganaderos. En resumen, una vulnerabilidad acentuada frente a la llegada de una nueva generación de campesinos haciendo valer su derecho al acceso a la tierra y solicitando el fraccionamiento de las dotaciones. Eso sólo podía acentuar la orientación de esa clase hacia la agricultura y la renta de su fuerza de trabajo.

Ese cisma social se reflejó también en la distribución de los recursos económicos entre los diferentes pueblos del ejido: en 1960, Turitzio concentraba alrededor del $80 \%$ de la población bovina del ejido y los ganaderos de ese pueblo podían beneficiarse de los agostaderos situados en 
las otras comunidades, mientras en Charácuaro, sólo dos campesinos de unos 40 ejidatarios tenían algunas reses sin llegar al número de diez.

\section{La ocupación del espacio agropecuario}

En relación con las evoluciones ya descritas, los dos primeros decenios del ejido corresponden a la colonización y la ocupación progresiva del espacio agropecuario. Por supuesto esa dinámica fue en gran parte promovida y aprovechada por los ganaderos.

El primer índice de esa evolución nos está dado por el número de ejidatarios capacitados, el cual pasa de 80 en la fecha de creación del ejido, a unos 205 en 1960, según las estimaciones de los testigos entrevistados. Pero la expansión no se hizo de manera equitativa en todas las comunidades: a partir de los años cuarentas los campesinos de Zicuirán y Charácuaro tuvieron que recibir un flujo de jóvenes que llegaban de Turitzio, pero también de otras partes de la región, solicitando las tierras que quedaban libres.

Esas migraciones se hicieron gradualmente a partir de Turitzio hacia Charácuaro el pueblo más alejado. A fines de los años treintas todas las tierras alrededor de Turitzio habían sido distribuidas y la política de los ganaderos y de las autoridades políticas ejidales, todos originarios de Turitzio, fue mandar a los solicitantes hacia las demás comunidades a fin de evitar la saturación del espacio en la cabecera ejidal. De hecho, el espacio disponible era mucho más importante en las tierras correspondientes a los antiguos ranchos de San Bartolo y Charácuaro, donde su uso había sido más extensivo.

Los primeros "colonos" se instalaron en Zicuirán y luego formaron el caserío de El Embarcadero, en los terrenos confiscados al rancho de San Bartolo, en la mitad de los años cincuentas. La ubicación frente a Zirándaro permitía además aprovecharse de la circulación y los intercambios entre esa ciudad y Huetamo. Como ya lo vimos, fue en Charácuaro donde quedó más espacio desocupado. La disponibilidad de tierra y la posibilidad de conseguir una dotación de 6 a 8 hectáreas en los años cincuentas eran atractivas para los solicitantes. Su instalación fue muy rápida: en 1958 se distribuían las últimas parcelas de 3 a 4 hectáreas. Siguiendo ese ritmo, el número de ejidatarios pasó de unos 20, en la creación del ejido, a más de 50 en 1960 en Charácuaro; se llegó a una ocupación total de las tierras consideradas de temporal en la resolución de creación del ejido. El mapa 6 refleja, comparándolo con el mapa 3 esa ocupación del espacio agrícola que llegó a ser completa. 
MAPA № 6.

OCUPACION DEL ESPACIO AGROPECUARIO A FINES DE LOS AÑOS '50

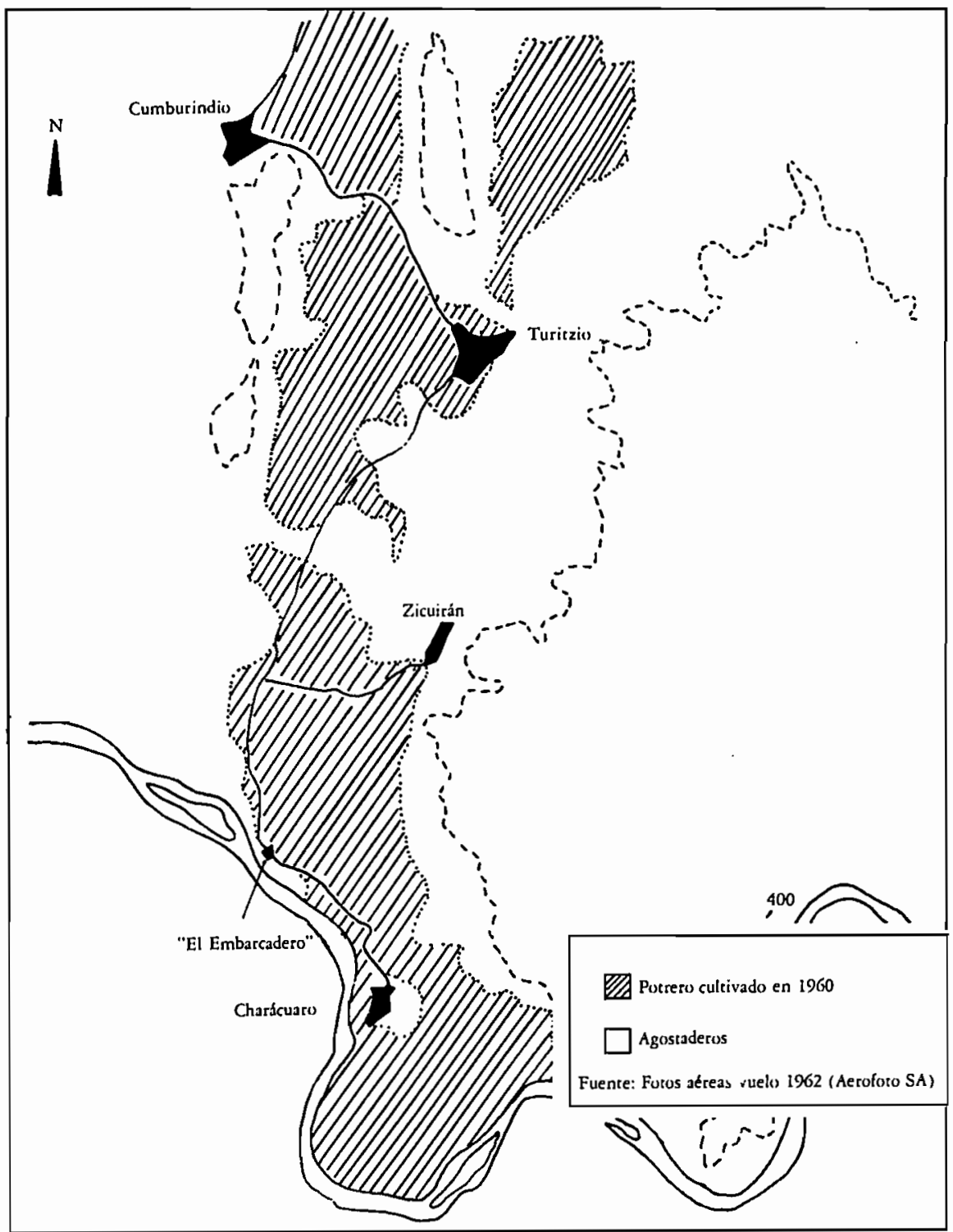


Esas migraciones permitieron a los ganaderos de 1 uritzio librarse de una presión importante sobre las tierras de su comunidad y la apertura de nuevos terrenos al cultivo les ofrecía un espacio forrajero más amplio para la estación seca. En relación con la disminución de la importancia relativa del maíz en las rotaciones de cultivos que implicaba una reducción de las U.F. disponibles por unidad de superficie en el ejido (y más globalmente a nivel regional) el aumento del espacio cultivado se volvía una necesidad para el mantenimiento de hatos más grandes y numerosos. Por otra parte, la gran mayoría de los nuevos instalados carecía de animales de tracción y de capital para invertir en medios de producción. Eso ofrecía a los ejidatarios ricos la perspectiva de un incremento de sus recursos por la renta de animales, la usura o más sencillamente la posibilidad de ampliar su superficie cultivada por la renta de tierra a campesinos que no alcanzaban a cultivar la totalidad de su dotación. En ese sentido hubo para la "colonización" del espacio en Charácuaro convergencia de intereses entre los campesinos sin tierra, los ganaderos de Turitzio y los dueños de la pequeña propiedad que conservaban ahí el monopolio de la fuerza de tracción, aunque al final, la llegada masiva de ganado proveniente de Turitzio durante la estación seca, limitó considerablemente las posibilidades de desarrollo del hato del rancho de Charácuaro.

Esa ocupación y explotación de la totalidad del temporal implicó una modificación del calendario forrajero en comparación con la forma que tenía antes de la creación del ejido y algunos años después:

Grafica No 4

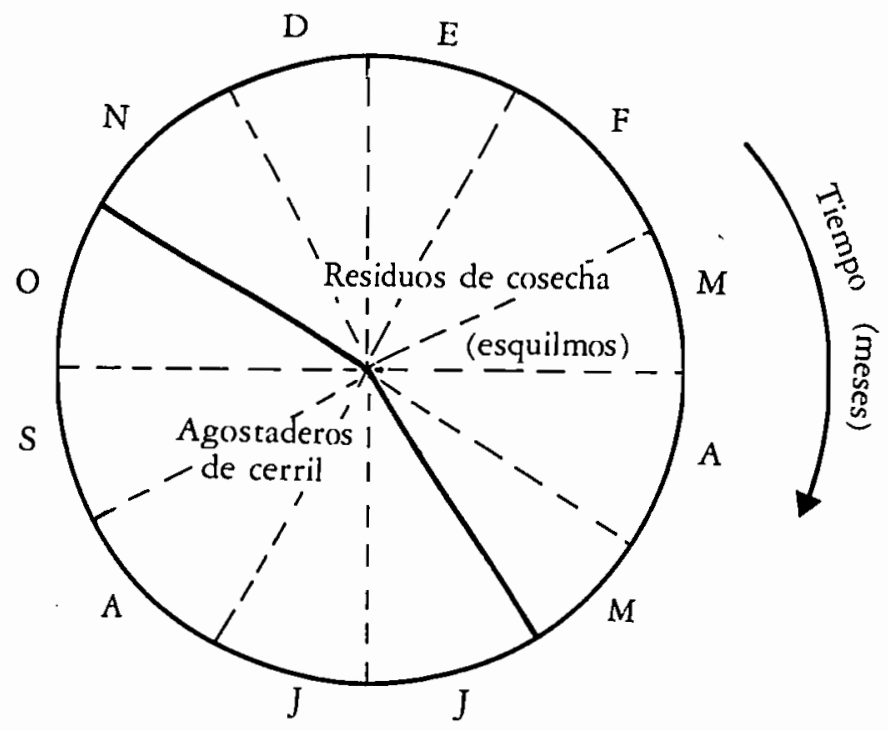


El pequeño número de ganaderos y el tamaño aún reducido del hato del ejido no implicaba todavía saturar la capacidad forrajera del espacio de cultivo. ${ }^{19} \mathrm{El}$ periodo siguiente iba a cuestionar el equilibrio de este sistema.

\section{CRECIMIENTO GANADERO Y SATURACION DEL SISTEMA AGRARIO (1960-1980)}

Al finalizar los años cincuentas, la región de la cuenca michoacana del río Balsas se encontraba cada vez más estrechamente integrada a la economía nacional. En relación con ese fenómeno, el crecimiento de las poblaciones humanas y animales en un terruño limitado iba a precipitar al sistema social de producción en una situación de estanca miento en la cual no parecía haber salida para los pequeños productores.

\section{Crecimientos demográficos y saturación del espacio agrario}

Ya se ha indicado cómo en el curso de los años cincuentas se había llegado a una ocupación casi completa del espacio agrícola disponible y en el aspecto pecuario a una adecuación entre los recursos forrajeros y la carga animal. A partir del inicio de los años sesentas la precaria estabilidad del sistema desaparece bajo la presión del crecimiento de las poblaciones humana y bovina.

La población humana, 25 años después de la creación del ejido llega a duplicarse. Pero más que todo, en esa época surge una nueva generación de

19. Bajo las hipótesis, a nivel del ejido, de un rebaño de 1,500 cabezas en 1955 (probablemente sobreestimado) y de una superficie cultivada de 1,600 hectáreas cultivadas en rotación bi-anual maíz-ajonjolí, la carga por hectárea durante los seis meses y medio de estación de los animales en los terrenos de cultivo se establece a 0.9 unidades animales ( $1,500: 1,600$ ). Las necesidades forrajeras ( 4 unidades forrajeras por día y por animal) alcanzan entonces para los 200 días considerados:

$$
200 \times 4 \times 0.9-720 \text { U.F. }
$$

Consideramos el potencial forrajero de una hectárea en rotación maíz-ajonjolí:

$-1 / 2$ hectárea de rastrojo de maíz 550 U.F. disponibles

$-1 / 2$ hectárea de arón de ajonjolí 200 U.F.

Sea un total de 750 U.F., lo que alcanza a mantener 0.9 unidades de ganado durante casi 7 meses pero no más.

El equilibrio del sistema en cuanto al mantenimiento de la fertilidad es mucho más discutible: una unidad puede aportar 4 toneladas de estiércol durante su permanencia, lo que cubre solo la mitad de las extracciones en una hectárea de maíz, y es la única fuente de fertilizante. 
campesinos, hijos de los primeros ejidatarios, solicitando el acceso a la tierra y el derecho a tumbar el monte que servía de agostadero en las vertientes del cerro de Turitzio. En 1960, los últimos pedazos de temporal del ejido se repartieron y no quedó entonces más salida a los problemas de tierras que los agostaderos comunales.

El aspecto de esos terrenos ha cambiado mucho en 20 años: la explotación del monte para leña y madera de construcción, conjugada con el aumento permanente de la carga de animales en la estación de lluvias ha contribuido a la deforestación, la disminución de la cobertura vegetal en los cerros y el incremento de la erosión pluvial. Lo anterior sumado a la desaparición de grandes áreas de monte para uso agropecuario, llega a explicar las disminuciones del régimen de las lluvias y de la duración del temporal que todos los ancianos mencionan: "Las lluvias se hicieron más escasas y a la vez más fuertes. Ya no se pudo sembrar antes del 20 de junio"; "desde hace 30 años el arroyo que pasa por Turitzio se seca en la cuaresma" y en Charácuaro "desde hace unos 20 años, los pozos se secan en mayo".

El aumento consecuente de los riesgos para la agricultura tuvo su equivalente en el manejo del ganado: con la disminución de la superficie en agostaderos y de los árboles que los animales puedan ramonear y con la escasez de las lluvias pasado el primero de octubre, anticipar el regreso de los rebaños hacia el potrero cultivado se hizo una necesidad cada vez más aguda para los ganaderos.

Como lo vimos antes, para la creación del ejido, el terruño se había dividido en sólo dos partes: los agostaderos y un potrero común donde el ganado podía desplazarse y pastorear libremente. Esa organización requiere una gran concertación de esfuerzos entre los productores para que el ganado no se introduzca en el potrero antes del final de las cosechas, o sea antes de mediados de diciembre. Las incursiones de ganado, cada vez más frecuentes desde la mitad de noviembre generaron conflictos agudos entre los ganaderos y los agricultores. Además, el crecimiento de los hatos y la saturación evidente de los recursos forrajeros del potrero quitaban a muchos agricultores toda posibilidad de poder algún día acumular algunas cabezas y mantenerlas en su parcela: los grandes ganaderos tenían una capacidad de paliar la escasez de forrajes mucho mayor.

Después de haber rechazado la solicitud varias veces, los ganaderos tuvieron que conformarse con la voluntad de la mayoría y aceptar que cercaran las parcelas individuales. El movimiento se fue propagando poco a poco de Turitzio hacia las demás comunidades a medida que los hatos de la cabecera ejidal iban extendiéndose hacia la periferia del ejido. El potrero de Turitzio fue, en su mayor parte, cercado con los recursos propios de los ejidatarios. En las demás comunidades donde la acumulación individual había sido menor, la individualización de las parcelas se hizo frecuentemente por acuerdo entre el ejidata rio y un ganadero. Este entregaba la totalidad del 
alambre necesario para cercar la parcela a cambio del derecho a aprovechar durante cierto número de años ( 5 a 10 por lo general) los esquilmos que quedaban. Después de ese tiempo, el dueño de la parcela se volvía teóricamente dueño del pasto también.

En 1965, todo el potrero de Turitzio había sido cercado y en 1970 , era el caso en Zicuirán y El Embarcadero. En Charácuaro el proceso se atrasó hasta el principio de los años ochentas. Ahí la carencia de recursos individuales y la ausencia de ganado en las manos de los ejidatarios, así como el aislamiento de la comunidad reducían la autonomía de decisión de los agricultores: la permanencia del ganado durante la temporada seca seguía siendo una necesidad para la reposición de la fertilidad de los suelos ante la ausencia de fertilizantes químicos. Por otro lado, se llegó a un acuerdo con los ganaderos, los cuales aceptaron pagar contribución por cabeza que se mantenía en el potrero de Charácuaro. Sin embargo, al acentuarse la presión sobre los recursos forrajeros, los mismos ganaderos provocaron por fin el fraccionamiento del potrero de Charácuaro: el ganadero más importante del ejido inició en 1983 ese proceso por el sistema de financiamiento del alambre que se acaba de describir. En dos años, la totalidad de las parcelas han sido cercadas.

En consecuencia, la división física de los terrenos de cultivo daba un arma a los agricultores frente a los ganaderos. Además de ofrecerles inmediatamente o a corto plazo un recurso anexo por la venta de los esquilmos, esa individualización de las parcelas les dejaba la posibilidad de poseer algunas reses ${ }^{20}$ sin sufrir de la saturación global de los recursos forrajeros a nivel del ejido.

Para los ganaderos, fuera de los cálculos individualistas, la situación se hacía más preocupante y limitaba sus perspectivas de expansión. A fin de prevenir la carencia de forraje a principios de la temporada seca, cuando todavía no se podía acceder a las parcelas de maíz y para proveerse de un fondo de reserva en forrajes, algunos de los ganaderos empezaron desde el principio de los años sesentas, pero sobre todo después de la individualización de las parcelas en el potrero de Turitzio, a apropiarse de una parte de los agostaderos cercanos al pueblo. Cabe destacar que los ganaderos más importantes, aprovechándose de su poder económico y político encabezaron el proceso. Este se fue desarrollando con cierta velocidad. En el curso de los años setentas un total de 35 a 40 ganaderos habían cercado partes de monte con una superficie aproximada de 300 hectáreas. Los terrenos presentaban dimensiones variables de 5 a 50 hectáreas cada uno.

20. Como ya lo vimos una hectárea de maíz (1,100 U.F.) permite mantener 1.3 unidades de ganado durante los 7 meses de estación seca; unos 8 animales en una dotación de 6 hectáreas. 
Por supuesto, las partes más húmedas y aprovechables de los agostaderos fueron el objeto de esa apropiación. Los agricultores y pequeños ganaderos vieron así impedido su acceso a los arroyos cercanos a los pueblos.

Dado el ejemplo, algunos de los hijos de ejidatarios pobres se atrevieron entonces a tumbar parcelas de monte para sembrar la milpa. Pequeñas áreas de cultivo del maíz aparecieron cerca de Turitzio y Zicuirán en condiciones riesgosas y en áreas de fuerte erosión: un año de descanso se impone después de uno o dos años de cultivo; cuando el terreno se va agotando se siembra eventualmente ajonjolí antes de abandonar la parcela por un tiempo más largo.

Frente a la amenaza de una ocupación de los agostaderos por los agricultores los ganaderos lograron impedir que se tumbaran nuevos espacios, procediendo a efectuar denuncias ante la Dirección Forestal en caso necesario. De esa manera, se logró limitar aunque no impedir las ocupaciones a nárquicas de los agostaderos que amenazaban su prosperidad y pudieron mantener las cercas que habían puesto.

Se había llegado a una saturación casi total del espacio agropecuario, situación que se refleja en el mapa 7. 


\section{MAPA No 7.}

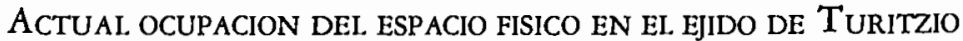

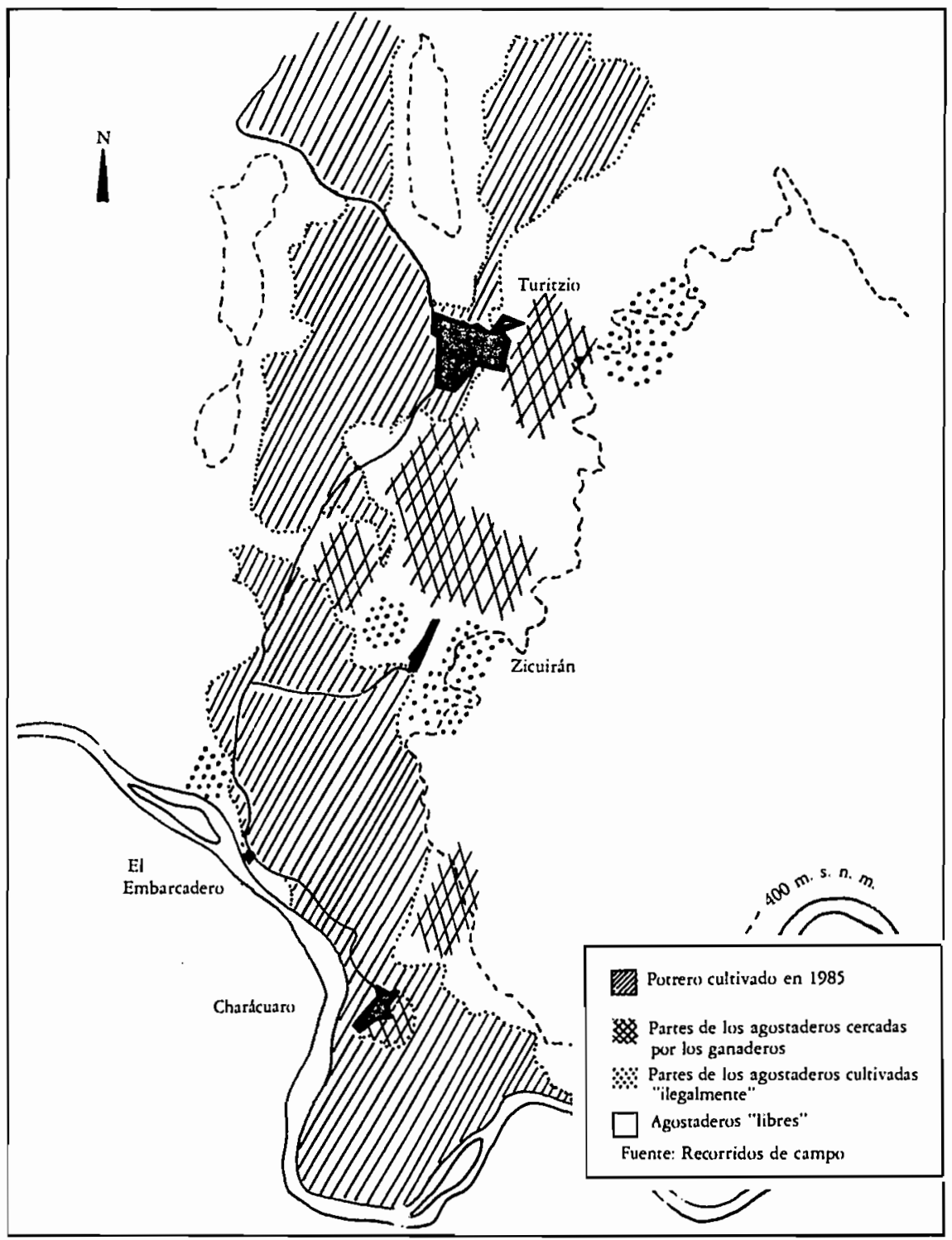




\section{Modificación de las condiciones macro-económicas}

Los años sesenta son también, a nivel nacional, la afirmación de una especialización económica regional y, globalmente, de tecnificación y mecanización de grandes sectores de la agricultura, que no dejó de tener una influencia sobre la economía de una región tan aislada como lo era entonces la cuenca michoacana del río Balsas.

La difusión de los avances de la revolución verde, con su cortejo de mecanización, proliferación de químicos, en una palabra, tecnificación de la agricultura, permitió la especialización cerealera de regiones enteras en el norte del país que se volvieron en poco tiempo los graneros de la república al igual que el bajío guanajuatense. En el bajío esa evolución tuvo como consecuencia la desaparición de las yuntas de bueyes reemplazadas por tractores o tiros de bestias más ligeros y cómodos para los trabajos de limpieza. Desde 1947 durante la epidemia de fiebre aftosa en la población bovina, la política del "rifle sanitario" 21 había favorecido esa substitución y la introducción de los tractores en el bajío. 22

Al bajar la demanda de novillos para amansar, se cerró un mercado importante para los ganaderos de Huetamo (véase el caso de la Sierra Madre del Sur, Capítulo IV).

Otra especialización regional fue la emergencia en las Huastecas de Veracruz, San Luis Potosí, Tamaulipas y en los estados de Querétaro, México y Tabasco, de zonas de engorda de ganado, beneficiándose de condiciones climáticas (abundancia de pasto en el trópico húmedo) o de una ubicación (proximidad de los centros de producción de granos y alimentos) muy favorables. En Huetamo, el aislamiento - la carretera pavimentada no llega a la ciudad antes de 1973-y la escasez de forraje en la estación seca limitaban las posibilidades de engorda y la competitividad de las unidades de producción en el mercado nacional. En contrapartida, la especialización hacia la engorda de las regiones de trópico húmedo incrementaba la demanda en novillos de uno a dos años y permitía la integración de las zonas áridas de la costa del Pacífico en el proceso de producción.

En esta área, la producción de animales para amansar o para matanza ya no se justificaba y los numerosos nexos extablecidos mediante las migraciones temporales con las regiones del trópico húmedo, facilitaron la reorientación del sistema social de producción hacia una mayor integración en un sistema agrario eminentemente ganadero.

21. Jean Meyer, "La fiebre aftosa y la Unión Nacional Sinarquista (1947)", Relaciones. No. 16, El Colegio de Michoacán, Zamora, Mich., 1983, p. 93.

22. Ver Capítulo II. 


\section{Evoluciones de los sistemas de producción}

Una nueva orientación ganadera

Las evoluciones del mercado del ganado y el estancamiento de los recursos forrajeros en la región coincidieron para fomentar un cambio importante en la orientación y las bases técnicas del sistema ganadero tradicional. En pocos años, los ganaderos de Turitzio se especializaron en la producción de novillos de uno a dos años de edad para la venta en los estados de Querétaro - México pero también - aprovechando las relaciones establecidas por los comerciantes - hasta Veracruz o Tabasco. Se establecía así en la región un ciclo de cría más corto en comparación con el que se encaminaba a la producción de bueyes de trabajo amansados o de ganados para matanza: un año menos (el tercio del período de cría). Esta evolución permitía incrementar el número de vacas madres y de cabezas para venta que alcanzaban a mantener el espacio forrajero, o sea, una "intensificación" muy relativa en términos de productividad.

La nueva orientación ganadera se benefició de varias aperturas técnicas dentro de las cuales destaca la generalización de la sangre cebú en los hatos. Los primeros toros "finos" o cruzados aparecieron en los años cincuentas en el ejido de Turitzio pero tomaron importancia real en el curso de los sesentas gracias a la acción de Lázaro Cárdenas, entonces presidente de la Comisión del Balsas y la cruza con sementales cebú se sistematizó en los hatos de los ganaderos adelantados. Esta mezcla de sangre permitía una mayor adaptación del ganado a los cambios climáticos así como a la relativa penuria de los recursos forrajeros. Además, las evoluciones morfológicas consecuentes respondían a las necesidades del mercado hacia la producción del ganado de carne de buena conformación. El mejoramiento genético fue durante mucho tiempo -y sigue siendo, aunque en un grado menor- el privilegio de los ganaderos-comerciantes, miembros de la asociación ganadera local, quienes podían traer sementales de Veracruz o Tabasco, comprados con las ganancias de las actividades comerciales de cuaresma.

Correlativamente al mejoramiento de los hatos, se observó en las unidades de producción de los ganaderos una evolución de los sistemas de cultivo hacia la producción forrajera. En esas unidades, el ajonjolí que había sido progresivamente marginilizado a los terrenos pésimos e impropios para el cultivo del maíz, fue reemplazado por el sorgo o el sudán en el curso de los años sesentas. Esta sustitución no se limitó a las unidades ganaderas sino que se extendió a los ejidatarios viejos o ausentistas, quienes carecían de mano de obra, y podían así rentar a mayor precio su parcela a los ganaderos durante la sequía: al contrario del ajonjolí que requiere numerosos trabajadores para las escardas con tarecua, la apiñada y la sacudida, el sorgo o el sudán no se escardan (en el mejor de los casos se da una raya con el tronco) 
$y$, en algunos casos, ni siquiera se cosechan, ${ }^{23}$ se pueden producir con gastos limitados a la preparación del terreno y el abasto de semillas.

La adaptación de las plantas forrajeras al medio físico de la Tierra Caliente de la cuenca del Balsas se hizo sin dificultad y éstos se difundieron con rapidez en los sistemas de producción.

Paralelamente se desarrollaron entre los ganaderos dos prácticas para prevenirse contra la carencia de forrajes a fines de la cuaresma. Algunos ganaderos fueron a buscar otras comunidades dónde poder mandar sus animales a partir del mes de marzo. Los terrenos de riego de Zirándaro, donde la producción de elotes en febrero y marzo liberaba una cantidad grande de rastrojo verde en el periodo crítico, les daba esa oportunidad. Del otro lado del río Balsas algunas comunidades hicieron, después de Zicuirán y Charácuaro, la experiencia del expansionismo ganadero de los ejidatarios de Turitzio. Pero la estrategia que cobró más importancia fue la de recurrir, cuando se terminaban los residuos de cultivo, a la administración de alimentos balanceados, fabricados en la unidad de producción o comprados afuera. Se podía procurar en Huetamo salvado y pasta de ajonjolí (residuos proteicos que resultan de la extracción del aceite) a precios reducidos (hasta fines de los sesentas funcionó en Huetamo el molino de ajonjolí). Los ganaderos acostumbraron rápidamente moler y mezclar el arón del ajonjolí, que los agricultores les regalaban a cambio de la limpieza del terreno, el grano del sorgo y las mazorcas de maíz para proveer a las necesidades del ganado en los tres últimos meses de sequía. Con la aparición del Sistema Alimentario Mexicano (S.A.M.) y el desarrollo de las tiendas rurales CONASUPO, se ha llegado en algunos casos a moler la totalidad de la cosecha de maíz para el abastecimiento del ganado: el maíz se vuelve planta forrajera al igual que el sorgo y el sudán.

Con estos cambios, no es que el sistema se haya librado del riesgo de saturación de la capacidad forrajera sino que el número de cabezas se incrementó hasta alcanzar esta nueva capacidad. El calendario forrajero cambió parcialmente hasta tener esta apariencia:

23. Algunos ganaderos dejan la planta con panoja y todo a disposición del ganado. En la mayoría de los casos, se cosecha el grano para moler y suministrar a los animales un complemento energético más digerible a fines de la temporada seca. 


\section{GRAFICA No 5}

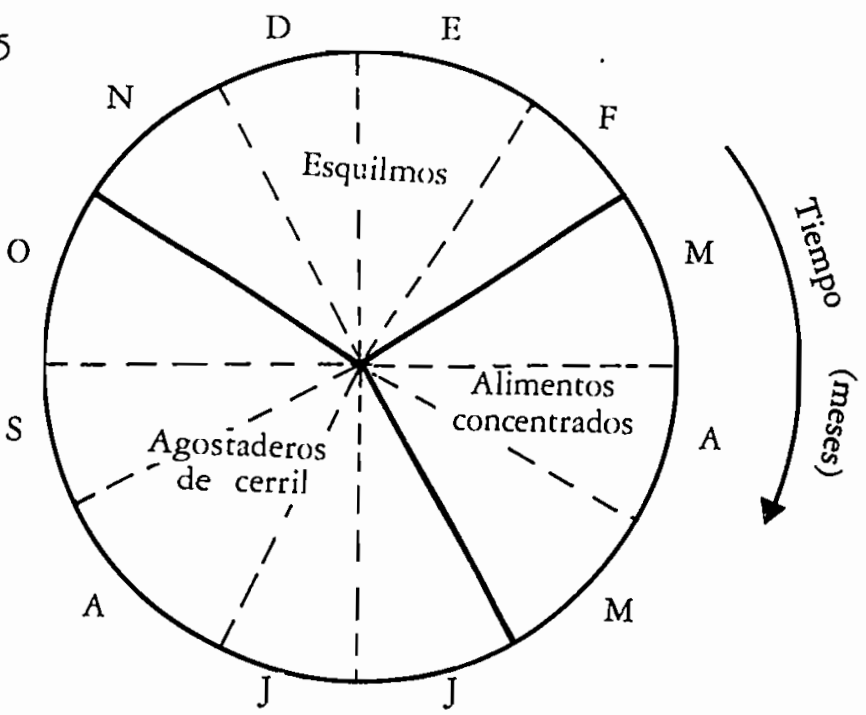

Se observa por otra parte la constante reducción del tiempo de permanencia del ganado en los agostaderos.

La generalización del uso de los alimentos concentrados permitió otro cambio en el manejo de los animales: el período de ordeña de las vacas paridas se desplazó hacia la temporada seca, lo que permitía su extensión de 4 a 667 meses así como la disminución de la mano de obra movilizada para el cuidado del ganado. ${ }^{24}$ Además, la producción de leche en esta época del año permitió encontrar precios muy ventajosos en el mercado local de Turitzio, Zirándaro y Huetamo donde no competía con la leche de los sistemas tradicionales (ordeña en los meses de junio a octubre). Para tal estrategia, el relativo aislamiento de la región y su alejamiento de los centros lecheros del Bajío es una ventaja y permite una remuneración bastante alta, pese a los niveles de producción mediocres de los cebúes: en Huetamo en abril de 1987, el litro se compraba a 300 pesos, $50 \%$ más caro que en el Bajío (200 pesos en Maravatío, región lechera). Para los pequeños ganaderos de Charácuaro y Zicuirán, más apartados de los circuitos de comercialización e incapaces de asegurar una cantidad fija y elevada de leche, queda la posibilidad de hacer quesos caseros los cuales son localmente mucho menos remuneradores que la leche bronca. Los residuos de la extracción de aceite 一que se podían conseguir a precios bajos hasta 1984-, permitían mejorar notablemente los niveles de producción de las vacas. Por otro lado, la

24. Las vacas paridas se quedan toda la sequía en una parcela o un corral cerca de la casa del dueño donde aquel tiene toda facilidad para ordeñar $y$ administrar los alimentos concentrados, complementando así el rastrojo que queda en la parcela. 
difusión en la región de leche en polvo reconstituida, tipo lecherina, para becerros con un costo de oportunidad importante a favor de la leche bronca, permite ordeñar hasta el agotamiento las vacas sin poner en peligro la renovación del rebaño.

Estas nuevas condiciones de la actividad ganadera ofrecían a fin de cuentas y pese a costos de producción mayores, iguales perspectivas de una acumulación acelerada. La acumulación se expresó por la capitalización de medios de producción y de comercialización sin cuestionar las condiciones del auge ganadero.

Los años sesentas y setentas corresponden, como ya lo hemos visto, al incremento muy importante de la población económicamente activa en la región y, consecuentemente a la división y fraccionamiento de los patrimonios familiares. Siguiendo ese proceso, un cierto número de unidades de producción se encuentran por debajo del límite de reproducción o sencillamente, de sobrevivencia. A corto o mediano plazo, estas unidades están condenadas a desaparecer. Se ofrece entonces a las familias ganaderas nuevas perspectivas para establecer a sus hijos y ampliar su patrimonio: basta con ofrecer una remuneración suficiente al ejidatario que deja su parcela. En el ejido de Turitzio se ha producido así, desde hace 25 años, la concentración de las tierras de labor y de una buena parte de los agostaderos en las manos de unas pocas familias (4 o 5 en Turitzio) o, eventualmente, de algunos individuos (en 1987, un ganadero de Turitzio trabajaba siete dotaciones inscritas con prestanombres). La renta de parcelas de ejidatarios que se habían ido a probar suerte a México, Lázaro Cárdenas o Apatzingán es también un medio de ampliar sus tierras de labor.

Con la compra de nuevos animales de sangre mejorada, la adquisición de máquinas vino a completar la acumulación de medios de producción por parte de los ganaderos. El primer tractor fue comprado por el ganadero más grande de Turitzio en 1958. En 1966, el ejido contaba ya con 3 tractores de 3 dueños distintos: en 1974 eran 6 tractores y 5 dueños; 8 tractores y 5 dueños en 1986. Esto parece indicar que se había llegado a la saturación de las necesidades en tractores èn el ejido; pero también, que se estaba dando una concentración de esos tractores en manos de unos pocos. El intento por parte de Banrural de fomentar la compra de máquinas con crédito por parte de grupos de campesinos, resultó un fracaso y los tractores se vendieron para pagar las anualidades, a menudo a los ganaderos ricos. Estos, pese a la desaparición gradual de las yuntas de trabajo, siguen controlando así la fuerza de tracción, como lo veremos más adelante, y la dependencia de los agricultores sigue siendo la misma. Los tractores funcionan esencialmente durante el mes de junio cuando la llegada de las primeras lluvias precipita los trabajos de barbecho y de siembra. En esas condiciones, la rentabilidad de la posesión de un tractor puede parecer dudosa. Sin embargo durante ese mes el tractor trabaja día y noche lo que permite barbechar y sembrar por lo 
menos 100 hectáreas. Los cálculos de rentabilidad económica eran los siguientes para el año 1986:

Ganancias: Barbecho con discos en seca (20 has):

$\$ 240,000.00$

Rastreo en humedad (100 has):

$\$ 600,000.00$

Siembra (100 has):

$\$ 400,000.00$

Molienda cuaresma 86-87 (100 T. maíz, sorgo, arón):

Total ganancias:

$\$ 1,500,000.00$

$\$ 2,740,000.00$

Pasivo: Amortización tractor y material: (10 años)

$\$ 1,500.000 .00$

Combustible (diesel f):

Refacciones:

$\$ 500,000.00$

Total:

$\$ 200,000.00$

$\$ 2,200,000.00$

Si no falla en forma prolongada el tractor durante el periodo de trabajo, el beneficio neto que se puede esperar es de más de medio millón de pesos.

La acumulación por parte de los ganaderos se expresa también en el desarrollo de cadenas verticales de comercialización del ganado: pocas veces los ranchos de engorda se encargan del transporte de los novillos desde las regiones productoras. Varios ganaderos de la región de Huetamo aseguran entonces la prospección y la compra de los novillos en las rancherías y los ejidos del municipio.

De preferencia, en el periodo de octubre a febrero, cuando están bien repuestos por la temporada de lluvias y la disponibilidad de forraje seco, los llevan a las regiones de engorda. La compra del ganado se hace en esos meses que siguen a las lluvias, pero también antes de la temporada de cultivo, cuando faltan recursos para la siembra y los pequeños ganaderos se deshacen de algunos animales a precios sacrificados: el mantenimiento de esos animales en los agostaderos ejidales no cuesta nada al comerciante y su venta antes del mes de marzo permite librarse de gastos importantes en alimentos balanceados. El ciclo comercial se completa trayendo de regreso alimentos balanceados comprados en los estados de Querétaro y México, para venderlos con valor agregado en el ejido.

Más allá de las nuevas orientaciones de los sistemas de producción ganaderos, lo que caracteriza a este periodo, tratándose de ese tipo de productores, es el paso de un caciquismo tradicional, descrito en las partes anteriores, a un caciquismo de clase más poderoso y estable y que involucra a 
unas 5 o 6 familias en el ejido de Turitzio. Con el tiempo, el poder económico de cada cacique se ha difundido entre sus herederos pues hoy en día ningún ganadero cuenta con un rebaño de más de 300 reses, lo que ya es considerable, pero se ha formado una clase de ganaderos de igual peso económico y de fuerza política superior gracias al número. Los cambios técnico-económicos de los años sesentas y setentas han provocado la desaparición de los ganaderos pequeños y medianos que habían juntado poco a poco algunas cabezas y no supieron o no pudieron adaptarse a las exigencias del mercado y resistir la presión generalizada sobre los recursos forrajeros. Las grandes familias ganaderas aprovecharon en mayor medida, por supuesto, su desaparición.

Frente a las modificaciones estructurales del sistema ganadero, la preocupación del ejidatario pobre sigue siendo alcanzar la manera de incorporarse a la dinámica de acumulación para sobrevivir.

Agricultores y cambios tecnológicos

Mientras en los sistemas de producción de los ganaderos el sorgo reemplazaba gradualmente al cultivo del ajonjolí, el aumento de los riesgos climáticos en la macro-región daba mayor importancia a este último en las estrategias de los agricultores. Más que nunca, en estos dos decenios que van de 1960 a 1980, el ajonjolí se impuso como el medio para acceder a la capitalización de algunas cabezas de ganado. Por su misma capacidad de resistencia a un medio ambiente desfavorable, el ajonjolí permitía también colonizar partes cerriles pese a los suelos delgados y a la oposición de los ganaderos celosos de la integridad del agostadero.

El cultivo del ajonjolí fue tomando más importancia en las rotaciones de cultivo: su resistencia permite dar prioridad al maíz desde las primeras lluvias adelantando así su ciclo de desarrollo para que florezca antes de la canícula de agosto-septiembre ${ }^{25}$ (véase gráfica 2). Así también se puede cosechar el maíz antes de diciembre, en el tiempo en que se sale a Veracruzo a las huertas de Apatzingán o Sinaloa. El ajonjolí se siembra después, a veces hasta el 15 de julio cuando las primeras lluvias son escasas, y su cosecha en octubre no detiene el calendario de trabajo. Además de colonizar los suelos marginales con rotaciones del tipo tres años de cultivo puro, un año de descanso, el ajonjolí se integró con un peso cada vez mayor en las rotaciones con el maíz.

La gran variabilidad climatológica tuvo otra consecuencia; la desaparición del frijol judío de su asociación tradicional con el maíz y la calabaza. La difusión de la fertilidad química pudo haber agravado la situación, al

25. El maiz se puede recuperar de sequías prolongadas pero es particularmente sensible a un "stress" hídrico ocurrido en la época de la floración hembra (a los 60-70 días). 
favorecer la proliferación de plagas en las leguminosas ${ }^{26}$ pero aquí los testimonios concuerdan en dar mayor responsabilidad a los factores climatológicos.

Esas condiciones así como la relativa tecnificación del sistema ganadero contribuyeron a la polarización de los sistemas de producción entre la ganadería y la agricultura y la simplificación del sistema de cultivo de los ejidatarios pobres a dos plantas: maíz y ajonjolí. Los cambios tecnológicos acompañaron y acentuaron aún más esas tendencias.

Ya hemos visto cómo la cría y el adiestramiento de bueyes había dejado de ser una preocupación del ganadero y cómo la acumulación de bienes de producción se expresó por la introducción de tractores en el ejido. De hecho el uso de bueyes para las labores cayó en desuso y hoy en día sólo dos ejidatarios en Turitzio siguen trabajando con yunta, generalizándose el empleo de troncos de mulas o de burros. Su adquisición era mucho más accesible para el común de los ejidatarios; sin embargo, no dejó de ejercerse la dominación de los ganaderos sobre la fuerza de tracción.

En efecto, la irregularidad de las lluvias y la posibilidad de que se retrasen hasta fines de junio hacían barbechar y preparar el terreno lo más rápidamente posible para sembrar temprano y evitar la floración de maíz en la época de mayor riesgo de canícula. Así, se impuso el uso del tractor por su rapidez de intervención y su capacidad de barbechar terrenos trabajosos, lo que le daba ventaja neta sobre los troncos de equinos. Ofrecía además la posibilidad de un barbecho profundo en seco que permite adelantarse en las mejores condiciones para lograr el cultivo. De hecho, y salvo en las lomas pedregosas, el tractor se ha impuesto y el $90 \%$ de los ejidatarios lo emplea para la preparación del terreno y la siembra: se puede hacer en un día lo que antes necesitaba cinco días de labor con la yunta o el tronco. Además, el costo de su uso - $\$ 10,000.00$ en 1986 para la rastra y la siembra de una hectáreaestá más que compensado por la disminución de los riesgos que implica y el ahorro de tiempo que permite al campesino, los cuatro días que le quedan libres, emplearse como peón cobrando $\$ 2,000.00$ la jornada (junio-julio de 1986). El uso de los troncos de mulas o burros se limita entonces a los trabajos de raya para limpiar el cultivo y al barbecho de las lomas pedregosas, donde los tractores no tienen acceso. Pese al avance técnico que representó la difusión en los años sesentas de los arados de vertedera que permiten voltear la tierra e incorporar útilmente los residuos órganicos y las malezas al suelo, el uso de la tracción animal estuvo confinada a las tareas que no podía realizar el tractor.

Sin embargo, frente a las ventajas que representa el uso del tractor, no 
todos los ejidatarios se encuentran en situacıun ue ıguaıdad, sea por razones financieras puesto que a fines de la temporada seca, contados son los que pueden pagar el costo de un barbecho profundo en seco que es el doble de una rastra en tierra húmeda ( 12,000 pesos en lugar de 6,000 por hectárea en 1986); sea por el peso político y económico de cada persona pues la disponibilidad en tractores en Turitzio corresponde exactamente a lo que se puede trabajar en el ejido durante un mes. ${ }^{27}$ Por supuesto, no se puede esperar las mismas probabilidades de éxito por una milpa que ha sido sembrada a principios de este mes y un cultivo sembrado en julio. Entran entonces en consideración las relaciones familiares ode compadrazgo con el propietario del tractor para obtener su uso lo más temprano que se pueda: los ganadores siempre son los mismos y se aceptan las "mordidas". La consecuencia es evidente; son los notables y ganaderos del ejido quienes siembran primero y disminuyen los riesgos de mala cosecha, una cosecha que se consagra en su casi totalidad al mantenimiento del ganado.

La generalización del uso del tractor puede tener por otra parte consecuencias sociales, pues acelera la marginalización de la franja más pobre de la población quitándole trabajo y tierra por la extensa posibilidad que ofrece a los poseedores de tractor de extender su superficie cultivada, es que constituye un factor más de emigración.

Al cambio tecnológico que representa el uso del tractor se suman las distintas formas de intervención del estado, o sea la introducción del crédito, de las variedades mejoradas y de los fertilizantes químicos.

Por lo que se refiere a las variedades híbridas, de maíz en especial, su introducción resultó un fracaso rotundo. Primero porque su uso ubica al campesino en una situación de dependencia y consecuentemente de vulnerabilidad para el acceso a las semillas y a insumos más importantes (fertilizantes, quimicos, etc.), y segundo porque las variedades propuestas presentan una sensibilidad más grande hacia las plagas, tanto en la parcela (los elotes crecen más cerca del suelo y quedan al alcance de los "cuiıiques" o ratas de campo) como en el almacén (elote más tierno y menos protegido). El principal problema es la aleatoriedad que representan estas variedades híbridas: "por lo regular, se levanta muy buena cosecha o nada", un riesgo que no pueden asumir la mayoría de los ejidatarios. Por su parte, los ganaderos se quejan de la menor cantidad de rastrojo que crece en comparación con las variedades criollas, lo que constituye una desventaja mayor para una planta que destinan en prioridad a un uso forrajero.

El uso del crédito y de los abonos químicos - estando los dos

27. Según fuentes de la SARH, los terrenos laborables con tractor representan 1,000 a 1,200 hectáreas en el ejido. En un mes de pleno uso, un tractor alcanza a barbechar, rastrear y sembrar unas 120 a 150 hectáreas. Hay 8 tractores en el ejido. 
fuertemente vinculados entre sí- se difundió mucho más en la región. De hecho, el empleo de los abonos químicos parece muchas veces una manera de acceder al crédito de avío que ofrece Banrural y permite al ejidatario pobre librarse en parte del dominio del usurero. Las dosis de fertilizante que sugiere el banco son de 100 kilogramos de "triple 17" y 200 de sulfato de amonio (20.5 - 0-0) por hectárea de ajonjolí y 100 de "triple 17 " y 400 de sulfato para el maíz, o sea aportaciones de 58 kilos de nitrógeno, 17 de fosfato y 17 de potasio por hectárea de ajonjolí y 100, 17 y 17 en el caso del maíz. En este último caso, esa fórmula podría permitir teóricamente aumentar los rendimientos de una tonelada. En la realidad esa ganancia está muy limitada por la irregularidad y la escasez de las lluvias; lo que es más, la aplicación de abonos aumenta los movimientos del agua en la planta y puede acentuar su vulnerabilidad a la canícula. Por otro lado, la estación de un ganado numeroso durante más de siete meses en las parcelas parece asegurar la renovación de la fertilidad química y orgánica de los terrenos de cultivo. Por cierto, los pequeños ejidatarios, principales productores de ajonjolí, no se benefician tanto de esas aportaciones de estiércol, puesto que el ganado permanece poco tiempo en las parcelas donde queda arón, cuando éste no ha sido llevado para moler por algún ganadero. El abono químico puede entonces ofrecer la perspectiva de restablecer el equilibrio de fertilidad en esas parcelas, pero a menudo el ajonjolí se da en suelos delgados donde los químicos tienen poca eficiencia. Esas precisiones llevan a pensar que los abonos químicos están considerados más bien como un medio de acceder a los créditos de avío que como un componente indispensable para la elaboración de buenos rendimientos. Sería, sin embargo, injusto no señalar que su utilización puede tener un papel eficaz en las rotaciones bianuales maíz-ajonjolí que acostumbra hacer la mayoría de los agricultores.

El crédito si se plantea como contrapeso del poder de los ganaderos y comerciantes usureros no resuelve todos los problemas de financiamiento de los agricultores en la época de siembra. La falta de integridad de varios empleados de Banrural en Huetamo no deja de ser famosa y abundan los testimonios de robos de partes importantes de la cosecha de ajonjolí en "pago" del crédito a campesinos analfabetas. Regularmente llegan los créditos en julio, cuando ya barbecho y siembra están hechos y los ejidatarios pobres han tenido que pedir préstamos con tazas del 10 al $12 \%$ mensual. Tampoco son raros los acuerdos entre el funcionario del banco y los representantes campesinos para diferir la entrega del dinero a algunos, con el fin de hacerlo fructificar un poco. En cuanto al incumplimiento del seguro para las pérdidas parciales de la cosecha, las quejas son unánimes. La situación de aislamiento que la región de Huetamo ha conocido y sigue conociendo en un menor grado, sin duda facilita esas prácticas. El resultado es la rebelión frecuente de ejidatarios pobres que deciden no reembolsar el 
crédito y dejan de recibir asistencia. Recurren entonces a los usureros para los préstamos y la venta de los abonos que éstos consiguen con el banco y no usan. Habría también mucho que comentar sobre la inadecuación que existe entre la visión sectorial de las políticas del estado y las estrategias campesinas. ${ }^{28}$

Los cambios tecnológicos y de apoyo político al campesino en Tierra Caliente del Balsas no han fomentado nuevas perspectivas de acumulación para el ejidatario pobre y en el curso de los años sesentas y setentas la única cría de animales que quedaba al alcance de los ejidatarios agricultores era el mantenimiento de gallinas y puercos. Se volvió una característica de los estratos medios y bajos de ejidatarios en la medida que no se encuentra en las unidades de producción ganaderas. Los puercos y gallinas andan sueltos en las calles de los pueblos donde se crían con los desperdicios y el estiércol del ganado. Se completa eventualmente su alimentación con el maíz sobrante y por su puesto las calabazas que se siguen asociando al maíz en los cultivos. La mortalidad en las dos especies es elevadísima entre la virosis que persiste en estado latente en las poblaciones y los piquetes de alacrán, tarántula, etc. Sin embargo representan la mejor forma de valorizar los distintos excedentes de la casa (nunca se les da alimento concentrado) y de formar con gastos menores un pequeño capital: así, la venta de un cerdo de 60 a 80 kilos a fines de la sequía puede permitir sembrar la milpa sin endrogarse. Constituyen además una reserva de proteínas y grasa a disposición de la familia. Las variedades criollas rústicas son las únicas que se encuentran, por el papel que se les asigna y sus pocos requerimientos en alimentos.

Las chivas en cambio, aunque notoriamente adaptadas al medio físico y a las necesidades y recursos de los ejidatarios pobres, no "pegaron" en la región. La razón principal es la inadecuación de su manejo con el sistema de cercas que impone la ganadería mayor por lo que se necesita mantener a los animales gran parte del día en un corral cercado, para que no vayan a vagar en los terrenos de cultivo, y luego acompañarlos en grandes recorridos en los agostaderos. Movilizan así un trabajador permanente, lo que no deja de plantear problemas durante la temporada de cultivos. Aunque el negocio sea rentable (un chivo del año se vendía entre 15 a 20,000 pesos en la cuaresma 1986-87 y los gastos de mantenimiento son muy reducidos) y exista en la región un mercado seguro, sobre todo en las fiestas de Navidad y Pascua, la oposición de los ganaderos y demás ejida tarios es tal, que el ejido de Turitzio con sus 1,635 habitantes ${ }^{29}$ no cuenta con más de cinco chiveros y ninguno de

28. Sobre ese tema cf. T. Linck, Le paysan dépossédé. Pouvoir Technique et decision au Mexique. Thése de doctorat d'Etat CEDEC, Université Aix-Marseilles, 1985 (3 tomos). Véase también el Capítulo III de este libro.

29. Secretaría de Programación y Presupuesto, Censo General de Población y Vivienda, 1980. 
ellos cuenta con más de 60 animales.

Por lo tanto las evoluciones en los sistemas de producción en los dos decenios pasados no han logrado más que afianzar la vinculación entre ganadería mayor y agricultura para beneficio de los ganaderos. El cuadro 2 donde figuran los calendarios de trabajo agrícola y de forrajes refleja la estrecha coordinación a la que se ha llegado en la ocupación del espacio agrícola entre el hombre y el ganado. En ese marco, no hay lugar para el desarrollo de las clases desfavorecidas dentro del espacio ejidal.

\section{Un sistema saturado}

El abismo que separa económica y socialmente a ganaderos y agricultores no ha dejado de crecer. Se llegan a dibujar dos grandes sistemas de producción, muy distintos entre sí pero que se quedan en el marco de un sistema social de producción cuya dinámica es netamente gánadera: los agricultores, aunque sus intereses sean totalmente divergentes respecto a los de los ganaderos, dependen de éstos en cada etapa del proceso de producción para obtener maquinaria, crédito y fertilización. En el seno del ejido la única forma de sobrevivencia a largo plazo para las unidades de producción agrícolas es incorporarse a fuerza a la dinámica de acumulación ganadera. Pero la super-saturación del espacio for rajero y especialmente de los agostaderos, la tecnificación del sistema de cría y, sobre todo, la devaluación constante desde hace unos 10 años de la remuneración del ajonjolí y la reducción de su rentabilidad frente a todos los demás cultivos, impiden este desarrollo.

El crecimiento de la población en el ejido y en el seno de cada unidad de producción provoca el fraccionamiento de las dotaciones en unidades de superficie reducida, cuya mayor riqueza es la fuerza de trabajo del campesino, donde las perspectivas de acumulación son más limitadas todavía. Se va formando poco a poco una capa de unidades de producción que se sitúan debajo de un cierto nivel de reproducción que están condenadas a mediano plazo. Mientras los ganaderos recuperan estas tierras, que se abandonan porque su trabajo no es redituable, para constituir fincas de dimensiones cada vez mayores, la capa menos favorecida del ejido se proletariza y constituye una mano de obra disponible y barata en la región y en las plantaciones cañeras del trópico húmedo, o migra de manera definitiva hacia las colonias marginadas del Distrito Federal o de Acapulco.

Finalmente, el sistema tal como se ha conformado no of rece ninguna salida o perspectiva para la clase baja. En esas condiciones toda fuente de acumulación nueva debe de ser ajena. A partir de la mitad de los años setentas se desarrollan con fuerza las migraciones hacia Estados Unidos, así como el impacto del narcotráfico en toda la región. Siendo las únicas salidas para un número creciente de campesinos, estos dos factores van a cobrar 
CuAdro No 2

CALENDARIOS DE TRABAJO AGRICOLA Y DE ABASTECIMIENTO EN FORRAJES:

LA OCUPACION COMPLEMENTARIA DEL ESPACIO CULTIVADO

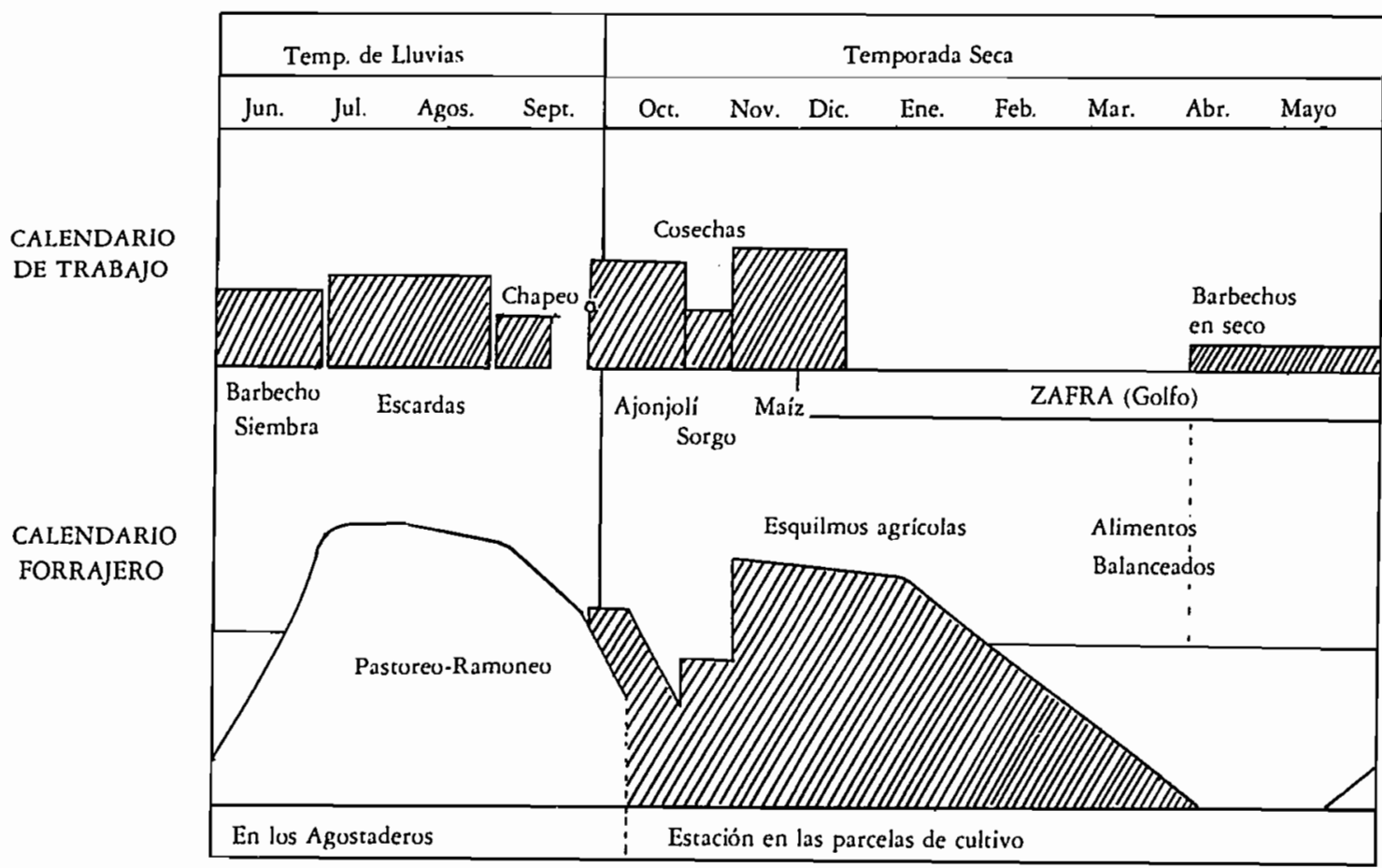




\section{ACUMULACION FORANEA Y APERTURA A UNA NUEVA DINAMICA GANADERA (1980-1987)}

Se acelera el proceso de acumulación: migraciones a EE. UU. y cultivo de la marihuana

Los movimientos migratorios hacia los estados del norte y Estados Unidos no son un hecho reciente en la historia regional. Ya vimos cómo los programas braceros habían permitido a algunos campesinos aprovechar remuneraciones elevadas en los años cuarentas y cincuentas. Después de 1962 y el cierre de los programas braceros, siguió la migración en forma clandestina y los movimientos fueron cobrando cada vez mayor importancia, sobre todo en la segunda mitad de los años setentas, cuando pareció evidente la saturación total del sistema social de producción y su estancamiento. En diez meses de trabajo en Estados Unidos se puede ganar más de lo que se ahorra en 8 o 10 cosechas de ajonjolí, comprar algunas reses o una pequeña tienda de abarrotes y tener así su fondo de seguridad que distingue al ejidatario acomodado del más pobre.

Frente a esa perspectiva no hacen falta los voluntarios. Sin embargo las condiciones de migración generan una selección entre los candidatos. Las perspectivas de acumulación son muy distintas entre el mozo de un restaurant de Houston o de Los Angeles, quien se beneficia de un empleo fijo en una ciudad donde el anonimato constituye una prueba de seguridad, y el jornalero, quien se va de huerta en huerta y queda a la merced de los servicios de migración muy activos en el campo. Mientras éste se fue hasta la frontera a conectar al coyote, quien se encargaría de hacerlo pasar "del otro lado", y luego anduvo de rancho en rancho en busca de trabajo, aquel pasó por tramitaciones muy bien estructuradas que lo llevaron desde Huetamo hasta la ciudad en donde hay gente que lo hospeda y le consigue "chamba". Por supuesto, los costos de las dos vías no son nada parecidos, el de la segunda se lleva por lo menos 700 u 800 dólares o sea más de lo que podía esperar un peón en todo un año de trabajo en 1986. De todos modos, cualquiera que sea el camino que se usa, el migrante tiene que disponer de 400 a 500 dólares para poder esperar cruzar la frontera. Contados son los que disponen de antemano de esta suma en especie.

Se recurre entonces a los ganaderos y comerciantes usureros de Huetamo o del ejido para conseguir el dinero con tazas del 10 al $12 \%$ mensual. "Sólo se presta a los ricos" y el que no tiene nada que ofrecer a cambio del dinero, no obtiene nada. Se estima la solvencia de alguien por número de vacas que posee o a sus lazos familiares con la oligarquía ejidal. Así se cierra el círculo, y la selección previa de los candidatos a la migración, 
corta muchas perspectivas a los ejidatarios pobres. Genera también desigualdad entre los grupos que componen el ejido, puesto que los habitantes de Zicuirán, El Embarcadero o Charácuaro tienen menor peso económico y sus relaciones con los ganaderos de Turitzio son más débiles. ${ }^{30}$

A las diferencias entre "mojados" se puede agregar la ventaja que tienen algunos hijos de ganaderos que disponen de cuenta bancaria y de pasaporte que les permite andar a gusto y, eventualmente, cumplir con el papel de coyote de uno y otro lado de la frontera, una de las tareas más lucrativas.

Es obvio que esta desigualdad en las oportunidades se traduce en desigualdad en la acumulación y son los más ricos quienes obtienen mayor beneficio de las migraciones a Estados Unidos. Pese a esas circunstancias, ir al norte es para los más desfavorecidos una perspectiva inesperada de adquirir los medios de mantenerse en el ejido. El fenómeno ha cobrado una enorme importancia social y económica en toda la región y especialmente en el ejido de Turitzio.

De ahí que de las 61 entrevistas económicas que se llevaron a cabo en la temporada seca $86-87,41$ productores $(68 \%)$ personalmente habían participado en esas migraciones ( 18 personas, $30 \%$ de la muestra) o tenían familiares, generalmente hijos, en Estados Unidos (23 personas, 38\%). De los 20 que no tuvieron nexos con las migraciones al norte, 8 habían salido a trabajar algunos años en otras partes de la república. ${ }^{31}$ Aunque probablemente más acentuado en Turitzio por la prosperidad del pueblo, el fenómeno es generalizado en toda la región y hasta los ranchos más aislados cuentan con sus migrantes. El peso económico de las migraciones es todavía más importante en los balances económicos de las unidades de producción y llega a alcanzar el 65\% de los ingresos familiares y los 10,000 dólares al año, según las entrevistas realizadas.

Mucho más lucrativo todavía que la migración a Estados Unidos, es el cultivo de la marihuana, que se ha desarrollado muchísimo desde la década de los setentas y constituye hoy día la manera más rápida y fácil de ascender en la escala social en las comunidades ejidales. Tanto la sierra de Guerrero como las partes centrales y del noroeste del municipio de Huetamo ofrecen

30. Los resultados de los censos de 1970 y 1980 nos dan elementos del impacto relativo de las migraciones en las diferentes comunidades: en 10 años la población de Turitzio pasaba de 1352 a 1103 habitantes (-18.5\%), Ja de Zicuirán de 135 a $122(-10 \%)$ y la de Charácuaro crecía de 301 a 345 habitantes ( $15 \%$ ). En el mismo tiempo, la población total del municipio aumentaba en un $18 \%$.

31. Cabe destacar que en ese periodo del año, la parte más pobre de la población del ejido está en el estado de Veracruz para el corte de caña. A hí se encuentra la gente que menos posibilidades tiene de financiar el pase a Estados Unidos. Sin embargo, las cifras propuestas son representativas para las clases medias y medias-bajas del ejido. 
lugares escondidos y aislados propicios para sembrar la hierba. La presencia activa de un batallón del ejército, revela la importancia que ha tomado la región de Huetamo en la producción y la comercialización de la marihuana.

Por supuesto, los ejidos que se extienden a lo largo de la carretera Huetamo-Zitácuaro o del río Balsas, están demasiado comunicados con el centro municipal como para of recer oportunidades de sembrar. Pero queda para muchos las posibilidad de sembrar a medias en ranchos más aislados durante una temporada. La poca cantidad de trabajo que requiere el cultivo, ya que se siembra entre el monte y sólo se cosecha lo que ha crecido algunos meses después, permite incluso seguir cultivando su parcela en el ejido y que nadie sospeche el negocio. Más costeable todavía resulta la compra-venta de la marihuana y en ese aspecto varios comerciantes tienen todos los medios -camionetas, negocio oficial de comerciante de ganado o de alimentospara hacerlo en las mejores condiciones.

Sin embargo, la dimensión de los riesgos que toman productor y negociante es inmensa y son probablemente pocos los que se atreven a meter la mano en el narcotráfico. Además, para los más pobres que no se benefician de la protección de redes familiares o del compadrazgo, el riesgo es todavía más grande.

Expresiones de la acumulación: avances en la ganaderización del sistema agrario

La fuerte acumulación proveniente de Estados Unidos y en menor grado del narcotráfico se expresa esencialmente en la adquisición de bienes raíces y de ganado, la orientación del sistema agrario impide prácticamente cualquier otro tipo de especulación en el seno del ejido.

En el pueblo de Turitzio, es sorprendente el número de casas de tabique y cemento que quedan desocupadas y se extienden en las orillas del pueblo junto con las barracas de cartón de los peones. Construir una casa "decente" donde instalar un hogar es en la mayoría de los casos la preocupación prioritaria del migrante. La construccción conoce en toda la región un auge que aún no se detiene. El ejido de Turitzio que contaba con 1,625 habitantes permanentes en $1980^{32}$ ocupa 32 talleres de fabricación de tabiques y tejas, con una producción de 1,195 millares de tabiques y unos 83 albañiles ocasionales. ${ }^{33}$ Durante toda la temporada seca, se multiplican las obras de construcción que confieren a Turitzio un aspecto dinámico en contraste con el que ofrecen otros pueblos de la región o del mismo ejido.

32. Fuente: Censo General de Población y Vivienda, 1980.

33. Fuente: SPP, Censos económicos: Huetamo, 1983. 
Más allá del hecho de poseer una vivienda nueva, se plantea para el migrante la necesidad de adquirir los medios de mantenerse en el ejido, o sea conseguir una parcela y un número suficiente de cabezas de ganado mayor como para disponer de un fondo de seguridad y un triunfo para su integración en la comunidad ejidal. En la situación de escasez de terrenos laborables, la adquisición de ganado se vuelve el modo más seguro de acceder a los recursos del ejido mediante los derechos de un padre ejidatario. El crecimiento del rebaño permite luego adquirir un poder económico suficiente para comprar el derecho de un campesino pobre que no puede seguir o no tiene heredero. Dos jóvenes se pueden también juntar para comprar y luego compartir una dotación. Pero la acumulación foránea también ha sido un medio para algunas familias de afianzar su poder económico y constituir rebaños de varios centenares de animales. Existe en Turitzio el caso de un ejidatario quien, gracias a las ayudas de cuatro hijos viviendo en Estados Unidos se ha vuelto dueño de un hato de 250 cabezas.

Sin embargo, los que más se aprovecharon del flujo de dólares fueron las familias ganaderas y comerciantes: sus recursos en tierras y en dinero les permiten asumir el aumento de la carga en ganado, comprar nuevas dotaciones y hasta pequeñas propiedades o nuevos medios de comerciar, sean camionetas o tiendas. Mientras tanto, es mucho más difícil para los pequeños ejidatarios rebasar la capacidad de mantenimiento de sus dotaciones sin un fuerte y peligroso aumento de los costos de explotación: abundan los casos de nuevos ganaderos que tuvieron que vender en el peor periodo del año parte de las cabezas recién adquiridas. En cuanto a los más pobres, los que se fueron "de mojados" con un mínimo de seguridad, por lo regular nunca consiguen empleo bastante remunerador como para hacer algo más que mejorar las condiciones de su vivienda.

Sin embargo, el impacto de la aportación de dólares sobre los sistemas de producción y el equilibrio del sistema agrario es impresionante. En el ejido de Turitzio, el número de cabezas de ganado mayor alcanza la cifra de 2,500 que se reparten de la manera siguiente: 1,800 en Turitzio, 300 en Zicuirán y 400 en Charácuaro. ${ }^{34}$ Es el mayor número en todo el municipia $\mathrm{Si}$ se consideran los coeficientes de agostadero en temporadas de lluvias y de sequía, se llega a cargas de 0.8 animal por hectárea de agostaderos y 1.5 animal por hectárea cultivada. ${ }^{35}$ Esas cifras considerables traducen la inestabilidad del sistema ganadero actual: los recursos en forrajes brutos -residuos de cultivo y sorgo- alcanzan apenas a mantener los dos tercios de los animales durante los siete meses de la sequía. En cuanto a los

34. Fuentes: SARH, Delegación de Huetamo; Asociación ganadera local; SPP, Delegación de Huetamo; observación directa.

35. Si se estiman $3,000 \mathrm{Has}$. de agostaderos y 1,650 de sembradíos. 
agostaderos, tal carga supone un fuerte sobrepastoreo con todos los riesgos que puede generar tanto para los animales como para el equilibrio ecológico (erosión, irregularidad y violencia de las lluvias, etc.). Los animales, que antes se recuperaban en el cerro de una larga temporada seca, ahora ya no pueden hacerlo. En el otoño de 1986, debido a una pluviosidad insuficiente, los bovinos regresaron tan flacos como se les había mandado, según los ejidatarios.

"Ya no se puede seguir así", estiman muchos. Pero, ¿cómo impedir a los pobres lo que se puede considerar como la única alternativa a la migración definitiva hacia el Distrito Federal o a los demás centros urbanos, la adquisición de unas pocas reses cuando pueden hacerlo? Por otro lado, en esa situación, los dueños de hatos importantes, por su mayor capacidad de resistencia a lo imprevisible del clima y al estancamiento de los recursos forrajeros, se imponen con toda seguridad como los últimos dueños de los agostaderos.

¿Cuáles pueden ser, entonces, para el conjunto de los ejidatarios las respuestas a una situación que todos presienten como dramática a corto plazo?

\section{¿Hacia qué tipos de estrategias?}

Los pequeños ejidatarios frente a la no rentabilidad del cultivo del ajonjolí Los años ochentas son para los productores de maíz y ajonjolí los del cuestionamiento de sus sistemas de cultivo y de producción tradicionales. La disminución de la rentabilidad del ajonjolí frente a la ganadería no se ha frenado en los últimos diez años como lo ilustra el cuadro 3.

El estancamiento de los precios reales de ajonjolí se le presenta al productor desde 1979, hasta 1984 y para los dos cultivos, entre 1980 y 1984. Sobre todo desde 1978 ya no es costeable sembrar ajonjolí en lugar de maíz y los testimonios de los productores confirman los cálculos. A esto se suma el hecho de que el ajonjolí necesita una mano de obra más intensiva que cualquier otro cultivo de temporal en la región y en fechas muy precisas, lo que eleva sensiblemente los costos de producción. La cosecha del grano no puede esperar muchos días después de la maduración ya que los trabajos de corte, apiñada y sacudida requieren el empleo de numerosos peones (aproximadamente cuatro personas para cortar las plantas, cuatro para levantar y amarrarlas y luego dos para sacudir las pajas y liberar el grano, o sea unas diez personas por hectárea). En cambio, la cosecha del maíz no moviliza tanta gente (unas cuatro para cortar las mazorcas y una para transportarlas al granero) y se puede extender sobre un lapso más importante si no urgen aprovechar el rastrojo para el ganado. El productor de maíz puede así optimizar la utilización de su mano de obra familiar. Otra 


\section{CUADRO No 3}

\begin{tabular}{|c|c|c|c|c|c|c|}
\hline & \multicolumn{3}{|c|}{ Maíz } & \multicolumn{3}{|c|}{ Ajonjoli } \\
\hline Años & $\begin{array}{l}\text { Precio } \\
\text { medio' } \\
\text { anual } \$ / \mathrm{t}\end{array}$ & $\begin{array}{l}\text { Precio } \\
\text { real }^{2} \\
\$ / t\end{array}$ & $\begin{array}{l}\text { Producto } \\
\text { bruto/ha } \\
{ }_{3} \$\end{array}$ & $\begin{array}{l}\text { Precio } \\
\text { medio' } \\
\text { anual \$/t }\end{array}$ & $\begin{array}{l}\text { Precio } \\
\text { real }{ }^{2} \\
\$ / \mathrm{t}\end{array}$ & $\begin{array}{l}\text { Producto } \\
\text { bruto/ha } \\
\$\end{array}$ \\
\hline 1978 & $2,902.3$ & & 2,612 & 11,298 & & 3,578 \\
\hline 1979 & $3,506.3$ & & & $13,483.3$ & & \\
\hline 1980 & 4,715 & & 4,243 & 11,510 & & 3,453 \\
\hline 1981 & 6,430 & 4,889 & & 14,956 & 11,373 & \\
\hline 1982 & 10,527 & 4,972 & & 31,370 & 14,818 & \\
\hline 1983 & 20,184 & 4,805 & 18,165 & 56,745 & 13,510 & 17,023 \\
\hline 1984 & 33,200 & 4,727 & & 112,555 & 16,026 & \\
\hline 1985 & 53,584 & 5,628 & & 159,012 & 16,702 & \\
\hline $1986^{4}$ & 97,000 & & 87,300 & 275,000 & & 82,500 \\
\hline $\begin{array}{l}\text { 1. En el } \\
\text { 2. Base } 1 \\
\text { 3. Toman } \\
\text { maíz (e } \\
\text { 4. Según }\end{array}$ & $\begin{array}{l}\text { do de Mich } \\
\text { en } 1980 \text {. } \\
\text { como refer } \\
\text { naciones d } \\
\text { testimonio }\end{array}$ & $\begin{array}{l}\text { rendim } \\
\mathrm{ARH}_{1} \\
\text { re los } \mathrm{P}\end{array}$ & $\begin{array}{l}\text { de } 300 \mathrm{k} \\
\text { mo). } \\
\text { en novie }\end{array}$ & $\begin{array}{l}\text { Ha. para el a) } \\
\text {-diciembr }\end{array}$ & $\begin{array}{l}\text { lí y } 900 \text { a } 1 \\
1986 .\end{array}$ & $\mathrm{kg} / \mathrm{Ha}$. para el \\
\hline
\end{tabular}

Fuentes: Anuario de estadísticas estatales INEGI.

Anuario de estadísticas de los Estados Unidos Mexicanos. INEGI.

desventaja para el ajonjolí, son los trabajos de limpia (escardas pesadas con tarecua), ya que la difusión de herbicidas (esterón) en la región desde unos cinco años permite liberarse de las escardas del maíz por un costo menor. El fenómeno migratorio amplifica el problema, pues priva a las unidades de producción de la fracción más dinámica y activa de la mano de obra familiar y crea una dependencia para todos los trabajos del campo.

Pese a la ligera mejoría de la remuneración del ajonjolí en 1986, esos factores influyen a favor de la reducción del peso de este cultivo en los 
sistemas de producción. Se siembra en muchos casos para pagar el crédito o permanece en los suelos delgados donde no se da el maíz y donde los trabajos de escarda están limitados por la rareza de las malezas. Pero aún ahí, el ajonjolí está en competencia con el sorgo forrajero que se puede vender en pie a los ganaderos. En la temporada seca 1986-87, mientras una hectárea de ajonjolí proporcionaba un ingreso bruto medio de 82,500 pesos $(90,000$ si se esperaba hasta enero para vender el grano, lo que pocos productores pueden hacer), la misma hectárea sembrada de sorgo se podía vender por 80,000 pesos a la misma fecha a un ganadero que careciera de forraje seco y con costos de producción limitados al barbecho y a la raya con tiro de animales.

Esas circunstancias contribuyen a la simplificación de los sistemas de producción de los ejidatarios más pobres y su orientación hacia la producción de maíz y la adquisición de algunas cabezas de ganado para procurar a las unidades de producción una seguridad económica que el cultivo del ajonjolí ya no proporciona.

Los que alcanzaron esa meta se encuentran confrontados con la disminución de los recursos de los agostaderos y en situación de vulnerabilidad frente a la capacidad de resistencia mayor de los ganaderos. En Charácuaro esta preocupación determinó que en sólo dos años se pusieran las cercas alrededor de todas las parcelas individuales. Pero la individualización de los esquilmos no permite proseguir la acumulación de animales más allá de la capacidad de mantenimiento de su parcela. Algunos intentan aumentarla cosechando las hojas de maíz y distribuyéndolas cuando se acaba el rastrojo para evitar un desperdicio excesivo. Pero esa estrategia no permite librarse del agotamiento del agostadero que amenaza toda perspectiva de acumulación.

Los ganaderos hacia la diversificación y la "intensificación" de los sistemas de cría

Frente al mismo problema y a la imposibilidad de hacer crecer los rebaños sin un aumento considerable en la carga de insumos de las unidades de producción, los ganaderos parecen orientarse hacia el aumento de la productividad de sus hatos y la disminución de la mano de obra de sus sistemas de producción.

Desde hace algunos años, los ganaderos más grandes han hecho varios intentos de introducir en sus hatos vacas lecheras de sangre Holstein o Suiza. Eso supone modificar en gran parte el sistema de manejo del ganado y de las parcelas, apartando una porción del terreno para mantener cerca de su vivienda las lecheras durante todo el año. Esta necesidad contribuye a favor de la apropiación de una fracción del agostadero por parte de los ganaderos que tienen la producción lechera y del recurso sistemático a la administración 
de alimentos balanceados para alcanzar el potencial genético de esos animales. El incremento de las cargas de explotación consecuente se justifica plenamente por el nivel de remuneración de la leche en la región. De hecho, el negocio parece costeable pero a todos los ganaderos que lo experimentaron se les planteó el problema de la adaptación de los animales al clima tórrido y a la falta de forrajes verdes en la región. Esto se comprobó con la rápida desaparición de las vacas Holstein que nunca concretizaron las esperanzas de sus dueños. La raza Suiza ha conocido, al revés, una lenta difusión de los hatos, ya sea por la compra de animales de registro, o por la cruza con el ganado cebú que permite aprovechar el efecto heterosis ${ }^{36}$ sin modificar en mayor grado el sistema de manejo del rebaño.

Aunque todavía es limitada su difusión, esta estrategía refleja la preocupación de los ganaderos frente a la penuria de forrajes brutos y a los limitantes del sistema de manejo tradicional. Traduce también una toma de conciencia hacia la necesidad de intensificar el sistema ganadero y diversificar sus producciones mediante, en este caso, la mejora genética y el recurso más frecuente del uso de alimentos balanceados.

Frente al aumento de las cargas de explotación consecuente al uso cada vez más importante de los alimentos balanceados, se intenta por otro lado reducir la carga de mano de obra. El desarrollo del cultivo de forrajes tales como el sorgo o el sudán permite alcanzar esta meta: se siembran, reciben una raya por el único trabajo de limpia y en muchos casos ni siquiera se cosechan, ya que planta y grano se quedan a disposición del ganado. La cantidad de trabajo que se aporta en este caso es muy limitada. La progresiva aparición de químicos en el cultivo del maíz va en el mismo sentido. Desde el principio de los años ochentas se han difundido los herbicidas en la región y se usan en forma generalizada desde hace dos años. Permiten librarse de las tareas de escarda, que son las mayores consumidoras de trabajo en los cultivos de monocotiledones (maíz y sorgo, pero no sirven para el ajonjolí). Sin embargo, su uso presenta la gran desventaja de impedir el cultivo de la calabaza asociada al maíz y de limitar la cantidad de pas to disponible para el ganado en la estación seca, lo que ha limitado considerablemente su difusión.

La última estrategia desarrollada por los ganaderos frente al cuestionamiento del sistema ganadero tradicional es la de dar más peso a las actividades comerciales en los ingresos familiares. Las familias más ricas de Turitzio siguen invirtiendo en vehículos para el transporte de carga o de personas, o en tiendas, como en Huetamo, Zirándaro o hasta Zitácuaro.

Los cambios de los diez últimos años han contribuido a la composición

36. Los animales provenientes del cruzamiento entre dos razas distintas, se benefician de cualidades superiores al valor mediano de las razas parentales (en este caso, conformación para producción de carne y potencial lechero). 
de una sociedad ejidal cuyos caracteres son quizá más complejos que lo que eran 20 años antes. Dibujan sin embargo tipos de campesinos muy distintos por sus recursos y sus estrategias.

\section{Elementos de una tipología evolutiva}

La siguiente tipología se establece a partir de 61 entrevistas realizadas en los cuatro pueblos que componen el ejido de Turitzio. Tal y como se explica en la introducción, no se ha tratado de elegir una muestra aleatoria sino de buscar una variabilidad máxima de los sistemas de producción, en base a los elementos de la historia agraria que precede. Esta tipología no pretende reflejar exactamente la compleja realidad sino más bien intenta presentar las grandes clases de sistemas de producción y las estrategias con las cuales están vinculadas. En ese objetivo se han individualizado los criterios siguientes: el número de cabezas de ganado mayor en posesión del jefe de la unidad de producción (u.p.), la superficie total y la superficie trabajada en manos del mismo (ahí interviene la posesión ilegal de partes de los agostaderos), la existencia de inversiones en actividades comerciales (se incluye en este caso la compra de máquinas agrícolas que se maquilan), la parte relativa al ajonjolí y a los cultivos forrajeros en las rotaciones de cultivo, el nivel de la fuerza de trabajo familiar ${ }^{37}$ y su grado de empleo en la u.p. familiar.

Se pudieron así distinguir seis tipos de sistemas de producción:

Unidades ganaderas semi-capitalistas

Ese grupo concentra las pocas familias que siempre estuvieron a la cabeza de la acumulación y que han ido concentrando medios de producción como tierras, ganado, máquinas, al mismo tiempo que diversificaban sus recursos en comercios e incluso en fábricas.

La orientación ganadera es muy marcada y casi todas esas unidades cuentan con más de 80 cabezas, algunas juntan hasta 300 . Corresponde a la concentración de ganado una importante extensión de las tierras de labor y los ganaderos poseen comúnmente 3 o 4 dotaciones ejidales o rentan hasta 7. Se concentran también los potreros dedicados al pastoreo del ganado por apropiación de partes de los agostaderos comunales o compra de pequeñas propiedades. Los cultivos se destinan únicamente a la producción de forrajes: maíz, sorgo, sudán pero los que se benefician de las condiciones de riego por estar cerca del río Balsas no desprecian oportunidades de sacar beneficio de cultivos de hortalizas, de melón, de sandía en la temporada seca.

La diversificación de las actividades es otra de las características del

37. Esta se expresará en Unidad de Mano de Obra (U.M.O.) que corresponde al empleo de un trabajador adulto a tiempo completo (jornadas de 8 h.) en la unidad de producción. 
grupo. Todos poseen tractor(es) que es usado por los demás ejidatarios (véase tercera parte) o camionetas y camiones de transporte de personas o de flete. Igualmente, todos están comprometidos en un comercio local, con tiendas en el ejido o en Huetamo o interregional con la compra-venta de ganado. La permanencia de uno o varios hijos en Estados Unidos procede de la misma estrategia; algunos están establecidos allí desde mucho tiempo y contribuyen a la prosperidad de la familia.

Esos elementos permiten alcanzar productos brutos que oscilan entre 10 y 20 millones de pesos. La parte correspondiente a actividades comerciales ha ido creciendo y alcanza el 60 o $70 \%$ del total. Las dificultades con las cuales se topa la actividad ganadera contribuyen a este hecho y los gastos vinculados con el mantenimiento de los animales llegan a veces al $70 \%$ de las cargas totales de la u.p. o pueden equivaler al $65 \%$ del producto de la ganadería. Sin embargo, los márgenes se mantienen muy elevados, generalmente arriba de los 10 millones de pesos.

Los representantes de este grupo se consagran entonces prioritariamente a sus negocios y recurren a trabajadores asalariados en la unidad de producción. Así, se han convertido en gerentes de empresas semicapitalistas. Su actual estrategia es ampliar la superficie forrajera, si es necesario comprando nuevos predios, para reducir los costos de alimentación del ganado y orientar más las inversiones bacia el sector comercial.

\section{Unidades de orientación ganadera estricta}

Los representantes de esta clase provienen de las grandes familias ganaderas de los años cincuentas. Recibieron una dotación y varias cabezas de ganado mayor en herencia y participaron en el movimiento de apropiación de los agostaderos. Hoy cuentan con superficies de 10 a 15 hectáreas de tierras de labor, una porción de tamaño variable de agostaderos y rebaños de 50 a 120 cabezas. Esas unidades de producción están totalmente dedicadas a la producción de novillos y han abandonado las actividades comerciales que persiguen los miembros del grupo anterior.

Siguiendo esa orientación, la superficie disponible se consagra al cultivo de forrajes (maíz, sorgo, sudán). Para disminuir el uso de los alimentos balanceados se busca extender la superficie forrajera por medio de la renta de parcelas. La disponibilidad de mano de obra, en general superior a 2 U.M.O. familiar, y el uso corriente de las máquinas y de productos químicos permiten alcanzar ese objetivo sin recurrir en un mayor grado a una fuerza de trabajo asalariada. La estrategia más generalizada en este grupo es optimizar la producción forrajera de la unidad limitando los costos de producción.

Sin embargo, los costos de alimentación del ganado quedan relativamente elevados. Entre la compra de residuos de cosecha y de alimentos 
balanceados, éstos pueden rebasar el millón y medio de pesos y constituir el $60 \%$ de las cargas de explotación. Pero las ganancias que permite la ganadería son elevadas $y$, gracias a un buen aprovechamiento del potencial lechero de hato, alcanzan por lo menos los 2 millones y medio de pesos. Las ayudas provenientes de los familiares en Estados Unidos completan los beneficios y otorgan márgenes del orden de dos a dos millones y medio de pesos.

La polarización de esas unidades de producción hacia la ganadería les expone a grandes riesgos frente al agotamiento de los pastizales comunales. Pero la presencia de hijos en Estados Unidos en una situación bastante estable constituye una seguridad así como los previene del peligro del fraccionamiento.

\section{Unidades de orientación mixta con predominio ganadero}

Se trata aquí de una clase de ejidatarios "clásicos", de edad ya avanzada (en la muestra casi todos tienen más de 55 años) que fueron acumulando ganado por la vía tradicional, gracias al producto del cultivo del ajonjolí, o más recientemente, gracias a las migraciones de sus hijos; tienen entre 10 y 20 cabezas de ganado mayor. Sus dotaciones de 7 a 8 hectáreas de sembradío que todavía no han sido divididas les permiten mantener esos animales una buena parte de la temporada.

La orientación ganadera no es tan evidente en el sistema de producción: la rotación tradicional maíz-ajonjolí domina todavía los patrones de cultivo, aunque la superficie sembrada de ajonjolí esté en descenso y que el sorgo haya aparecido en algunas unidades de producción. El excedente de maíz se sigue vendiendo, pero una parte creciente del grano se muele para su uso forrajero. Esos índices asi como los testimonios de los productores parecen revelar que esas unidades se dirigen hacia la ganaderización de su sistema de producción; la poca rentabilidad de los cultivos en el mercado las conduce hacia este camino.

Las actividades ganaderas tienen ya una parte predominante entre el 60 y el $80 \%$ del producto bruto, pero esta parte se podría mejorar notáblemente gracias a un aprovechamiento superior de la capacidad lechera del rebaño. El $80 \%$ de las unidades que se investigaron reciben la ayuda de uno o varios hijos en Estados Unidos. Así se pudo llegar a juntar animales y se alcanzan ingresos del orden del millón y medio a dos millones y medio de pesos.

El nivel técnico, relativamente bajo, así como la disponibilidad de la mano de obra familiar, alrededor de 2 U.M.O. por lo regular, limitan los costos de producción. Sin embargo, todos recurren al uso del tractor para las labores de preparación del terreno y todos necesitan comprar alimentos balanceados y algunos esquilmos para el mantenimiento de sus animales a fines de la temporada seca. Los márgenes se sitúan entonces entre 700,000 y 
el millón y medio de pesos esencialmente gracias a la ayuda de los hijos.

De manera que esas unidades se encuentran en situación inestable frente al poco control que tienen de los recursos forrajeros y a los efectos de la ley Simpson-Rodino. El nivel de sus recursos y su tamaño los expone además a un próximo fraccionamiento entre herederos que los ubicaría inmediatamente en el grupo siguiente.

Unidades de orientación mixta y superficies limitadas

Los ejidatarios que componen este grupo recibieron sus tierras desde 1965 y tuvieron que compartir la dotación familiar con un hermano. Esto explica el tamaño reducido de las superficies: no rebasan las 5 hectáreas por lo regular y no se siembran más de 4 . En efecto se conserva una parte del terreno en baldío para el mantenimiento de las 3 a 5 vacas que constituyen el capital de la unidad de producción. Este capital proviene de un paciente ahorro o, más a menudo, de las ayudas que manda un hijo que se fue a probar suerte a Estados Unidos. En varios casos esta acumulación ha rebasado la capacidad de mantenimiento de la u.p. y los campesinos tuvieron que vender algunos animales para no tener que enfrentarse con costos de producción demasiado elevados. Aprovechando ese flujo de dinero y los recursos en mano de obra que rebasan los requerimientos de las unidades, la estrategia más común en el grupo es diversificar al máximo las actividades lucrativas tales como la agricultura, la ganadería, el comercio, la alfarería, el trabajo asalariado, etc., puesto que la superficie disponible no es suficiente para limitarse a los recursos agropecuarios.

De hecho, las ganancias están compuestas por varias especulaciones. $\mathrm{La}$ venta de productos agrícolas sigue constituyendo una parte importante de ellos: la rotación maíz-ajonjolí ocupa todavía el patrón de cultivos, y el sorgo no ha aparecido en la mayor parte de los sistemas de producción. La ganadería constituye ya para muchas unidades la fuente más importante de ganancias, esencialmente gracias a la venta de uno o dos novillos y de puercos: los gastos que implica la administración de alimentos balanceados no permite aprovechar el potencial lechero de los animales. El beneficio de una pequeña tienda rural o de un taller de tabiques o de vasijas de barro viene a completar los ingresos. Los que no recurren a ese tipo de negocios salen a menudo al corte de caña en la temporada seca y encargan sus animales a un vecino. De manera general, muchas unidades recurren todavía al trabajo asalariado para mantenerse cuando no reciben ayudas regulares de un hijo trabajando en Estados Unidos o en el Distrito Federal.

Los ingresos se mantienen así entre 800,000 y el millón y medio de pesos. El nivel relativamente bajo de las cargas de explotaciones - nivel técnico débil-permite sacar márgenes de 500,000 a un millón de pesos que deja sin embargo esas unidades en una situación inestable y expuesta. El 
único factor de optimismo, es la edad de los campesinos que oscila, en general, entre 35 y 55 años y que los libra, por el momento, del peligro de la sucesión.

Pequeñas unidades de orientación agricultora

Aquí se encuentran campesinos cuyas dotaciones están compuestas de tierras pésimas o que heredaron una fracción de la dotación familiar: provienen de familias que siempre permanecieron fuera de los circuitos de acumulación. Las superficies cultivadas nunca rebasan las cuatro hectáreas y los únicos bienes de esos ejidatarios son, en el mejor de los casos, un tiro de burros, una marrana y su fuerza de trabajo. Con esas bases su estrategia se limita a reducir al máximo los costos de producción y valorizar la mano de obra familiar.

Esas unidades de producción dependen entonces en un mayor grado de la cosecha de maíz y ajonjolí. El excedente de maíz se emplea en parte para criar unos tres o cuatro puercos que incrementarán notablemente los ingresos familiares. Un mal temporal significa poca ganancia con el ajonjolí, pero también la necesidad de vender la marrana, unico capital para seguridad de la familia.

Los campesinos del grupo constituyen con los peones de la categoría siguiente lo grueso del ejército de cañeros que sale hacia las plantaciones del trópico húmedo desde diciembre hasta los primeros días de junio. Los que se quedan pueden contar con un empleo en uno de los talleres de tabiques o en las huertas de melón que se desarrollan en la región (cfr. conclusiones). En general, sus familias son numerosas: los hijos representan una seguridad a largo plazo y vienen a incrementar una fuerza de trabajo familiar que rebasa con frecuencia las 2 U.M.O.

Las actividades asalariadas vienen a completar el producto de la venta del ajonjolí, de las semillas de calabaza, un poco de maíz, de las pajas de maíz y ajonjolí y 2 o 3 puercos. Así se pueden obtener ganancias de un millón de pesos y márgenes de más de 500,000 pesos. Estos ingresos apenas permiten a las familias mantenerse y de todos modos las deja fuera de los circuitos de acumulación.

Los campesinos sin tierra

Esta categoría reúne a los más desheredados, los que no tienen ninguna perspectiva de conseguir algún pedacito de tierra y los que obtienen a veces media hectárea o una hectárea prestada o rentada por un familiar ejidatario. Aún entre los más pobres existen divisiones sociales. La única alternativa es valorizar la mano de obra familiar.

Tener numerosos hijos es un triunfo, ya que por su trabajo permiten 
CUADRO No 4

TRAYECTORIAS SIMPLIFICADAS DE LOS DIFERENTES GRLPOS CAMPESINOS

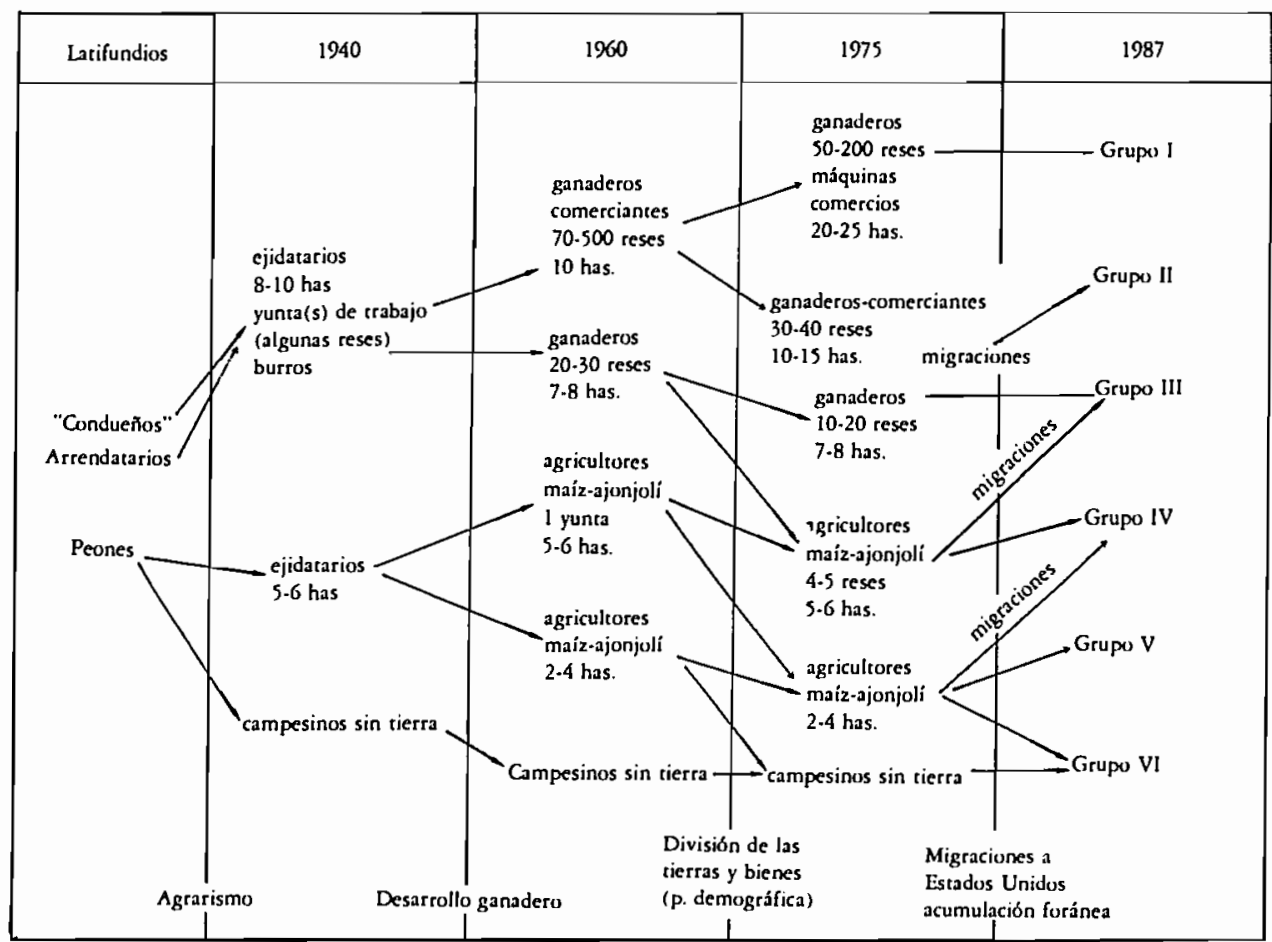


incrementar los ingresos de la familia. Pero frecuentemente el que no tiene tierra no encuentra esposa: pasa su vida entera sin ninguna perspectiva de futuro, a veces ni tiene techo.

Los más "afortunados", los que pueden sembrar una parcelita aseguran su abasto y eventualmente pueden criar un puerco, algunas gallinas. Algunos consiguen un empleo fijo con uno de los grandes ganaderos y se pueden establecer. Pero la gran mayoría pasa su tiempo entre el ejido y las plantaciones de caña hasta que se canse y se vaya hacia los suburbios de México o Acapulco. Se gana 500 a 600,000 pesos al año sin tener ninguna perspectiva de ahorro, pero este dinero les permite sobrevivir y esperar.

\section{CONCLUSIONES: PROYECTO DE DESARROLLO \\ Y TRANSNACIONALES: ¿CUALES SON LAS ALTERNATIVAS ANTE LA SATURACION DEL SISTEMA AGRARIO?}

En las actuales condiciones de la actividad agropecuaria en la cuenca michoacana del río Balsas, las intervenciones de la administración estatal o federal pueden tener un impacto determinante sobre la dinámica futura de los sistemas de producción. En el caso específico del ejido de Turitzio, dos proyectos concretos pueden modificar radicalmente el equilibrio social y las relaciones de producción. El "Plan ganadero del Sur" promovido por la S.A.R.H. y el gobierno del estado de Michoacán ofrece la oportunidad de incrementar sensiblemente el potencial forrajero de las tierras de baldío y de agostadero. Mientras tanto, existe el proyecto de abrir a la irrigación una parte de los terrenos de Charácuaro para fines de 1987, lo que ofrecería perspectivas inesperadas a los ejidatarios de esa comunidad. Tal hecho podría llevar a una confrontación con compañías meloneras estadounidenses que se implantan sistemáticamente en todos los nuevos perímetros de riego que se abrieron últimamente en las orillas del río.

El Plan Ganadero del Sur y la perspectiva de la apropiación definitiva de los agostaderos

A fines de 1986 el gobierno del estado de Michoacán anunciaba el lanzamiento de un programa de rehabilitación y desarrollo de las áreas de temporal "de vocación ganadera" del sur del estado, destinado a hacer de Michoacán una potencia en el ramo. ${ }^{38}$ Este programa preveía la siembra y la

38. "Michoacán será una Potencia Ganadera con el Plan del Sur", La Voz de Michoacán. 5 de julio de 1987. 
explotación intensiva de 700 mil hectáreas de pastizales tipo Jaragua y Buffel en 25 municipios del sur. Huetamo fue integrado al programa y considerado como polo de desarrollo.

Paralelamente, se daría apoyo a las asociaciones ganaderas locales ya que la Unión Regional Ganadera Estatal participa en la realización del proyecto para promover la difusión de sementales de alto registro genético y la inseminación artificial. A mediano plazo, se intentará también aclimatar al ganado lechero Holstein y Suizo y cruzarlo con cebú para formar animales de doble propósito.

El objetivo final es incrementar la producción de animales pero también reducir la salida de novillos hacia las Huastecas permitiendo llevar a cabo el ciclo de cría en las zonas que abarca el proyecto o por lo menos alargarlo. ${ }^{39}$

El programa cuenta con el apoyo del Banco Mundial, del FIRA y del FOlR que, por intermedio de Banrural, propondrán una línea de crédito de 30 mil millones de pesos en seis años. ${ }^{40}$

Las instituciones involucradas en la realización de este programa son, por parte de la Federación: la S.A.R.H., la S.R.A, la S.C.T., el Banrural y ANAGSA; y , por parte del gobierno del estado: la Secretaría de Fomento y Desarrollo Agropecuario y Forestal. Cabe mencionar que esta última dependencia ha concentrado, en los meses pasados, todos sus recursos humanos, materiales y financieros en la zona del proyecto; la mayoría de sus oficinas situadas en el bajío o en el eje neo-volcánico han sido cerradas y sus empleados fueron despedidos o deplazados hacia los polos de desarrollo del programa. No cabe la menor duda sobre la importancia que se da a nivel federal y estatal al nuevo Plan del Sur.

A parte de las preguntas que puede levantar el hecho de declarar "zona de vocación ganadera" una región donde la producción de maíz y frijol para el consumo humano va bajando por la extensión de la ganadería y en la que las migraciones tanto temporales como definitivas se han vuelto un elemento fundamental de los sistemas de producción, el Plan del Sur se prepara para fomentar cambios de muchas consecuencias sobre la sociedad campesina.

Según los discursos de los promotores locales del proyecto, la siembra del nuevo pastizal Rodex se destina a los terrenos que no se pueden aprovechar por la agricultura, o sea más concretamente los que no están cultivados; en el caso del ejido de Turitzio son los agostaderos comunales. Tuvimos la oportunidad de asistir a la primera presentación del proyecto en Turitzio por parte de los funcionarios de la S.A.R.H. y S.R.A. y lo que se dijo

39. Ibid.

40. Ibid. 
entonces fue inquietante para el futuro de la comunidad. Se preve la división de los agostaderos para permitir su aprovechamiento ganadero individual. El simple hecho de que la asamblea general de los ejidatarios decida qué partes le tocará a cada quien, permite dudar de la equidad del proceso, pues la experiencia de los tres decenios pasados lleva a cuestionarse. Sobre todo, se considera que como el fenómeno de apropiación de partes del agostadero por algunos ganaderos no produjo denuncias a nivel oficial, el conjunto de los ejidatarios está conforme y ha consentido el hecho. Esas acaparaciones serán entonces certificadas por la S.R.A. y los beneficiarios protegidos de todo reclamo. Pero el proyecto va más lejos: a cualquier ganadero que cerque con sus propios recursos un pedazo de agostadero, con el supuesto consentimiento de la asamblea ejidal, se le proporcionará la semilla del pasto y sobre todo el certificado de derecho de la Secretaría de la Reforma Agraria. Por cierto, se ofrece a los pequeños ganaderos la posibilidad de juntarse para delimitar un área de agostadero y recibir a crédito el alambre y las semillas para este pedazo. Pero frente al poder político-económico de los grandes ganaderos y su capacidad de financiamiento se puede dudar del peso real y de las oportunidades de esos grupos para conseguir terrenos de buen potencial. Por otro lado, los ejidatarios que no poseen ganado no recibirán ningún apoyo ya que "no tiene caso facilitarles terrenos de uso ganadero". Los pastizales comunales, última salida a los problemas de presión sobre la tierra en los ejidos, se cerrarán a los más pobres. Como se sigue prohibiendo el uso agrícola de las tierras de cerros, en el mejor de los casos, para esos ejidatarios pobres quedará la posibilidad de vender a algún ganadero el pedacito de agostadero que habrán podido conseguir. Se harán así actores de su propia marginación.

En una segunda etapa, que sigue a la siembra del pasto, el "programa pastizales" considera las posibilidades de constituir abrevaderos, represas y bordos para efectuar riegos de auxilio durante la temporada seca. Esas obras se harán necesariamente donde están los aguajes y en los lugares húmedos donde se concentran las aguas durante la temporada de lluvias. Pero esas zonas han sido apropiadas previamente por los grandes ganaderos, para prevenirse de la presión sobre la tierra. Es probable entonces que las obras complementarias del proyecto beneficien también en mayor grado a los grandes ganaderos, reforzando su capacidad de acumulación y dándoles un poder político que había ido reduciéndose desde hace una década como cosecuencia de las migraciones a Estados Unidos.

Las consideraciones precedentes son intencionalmente alarmistas y son consecuencia directa de la manera como ha sido presentado el proyecto. De las precauciones que se tomarán para su aplicación depende su impacto social que, por cierto, puede ser dramático. Importa que se dé un peso mayor a los grupos de ejidatarios, frente a los grupos de ganaderos, para la atribución de los pastizales; se debe entonces definir superficies máximas 
atribuibles a un sólo individuo y alargar los plazos impuestos para la formación de los grupos y la delimitación de las dotaciones: los criterios cualitativos deben de imponerse a los datos cuantitativos con los cuales se evalúan muy frecuentemente los proyectos de desarrollo.

Las consecuencias de este plan pueden ser dramáticas y cortar toda perspectiva a los ejidatarios más pobres como los agricultores y los pequeños ganaderos provenientes de la última fase de acumulación. Si se cierra para ellos el acceso a los agostaderos, su porvenir en el ejido estará sellado. Será probable entonces la expulsión de un número mayor de la población para beneficio de los grupos uno y dos de la tipología. Por otro lado, la realización del "programa pastizales" tal como está definido, puede dar ocasión a una confrontación directa entre los grupos de intereses divergentes en el ejido y llevar al cuestionamiento del "poder ganadero". Pero esa hipótesis es mucho menos probable que la precedente.

\section{Irrigación y expansión capitalista: el proyecto de Charácuaro}

Desde 1984, se ha elaborado por parte de la S.A.R.H. un proyecto de bombeo de las aguas del río Balsas para la irrigación de 268 hectáreas para beneficio de los 57 ejidatarios de Charácuaro. ${ }^{11} \mathrm{La}$ instalación de las bombas y la entrada en servicio del sistema de irrigación están previstos para el final de 1987 según los responsables del proyecto. Los beneficiarios dispondrán de superficies de riego que varían de 0.7 a 11.2 hectáreas. ${ }^{42}$

Al lado de las cifras y de los datos cuantitativos no se plantea sino la perspectiva de un cuestionamiento de la lógica ganadera que rige la dinámica del sistema agrario desde décadas atrás, así como el desplazamiento del centro de gravedad geográfico del mismo sistema de Turitzio hacia Charácuaro.

Para los ganaderos de Turitzio la apertura de un perímetro de riego en Charácuaro significa perder a corto plazo centenares de hectáreas de rastrojo, mientras que se está afirmando la penuria de forrajes brutos en toda la región. Para los ejidatarios de Charácuaro se plantea el problema de la utilización de esas tierras y de las estrategias que se podrán adoptar. A grandes rasgos se perfilan dos opciones.

La primera, consiste en conservar la orientación hacia la cual tienden los sistemas de producción, pero evolucionar hacia una intensificación de los sistemas de cría. La perspectiva de mantener praderas artificiales de gramíneas y leguminosas en los terrenos de riego permite optar por un

41. Dirección General de Obras Hidráulicas e Ingeniería Agrícola para el Desarrollo Rural, SARH, Morelia.

42. Ibid. 
ganado mixto de doble propósito, carne y leche: se podrían engordar durante la temporada seca los becerros y novillos con la pastura verde y vender así animales de buena conformación, con mayor valor agregado. Por otro lado, se puede considerar la posibilidad de mantener todo el año vacas lecheras de raza pura Holstein o Suiza o, más acorde con el objetivo de criar también novillos, híbridos de cebú con lecheras para alimentar con leche los mercados de Zirándaro, Turitzio y Huetamo donde los precios son muy remuneradores.

Esa opción se enfrenta con problemas importantes: supone un cambio fundamental de las técnicas de manejo para mantener durante una parte o la totalidad del año animales en corrales o en establos, y traer diariamente cantidades grandes de pastura que no se puede pisotear para que dure la pradera. Aparte de la inexperiencia de los productores de esas técnicas, encontramos detalles, como la falta de carreteras para el transporte de pastura, que dificultan esa orientación. Sobre todo se necesitarían inversiones importantes y fuera del alcance de la mayoría de los ejidatarios. La compra de animales finos o semi-finos de precio muy superior al del ganado que poseen los campesinos, así como la construcción de establos para vacas lecheras o de bodegas para la ventilación de la pastura, necesarias para evitar accidentes de meteorización en las condiciones de insolación de la región, requieren financiamientos desproporcionados. La actual orientación de la administración agropecuaria, ya sea federal o estatal, en sus opciones para el desarrollo regional permite dudar de algún apoyo de parte de alguno de estos sectores de la administración. Los recursos privados están en manos de los grandes ganaderos-comerciantes, quienes serían todavía más reticentes en invertir en tal proyecto. Sin embargo, la probabilidad del éxito y de la rentabilidad de tales inversiones es muy importante y las condiciones económicas favorables.

La orientación hacia la producción de hortalizas y en particular de sandía, melón y pepinos, sería sin duda alguna, más propicia para atraer fondos. El alto valor agregado de esos cultivos, sus rendimientos importantes y la cercanía de la carretera Huetamo-Zitácuaro con el lugar de producción, constituyen posibles factores de éxito. Además, al hacer dos cosechas en la temporada seca, se liberan grandes cantidades de materia verde que interesaría a los ganaderos de Turitzio y podría atraer su apoyo.

Esa perspectiva presenta mayores obstáculos. La producción de esas hortalizas requiere inversiones importantes en maquinaria, fertilizantes, pesticidas y mano de obra para poder esperar rendimientos regulares. Por otro lado, el acceso al mercado norteamericano - mucho más costeableestá totalmente controlado por compañías transnacionales. De hecho, esas sociedades capitalistas se están instalando sólidamente en toda la región. Aprovechándose del apoyo de las autoridades políticas, se implantan de manera sistemática en todos los nuevos perímetros de riego que se abren én 
las orillas del río Balsas, aún en las partes más aisladas. En la orilla michoacana se han instalado en las áreas de riego de Capeo, de San Jerónimo y de Tziritzicuaro. Se crearon desde 1985 e hicieron ya prospecciones en Charácuaro. El procedimiento siempre es el mismo: los representantes de la compañía se presentan a las autoridades ejidales antes de que se haya inaugurado el primer ciclo de cultivo de riego. Proponen la renta de la totalidad del perímetro que se abre, a un precio por hectárea superior al producto bruto que el ejidatario puede esperar de un cultivo de temporal (140,000 pesos en San Jerónimo en abril de 1987, cuando la tonelada de maíz se vendía a 100,000 pesos). El resultado es previsible: prevalece la decisión de la mayoría en la asamblea ejidal y se renta toda el área. Los campesinos careciendo de referencia, no ven el costo de oportunidad desfavorable en comparación con las ganancias que permiten dos ciclos de cultivo de riego. En cambio, se les ofrece una renta segura, aparentemente elevada y las perspectivas de empleo en las meloneras. El ejidatario se vuelve proletario en su propia parcela. La tierra se ocupa únicamente de octubre a mayo, cuando los melones no están en competencia con las producciones locales en el mercado norteamericano; pero se prohibe a los campesinos el cultivo de sus tierras durante el ciclo de temporal para que los terrenos estén listos y limpios para la siembra de octubre.

Para no perder ninguna oportunidad, los representantes de la compañía se comprometen a asegurar a las autoridades una "mordida" substancial de 10 a 20,000 pesos por hectárea; por lo general parece ser necesario el compromiso de la clase ganadera económicamente dominante en los ejidos sin el consentimiento de la cual no se puede hacer nada. Pero carecemos de información para definir en qué consiste el trato.

De todos modos el negocio es de los más jugosos para las empresas capitalistas: los rendimientos que se pueden esperar son del orden de 15 a 20 toneladas por hectárea y en el mercado norteamericano los meiones de 2 a 3 kg. de la variedad Honey Dew se venden a más de 3 o 4 dólares en invierno. La integración de todas las etapas, desde la producción hasta la comercialización, permite optimizar las ganancias en superficies de 400 a 600 hectáreas.

Y aún más, en tanto que las compañías sólo hacen contratos por 5 años, no se encargan de ninguna de las consecuencias de una explotación irracional del medio ambiente. Las empresas se pueden liberar antes de que se hagan sentir los efectos de la salinización del terreno ya que la multiplicación de los riegos - 16 en el ciclo de cultivo- en una época en que el río Balsas presenta un estiaje muy bajo ofrece ese riesgo. Además, el uso de herbicidas, que pueden impedir mucho tiempo cualquier otro cultivo excepto el de las cucurbitáceas, y la multiplicación de plagas, muy rápida en el caso del melón, pueden deteriorar más el ambiente. Junto a ello se encuentra la degradación de las terracerías por los trailers, que van y vienen a cargar los melones, aislando más a los ranchos. 
De manera que el peligro es cierto y muy importante para los ejidatarios de Charácuaro. La rapidez de la expansión de las transnacionales meloneras en toda la región demuestra su poder de convicción y parece díficil que los campesinos la resistan si ningún líder se manifiesta entre ellos.

Finalmente, el futuro de las comunidades campesinas plantea muchas más preguntas que soluciones. Entre la expansión de la ganadería y de los ganaderos y la perspectiva de la proletarización en sus propias tierras por empresas capitalistas que al final los dejan pendientes de los mismos ganaderos, los pequeños productores de la Tierra Caliente del Balsas disponen de un margen de independencia y de sobrevivencia que se reduce cada día más. El cultivo de la marihuana y los coyotes de la frontera norteamericana tienen todavía muchas perspectivas por delante. 


\section{CAPITULO II \\ LA VIA LECHERA: \\ UNA ALTERNATIVA AL MAL DESARROLLO \\ EN EL VALLE DE MARAVATIO}

Eric Léonard

\section{INTRODUCCION}

En 1983, el gobierno del estado de Michoacán decidió emprender un proyecto de desarrollo lechero en el valle de Maravatío, región que consideraba de alto potencial económico. La Secretaría de Fomento Rural (S.F.R.) pretendió crear en esa zona un polo de producción lechera, cerca de centros urbanos importantes (México, Toluca, Querétaro, Morelia...) para responder a los objetivos definidos a nivel nacional en cuanto a la autosuficiencia en productos lácteos.

A partir de los fracasos de los proyectos anteriores basados en la instalación de grandes establos colectivos en algunos ejidos del valle, el gobierno del estado se proponía promover la construcción de pequeños establos familiares, asesorar técnica, administrativa y políticamente (en sus relaciones con el Banco y las instituciones) a los productores lecheros e integrarlos en una estructura organizativa encaminada al procesamiento y comercialización de productos lácteos.

A partir de 1984 se constituyeron grupos de productores en ocho comunidades del valle. El centro de Estudios Rurales de El Colegio de Michoacán se propuso entonces participar en el proyecto en colaboración con la S.F.R. Su función sería realizar una primera evaluación (necesariamente parcial) del impacto del proyecto y llegar a una tipificación funcional de las unidades de producción de la porción central del valle, que pudiera utilizarse en vista del desarrollo de las colectividades.

Para alcanzar esos objetivos el estudio se hizo durante seis meses en dos comunidades representativas de la diversidad en cuanto al modo de acceso a la tierra, al nivel técnico y a los recursos. Los casos escogidos fueron el ejido de Campo Hermoso y la congregación de propiedades de Pomas. Posteriormente el estudio se extendió de manera más superficial a las demás comunidades del valle. Se buscó así llegar a una comprensión completa del sistema social de producción y ver en que forma la acción administrativa se podía incorporar a la dinámica de evolución de este sistema, para modificarla. El siguiente capítulo intenta determinar las bases de tal acción a 
partir del conocimiento de las sinergias y de las bases técnicas que caracterizan los sistemas de producción.

\section{EL AREA DE ESTUDIO}

\section{Ubicación}

El municipio de Maravatío está situado en el ángulo noreste del estado de Michoacán a $90 \mathrm{Km}$. de Morelia y a $35 \mathrm{Km}$. de Ciudad Hidalgo. Esa ubicación hace de Maravatío un importante cruce de caminos que comunican ciudades como Morelia, Toluca, Celaya y más lejos, México, Querétaro, Salamanca e Irapuato. Además, Maravatío fue siempre una parada en la carretera México-Morelia-Guadalajara y la llegada del ferrocarril en 1891 reforzó su papel en la comunicación. Ahora, la cabecera sigue siendo un lugar de paso muy frecuentado (véase mapa 8).

Este estudio se interesa más bien en la parte del valle ubicada inmediatamente al sur de Maravatío, aproximadamente entre las carreteras hacia Toluca y Ciudad Hidalgo. La zona investigada se extiende del norte al sur de $19^{\circ} 53^{\circ}$ a $19^{\circ} 45^{\prime}$ de latitud norte y del poniente al oriente de la carretera Maravatío-Ciudad Hidalgo al ferrocarril Maravatío-Zitácuaro (véase mapa 9).

Se presenta como un valle enmarcado por cerros al oriente y al poniente, con pendiente hacia el norte (de $2150 \mathrm{~m}$ al sur a unos $2020 \mathrm{~m}$ al norte). Pasando del norte del valle al sur, se observa la disminución de los ríos y canales, los cuales desaparecen al sur de la laguna del Fresno. El paisaje da entonces la impresión de una utilización más extensiva del espacio: aparecen parcelas en descanso, agostaderos amplios... La densidad de población se hace más débil, los asentamientos más dispersos.

El espacio se divide entre seis comunidades: los ejidos de Casa Blanca, Santa Elena, Campo Hermoso, Pomas y San Juan Huerta en las partes húmedas, y la congregación de pequeñas propiedades de Pomas en la parte seca del centro-sur.

Las aguas provienen de la laguna del Fresno, cuya cuenca se extiende sobre unos $57 \mathrm{Km} .{ }^{2}$. La presa está auxiliada en su llenado con los escurrimientos de los ríos Cachivi y San Ramón que pasan al este de la zona.

\section{El clima}

La estación meteorológica de la laguna del Fresno nos permite obtener datos de lluvia, evaporación y temperaturas bastante confiables. 
Mapa No 8. Ubicacion dei. Vai.l.e de Maravatio

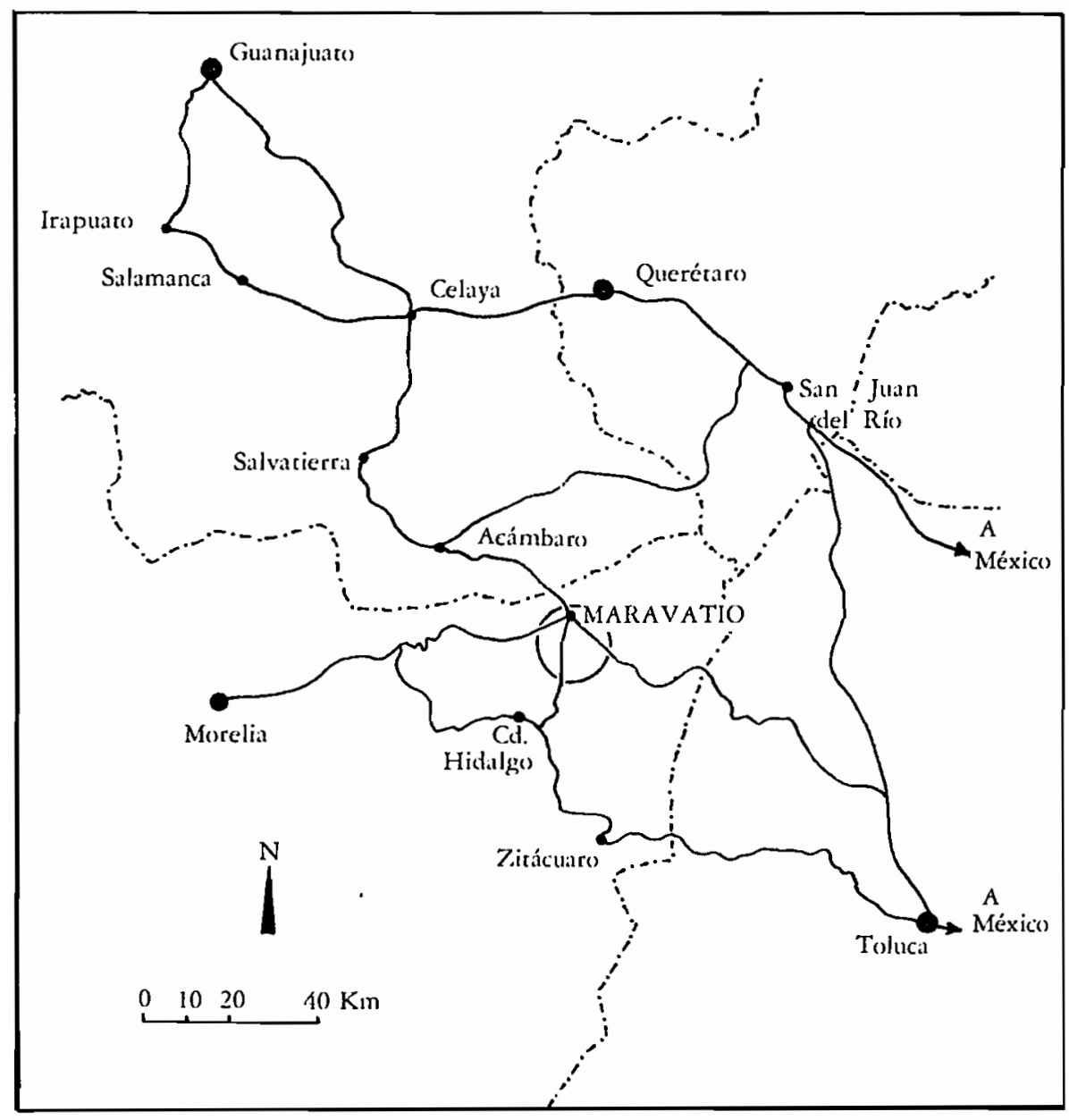




\section{MAPA NQ 9:}

EI. VAIIIE MERIDIONAI. DE MARAVATIO,

TIERRAS Y POBLAMIENTO

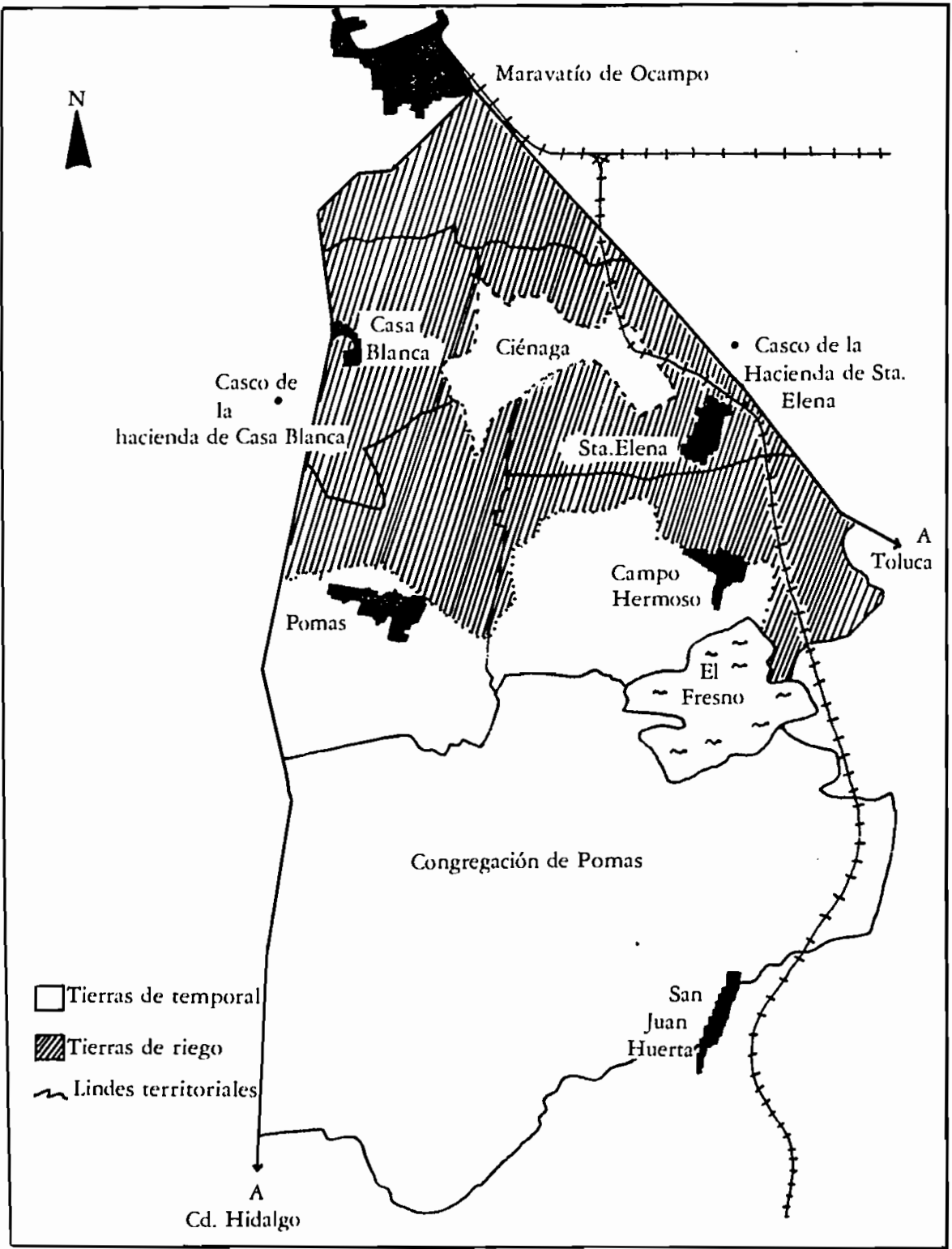


Las precipitaciones se sitúan por lo regular alrededor de $860 \mathrm{~mm}$. por año. Sin embargo, sequías como la de $1982(600 \mathrm{~mm}$.) o años muy lluviosos como 1984 (casi 1,000 mm.) confieren al clima de la región un aspecto muy variable.

Los meses de junio a octubre concentran según sea el año, entre $75 \%$ y 92\% del total de las precipitaciones. Las fechas entre las primeras y las últimas lluvias importantes son bastante variables, de manera que la duración de la temporada de lluvias puede ser de cuatro meses a más de cinco. En general, las lluvias llegan con mucha fuerza en la segunda parte del mes de junio.

El balance hídrico del suelo es deficitario durante todo el año, salvo en los meses de julio y agosto. Dicho déficit se agudiza en abril y mayo cuando se acaba de sembrar el maíz.

En general, se puede contar con unas 20 heladas por año concentradas en los meses de diciembre, enero y febrero, lo que impide el crecimiento de los pastos artificiales. Las heladas pueden proseguir hasta marzo y constituyen un problema para los cultivos de invierno y el maíz sembrado a fines de febrero.

\section{Los suelos}

Los suelos de esa parte del valle son pobres en materia orgánica y contienen una proporción importante de arcilla (más de 30 a 40\%, generalmente) lo que se traduce en una desecación importante en temporada seca. Durante la temporada de lluvias, la tasa de infiltración se revela insuficiente, el drenaje es muy lento y difícil pues esos suelos se hinchan y se saturan rápidamente. Además limitan la penetración radicular de los cultivos.

La profundidad de esos suelos es muy variable: es importante en las áreas de riego del norte de la zona y alcanza más de dos metros en Casa Blanca ${ }^{1}$ pero disminuye mucho hacia el sur, lo que limita su utilización agrícola y aumenta los efectos de la erosión.

La naturaleza de los suelos y la concentración de las precipitaciones en los meses de junio a septiembre tienen algunas consecuencias:

-En primer lugar, la erosión puede ser muy fuerte en esos meses, incluso en pendientes relativamente débiles. En el sur de la zona se pueden observar unas barrancas pronunciadas, lo que impide el cultivo de los cerros.

-En segundo lugar en tierras de temporal se impone por lo regular un año de barbecho o descanso entre cada cultivo: después de la cosecha del maíz en diciembre, los suelos se encuentran ya muy secos y no se puede

1. Fuente: SARH Maravatio. 
CuAdro No 5: Datos Climatologicos DE los 10 UI.TIMOS aÑos (LAGUNA DEL FRESNO) MEDIAS MENSUALES

\begin{tabular}{|c|c|c|c|c|c|c|c|c|c|c|c|c|c|c|}
\hline Meses & & $E$ & $\mathbf{F}$ & $M$ & A & $\mathbf{M}$ & $\mathrm{J}$ & $\mathrm{Jl}$ & $A$ & $\mathbf{S}$ & 0 & $\mathbf{N}$ & I) & Tutal \\
\hline \multirow[t]{3}{*}{ Temp. } & $\overline{\mathbf{m}}$ & 7.3 & 8.3 & [1.4 & 14.3 & 16.6 & 17.1 & 16 & 16 & 14.7 & 13.4 & 10 & 8.6 & \\
\hline & $\mathbf{M}$ & 20.5 & 21 & 23.5 & 25.7 & 26.7 & 26 & 23.7 & 23.3 & 23 & 22.7 & 22.1 & 21.3 & \\
\hline & $\mathrm{m}$ & 4.6 & 5.6 & 7.6 & 9.7 & 12 & 12.5 & 11.8 & 11.6 & 11.5 & 10.4 & 6.5 & 6 & \\
\hline \multicolumn{2}{|l|}{ Lluvias } & 16.2 & 9 & 3 & 10 & S5 & 125 & 184 & 205 & 126 & 60 & 19 & 20 & 832 \\
\hline \multicolumn{2}{|c|}{ Evapuración } & 151 & 172 & 251 & 266 & 242 & 185 & 144 & 155 & 138 & 147 & 146 & 148 & 2145 \\
\hline \multicolumn{2}{|c|}{ Balancia } & .135 & -163 & .248 & -256 & -187 & .60 & 40 & so & .12 & -87 & .127 & -128 & -1313 \\
\hline \multicolumn{2}{|c|}{ Dias de helad. } & 3.5 & 2.5 & I & & & & & & & & 1 & 5 & 18 \\
\hline
\end{tabular}

\section{Grafica No 6: Diagramas climatologicos}

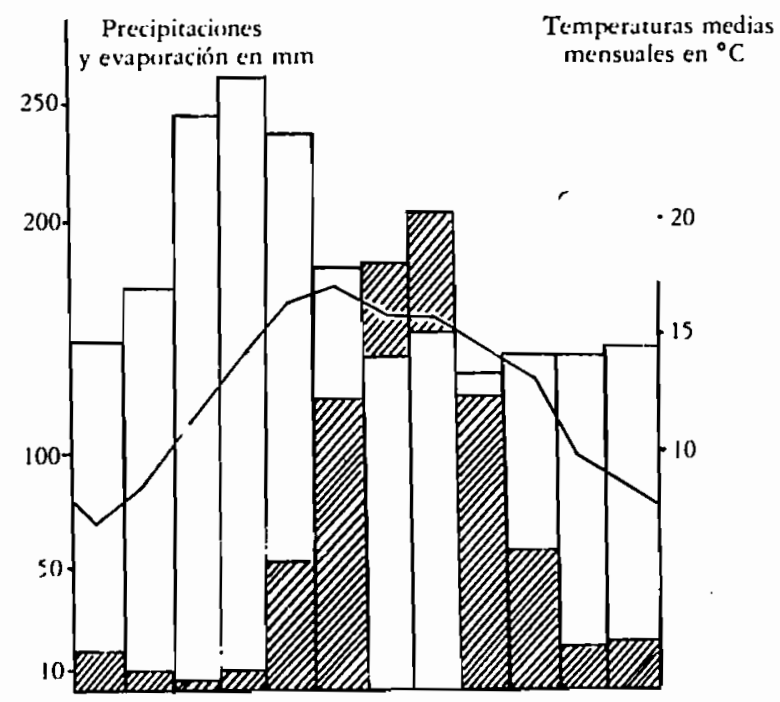

Total de la temporada de lluvias en el total de las precipitaciones:

de $75 \%$ en 1977 a $92 \%$ en 1984

Variaciones de las precipitaciones:

de $600 \mathrm{~mm}$. en 1982 a $995 \mathrm{~mm}$. en 1984

Extremas de la temporada de lluvias:

-Principio: del 4 de mayo (1985) al 20 de mayo (1986)

-Fin: del 17 de septiembre (1975) al 14 de octubre (1976 y 81)

-Duración: de 4 meses (23.05 al 22.09.83) a 5 meses (11.05 al 11.10.84)

-Precipitación: de $520 \mathrm{~mm}$. (1982) a $915 \mathrm{~mm}$. (1984).

Fuente: SARH Maravatio. 
sembrar en humedad residual en los meses de febrero-marzo por la falta de agua. Cuando llegan las primeras lluvias las parcelas se "tapan" muy rápidamente con las arvenses, y la competencia es entonces demasiado fuerte para las semillas. Además, se corre el riesgo de que éstas se pudran, de manera que se hace necesario dejar que las parcelas se carguen de agua, barbechar y destruir las arvenses sin sembrar, después de cada año de cultivo.

-Por último, en tierras de riego se pueden presentar esos problemas, aunque no padezcan la falta de agua: un cultivo de invierno, trigo o avena atrasado, puede impedir la siembra del maíz después del mes de mayo si las lluvias se adelantan.

\section{Población y poblamiento}

En la zona estudiada, la población se reparte en cuatro poblamientos que corresponden a los ejidos de Casa Blanca, Santa Elena, Campo Hermoso y Pomas y en un hábitat disperso en el caso de la Congregación de Pomas. La población de los ejidos varía de 700 habitantes (Campo Hermoso) a 1,500 (Pomas), según el censo de 1980. La Congregación de Pomas cuenta con unos 800 habitantes. De manera que la población de esa parte del valle se eleva a unos 6,000 habitantes, con una densidad de aproximadamente 100 habitantes por $\mathrm{km}^{2}$ lo que ya es considerable, pero no refleja la estricta realidad, pues la Congregación de Pomas abarca una quinta parte de la superficie de la zona y contiene menos de la séptima parte de su población.

Por lo demás, esa población sigue creciendo a un ritmo elevado como el resto del municipio desde los años cuarentas.

\section{CuAdro No 6}

\begin{tabular}{|c|c|c|c|c|c|c|}
\hline \multirow{2}{*}{ Año } & \multicolumn{3}{|c|}{ Población rural } & \multicolumn{3}{c|}{$\begin{array}{c}\text { Población urbana } \\
\text { (Maravario y San Miguel) }\end{array}$} \\
\cline { 2 - 7 } & Absoluro & $\%$ & Tasa crec. & Absoluto & $\%$ & Tasa crec. \\
\hline 40 & 25,943 & 83.3 & & 4,147 & 13.7 & \\
\hline 50 & 31,091 & 87.7 & 5.1 & 4,364 & 12.3 & 0.2 \\
\hline 60 & 37,656 & 87.5 & 6.5 & 5,388 & 12.5 & 1 \\
\hline 70 & 42.755 & 87.7 & 5.1 & 6,008 & 12.3 & 0.6 \\
\hline 80 & 49,342 & 89 & 6.5 & 6,121 & 11 & 0.1 \\
\hline
\end{tabular}

Fuente: Censos nacionales de población y vivienda 1940,1950,1960,1970 y 1980. Comunidades por la delegación SARH-Maravatío. 
Las comunidades rurales se desarrollaron con un ritmo mucho más importante que Maravatío y su suburbio San Miguel, lo que no es muy común en esa parte del país. Sin embargo, las migraciones hasta fuera del campo, que siguen siendo muy fuertes en todo el valle, se hacen hacia Estados Unidos y a los grandes polos urbanos cercanos tales como México, Toluca y Morelia, lo que desfavorece a la ciudad de Maravatío y afecta también al crecimiento de su propia población.

Aunque no dispongan de condiciones naturales muy favorables a las actividades agrícolas (contingencias climáticas, suelos de calidad mediocre) se plantea ya la necesidad de rentabilizar al máximo la utilización del espacio (teniendo en cuenta la densidad de población), lo cual puede ser posible por la ubicación privilegiada de Maravatío, las estructuras de la tenencia de la tierra (mayoría de ejidos) y la relativa abundancia de tierras de riego (alrededor del tercio de la superficie de la zona).

Sin embargo, no basta considerar las condiciones naturales y de poblamiento para entender o explicar la situación del sistema social de producción en esta parte del valle. Este es el producto de una larga evolución en el tiempo que necesitamos comprender para distinguir los procesos de diferenciación y el origen de los actuales sistemas de producción.

\section{HISTORIA AGRARIA DEL VALLE MERIDIONAL DE MARAVATIO}

1. Sistemas de producción en el valle de Maravatío a principio del siglo (1900-1935)

Las haciendas de Sta. Elena, Huerta y Casa Blanca

Aunque no se pueda determinar con mucha precisión el tamaño de esas tres haciendas, se sabe que con excepción de la Congregación de Pomas, compartían la parte suroeste del valle, es decir unas 10,000 Has. A principio del siglo, las propiedades de Santa Elena y Casa Blanca se juntaron en las manos del mismo dueño, Estanislao Vega.

La mayoría de las tierras que poseían los hacendados eran de temporal, sin embargo, según los testimonios de los ancianos, únicamente las parcelas de riego se cultivaban. El sistema de cultivo vigente era el siguiente:

-Los cereales de invierno, trigo y cebada se sembraban en enero y febrero. Se cosechaban en abril o mayo.

-Un periodo de descanso seguía con dos o tres barbechos entre agosto y octubre.

-En febrero y marzo se sembraba el maíz para cosecharlo en octubre. -Un año de barbecho precedía a un nuevo cultivo de cereales. 
Las tierras de temporal se utilizaban para el mantenimiento del ganado bovino y ovino que andaba todo el año en los potreros de las haciendas. Esos eran divididos en pastos de verano, en general cerros y tierras más altos que se explotaban en temporada de lluvias, y pastos de invierno que se dejaban cargar de agua durante las lluvias y que permitían el mantenimiento del ganado en temporada de secas, estando todavía húmedas. Las tierras de temporal tenían así el aspecto de grandes porciones de tierra delimitadas por cercas de piedras secas, en las que las haciendas tenían miles de cabezas.

Las vacas en lactancia estaban puestas en establos con sus becerros. El periodo de ordeña duraba tres a cuatro meses después de los cuales los animales, de tipo rústico, se secaban. Pastos de alfalfa cultivados en algunas parcelas de riego servían para mantener ese ganado que no salía del establo en toda la época de lactancia.

\section{Cundro No 7}

Extension de las haciendas de Casa Blanca, Sta. Elena Y LA HUERTA EN 1889

\begin{tabular}{|c|c|c|c|c|c|c|c|}
\hline \multirow{2}{*}{ Nombre } & \multirow{2}{*}{$\begin{array}{l}\text { Valor } \\
\text { fiscal } \\
\end{array}$} & \multicolumn{2}{|c|}{ Temporal has. } & \multicolumn{2}{|c|}{ Riego has. } & \multirow{2}{*}{$\begin{array}{c}\text { Para } \\
\text { criadero }\end{array}$} & \multirow{2}{*}{ Total } \\
\hline & & Total & Cultivado & Total & Cultivado & & \\
\hline $\begin{array}{l}\text { Casa } \\
\text { Blanca }\end{array}$ & 38,000 & 172 & 86 & 514 & 257 & 856 & 1,540 \\
\hline Sta. Flena & 50,000 & 172 & 85 & 685 & 342 & 1070 & 1,926 \\
\hline La Huerta & 37,000 & 941 & 770 & 428 & 342 & 3226 & 3,600 \\
\hline Total & 125,000 & 1285 & 942 & 1627 & 941 & 4152 & 7,066 \\
\hline
\end{tabular}

Fuente: Pérez Escutia, Ramón Alonso. El Distrito de Maravatío economía y sociedad 1910-1940, UMSNH, Morelia, 1987.

\section{CUADRO № 8}

Producciones de las haciendas de Casa Blanca, Sta. Elena y La Huerta EN 1889 (en toneladas)

\begin{tabular}{|c|c|c|c|c|c|}
\hline Nombre & Maiz & Trigo & Cebada & Frijol & Chile \\
\hline Casa Blanca & 70 & 32 & 7 & 0 & 8 \\
\hline Sta. Elena & 63 & 56 & 0 & 0 & 8 \\
\hline La Huerta & 105 & 40 & 21 & 7 & 7 \\
\hline Total & 238 & 128 & 28 & 7 & 23 \\
\hline
\end{tabular}

Fuente: Pérez Estucia, Ramón Alonso. op. cit. 
Ese manejo del ganado permitía:

-la rentabilidad de numerosas superficies de temporal por un manejo extensivo de ganado de carne,

-el aprovechamiento de la capacidad de producción lechera del ganado mediante un manejo temporalmente más intensivo (cerropastoreo) y la producción de queso,

-el aprovechamiento del estiércol acumulado en los establos y que se echaba en las parcelas de riego,

-la producción de numerosos animales de tiro que se podían eventualmente vender o rentar a las explotaciones vecinas.

Aparte de ese tipo de explotación del agostadero, aparecieron otras dos formas de rentabilizarlo a fines del siglo XIX y principios del siglo XX:

-La renta de pedazos grandes de 150-200 hectáreas a gente que luego empleaba medieros para cultivarlos. Esas condiciones parecen haber sido concesiones (la renta se pagaba después de la cosecha así que el arrendador tenía pocos riesgos) que los hacendados hacían a su gente de "confianza".

-Más tarde (año 1910) aparecieron contratos (verbales) de aparcería a medias. Los medieros se reclutaban entre los hijos de los pequeños propietarios más pobres. El préstamo de la tierra no tenía tiempo definido, así que el mediero se quedaba bajo las amenazas y los caprichos del hacendado.

Las condiciones variaban según las haciendas: la hacienda de La Huerta dejaba tierras a medias únicamente a las personas que tenían una yunta propia. Por el contrario, la hacienda de Santa Elena, más rica en ganado, prestaba a menudo los animales que podían aprovecharse de los agostaderos de la hacienda. Los medieros obtenían superficies muy reducidas que les permitían cultivar 4 a 5 hectáreas por año. Además de su trabajo (mano de obra y herramientas), tenían que entregar la mitad de la cosecha (grano y rastrojo) de maíz. El trigo se llevaba entero y se trillaba en la hacienda; el hacendado podía conservar toda la paja (enriquecimiento del estiércol) mientras el mediero se quedaba con la mitad del grano.

Los medieros que tenían más animales no los podían dejar en las parcelas en barbecho. Tenían que rentar los agostaderos de la hacienda: 50 centavos por animal y por mes en 1930, lo que no era excesivo. Sin embargo, muy pocos eran los que tenían animales además de la yunta. Los medieros no tenían ningún fertilizante, pues no tenían derecho de ir a recoger el estiércol en los agostaderos.

Los medieros estaban sometidos a las exigencias del hacendado en lo que concierne a su empleo en las tierras de la hacienda. Aunque fueran pagados como los peones esos requisitos implicaban una sumisión total, pues el hacendado podía romper el contrato cuando lo deseaba. Esos contratos sin embargo, constituían una oportunidad de diferenciación entre 
los campesinos sin tierra.

A pesar de los medieros, las haciendas recurrían al empleo de numerosos peones acasillados o temporales (los sueldos eran de 50 centavos por día en 1930). Los peones acasillados no tenían derecho a poseer animales, ni siquiera puercos o gallinas, lo que aumentaba su dependencia. Los hijos se empleaban como pastores para cuidar el ganado en los agostaderos, con sueldos todavía más bajos.

Las pequeñas propiedades

En la parte del valle que nos ocupa, las pequeñas propiedades estaban concentradas en la Congregación de Pomas. El origen de esas unidades de producción parece corresponder a la venta en el siglo XIX de las tierras marginales (las más altas y alejadas del casco de la hacienda). Muchos de los ancianos de la Congregación dicen que sus padres o abuelos compraron sus tierras pero ninguno lo comprobó. Esas pequeñas propiedades eran el objeto de transacciones comerciales frecuentes, entre campesinos y acaparadores. Los ranchos eran de tamaño variable:

- unos de más de 100 hectáreas, tales como la Troje Colorada de la familia García de más de 600 hectáreas; el rancho Puña de 300 hectáreas; las 200 hectáreas de la familia Romero o las 150 de los Gómez.

-Las propiedades medias, de un tamaño comprendido entre 30 y 80 hectáreas, representaban la mayoría de las unidades de producción. -Un grupo de pequeñas unidades de producción de 2 a 10 hectáreas, probablemente constituido por medieros de las haciendas que habían podido comprar tierras marginales y constituían todavía la mayoría de los medieros del valle.

Esas propiedades tenían entre ellas relaciones de producción, pues las más grandes empleaban medieros del tercer grupo para la explotación de parte de su patrimonio. Sin embargo, los ranchos más grandes (según los testimonios) no empleaban a más de 4 o 5 medieros. Las condiciones eran semejantes a las que se encontraban en las haciendas, pero más flexibles. Por ejemplo el dueño prestaba frecuentemente la yunta al mediero y le permitía cultivar hasta 10 hectáreas cada año. En lo que toca al ganado, el propietario no prestaba agostadero al mediero, así que el último tenía que mantener sus animales en las parcelas en barbecho y por eso conservaba la totalidad del rastrojo y podía aprovechar el estiércol de los bovinos.

Los medieros se reclutaban entre los hijos de los más pequeños propietarios. Esto permitía a los dueños no ofrecer bueyes ni herramientas, pero relativizaba su ventaja en las relaciones de poder respecto a aquéllos.

Los "contratos" eran en general de larga duración (frecuentemente de más de 10 años) y se renovaban por acuerdo tácito entre las dos partes. En el mismo sentido, el dueño no exigía que el mediero trabajara en sus propios 
sembradíos gracias a la gran disponibilidad de campesinos sin tierra que había en el valle. Esos contratos de aparcería no involucraban en aquella época al ganado de los ranchos.

El sistema de producción de los ranchos se orientaba hacia la producción de granos básicos, trigo y maíz y de carne mediante un manejo muy extensivo del ganado. El sistema de ganado admitía una carga bastante débil: menos de media cabeza por hectárea en los ranchos más grandes, pues según los testimonios ningún rancho tenía más de 250 bovinos (Troje Colorada: 600 has.). Esa actividad perseguía tres objetivos:

-Proporcionar una fuerza de tracción y de trabajo a la unidad de producción y eventualmente poder vender o rentar los bueyes a las unidades más chicas que no tenían ganado o que tenían muy poco.

- Ofrecer abonos orgánicos a la unidad de producción;

- Mejorar sensiblemente los ingresos (venta de carne y queso) de las propiedades y constituir un fondo de seguridad (y también de diferenciación) mediante una rentabilización de las tierras incultas, de los barbechos y de la mano de obra no especializada.

Los animales cuidados por niños andaban en los barbechos (en la temporada de lluvias) y en los agostaderos pedregosos o de cerros que se podían cultivar únicamente con dificultades. Se concentraban por la noche en corrales, lo que permitía recoger el estiércol. En las propiedades más grandes se mantenían también unos 10 a 40 borregos cuyo manejo no se diferenciaba del de los bovinos. Las unidades de producción no parecen haber aprovechado la leche con fines de comercialización, sino solamente en forma de queso (mayor producción en temporada de lluvias).

La cría de puercos era generalizada en todas las unidades de producción. No necesitaba mano de obra suplementaria pues los animales andaban tras los bovinos parte del día. Constituían un fondo de reserva y una fuente de grasa para la familia mediante una valorización de los excedentes de maíz.

El sistema de cultivo con el cual se vinculaba esa actividad pecuaria intentaba aprovechar lo mejor posible las tierras de temporal. Incluía en su forma más intensiva tres fases, por periodos de dos años:

-un tiempo de barbecho (descanso), desde la cosecha del maíz en noviembre-diciembre hasta septiembre.

-a fines de septiembre en las parcelas más húmedas se sembraba trigo llamado "aventurero", cultivo sujeto a contingencias debido a la temporada seca de noviembre-marzo y a los fríos del invierno. Algunos bordos cavados arriba de las parcelas permitían a veces disminuir los riesgos de falta de agua. Durante la cosecha, en marzo, los rendimientos eran bajos: 400 o 500 kilos, pero la pequeña cantidad de trabajo invertido justificaba el cultivo.

-entonces se sembraba el maíz con las primeras lluvias. Si no se había cultivado el trigo, el maíz se sembraba con coa ("al piquete") a 
principio de febrero, lo que permitía aprovechar la humedad residual del suelo (sembrando a una profundidad de $20-25 \mathrm{~cm}$. con menor densidad), alargar el ciclo del cultivo sin tomar mayores riesgos (si esa primera siembra fracasaba se volvía a sembrar para las lluvias). Además la carga de trabajo que requería esa técnica, ocurría en una época en la que los campesinos no tenían otras actividades. El maíz se cosechaba en noviembre-diciembre con rendimientos de 1 tonelada por hectárea en general.

Algunos de los que tenían pocas tierras se arriesgaban a hacer un tercer ciclo de cultivo sembrando trigo entre las matas de maíz en octubre y cosechando en marzo. Por supuesto ese cultivo era muy aleatorio y correspondía a un patrón de cultivo más intensivo que se encontraba en explotaciones pequeñas (tercer grupo de propiedades, medieros de los ranchos o de las haciendas). El frijol se sembraba comúnmente entre los surcos de maíz después de escardar, en mayo. Se cosechaba entonces en octubre.

Cuadro No 9 Rendimientos de los cul.tivos basicos en Maravatio 1924-33

\begin{tabular}{|c|c|c|c|c|c|}
\hline Cultivo & Terreno & Siembra & Semillas $\mathrm{K}_{\mathbf{g}} / \mathrm{h}$. & Cosecha & Rendimiento Kg./h \\
\hline \multirow{3}{*}{ Maiz } & Riego & feb-marzo & 12 & oct-dic & 1000 \\
\cline { 2 - 6 } & Hurnedad & marz-abril & 13 & oct-dic & 820 \\
\cline { 2 - 6 } & Temp. & mayo & 13 & nov-dic & 735 \\
\hline \multirow{2}{*}{ Trigo } & Riego & nov-dic & 46 & may-jun & 700 \\
\cline { 2 - 6 } & Humedad & oct-nov & 47 & may-jun & 580 \\
\hline Frijol & Temp. & may-jun & 9 & ocy-nuv & $230 \mathrm{~kg} / \mathrm{ha}$ \\
\hline
\end{tabular}

Fuente: Foglio Miramonte, Fernando.

Geografía agricola-económica del Estado de Michoacán, México, Editorial Cultura, 1938.

Los ranchos más grandes ( 50 hectáreas o más) recurrían de manera sistemática a la mano de obra ajena a la familia, y al trabajo de peones acasillados: el rancho Piña empleaba ocho peones de planta sobre sus 300 hectáreas y hasta algunos ranchos chicos tenían un empleado de tiempo completo en las mismas condiciones que los de las haciendas. Esos peones, acasillados o temporales, se encontraban en abundancia en el valle.

Los campesinos sin tierras

En los años 1920-35 eran muchos los que tenían su fuerza de trabajo como único bien. La mayoría eran acasillados en las haciendas y los ranchos en las condiciones que ya hemos visto y la mayor parte se encontraban muy endrogados, sin posibilidad de criar puercos o aves de corral.

Sin embargo, se habían establecido en los límites de las haciendas (ocupación de la tierra con el acuerdo tácito del hacendado quien necesitaba esa mano de obra), pequeñas comunidades de proletarios que rentaban su 
fuerza de trabajo en todo el valle. Estos tenían la gran ventaja de poder criar animales en la medida en que se les autorizaba llevar los puercos al lado de los caminos y de las parcelas.

Organizaciones del trabajo

Ya se ha dicho lo esencial respecto a la organización del trabajo y a los diferentes tipos de acceso a la tierra. El trabajo asalariado era muy común y era particularmente abundante en las épocas de cosechas. Los medieros constituían entonces una reserva de mano de obra para los hacendados y los grandes rancheros. Se necesitaban importantes cantidades de mano de obra y las pequeñas superficies que tenían los medieros y los campesinos más pobres permitían liberar temprano una fuerza de trabajo no desdeñable. Además, bajaba de los cerros mucha gente de las comunidades indígenas.

Sin embargo, en las pequeñas propiedades de menos de 50-60 hectáreas (que eran la mayoría) y entre los medieros, dominaba el trabajo familiar. Los hijos de un propietario se quedaban en la unidad de producción (mientras podían criarlos y cuando ya no, pedían un contrato de mediero) hasta la muerte del padre. Cada uno de los hijos e hijas tenía derecho a la tierra y esa se repartía según el deseo del muerto, en unidades más chicas.

Hay que observar que los trabajos con yunta y arados de palo necesitaban mucho esfuerzo y una mano de obra abunante: para "barbechar" (abrir sería más apropiado) una hectárea con el arado de palo se necesitaban diez días y tres pasadas por lo menos. Los primeros arados de hierro aparecieron en el curso de la revolución, en el año 1915. Permitían dividir la cantidad de trabajo por dos y multiplicar por tanto su eficiencia (incorporación de las adventicias). Por supuesto las haciendas se beneficiaron primero de ese mejoramiento. Sin embargo, costosos y mal concebidos, el uso de los arados de hierro no se generalizó antes de los años treintas, cuando el gobierno trajo herramientas con bajos costos y mejor adaptación.

El desarrollo de los intercambios

Maravatío siempre fue un nudo de comunicación entre México y Morelia, así que tuvo una situación privilegiada para el desarrollo de los intercambios.

La mayor parte de los productos se vendían tradicionalmente en Maravatío. Sin embargo, algunos productores iban a vender los granos básicos hasta Tlalpujahua donde se obtenían mejores precios gracias a la concentración de la población minera. Arrieros de Tlalpujahua y San Francisco de los Reyes venían hasta las pequeñas propiedades a comprar maíz y trigo igualmente.

La llegada del tren a fines del siglo XIX (1891) acentuó la polarización de la comercialización hacia Maravatío y después hacia México o Morelia. Permitió sin duda el desarrollo de la actividad lechera y quesera en las haciendas. Favoreció la introducción de nuevas técnicas (pastos de alfalfa, 
arados de hierro, etc.).

Esa apertura al exterior favoreció los movimientos migratorios de mano de obra que aparecieron en los años veintes. Los primeros contratos fueron propuestos en Estados Unidos a fines de la primera guerra mundial y algunos peones salieron, pero los bajos sueldos impidieron grandes movimientos.

En los años veintes son los hijos de los pequeños propietarios y los medieros los que empezaron a irse al norte. En aquel tiempo, el pase de la frontera costaba 5 pesos, o sea 10 días de sueldo de un peón. Eso y los gastos de viaje impedían a los peones el intento.

Al contrario, muchos de los medieros que se fueron en aquella época se quedaron bastante tiempo y pudieron regresar con un capital nada despreciable que iba a tener importancia en la evolución de los años treintas.

\section{Creación de los ejidos y nueva dinámica de diferenciación (1935-1947)}

Creación de los ejidos

En 1935 el gobierno cardenista generalizó la desintegración de las haciendas en el valle de Maravatío. Se constituyeron entonces siete ejidos en la parte del valle que nos interesa. El reparto de tierras fue organizado por los ingenieros del departamento agrario. Las dotaciones beneficiaron principalmente a los peones y medieros de las haciendas. Sin embargo, los pequeños propietarios tuvieron bastante influencia como para que se les abriera el acceso a las tierras de la hacienda de Casa Blanca: sobre las 93 dotaciones del ejido de Pomas, unas 60 fueron ocupadas por hijos de pequeños propietarios, los cuales conservaban a pesar de eso sus derechos de sucesión sobre la pequeña propiedad.

Las amenazas morales (de la iglesia) o físicas (de un grupo de cristeros que se quedó bastante tiempo en el valle) facilitaron probablemente esa implantación de los pequeños propietarios en los ejidos pues muchos peones renunciaron a sus derechos.

En un principio, las dotaciones eran casi iguales en cada ejido: 465 hectáreas de riego por beneficiado. Sin embargo, las superficies de temporal atribuidas a cada ejido variaban sensiblemente, lo que iba a tener un papel importante cuando se fraccionaran los agostaderos y se repartieran las tierras de temporal entre los ejidatarios.

Heterogeneidad entre los ejidatarios

Se encontraban aproximadamente dos tipos de ejidatarios en las nuevas unidades de producción así constituidas:

-Los antiguos peones que llegaban sin animales ni herramientas y tenían que comprarlos o rentarlos. El gobierno proponía precios bajos 
para los ejidatarios (12 pesos una vaca, contra 35 en Maravatío, 6 pesos un arado de hierro). Sin embargo, esos precios estaban en un primer momento fuera del alcance de un peón que ganaba 50 centavos diarios en la hacienda.

-Los antiguos medieros y los hijos de propietarios que ya disponían en general de la fuerza de tracción y de las herramientas. Gozaban de una gran ventaja: en el ejido de Campo Hermoso, al principio se encontraban cinco yuntas de bueyes (y 54 dotaciones...).

De manera que desde el principio se perfiló en los ejidos un fenómeno de diferenciación entre una mayoría que tuvo que trabajar con herramientas rudimentarias y superficies reducidas, y unos pocos, que con su capital, la

\section{CuAdro № 10}

CONSTITUCION Y EXTENSION DE TIERRAS DE LOS EJIDOS DE CASA BLANCA, Santa Elena, Pomas y Campo Hermoso en 1937

\begin{tabular}{|c|c|c|c|c|c|c|}
\hline Ejido & Beneficiario & Riego & Temporal & Agostadero & Ciénega & Total \\
\hline Casa Blanca & 120 & $352-60$ & $26-40$ & $618-69$ & $61-03$ & $1060-72$ \\
\hline Sta. Elena & 150 & $597-80$ & 0 & $290-22$ & $76-26$ & $987-28$ \\
\hline Pomas & 156 & $307-80$ & $28-40$ & $1232-94$ & $113-91$ & $1683-05$ \\
\hline Campo Her & 69 & $294-00$ & $84-00$ & $361-00$ & 0 & $739-00$ \\
\hline Total & 495 & $1552-20$ & $138-80$ & $2502-85$ & $251-20$ & $4467-05$ \\
\hline
\end{tabular}

Fuente: Pérez Escutia, Ramón Alonso, op. cit.

ayuda de sus familias y del gobierno (política de bajos precios) podían trabajar a medias partes importantes de las dotaciones del ejido o de otros ejidos. Esas unidades de producción se encontrarán más tarde encabezando el fenómeno de acumulación y de evolución hacia la mecanización y concentración de tierras.

Sin embargo, ya en 1945 el equipo de todas las unidades de producción se había completado y la gran mayoría de los ejidatarios disponía de la yunta de bueyes y del arado de metal.

Las pequeñas propiedades empiezan a dividirse.

La creación de los ejidos parece corresponder al principio del fraccionamiento de las pequeñas propiedades en unidades de producción más reducidas.

Hasta esa fecha, la política de los pequeños propietarios parece haber concentrado las tierras familiares en una sola unidad de producción y la 
mano de obra en una fuerza de trabajo organizada y autosuficiente.

Algún freno debía existir para disminuir el efecto del sistema de herencias en familias numerosas, todos los hijos tenían derecho sobre la tierra. Pero, el temor de la expropiación provocó rápidamente la desintegración de los ranchos más, grandes y también de las unidades de producción más chicas. Parte del patrimonio se repartió entre los diferentes herederos y, la integración de varios hijos en los ejidos impidió repartir las propiedades de manera irracional.

Sin embargo, esa actitud tuvo importantes consecuencias, pues el sistema de herencia directa se generalizó en esas nuevas unidades de producción, recibiendo todos los hijos un pedazo a la muerte del dueño. Otros ranchos como la Troje Colorada fueron vendidos en varias partes.

A ese fenómeno de división de las propiedades se sumó un fenómeno de concentración de la tierra en manos de un número más reducido de familias, pues los propietarios más pequeños vendieron sus terrenos para integrar los ejidos, o sus hijos ejidatarios se separaron luego de esas herencias poco productivas en comparación con las parcelas de riego de sus dotaciones. Son a menudo las familias económicamente más importantes y de la Congregación de Pomas las que compraron esas tierras para disminuir los efectos del fraccionamiento. Así se redujo de manera significativa el número de familias en la Congregación. El cuadro 11 ilustra esos movimientos de propiedad.

CUADRO No 11

\begin{tabular}{|c|c|c|c|c|}
\hline Vendedor & Comprador & Fecha & Sup. & Precio \\
\hline \multirow{3}{*}{ Angel Nava } & Antonio García & $07-08-36$ & 54.74 has & $\$ 200.00$ \\
\cline { 2 - 5 } & $\begin{array}{c}\text { Angela García } \\
\text { Ma. Mercedes }\end{array}$ & $?-36$ & 109.48 .36 has & $\$ 400.00$ \\
\cline { 2 - 5 } & Fco. García & $?-36$ & 54.74 .18 has & $\$ 200.00$ \\
\hline$?$ & $\begin{array}{c}\text { Ma. del C. García } \\
\text { Delfina }\end{array}$ & $?-36$ & 109.48 .36 has & $\$ 400.00$ \\
\hline & Fam. García & 1936 & 328.45 .08 has & $\$ 1200.00$ \\
\hline
\end{tabular}

Fuente: Pérez Escutia, Ramón Alonso, op. cit.

Aparición del fenómeno migratorio

Con la entrada de Estados Unidos en la segunda guerra mundial, la atracción de mano de obra hacia el norte se propagó hasta Maravatío. Esa fecha marca realmente el principio de las importantes migraciones que se han verido produciendo hasta ahora. 
Muy a menudo son los hijos de los más grandes propietarios y los ejidatarios "equipados" los que participaron prioritariamente en esas migraciones. Los ex-peones no habían acumulado bastante para arriesgarse a dejar sus cultivos durante el tiempo del contrato ( 6 meses o más) pues tenían que hacer una cantidad de trabajo superior debido a la falta de herramientas y no podían pagar el trabajo de peones mientras estuvieran en Estados Unidos.

De esta manera, al fin de ese periodo se había acentuado la diferenciación en el seno de las comunidades entre los más ricos que habían podido expatriarse y regresaban con un capital importante, y los ex-peones y pequeños propietarios que no pudieron tomar ese riesgo.

3. Tecnificación de la agricultura y acentuación del fenómeno de diferenciación (1947-1970)

La matanza de ganado de 1947

1947 es el año de la fiebre aftosa. Bajo las presiones del gobierno estadounidense la administración Alemán decidió la matanza de todos los bovinos, ovinos y caprinos. Esa se extendió a todas las unidades de producción del valle.

En aquella época, la casi totalidad de los ejidatarios había podido adquirir su yunta de trabajo. La matanza exterminó todo el ganado y de hecho favoreció a los que habían acumulado la mayor cantidad de animales, es decir a los que tenían las primeras yuntas y habían ido a Estados Unidos. Esos pudieron comprar rápidamente nuevas yuntas o uno de los primeros tractores y cultivar tierras a medias, en las dotaciones de los más pobres.

Es cierto que existía una indemnización de 40 pesos por cada animal, pero se sospecha que hubo acaparamiento de esas indemnizaciones por parte de los responsables ejidales, que a menudo pertenecían al estrato más rico de los ejidatarios: el proceso de acumulación-diferenciación se repitió.

En las pequeñas propiedades también hubo efectos diferenciales de la matanza, pues se dice que los que tenían más ganado (200 reses) presentaron unos 50 animales a los soldados y escondieron la mayor parte de los bovinos en los cerros vecinos. Aunque los propietarios menores de ganado pudieron esconder también parte de los animales, la matanza de todos modos les afectó con más fuerza.

Consecuencias de la matanza: motorización de los ejidos

La primera de las consecuencias fue así la acentuación de la diferenciación entre las unidades de producción y, a mediano plazo, un incremento en la acumulación en las unidades de producción más avanzadas.

Pero la consecuencia más evidente fue la mecanización de la agricultura en los ejidos. Esa evolución hubiera ocurrido de todos modos, pero la 
matanza aceleró el proceso. En la mayoría de los casos, las yuntas fueron reemplazadas por troncos de caballos pues esos no habían sido eliminados. Las yuntas siguieron siendo utilizadas únicamente en las pequeñas propiedades de la Congregación de Pomas, donde la naturaleza de los suelos no permitía el empleo de los caballos (falta de potencia).

Sobre todo, a fines de los años cuarentas y principio de los cincuentas aparecieron los primeros tractores en los ejidos. El gobierno propuso a los ejidatarios, tractores con precio muy atractivo, aunque fuera del alcance de la mayoría. Así, en 1948, solamente un año des pués de la matanza se juntaron en Campo Hermoso 12 socios, dentro de los cuales se encontraba la mayoría de los antiguos medieros y de los que se habían ido a Estados Unidos. Entre 1950 y 1952 se compraron otros dos tractores, lo que correspondía a un principio de concentración de las máquinas en las manos de unas pocas familias (Palomino, Domínguez y Nava, todos antiguos medieros de las haciendas). A fines de los cincuentas Angel Palomino compró la primera cosechadora-trilladora, la cual se pudo rentar bastante tiempo como para reembolsar varias veces la inversión que había realizado.

Eso demuestra que la diferenciación entre ejidatarios y el proceso de acumulación corrieron rápidamente.

La primera solicitud de colonización del agostadero en el ejido de Campo Hermoso - cuyo resultado fue la autorización para cada ejidatario de cultivar una hectárea-, corresponde a las presiones de la parte de la población que iba concentrando los medios de producción.

Sin embargo, ese movimiento no tocó a la Congregación de Pomas ni a las pequeñas propiedades. La razón principal es probablemente que el gobierno no dio tantas facilidades a los pequeños propietarios como a los ejidatarios. De otro lado, la reducción de las superficies de las unidades de producción y la abundancia de mano de obra fa miliar o ajena no favorecía esa evolución. Teniendo en cuenta la naturaleza de los suelos en la Congregación (temporal que se carga muy rápidamente de agua en la temporada de lluvias y limita la utilización de máquinas pesadas durante cuatro de los nueve meses del periodo de cultivo), la mayoría de las pequeñas propiedades no tenían mucho interés en endeudarse para mecanizarse. Sin embargo, se generalizó poco a poco la renta de los tractores para los trabajos de barbecho.

Tecnificación y especialización de la agricultura

A fines de los años cincuenta, y sobre todo en el curso de los sesentas apareció y se generalizó el uso de fertilizantes químicos. Eso provocó a menudo el abandono del estiércol (que tanto ejidatarios como pequeños propietarios recogían en los corrales en los cuales se encerraban los animales cada noche), sobre todo desde que, a fines de los años sesentas el Banco de Crédito Ejidal propuso un sistema de crédito en todo el valle para la compra de fertilizantes. Sin embargo, ningún testimonio indica que el uso 
de los fertilizantes químico haya permitido aumentar el nivel de los rendimientos.

Al contrario, la generalización del uso del fertilizante químico correspondió a la proliferación de plagas del frijol, provocando su disminución y en algunos casos su desaparición en las superficies cultivadas. El enriquecimiento de los suelos en nitratos pudiera haber provocado una debilitación de la resistencia de la planta a esas plagas. Un campesino entrevistado ligó directamente las dos circunstancias. El periodo de cultivo del frijol se desplazó también de mayo-septiembre a marzo-julio para evitar la proliferación de plagas en la temporada de lluvias.

Aunque el uso de fertilizantes hubiera permitido suprimir el año de descanso en las tierras de temporal (indispensable antes para la renovación de la fertilidad), esto no sucedió así porque después de la cosecha del maíz (en diciembre) la falta de humedad residual en el suelo impedía una nueva siembra desde el mes de febrero. Luego, esperar la llegada de las primeras lluvias implicaba correr el riesgo de que las arvenses se adelantaran al desarrollo de la milpa y que se crearan cuellos de botella en el calendario de trabajo. Sobre todo, los barbechos seguían constituyendo una base para el abastecimiento de forrajes del ganado sin tener que aumentar las superficies de agostadero.

Otro cambio en el sistema de producción, es que a principio de los años sesentas aparecen las variedades de trigo de paja corta de la revolución verde. La generalización de esas variedades provocó la desaparición del cultivo del trigo en el valle. Las unidades de producción no podían resistir la competencia de las regiones productoras del trigo del norte y la baja de los precios del grano que se mantuvo hasta fines de los años sesentas. Así que el cultivo "aventurero" desapareció de las tierras de temporal y muchas parcelas de riego se dejaron en descanso en invierno desde fines de los años sesentas hasta fines de los setentas.

Mas anecdótica es la enfermedad que atacó y destruyó la mayor parte de los magueyes. Sin embargo, los magueyes constituían una valorización de las parcelas de agostadero y un complemento de los ingresos de las unidades de producción más pobres.

Ese periodo 1947-1970 corresponde a una tecnificación (uso de los tractores y de los fertilizantes químicos) y a una simplificación de las bases técnicas de los sistemas de producción (maíz-ganadería extensiva).

Acentuación de la presión sobre la tierra y generalización de las migraciones Ese periodo también corresponde a la llegada de una nueva generación de campesinos que piden el acceso a la tierra. El problema se hizo más importante en los ejidos, pues la única salida hubiera sido repartir los agostaderos, lo que no podía permitirse por el nivel que habían alcanzado las fuerzas productivas. Sin embargo, en Campo Hermoso se produjo una 
ampliación del ejido y 11 de los jóvenes pudieron compartir 60 hectáreas de temporal a las orillas de una comunidad indígena a unos $8 \mathrm{~km}$ del ejido en el que siguieron viviendo.

En las pequeñas propiedades, la presión sobre la tierra se expresó por la continuación del fraccionamiento de las unidades de producción. Los hijos, después de haber trabajado como ayudantes familiares, se instalaban - por lo regular después de casarse - en parcelas familiares, como medieros del padre. En general conservaban el derecho de herencia sobre esas parcelas de manera que las explotaciones conocían una fragmentación más precoz. Otra consecuencia es que los hijos mayores se apropiaban de las partes más grandes y les quedaba poco a los hijos menores y, sobre todo, a las mujeres. De manera que muchas de las propiedades fueron divididas en el curso de los cincuentas y sobre todo a partir de los años sesentas en unidades que resultaban cada vez menos viables.

Una salida a esos problemas de presión sobre la tierra fue la migración hacia el Distrito Federal o, muy a menudo, hacia Estados Unidos. Sin embargo esas migraciones no deben ser consideradas únicamente como una manera de huir del fenómeno de la sobrepoblación relativa del valle. Era también una inversión para los más ricos de los ejidatarios o de los propietarios que mandaban hijos a hacerse de un capital en Estados Unidos para luego comprar una propiedad o una dotación ejidal a un anciano. Los más pobres, después de que se hubieron acabado los contratos en 1962 tuvieron que pasar como "mojados" y aceptar los pequeños empleos que se les proponían.

Asi que las migraciones, temporales o más largas, constituyeron poco a poco un elemento importante de la economía campesina e hicieron también el papel de diferenciador entre los campesinos.

Por consecuencia ese periodo, 1947-1970 se caracteriza sobre todo por la diferenciación de las unidades de producción y la concentración de los medios de producción (máquinas, ganado y también tierra) en manos de un número reducido de campesinos. Esa evolución es más perceptible en los ejidos: en Campo Hermoso, tres familias concentran la mayor parte de los tractores, la totalidad de las cosechadoras y una gran parte de las dotaciones compradas a los primeros ejidatarios que no las podían cultivar. En las propiedades privadas, esa evolución, aparece poco a poco, en particular en el caso del rancho Melo que, a fines de los sesentas alcanza un tamaño de 250 hectáreas, gracias a la compra de unidades demasiado parceladas y ya no rentables.

Otra característica de este período es la diferencia que aparece entre las propiedades de la Congregación de Pomas, que se manejaban de manera todavía tradicional, y las unidades de producción de los ejidos que ya para entonces alcanzaron un nivel técnico importante y donde se distinguen una clase de campesinos acomodados, capaces de inversiones importantes y muy 
bien dispuestos para la etapa siguiente.

\section{Hacia una especialización de los sistemas de producción $1970-85$}

Situación de las unidades de producción a principios de los setentas.

Ya se ha dicho que las unidades de producción habían evoluciorado hacia modificaciones estructurales que preparaban cambios ulteriores en el manejo de las unidades que seguían siendo muy tradicionales pese a la relativa tecnificación de la agricultura (empleo de máquinas y de productos químicos). Los sistemas de producción seguían basados en la producción de maíz (con la disminución de los cultivos de trigo y frijol) y un manejo extensivo del ganado mediante la utilización de tierras de agostadero y de las parcelas en barbecho. El único cambio que se había podido notar era la generalización de la cría de borregos, sobre todo en las pequeñas propiedades, aunque también en los ejidos. Bajo la condición de tener bastante agostadero para auxiliar a las necesidades de los borregos en temporada seca (pues no puede utilizar el rastrojo de maíz), ese tipo de cría corresponde muy bien a las necesidades de las unidades de producción: los borregos no requieren más cuidado que las reses y constituyen un capital en pequeñas unidades, las cuales se pueden vender una por una sin representar una pérdida tan importante como la de una res.

Las diferencias más notables respecto al sistema anterior se refieren sobre todo al tamaño de las unidades de producción. Al fenómeno de concentración de tierra en propiedades privadas.

Generalización del fenómeno de mecanización.

La presión demográfica en los ejidos provocó la decisión de fraccionar los agostaderos y distribuir las parcelas de temporal entre los ejidatarios para aumentar las superficies por dotación. Esa evolución correspondía al deseo de los más ricos que veían así la posibilidad de extender sus unidades de producción mediante renta o contratos de mediería, lo que no era posible antes debido a la sobrepoblación. En el ejido de Santa Elena, sin embargo, la naturaleza del temporal (mayoría en pantano o en cerros) no permitió la distribución de más de dos hectáreas por ejidatario; pero en Campo Hermoso y Pomas, esas tierras liberadas representaron entre 7 y 10 hectáreas por dotación: una alternativa se presentaba así a las unidades de producción.

Esa decisión, aunque favoreció sobre todo a los poseedores de tractores, provocó también la aceleración de la motorización y hasta la sobremotorización de los ejidatarios. Corresponde a la generalización de condiciones muy ventajosas de crédito para la compra de máquinas. Muchos ejidatarios se juntaron para beneficiarse a partir de 1978 de esos créditos bancarios (ver 
CUADRO № 12: EVOLUCION DE LA POTENCIA Y EL NUMERO DE MAQUINAS aGRICOI.AS AUTOMOTRICES EN EL EJIDO DE CAMPO HERmoso

\begin{tabular}{ccc}
\hline Años & No máquinas automotrices & Potencia (en caballos HP) \\
\hline 1948 & 2 & 90 \\
\hline 1950 & 4 & 180 \\
\hline 1955 & 4 & 170 \\
\hline 1960 & 3 & 190 \\
\hline 1965 & 4 & 250 \\
\hline 1970 & 6 & 415 \\
\hline 1975 & 7 & 500 \\
\hline 1980 & 12 & 900 \\
\hline 1985 & 22 & 1700 \\
\hline
\end{tabular}

Grafica № 7: EvOlUCION DE LA POTENCIA EN LAS MAQUINAS AGRICOLAS EN EL ejIDO de CAMPo HeRmoso

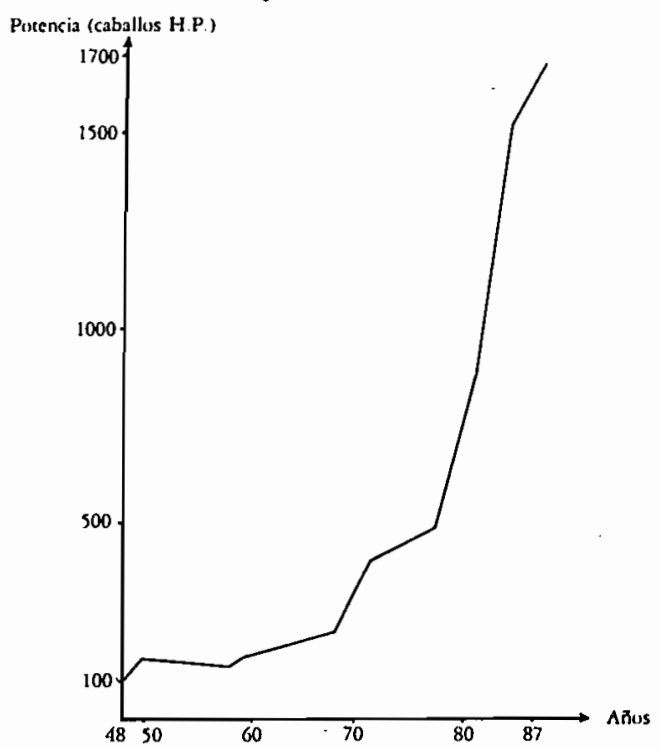

Revela el boom de la motorización en los 10 últimos años: aumento del número de máquinas de 15 unidades $(+200 \%)$ y de la potencia de $1200 \mathrm{c}$ $(+240 \%)$.

cuadro 12 y gráfica 7) e incluso el fenómeno tocó a las pequeñas propiedades de Pomas. Sin embargo, no es sorprendente observar que el rancho Melo, el 
más grande de la Congregación fuera el primero en comprar un tractor. Pero entre las pequeñas propiedades, el tamaño reducido de las unidades limitaba esa evolución puesto que la mayoría de los campesinos consagraba la mayor parte de su capital a la compra de tierras para constituir explotaciones de más de 20 has. Luego intervenía la preocupación por mecanizarse.

Sin embargo, es muy probable que entre 1975 y 1985 , el número de tractores en esa parte del valle fuera multiplicado por más de cuatro. Esa evolución era necesaria para seguir el ritmo impuesto por los ejidatarios más ricos, sin embargo iba en sentido opuesto al interés de la mayoría de la población pues desempleaba a muchos de los hijos de ejidatarios y de los campesinos sin tierra, lo que aceleró todavía más la salida de muchos jóvenes y favoreció un poco más la concentración de tierra. Por el contrario, el costo de utilización del tractor permite su difusión rápida. ${ }^{2}$

Desarrollo de la actividad lechera

Las primeras vacas llegaron temprano a los ejidos donde la diferenciación y la acumulación estaban más avanzadas (Campo Hermoso y en un grado menor, Pomas), y donde la presión sobre los agostaderos era más fuerte. Los primeros intentos de cruzar vacas Suizas y Jersey con los animales corrientes aparecieron en Campo Hermoso a principio de los años sesentas, lo que revela la capacidad de los más ricos para arriesgarse a un tipo de cría más intensiva.

Sin embargo, las primeras Holstein no llegaron antes de los años 1971-72. Campo Hermoso tuvo un papel principal en la introducción, el desarrollo y la extensión de la especulación lechera. La implantación de las vacas lecheras fue apoyada por algunas sociedades proporcionando publicidad y transporte. Los precios eran accesibles según los testimonios, lo que puede explicar que algunos compraron una o dos vacas sin tener pastos, dejándolas en el agostadero.

Es cierto que la baja de los precios del trigo entre 1970 y 1980 facilitó la implantación de las vacas lecheras pues las parcelas de riego abandonadas por el trigo se podían entonces sembrar con pastos artificiales tipo trébol y ray-grass. Así una mayor parte de los ejidatarios de Campo Hermoso parece haber comprado en los años $72-78$ vacas Holstein y participado, al menos en parte, en la especulación lechera, sea o no apoyándose en el uso de pastos artificiales.

El fraccionamiento del agostadero en 1978 dio un nuevo impulso al

2. En 1985, para barbechar, cruzar y rastrear una hectárea, la renta de un tractor costaba $\$ 20,000.00$ mientras alquilar un tronco costaba $\$ 17,000.00$ y ocupaba unos 13 días de trabajo. Aunque parezca más barato rentar el tiro, para un campesino que se puede emplear afuera (a $\$ 1,000.00$ la jornada) el costo de oportunidad es de unos $\$ 10,000.00$ a favor del tractor. 
desarrollo de la actividad lechera ya que permitió dedicar una superficie importante del riego al cultivo de pastos y avena, mientras el cultivo del maíz - todavía necesario a las unidades de producción- se desplazaba en parte hacia el temporal. Así, cada ejidatario de Campo Hermoso poseedor de vacas lecheras pudo mantener una cierta superficie de pastos, lo que era absolutamente necesario para un buen manejo de sus animales.

Ese desarrollo de la actividad lechera correspondía también a la necesidad de intensificar los sistemas de producción y poder así mantener más gente en la unidad de producción: esa orientación requiere una movilización importante de la mano de obra en la construcción de edificios, en traer los forrajes a los animales, ordeña, etc. Ni siquiera con los movimientos de migración hacia Estados Unidos se detuvo este desarrollo.

Campo Hermoso era sin duda la comunidad donde se encontraban las condiciones óptimas para el desarrollo del ganado lechero: las tierras de riego permitían mantener pasturas, y al lado las tierras de temporal en cantidad importante $\mathbf{- 8}$ hectáreas por dotación- permitían la transferencia de las actividades agrícolas tradicionales (maíz, frijol...). Los ejidatarios de Santa Elena no tenían esa ventaja pues poseían únicamente una hectárea de temporal cultivable por dotación. En el ejido de Pomas se encontraban condiciones similares a las de Campo Hermoso, con superficies todavía más importantes de temporal ( 10 a 12 hectáreas por dotación). Pero la mayoría de los ejidatarios tenían una pequeña propiedad y se orientaron a menudo hacia una especialización más agrícola mediante la compra de máquinas en lugar de vacas: en ese caso, las superficies de temporal de las que se beneficiaban fueron demasiado importantes para que el desarrollo lechero fuera interesante: la remuneración del trabajo era desventajosa en comparación con una especialización agrícola.

El proyecto de desarrollo lechero promovido por la Secretaría de Fomento Rural del gobierno del estado intervino en 1982 en forma favorable. El problema era sencillo: se trataba de canalizar y desarrollar ese potencial de producción lechera que se encontraba en el valle. Con la experiencia del proyecto de desarrollo de grandes establos colectivos ( 4 unidades de 250 vacas manejadas colectivamente) en otra parte del valle, ${ }^{3}$ la

3. Este proyecto fomentó la creación de cooperativas de producción, agrupando a unos 300 40 socios. Las malversaciones de fondos por parte de los responsables campesinos así como problemas muy grandes en la repartición de los trabajos (las vacas carecían de cuidados estando en mal estado sanitario y con niveles de producción más bajos que en las unidades familiares) llevaron al fracaso. El reembolso del crédito de pago de las vacas y de la infraestructura nunca permitió pagar debidamente a los pocos socios que trabajaban en el funcionamiento de la cooperativa y liberar utilidades. De los cuatro grupos que se constituyeron, uno solamente ha pagado en forma colectiva su deuda; en otros dos se repartieron las vacas entre los socios y se abandonaron los establos colectivos. 
administración del nuevo proyecto se orientó hacia la organización de pequeñas unidades de producción familiares. A partir de 1984 se fomentaron grupos de productores en los ejidos de Campo Hermoso, Santa Elena, Casa Blanca, Pomas y en la Congregación de Pomas, construyendo establos y sembrando pastos con la asistencia técnica de la Secretaría. Se procuró créditos a algunos grupos para la compra de ganado. Se trajo así asistencia a unos 88 productores de todas partes del valle.

El proyecto de la Secretaría de Fomento permitió sin duda alguna el desarrollo de la actividad lechera en las pequeñas propiedades de la Congregación de Pomas. Unas nueve unidades de producción participaron en el proyecto y recibieron vacas en la primavera de 1985 . Sin embargo, esas propiedades padecen de la ausencia de posibilidades de riego y de la necesidad de producir grandes cantidades de forrajes conservados para el mantenimiento de sus animales en buenas condiciones todo el año. Ese manejo necesita la desaparición de todos los conceptos tradicionales, sobre todo el de autosuficiencia de la familia (dedicación de toda la superficie a la producción de forrajes).

En síntesis se puede considerar que en unos diez años la producción lechera se generalizó a todas las partes del valle, aunque de manera muy irregular.

Hacia dos tipos de especialización

La especulación lechera corresponde a la necesidad de la mayor parte de las unidades de producción para optimizar los ingresos por unidad de superficie disponible, utilizando una mano de obra familiar, en general abundante, e intensificando así el sistema de producción. Eso necesita la reducción de los otros tipos de ganadería y hasta su desaparición en algunos casos y la orientación de las actividades agrícolas hacia la producción de forrajes de calidad homogénea todo el año.

La producción de leche y su transformación en queso permite la utilización de una mano de obra que no aprovechan otros sistemas de producción como la de los niños que ordeñan y cuidan los animales y la de las mujeres para la fabricación de los quesos mientras la mano de obra varonil se consagra a la producción forrajera.

El proyecto intentó arreglar los problemas de comercialización de los productos mediante la construcción de un centro de acopio y de procesamiento de la leche en Campo Hermoso, el cual entró en servicio en febrero de 1987.

Pero si ese tipo de especialización parece corresponder a las necesidades y las estructuras de la mayoría de las unidades de producción, otro tipo de especulación existe también, implicando unidades de tamaño más importantes. En esa categoría se encuentran los ejidatarios y propietarios que siempre estuvieron en la punta de la pirámide de la acumulación diferencial, siendo 
los primeros en migrar y en comprar terrenos, máquinas y animales.

Mediante la posesión de máquinas e inversiones en compra de material nuevo, esas explotaciones se especializaron poco a poco hacia la rentabilización de esas inversiones: alquilando las máquinas (tractores y cosechadoras, eventualmente camiones para el transporte de carga), trabajando tierras a medias o rentándolas, y comprando propiedades o dotaciones, lo que se traduce en una especialización agrícola gracias a superficies importantes.

Sin embargo, eso no significa que las unidades de producción no tengan ganado. Este sigue sirviendo de reserva de capital para las inversiones y valoriza las parcelas en barbecho.

En ese objetivo de especialización relativa hacia la agricultura, algunas propiedades de la Congregación de Pomas financiaron la construcción de obras de riego (excavación de un pozo profundo, eventualmente construcción de acueducto...), las primeras en ese lugar, lo que revela la capacidad de inversión de esas unidades de producción.

Sin embargo, esos dos tipos de especialización que parecen dibujar las líneas directrices de una futura evolución no se excluyen mutuamente, pues se encuentran juntas en las unidades de producción más ricas: en Campo Hermoso los dos propietarios de cosechadora y el más importante terrateniente participaron en el proyecto de desarrollo lechero y están entre los más grandes propietarios de ganado Holstein.

La evolución de los sistemas de producción en el curso de los cincuenta últimos años se hace en el sentido de su diferenciación y su tecnificación. A parece entonces necesario centrarse más sobre las bases técnicas de dichos sistemas a fin de llegar a una caracterización precisa de ellos.

\section{SISTEMAS ACTUALES DE CULTIVO Y GANADO}

\section{Sistemas de cultivo}

En unidades de producción de orientación mixta o de tendencia agrícola. En esos dos tipos de unidades de producción los patrones de cultivos tienden hacia tres objetivos:

-el abastecimiento de productos básicos a la familia, principalmente maíz,

-el abastecimiento de forrajes para el ganado,

-el aumento de los ingresos familiares mediante la venta del maíz, sobrante o de cultivos de renta (trigo, cebada, frutas...) o del ganado pequeño (aves de corral, puercos) criado con el excedente de grano.

La importancia de esos tres factores varía sensiblemente según la 
orientación mercantil de las unidades de producción. En las que son más agricultoras domina la tercera preocupación y la segunda tiene, en general, muy poca importancia.

A esos imperativos económicos se suman otros directamente ligados con la naturaleza de los suelos y su capacidad de retención de agua.

Las tierras de riego, por lo regular aceptan dos ciclos de cultivo al año; sin embargo, los más bajos y húmedos, en proximidad con la ciénaga de Santa Elena, se trabajan difícilmente y son poco productivos durante la temporada de lluvias.

Las partes de temporal, como ya lo dijimos, presentan otros imperativos y con frecuencia se necesita imponer un año de barbecho-descanso entre cada año de cultivo.

De manera que en estos dos tipos de unidades de producción la organización de los cultivos es la siguiente:

En tierras de temporal, el cultivo de maíz sigue siendo predominante en todos los casos por los diferentes papeles que puede tener en las unidades de producción (abastecimiento de la familia y del ganado, valor comercial mínimo asegurado). Sin embargo, se encuentran también cultivos comerciales. El trigo, cuyo ciclo de vegetación es más corto que el del maíz, se puede sembrar más tarde sin correr el riesgo de falta de agua en mayo-junio y es menos exigente en agua; los frutales - duraznos - o el chile, se siembran igualmente con la condición de disponer de un sistema de riego de apoyo. $\mathrm{El}$ frijol que ha desaparecido en muchas partes del valle debido a la proliferación de plagas, pero que se acostumbra sembrar en un cuarto de hectárea para el abastecimiento familiar.

En las tierras de riego más altas la rotación de cultivos más común es el trigo de invierno y maíz, gracias a que la altura de las percelas permite un satisfactorio drenaje de las primeras lluvias. En las tierras más bajas, se cultiva principalmente avena o haba en invierno pues su ciclo de vegetación es más corto y permite adelantar la siembra del maíz. En ese caso la avena, así como las pajas de haba, sirven para la alimentación del ganado aunque la avena se pueda vender en grano en el mes de mayo. Algunas parcelas muy húmedas no se cultivan en invierno y se siembran a fines de febrero con maíz y frijol; así se evita la proliferación de plagas que perjudican al frijol en temporada de lluvias. Otras se cultivan únicamente en invierno con trigo, pero existen entonces riesgos de no poder cosechar si las lluvias llegan temprano.

Unidades de producción de orientación lechera

En las unidades de producción, el abastecimiento de forraje para el ganado es el objetivo principal. Sin embargo, las familias siguen buscando, en la mayoría de los casos, la solución al problema de abasto mediante el fomento de cultivos comerciales, tales como duraznos o trigo. 
El cultivo del maíz sigue dominando las rotaciones en todos los tipos de suelo y representa la base del sistema forrajero ya que el grano se utiliza como complemento concentrado. También se usa el rastrojo y poco a poco aparecen técnicas de ensilado en el valle. Para los ganaderos lecheros que disponen únicamente de tierras de temporal, el ensilado de maíz se convirtió en el principal forraje concentrado de los sistemas de producción. Las parcelas que se ensilan son, a menudo, las de mayor altura, ya que se trata de cosechar con máquinas pesadas en una época en que las lluvias todavía pueden ser abundantes a fines de septiembre.

En tierras de riego se extendieron sobre las parcelas más húmedas pastos de trébol y ray-grass que en general se renuevan cada seis u ocho años, intercalándose entre las dos pasturas un ciclo de trigo o de avena de invierno. Los pastos se extendieron a todo el valle desde hace unos cinco o seis años y pueden ser objeto de venta de parte de los que poseen muy pocas vacas.

Así se ha venido organizando la utilización de los suelos según los objetivos de las diferentes unidades de producción, aprovechando en la medida de lo posible las características de los diferentes tipos de suelos, el relieve del terreno, la abundancia o no de las aguas de riego, etc. A esa lógica corresponde una utilización muy racional de los suelos que en el caso del ejido de Campo Hermoso se puede observar en el mapa 10.

Sin embargo tal aprovechamiento de los suelos es bastante escaso y la mayoría de las comunidades disponen todavía de agostaderos que no se podrían cultivar porque son demasiado pedregosos, demasiado húmedos, como la ciénaga de Santa Elena, o porque las pendientes no lo permiten.

Técnicas y calendarios de trabajo

En la actualidad, el valle suroeste de Maravatío se encuentra mecanizado. El uso de maquinaria se ha generalizado pero no siempre se tradujo en una ventaja importante en términos de costo de oportunidad pese a que representa una mayor productividad del trabajo. $Y$ es que los trabajos de barbecho se realizan principalmente entre agosto y octubre y entre febrero y marzo, cuando los cultivos no requieren mucha atención. Con todo, los medieros con escasos recursos son los únicos que no recurren al empleo del tractor.

Troncos de caballo y yuntas de bueyes se usan más bien para las siembras, las escardas y para el transporte de las cosechas. Las fechas de los trabajos de escarda del maíz, frijol, etc., impiden a menudo el empleo de tractores que ni siquiera pueden entrar en parcelas muy húmedas. Luego se puede recurrir al trabajo humano directo en las operaciones de chapeo al machete en los meses de julio y agosto cuando ni los animales se pueden mover en las parcelas.

Actualmente casi la totalidad de las unidades de producción del valle acostumbran utilizar abonos químicos ( $99 \%$ de la superficie total cultivada 


$$
\text { MAPA } N^{2} 10 .
$$

OCUPACION DE LOS SUELOS EN EI. EJIDO DE CAMPO HERMOSO

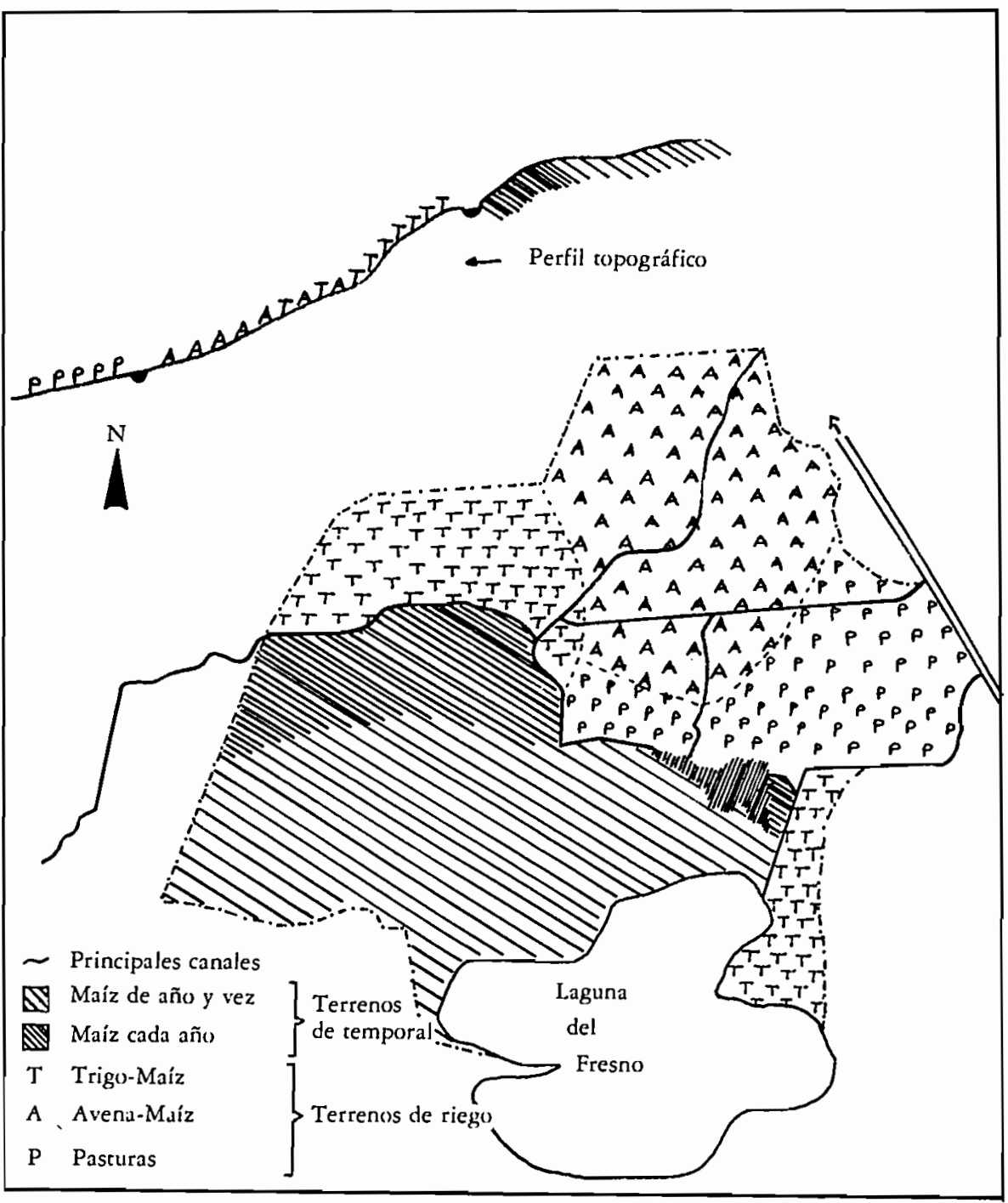


en $1981-82$ y $82-83,98 \%$ en $1983-84){ }^{4}$ Esos fertilizantes se procuran mediante el sistema de crédito propuesto por el Banrural con pago en la cosecha. Los abonos y las dosis empleados siguen las indicaciones del banco el cual tiene como referencia las parcelas experimentales. Las fórmulas más comúnes son $600 \mathrm{~kg}$ de sulfato de amonio (20.5-0-0) y $300 \mathrm{~kg}$ de superfosfato de calcio (0-19.5-0) por hectárea, aproximadamente $120 \mathrm{~kg}$ de nitrógeno y $60 \mathrm{~kg}$ de fosfato. Se aplican cuando las plantas tienen unos 30 ó $40 \mathrm{~cm}$. de alto, alrededor de un mes o mes y medio después de la siembra. Esas dosis permiten teóricamente un incremento de producción de más de una tonelada por hectárea o sea que en 1985 una inversión de $\$ 20,000.00$ daba una ganancia de $\$ 45,000.00$. Ese margen puede hacer reflexionar a los dueños de parcelas trabajadas a medias, pues ellos acostumbran pagar los fertilizantes. Una vez compartida la cosecha, le quedan unos $\$ 2,500.00$ de beneficio neto, lo que les orilla a disminuir las cantidades de abono empleadas por hectárea o hacer presión sobre el mediero para compartir los gastos, práctica que se está generalizando cada vez más.

El uso de herbicidas antidicotiledóneas ("esterón") disminuyó la importancia de las operaciones de limpia. Se generalizó desde hace unos 6 a 8 años a todo el valle. Sin embargo su empleo sigue siendo todavía reducido, debido a los problemas de remanencia que impiden el cultivo de frijol, haba, chile y trébol después de un ciclo de maíz o de trigo. De manera que los herbicidas no se usan de manera sistemática y nunca en pre-siembra: todas las unidades de producción recurren todavía a la escarda con arado. Esa actitud tiene como consecuencia que las parcelas de temporal, que se podrían cultivar año por año retrasando la fecha de siembra hasta las primeras lluvias y luchando contra las malezas con un tratamiento herbicida en pre-siembra, siguen manejadas con el ciclo tradicional maíz-barbecho-maíz. La proliferación de las malezas, si bien no es el único obstáculo al cultivo "intensivo" del temporal, es el mayor impedimento para su generalización.

Como los trabajos de la tierra, las operaciones de cosecha se mecanizaron fuertemente desde hace unos 15 a 20 años. La cosecha del trigo fue, por supuesto, la primera afectada por la mecanización. La presencia de máquinas cosechadoras combinadas en el valle, en Campo Hermoso y Pomas, permite asegurar la cosecha sin pérdida de tiempo. Más recientemente llegaron máquinas para ensilado del maíz y de los pastos (1984) y de cosecha del maíz en grano (1985), pero su empleo permanece aún relativamente marginal: la cosecha del maíz es todavía la operación que moviliza más mano de obra y, se recurre mucho al trabajo de los peones.

Así se encuentran conjuntamente en esa parte del valle de Maravatío

4. SARH, Maravatío. 


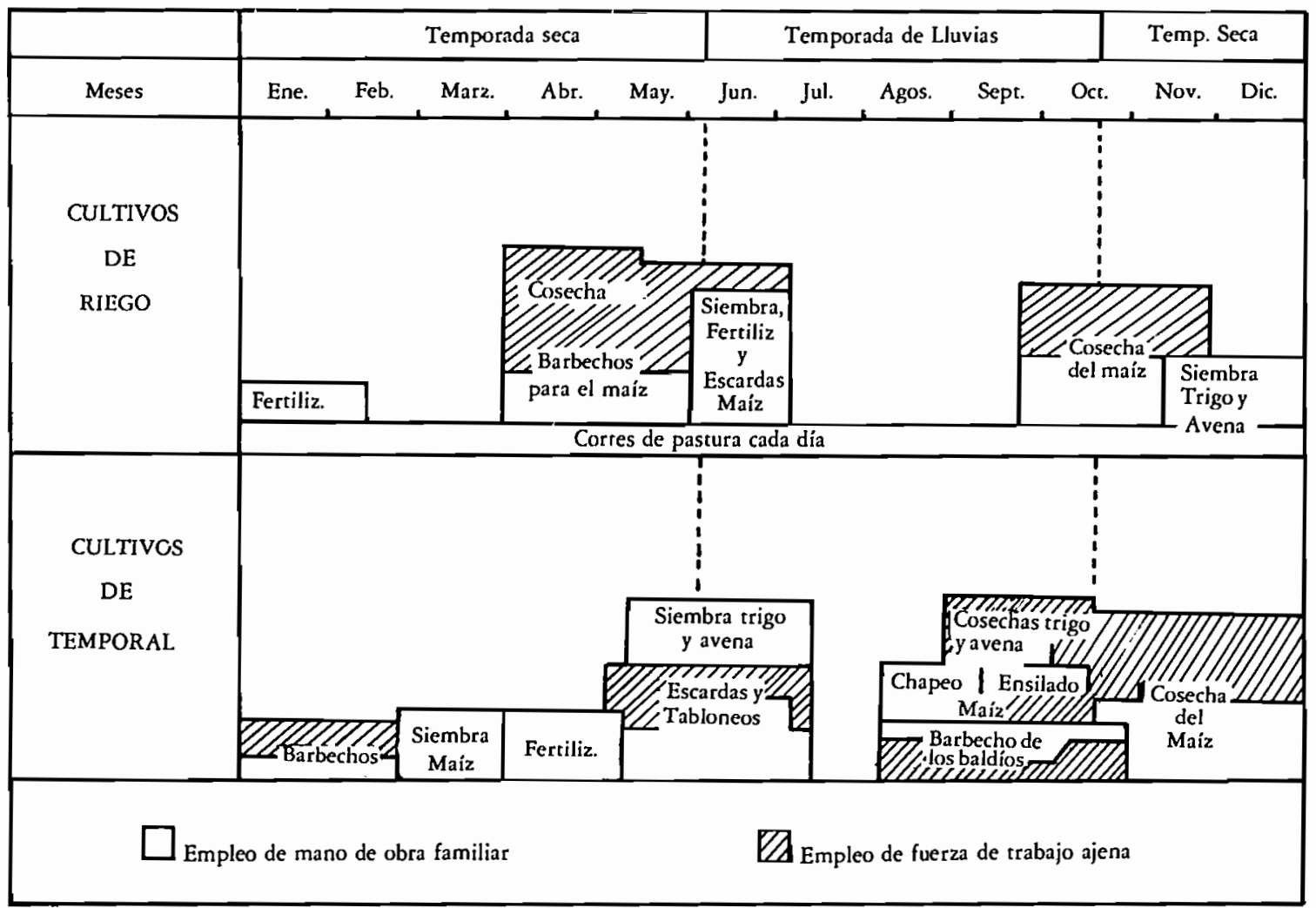


Congregación de Pomas; la cosecha manual del maíz prosigue en casi todas las unidades de producción. En el mismo sentido la introducción de semillas de maíces híbridos fue un fracaso, pues las variedades propuestas degeneran rápidamente de manera que se tienen que comprar cada año, lo que va en sentido opuesto a las costumbres y a los intereses económicos de los campesinos. La S.A.R.H. de Maravatío tiene las estimaciones del uso de semillas mejoradas en tanto por ciento de la superficie sembrada de maíz:

1981/82: $11 \%$

1982/83: $\quad 6 \%$

1983/84: $10 \%$

Los calendarios de trabajo descritos en el cuadro 13 dejan ver tres épocas de mayor carga de trabajo:

-El primero aparece desde fines de marzo hasta principios de mayo, que corresponde a la siembra y la fertilización del maíz, la cosecha de la avena y, a veces, del trigo; incluye la preparación del terreno de riego. -El segundo, de fines de mayo a principio de julio: es la época de siembra del maíz de riego, luego las escardas y fertilización del maíz, de la siembra del trigo, de la avena, del cempasúchil en temporal y de la cosecha del frijol precoz.

-El último, en noviembre y diciembre corresponde a la cosecha de maíz y luego a la preparación del terreno para sembrar trigo y avena en tierras de riego.

En esas fechas, la mano de obra familiar de las unidades de producción tiene que ser auxiliada por una fuerza de trabajo exterior, sea con máquinas para los trabajos que permiten su empleo en barbechos, cosechas de avena y trigo, ensilaje, etc., o con peones. Estos se reclutan entre la numerosa población de medieros y campesinos sin tierras que se encuentran en cada comunidad, intervienen principalmente en lo trabajos de cosecha del maíz, siembra, escarda y chapeo. Su papel se ve reforzado por las migraciones frecuentes de una parte de la mano de obra familiar de las unidades de producción hacia Toluca, el Distrito Federal o Estados Unidos. De esa manera, la solución a los cuellos de botella creados por los periodos más intensos de trabajo depende mucho de las posibilidades financieras de los campesinos y de su capacidad de contratar fuerza de trabajo.

Los mayores problemas aparecen cuando se retrasa la temporada de lluvias. Todos los trabajos de fertilización, escarda, tabloneo, siembra del trigo y de la avena de lluvia, etc., se concentran en los meses de junio y julio en condiciones muy penosas y arriesgadas pues las tierras se transforman de pronto en cenagales.

Los sistemas de ganadería comunes en el valle suroeste pretenden adaptarse a esos sistemas de cultivos y sus imperativos. Su evolución está totalmente ligada a las características que se acaban de describir. 


\section{Sistemas de ganado}

Estos sistemas están fundamentalmente definidos por el tipo de animales de que se trate. Existen campesinos que se especializan en la producción lechera que siguen manejando sus animales criollos, "corrientes", de manera tradicional, mientras sus vacas Holstein se benefician del mucho cuidado y de las técnicas de manejo diferentes.

Manejo tradicional del ganado

La presencia de agostaderos todavía bastante importantes en el valle como la ciénaga de Santa Elena, los cerros El Tejerro de Santa Elena y los Coyotes de Pomas y la Congregación de Pomas permiten que se prosiga con el manejo tradicional. El ejido de Campo Hermoso, el más adelantado en la especialización lechera, es el único que no cuenta con agostaderos y con muy poco ganado criollo. El sistema pecuario tradicional permite a productores de bajos recursos económicos hacerse de un capital bovino y valorizarlo a bajo costo. Dicho sistema está basado en la utilización y rentabilización de los residuos de cosecha y de las tierras incultas, aprovechando la mano de obra disponible y poco experimentada de los niños. Los animales se llevan a pastorear en los agostaderos de junio a diciembre y en la ciénaga casi todo el año, pero más bien de septiembre a diciembre y de febrero a junio. De manera que durante los meses fríos de la temporada seca y hasta su utilización completa, el rastrojo de maíz seco constituye la base de la alimentación de los animales.

El calendario forrajero se presenta así:

GRAFICA No 8

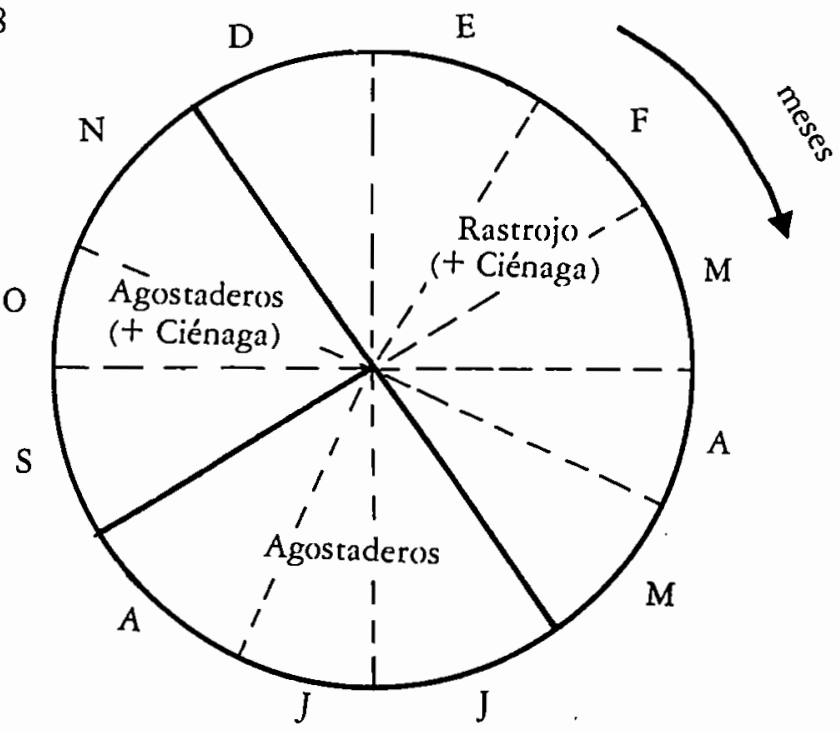


La temporada de lluvias dificulta bastante el aprovechamiento de la ciénaga debido a la proliferación de parásitos. En la Congregación de Pomas, que no cuenta con ciénagas, el sistema es todavía más simplificado y es muy difícil asegurar el enlace rastrojo-pastoreo a fines de las secas, si las lluvias tardan mucho.

En los ejidos, los animales de los diversos productores se encuentran gran parte del tiempo, reunidos en los agostaderos. Las montas no están controladas y los partos suceden en cualquier periodo del año. Los becerros se quedan entonces con las madres hasta que éstas se sequen. El tiempo entre dos partos alcanza frecuentemente dos años, o sea el tiempo de engorda del becerro para su venta o de un adiestramiento como animal de tiro. Las hembras se crían o se venden en la medida de las necesidades financieras del campesino. La ordeña dura en general hasta que se vuelva a preñar la vaca y se hace una vez al día. En la noche los animales se encierran en corrales propios a cada unidad de producción, lo que permite juntar una parte del estiércol. Los tratamientos sanitarios (vacunas, desparasitaciones) son todavía prácticas marginales en ese tipo de manejo.

Entre los pequeños propietarios es frecuente que cada unidad de producción disponga de sus propios agostaderos. Los animales de diferentes dueños no se mezclan, lo que permite un mayor control del ganado.

Es una práctica relativamente corriente, sobre todo a nivel de las pequeñas propiedades, que los borregos anden con el ganado vacuno y se manejen de manera idéntica, ocasionándose pérdidas importantes en las secas pues las ovejas digieren el rastrojo con mayor dificultad.

Este sistema tradicional tiene como función constituir un fondo de acumulación para los productores, y su existencia no impide que algunas unidades de producción tengan formas modernas y muy tecnificadas de agricultura (posesión de cosechadoras, especulaciones anuales sobre los cultivos, etc..). Tal manejo corresponde entonces a unidades de producción grandes que se especializan en producciones estrictamente agrícolas o a familias más pobres que no tuvieron la oportunidad, ni la posibilidad de invertir en formas más intensivas de producción.

Sistema de ganado lechero

Las formas más desarrolladas de ese nuevo sistema de producción se encuentran en el ejido de Campo Hermoso. Corresponde a una nueva definición del papel del ganado que más que forma de acumulación original se vuelve factor de producción fundamental de las unidades familiares.

Se plantea para los campesinos la necesidad de asegurar un nivel de producción lechera relativamente constante en el curso del año pues ésta representa la fuente de mayor ingreso para la familia. Además, requiere de un manejo mucho más cuidadoso ya que se trata de animales más frágiles que los criollos, y representan una inversión de capital mucho más 
importante.

El valor nutritivo de los agostaderos, aunque equilibrado, es demasiado bajo. Disminuye todavía más durante toda la temporada seca mientras baja la cantidad de forrajes. Además, el pastoreo itinerante de animales de alto potencial lechero perjudica mucho a sus capacidades de producción.

El manejo del ganado descansa entonces sobre el mantenimiento de los animales en corrales o, a veces en establos construidos al lado de la casa familiar, lo que facilita el cuidado de los animales, las operaciones de ordeña y de almacenamiento del estiércol. Por otro lado, se necesita producir la totalidad de los forrajes, llevarlos al lugar de concentración de los animales y asegurar una producción forrajera regular en calidad y cantidad todo el año.

Para lograr ese objetivo, los campesinos disponen de varios recursos. El rastrojo de maíz sigue constituyendo una de las bases del sistema forrajero pese a su poca digestibilidad por lo que se asocia a veces con melaza para aumentar su apetencia. Las unidades de producción que disponen de recursos suficientes muelen ese rastrojo, lo que mejora considerablemente su utilización por parte de los animales. Además de su uso forrajero, el rastrojo, debido al desperdicio que hacen los animales, se incorpora al estiércol y lo enriquece. Sin embargo, la importancia del rastrojo va poco a poco disminuyendo gracias a la introducción de nuevos forrajes y de nuevas formas de almacenamiento.

Las pasturas aparecieron apenas hace unos 12 años en el ejido de Campo Hermoso y desde entonces se generalizaron a todos los ejidos que disponen de tierras de riego. En la mayoría de los casos los animales no se llevan a pastorear, sino que se hacen cortes diarios que se traen al establo, lo que permite aumentar el tiempo de vida de las pasturas y mantener su buen estado y calidad. Eso permite utilizar el forraje en su punto óptimo de calidad proporcionando a los animales una ración verde y equilibrada casi todo el año. En los meses de diciembre a febrero se presenta un periodo en el que por el frío los pastos casi no crecen y se necesita espaciar mucho los cortes. Las importantes reservas de rastrojo con que cuentan las unidades de producción en ese periodo permiten rellenar esa diferencia en cantidad pero no la de materias proteicas procuradas por el pasto.

El cultivo de la avena en invierno en las parcelas de riego o de verano en tierras de temporal se ha generalizado ta mbién a los ejidos. Por lo regular, se hacen cortes diarios mientras las plantas están todavía verdes. Eso también reduce la falta de pasto verde en los meses de febrero y marzo. Además, en algunas unidades de producción recientemente apareció otro modo de aprovechar el forraje: henificado. El corte se hace al espigar durante el mes de febrero cuando la planta está en el momento óptimo por el alto valor nutritivo. Las secas permiten un buen secado del heno que se puede conservar bastante tiempo. Ese tipo de almacenamiento es todavía limitado a los poseedores de empacadora y de bodega que son unos cuantos 
productores.

El último tipo de forraje que se encuentra es el más reciente y todavía muy marginal en el valle: el ensilado de toda la planta de maíz. A pareció en las pequeñas propiedades lecheras del valle que no tenían tierras de riego. Al no poder producir forrajes en tiempo de secas, tuvieron que almacenar el único forraje de calidad suficiente que podían cosechar. Así apareció el ensilado de malz hace unos dos o tres años existiendo serios obstáculos para su extensión:

-la falta de equipo: máquinas costosas y demasiado pesadas para entrar en las parcelas a fines de la temporada de lluvias, la ausencia de lonas de plástico para cubrir los silos y permitir una buena conservación del forraje;

-la organización individual del trabajo que limita considerablemente la eficiencia de las operaciones de ensilado y dominio de una técnica de por si difícil. Esta se limita todavía a las pequeñas propiedades que solamente cuentan con tierras de temporal y a unos ejidatarios, los más ricos por lo general, que asumieron el riesgo que representa dicha técnica.

Por tanto, existe una variabilidad considerable en los calendarios de forrajes brutos. Los más comunes son los siguientes:

En las unidades de producción en tierras de riego, el ensilado puede suplantar al malz una parte del año en las pocas unidades que lo producen. Sin embargo, la gráfica siguiente esquematiza el calendario forrajero más empleado en esas unidades.

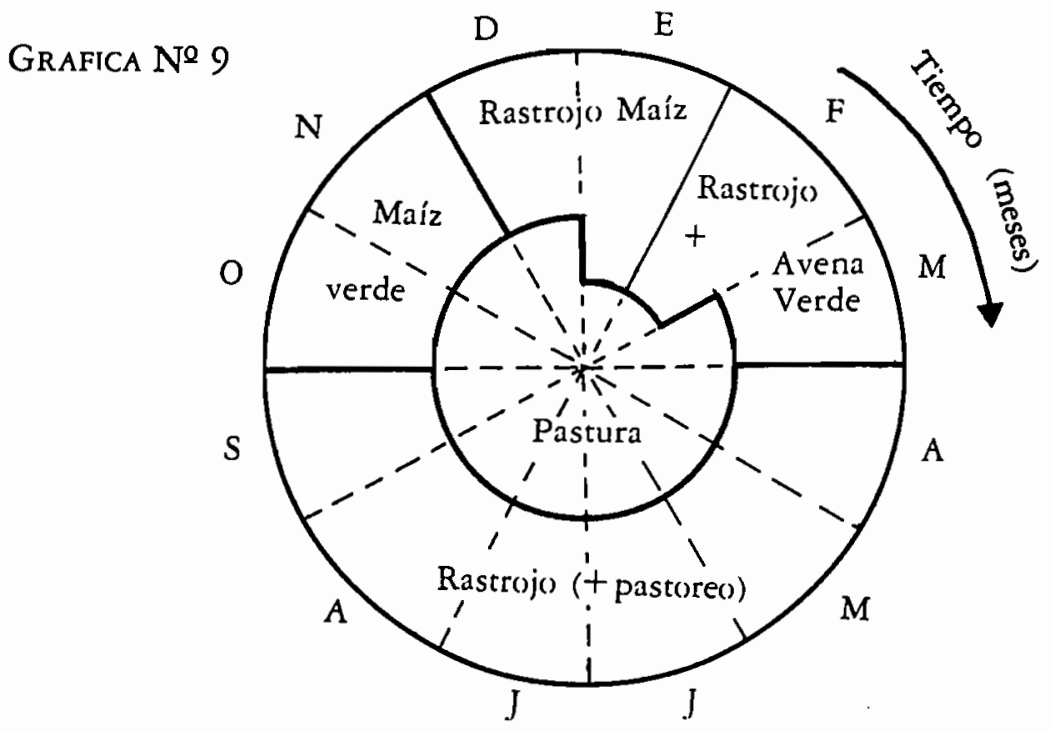


Muchas unidades de producción en tierras de temporal, se encuentran en general sin forrajes a fines de la temporada de secas y los tienen que comprar en los ejidos vecinos (gráfica 10 ).

GRAFICA № 10

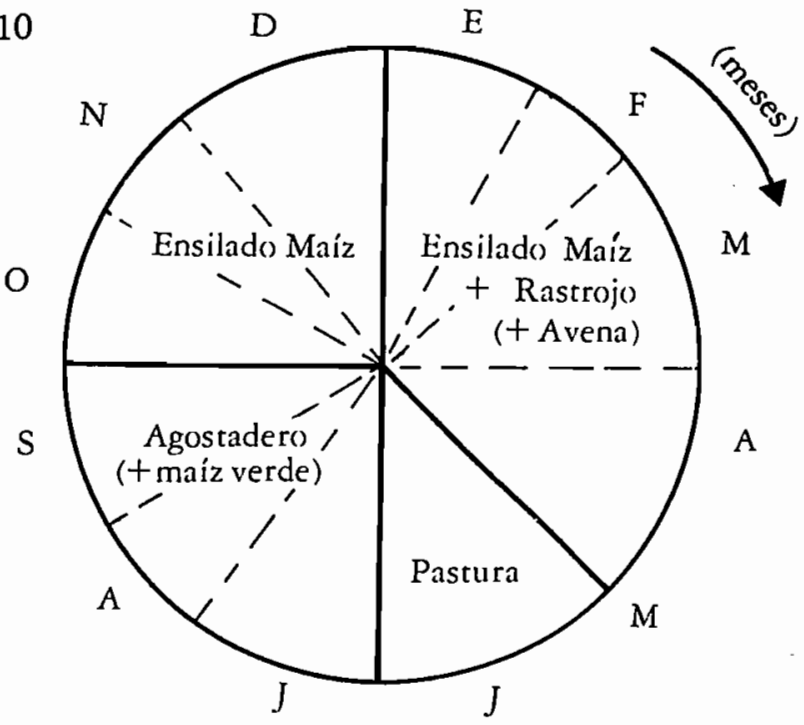

Durante ese periodo de mayo a septiembre las unidades de producción se encuentran en una situación difícil, con un déficit de forrajes y una baja producción lechera.

No existen análisis acerca del valor nutritivo de los forrajes conservados, o de la pastura a nivel del valle, de manera que no se pueden precisar los defectos y carencias de las raciones. Sin embargo, éstas presentan desequilibrios evidentes entre el valor energético y el valor proteico de los forrajes así como la carencia de minerales para las vacas lecheras. Los pastos permiten completar parcialmente el déficit proteico de las raciones, gracias al trébol que contienen, aunque esto no parece suficiente.

Muchos de los productores acostumbran dar concentrados a los animales en forma de harina de maíz o de trigo, contribuyendo a desequilibrar todavía más las raciones. En el mismo sentido pocos son los que compran minerales y se observan muchos animales con problemas de descalcificación; sólo los pequeños propietarios de la Congregación de Pomas compran concentrados de proteínas y minerales por la insuficiencia de su producción forrajera.

Reunir a los animales en un establo o un corral permite mejorar el cuidado de los mismos. Cada seis meses se les puede vacunar y desparasitar aunque ésta última práctica no está todavía generalizada. Los productores pueden también detectar de manera precoz los celos de sus animales. Se 
encuentran sementales de buen nivel genético en cada ejido, algunos de esos fueron regalados por el gobierno del estado y permiten cargar las vacas rápidamente después del parto (en general al segundo o tercer celo). La inseminación artificial tiene todavía un empleo muy reducido.

Las vacas tienen crías cada año, vendiéndose los machos chicos y a las hembras se les alimenta con suero y frecuentemente leche en polvo en lugar de la leche de la madre. Sin embargo, en algunas unidades se utiliza todavía el becerro para empezar la ordeña. La ordeña suele tener lugar dos veces al día y el periodo de lactancia dura de ocho a nueve meses. Eso depende también de la disponibilidad en forrajes cuando los animales se acercan a la fecha de agotamiento obligando a espaciar las ordeñas en un tiempo de cuatro o cinco días, lo que ocasiona a menudo mastitis y otras enfermedades de la ubre.

Los niveles de producción son muy variables, debido a las diferencias en el manejo que se observan en las unidades de producción, más que a las variaciones de calidad genética de los animales. Se observan producciones de 2,000 a 3,000 litros de leche por lactación, aunque la mayoría de los animales produce alrededor de 2,000 litros.

La comercialización y la saturación del mercado local

Se presentan dos formas de comercialización posible para los productores: la venta de leche bronca en las horas que siguen a la ordeña, debido a la ausencia de equipo de enfriamiento en las comunidades campesinas y el procesamiento de la leche en forma de queso blanco rústico, lo que permite una conservación más prolongada del producto.

Esos sistemas de comercialización están organizados en cada pueblo. Los poseedores de camionetas se encargan en general del acopio de la leche bronca después de la ordeña en la mañana y la transportan hasta Maravatío donde se vende en el mercado y en tiendas particulares, restaurantes, etc. Las utilidades que deja ese comercio alcanzan comúnmente un $40 \%$ y hasta el $60 \%$ del precio de compra (por un transporte de unos 10 kilómetros como máximo). Sin embargo esos precios varían mucho de un pueblo al otro hasta un $25 \%$.

La transformación de la leche en queso se hace en las comunidades mismas. En el ejido de Campo Hermoso, la especialización lechera permitió el desarrollo de pequeñas plantas en un ejido que cuenta con solo 69 unidades de producción. En las demás comunidades, el procesamiento de la leche es más bien una actividad casera que permite una rentabilización de la fuerza de trabajo familiar. En tal caso, cuando las cantidades son insuficientes se completan comprando a los vecinos la leche que falta. Los precios de compra-venta son similares a los que ofrecen los trans portadores de leche.

El procesamiento es muy sencillo y no dura más de medio día. Se trata de hacer cuajar la leche $\left(38-40^{\circ} \mathrm{C}\right)$, dejar gotear el cuajo unos 8-10 horas y, 
$*$

luego, eventualmente moldear el queso para darle un tamaño que corresponda a un estandard comercial. Los rendimientos de ese procesamiento son de un kilogramo de queso por cada 10 o 12 litros de leche. El valor agregado que representa el queso es de aproximadamente $60 \%$ en relación al valor correspondiente de la leche.

La producción de queso de todas las comunidades del valle se dirige hacia el centro de Maravatío que la absorbe por completo.

Toda la producción lechera del valle tiene como única salida comercial la ciudad de Maravatío. Eso corresponde en los períodos de mayor producción durante los meses de junio a noviembre con la consiguiente saturación del mercado local que apenas alcanza a absorber toda la producción. Lo que nos permite prever, teniendo en cuenta el ritmo de crecimiento de la producción lechera en el valle, una situación de sobreproducción dramática durante una buena parte del ciclo para los próximos años.

Los campesinos ya tomaron conciencia de esa situación y cuando se organizó en la Congregación de Pomas un sistema de acopio, transporte y venta de la leche con el apoyo de la Fundación Mexicana para el Desarrollo, los productores pidieron organizar ese sistema hacia el mercado de Ciudad Hidalgo pese a los gastos mucho más elevados que implicaba.

Veremos en la última parte lo que se puede proponer para evitar esa saturación total del mercado local y para encontrar otros mercados.

Distribución de los sistemas pecuarios en el área de estudio

Se trata sobre todo de una estimación del grado de evolución y de intensificación de las actividades pecuarias en el valle suroeste de Maravatío. Esa estimación se apoya sobre las observaciones realizadas en las diferentes comunidades así como sobre los datos comunicados por la Asociación Ganadera de Maravatío. Ese organismo está todavía muy lejos de poder concentrar los elementos característicos de todos los ganaderos; sin embargo, la información que posee nos permiten hacer una aproximación de la cantidad de animales presentes en cada pueblo.

Se observa una diferencia sensible entre las colectividades en cuanto al promedio de vacas por unidad de producción y al promedio de bovinos tot/promedio vacas. Se puede considerar que las unidades de producción de esa parte del valle se reparten entre dos polos: las unidades de producción tipo lecheras, muy comunes en Campo Hermoso (promedio vacas/u.p. igual a 7 y promedio bovinos tot/promedio vacas igual a 2) y las unidades más tradicionales, representativas de la Congregación de Pomas (promedio de vacas igual a 3, promedio bovinos/promedio vacas igual 3.3 que revela la orientación de las unidades de producción hacia la constitución de fondos de reserva y la producción de animales de tiro). Las otras comunidades parecen intermediarias entre esos dos tipos: Casa Blanca 4.3 y 2.6, Santa Elena 3.3 y 
CUADRO Ne 14

NUMERO DE BOVINOS REGISTRADOS EN EL. AREA

\begin{tabular}{|c|c|c|c|c|c|}
\hline \multirow{2}{*}{ Comunidades } & \multirow{2}{*}{$\begin{array}{c}\text { N de unidades } \\
\text { productivas }\end{array}$} & \multicolumn{2}{|c|}{ Vacas } & \multicolumn{2}{c|}{ Bovinos } \\
\cline { 3 - 6 } Casa Blanca & 35 & 151 & 4.3 & 384 & 11 \\
\hline Campo Hermosu & 42 & 294 & 7 & 640 & 15.2 \\
\hline Congreg. Pomas & 41 & 123 & 3 & 409 & 10 \\
\hline Pomas & 68 & 235 & 3.4 & 704 & 10.3 \\
\hline Sta. Elena & 34 & 114 & 3.3 & 328 & 9.6 \\
\hline $\begin{array}{c}\text { Total Valle } \\
\text { Surveste }\end{array}$ & 220 & 917 & 4.2 & 2465 & 11.2 \\
\hline
\end{tabular}

\section{9, Pomas 3.4 y 3 .}

Por supuesto, esas marcas no son muy rígidas y en la Congregación de Pomas se encuentran unidades de orientación lechera mucho más aparente y afirmada que en la mayor parte de las unidades de producción de Campo Hermoso. Sin embargo, esas estimaciones corresponden a una distribución esquematizada a nivel del valle.

Nos muestran también que la ganadería en todo el valle sigue una evolución muy profunda que corresponde al deseo por mantener la actividad en la mayoría de las unidades de producción. Para unidades de menor tamaño la orientación hacia una especialización lechera parece la más realizable y rentable de las opciones. Se plantea, también la necesidad de extender el mercado lechero local condición, sine qua non, para el desarrollo amplio de la actividad lechera en todo el valle.

En base a lo que precede nos podemos acercar a una tipificación de las unidades de producción. Tal paso es imprescindible si se quiere influir en la dinámica de evolución del sistema social de producción y determinar las herramientas de tal acción.

\section{TIPOLOGIA DE LOS SISTEMAS DE PRODUCCION}

\section{Criterios}

En función de las estrategias productivas que las caracteriza, hemos 
elaborado una tipología de las unidades de producción (u.p.) atendiendo a los siguientes criterios:

En relación a la densidad de población en esa parte del valle, el tamaño de las unidades de producción - superficie sobre la cual el campesino ejerce su derecho de propiedad o ejidal y superficie rentada o trabajada a mediaspuede ser un criterio importante. La voluntad de no establecer la tipología en función de la relación a la tierra - propiedad o derecho ejidal-imponía encontrar un elemento referencial común al temporal y al riego. En esta parte se usará el concepto de superficie equivalente-temporal. Una hectárea de tierras de riego se considera que vale 2 a 3 hectáreas de equivalentetemporal, lo que no refleja la realidad (la utilización de las tierras de riego es más del doble de las de temporal) sino que constituye una aproximación simplificada.

El grado de inversiones realizadas en vista de la producción agrícola -obras de riego, motorización- parece constituir un criterio que completa el precedente puestoque corresponde a menudo a una orientación estrictamente agrícola y mercantil de la u.p.

La posesión de ganado lechero y, sobre todo la parte de los productos lácteos en el producto bruto de las unidades de producción revela otro tipo de estrategia. Pero se necesita manejar ese criterio con cuidado ya que el ganado sigue sirviendo a menudo de fondo de reserva y de inversión, según las necesidades de cada quien.

La parte del trabajo familiar en las actividades de la u.p. refleja el compromiso del campesino en las actividades agrícolas y determina eventualmente cambios de estrategia radicales.

A partir de esos cuatro criterios básicos se definieron siete categorías de campesinos, relativamente homogéneas que tienen las siguientes características.

\section{Descripción}

Las unidades de producción (u.p.) semi-capitalistas

Se trata aquí de productores marginales a nivel del valle, con ideas originales en lo que se refiere al manejo y la suma de inversiones que realizan. Estos productores tienen casi siempre una actividad principal más remuneradora que la agropecuaria - comercio, fábrica, etc...-que les ha permitido buscar la intensificación del uso del terreno. Esta se realiza mediante la construcción de obras de riego en las pequeñas propiedades elevando el valor de las superficies arriba de 30 y hasta 50 hectáreas equivalente-temporal, de instalaciones para la cría intensiva de animales, vacas lecheras o puercos, y la compra de maquinaria. Tal evolución puede llevar con frecuencia a la sobremecanización, permitiendo reducir la importancia de una mano de 
obra esencialmente asalariada y definiendo la estrategia de este grupo: optimizar la productividad del terreno por unidad de superficie y disminuir la carga en mano de obra.

Los patrones de cultivo son dominados por los granos básicos - maíz, trigo, avena-, pero se emprenden también especulaciones temporales con fin de aprovechar las variaciones del mercado - flor de sempasúchitl, jitomate, pepino, chile, etc. Las crías intensivas que arriba mencionamos completan los ingresos. A nivel del valle, estas unidades de producción tienen los mayores productos brutos con más de 5 millones de pesos en 1985 y márgenes de utilidad con más de 2 millones de pesos así como los índices más altos de productividad del trabajo.

Grandes unidades mecanizadas

Los productores que componen ese grupo provienen de las familias que estuvieron encabezando el fenómeno de acumulación diferencial. Las migraciones a Estados Unidos les permitieron ampliar la acumulación de medios de producción y se encuentran en posesión de numerosas tierras (entre dotaciones ejidales y pequeña propiedad, las superficies rebasan con frecuencia las 30 hectáreas equivalente-temporal), de hatos importantes y de maquinaria. De manera que se llegó a definir esta categoría por su tendencia a rentabilizar las inversiones realizadas: alquiler de las máquinas, extensión de las superficies cultivadas, compra de terrenos.

Sin embargo, esta estrategia global se expresa por dos orientaciones que dependen esencialmente de la disponibilidad en terrenos de riego. Cuando ésta era suficiente las unidades de producción adquirieron a menudo ganado Holstein y efectuaron una especialización relativa hacia la producción lechera. Pero aún en esas condiciones el rebaño no alcanza la capacidad de mantenimiento de la u.p. Las unidades limitadas por las superficies de riego se orientaron hacia actividades agrícolas - maíz y trigo- y comerciales como alquilar sus máquinas agrícolas, hacer transporte de flete o de personas o abrir una tienda campesina. Pero la frontera entre estas dos orientaciones queda muy difusa y facilita el paso rápido de una forma de especulación a otra, según las oportunidades.

Por supuesto, los niveles de remuneración son altos, productos brutos y márgenes del orden de 3 y 1.5 millones de pesos en 1985, permitiendo proseguir la acumulación en medios de producción y especializarse más hacia una de las dos especulaciones descritas. Sin embargo, la orientación agrícola-mercantil tiene perspectivas limitadas por la feroz competencia en la adquisición de tierra y la maquilación de máquinas que se dibuja a nivel del valle.

Unidades estrictamente lecheras

Pese a haber surgido en el último decenio, este grupo se puede subdividir en 
dos tipos de unidades lecheras:

-las unidades ejidales que pudieron orientarse temprano hacia la especialización lechera gracias a la disponibilidad de terrenos de riego, que les permite asegurar el abastecimiento de forrajes de sus animales;

-Las pequeñas propiedades que tuvieron que esperar hasta 1985 para aprovechar el proyecto de la Secretaría de Fomento Rural y condiciones de crédito favorables para arriesgarse en esta vía. La ausencia de irrigación les impuso un manejo del ganado basado en el empleo de forrajes conservados -ensilado, heno- lo que limitó la producción e incrementó sus costos.

En ambos casos, se trata de unidades reducidas entre 10 y 15 hectáreas de equivalente-temporal; la fuerza de trabajo familiar se sitúa a 2 U.M.O., el número de vacas se mantiene entre 4 y 8 lecheras. Esas condiciones tienden a orientar las estrategias hacia la maximización de los ingresos por bectáreay el aprovechamiento de la mano de obra familiar.

Así las tierras y la fuerza de trabajo se emplean prioritariamente en la producción de forrajes. La transformación de la leche en queso responde a la preocupación de emplear la mano de obra femenina a menudo sub-utilizada, dando al producto un valor agregado nada despreciable. Esta especialización permite alcanzar productos brutos de más de 2'200,000 pesos por año en 1985. En ese total, las producciones animales y sobre todo lácteas representan respectivamente el 80 y el $55 \%$. En estos casos, las productividades del terreno y de la mano de obra son de las más elevadas a nivel del valle.

Ese grupo corresponde al modelo más racional y generalizable de desarrollo para la mayoría de los productores del valle, pero enfrenta dos tipos de problemas:

Las pequeñas propiedades han quedado en una situación de dependencia para el abastecimiento en forrajes que pone en peligro su rentabilidad y porvenir, la costumbre de conservar parcelas de maíz para el abasto de la familia así como el dominio imperfecto de las técnicas de conservación del ensilado no les permiten cubrir sus necesidades forrajeras durante la seca. Por otro lado, urge que todas las unidades busquen nuevos mercados para la leche y los quesos, fuera del valle, a fin de conseguir remuneraciones más elevadas. Una organización común de las inversiones -obras de riego, extensión de las superficies forrajeras-y de los trabajos - técnicas de ensilado-sería también necesaria para llegar a intensificar todavía más los sistemas de producción.

Las unidades no especializadas

Se encuentran aquí, productores de más de 50 años en su mayoría, quienes se han instalado gracias al ahorro de capital previamente acumulado en Estados Unidos o el Distrito Federal (cf. el período 1950-1970). Sin embargo no se ha podido hacer inversiones que permitan intensificar el 
sistema de producción y efectuar una especialización. En esas condiciones, la estrategia del grupo sigue siendo asegurar el abastecimiento de la familia con gastos y riesgos mínimos mediante la adecuación entre la superficie cultivada de 8 a 12 has. eq. temp. y la fuerza de trabajo familiar de 1.5 a 2.5 U.M.O.

La superficie total, incluyendo los agostaderos, puede alcanzar hasta 40 hectáreas en el caso de algunas pequeñas propiedades. Esta disponibilidad en agostaderos permite el mantenimiento de rẹbaños de 6 a 10 bovinos criollos y de algunos borregos, sobre todo en las pequeñas propiedades, siguiendo un manejo extensivo. La actividad ganadera queda estrechamente vinculada con el sistema de cultivo. Las parcelas de temporal se siembran de maíz, respetando el año de descanso entre cada cultivo. En terrenos de riego, el aprovecha miento se vuelve más intensivo y el trigo aparece como cultivo invernal en rotación con el maíz.

En estas condiciones el producto bruto de las unidades se sitúa alrededor de 1'100,000 pesos en 1985 debido a la escasez de las ventas, pero el bajo nivel de los gastos permite alcanzar márgenes de más de 600,000 pesos así como una productividad de trabajo regular. Sin embargo la importancia de los productos agrícolas en este total -más de $60 \%$ del producto bruto - ubica esas unidades en una situación precaria frente a las contingencias climáticas, tanto más que no disponen de capital aparte del ganado. Para poder mantener una nueva generación de hijos, esas unidades deben evolucionar hacia una intensificación de su sistema de producción. En este sentido, deben estar en el centro de las preocupaciones de los proyectos de desarrollo, ya que representan un número importante de productores del valle.

Pequeñas unidades de producción

Este grupo está compuesto por campesinos jóvenes cuyo promedio de edad es inferior a los 40 años; entre los productores entrevistados que disponen de superficies limitadas los sembradíos no rebasan las 5 hectáreas eq. temporal. Esta pequeñez de las unidades se debe a la división de la pequeña propiedad o de la dotación ejidal original entre varios herederos, o bien a la inversión del pequeño ahorro que ha podido realizar un mediero en la compra de una pequeña porción de terreno.

La fuerza de trabajo familiar rebasa con frecuencia las 1.5 U.M.O. y la ausencia de un capital que permita intensificar el sistema de producción lleva a esos campesinos a buscar valorizar la mano de obra para mejorar los ingresos familiares.

Tal estrategia encuentra varias expresiones como el trabajo asalariado - jornalero agrícola u obrero-, la búsqueda de tierras en aparcería (unas 2 63 hectáreas de temporal), las migraciones temporales etc... Las actividades agropecuarias tienden a satisfacer las necesidades del abasto de la familia y 
luego a incrementar el ingreso monetario sembrando trigo de riego cuando las actividades asalariadas no representan un costo de oportunidad mayor. El capital de las unidades está compuesto por el tiro de animales, 2 o 3 vacas criollas y eventualmente unos 5 borregos.

El producto bruto no rebasa los 700,000 pesos y el margen monetario los 400,000 pesos. Estos niveles no permiten ninguna acumulación y cualquier inversión para la intensificación del sistema de producción es muy problemática, quedando así muy reducido su margen de sobrevivencia.

Sin embargo, tal intensificación es imprescindible a mediano plazo para asegurar el porvenir de esos productores. En este sentido, el proyecto promovido por el gobierno del estado tiene un interés mayor para ellos pero se mantendrán de todos modos una cierta inseguridad en cuanto a las fluctuaciones de los precios de la leche y al abastecimiento en forrajes de unidades de tamaño reducido.

Los campesinos ausentistas

El ausentismo y el recurrir a un sistema de aparcería se debe a dos motivos:

-la edad del campesino y la disminución de su poder y papel social,

-el costo de oportunidad mayor de las migraciones a Estados Unidos o

el Distrito Federal.

En ambos casos el objetivo es aprovechar el acceso o una renta minima que procura la u.p. mientras se conserva el derecho sobre la tierra.

Los contratos de aparcería abarcan superficies de 6 a 10 hectáreas en general que se trabajan con el fin de disminuir los riesgos: maíz "de año y vez" o rotación maíz-trigo en tierras de riego. El dueño puede eventualmente dejar unas cinco reses o unos cuantos borregos a medias también. Los términos que conciernen la fuerza de tracción son objeto de una fuerte variabilidad: ponen cada día en mayor desventaja al mediero en la medida en que la densidad de población y las necesidades de agua aumentan (en Campo Hermoso el mediero tiene que poseer o rentar el tiro mientras en la Congregación de Pomas el dueño se lo proporciona). Estos contratos suelen durar entre 5 y 10 años.

Debido al tamaño variable de los predios, el producto de las unidades es muy variable. Cabe destacar, sin embargo, que la productividad del terreno es la más baja que se puede encontrar entre todos los sistemas de producción del valle con unos 12,000 pesos por hectárea en 1985 .

Al fin y al cabo, esta categoría corresponde a la última evolución de un sistema de manejo basado en la reducción de los riesgos y de los gastos. Tendrá que evolucionar hacia su desintegración y la distribución de las unidades entre los demás grupos, ya sea por la realización de inversiones por parte del dueño, sea por la venta e integración a unidades más grandes. 
Campesinos sin tierra

Este grupo, probablemente el más numeroso a nivel del valle, junta dos tipos distintos de campesinos que tienen perspectivas diferentes:

-gente que llegó tarde y no obtuvo derecho a la tierra en los ejidos;

-hijos de pequeños propietarios o ejidatarios quienes trabajan de medieros en espera de la herencia.

Sus papeles varían también sensiblemente en el valle:

-En los ejidos, la concentración de la población deja pocas tierras. Por el contrario, la presencia de cultivos de riego genera fuertes necesidades de trabajo todo el año: los sin tierra se orientan hacia la venta directa de su fuerza de trabajo.

-En la Congregación de Pomas las condiciones son opuestas encontrándose suficiente disponibilidad en tierras para conseguir contratos de aparcería.

En general, el campesino sin tierra busca siempre conseguir un contrato de mediero sobre 2 ó 3 hectáreas. Estas proporcionan el maíz necesario al abasto de su familia, si se consideran rendimientos de $2 \mathrm{~T} / \mathrm{ha}$ y necesidades de $250 \mathrm{~kg}$. de maíz por persona al año; se necesita sembrar dos hectáreas y media para mantener una familia de ocho personas. El mediero recibe de su patrón el tiro de animales en la Congregación de Pomas y si ya lo tiene, los abonos que normalmente se pagan por mitad, quedan a cargo del dueño, pero eso se produce muy pocas veces en los ejidos más poblados. A menudo 263 reses y unos borregos se agregan al contrato: la mitad de las crías pertenecen entonces al mediero y a su familia y constituyen la casi única forma de acumular medios de producción.

De hecho, no se saca ingreso monetario de las tierras cultivadas y se necesita contar con las actividades asalariadas para obtenerlo. La estrategia del grupo es valorizar al máximo la fuerza de trabajo familiar; los hijos representan una inversión en esta perspectiva y las familias son numerosas. Aún así, los ingresos monetarios no rebasan los 250,000 pesos (1985) y los campesinos sin tierra se quedan en un estado de pobreza permanente, pues la mecanización de la agricultura en el valle les quita toda oportunidad de conseguir un pedazo de tierra y poder instalarse.

\section{CONCLUSIONES}

\section{Dos vías de evolución}

Como ya lo vimos con la historia agraria, la orientación agrícola mercantil, es decir, el grupo 2 de la Tipología, implica a las unidades de tamaño importante que siempre se encontraron en la cima de la pirámide de acumulación diferencial. Aprovechando la desaparición de un cierto número 
CUADRO № 15

TIPOLOGIA GENERAL DE LAS UNIDADES DE PRODUCCION

\begin{tabular}{|c|c|c|c|c|}
\hline Tipo de u.p. & Estrategia & Sup. utilizada (Has.) & Mecanización & Ganado lechero \\
\hline $\begin{array}{l}\text { Grupo 1: } \\
\text { Semi } \\
\text { Capitalistas }\end{array}$ & $\begin{array}{l}\text { Optimizar la pro- } \\
\text { ductividad del te- } \\
\text { rreno disminuyen- } \\
\text { do la carga en M.O. }\end{array}$ & $25-50$ & $+++t$ & +1 \\
\hline $\begin{array}{l}\text { Grupo 2: } \\
\text { Grandes unidades } \\
\text { mecanizadas }\end{array}$ & $\begin{array}{l}\text { Rentabilizar las in- } \\
\text { versiones (máqui- } \\
\text { nas, tierra, gana- } \\
\text { do) }\end{array}$ & $24-40$ & $+t$ & ++ \\
\hline $\begin{array}{l}\text { Grupo 3: } \\
\text { Unidades de } \\
\text { producción } \\
\text { lecheras }\end{array}$ & $\begin{array}{l}\text { Optimizar la renta } \\
\text { por hectárea apro- } \\
\text { vechando la mano } \\
\text { de obra familiar. }\end{array}$ & $10-15$ & + & ++++ \\
\hline $\begin{array}{l}\text { Grupo 4: } \\
\text { Unidades de pro- } \\
\text { ducción no especia- } \\
\text { lizadas }\end{array}$ & $\begin{array}{l}\text { Producir con gas- } \\
\text { tos mínimos. }\end{array}$ & $10-20$ & 0 & 0 \\
\hline $\begin{array}{l}\text { Grupo 5: } \\
\text { Unidades } \\
\text { pequeñas }\end{array}$ & $\begin{array}{l}\text { Valorización de la } \\
\text { mano de obra fa- } \\
\text { miliar asegurando } \\
\text { el autoabasto. }\end{array}$ & S-10 & 0 & + \\
\hline $\begin{array}{l}\text { Grupo 6: } \\
\text { Campesinos } \\
\text { ausentistas }\end{array}$ & $\begin{array}{l}\text { Conservar el dere- } \\
\text { cho sobre la tierra } \\
\text { aprovechando una } \\
\text { renta mínima. }\end{array}$ & variable & 0 & 0 \\
\hline $\begin{array}{l}\text { Grupo 7: } \\
\text { Campesinos } \\
\text { sin tierra }\end{array}$ & $\begin{array}{l}\text { Valorización de la } \\
\text { mano de obra fami- } \\
\text { liar. }\end{array}$ & $2-3$ & 0 & 0 \\
\hline
\end{tabular}


de productores, ejidatarios y sobre todo pequeños propietarios, que no podrán tomar el tren de los cambios técnicos y de la intensificación de su sistema de producción, es probable que el papel socio económico de ese grupo alcance un crecimiento considerable en un futuro cercano. Sin embargo seguirá representando una parte marginal de las unidades de producción de la región.

La especialización lechera parece representar el camino más accesible para la mayoría de las u.p. del valle, en el caso de las que tienen una superficie de 10-20 hectáreas equivalente-temporal. El desarrollo de esas unidades está asegurado; sin embargo se necesitan progresos en el manejo técnico de las unidades y en la búsqueda de nuevos mercados para la comercialización de la leche. Ya veremos cómo puede realizarse este cambio y cuál puede ser el papel de la administración en ese proceso.

El éxito es mucho más difícil de conseguir para las pequeñas propiedades de la Congregación de Pomas, (grupo 4 de la tipología) cuyas superficies disponibles no sobrepasan las 10 hectáreas de temporal. El problema se plantea claramente: ¿Cómo evitar la desaparición de estas unidades de producción en beneficio de los campesinos del segundo grupo de la tipología?

La especialización lechera es problemática para las unidades muy aisladas, cuya capacidad de producción forrajera seguirá siendo de todos modos muy limitada. La salida más evidente sería emprender una política de obras de riego, necesariamente muy costosa y por tanto, poco realista. Se podría también favorecer la compra de los terrenos que se liberan por parte de la gente de ese grupo mediante un sistema de crédito, quizá irrecuperable, que permitiría reducir el proceso de desaparición de esas unidades y favorecería la emergencia de propiedades de más de 10 ó 15 hectáreas que se podrían así inocorporar al proceso de desarrollo lechero.

De todos modos se deberán canalizar gastos importantes para salvar del fracaso un número de propiedades relativamente limitado a nivel de todo el valle.

\section{Qué tipo de apoyo se puede dar al desarrollo lechero}

Debido a las formas que había escogido la Secretaría de Fomento Rural para el manejo de su proyecto, el apoyo a los productores lecheros se orientaba sobre todo hacia el mejoramiento genético y sanitario del ganado. Por el contrario, en los distintos sistemas de producción que hemos descrito, los principales obstáculos al desarrollo de la actividad lechera residen en el manejo de los animales y del calendario forrajero. En este aspecto, la falta de zootecnistas en el seno del equipo del proyecto fue importante.

Además, con el cambio de gobierno y consecuentemente de las 
orientaciones de la política agropecuaria en el estado de Michoacán (véase el primer capítulo) la nueva administración abandonó a principios de 1987 toda asesoría y apoyo al proyecto cuando el nuevo centro de acopio y procesamiento de la leche estaba por entrar en servicio en el ejido de Campo Hermoso. Desde entonces se plantea el problema de definir en qué forma y bajo qué condiciones se podría solicitar y planear la intervención de la administración pública.

Pensamos que el papel de la S.F.R. en una región donde el potencial lechero es alto, debía ser el de ampliar su acción a un máximo de productores y no sólo a los socios del proyecto inicial, e intentar limitar la diferenciación social, ya avanzada en las comunidades, promoviendo sistemas de cooperación y acondicionamiento de los forrajes, acopio, procesamiento y comercialización de los productos lácteos.

En ese objetivo preciso los esfuerzos de cualquier administración se podrían concentrar en dos aspectos:

-El abastecimiento de forrajes, pues parece que en muy pocas unidades las vacas alcanzan su potencial de producción debido a la irregularidad en cantidad y calidad de los forrajes;

-La comercialización de los productos lácteos y la búsqueda de salidas más allá de un mercado local saturado.

Las acciones deben dejar autonomía e iniciativa a los productores pero también limitar las posibilidades de que unos pocos obtengan los beneficios de los esfuerzos comunes.

En el aspecto de los forrajes, se pueden mejorar las técnicas que los productores ya acostumbran, más que buscar nuevas técnicas cuyo éxito sería aleatorio y que podrían favorecer la diferenciación social en beneficio de unos pocos (el grupo 2 por ejemplo). La necesidad primera es rellenar el déficit forrajero de la temporada seca en los meses de febrero a junio. La siembra de avena inmediatamente después de la cosecha del maíz permite lograr en parte ese objetivo. Además, se integra perfectamente al actual sistema de cultivo: cosechándose de enero a febrero, al momento óptimo de su valor forrajero (verde, con espiga de $10 \mathrm{~cm}$ ), permite liberar las tierras a tiempo para la siembra del maíz, o eventualmente, emprender un nuevo ciclo del cultivo. Al hacer un primer corte en enero, se puede volver a sembrar enseguida y esperar un nuevo corte en marzo o abril, lo que deja todavía tiempo para el cultivo del maíz. La avena se puede secar después del corte, empacar y luego almacenar en previsión de la época de falta del forraje: el clima seco en ese periodo del año lo permite. La asociación con una leguminosa de ciclo similar como haba o garbanzo permitiría equilibrar y mejorar el valor nutritivo del forraje.

Se puede mejorar también la utilización de los barbechos en temporada de lluvias, lo que sería particularmente provechoso para las pequeñas propiedades, sembrando cucurbitáceas, col, o especies adaptadas a las 
condiciones del medio. Sin embargo esos cultivos servirían en una época en la que no se observan por lo regular faltas de forrajes.

Una de las medidas más sencillas consistiría en intentar mejorar el valor y la utilización del rastrojo de maíz por los animales, base del sistema forrajero en la mayoría de las u.p. incorporando amoníaco o urea en pequeñas cantidades a las raciones: así se aumenta sensiblemente la digestibilidad y el valor nutritivo del for raje. Mediante costos limitados de esta manera se podría incrementar la producción lechera del hato.

El mismo tratamiento podría darse a las pajas de trigo. Sin embargo, su empleo, ahora muy marginal y únicamente como forraje, sería quizás más provechoso incorporándolas al estiércol (literas). Eso permitiría aumentar considerablemente la cantidad (retención de las orinas) de los fertilizantes orgánicos y disminuiría la carga financiera de las u.p.

El acondicionamiento del maíz en forma de ensilado es una técnica que hay que promover con mucha cautela: se necesita un cuidadoso control de las diferentes etapas del proceso, una organización colectiva del trabajo que todavía no existe entre los campesinos. Eso favorecería además a los ganaderos más grandes mecanizados en perjuicio del productor de base. Sin embargo esa técnica ya está siendo experimentada con bastante éxito en el ejido de Campo Hermoso; además es la forma más eficiente de conservar el forraje en las pequeñas propiedades de temporal de la Congregación de Pomas y eso permite la siembra de la avena en humedad residual desde el mes de octubre: con un riego de auxilio la avena llega al estado de cosecha y constituye una ayuda muy importante a fines del secano.

Pero esas medidas quedarán sin utilidad alguna si los productores no consiguen una remuneración elevada, necesaria y estable de la leche, sobre todo en las pequeñas propiedades. La construcción de un centro de acopio y de procesamiento de la leche en el ejido de Campo Hermoso debe permitir alcanzar ese objetivo. La situación privilegiada de Maravatío y la proximidad de grandes centros urbanos como México, Toluca, Querétaro, Morelia permite buscar el mercado remunerador de las élites urbanas produciendo quesos, dulces, yogures de calidad y alto valor agregado.

Ese tipo de producción se impone tanto más que la fabricación de quesos tradicionales en el centro de acopio no podrá procurar a los campesinos una remuneración suficiente: la producción casera en el seno de las unidades familiares sería menos costosa y el nuevo centro serviría, entonces, únicamente para la comercialización. Esa posibilidad debe estar presente en la conciencia de los promotores del proyecto. El centro de acopio puede cumplir ese papel de comercializador de productos previamente procesados por los mismos campesinos, pero en el marco de una acción más amplia y más ambiciosa.

El centro de acopio es una etapa fundamental en la realización de las metas que se había fijado el proyecto y por eso podría ser también un factor 
de fracaso si no se toman las medidas apropiadas. Debe focalizar la voluntad de cooperación entre los campesinos así como su dinamismo. Teniendo el centro de acopio el valor de muestra y de acontecimiento para toda la región, estaremos cerca de los objetivos del proyecto y la iniciativa campesina podría tomar el papel principal en la dinámica de desarrollo regional. Un fracaso inicial del centro de acopio pondría un freno a esa dinámica colectiva y aumentaría la vulnerabilidad de las unidades de producción más desfavorecidas. En ese sentido el problema debe estar al centro de las preocupaciones de los dirigentes de la administración agropecuaria estatal. 



\section{CAPITULO III \\ FRACASA LA VIA MAICERA EN EL BAJIO SECO AGUANUATO}

Jean-Damien de Surgy

Rocío Martínez Kemp

Lilia Zizumbo Villarreal

Thierry A. Linck

\section{INTRODUCCION}

En este capítulo nos proponemos analizar la organización y la dinámica de la producción agropecuaria en un ejido representativo de las condiciones medias de la agricultura de temporal del Bajío michoacano.

Tanto el interés por esa región como la adopción de un enfoque sistémico se fundamentan en el hecho de que el reciente y creciente apoyo del estado a la agricultura de temporal en relación a la expansión del crédito, la mayor difusión de insumos modernos, el SAM y, después, el PRONAL, no pudo contrarrestar, por lo menos aquí, el decaimiento o el estancamiento de las actividades agropecuarias en general y de la producción de alimentos básicos en particular.

El trabajo de campo evidencia que esa tendencia en gran parte se debe a una incompatibilidad real entre los proyectos y estrategias del estado y las de los campesinos. La visión sectorial del primero choca sin poder integrarse ni adaptarse a la organización horizontal y global de los segundos. Mientras planes y programas ponen énfasis en algunas actividades aisladas (maíz), persiguiendo ilusorias economías de escala, los sistemas de producción campesinos -y, luego, la organización del trabajo en la familia y en la comunidad- logran su máxima eficiencia mediante el aprovechamiento de las sinergias permitidas por la combinación de múltiples actividades y recursos complementarios, con objetivos que no son necesariamente la elevación de los rendimientos. Esa incompatibilidad puede vincularse con el estilo centralizado, autoritario y paternalista de la administración agropecuaria. Lo cierto es que este rasgo tampoco es compatible con el aprovechamiento de los conocimientos, de la experiencia y auto-organización; en pocas palabras, de las fuerzas vivas del campesinado y sin las cuales no hay verdadero desarrollo posible.

El Bajío, antiguo granero de México, está situado en el suroeste del altiplano, con tierras cultivadas en una altitud que oscila entre 1,500 y 2,300 metros. Es una amplia meseta surcada por elevaciones menores, recargada hacia el sur, sobre el Eje Neovolcánico y hacia el oeste, sobre la Sierra Madre 
Occidental. El aprovechamiento de las aguas del río Lerma, de bordos, de presas y, más recientemente, de pozos, ha permitido el desarrollo de enclaves de riego altamente productivos. Sin embargo, la mayor parte de sus suelos de origen volcánico antiguo se aprovechan mediante sistemas de producción que combinan maíz, frijol de temporal y ganadería extensiva en áreas totalmente desprovistas de riego.

El ejido de Aguanuato se localiza en la vertiente sur de la cuenca del Lerma, en el noroeste de Michoacán a unos treinta kilómetros al norte de la ciudad de Zacapu, en pleno Bajío michoacano (ver mapa 11). Está unido a Panindícuaro, su cabecera municipal, y a la red de carreteras por un camino de terracería de ocho kilómetros de largo.

Varios criterios importantes determinaron la elección de Aguanuato como objeto de este estudio:

- Aunque está rodeado de pequeñas propiedades, el pueblo coincide y se identifica con el ejido y su territorio. De los campesinos del municipio de Panindícuaro, alrededor de la mitad son ejidatarios, y la otra mitad "pequeños propietarios". Entre éstos se encuentran los principales promotores del cambio tecnológico en la agricultura de temporal, mientras las versiones oficiales ven al ejido como una estructura que impide el logro de una productividad satisfactoria. Por esta razón quisimos privilegiar el análisis de la organización campesina en el marco de una estructura ejidal.

-No hay riego en el área y los cultivos son los característicos de la agricultura de temporal del Bajío, con la única pero notable excepción del sorgo, que no existe ahí.

-La emigración de los campesinos, rasgo característico del Bajío michoacano, es muy pronunciada en Aguanuato.

-El centro de población, con un millar de habitantes, es de un tamaño que permitió, además de las entrevistas indispensables ${ }^{1}$ el levantamiento de un censo de población y agropecuario exhaustivo. ${ }^{2}$

Observando mapas y platicando con los campesinos, fácilmente se deduce que Aguanuato mantiene relaciones privilegiadas con las comunidades vecinas de Caurio, Tanhuato, Bellavista y con la cabecera municipal, lo suficientemente homogénea como para definir una micro-región articulada con los polos regionales de Zacapu y La Piedad. ${ }^{3}$ El espacio micro-regional

1. Entre las personas entrevistadas se encuentran don Juan Olvera G., comisario ejidal; don José Rodríguez L., jefe de tenencia; Ing. J. Pacheco, jefe de la Unidad de Temporal de Panindícuaro-Villa Jiménez. (Distrito de Temporal II-Puruándiro-SARH).

2. Con la ayuda de los alumnos de la Telesecundaria y su director Ing. Guillermo Castro $R$.

3. En cambio se hablará de "área" de estudio para un espacio más restringido: el territorio ejidal de Aguanuato y las pequeñas propiedades circundantes. 


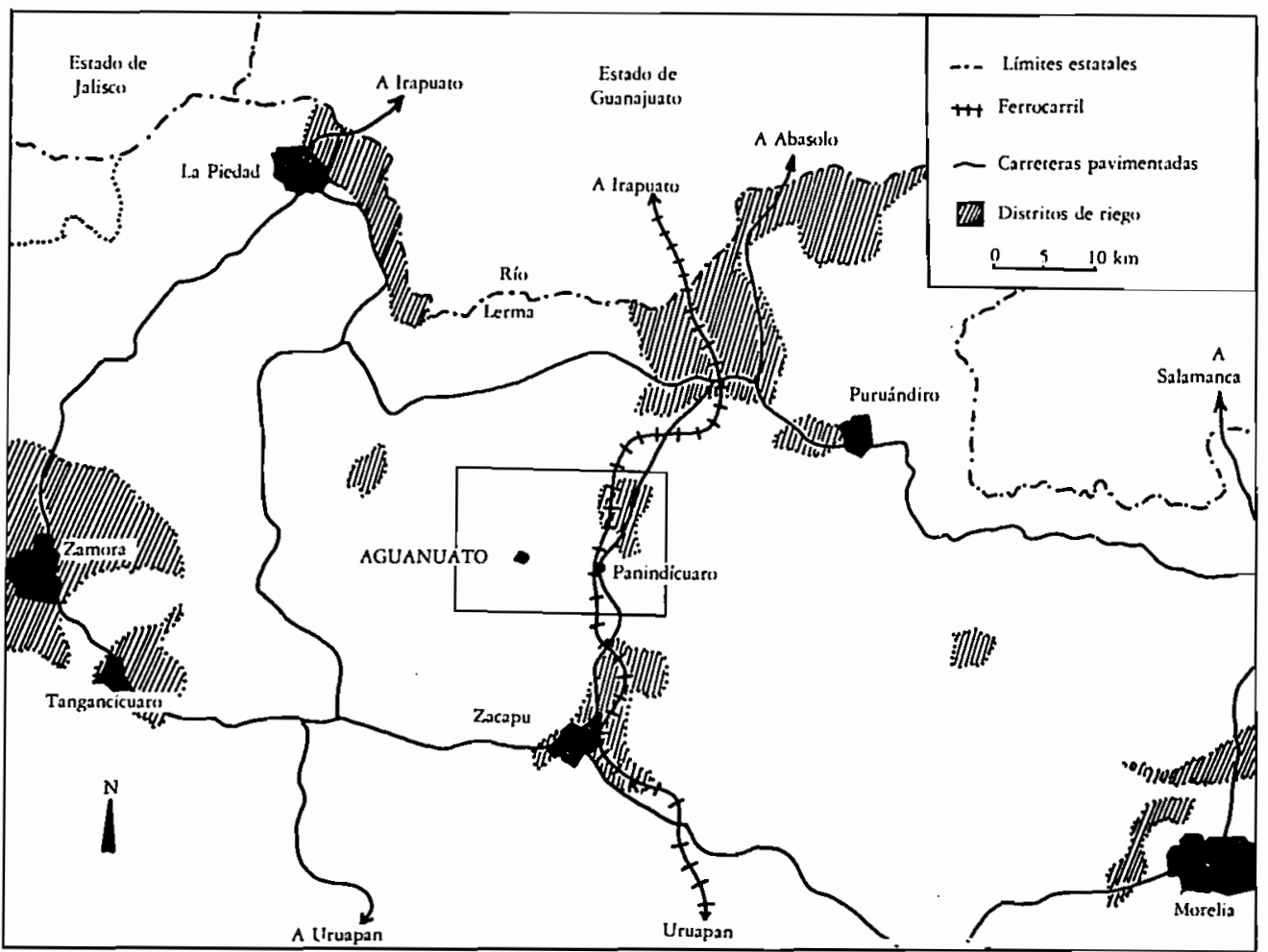


así definido (ver mapa 12) se organiza fundamentalmente en torno a las tierras de temporal y al valle de riego que queda a un lado de la villa de Panindícuaro, en el cual numerosos campesinos encuentran fuentes de ocupación alternativa como jornaleros en los cultivos intensivos (fresa).

Sin embargo, la fuerte integración de Aguanuato en la colectividad nacional y su dependencia creciente de centros de decisión exteriores no impiden, todavía, que la organización del trabajo se adecúe estrechamente a las condiciones de valoración de su territorio. Las modalidades de acceso y transformación de los recursos y el peso relativo de cada actividad reflejan la complementariedad de los esfuerzos de todos y define el sistema social de producción.

La mayor parte de este territorio (mapa 12) se encuentra en una leve depresión rodeada por cerros de baja altura cubiertos esencialmente de matorrales. Llegando a Aguanuato se aprecia la escasa disponibilidad de agua: el cauce más importante, un arroyo que después de cruzar el pueblo sale hacia el norte, está seco durante 6 ó 7 meses del año. Alrededor se observan los elementos dominantes del sistema de producción: cultivo del maíz, en ocasiones asociado con frijol y calabaza, y los numerosos animales que recorren los agostaderos (vacas, cabras) o las calles del pueblo (puercos).

\section{EVOLUCION Y DIFERENCIACION DE LA COLECTIVIDAD AGUANUATENSE}

\section{Origen}

Durante el siglo XVI, la región contaba todavía con comunidades indígenas (Aguanuato significa cerro del conejo en el idioma purépecha) que no tardaron en ser desposeídas y luego amestizadas. A principios del siglo XX, Aguanuato era un pueblo de medieros y peones "libres" que prestaban sus servicios en las haciendas vecinas de Bellavista, San Antonio Carupo y Braulio-Guerrero, y en varios ranchos más pequeños, ya que la gran propiedad había entrado en el proceso de división característico del nor seste de Michoacán a la vuelta del siglo. ${ }^{4}$

Los aguanuatenses cultivaban año con año, maíz, frijol, trigo y garbanzo usando la tracción animal. La relación productiva dominante era la mediería; los hacendados se mantenían y alimentaban una numerosa población ganadera con su parte de las cosechas; vendían animales y algo de

4. Heriberto Moreno G., Después de los latifundios. El Colegio de Michoacán-FONAPAS, Morelia, 1982, Pp. 33-49. 


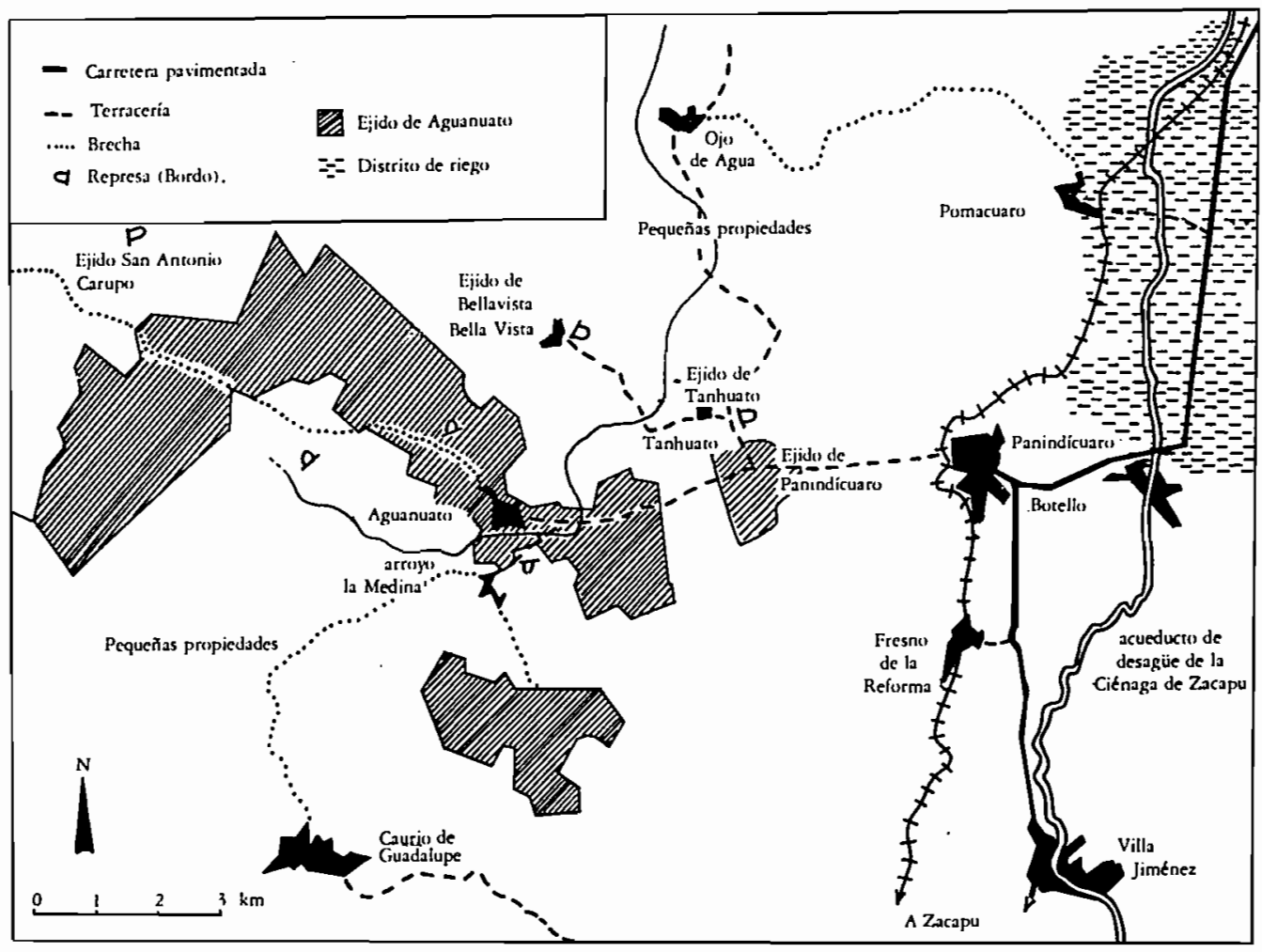


grano, mientras los medieros apenas podían mantenerse con lo que les tocaba del maíz y frijol. El cuero se vendía a los artesanos del pueblo y a veces también a medieros que hacían huaraches, botas, collares, riendas para el tiro y sillas de montar que se comercializaban afuera.

Las guerras de la revolución dañaron mucho al pueblo, donde temprano se destaco una mayoría agrarista que contaba incluso con los propietarios más pequeños; causaron la destrucción de la escasa infraestructura hidráulica y la desaparición de la mayor parte del ganado en la zona, lo que puso un término a la artesa nía del cuero. De hecho, casi todos los que no trabajaban la tierra emigraron a otros lugares.

A nivel microrregional, Aguanuato fue de los primeros poblados en beneficiarse de la Reforma Agraria (1927), antes de la gubernatura de L. Cárdenas y bajo la influencia de lo ocurrido en la ciénaga de Zacapu. Este hecho, en el momento más fuerte de la rebelión cristera, sugiere todavía una gran movilización agrarista en el área. Sin embargo, el reparto no fue del todo equitativo: estimamos en más de 50 el número de familias marginadas, varias de las cuales tuvieron que emigrar. Los solicitantes de tierra eran demasiado numerosos como para que todos pudieran beneficarse del mínimo de 7 hectáreas que se había fijado. Se decidió entonces dotar a cada ejidatario de las parcelas que antes cultivaba a medias, más todo lo que pudiera desmontar. El proceso favorecía la diferenciación social porque privilegiaba a los ejidatarios que poseían animales de trabajo y que por lo tanto podían desmontar y trabajar una mayor extensión de terreno. También se fomentó una notable división del trabajo: muchos de los nuevos ejidatarios desprovistos de animales no tenían otra alternativa que arrendar sus tierras y emplearse como jornaleros o medieros en los predios más grandes.

En 1935 ocho ejidatarios y algunos propietarios de pastizales se separaron de Aguanuato para formar la colonia de Piritzio, y en 1940 ocurrieron los últimos cambios agrarios, que dieron a la comunidad la fisonomía que tiene hoy en día: cuarenta familias excluidas del reparto oficial recibieron el derecho de desmontar y cultivar la superficie de monte que pudieran, como "allegados" del ejido... en los peores suelos y sin animales de trabajo. Casi todos los jefes de familia del pueblo obtuvieron así derechos sobre la tierra, aunque los "allegados" quedaban algo marginados y mandaban braceros con más frecuencia a Estados Unidos.

Con todo, el logro básico de la revolución y del reparto agrario fue para los ejidatarios, además de mejorar un poco su nivel de vida, la posibilidad de acumular ganado, aprovechando la parte de las cosechas que antes era destinada a los hacendados. Así creció regularmente la población ganadera de Aguanuato hasta los años setentas. Además de los desmontes del reparto, que proporcionaban rastrojo para mantener más ganado, los mayores ingresos de los más afortunados les permitían comprar tierras de labor en 
los alrededores, que a su vez ampliaban la capacidad de sostener un hato en crecimiento.

Así, el pueblo acumuló en un proceso combinado, ganado y tierra de labor tanto ejidal como de pequeña propiedad; pero esta acumulación fue muy desigual, y sólo la realizaron las familias que tenían animales de trabajo de antemano, mientras que para muchos allegados y medieros que, aún hoy todavía no tienen ni una vaca y cuyas familias fueron más afectadas por la emigración, dicho proceso nunca pudo empezar. La consecuencia es que en estas condiciones de acumulación desigual, el terruño de Aguanuato nunca ha podido mantener a más de unas 170 familias después de la revolución.

A principios de los años setentas - como lo evidencia a partir de entonces un incremento notable de la mortalidad animal durante la estación seca-, la acumulación encontró un límite: la superficie de pasto ejidal disponible. Este límite parece corresponder a una carga de 0.4 U.A./Ha. ${ }^{5}$ (tomando en cuenta todos los animales e incluyendo las superficies de maíz-frijol).

Más allá de ese umbral, la acumulación — de animales sobre todo- no pudo seguir de la misma manera. En el marco que define la organización socio-económica vigente en los años recientes, un mayor enriquecimiento de los más acomodados llegó a implicar, mucho más que en el pasado, una redistribución desigual de los recursos comunitarios a expensas de los menos afortunados. En su etapa actual, el proceso de acumulación tiene todas las características de una lucha desigual en el pillaje y la destrucción del patrimonio comunitario: los propietarios de hatos importantes tienen de antemano, con su capacidad mayor de resistir los periodos críticos, la seguridad de imponerse como últimos dueños de los agostaderos.

\section{Emigración}

Aguanuato puede caracterizarse ahora por la fuerte emigración de sus habitantes. El movimiento cobra dos formas principales:

-una emigración definitiva hacia Panindícuaro, Zacapu, Tijuana, Mexicali y, sobre todo, hacia los Estados Unidos;

-una emigración estacional hacia los Estados Unidos, para trabajar en las cosechas agrícolas (uva).

Como lo indica el siguiente cuadro, dos tercios de los jefes de familia se han ido de braceros por lo menos una vez en su vida, y varios lo siguen haciendo con regularidad.

5. Una "unidad animal" corresponde aproximadamente a una cabeza de ganado "corriente" de $350 \mathrm{Kg}$. 


\section{CuAdro Ne 16}

MigRACION ESTACIONAL DE I.A POBLACION RESIDENTE en Aguanuato (fuente: encuesta directa)

\begin{tabular}{|c|c|c|}
\hline Han ido a EEUU & No. de jefes de familia & $\%$ \\
\hline 1 vez & 36 & 23 \\
2 veces & 17 & 11 \\
3 veces & 14 & 9 \\
4 veces & 9 & 5 \\
5 o más & 20 & 13 \\
nunca & 55 & 36 \\
no se sabe & 4 & 3 \\
\hline Total & 155 & 100 \\
\hline
\end{tabular}


La emigración es todavía más notable entre los jóvenes no casados. En 1982, 144 habitantes del pueblo ( $16 \%$ de la población) salieron a los Estados Unidos; esta cifra da una idea del impacto de la migración sobre la vida del pueblo. Hay que agregarle las consecuencias de las muy importantes migraciones definitivas: se han ido familias enteras y un gran número de las que quedan tienen a varios de sus hijos en el "norte". En ese aspecto es significativo el hecho de que el tamaño de las familias no exceda, en promedio, seis personas residentes en Aguanuato.

Tal como sucedio de manera generalizada en el Bajío michoacano, la emigración se inicia con el siglo XX, se acelera durante la revolución y recrudece con el programa bracero (1942-1964) para mantenerse, aunque ilegal, al mismo nivel en la actualidad. Entre 1950 y 1983, de acuerdo con la información censal, el crecimiento de la población era muy bajo $(0.5 \%$ de promedio anual) y contrastaba con un crecimiento natural alto, del orden de $4 \%$. La diferencia - $3.5 \%$ anual - nos indica la magnitud aproximada del balance entre esas dos fechas, alrededor de 1,700 aguanuatenses habian tenido que establecerse fuera de su pueblo natal. La población de Aguanuato, como en muchas localidades del norte de Michoacán, se beneficia además de estructuras permanentes para la emigración: presencia de familiares o conocidos en Estados Unidos y en la frontera y una red muy densa de autotransportes entre la región y las ciudades fronterizas. Este es un factor común a todo el municipio de Panindícuaro, que cuenta con una de las tasas de emigración más fuertes en el estado y se refleja en el estancamiento de su población desde los años sesentas (gráfica 11).

En la gráfica 11 aparece también el efecto de las transformaciones ocurridas en el valle de riego en los años cincuentas, así como del desarrollo de las comunicaciones en el municipio; los lugares más incomunicados y donde la agricultura es sólo de temporal cesan su crecimiento demográfico más temprano, y en 1980 no tienen más habitantes que en 1950. Ahí los índices de emigración son mucho más altos que el promedio michoacano y desde mucho tiempo atrás, lo que evidencia en estas zonas "deprimidas" la presencia de factores expulsores mucho más poderosos que la simple "atracción" de las ciudades y de los Estados Unidos. En otras palabras, la emigración puede verse también como un índice de la incapacidad del terruño y de la organización económica para proporcionar su sustento a una población en crecimiento. Más todavía, si se toma en cuenta la desaparición de algunas actividades como la fabricación de carbón, la venta de trigo y frijol, la arriería y varias artesanías, cabe preguntarse si la evolución de los sistemas de producción no tiende a una disminución importante de dicha capacidad. La evolución histórica de las actividades que participan en los sistemas de producción puede caracterizarse por los rasgos siguientes:

En primer lugar muchas de las actividades que se practicaban a principios del siglo han desaparecido: artesanías del cuero, fabricación de 
sombreros y de herramientas para la agricultura (arados de madera..etc), quema de la leña para hacer carbón, actividades comerciales (arrieros)..etc, lo que limitó a los campesinos a las actividades meramente agropecuarias.

Además, a partir de 1960 se dio una especialización regional con:

-la desaparición del trigo de temporal y de riego que se estuvo concentrando en el Bajío guanajuatense, en Sonora y en Estados Unidos, a costos mucho menores por involucrar poca mano de obra; desde luego el molino industrial del municipio, ubicado en Botello, tuvo que importar trigo por ferrocarril.

-El principio de la producción de sorgo-grano en todas las zonas de riego del Bajío, en relación con la cuenca porcícola de La Piedad. El sorgo - y más tarde la fresa - reemplazaron al trigo en el valle de Panindícuaro, mientras los puercos rancheros empezaron a sufrir la

\section{GRAFICA No 11 :}

Población total relativa

(índice 100 en 1940)

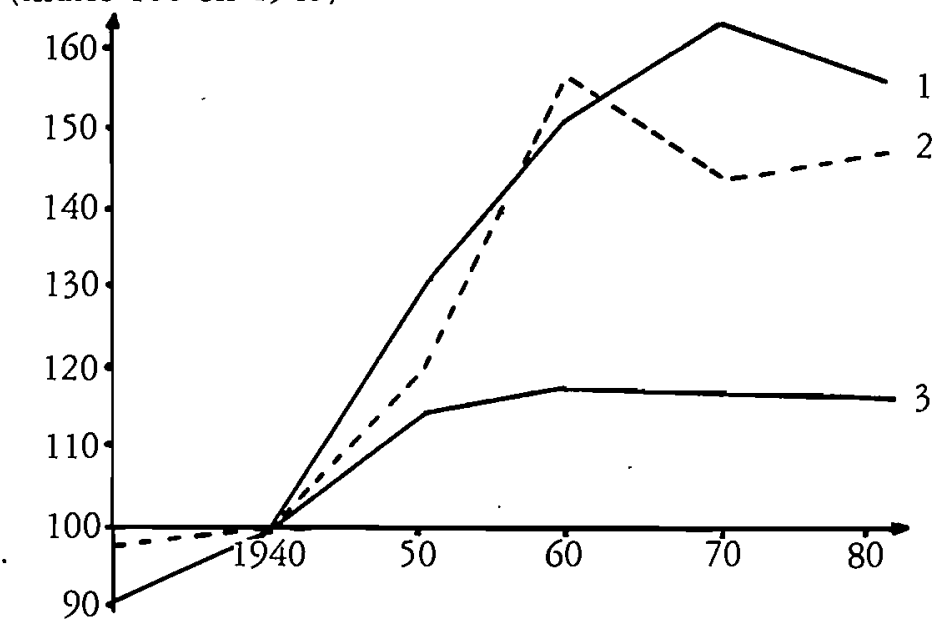

1 Municipio entero (18,054 hab en 1980)

2 Cabecera municipal $(5,411$ hab en 1980$)$

3 Localidades del área temporalera comunicada por la salida occidental de Panindícuaro: Aguanuato, Piritzio, Tanhuato, Bellavista, Ojo de Agua, Ranchos de Epejan y San Miguel Epejan (total 2,450 hab en 1980).

Fucnte: SPP: Censos de Población y Vivienda. 
competencia de los puercos industriales; así, Agua nuato se especializó en la producción de lechones para las granjas de engorda de La Piedad.

Se dió también una especialización microregional, con la disminución de la producción de frijol en Aguanuato por razones físicas detalladas a continuación y por el mantenimiento de precios demasiado bajos e incontrolables: el cultivo se redujo a las necesidades de autoabasto mientras el frijol de venta se concentró en el valle de riego, donde lo pueden cultivar en otoño-invierno y vender mucho más caro. Aquí tenemos probablemente una de las limitantes al mantenimiento de una numerosa población en Aguanuato.

\section{CARACTERIZACION DE LOS SISTEMAS DE PRODUCCION}

\section{Organización colectiva del trabajo}

Las modalidades de uso de la fuerza de tracción animal constituyen un punto clave en las relaciones productivas que caracterizan el ejido de Aguanuato: la ganadería y la agricultura son actividades comunes a gran parte de los campesinos por la estrecha necesidad de alimentar los animales con rastrojo de maíz y frijol, pero éste es además conseguido por los ganaderos importantes a través de la renta de yuntas y de la mediería. Así no necesitan sacar un producto agrícola tan importante, mientras para completar sus necesidades forrajeras aprovechan un mecanismo más redituable que la compra de rastrojo.

La realización del equilibrio entre ganadería y agricultura tiene también una importante dimensión espacial, que se nota en la organización colectiva del aprovechamiento del agostadero ejidal, adaptada a la configuración del territorio (véase gráfica 12).

El ejido tiene dos áreas principales de cada lado del pueblo - cada una con un bordo de agua principal que se llena por gravedad. Un campesino puede llevar sus animales a todo el pastizal, del lado donde tiene sus parcelas de labor, y hacerles tomar agua en el bordo correspondiente. Este arreglo muestra cómo la organización colectiva se combina con las necesidades de relacionar el ganado con las tierras de labor individuales: cada uno lleva sus animales a pastar en los terrenos después del cultivo de maíz-frijol, para limpiar y fertilizar su parcela; también recolecta el estiércol que deja el ganado en los pastizales cercanos para completar esta fertilización orgánica. Esta organización limita el gasto de tiempo y energía en el transporte del estiércol; a la vez se evitan el tránsito por el pueblo y las pérdidas de estiércol en el camino. 


\section{Grafica No 12 :}

ESQUFMA SIMPLIFICADO DE OCUPACION

DEI. ESPACIO HN EI. FjIDO DE A GUANUATO

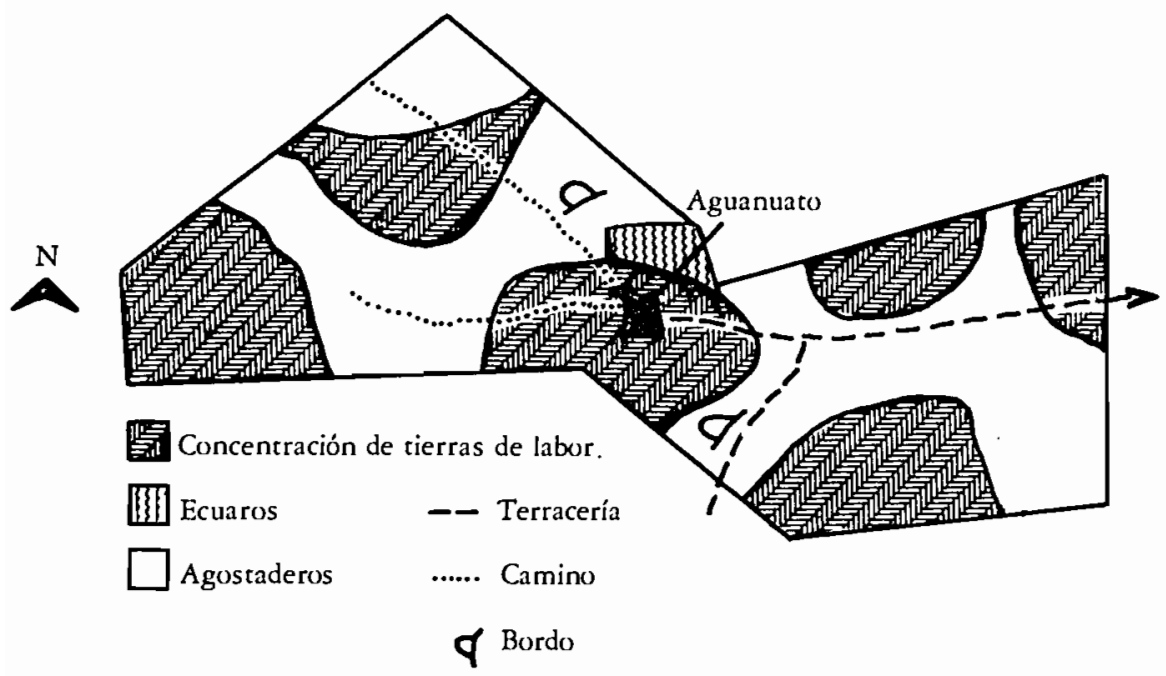

El estiércol de las cabras se aprovecha también, bajo el tradicional sistema de las "majadas", en las numerosas parcelas de labor cercadas con piedra que rodean al pueblo: los que las cultivan piden a los chiveros que estacionen ahí sus cabras durante algunos días en corrales amovibles, para abonar el suelo de manera sistemática a cambio del suministro de forraje.

\section{Sistemas de ganado}

A continuación se describen las características del aprovechamiento de las distintas especies:

Los bovinos

Son animales de carne en primer lugar, con producción marginal de leche durante parte de julio, agosto y parte de septiembre, durante las lluvias. Las vacas, los becerros, los toros y los bueyes cuando no se utilizan, van juntos en rebaños de todos tamaños ( 3 a 80 cabezas); cada día van al agua en lugares diferentes, según la estación y se regresan a los corrales en la tarde cuando necesitan rastrojo; así se junta el estiércol, que después se acarrea en burros. 
Unos pequeños propietarios tienen potreros con cercas de piedra.

La mayor parte de las vacas tienen su criadero en mayo-junio. ${ }^{6}$ Cuando los ganaderos sacan la leche ordeñan en las mañanas ( 1 a 3 litros por vaca) y dejan al becerro con la vaca en las tardes. Las vacas pueden tener hasta un becerrito cada año, cuando están bien alimentadas en tiempo de secas. La leche sirve para tomar o hacer queso que, sobre todo, se vende en el pueblo. Los novillos crecen hasta 2 años y medio y se venden, sobre todo en otoño después de engordar un poco en la estación de lluvias, y cuando hay más oportunidades porque regresa gente de Estados Unidos que consume carne; algunos los apartan para tener nuevos bueyes de trabajo.

Durante la estación lluviosa, la alimentación está constituida por el pasto natural: tiene muchas gramíneas y un poco de "carretilla" (leguminosa de otoño). En la estación seca los animales aprovechan mucho más las hojas de los arbustos (capitanera, cazahuate). El complemento alimentario no se compone exclusivamente de rastrojo: se recolectan vainas de huizache y hojas de nopal, que se queman; así se aprovecha toda la vegetación del lugar. El grano sirve para animales que necesitan un complemento energético como vacas en lactancia y bueyes en temporada de trabajo. Las necesidades en rastrojo se cubren con la producción agrícola, si no se presta dentro de la red familiar. A veces se vende a precios muy bajos - apenas $\$ 1,500 / \mathrm{Ha}$. recogido en la orilla de las parcelas en 1984.

Este ganado es principalmente de tipo rústico "corriente" (razas descendientes del ganado traído de España). Los rebaños individuales no están estrictamente separados en el pasto, por eso la reproducción natural, sea de toros individuales o del ejido, tiene rasgos colectivos. Parece que se generan más crias en mayo-junio, lo que es una condición para que sobrevivan los becerros pues las vacas sólo tienen leche suficiente en la temporada de lluvias. Esta adaptación puede ser el resultado de una selección natural, que reduce la necesidad de controlar la reproducción. No se usa la inseminación artificial; además la introducción reciente de dos toros cebús ejidales en el pasto colectivo es muestra de que se busca una especialización en animales de carne rústicos - aunque no sean buenos para el tiro.

\section{Los Puercos}

La influencia de la porcicultura industrial de La Piedad ha orientado la producción de las marranas caseras de Aguanuato hacia lechones de un mes y medio para abasto de las granjas industriales de engorda; el pueblo sólo engorda los animales que no puede vender para consumo local.

6. En estas zonas, dada la alimentación, las vacas solamente son fértiles durante la época de lluvias. 
Las marranas se alimentan con calabaza y unos 2-3 litros de maiz y garbanzo diarios, más la basura. Ya se está "tecnificando" un poco la cría de puercos: vacuna sistemática de las marranas contra el cólera y alimentos balanceados para lechones al momento del destete. Sin embargo, las puercas son fecundadas por cerdos del mismo pueblo y tienen dos crías en promedio al año, cada una dan de 3 a 10 lechones: eso hace aún más variable la rentabilidad de una marrana.

Las cabras

Hay unos 10 rebaños importantes en el pueblo con 20 cabezas ó más. Las utilizan para producir leche y hacer queso que se vende en el pueblo y en Panindícuaro de julio a octubre, o para criar cabritos que se venden dos veces al año siendo Navidad la época más lucrativa. Las cabras se utilizan mucho para limpiar y fertilizar los ecuaros.

\section{Sistemas de cultivo}

Por no haber riego en Aguanuato, la temporada de lluvias es la única fuente de agua para la producción agrícola.

El clima de las partes meridionales del Bajío a 2,000 metros de altura se caracteriza por lluvias anuales de alrededor de $750 \mathrm{~mm}$., desgraciadamente repartidas sólo entre 4 ó 5 meses (véase gráfica 13 ).

Durante la estación seca, la ausencia de lluvias y la fuerte evaporación impiden que la humedad residual de los suelos sea suficiente para cultivar. En los meses de marzo a mayo sólo persiste una vegetación rala, reseca, en forma de matorral que proporciona una dieta pobre a una población animal debilitada. Durante ese periodo es imprescindible complementar la alimentación del ganado con el rastrojo obtenido de la cosecha de maíz. Este rasgo y, en menor medida, el hecho de que se libere un espacio máximo durante el periodo crítico para las producciones animales, destaca la fuerte complementariedad entre maíz y ganadería mayor. Sin embargo, la sinergia que permite esta complementariedad también tiene sus límites: la ausencia de cultivos y el sobrepastoreo exponen los suelos desprotegidos a la acción erosiva de los fuertes vientos de abril y mayo.

La gráfica 13 demuestra también que el maíz es un cultivo sumamente bien adaptado a las condiciones de temporal. Su ciclo vegetativo se inicia con la estación de lluvias y sus requerimientos de agua evolucionan en el mismo sentido que las frecuencias mensuales de lluvia. Sin embargo no se trata aquí sino de condiciones promedio: las fuertes fluctuaciones interanuales del volumen de agua —de 400 a $1,200 \mathrm{~mm}$. en los años extremosos, o sea una variación de 1 a 3- muestran que el cultivo del maíz está sometido a grandes riesgos y que las cosechas siempre son aleatorias; esto se verifica 


\section{GRAFICA No 13}

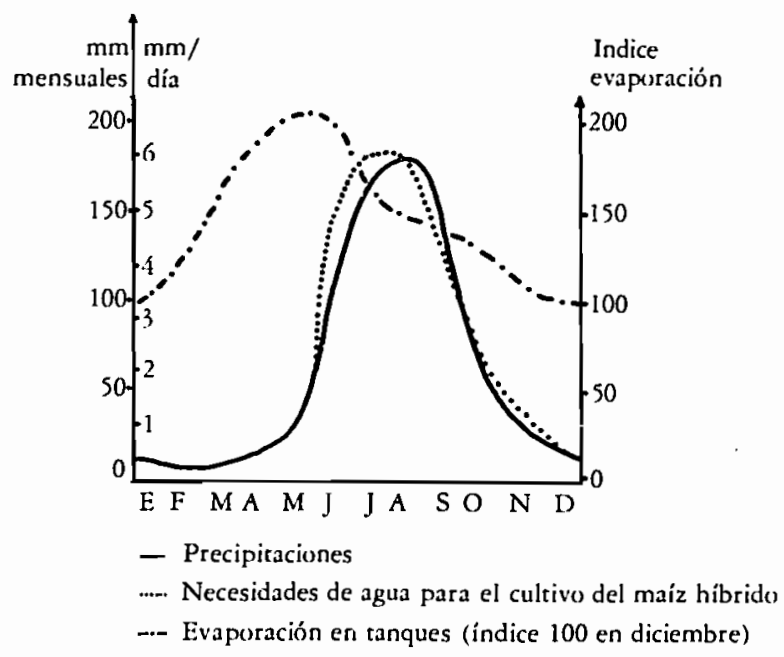

Fuente: Plan I.ERMa, Meteorología-Boletín № 2, Angamacutiro, Mich., promedio de 25 años. Diagrama casi idéntico para todas las localidades del Bajío-Sur).

todavía más para las variedades híbridas, cuyas necesidades, como lo enseña la gráfica, apenas se cubren con el nivel promedio de las lluvias en sembradíos de alta densidad. El periodo más crítico es en agostoseptiembre: cualquier déficit hídrico durante la floración del maíz tiene graves consecuencias sobre el rendimiento. En este sentido, la ausencia de obras hidráulicas livianas que permitan un riego de ajuste durante la estación de lluvias, pesa mucho sobre la aleatoriedad del cultivo.

Además, se ha observado que en muchos lugares de la cuenca del Lerma el promedio de precipitaciones anuales ha estado bajando en los últimos treinta años, sobre todo por deforestaciones que dificultan la condensación y provocan además una disminución de las reservas subterráneas en la estación seca; esto pone en peligro el cultivo del garbanzo en otoñoinvierno, que con lluvias anuales de $750 \mathrm{~mm}$. aún se puede practicar, después del maíz, en los suelos más profundos de Aguanuato, aprovechando su mayor capacidad de retención del agua.

A la vez, estos fenómenos se acompañan de una mayor erosión hidráulica. Sin embargo ésta suele ser más efectiva en los andosoles rojos (tipo "charanda") muy frecuente en Michoacán. Afortunadamente, muchos suelos arcillo-arenosos de Aguanuato, bastante resistentes por tener su origen en un volcanismo diferente y más antiguo, todavía permiten cultivar 
el maíz-frijol año con año en la misma parcela; ${ }^{7}$ la erosión fuerte solamente se localiza en lugares predilectos, es decir donde transitan muchos animales $y$ al lado de los arroyos.

En el cuadro 17 están registrados los procesos de trabajo agrícola. Son específicos del área, aunque muchos de sus rasgos son frecuentes en el temporal del Bajío michoacano.

El éxito y la reproducción del sistema dependen sobre todo de la cosecha de maíz-frijol. Frente a las fuertes variaciones climáticas los campesinos han desarrollado la siguiente estrategia: en primer lugar la densidad de siembra, expresada en la distancia entre cada mata, se mantiene a bajo nivel. Si llueve poco, las reservas del suelo todavía alcanzan para el bajo número de plantas por unidad de superficie. También se trata de aprovechar una máxima parte de las lluvias de la estación, sembrando después de las primeras lluvias importantes, incluso, si éstas caen temprano. El riesgo de tener que resembrar es en parte enfrentado por la colocación de dos semillas en cada hueco. También se destaca aquí una ventaja de la semilla criolla, seleccionada a través de años de práctica en el lugar: en un mal temporal da todavía algo de cosecha, lo que es más importante que el logro de rendimientos muy altos en los años de buen temporal (los aguanuatenses han alcanzado 2.5 ton/ha).

Eso hace de la siembra la fase más vulnerable de todo el ciclo de cultivo, por lo que su fecha y sus modalidades condicionan la magnitud de los futuros riesgos vinculados con el temporal de lluvias. Para poder sembrar temprano, la mano de obra necesaria sólo se dedica a esto en jornadas muy largas, mientras la cosecha ocupa a un mayor número de personas, pero en jornadas mucho menos intensas.

El calendario de trabajo nos permitió precisar la repartición anual del trabajo familiar (gráfica 14). Primero se destaca la subocupación importante (partes en blanco) que se manifiesta entre los hombres; muchas veces se ven ociosos en el pueblo y es que la mayor parte de los trabajos agrícolas sólo requieren de uno o dos hombres de tiempo completo por familia. Por eso también es raro que las jornadas rebasen las 7 u 8 horas.

En Aguanuato se da todavía prioridad al buen cuidado de los cultivos por encima de la emigración: la mayor parte de los que se van a Estados Unidos por una temporada salen después de la segunda escarda, encargando el deshierbe - que requiere menos atención y experiencia- a los miembros de la famila que se quedan. La temporada de migración más frecuente tarda hasta la cosecha del maíz, por eso se instituyó el corte del frijol como trabajo esencialmente femenino mientras los hombres que se han quedado

7. Además existen en algunos lugares suelos limosos ("tierras amarillas") considerados de mayor fertilidad. 
Procesos de trabajo agricola en Aguanato: maiz-Frijol-Calabaza

\begin{tabular}{|c|c|c|c|}
\hline Concepto & Tiempo días/ha & $\begin{array}{l}\text { Herramienta y fuerza } \\
\text { de trabajo }\end{array}$ & Técnicas \\
\hline $\begin{array}{l}\text { Barbecho y siembra } \\
\text { Maíz asociado-1ª abono. } \\
\text { (mayo-junio) }\end{array}$ & $2-3$ & $\begin{array}{l}\text { yunta de bueyes } \\
+ \text { arado de vertedera }\end{array}$ & profundidad $10 \mathrm{~cm} 2$ semillas cada paso \\
\hline $\begin{array}{l}\text { 1a. escarda } \\
\text { 20 abono } \\
\text { 2a. escarda }\end{array}$ & $\begin{array}{l}2 \\
\text { cada vez }\end{array}$ & $\begin{array}{l}\text { yunta de bueyes } \\
+ \text { arado de doble } \\
\text { vertedera }\end{array}$ & $\begin{array}{l}\text { alternando maíz y frijol la yunta tapa } \\
\text { el surco al regresarse } \\
\text { sirve para limpieza, fertilización } \\
\text { y conservación de la humedad }\end{array}$ \\
\hline $\begin{array}{l}\text { Chaponeo } \\
\text { (septiembre) }\end{array}$ & variable & hoz o machete & $\begin{array}{l}\text { el "zacate" se descompone luego al pie } \\
\text { de las matas. }\end{array}$ \\
\hline Cosecha del elote (sept.) & & mano & sólo en los ecuaros \\
\hline $\begin{array}{l}\text { Corte del frijol (octubre) } \\
\text { Desenvaine (noviembre) }\end{array}$ & $\begin{array}{l}1 / 4 \text { pers. (mujeres) } \\
\text { variable }\end{array}$ & $\begin{array}{l}\text { hoz } \\
\text { con caballo }\end{array}$ & $\begin{array}{l}\text { se junta y se fumiga en la orilla de la } \\
\text { parcela, el rastrojo se queda. }\end{array}$ \\
\hline Roza del Maiz (octubre) & $1 / 3$ pers. & machete & $\begin{array}{l}\text { se amontona el maíz aún no maduro para } \\
\text { sembrar garbanzo y trigo }\end{array}$ \\
\hline Pizca (dic.-enero) & $1 / 8$ pers. & pizcador & \\
\hline $\begin{array}{l}\text { Barbecho en seco } \\
\text { (m-abril) }\end{array}$ & 2 & Yunta + arado vert. & Para la siembra siguiente \\
\hline
\end{tabular}


Grafica N ${ }^{2}$ 14: Reparticion Del. trabajo familiar en Aguanuato
E
$\mathrm{F}$
$\mathrm{M}$
A $\quad M$
$J \quad J$
$A$
$\mathrm{S}$
o
$N$
$\mathrm{D}$
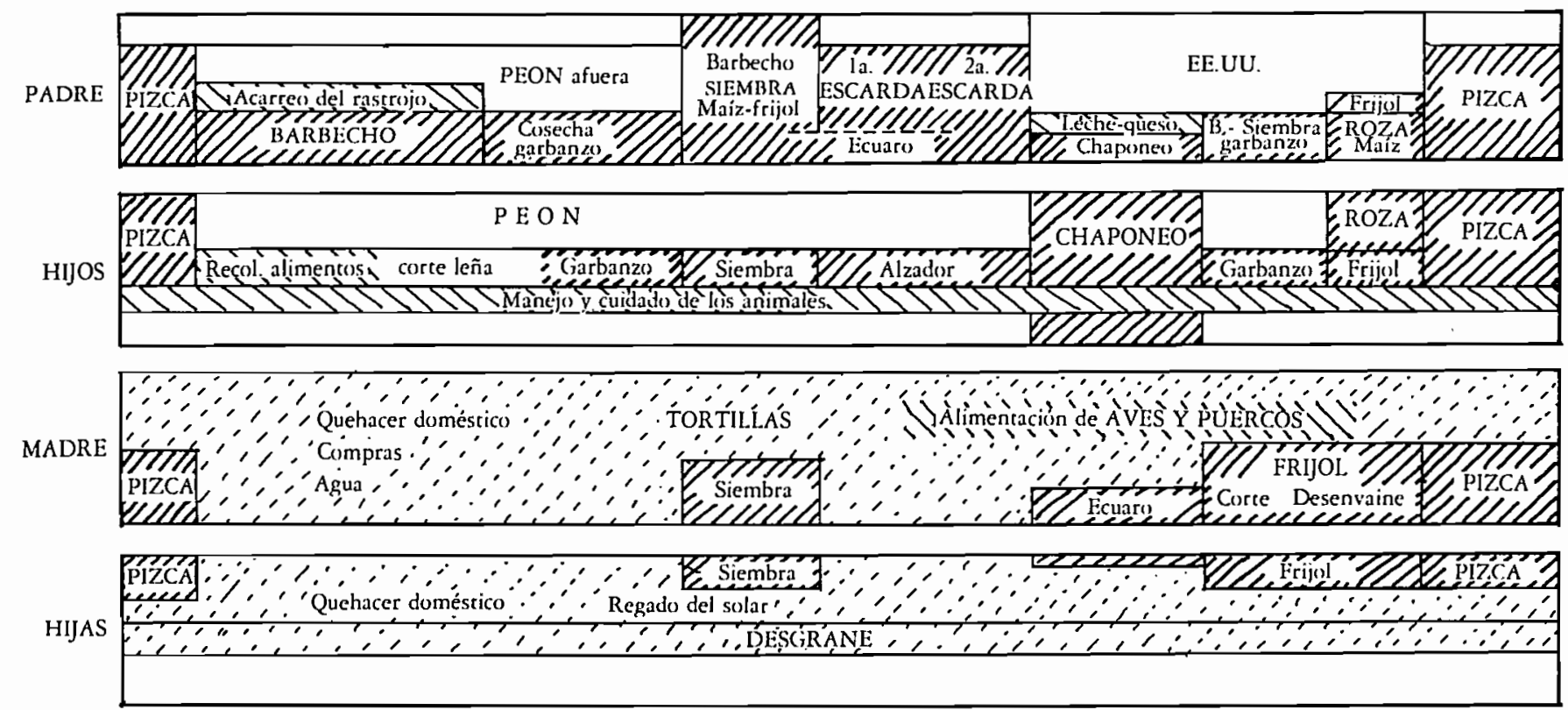

F $\quad$ M

ป

A $\quad \mathrm{M}$

A

$S$

O

N

D

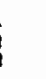

EZd Trabajos AGRICOLAS

DVGanaderos

E⿺辶DOMESTICOS

$\square_{\text {ocupaciones }}^{\text {Otras }}$ 
siembran el garbanzo.

Así se ve que la emigración está organizada en torno al mantenimiento del mejor cuidado de los cultivos básicos, y que todo el proceso agropecuario en este contexto no podría funcionar sin una participación bien definida de todos los miembros de la familia en determinados momentos del año. Los aguanuatenses han logrado así una organización del trabajo que, dejando tres meses libres para los jefes de familia en la época de cosechas en California, integra la emigración estacional como una constante estructural y permite un aprovechamiento maximal de los ingresos atractivos del trabajo en Estados Unidos. Esta organización evidencia la importancia cobrada por la emigración en la comunidad aguanuatense: los jefes de familia pueden salir a Estados Unidos, mientras que en otros lugares solamento lo hacen los jóvenes solteros.

\section{Reproducción de la fertilidad}

Aguanuato es un buen ejemplo para destacar el tipo de lógica que puede asistir en la combinación de sistema de cultivo y sistemas de ganado. Muchas veces, uno de los objetivos de esta combinación es el poder alcanzar un nive! suficiente de fertilidad en las tierras sembradas por un mecanismo de concentración de la materia orgánica producida en bosques y agostaderos. La gráfica 15 resume las relaciones que existen entre los recursos del terruño y las producciones, tanto a nivel de la unidad de producción familiar como al del terruño.

\section{GrafiCA № 15}

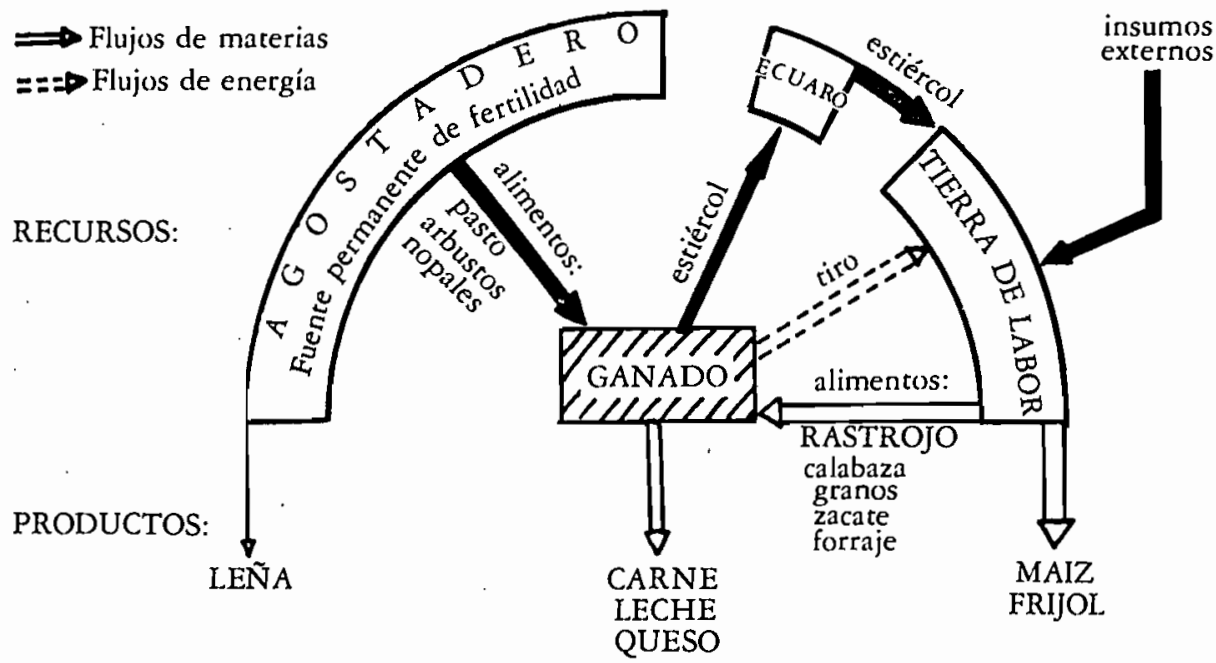


Dentro de estas relaciones cabe señalar el papel muy importante que juegan los "ecuaros" y los "corrales": son los lugares privilegiados de la relación entre ganadería y agricultura, ya que ahí les dan de comer el rastrojo a los animales, y también de ahí sacan el estiércol que se esparce sobre la tierra. Esto permite a la vez que los ecuaros se beneficien de mucha materia orgánica, lo que repercute en una alta productividad del maíz (que viene en la estación de posible escasez de grano, antes de la cosecha del maíz). Esta relación no existiría sin los medios de transporte que son los burros, los cuales juegan en el acarreo del estiércol un papel tan importante como el de transportar las cosechas. Así resulta que la ganaderia en Aguanuato no se debe contemplar únicamente como producción extensiva de animales de abasto, sino también como reproducción de los medios de trabajo agropecuario del lugar: bueyes, burros y caballos, cuya población rebasa la de vacas y becerros.

Además esta ganadería está sumamente adaptada a las condiciones de producción forrajera del lugar en cuanto al clima: 6 meses de alimentación con rastrojo no sirven para la producción de leche o la engorda intensiva. En cambio, sí conviene para mantener a los animales en condiciones de trabajo. Esta fuerte dependencia del ganado frente al maíz explica, en parte, que este no se encuentre en decadencia; pese a los ingresos obtenido en Estados Unidos se le proporciona el mismo cuidado que 40 años atrás. Así el cultivo del maíz se beneficia con el desarrollo de la ganadería al máximo. El mantenimiento de la producción maicera se relaciona también con el desarrollo de la producción porcícola: calculamos que en los sistemas vigentes en Aguanuato (por ejemplo la venta de lechones) la gente puede ganar un promedio de $\$ 7,000$ a 10,000 , por encima del precio de garantía que es de $\$ 19,200$, por tonelada de maíz utilizada para las marranas a fines de 1983. Y por la menor inversión que se requiere en este tipo de ganadería, casi todos los campesinos la pueden practicar en Aguanuato.

Ingresos. Papel económico de cada actividad en los sistemas de producción

Calculamos en base a los datos obtenidos de la encuesta, el promedio cuantitativo de los factores que participan en un sistema de producción individual de Aguanato (véase gráfica 16).

1.5 toneladas de maíz y 1 tonelada de frijol (las 3 hectáreas asociadas) corresponde aproximadamente a las necesidades de una familia de ocho personas. El trigo sirve a veces para hacer pan, los frutales y aves, y parte de la leche y del queso también sirven para alimentar a la familia.

Los productos sobrantes, entre ellos parte del maíz, sirven para pagar los créditos y obtener ingresos monetarios. Sigue un cálculo de ingresos 
GRAFICA NQ 16: 5 HECTARI:AS IJE L.ABOR BAJO VARIOS TIPOS DE TENENCIA (OJO: NO HAY ROTACIONES,

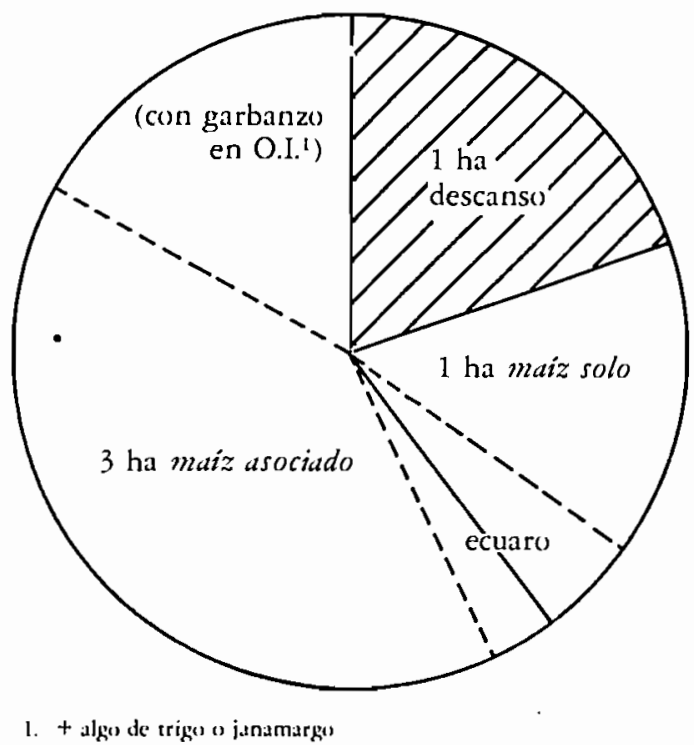

- 3 vacas + becerros

- 1 ó 2 marranas para lechones

- 5 a 10 gallinas o guajolotes

- 1 buey, 1 caballo, 1 ó 2 burros

- algunos frutales

(cuadro 18) que es sólo un promedio a grandes rasgos, puesto que hay mucha incertidumbre sobre algunos precios y sobre las cantidades vendidas principalmente en lo relativo a la ganadería, ya que además la situación cambia mucho de una familia a otra.

Se nota la importancia de la ganadería en las fuentes de ingresos monetarios, aunque esto es muy variable acerca de los bovinos. Cuando los campesinos traen dinero, de Estados Unidos por ejemplo, lo aprovechan a veces para comprar ganado ${ }^{8}$ que venderán cuando haya escasez de dinero. Así, el ganado juega un papel de "fondo de reserva",9 sobre todo para los ganaderos menores. En esto, los ingresos de la emigración, cuyo importe casi iguala en promedio los ingresos monetarios de las actividades agropecuarias, son los que permiten iniciar la inversión en la ganadería.

En fin de cuentas, los ingresos monetarios que se obtienen del cultivo del maíz son muy bajos; resulta que el garbanzo constituye a veces una parte apreciable de los ingresos provenientes de la agricultura, y los problemas que afectan a este cultivo tienen fuertes repercusiones sobre el ingreso

8. En la mayoría de los casos, este dinero les sirve para mantenerse, o posiblemente mejorar la vivienda; algunas veces para comprar vehículos.

9. Ver Thierry A. Linck, "Estrategias campesinas y agropolítica: un caso en la Meseta Tarasca" en Relaciones. No. 9, El Colegio de Michoacán, invierno 1981-1982, Zamora, Mich., Pp. 49-96. 


\section{CuAdro № 18}

\section{INGRESOS MONETARIOS DE UNA FAMILIA PROMEDIO DE AGUANUATO (7 PERSONAS)}

\begin{tabular}{|c|c|c|c|}
\hline Productos & Cantidad anual & Importe en dic. 1983 & $\%$ Ingreso \\
\hline Maiz ( 4 ha a 1.2 tonelada/ha) & $\begin{array}{l}5 \text { ton. menos el autoconsumo } \\
(2 \text { ton. fam. }+ \\
2 \text { ton. animales })=1 \text { ton. }\end{array}$ & $\$ 19,000$ (precio de garantía) & \\
\hline Garbanzo ( 1 ha a 0.4 ton/ha) & 0.4 ton. & $\begin{array}{l}\$ 6,000 \\
\text { Total Agricultura: } 25,000\end{array}$ & $19 \%$ \\
\hline $\begin{array}{l}\text { Puercos (2 marranas, } 1 \text { vendida } \\
\text { cada } 2 \text { años) }\end{array}$ & $\begin{array}{l}20 \text { lechones a } \$ 1,500 \mathrm{c} / \mathrm{u} \\
100 \mathrm{~kg} \text {. carne }\end{array}$ & $\begin{array}{l}\$ 30,000 \\
\$ 10,000 \\
\text { Total Porcicultura: } 40,000\end{array}$ & $31 \%$ \\
\hline $\begin{array}{l}\text { Bovinos ( } 3 \text { vacas, } c / u \text { tiene } \\
1 \text { becerro cada } 2 \text { años) }\end{array}$ & $\begin{array}{l}1 / 2 \text { vaca o buey de desecho } \\
1.5 \text { novillo de } 2.5 \text { años }\end{array}$ & $\begin{array}{l}\$ 15,000 \\
\$ 45,000 \\
\text { Total Bovinos: } 60,000\end{array}$ & $46 \%$ \\
\hline Leña & 20 cargas de 50 palos a $\$ 250 /$ carga & $\begin{array}{l}\$ 5,000 \\
\text { Total Diversos: } 5,000\end{array}$ & $4 \%$ \\
\hline
\end{tabular}

Pongamos que una persona de la familia pasó 3 meses en Estados Unidos; puede traer, en promedio, 300 dólares por mes de permanencia, menos el pasaje; es decir 550 dólares de ingreso neto para la temporada (calculado según informes de campo de Humberto González, El Colegio de Michoacán; encuesta en Estados Unidos, 1983).

Un jornalero agrícola de Aguanato que trabaja 90 días completos en el año gana $90 \times 350=31,500$ pesos al año en 1983: apenas para 2 personas en las mismas condiciones, puesto que no tiene siempre reservas de grano. 
monetario de los agricultores.

Por último, se observa que el agricultor promedio de Aguanuato tiene un ingreso monetario apenas comparable con los sueldos más bajos pagados en las ciudades. La comida les cuesta mucho menos, pero en cambio tienen gastos adicionales como los ocasionados por los múltiples viajes a Paníndicuaro que realizan ante cualquier necesidad. Todo esto evidencia lo difícil que resulta mantener a una familia numerosa y la realidad de las presiones para la emigración. Los ingresos que se sacan de ésta son muy variables, y en algunos casos mucho más elevados que lo descrito en el cuadro 18. Sin embargo, los problemas inherentes al trabajo en Estados Unidos hacen que, en promedio, estos ingresos sean muy aleatorios; por eso las actividades agropecuarias se mantienen y la emigración todavía no es un factor importante de desagregación de la comunidad.

\section{Diferenciación socio-económica.}

El censo agropecuario, al proporcionarnos una imagen actual de las modalidades de acceso a los recursos, resulta útil para precisar los factores de diferenciación y cuantificar las consecuencias de los procesos que acabamos de describir. Se pueden oponer dos rasgos principales:

a) Una escasa concentración de las tierras de labor en el ejido.

El número de hectáreas agrupa todas las formas de tenencia qe pueden existir a la vez en la superficie trabajada por un campesino con su familia: - parcelas ejidales de dotación (tamaño variable debido a las características del reparto);

-parcelas ejidales trabajadas como "allegado" (derecho ejidal interno a la comunidad);

- parcelas ejidales o de propiedad privada trabajadas a medias para migrantes o ejidatarios que no pueden trabajar solos su tierra. Aquí, las relaciones familiares entre mediero y arrendador son frecuentes; - parcelas en propiedad privada, a veces compradas poco a poco, con extensiones muy variables;

-parcelas recibidas en empeño de alguna deuda (son escasas porque el ejido pone una vigilancia estrecha).

b) ...pero un acceso desigual a los recursos comunitarios.

La repartición desigual de las tierras de labor sólo constituye un reflejo parcial del derecho real de cada ejidatario sobre el espacio. Las dos terceras partes del territorio ejidal $(2,065 \mathrm{Ha}$.) las constituyen agostaderos no parcelados, aprovechados en forma colectiva. En este contexto, la ausencia de reglamentación del crecimiento de los hatos individuales y de administración colectiva del agostadero fomenta el sobrepastoreo y privilegia a los 
GRAFICA NQ 17: LA GRAFICA ABARCA UNAS 700 HAS. EJIDALES Y I.OS PEDAZOS DE PROPIEDAD PRIVADA, PERO NO L.AS PEQUEÑAS PROPIEDADES "IMPORTANTES" DEL I.UGAR, QUE PUEDEN INCLUIR HASTA 50 HAS. DE TIERRA DE I.ABOR

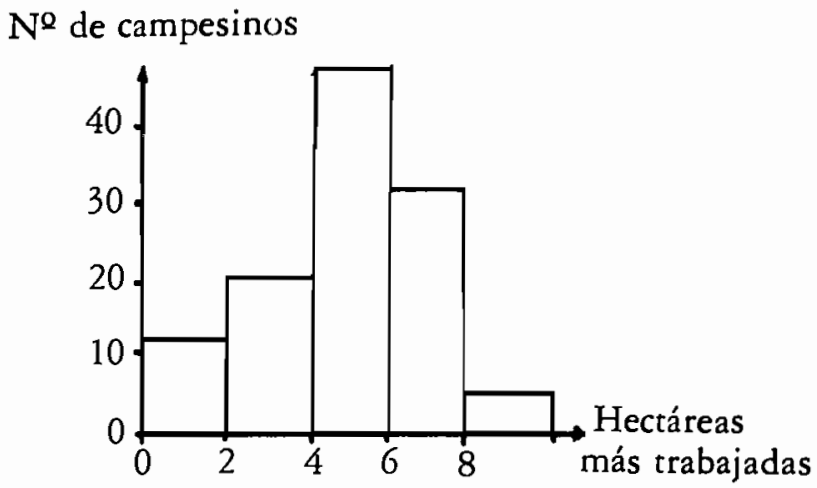

propietarios de hatos grandes. Simultáneamente, esa situación con la erosión y la competencia entre los animales, incrementa el carácter aleatorio de la ganadería y por ende, favorece a los "grandes" ganaderos mejor armados para resistir los periodos de crisis.

Las gráficas 18 y 19 nos proporcionan una imagen de la repartición de los agostaderos entre los ejidatarios. Pudieron elaborarse gracias al conocimiento de la repartición del ganado mayor.

En ausencia de fuerte concentración de las ierras de labor, el conocimiento de la repartición de los recursos de uso comunitario entre los ejidatarios resulta de primera importancia. De hecho, la existencia de una distribución sumamente desigual del ganado evidencia la repartición polarizada de los agostaderos y permite definir la ganadería como el vector fundamental de diferenciación entre los ejidatarios, y como la actividad que jerarquiza el sistema social de producción.

Un análisis más detallado de los datos del censo permite evidenciar cierta correlación entre diferenciación ganadera y concentración de las tierras de labor: de hecho, el $53 \%$ (gráfica 19) de la población ejidal desprovista de derechos efectivos sobre los agostaderos lo constituyen medieros y ejidatarios menos dotados con tierra, que son la mayoría de los que no tienen animales. En cambio, los ganaderos con más de 10 vacas cultivan cada uno 7 hectáreas, dos más que el promedio de los ejidatarios, lo que refleja en parte la ventaja en la ganadería de los que tienen acceso a mayores cantidades de rastrojo.

Pero la diferencia se fundamenta en algo más que una simple desigualdad cuantitativa: se trata de la existencia de relaciones productivas 
Grafica No 18: Reparticion del numero de vacas entre los Aguanuatenses, QUE REFIEJA I.A DISTRIBUCION DEI. AGOSTADERO EJIDAI.

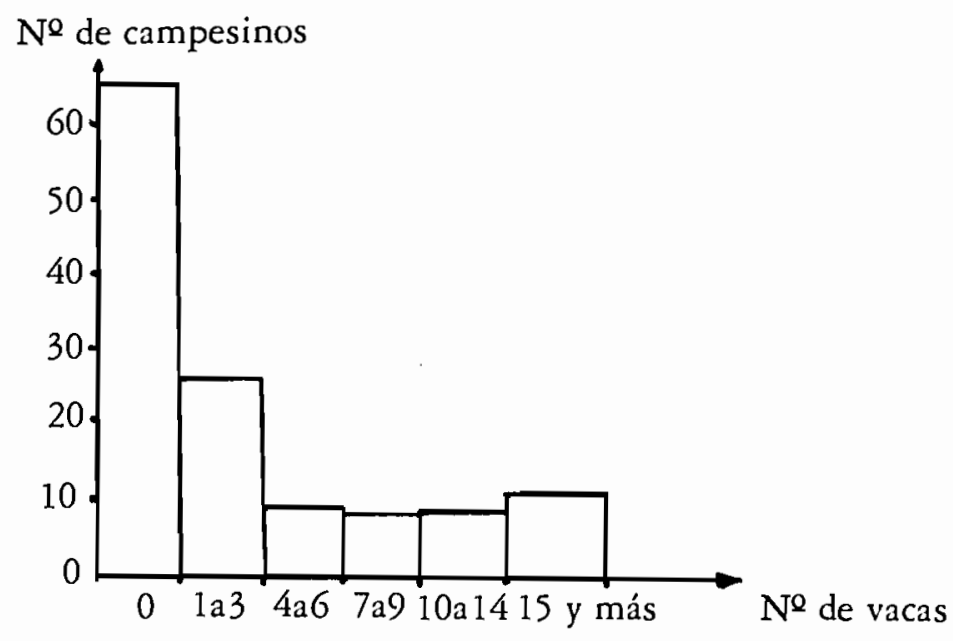

GRAFICA No 19: R R:PARTICION ACUMUI.ADA DEI. GANADO MAYOR Y DI:L. APROVECHAMIINTTO DEL AGOSTADERO EJIIDAI. (AQUI NO SI TOMAN INN CUENTA I.OS RIEBAÑOS GRANI)ES DI: IOS PROPIETARIOS DI: PASTIZALIES)

$\%$ del ganado y del agostadero

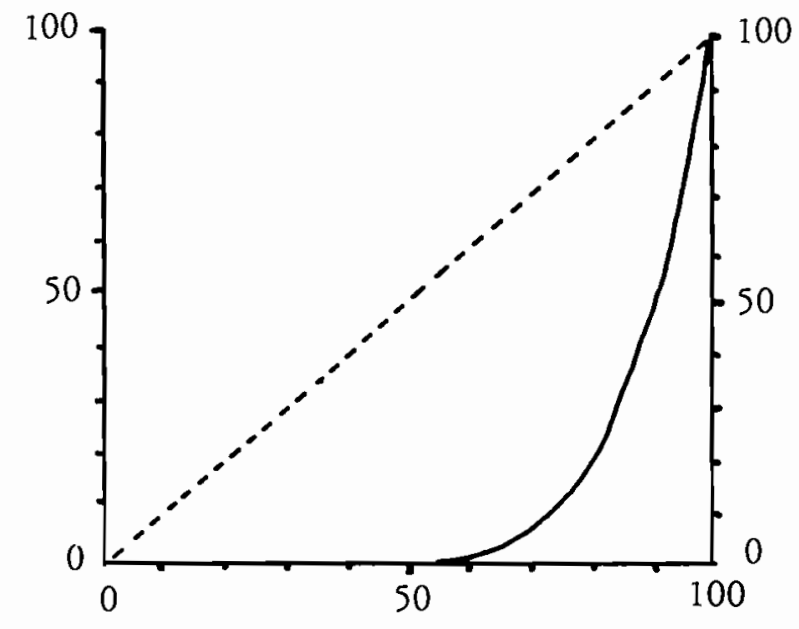

$\%$ de los campesinos de Aguanuato 
asimétricas, generada por la repartición desigual de los medios de trabajo como consecuencia de la acumulación ganadera; el factor más costoso, que es la tracción animal, lo detentan unas 15 familias ganaderas que rentan bueyes o yuntas enteras ${ }^{10}$ a unas 30 ó 40 que no tienen bestias, aparte de los medieros que trabajan con la yunta del dueño. Cobran de 12 a 14 anegas ${ }^{11}$ de maíz (1983) por ciclo de cultivo, según este empiece en octubre o en diciembre, y hasta agosto, pero además el mantenimiento de los bueyes con rastrojo y grano de maíz en la estación seca está a cargo del arrendatario durante los cuatro o cinco meses en los cuales ocupa los animales. Por este mecanismo, disponen los ganaderos de una superficie forrajera cultivada que rebasa los límites de su propia tierra de labor.

En este proceso de concentración de los medios de producción se nota el papel de los ingresos monetarios en la acumulación diferencial: los comerciantes y albañiles son algunos de los ganaderos más importantes. Las mismas familias son de las que tienen arriba de 2 caballos ó 3 burros, además de algunos bueyes para rentar. Muchas veces el peso económico de estas familias les confiere mucha influencia en la vida política del pueblo.

Quienes trabajan de jornaleros son por lo regular los que sacan de su parcela, si es que tienen, ingresos demasiado pequeños siendo así los más propensos a la emigración definitiva. Sin embargo, a la desigualdad social se opone el hecho de que las diversas generaciones tienen una posición diferente en la tenencia de la tierra: la encuesta señala que los ejidatarios tienen en promedio 52 años, mientras los medieros sólo 41; los jefes de familia de menos de 35 años casi siempre son medieros o jornaleros. Así se destaca que el acceso a los recursos del ejido depende también de una división del trabajo por edades a nivel de la comunidad; los jóvenes casados tienen a menudo que emplearse como jornaleros o medieros - a veces de su propio padre - y sólo obtienen el usufructo de las parcelas y de los animales de trabajo a una edad ya avanzada.

\section{Tipología de los productores}

Acabamos de evidenciar los rasgos de lo que sería la "estrategia dominante" de los campesinos de Aguanuato.

Pero los procesos de evolución no se entienden sin recurrir a las estrategias de grupos que aunque muy poco numerosos, son "claves" en la acumulación diferencial. A continuación describimos los principales tipos

10. Sin embargo los bueyes se prestan mucho entre familiares para periodos cortos. Además los animales no son necesarios en todas las parcelas: los "ecuaros" para producción de elote se cultivan a mano, con azadón.

11. 1 anega $=100$ litros $=70$ a $80 \mathrm{Kg}$. 
de sistemas registrados con la racionalidad socio-económica que los caracteriza.

Pequeños propietarios-ejidatarios

A pesar de ser ejidatarios, su sistema de producción se fundamenta mucho más en las propiedades compradas o heredadas al lado del ejido. A veces tienen dotaciones en varios ejidos. Las tierras que trabajan pueden rebasar las 40650 hectáreas de labor, contando las parcelas en las cuales dan un "servicio" de barbecho con tractor y otras que toman en el ejido pagando una renta. Tienen ganado mayor en cantidades superiores a 30 ó 60 cabezas, parte de las cuales se rentan a campesinos de Aguanuato como yuntas. Estos animales se mantienen en el agostadero ejidal. Estos propietarios casi siempre lograron adueñarse de jagüeyes, bordos y tierras que quizá pueden ser regadas en invierno con estas presas. Son los único que por lo tanto siguen con trigo de invierno en sus sistemas de cultivo.

En estos sistemas lo que se busca es una máxima remuneración del capital invertido, en especial la maquinaria. Por lo tanto estos agricultores tienden a:

-incrementar al máximo la superficie trabajada (usando sembradoras) -incrementar al máximo el ganado mantenido, con la limitante de la capacidad del agostadero ejidal, contratando vaqueros si hace falta.

Aquí las cosechas de maíz son para vender y el trabajo requiere una mínima cantidad de mano de obra. Por lo tanto es más remunerador aplicarle un "paquete tecnológico", sobre todo cuando los riesgos están muy atenuados por la posibilidad de usar riego de auxilio. En la práctica, estos productos son los únicos que responden al modelo de divulgación del estado (detallado a continuación).

Ejidatarios con más de 5 hectáreas

El límite de 5 hectáreas corresponde:

-a la superficie que puede ser trabajada con una yunta;

-a la obtención de excedentes significativos de maíz en comparación con las necesidades de autoabastecimiento de una familia (estimadas en $2,500 \mathrm{~kg}$./año en promedio).

Estos ejidatarios están en posición de acumular medios de producción aunque en pequeñas cantidades. La mayoría tiene arriba de 5 cabezas de ganado mayor, y todos han participado en la adquisición de tractores ( 2 x 14 socios). Con esto es muy frecuente el cultivo de 3 ó 4 hectáreas en renta además de la dotación ejidal. Estos agricultores prestan yuntas de trabajo, sobre todo dentro de una red familiar.

La estrategia de estos productores sería, una vez cumplidas las necesidades de autoabastecimiento de la familia, la obtención del máximo ingreso por unidad de superficie; en la práctica sólo el cultivo del maíz puede 
responder a este objetivo, dada la ausencia de riego para cultivos de invierno. Actualmente el precio garantizado por la CONASUPO no está vigente en el pueblo por las cantidades tan pequeñas que se entregan. Los agricultores tienen que llevar su cosecha hasta las bodegas distantes unos 15 $\mathrm{Km}$. donde se les hacen descuentos por calidad irregular y exceso de humedad. El precio puede bajar así hasta un $20 \%$, lo que hace más redituable el venderlo a acaparadores de Panindícuaro o Zacapu pues ya no hay que transportarlo. Además, los créditos de avío se tienen que pagar antes de marzo, lo que les impide guardar los excedentes hasta que suba el precio (primavera-verano).

Con todo esto, son muy variables las condiciones de logro del máximo ingreso neto por hectárea. En muchos casos el campesino ganará más en promedio con el mínimo uso de insumos y rendimientos bajos, dados los riesgos climáticos. En otros, tendrá interés en conservar un cultivo asociado de maíz con frijol por lo que no es suficiente la cosecha de frijol para abastecer al pueblo: los que saquen excedentes los pueden vender en el verano a un precio muy superior a los $\$ 25 \mathrm{el} \mathrm{kg}$. pagados durante la estación de cosecha - noviembre de 1983 - en el mercado regional.

Varios de estos ejidatarios tienen otro recurso: la producción lechera para queso, que se lleva a cabo en las unidades de producción que disponen de algunos predios de humedad en los cuales se dan pasturas de raíces profundas (janamargo) durante el invierno: así se alcanzan lactancias de 5 ó 6 meses, bastante redituable como para aprovechar una pequeña producción de queso tradicional. Las posibilidades de acumulación quedan, sin embargo, muy reducidas porque parte del ingreso se tiene que ocupar para pagar a los cosechadores de maíz.

Ejidatarios con menos de 5 hectáreas

Cuando tienen ganado, no es más que una yunta de bueyes. Ellos no están en condiciones de poder tener otra estrategia que la de abastecer a su familia con cosechas reducidas en promedio pero muy seguras: asociación de cultivos en parcelas repartidas en todo el territorio, baja densidad de siembra y uso exclusivo de variedades criollas.

En este tipo de sistema de producción ha habido posibilidades de acumulación; pero muchas veces después de la primera inversión para ir a Estados Unidos, esta práctica se ha vuelto constante para traer los ingresos monetarios, al contrario de lo que pasa con los ejidatarios más dotados. Aquí los ingresos del jornal en el "otro lado" se ocupan exclusivamente para las necesidades monetarias de la familia: no se ocupan en la inversión de ganado y sirven básicamente para mantenerse arriba de las mínimas necesidades de reproducción del sistema. La única inversión frecuente se da con pequeños rebaños de cabras para vender cabritos 2 veces al año, a un precio muy desventajoso por la presencia en Purépero de un ganadero que tiene 1,500 
cabezas.

Medieros

A veces tienen una o dos hectáreas en propiedad privada pero ninguna dotación ejidal. Tienen una racionalidad socio-económica muy parecida a la precedente excepto que con posibilidades de acumulación aún más bajas. Cuando hay aparcería el usufructuario de la parcela no tiene interés en poner fertilizante y otros insumos químicos. Menos todavía lo tendrá el mediero con ingresos monetarios muy reducidos y una máxima necesidad de asegurar la cosecha; constituyen un grupo muy numeroso de campesinos que no pueden usar ni una parte de los paquetes tecnológicos propuestos. Además nunca alcanzan el nivel de acumulación necesario para salir a Estados Unidos, y se deben contentar con trabajo de peones en los valles de riego de la comarca (cosecha de la fresa en Panindícuaro en los meses de invierno).

Jornaleros

Estos ya no son muy numerosos en Aguanuato: básicamente se empleaban en la pizca del maíz de noviembre a febrero y en el resto del año se contrataban en los valles de riego. Con la disminución de las exigencias del maíz en mano de obra, muchos ya no tienen por qué quedarse en Aguanuato; algunos siguen recolectando leña para venderla en Panindícuaro - si tienen un burro el ejido no les cobra - pero por la difusión de las estufas de gas se vuelve difícil este negocio.

Así se evidencia en la comarca una extrema concentración de los recursos y concretamente una imposibilidad de acumular capital en las unidades de producción con otros ingresos que los de la ganadería. Esto ubica a los pequeños propietarios como los únicos susceptibles de incrementar su productividad en el cultivo de granos básicos. A continuación se detallan los mecanismos que siguen vigentes en la diferenciación, y los resultados de la intervención del estado en tal contexto.

\section{MAIZ Y GANADO PARA LA PEQUEÑA PROPIEDAD}

\section{Especialización del terruño y factores de evolución}

Hemos observado una división espacial del trabajo y de la producción en el seno de la micro-región a la cual pertenece Aguanuato, a lo largo de los últimos cuarenta años. Pero a escala más detallada, dentro del terruño de Aguanuato, se están dando cambios en la localización de las actividades que reflejan la evolución diferenciada de los sistemas de producción individuales:

Primero, en el campo aguanuatense se ven parcelas de labor abandona- 
das desde hace 6 y 7 años o más. Muchas veces se ubican en lugares desmontados por los "allegados" en los años cuarentas donde los suelos son más delgados y donde el rendimiento está bajando más rápidamente. Son también las parcelas que se dan a medias, por el interés que tiene el dueño en arrendar los terrenos que rinden menos.

Estos campesinos -allegados, medieros-, que muchas veces no tienen ganado, son los que más tienden a emigrar de manera definitiva. Así, en lugares donde las parcelas eran esparcidas, se liberan zonas de agostadero donde los ganaderos más importantes del ejido pueden fomentar potreros grandes de acuerdo con las autoridades locales, con cercas rehabilitadas y agua en la temporada de lluvias. En estos potreros pueden hacer rotaciones para mejorar la regeneración del pasto, poniendo a veces un año de cultivo de maíz cada cinco o seis años; estas prácticas no corresponden a la sobrevivencia de algún sistema de cultivo arcaico, sino que podemos ver en ellas una adaptación poco costosa a las exigencias impuestas por la reconstitución de suelos delgados, poco aptos a los cultivos anuales de un sistema de producción en el cual se da una especialización y tecnificación ganadera hacia la producción de carne (con un retroceso de los animales de tiro, como lo evidencia la introducción de sangre cebú). Esta especialización territorial de la ganadería tiene un impacto sobre la producción de maíz, que tiende a concentrarse en los terrenos más profundos y menos pedregosos, que se pueden barbechar con tractor. Así, la evolución del aprovechamiento del terruño está orientada por los ganaderos de mayor importancia, que en muchos casos son ejidatarios o pequeños propietarios que cultivan con tractor superficies apreciables de maíz.

\section{Tractorización}

Muchos pequeños propietarios de la región ya tienen su tractor desde varios años atrás en el ejido apenas estan empezando: en 1953 dos grupos de 14 ejidatarios compraron cada uno un tractor con crédito sobre 8 años y cada grupo tiene que devolver $\$ 300,000$ al año a partir de 1985 . Al principio hubo una oposición fuerte en el pueblo, incluyendo a las autoridades, supuestamente por el riesgo que implicaba la magnitud de la inversión y porque unos no iban a poder utilizar los tractores en sus malas parcelas. El poder político de los tractoristas fue más fuerte.

Esto demuestra que las diferenciaciones existentes entre los ejidatarios pesan mucho sobre la difusión de este tipo de cambio tecnológico. Gran parte de los miembros de los grupos de trabajo constituidos son albañiles, comerciantes o "grandes ganaderos" (más de 10 vacas) y barbechan 7 hectáreas cada uno en promedio. Se observa que pueden disponer más fácilmente de los recursos necesarios para cubrir el importe de la cuota anual 
para pago del crédito de los tractores que es de $\$ 2,500$ por hectárea cada uno, cuando el banco sólo financia $\$ 1,500$; pueden vender algunos animales, rentar los bueyes de tiro que ya no necesitan y aumentar la rentabilidad de sus tractores al arrendar la maquinaria a los demás ejidatarios cobrando $\$ 2,500 /$ ha.

Por otro lado, no es cierto que el uso de un tractor cueste más que la renta de una yunta y por eso se puede augurar una difusión rápida: todos invocan las ventajas del ahorro de trabajo - y no de un hipotético mejoramiento del cultivo- que permite el uso del tractor en una producción poco remunerativa: en vez de mes y medio de trabajo efectivo, el tractor solamente ocupa cuatro a cinco días para barbechar y sembrar cuatro hectáreas.

\section{CUADRO No 19}

\section{COSTO COMP ARADO POR 4 HECTAREAS}

(lo que una yunta de bueyes puede trabajar anualmente) EN 1983-84:

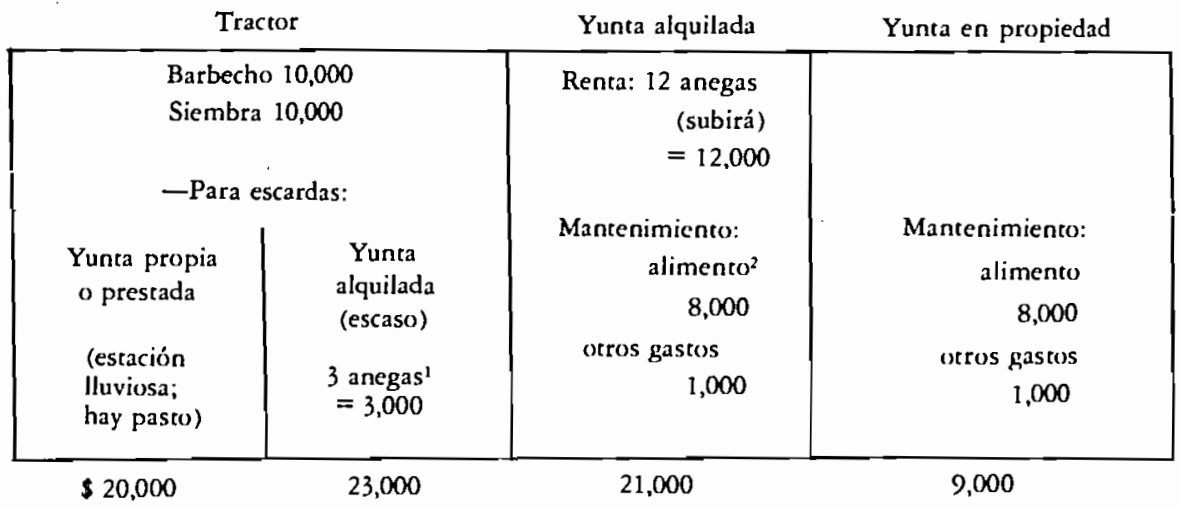

1. 1 anega de maíz de $70 \mathrm{Kg}$. a $\$ 15.00=1,000$ pesos (precio de venta a acaparadores).

2. Simplificando: 6 meses secos a $3 \mathrm{~kg}$. de grano diarios $=180 \times 3 \times 15=\$ 8,000$. Rastrojo y pasto se consideran graruitos.

Si el campesino puede vender el maíz consumido por su propia yunta, casi le resulta más rentable barbechar con tractor; y el que tiene yunta propia gana más rentándola $(\$ 21,000)$ y barbechando con tractor. Por eso los migrantes cuasi-permanentes prefieren mandar arar sus tierras con maquinaria, así gastan menos que con un mediero.

Así tenemos que desde un punto de vista financiero, los subsidios importantes, expresados en las tasas de crédito refaccionario, que se dan para apoyar una introducción rápida de los tractores en las zonas de temporal, logran poner al mismo nivel los costos de la tracción animal y mecánica.

La dinámica consecuente de los sistemas de producción se puede deducir ahora mismo sin mayores problemas. El uso de tractores y, luego, de 
sembradoras, permite reducir considerablemente el tiempo dedicado a la siembra y disminuir sus riesgos ${ }^{12}$ así como sus costos en trabajo. ${ }^{13}$

En cambio, el uso de la sembradora mecánica puede afectar el cultivo de frijol intercalado. Con la desaparición del frijol, la aleatoriedad de los cultivos se incrementó: cuando sembraba maíz con frijol en varias parcelas, el campesino repartía los riesgos y tenía la seguridad de compensar las pérdidas sufridas por un cultivo en un lugar dado por una producción mayor del otro.

El uso de tractores, como factor de desempleo muy específico, modifica también la organización del trabajo en la colectividad y las relaciones de cooperación:

-Quita trabajo a varios miembros de las familias (siembra, mantenimiento de los bueyes);

-Quita trabajo indirectamente a los artesanos y pequeños empresarios que fabrican herramientas para la tracción animal;

- Aumenta mucho el número de hectáreas que puede trabajar un solo hombre, por eso se sustituye al trabajo de los medieros, que antes eran indispensables para todos los que tenían más de 6 y 7 hectáreas, y para los migrantes.

En muchos casos, estos medieros no tienen otra alternativa que la emigración, y es probable que a largo plazo la disminución consecutiva de la población de Aguanuato repercuta sobre el número de peones disponibles para la pizca, hasta que se mecanicen también las cosechas.

La introducción sistemática de los tractores trae también otro tipo de consecuencias a largo plazo: ${ }^{14}$

-Erosión más fuerte cuando se barbecha con tractor y arado de disco ya que el suelo se seca más rápida mente y el viento se lleva los elementos delgados, que condicionan la fertilidad del suelo.

- Concentración en pocos días del esfuerzo de producción energética para labrar la tierra: cuando los bueyes trabajan durante seis meses del año, (procurando así barbechar una superficie anual máxima de 4 a 5 Has. por yunta (véase cuadro 17). ${ }^{15}$

12. Facilita la resiembra en caso de atraso en el calendario de lluvias. Esto explica la motivación fuerte de todos los campesinos de Aguanuato para trabajar con tractor (aunque sea rentado) y la fuerza política de los tractoristas en el pueblo.

13. Lo que, en una situación de subempleo crónico, no constituye una prioridad.

14. Ver Thierry A. Linck, Le paysan depossedé... op. cit.

15. Ahí tenemos un ejemplo de "sinergia" en el sistema de producción: las temporadas de descanso de las yuntas corresponden a las de mayor pasto disponible en los agostaderos. Al contrario, solamente les quedan las reservas en las estaciones de trabajo, precisamente cuando es más oportuno darles una alimentación concentrada y almacenada por el corto tiempo diario disponible. 
-Mayor dependencia frente a la compra de insumos: fuente energética concentrada (diesel) y ajena a la región; maquinaria, implementos y tecnología importados; fertilizantes, herbicidas e insecticidas.

Esta dependencia implica un riesgo por la dificultad, en regiones temporaleras, de conseguir aumentos de productividad suficientes para pagar, año tras año, los nuevos costos con maíz que no cesa de devaluarse frente a esas mercancías.

Continuando con perspectivas a largo plazo, la especialización territorial y la motorización pueden afectar poco a poco un elemento importante de la coherencia interna del sistema social de producción: se trata de los traslados de fertilidad que se llevan a cabo mediante el uso de los excrementos animales: en unidades de producción de tamaño mediano - por ejemplo, 30 reses con agostadero ejidal y 15 hectáreas de labor-, una mano de obra reducida difícilmente podrá asumir el esfuerzo de acarrear todo el estiércol hacia las parcelas cultivadas; en la actualidad ya existen ejidatarios que han dejado de hacerlo, y la tierra de labor sólo se sigue abonando durante el pastoreo del zacate. Por otro lado, no se puede ni pensar ahí en el aprovechamiento de tractores, expansores y remolques individuales como solución al problema, que de todos modos no resolvería la recolección de estiércol esparcido en los agostaderos.

Aunque no se manifiesten los efectos, esta tendencia pone en peligro el mantenimiento de la fertilidad de los suelos, ya bastante afectada por los procesos de erosión: un suelo que recibe mucho fertilizante químico, pero poca materia orgánica, tiene una estructura menos estable que aumenta su sensibilidad a los deslaves, a la asfixia en caso de lluvias demasiado fuertes, y a la erosión por el viento. En la actualidad, los animales siguen aprovechándose como transformadores y transportadores de energía y nutrientes: trasladan la fertilidad natural de los pastizales hacia ecuaros o solares, y luego a las parcelas de labor. Con el probable retroceso de la fertilización orgánica, esa fuente de fertilidad tendrá que ser sustituida por otras, pero con desventajas, dado que ninguna combinación de fertilizantes industriales tiene la calidad de los abonos orgánicos.

Reproducción de los sistemas y concentración de los recursos: una visión prospectiva

Podemos tratar ahora de dar una visión a largo plazo del impacto de la mecanización y de los principales cambios actuales sobre la estructura social de la comunidad.

Por una parte podemos observar una relación desigual entre los poseedores de tractor o yuntas y los arrendatarios, que coloca a aquéllos en condición de orientar como más les conviene la evolución del sistema social 
de producción. La imposibilidad de alquilar esos implementos en otras partes pesa directamente sobre el nivel del alquiler. Esto se comprobó en 1983: augurando una buena cosecha, los dueños subieron la renta de yuntas de 12 a 15 anegas para 1984 (renta de situación). El proceso marginaliza a los beneficiarios de parcelas pedregosas o de fuerte pendiente que no pueden usar tractores y que se verán inducidos a abandonar la agricultura.

Como se vió anteriormente, la ganadería extensiva en terrenos comunitarios favorece a los dueños de hatos grandes: no cuesta más trabajo cuidar veinte o treinta cabezas que dos o tres mientras los pequeños ganaderos están en la obligación de subemplear su mano de obra en la ganadería o de pagar los servicios de un vaquero para juntar su ganado a los grandes hatos y ocuparse en actividades asalariadas.

Los mismos ganaderos y "tractoreros" - a lo más 30 productores-, ponen a los demás en una situación de competencia desfavorable: mayor productividad del trabajo agrícola (que les permite aguantar bajos precios de garantía), especialización ganadera y a veces intensificación (muelen rastrojo de maíz con tractor para complementar la alimentación, haciendo silos a los cuales se incorpora melaza, que pocos pueden comprar...).

Más significativo todavía resulta el hecho de que los propietarios de tractores, los poseedores de más tierras o animales están poco a poco controlando el uso de la tierra -o la tierra misma. Pudimos identificar los mecanismos siguientes:

-El uso del tractor permite cultivar directamente extensiones mucho mayores, con lo cual se cuestiona el derecho implícito de los medieros sobre la tierra.

-Permite a la vez competir ventajosamente en el control de las tierras de los migrantes: éstos rentan cada vez más sus parcelas a los tractoristas, en vez de pagar solamente el servicio de barbecho con tractor y tener que cuidar los demás trabajos.

-El crecimiento más seguro y rápido de los hatos permite el control de una mayor proporción de las tierras colectivas.

- Cada vez más se rentan tierras ejidales a los pequeños propietarios del área que las trabajan con maquinaria.

Esta "redistribución" de los recursos sigue en proceso. Sin embargo, sus efectos discriminatorios son ya notables. Los familiares de los pequeños propietarios y de ciertos ejidatarios tienen una mayor propensión a quedarse en el pueblo o en el área. En cambio, los migrantes se reclutan con mayor frecuencia entre los hijos de ejidatarios pobres, medieros, jornaleros y allegados, cuyo peso en la población activa tiende a disminuir.

Estos efectos tienen muy resentidos a una mayoría de productores, sobre todo frente al acaparamiento, de la tierra y sobre todo del agua por parte de pequeños propietarios. A principios del siglo, todos los predios que incluían represas o bordos fueron parcelizados y puestos a salvo del reparto 
agrario. Así, los ejidatarios fueron excluídos de todas las tierras que podían contar con riego de complemento para asegurar las cosechas o hacer un cultivo de otoño-invierno, y actualmente están en una situación de dependencia; pues gran parte de sus animales no pueden tomar agua sino en bordos privados siempre y cuando el propietario no la use para sus cultivos. Además la construcción de obras de pequeño riego solamente se puede hacer en predios privados, que estratégicamente fueron conservados por los propietarios, con lo que los ejidatarios se ven acosados para utilizar técnicas mucho más costosas: excavación y bombeo eléctrico.

Esta situación frena de manera irremediable el desarrollo agrícola de los ejidos en el área, los cuales se pueden considerar entonces como "marginados" globalmente a pesar de su diferenciación socio-económica interna.

El cambio tecnológico y el crédito: intervención del estado y "autodeterminación" campesina

Tomando en cuenta a la vez a ejidatarios y "pequeños" propietarios, se observa una evolución en primer lugar paradójica: los campesinos se hacen más escasos en lugares donde crece la producción agrícola. La introducción de tractores en Aguanuato es un buen ejemplo de la articulación entre estas dos tendencias, pero tenemos que analizar de manera más completa, en el caso de Aguanuato, la incidencia del cambio tecnológico - promovido en gran parte por el estado- sobre los procesos de evolución de la comunidad. Primero se observa que el estado interviene poco en el área, porque ésta no ofrece garantías para la rentabilidad de los proyectos; los recientes programas del SAM (Coordinación General del Plan Nacional de Zonas Deprimidas y Grupos Marginados, COPLAMAR; Programa Nacional de Granos Básicos, PRONAGRA; Riesgos Compartidos) ${ }^{16}$ nunca llegaron realmente a Aguanuato. La única excepción notable a la ausencia de crédito refaccionario fue la de los tractores, obtenidos a la fuerza, después de tres años de negativas por parte del Banco.

Crédito y uso de fertilizantes

Se nota en la región una fuerte vinculación entre el uso del crédito de avío y la aplicación de fertilizantes, inclusive desde 1978 cuando se empezó a incluir otros insumos y trabajos en las líneas de crédito; y es que una de las finalidades más importantes del crétido es ayudar a la difusión del cambio tecnológico, que en la agricultura de temporal, se traduce sobre todo en una

16. SAM: Sistema Alimentario Mexicano.

COPLAMAR: Comité de Planificación para las Zonas Deprimidas y Grupos Marginados.

PRONAGRA: Programa Nacional de Granos Básicos. 
política de aumento de la producción maicera a través del uso de fertilizante químico.

En Aguanuato no parece siempre obvia la ganancia, como lo subrayan las observaciones siguientes:

-En 1983 la Unidad de Temporal de Panindícuaro-Villa Jiménez (SARH) realizó un estudio (véase cuadro 21) sobre los costos promedios del cultivo de maíz con tracción animal y semilla criolla en el temporal del municipio vecino de Villa Jiménez (zona muy parecida al área que nos interesa). Según este estudio, los fertilizantes e insecticidas entran en un $61 \%$ en los gastos monetarios del campesino. Con tal costo, éste debía conseguir un rendimiento mínimo de $1.2 \mathrm{Ton} / \mathrm{Ha}$. sólo para cubrir los gastos; mientras que si sacaba $800 \mathrm{Kg} / \mathrm{Ha}$. sin fertilizante en las condiciones ya descritas en dicho estudio, su ganancia alcanzaba los $\$ 3,000.00 / \mathrm{Ha}$. $(\$ 9,000.00$ de costos), aun vendiendo la cosecha a un acaparador al precio de $\$ 15,000.00 /$ ton. El cálculo de los gastos reales estimados en Aguanuato (cuadro 20) llega a las mismas conclusiones.

Si uno se refiere a la experiencia de varios campesinos que no usan fertilizante, la primera conclusión es que éstos tienen tierras de baja calidad con suelos delgados, pedregosos o secos donde el abono químico no sirve. Pero parece que esta estrategia responde a una lógica económica: los campesinos que no usan fertilizante en Aguanuato son casi siempre medieros, y está comprobado que para un arrendatario que tiene que poner todo el abono, y solamente se queda con $1 / 2 \mathrm{O}^{2} / 3$ de la cosecha, la ganancia puede ser más importante con una dosis nula de fertilizante. Esta observación subraya la importancia de tomar en cuenta las formas efectivas de tenencia de la tierra para entender la racionalidad existente en el manejo de los insumos agrícolas. Esto puede ser un elemento de explicación para el hecho de que muchos campesinos de Aguanuato se oponen a la introducción sistemática de los abonos químicos en sus procesos de cultivo.

Por supues to se pueden lograr importantes alzas de rendimiento con la dosis de fertilizante aplicada por los más "avanzados" y recomendada por los técnicos (unas 80 unidades de nitrógeno por hectárea). Sin embargo para eso se necesita que sean controladas las demás condiciones. En Aguanato precisamente, la escasez y la irregularidad de las lluvias, así como la ausencia de "pequeño riego" -obstaculizado por los pequeños propietarios a pesar de los esfuerzos desarrollados por las dependencias locales de la SARH- ${ }^{17}$ impiden que se alcancen cada año las 1.2 Ton/Ha.: 1981 y 1982 lo

17. Estos esfuerzos no son secundados a nivel estatal o nacional en la SARH: el financiamiento para este tipo de obras solamente se canaliza hacia las áreas de temporal llamadas "conflictivas", donde las demandas de los campesinos conducen a una movilización política. Se destaca aquí el papel político "apaciguador" de lás inversiones públicas en el campo. 
Cuadro No 20

Costo monetario/ha supuesto en Aguanato en 1983

\begin{tabular}{|c|c|c|c|c|c|c|c|c|c|c|}
\hline \multirow[t]{2}{*}{ Concepto } & \multirow[t]{2}{*}{ Implemento } & \multirow{2}{*}{$\begin{array}{l}\text { Jornadas } \\
\text { campesino }\end{array}$} & \multirow{2}{*}{$\begin{array}{l}\text { Jornadas } \\
\text { fornáeas }\end{array}$} & \multirow{2}{*}{$\begin{array}{l}\text { Costo peones } \\
\text { foráneos } \\
\text { \$ } 350 / \text { jornada }\end{array}$} & \multicolumn{2}{|c|}{ Tracción animal* } & \multirow{2}{*}{\multicolumn{2}{|c|}{$\begin{array}{c}\text { Costo } \\
\text { insumos }\end{array}$}} & \multirow{2}{*}{\multicolumn{2}{|c|}{$\begin{array}{l}\text { Custa } \\
\text { total }\end{array}$}} \\
\hline & & & & & $\begin{array}{l}\text { renta/ } \\
\text { yunta }\end{array}$ & comida & & & & \\
\hline \multirow{2}{*}{$\begin{array}{l}\text { Barbecho } 1 \\
\text { Barbecho } 2 \text { - siembra }\end{array}$} & \multirow{2}{*}{$\begin{array}{l}\text { arado vert. } \\
\text { arado vert. }\end{array}$} & \multirow{2}{*}{$\begin{array}{l}3 \\
2\end{array}$} & - & & 1000 & 800 & \multicolumn{2}{|c|}{ - } & \multirow{2}{*}{\multicolumn{2}{|c|}{$\begin{array}{l}1800 \quad 18 \\
1900\end{array}$}} \\
\hline & & & - & & 1000 & 600 & $300(\mathrm{~s}$ & milla) & & \\
\hline \multirow[t]{2}{*}{ Fertilización ( $y$ desinfección) } & & & & & & & (1) & (2) & (1) & (2) \\
\hline & & & & & & & 3700 & 9000 & 3700 & 9000 \\
\hline Intereses Banco aprox. (7\%) & & & & & & & 300 & 600 & 300 & 600 \\
\hline 2 escardas & arado 2 alas & 4 & - & & 1000 & 600 & & - & 16 & 00 \\
\hline Chaponeo & manual & 4 & 4 & 1400 & & & & - & 14 & 00 \\
\hline Pizca & manual & 3 & 6 & 2100 & & & - & - & & 00 \\
\hline
\end{tabular}

El costo de la fertilización está calculado según fertilizante otorgado con crédito y precios de BANRURAL en diciembre de 1983.

(1): Con sulfato de Amonio y Superfosfato de Cacio Simple.

Para pagar los costos monetarios el campesino debe lograr 0.85 ton/ha de maíz (venta a acaparadores).

(2): Con fertilizante complejo recomendado por SARH en el lugar para 1984.

Para lograr los costos monetarios el campesino debe lograr 1.23 ton/ha de maiz.

* Se afecta una tercera parte del costo anual de los bueyes a cada rrabajo. 
Cuadro No 21

Maiz TCF anAlisis DE COSTO INTEGRAL DE CULTIVO/HA (CONDICIONES PROMEDIO DEL TEMPORAL DE VILLA JiMENEZ, MiChOACAN)

Tracción animal Semilla criolla



Valor del producto: Precio oficial dic. 1983: S 19200/ton. Para pagar los costos monetarius el campesino debe lograr por lo menos un rendimiento de 1.2 coneladas de maiz/ha. 
comprobaron. Eso es peligroso para los campesinos, porque una estrategia de "auto consumo" les permite seguir mucho más allá con un cultivo no "rentable" en términos empresariales. Pagan un fertilizante inútil con ingresos provenientes del exterior (E.U.) sin que SARH ni BANRURAL tengan que arriesgarse. Así, las dosis empleadas están desproporcionadas en relación a los rendimientos realizables, y es fuerte la tentación de relacionar esto con una política industrial que busque la venta de grandes cantidades de fertilizante al campesino mexicano, negando una utilización adecuada. En Aguanuato se comprueba eso cuando se observan, en la estación de lluvias, matas de maíz con fuertes carencias de fósforo ahí donde se puso mucho nitrógeno. Por economías de escala, no se han implementado fertilizantes resistentes a la "retrogradación" fuerte del fósforo en los suelos ácidos, o abonos que tengan nitratos para no incrementar la acidificación del suelo que resulta de la aplicación del sulfato de amonio, realizando así ahorros de fósforo. Tampoco se ha buscado la forma de incorporarlos en las líneas de crédito.

A pesar de todo, la aleatoriedad que implica el manejo actual del fertilizante no repercute en un derrumbe de los ingresos monetarios del campesino, sino en las múltiples "carteras vencidas" en el Banco, y en el frecuente uso de la Aseguradora para que el Banco recupere los créditos correspondientes a las cosechas que no han dado la utilidad esperada. ${ }^{18}$ Por eso, casi todos los ejidos castigados del área, están en programas de crédito llamados de "cuotas restringidas". Todo esto implica muchos gastos públicos improductivos, y en eso la SARH funciona más como promotor de la habilitación de créditos "a fuerza" para fertilizar el maíz, ${ }^{19}$ que como asesor técnico para la canalización de los recursos financieros hacia un mejor desarrollo local.

Con el fertilizante tenemos un ejemplo de los mecanismos que afectan la redituabilidad del crédito. No es su condición de ejidatarios la que hace que los campesinos de Aguanuato sean improductivos y poco rentables, sino que para ellos falta una visión integral acerca de los insumos (naturaleza y cantidad que deberían de entrar en los programas de crédito). La tendencia actual del estado hacía una concentración de los créditos para paquetes de insumos en zonas de "potencialidad comprobada", manteniendo cuotas mínimas de crédito en las demás zonas de temporal, es una manera muy

18. La misma aseguradora pierde mucho dinero cuando impone fechas de siembra que no corresponden en forma adecuada a las condiciones locales.

19. Además lo hace a un nivel muy general y centralizado: las líneas de crédito para maíz de temporal incluyen una cantidad y dosis determinada de fertilizante, lo que no deja al campesino la oportunidad de escoger $y$ adaptar sus abonos a sus propias condiciones $y$ eso a pesar de los constantes esfuerzos de las dependencias locales de la SARH por adaptarse a las condiciones del lugar. 
costosa de conseguir aumentos en la producción, mientras que existe la posibilidad de otros enfoques para una mejor utilización del crédito de avío en todos los lugares.

Por otro lado las obligaciones profesionales de los técnicos "de campo" en la organización actual crean obstáculos al mejor desarrollo local: tienen mucho trabajo administrativo - asesoría al Banco y a la Aseguradora-que al fin de cuentas repercute sobre la poca asistencia técnica y la capacitación. Los buenos conocimientos que tienen los técnicos locales de la SARH de su área de trabajo, no pueden fructificar por el fuerte condicionamiento administrativo ejercido sobre ellos por parte de BANRURAL y ANAGSA, tal y como lo demuestra el caso de Aguanato.

En estas condiciones, los técnicos son casi los únicos en posición de informar al campesino sobre los programas de crédito o los nuevos programas federales de alcance más general, aunque de hecho esto es casi imposible, ya que la presencia de técnicos en zonas poco productivas es escasa; cuando un ejidatario está en programa de cuotas restringidas, no se entera del "por qué no le quisieron dar este año para barbechar", y no tiene todos los elementos para manejar su propia economía. A veces esta situación de "desinformación" es menos inocente por parte del estado: los campesinos de Aguanuato no supieron nada del programa de "riesgos compartidos", porque el estado se comprometió a compartir riesgos solamente ahí donde éstos no existían. Muchos otros ejemplos demuestran una voluntad de limitar el poder de los campesinos en todos sus aspectos, solamente se olvida que estas limitaciones se extienden a la vez a las posibilidades para el campesino de "autodeterminar" sus prácticas para producir mejor.

Visión sectorial del estado: frijol y demás cultivos Por supuesto la agricultura en Aguanuato no se reduce al cultivo del maíz; existe una línea de crédito para maíz-frijol, pero no se aplica porque tiene exigencias que van en contra de la técnica de siembra elaborada durante siglos en el lugar y supuestamente la más segura en Aguanuato, mientras la técnica "óptima" del Banco fue probada en lugares distintos (INIA, Pátzcuaro). Esto, como la aplicación de dosis impuestas de fertilizante, es muestra de un desconocimiento de las técnicas campesinas y de los sistemas de producción por parte de BANRURAL y ANAGSA, dentro de una voluntad expresa de desconocerlas e imponer sistemas de cultivo diferentes. Puesto que estos sistemas no corresponden a lo que buscan los campesinos, hay un verdadero desplazamiento de los centros de decisión del agricultor hacia el estado, teniendo que limitarse los campesinos a ser meros ejecutores de sus planes y programas.

En el caso del frijol este problema de crédito tiene otras consecuencias: para conseguirlo hay que hacer las solicitudes como si se sembrara maíz solo, 
de lo cual resulta una fertilización sumamente inadaptada. Tal vez eso explica las quejas de la gente: las cosechas de frijol vienen cada vez más irregulares, se emplagan muy fácilmente desde hace 15 años... probablemente por el exceso de nitrógeno. ${ }^{20}$ Además una fertilización que incluye mucho nitrógeno puede dañar todos los cultivos a la vez, acelerando la circulación del agua en las plantas y acabando más pronto con las reservas de agua del suelo, sobre todo cuando éste no está cubierto por las hojas de la calabaza o del chilacayote, que tampoco entran en los programas de crédito; esto aumenta el riesgo de no cosechar en años de lluvias escasas, y de no poder sembrar el garbanzo. ${ }^{21}$

Así, el enfoque sectorial, es decir, una visión del desarrollo por producciones, de la divulgación estatal hacia un solo cultivo como el maíz, crea sus propias condiciones de riesgo para este cultivo. Este problema tiene sus raíces en una planeación que contempla las zonas temporaleras exclusivamente maiceras, negando las relaciones entre los diversos cultivos y los animales dentro de las estrategias campesinas, sobre todo cuando se trata del frijol que es una producción indispensable para al autoabasto.

Variedades mejoradas

Como reflejo de este enfoque sectorial está la divulgación de las semillas mejoradas de maíz (híbridos), tema relevante del cambio tecnológico impulsado por la SARH en la región con el programa SARH-INIA "Maíz para el Bajío", iniciado en 1982 con parcelas experimentales en varios ejidos de temporal y de riego. Estos experimentos, como el que tuvo lugar en una parcela de Aguanuato en 1983, son buenas pruebas de la inadecuación de estas variedades para los ejidatarios del Bajío seco michoacano:

-Participa poca gente, la mayor parte siendo pequeños propietarios o campesinos que tienen tierras de riego;

-Los que prestan las parcelas, su trabajo y su tractor son pequeños propietarios (un ejidatario no puede arriesgarse);

-Las variedades probadas en 1983 "pegan" muy bien, en tierras de riego como en los peores terrenos de temporal (con paquete tecnológico adecuado), pero en éstos solamente en los años de buenas lluvias; - Las variedades más exitosas ya tienen una dinámica de expansión en el área temporalera, pero únicamente con pequeños propietarios, de los cuales muchos tienen infraestructura para riego de complemento.

En fin, los ejidatarios de Aguanuato expresaron claramente las razones de su falta de entusiasmo:

20. El decaimiento del cultivo del frijol en el bajío seco merecería un estudio agronómico mucho más profundo.

21. Ya olvidado por el estado: los inspectores de la Aseguradora vienen a revisar las cosechas de maíz mucho después del periodo de siembra del garbanzo. 
-Habían comprobado que estas variedades resistían menos que el criollo a la sequía, lo que es imprescindible, ya que para cualquier alza de rendimiento aumentará la circulación del agua en la mata y la transpiración;

- Tienen criollos que con un tratamiento adecuado casi alcanzan los rendimientos de los híbridos, mientras que con éstos se tiene que comprar cada año la semilla;

-Sobre todo, los híbridos tienen un grano blanco y dulce, lo que para ellos significa:

-menor densidad del grano, menor rendimiento real en peso,

- ninguna resistencia a las plagas de almacén (por la variedad y la mayor utilización de fertilizante), lo que es importante cuando el maíz se tiene que conservar un año entero.

Es evidente que los campesinos de Aguanuato no quieren incrementar los riesgos que corren por introducir las semillas mejoradas. No se trata de un arcaismo, sino de la defensa de su estrategia de mantenimiento. Para ellos se podría probar el mejoramiento de semillas a partir de los que mejor rinden dentro de los criollos locales.

Asimismo, se entiende mejor el "dinamismo" de los pequeños propietarios frente a este tipo de cambio tecnológico: lo adoptan porque se adapta a su sistema de producción, donde una mayor parte del grano se vende; también tienen la capacidad económica necesaria para soportar riesgos de experimentación sobre parte de sus parcelas. Por el contrario, el ejidatario "promedio" se pone en peligro de no reproducir su sistema si usa semilla mejorada, solamente porque tiene que guardar su cosecha y por otro lado, porque no controla el manejo del agua en la agricultura.

El Estado como promotor de la marginación campesina

Si esto es verdad, se llega a otro planteamiento muy importante: bajo este contexto, es imposible que "frente al ejemplo de los más dinámicos" la mayoría de los ejidatarios sigan adoptando el "cambio tecnológico" impulsado por las instituciones, porque se les hace imposible que este tipo de divulgación agrícola no funcione aquí.

Siguiendo esta política de divulgación, se está ayudando en realidad, sin que el estado lo haya planeado así, al desarrollo de los pequeños propietarios del área y de algunos ejidatarios que de hecho están concentrando el uso de la tierra. Es decir que en vez de una "reproducción mejorada" de todos los sistemas agropecuarios individuales del ejido, esta política está fomentando una aceleración de la diferenciación social previamente descrita. Una intervención enfocada hacia el cultivo del maíz está, de hecho, dando nuevas herramientas a los únicos que se encuentran ahora en condiciones de cultivar maíz-solo, con tecnología avanzada y con el propósito de comercializarlo. 
Así, tal vez, se podría lograr el incremento de la producción de maíz en la región pero apoyándose sólo en 3 ó 4 productores. ¿Será este el objetivo perseguido?

\section{CONCLUSIONES}

Resumamos la situación de un ejido "productor de maíz" de las regiones temporaleras del Bajío michoacano:

-La ganadería (bovinos de abasto, puercos) es la actividad de mayor relevancia económica, y la que tiene la mejor posición frente al mercado. Por otro lado, es el factor más importante de diferenciación social;

-Los campesinos que no tienen ganado gozan de muy pequeñas superficies de tierra de labor y reciben apoyos efectivos muy reducidos; - Una mayor parte de ellos tiende a producir grano únicamente para autoconsumo;

-La emigración es muy fuerte, ${ }^{22}$ y el número de gente que se queda apenas excede la mano de obra necesaria en las épocas de siembra y cosecha, la cual tiende a disminuir.

Dentro del ejido existen importantes diferencias socio-económicas, vinculadas con una cierta división del trabajo - presencia de jornaleros y medieros - un acceso desigual a los recursos comunitarios - agostaderos, explotados en forma destructora- y a la fuerza de tracción - bueyes, tractores-; los que sobresalen tienen mucho ganado mayor, más productividad del trabajo agrícola (barbecho y siembra con tractor), y sobre todo, se benefician mucho más que el resto del ejido, de la intervención del estado con crédito, asistencia técnica que sólo sirve para mejorar el cultivo del maíz para venta, etc. Por medio de este tipo de intervención y quizás sin que sea voluntario, el estado acelera la marginación de parte del campesinado en este tipo de regiones y la concentración de los recursos por los que se quedan.

En cuanto a la producción de maíz en la región, no se puede hablar en absoluto de una disminución sino de un incremento del carácter aleatorio en el cultivo y de una concentración de la producción del maíz para venta en manos de los ejidatarios que barbechan con tractor y de los pequeños propietarios, mientras los demás campesinos son poco a poco excluidos del mercado.

22. L.os ingresos de las migraciones a Estados Unidos se invierten poco en las actividades agropecuarias: mantenimiento para los más pobres, mejoramiento de la vivienda o construcción de casas para los más afortunados. 
Si algún día se hace efectiva la bodega local de la CONASUPO — lo que demuestra por parte del estado una certidumbre en cuanto a la capacidad productiva del área-, esto sólo va a aumentar los ingresos de los campesinos que venden una parte importante de su cosecha y que ya aprovechan mejor la divulgación por parte de la SARH. En otros términos, eso puede incrementar la diferenciación social, ya que es demasiado tarde para que la CONASUPO logre ayudar a un desarrollo global del ejido.

Si se busca mantener a toda la población de este tipo de ejidos con un costo social supuestamente más bajo que para el mantenimiento de los mismos en la ciudad de México, el estado tendrá que encontrar otros enfoques de desarrollo, que ayuden a los campesinos sin incrementar esos factores de diferenciación social, es decir actuando sobre condiciones que beneficien a todos y sobre los sistemas de producción de los productores que van quedando marginados: granos para autoconsumo, pequeña ganadería, etc.

En la agricultura lo importante para la mayor parte de los campesinos es tener una producción de maíz frijol que no sea tan riesgosa y la posibilidad de sembrar garbanzo cada año en las tierras más húmedas.

Esto implica, en primer lugar un esfuerzo sobre el manejo del agua. No se trata de cambiar ni de intensificar los sistemas de producción con la introducción del riego, lo cual es muy costoso en Aguanuato, arriesgado y supuestamente incoherente con los deseos de los campesinos. Precisamente, ellos carecen de una infraestructura liviana que permita algunos riegos de complemento cuando fallen las lluvias durante la floración del maíz o la humedad residual para el garbanzo. Esto se hubiera podido incluir en un programa de la SARH -que consideraba "bordos", "ollas de agua" (varias presas de tamaño muy reducido), y acaso bombeo desde algunos pozos-que nunca se ha llevado a cabo en la región, aunque se reconocía la existencia de las fuentes de agua necesarias. También se destaca aquí la necesidad de una acción política de las instituciones en contra del monopolio ejercido por los pequeños propietarios sobre las fuentes de agua.

Si algún día se superan estos obstáculos, este tipo de infraestructuras podría instalarse en varios lugares del territorio y permitiría un pequeño incremento de la superficie sembrada en garbanzo y cultivos forrajeros de otoño-invierno como janamargo o avena, que no compiten con la producción de granos básicos en lo que se refiere a tierra y a trabajo.

Bajo la condición de que haya un control colectivo del crecimiento de los hatos, esto podría tener efectos positivos a varios niveles sobre la ganadería:

Con más cultivos forrajeros se disminuye la carga que sufren los agostaderos y se mejora la regeneración del pasto natural. Además, combinado con algo de reforestación, esto tendría efectos favorables sobre la erosión: agostaderos en mejor estado, mayor ocupación de la tierra de labor en la estación seca y menores efectos del viento. 
Se podría incrementar un poco la estación lechera y la cantidad de queso que se fabrica. Esto beneficiaría a los pequeños ganaderos que de esta manera, podrían intensificar el empleo de su mano de obra.

Resulta que este tipo de región temporalera no necesita cambios drásticos en el sistema de producción, ni grandes paquetes de insu mos que no son aceptados por los campesinos, porque no se pueden integrar al sistema de producción. Por otro lado, el estado tiene mucho poder en esos lugares por controlar la mayor parte de los procesos de cultivo. Por lo mismo, es quien tiene mayor capacidad de fomentar cambios hacia un uso más adecuado de los recursos externos, analizando globalmente las condiciones locales y respondiendo en forma igualitaria a las necesidades del conjunto tanto a las de los ejidatarios, como a las de los pequeños propietarios. Lo que urge por tanto no es una capitalización de la agricultura como respuesta a las carencias de los ejidos, sino el mejoramiento de las condiciones administrativas, de operación y de la seguridad en el sistema de producción vigente.

\section{ANEXO 1}

\section{DATOS ESENCIALES SOBRE AGUANUATO Y SU EJIDO}

\section{Pueblo de Aguanuato: diciembre de 1983}

-889 habitantes

-155 casas ocupadas

-130 jefes de familia cultivan la tierra

\section{Estructura agrícola}

-102 ejidatarios (ejido creado en 1927)

-1 pequeño propietario sin tier ras ejidales (los demás pequeños propietarios que tienen tierras en el área de estudio radican en la cabecera municipal). -alrededor de 50 campesinos sin derecho permanente sobre la tierra. -superficie total del ejido: 2,065 Has.

-supercicie de labor: alrededor de $700 \mathrm{Has}$ (promedio de apenas $7 \mathrm{Ha}$. de temporal por ejidatario, y de $5 \mathrm{Ha}$, por campesino, en Aguanuato). -los ejidatarios tienen de 0 a $3 \mathrm{Ha}$. de propiedad privada cada uno. -el resto lo constituyen 1,400 Has. de agostadero colectivo en forma de matorral.

Cultivos (aproximación de las superficies sembradas en 1983): 
-550 Has. de maíz de temporal (a menudo asociado con frijol y calabaza), -130 Has. de garbanzo de humedad residual,

- 40 Has. de trigo-avena-janamargo de temporal,

-El pueblo cuenta con 3 tractores, 2 en sociedad y 1 particular.

Ganadería: reses de triple propósito, puercos, cabras. 


\section{CONCLUSIONES}

Los capítulos uno dos y tres dibujan esquemas de evolución de sistemas de producción muy parecidos entre sí. Estos se caracterizan por la aceleración de la acumulación diferencial entre ejidatarios mediante la ganadería extensiva y en menor grado a causa de factores externos. Todos los esquemas de evolución llegan a definir un número limitado de grandes tipos de productores. Detallamos aquí los rasgos comunes de estas tipologías.

En primer lugar, se encuentra una pequeña minoría de productores cuya estrategia tiende a rentabilizar las inversiones realizadas en la unidad de producción misma - maquinaria, tierras, obras de riego, ganado y otros medios de producción - así como fuera de ella con comercios diversos, fábricas, etc., y llegar a optimizar el uso de una mano de obra esencialmente asalariada. Los sistemas de producción de este pequeño número son netamente especializados: en Huetamo, hacia la producción de novillos de uno a dos años para la venta en las regiones de engorda; hacia la producción intensiva de leche en el valle de Maravatío; o la cerealicultura en Maravatío y Aguanuato, en donde este sistema es exclusivo de los pequeños propietarios.

Existen unidades de producción de tamaño más reducido - menos de 10 hectáreas de labor - que tienen en su sistema una producción que permite aumentar la remuneración por bectárea y valorizar el empleo de la mano de obra familiar como es el caso de la leche en Maravatío. Tal estrategia, aunque resulta muy interesante en la perspectiva de políticas que buscan incrementar la productividad de los ejidos, no es siempre posible. Los precedentes capítulos lo ilustran y las oportunidades como la del desarrollo lechero en el valle de Maravatío no son frecuentes: este tipo de productores casi no se encuentra en Huetamo y Aguanuato. Lo sobresaliente es que el maíz, por ejemplo, no puede responder a tal estrategia campesina ya que según una visión sectorial, siempre se dificultará su "desarrollo".

Por supuesto, estos dos primeros grupos de productores son los principales actores del desarrollo en los ejidos. La falta de recursos económicos en el segundo, cuando no se pueden aprovechar las ganancias 
generadas por migraciones o cultivos prohibidos, hace de las unidades semicapitalistas las principales beneficiarias de las políticas estatales. La orientación que se da a éstas ubica en situación marginada a los grupos que siguen en la tipología.

Existe en los ejidos una gran mayoría de las unidades de producción que elabora su estrategia arededor de las necesidades del abastecimiento familiar. Se necesita entonces buscar ingresos monetarios en la medida de las oportunidades que presenta el sistema de producción:

- por la venta de un producto particular (ajonjolí en la cuenca del Balsas y trigo en Maravatío)

- por la venta del maíz sobrante (en forma directa o transformada: puercos y aves de corral)

-por las migraciones, un trabajo asalariado, un pequeño comercio, etc., si se puede.

Es imposible recurrir al implemento de "paquetes tecnológicos" para promover el desarrollo de estas unidades: las estrategias de disminución de los riesgos que emplean lo impiden. De ahí el fracaso de los proyectos de "desarrollo" que se revelan inadaptados a las necesidades de una mayoría.

El último grupo está compuesto por unidades donde las producciones agropecuarias tienen un papel menor en los ingresos familiares. Los pequeños medieros, jornaleros, etc., que escasean en relación directa con el grado de mecanización del sistema social de producción, constituyen el grueso de las legiones que dejan el campo y van hacia los centros urbanos y sus ciudades perdidas.

En la medida en que se va persiguiendo la acumulación diferencial en los ejidos -en este sentido, hubiera sido interesante enfocar la atención sobre ejidos de antigüedad diferente, a fin de poder evaluar el grado de esta diferenciación en función del tiempo - se eleva el umbral de reproducción de los sistemas de producción. Por ejemplo, en Aguanuato, los "allegados" que no pueden esperar aumento significativo de la productividad en parcelas pedregosas y con suelos pobres y no tienen alternativa por su sistema de cultivo, son las principales víctimas del estancamiento de los precios del maíz y de los puercos. Esto lleva a la eliminación de las unidades que tienen un nivel de reproducción más bajo, o sea los productores de los dos últimos grupos. Una "privatización" de los ejidos tal como la evocamos en la introducción de esta parte contribuiría a acelerar el fenómeno.

Cabe destacar que, dentro de los capítulos precedentes, el único proceso de desarrollo de las fuerzas productivas que permitió una intensificación (aumento de la remuneración por hectárea y por unidad de mano de obra familiar) de los sistemas de producción más desfavorecidos se produjo con la producción lechera en el valle de Maravatío. Ahí, los ejidos se beneficiaron con tierras de riego y en muchos de ellos, la totalidad de los agostaderos ha sido repartida de manera igualitaria entre todos los ejidatarios. Ese 
fenómeno no tiene nada que ver con lo que está pasando en el ejido de Turitzio, donde subrayamos las consecuencias dramáticas de un reparto proporcional al número de cabezas de ganado en posesión de cada ejidatario. En el valle de Maravatío, esta medida impidió la aceleración de la acumulación mediante el fomento de hatos importantes y permitió la colonización de los antiguos agostaderos por los cultivos de granos básicos. Parte de las tierras de riego se pudieron así aprovechar para el abastecimiento de vacas lecheras con forrajes de calidad constante, lo que corresponde a la elevación de la productividad del trabajo, del terreno y del capital inmovilizado.

Aún sin llegar al cultivo de los agostaderos, su división equitativa parece ser una condición al incremento de la productividad de los ejidos. A nivel de las estrategias individuales, la renta de su parte de agostadero puede permitir al campesino que no la puede aprovechar en otra forma por falta de medios de producción, incrementar su ingreso monetario. De tal forma se elevan el grado de seguridad y el nivel de reproducción de la unidad. El posible ahorro monetario se puede entonces arriesgar en la compra de medios de producción que permiten aprovechar en forma directa el agostadero o bien, en el aumento de los rendimientos mediante la compra de insumos e integrarse así al proceso de acumulación.

Al fin y al cabo, los agostaderos colectivos, como condición a la difusión y la realización de la reforma agraria, se revelan hoy en día como uno de las limitantes más fuertes al desarrollo económico y social dentro de los ejidos. 



\section{SEGUNDA PARTE \\ COLONIZACION GANADERA EN LA SIERRA MADRE DEL SUR}




\section{INTRODUCCION}

La Sierra Madre del Sur es, sin duda, la parte más apartada y desconocida del estado de Michoacán. La escasez de vías de comunicación y las condiciones geográficas desfavorables hicieron de esta región una zona marginada y de bajo interés económico fuera de sus recursos minerales. La topografía abrupta de la sierra no deja aparecer superficies planas de importancia, por lo que la irrigación y el empleo de maquinaria agrícola no ofrecen alternativas al desarrollo agropecuario. Además, con excepción del corazón de la sierra, más húmedo y fresco, el clima tropical seco limita las posibilidades de aprovechamiento agropecuario.

Llegando por la carretera costera, se divisan cerros muy abruptos cubiertos por una selva baja caducifolia y espinosa muy poco desmontada. Entre ellos aparecen pequeñas llanuras costeras donde están ubicados ranchos y palmeras.

Al subir a la sierra siguiendo las barrancas húmedas o escalando los cerros, la vegetación es más densa. La selva se vuelve más espesa, pero también más desmontada. A medida que uno se eleva en las montañas de la sierra, encuentra desmontes cada vez más extensos. Llegando a los 1,000 msnm es cuando aparece la sierra toda desmontada y a veces empastizada. Más arriba el bosque templado de pinos y encinos sustituye a lo que queda de la selva tropical. Pueblos y ranchos están diseminados entre los cerros.

Sin embargo, se suele considerar que la historia de las zonas tropicales de México -en las cuales la forma predominante de aprovechamiento del medio fue siempre "el itinerante" o sea, a base de cultivo bajo roza-tumba y quema- se inicia cuando empieza la "marcha a la costa", cuando los colonos toman posesión de estas "tierras vírgenes", en realidad muchas veces aprovechadas por comunidades indígenas. Durante el siglo XIX, numerosos rancheros del Bajío central dejaron el altiplano sobrepoblado para bajar al plan de Tierra Caliente y conquistar los cerros de la Sierra Madre del Sur hasta Coalcomán. Los pocos indigenas que andaban en esas montañas fueron desposeídos al establecerse el régimen de la propiedad privada - "El 


\section{MaPA No 13.}

UBICACION DE I.OS MUNICIPIOS DE COAI.COMAN Y AQUII.A I:N H:I. FSTADO DE MICHOACAN

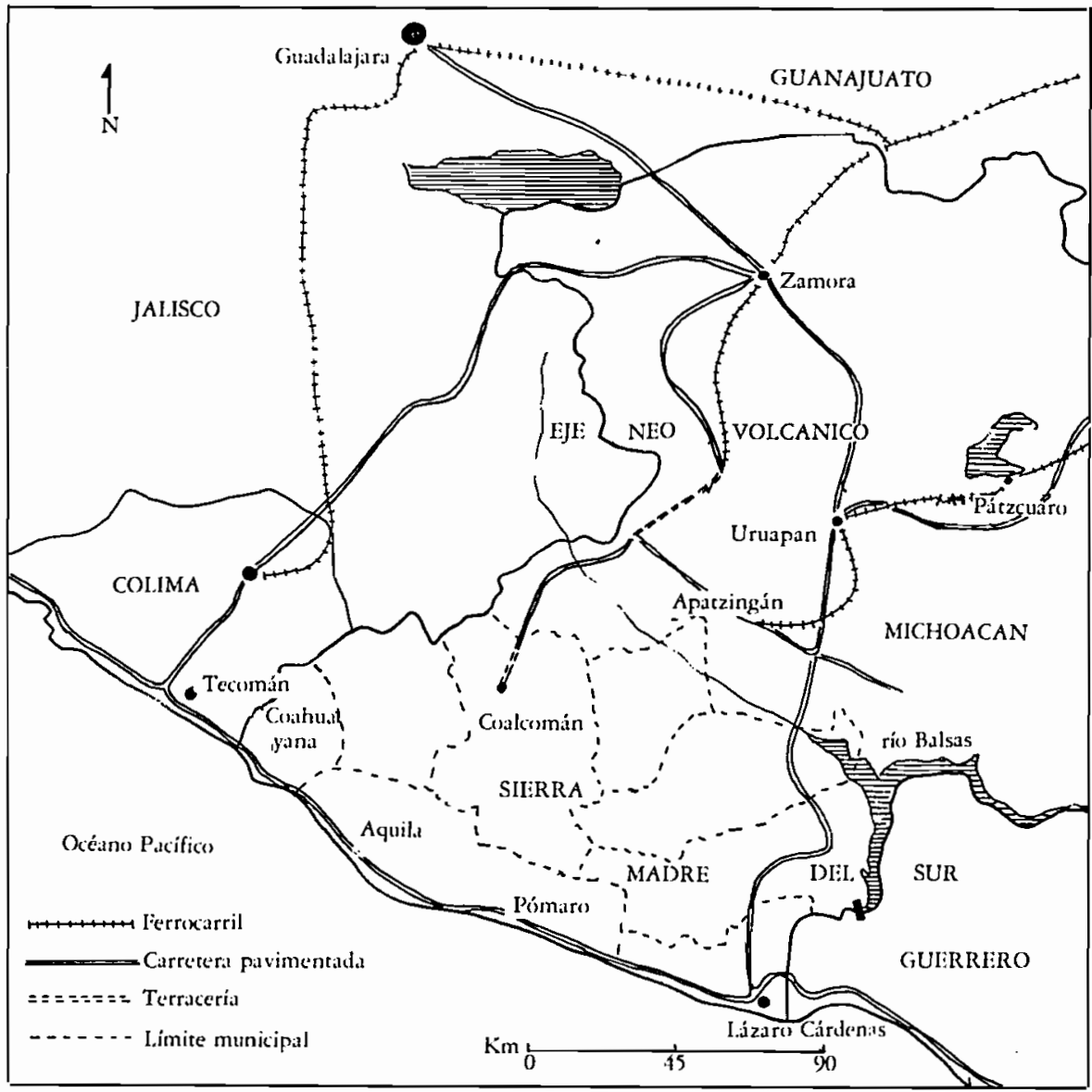

Rancho"- de la gente "de razón". Luego, fueron a comprar tierras más hacia la orilla del mar. Este movimiento de "colonización" sigue desarrollándose hacia la costa del Pacífico: fuente de enajenación y fuente de "ganaderización" puesto que los animales siempre van en primera línea precediendo al dueño mismo. El ganado se ha vuelto la primera forma de acumulación, motor de las invaciones de tierras pero, a la vez, el maíz de 


\section{MAPA NQ 14.}

\section{CARTA TOPOGRafica Dei. MUNiCIPIO de CoAi.COMAN}

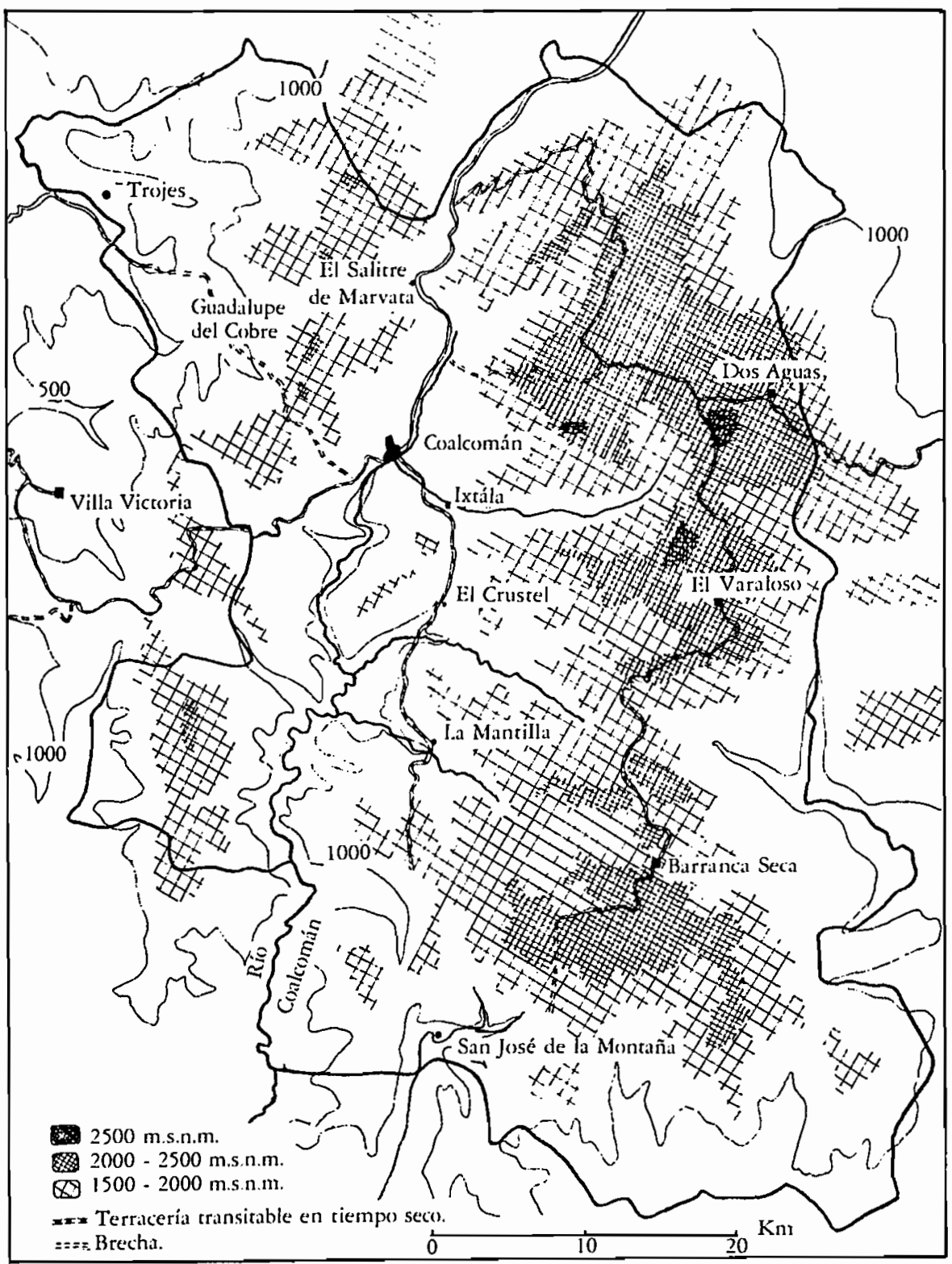


temporal deja su papel de piedra angular de los sistemas de producción.

En esta parte, nos proponemos estudiar las condiciones, causas y efectos de este movimiento de ganaderización, y cómo un cierto modo de aprovechamiento del medio llega paulatinamente a volverse exclusivo, a impedir que otros productores como medieros o indígenas escojan su propia forma de cultivar la tierra. Trataremos de entender el aspecto contradictorio de este movimiento de especialización regional (ganadería extensiva de cría) y su impacto en una de las regiones más conflictivas del estado.

En el apartado 4 estudiaremos la historia agraria del municipio de Coalcomán (véase mapa 13), foco histórico de instalación de los migrantes mestizos, y su especialización progresiva hacia la ganadería extensiva para carne. El apartado 5, dedicado a la comunidad indígena de Pómaro, municipio de Aquila, describe la última fase de este movimiento de "colonización" ganadera. Trata de explicar cómo la formación reciente de los pueblos a lo largo de la carretera costera y la evolución de los sistemas de producción son dos fenómenos estrechamente ligados a la enajenación de las tierras comunales y al desarrollo "tendencial" de la ganadería. 


\section{CAPITULO IV \\ GANADERIA Y APARCERIA \\ EN LA SIERRA DE COALCOMAN}

Hubert Cochet

\section{ORIGEN DEL POBLAMIENTO: DE LA COLONIA A 1870}

En los tiempos de la colonia, el valle de Coalcomán y las sierras circunvecinas carecían de población, mientras que la franja costera de la Sierra Madre del Sur era relativamente más poblada. En ella, las comunidades indígenas de Aquila, Maquilí, Ostula, Coire y Pómaro, diseminadas entre los cerros del actual municipio de Aquila, no fueron afectadas por la Colonia tanto como la vecina región de Coahuayana (véasea mapa 13), en la cual la población indígena sufrió un descenso dramático al trabajar en las plantaciones coloniales de cacao. El terreno de estas comunidades era demasiado accidentado como para que pudiera llamar la atención de los españoles. El impacto de la conquista fue entonces mucho más tardío. En 1540, el actual municipio de Aquila contaba con más de 10,000 habitantes, mientras que Coalcomán, en los límites aproximados del actual municipio no juntaba el millar (véase gráfica 20). Durante toda la época colonial, el valle de Coalcomán y sus alrededores quedaron casi sin habitantes; y los informes sobre población para esta época rara vez mencionan más de 100 tributarios. Las haciendas cañeras y ganaderas del norte en la depresión de tierra caliente tampoco llegaron a establecerse en el Valle de Coalcomán.

La historia minera del pueblo de Coalcomán se reinicia en las primeras décadas del siglo XIX. Pero a pesar de los numerosos informes ${ }^{1}$ que denunciaban la riqueza mineral de la región, el desarrollo de estas actividades no logró aumentar la población de la región en forma duradera; la población llegó a 1,071 habitantes en $1826 .{ }^{2}$ La ley de colonización del 31

1. Relación de Quacomán en Alvaro Ochoa S. y Gerardo Sánchez D., Relaciones y memorias de la provincia de Michoacán. 1579-1581. UMSNH-Ayuntamiento de Morelia, Morelia, 1985; J. G. Romero, "El partido de Coalcomán en 1863 " en Cuadernos Quabucomecas No. 1; testimonios S. XIX; Diego Lazaga, Descripción del partido de Motines, A.G.N., Ramo de Padrones (Octubre 23 de 1792); Santiago Ramirez, Biografía de D. Andrés Manuel del Rfo, Colegio de Minería, México, 1891; Manuel de Anda, Informe relativo a la exploración del distrito de Coalcomán. 1883.

2. Según M. J. Torres, Diccionario T. 1. p. 415 citado por R. Arreola Cortés, Coalcomán. 


\section{Grafica No 20: EvoluCiON DE LA POBLACION EN LOS MUNICIPIOS DF: Aquil.a y Coalcoman (1532-1822)}

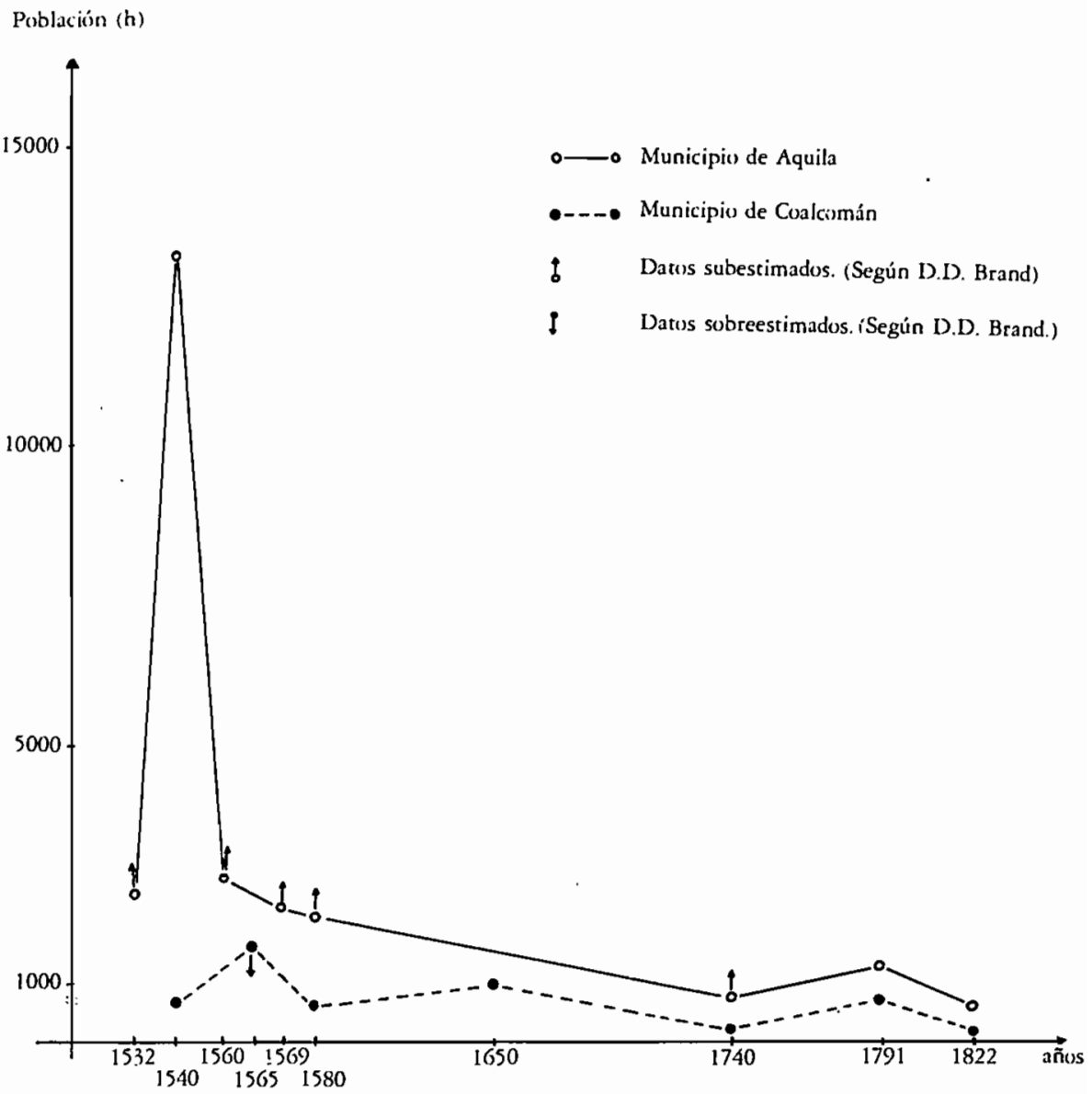

Fuente: Gráfica realizada a base de informaciones seleccionadas por Donald D. Brand: Coalcoman and Motines de Oro, an ex-distrito of Michoacán. México. The Institute of Latin American Studies. The University of Texas. Austin-Texas. 1960. 
de julio de 1828 y la propaganda ininterrumpida a favor de la región de Coalcomán no lograban convencer a mucha gente. La escasez de mano de obra y el aislamiento de la región no permitieron que la minería de Coalcomán se desarrollara tanto como en otras regiones del país.

Además, las denuncias de tierras realengas, hechas en los últimos años del siglo XVIII no facilitaron tampoco la formación de ranchos y explotaciones agrícolas. De las tierras denunciadas, muchas eran de las comunidades indígenas y las demás ya tenían "dueño" aunque fuese solamente alguien que reconociera estas comarcas como suyas sin tener títulos de propiedad. Cuando se hicieron los pregones, no hubo postores, ${ }^{3}$ que compraran estas tierras. En el mapa 15 se destaca que el Valle de Coalcomán no estaba ocupado por ninguno de los latifundios de aquella época. Del actual municipio de Coalcomán solamente la región de Trojes en el noroeste del municipio formaba parte de alguna hacienda. En los documentos o informes del siglo XVIII y primera mitad del siglo XIX, no se menciona ninguna "propiedad privada", rancho o hacienda en la parte central del actual munici pio de Coalcomán. Esta región pertenecía todavía a la comunidad indígena de Coalcomán aun cuando numerosos mestizos y algunos europeos tuvieron sus casas en el pueblo. En 1760, El Padrón de Gualcoman informa que había 140 indios y 38 "gentes de razón". En los documentos de esta época, se habla muy poco de esos indios. El cacao de Coahuayana, las perlas de la costa y las riquezas minerales de la sierra parecían más famosas que "los inmensos bosques de cedros, ocotes, oyameles, encinos y otra multitud de árboles de las tierras frías". ${ }^{5}$ Del actual municipio sólo se mencionaba el valle de Coalcomán y sus cultivos de maíz, frijol, chile, trigo y legumbres. ${ }^{6}$ Después del auge minero, hacia 1850 no quedaban más que 1,000 habitantes en Coalcomán según $\mathrm{E}$. Ruiz, ${ }^{7}$ y entre ellos numerosos mestizos o criollos que habían sido atraídos por las minas o huían de la acción de la justicia como "criminales".8 Algunos mestizos radicados en el pueblo eran apicultores, arrieros, agricultores o ganaderos, pero no poselan hacienda en la región. Las tierras estaban sin medir y eran comunales.

Monografías municipales, Gobierno del Estado de Michoacán, 1980, p. 167.

3. R. Arreola Cortés, op. cit., p. 152.

4. Padrón de yndios y gente de rrazon deste partido Señor Santiago Gualcoman del cura Francisco Lorenzo Chavarrieta. 1760. Padrones Legajo 294. Vkase Arreola Cortés, op. cit.

5. J. G. Romero, op. cit., p. 556.

6. Idem.

7. Eduardo Ruiz, Historia de la guerra de intervención en Michoacán, p. 87, citado por Arreola Cortés, op. cit., p. 187. D. Brand no menciona esta información en su estudio demográfico ya citado porque carece de precisión.

8. Eduardo Ruiz, op. cit., p. 87. 
MAPA $\mathrm{N}^{2}$ 15. UBICACION DE LAS HACIENDAS, RANCHOS Y COMUNIDADES INDIGENAS A FINES DEL SIGLO XVIII EN EI. DISTRITO DE COAI.COMAN

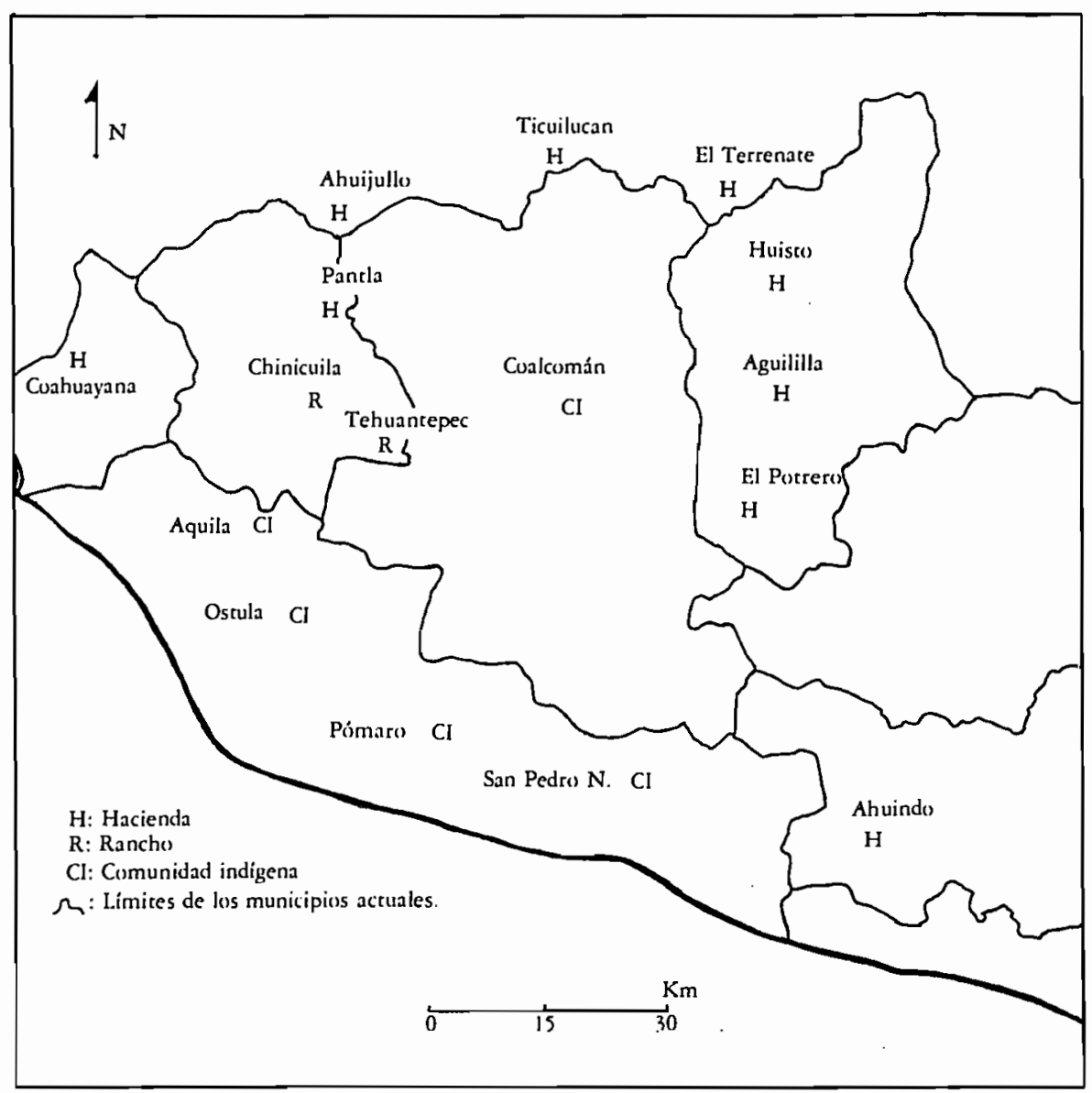

En los latifundios circunvecinos (ver mapa 15) la propiedad tampoco había sido deslindada. Eran terrenos inmensos cuyos linde ros no se conocían con precisión y los dueños no tenían títulos

Cobraban una renta a los campesinos que vivían en los ranchos y un peaje a los arrieros o comerciantes que andaban en ellos. ${ }^{9}$

9. Véanse las denuncias de tierras realengas por el comisionado Pacheco en 1798 en Arreola C., op. cit., p. 136 y siguientes. Cuando el comisionado llama a los propietarios 
Las estancias, lejos de ser unidades de producción, en ese momento, constituían un conjunto disperso de ranchos, independientes uno de otro, que se rentaban a campesinos de la región: era como si los campesinos de la sierra pagaran un tributo al dueño de la estancia, sin que esta fuera por eso una verdadera propiedad privada. Con todo, excepción hecha de los latifundios cafetaleros de Coahuayana, no había muchos peones y la aparcería ni se menciona.

\section{LA FORMACION DE LOS RANCHOS EN LA SIERRA DE COALCOMAN (1870-1920)}

\section{Evolución demográfica y migraciones}

Después de medio siglo de evolución irregular ligada a la explotación de las riquezas minerales de la región, la población de los municipios de la sierra (Coalcomán y Chinicuila) se triplica en dos décadas (1868-1889) pasando de 3,200 a 10,000 habitantes, o sea un aumento de $6 \%$ anual. Luego después de 10 años de aparente estabilidad, vuelve a crecer con gran velocidad: se duplica entre 1900 y 1920 (18,500 hab. en 1920). En los municipios costeros, la población crece menos: un $145 \%$ cuando la población de Coalcomán/Chinicuila se triplica y un aumento de $19 \%$ cuando se duplica la población de la sierra. En cambio, parece crecer bastante según los censos, entre 1895 y 1900 -un 40\% - cuando la población de Coalcomán se manifiesta estable (véase la gráfica 21).

Así, a principios de este siglo, la situación demográfica de la Sierra Madre del Sur no tiene nada que ver con la de los siglos anteriores. La distribución de la población entre costa y sierra ha cambiado a favor de las tierras altas, mucho más pobladas que las tierras calientes de las comunidades indígenas de la costa. En 1950, D. D. Brand interpreta esta evolución opuesta diciendo que la introducción de la ganadería, el desarrollo de las vías de comunicación en el siglo XX y de los polos de atracción económica orientados hacia el interior (Guadalajara, Morelia, México) favorecieron el desarrollo de las "tierras altas" de la sierra cuando la costa se aislaba más y más, siendo despoblada por la mortandad en las plantaciones coloniales. ${ }^{10}$ En realidad la causa fundamental de los aumentos demográficos citados se ubica en las inmigraciones observadas a partir de 1870 y que poblaron la sierra de Coalcomán. A pesar de que sea muy difícil cuantificar a ciencia cierta el papel de la inmigración en el crecimiento poblacional

para que expresen sus linderos y exhiban sus títulos la mayoría no se presentan "porque no poselan títulos de sus tierras y otros por soberbia" p. 146.

10. D. Brand, op. cit., p. 166. 


\section{GRAFICA No 21: EVOLUCION DE LA POBLACION EN LOS MUNICIPIOS COSTEROS (CoAhuayana y Aquila) y templados (CoAlcoman y Chinicuil.a) $1822-1930$}

Población (h)

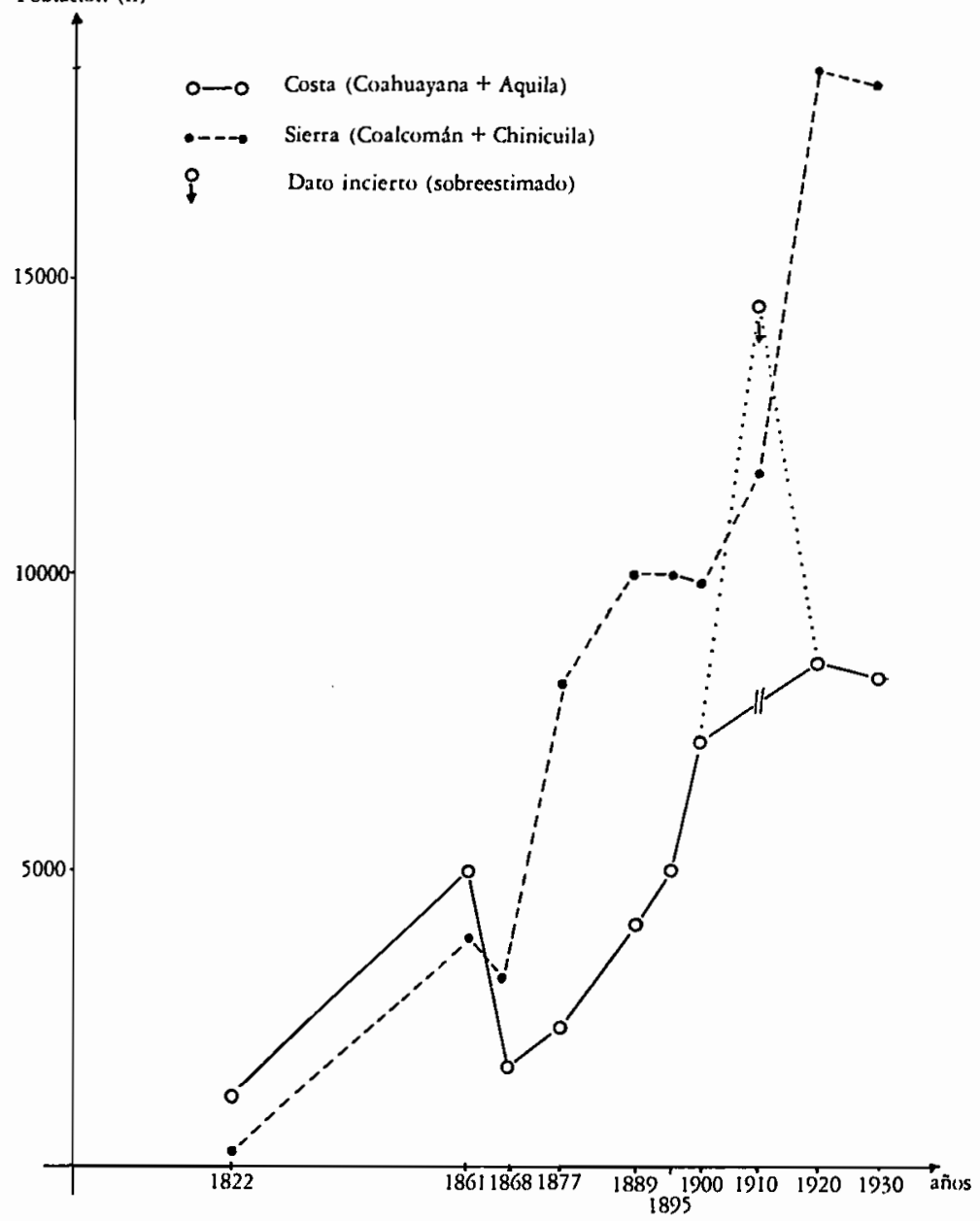

Fuente: Gráfica realizada en base a informaciones seleccionadas por D.D. Brand (1822-1895) y Censos Nacionales (1900-1930).

Nota: Entre 1822 y 1861, carecemos totalmente de información, y los "censos" seleccionados por D.D. Brand de 1861, 1868, 1877, 1889, sun de calidad desigual. En 1895 se publica el primer censo nacional. Para este periodo, D.D. Brand tuvoque hacer muchas correcciones para distribuir la población dada por los documentos dentro de los límites actuales de los municipios, juntando los municipios costeros (Aquila y Coahuayana) por una parte, y los municipios de la sierra (Coalcomán y Chinicuila) por otra. Para respetar la coherencia de la gráfica, agrupamos los municipios de la costa y los de la sierra hasta 1930. 
- también el aumento natural interviene pero nunca se ha visto una tasa de crecimiento natural de $6 \%$ anual - algunos testimonios del siglo XIX y las encuestas que hemos realizado dejan pensar que el fenómeno fue masivo.

Cabe recordar que durante más de medio siglo una propaganda ininterrumpida a favor de la sierra de Coalcomán y la ley de colonización del 31 de julio de 1828 no habían logrado que se establecieran muchas familias en la región. "No obstante las facilidades que se dieron, la colonización no dio resultado, pues los extranjeros no encontraron seguridad en sus tierras, comunicaciones suficientes y libertad religiosa para los que no eran católicos". ${ }^{11}$ En cambio, cuando se va disgregando la comunidad indígena de Coalcomán, llegan numerosos migrantes con el fin de adquirir terrenos. Se vuelven propietarios con las leyes de desamortización y el reparto oficial. Eso corresponde al primer flujo de migrantes y al aumento demográfico de los años setenta y ochenta. A principios de este siglo, vuelven a llegar numerosos migrantes provenientes de Cotija, Jiquilpan, Tamazula (véase mapa 16). Este segundo movimiento explica en parte el crecimiento demográfico que hemos notado desde 1910 hasta 1920.

\section{La colonización de la sierra}

Los mestizos que llegaron durante el auge liberal del siglo XIX "hicieron negocios con los indios": El papá de mi abuelo - platica un anciano de San José de la Montaña - había comprado una parte a la comunidad indígena de Coalcomán. Eran miles de hectáreas compradas con un espejo. ${ }^{12} \mathrm{El}$ abuelo Pablo se fincó a fines del otro siglo, comprando a los indios. A ellos les gustaba el vino. ${ }^{13} \mathrm{El}$ reparto of icial de las tierras comunales de Coalcomán se inició en 1871. Los terrenos se dividieron en 329 lotes cuyo tamaño y linderos desconocemos. Solamente tenemos el informe del prefecto de Coalcomán que habla de "400 fanegas de sembradura" como "medida del valle"14 o sea, aproximadamente 2,400 Has.

Esta medida no toma en cuenta los terrenos de faldas o agostaderos. La superficie repartida fue, sin duda alguna, mucho mayor. Los testimonios citados y el estudio de los mapas hacen pensar que se trata de una extensión comprendida entre 100,000 y 200,000 Has. A la inversa de lo que ocurrió en muchas partes de Michoacán, las tierras de la Comunidad de Coalcomán no

11. Raúl Arreola Cortés, op. cit., p. 170; el subrayado es nuestro.

12. Entrevista a Daniel Betancourt, San José de la Montaña.

13. Entrevista a Santos Virrueta, El Aguacatito, Coalcomán.

14. Comunicación del prefecto de Coalcomán al secretario de gobierno. 25 de enero de 1871 (APEM, Hijuelas, Coalcomán vol. 3 f. 3) citado por G. Sánchez Días, "Movimientos campesinos en la Tierra Caliente de Michoacáan 1869-1900" en Jornadas de Historia de Occidente, No. 4, Centro de Estudios de la Revolución Mexicana, A.C., 1980, p. 35.

15. R. Arreola Cortés, op. cit., p. 196. 
MAPA Ne 16: ORIGEN GEOGRAFICO DE ALGUNAS FAMILIAS DE COALCOMAN. INMIGRACION 1870-1910

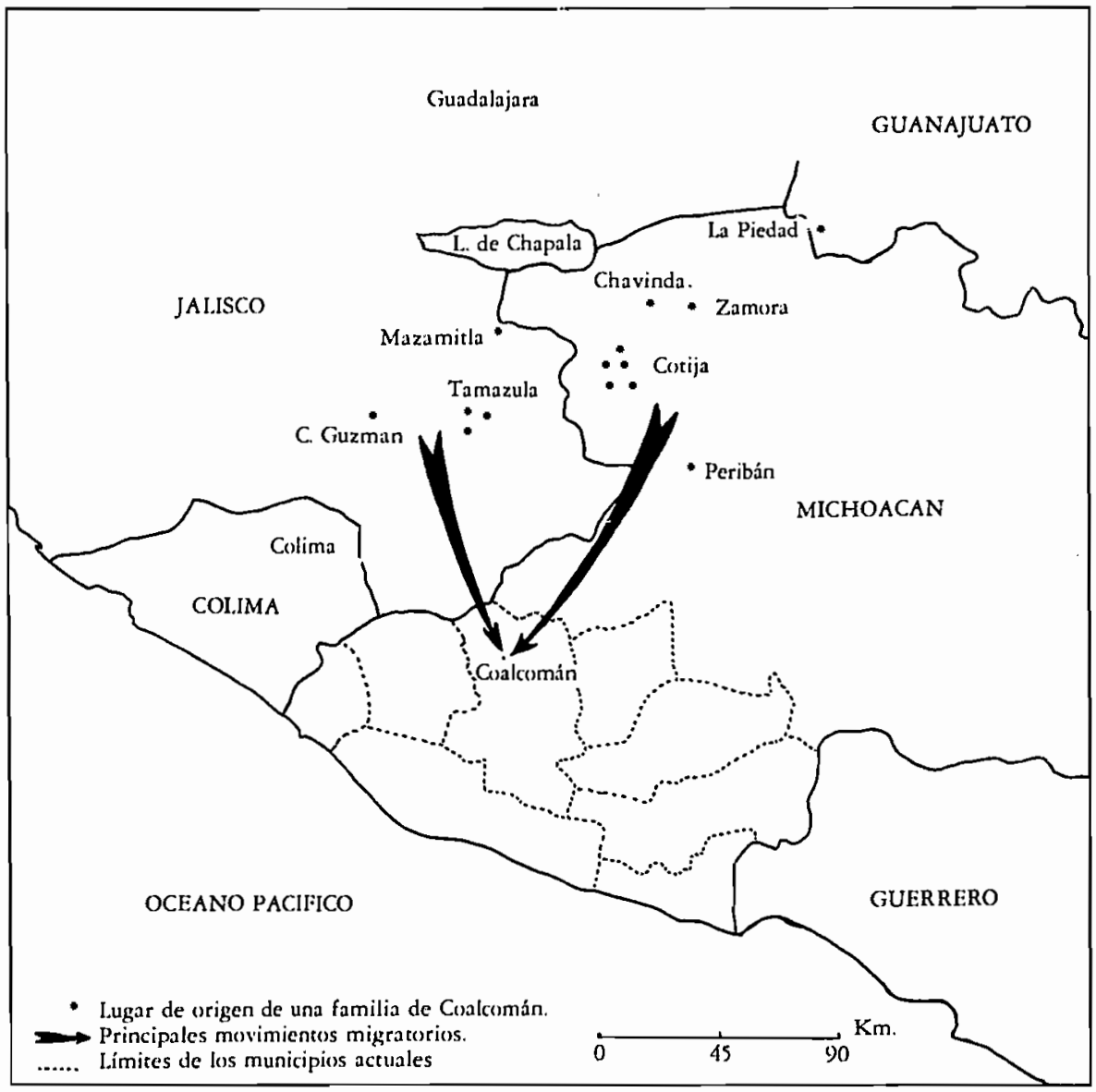

Fuente: entrevistas realizadas en el municipio de Coalcomán. Oct. I985 - Mayo 1986. 
se habían arrendado durante la primera mitad del siglo XIX. ${ }^{15}$ En cambio, el informe de J. G. Romero testifica que en 1868 -antes del reparto- la desamortización de las tierras comunales se encontraba en camino: "Que se le pida [al emperador] el repartimiento de terrenos baldíos entre los muchos indígenas que imprudentemente vendieron a vil precio sus predios de comunidad, y los que por no tener ocupación están próximos a lanzarse al robo o a la revolución". ${ }^{16}$ No conocemos la extensión de estos predios ya enajenados pero el proceso de despojo había empezado. Sin embargo, muchos comuneros iban a quedarse con uno de los lotes atribuidos; no por mucho tiempo.

La gente de razón, incluyendo a los migrantes recién llegados, adquirió las tierras. "...comenzaron los indígenas partícipes a enajenar la parte que en dicho reparto les tocó, y esto por menos de la mitad del justo precio en que debían de estimarlos..". ${ }^{17}$ "El representante de los indígenas aceptó la venta de la casa de la comunidad". ${ }^{18}$ Muchos testimonios evocan la ingenuidad de los indios para explicar la facilidad de los negocios. ¿Acaso bastaba regalar un espejo o un barril de vino para apoderarse de un terreno inmenso?

Algunos años después el "grupo de los 65" - los nuevos propietariosjustificaría su situación diciendo que los indios vendieron libremente; "...el consentimiento de las partes siendo [es] la piedra angular de los contratos". ${ }^{19}$ $Y$ de igual manera explican el desplazamiento espacial: "Los indios se fueron por el lado de la costa. Se corrieron solos", ${ }^{20}$ ¿o alguien los corrióo En realidad los funcionarios encargados del reparto eran mandados por el gobierno liberal pero poco escrupulosos. Se hizo un "simulacro de medición", no se afectaron los terrenos periféricos ya despojados por las haciendas circunvecinas del Terrenate y de Trojes que se extendían a costa de los terrenos comunales de Coalcomán. El prefecto y el comisionado se atribuyeron grandes extensiones de terrenos comunales de Terrenate.

Además, las gentes de razón ya propietarios, empezaron a introducir ganado "lo que pronto originó conflictos entre ganaderos y agricultores, debido a que los ganados pronto invadieron las tierras cultivadas por los comuneros". ${ }^{21}$ Los indígenas tenían poco ganado. Eran agricultorescazadores, descansando ambas actividades sobre el bosque (el sistema de cultivo era de roza, tumba y quema) y no había cercas para defenderse. Por si fuera poco, los puñales y los balazos acabaron de limpiar el terreno. El comunero Manuel Jiménez "fue muerto a puñaladas porque defendía sus

16. G. Sánchez Díaz, El Suroeste de Michoacán 1821-1851, op. cit., p. 44 a 55. Dr. José Guadalupe Romero, op. cit., p. 563.

17. Según lo informó el prefecto de Coalcomán citado por R. Arreola Cortés, op. cit., p. 197.

18. R. Arreola Cortés, op. cit., p. 197, véanse también los mapas 15 y 17.

19. R. Arreola Cortés, op. cit., p. 200.

20. Entrevista a Santos Virrueta, El Aguacatito, Coalcomán.

21. G. Sánchez Díaz en Movimientos, p. 36. 
siembras de una vaca que se las talaba". 22 Todo se acabó a principios del siglo $\mathrm{XX}$ con la matanza de Camichines donde murieron los últimos comuneros. ${ }^{23}$ Los trámites intentados por ellos para recuperar sus tierras (anulación del reparto, solicitud para que se hiciera otro reparto, medición de los terrenos) y la rebelión armada de 1875 quedaron inútiles. ¡Hasta el cura era de los nuevos terratenientes!

Cuando llegó la segunda ola de migrantes a principios de este siglo, ya no quedaban tierras que repartir. El valle y la sierra de Coalcomán tenian sus propietarios, sus rancheros. Muchos compraron tierras a los recién llegados de la primera generación (1870-90). Así se fincaron las familias Moreno, Munguía, Contreras, Tejedo, etc. Las tierras compradas a los indígenas con un espejo o un barril de vino se vendieron a un precio mucho mayor. Las ganancias así realizadas por los migrantes de la primera generación les permitieron adquirir grandes terrenos más hacia la costa. Allá, en las comunidades indígenas de Huitzontla, Maquilí y Pómaro no se había llevado a cabo el reparto de las tierras pero el alza de las contribuciones catastrales les forzaba a arrendar, hipotecar o vender partes de sus tierras. ${ }^{24}$ Las familias Magallón, Pallares, Sánchez, entre otras, se establecieron así en los terrenos comunales de Huitzontla y Ostula (Estopila). En 1911 se formaba la hacienda de Cohuayula sobre los terrenos comunales de Ostula (Estopila). Los Mendoza y los Betancourt se fincaron en las tierras de Pómaro (San Antonio, E1 Fresno, etc...). ${ }^{25}$

Algunos ganaderos no volvieron a comprar tierras; con el dinero proveniente de la venta de sus propiedades a los compradores de la "segunda generación" adquirieron más ganado. Empujaron los animales hacia los terrenos de las comunidades de la costa para que pastaran allá mediante una pequeña "contribución" pagada a las autoridades indígenas. Sin necesidad de comprar tierras, se apoderaron así de superficies inmensas hasta las playas del Pacífico.

Entre los migrantes de la "segunda generación" es probable que muchos hay an comprado partes de los latifundios que rodeaban la región de Coalcomán en el siglo XVIII (véase mapa 17). Algunos se habían extendido en detrimento de la comunidad indígena de Coalcomán pero otros se

22. Informe del presidente municipal al prefecto de Coalcomán 23 de noviembre de 1872 (APEM Hijuelas, Coalcomán, vol. 3 f. 29) citado por G. Sánchez, idem.

23. G. Sánchez, El suroeste de Michoacán 1852-1910, p. 330.

24. G. Sánchez, "Reparto y resistencia en las Comunidades Nahuas de la Costa de Michoacán 1869-1908" en Boletín del Centro de Estudios de la Revolución Mexicana "Lázaro Cärdenas", A.C., Mayo 1982, p. 3 a 11.

25. Entrevistas a Manuel Moreno, Santos Virrueta, Daniel Betancourt, Esteban Valdovinos; G. Sánchez Dlaz, Reparto, pp. 3 a 11; ver también el Capitulo 5. 


\section{MAPA No 17. TENencia DE la TIERRA Y Formacion DE LOS RANCHOS EN LA SIERRA DE COALCOMAN $1870-1920$}

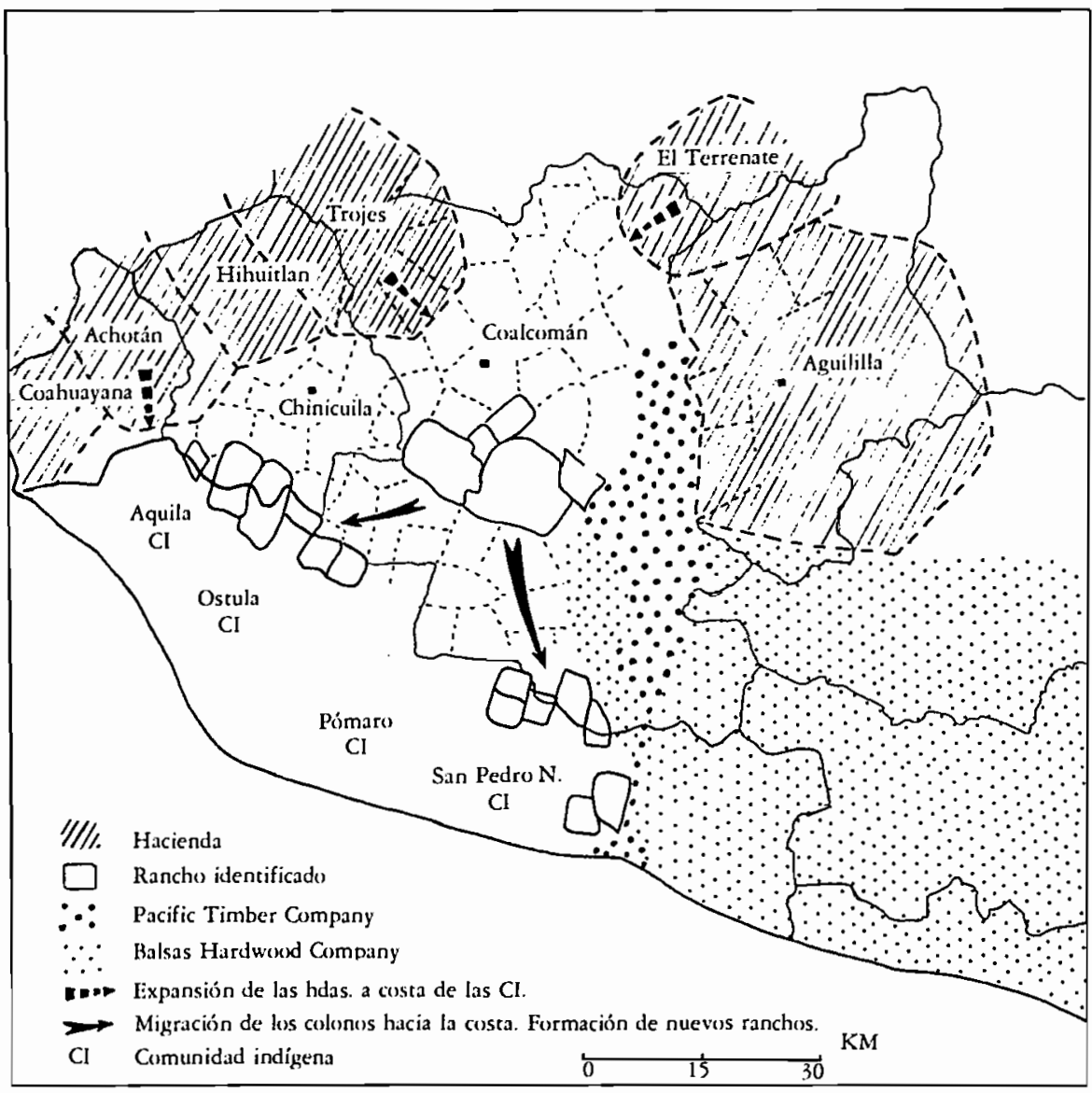

Fuente: Mapa establecido a partir de la bibliografía citada en el texto y de las entrevistas realizadas en la región. Los linderos de los ranchos y de las haciendas no se conucen con precisión. Se marcaron solamente los ranchos para los cuales la información que tenemos basta para ubicarlos en el mapa. 
estaban fraccionando como la hacienda de Hihuitlan, ${ }^{26}$ la de Trojes, ${ }^{27}$ o la de Aguililla. ${ }^{28}$ Quedará por investigar si los compradores de estas fracciones fueron los antiguos arrendatarios o gente de fuera (nuevos migrantes). La llegada de numerosos migrantes al municipio de Aguililla durante el Porfiriato hacen pensar que ellos fueron los principales adquisitores. ${ }^{29}$

\section{Nace la pequeña propiedad}

Ambos flujos de migrantes transformaron totalmente la estructura agraria de la región de Coalcomán constituyendo a la pequeña propiedad como fundamento jurídico de una nueva unidad de producción agropecuaria: el "rancho". Los mestizos acabaron con los indígenas de Coalcomán y sus terrenos comunales. Se fueron comprando tierras más allá de los linderos actuales del municipio de Aquila, quitando a las comunidades de la costa, parte de sus terrenos. Las propiedades así formadas no eran latifundios inmensos como los del siglo XVIII. Tampoco eran minifundios. Su tamaño iba de algunos centenares hasta varios miles de hectáreas. ${ }^{30}$

Este cambio de las estructuras agrarias en el valle de Coalcomán y en las sierras circunvecinas no invalida la formación simultánea de dos "neolatifundios" forestales por parte de compañías norteamericanas. Entre 1908 y 1911 la Pacific Timber Company compró las extensiones boscosas de pino y encino ubicadas sobre las mesetas calcáreas del sureste del municipio (Barranca Seca, Ojo de Agua de Vargas, El Varaloso, La Soledad, Joya Grande), numerosas barrancas cerca de la costa, ricas en maderas preciosas (La Patacuera, Cabeza de Vaca, La Palmita) y todo el valle del río Guagua y su boca en el mar, para sacar la madera por vía marítima. Todas hacían un total de 40,000 hectáreas. En 1911, un tal Rodríguez alcanzó a comprar 350,000 hectáreas en los municipios de Coalcomán, Aquila, Tumbiscatío, Arteaga y Lázaro Cárdenas (municipios actuales) para rentarlos a la Balsas Hardwood Company con el objeto de explotar la madera. De este modo, estas empresas

26. G. Sánchez Dlaz, El suroeste de Michoacán 1852-1910, p. 155

27. Entrevista con Fernando Sánchez, el Salitre de Maruata.

28. La hacienda de Aguililla tenía 142,000 hectáreas en 1884 (G. Sánchez, op. cit. p. 104) pero parece fraccionarse poco después.

29. Roger Rouse, Population mouvements in the municipio of Aguililla, southwest Michoacan from the middle of the nineteenth century to the revolution. Stanford University, Coloquio Migraciones, CEMCA Julio 1986.

30. François Chevalier delimita la superficie de la "pequeña propiedad" en el occidente de México asf: "Su tamaño es muy variable: desde una o dos estancias de ganado (de 1,700 Has.) en zonas poco pobladas, hasta una o varias caballerías de tierras de labor de temporal (de 43 Has.) y a veces menos". "Acerca de los orígenes de la pequeña propiedad en el occidente de México. Historia comparada", en Después de los latifundios. III Coloquio de Antropología e Historia Regionales. El Colegio de Michoacán, Zamora, 1981, p. 3. 
capitalistas apartaron a regiones inmensas de la economía campesina. ${ }^{31}$

Origen de los migrantes y acumulación

Hemos identificado dos regiones proveedoras de migrantes. el Sur del estado de Jalisco (Tamazula, Cd. Guzmán, Mazamitla) y la parte noroeste de Michoacán iCotija, Zamora, Chavinda, La Piedad). Ambas regiones estan ubicadas al norte de Coalcomán distantes de cien a ciento cincuenta kilómetros en línea recta (véase el mapa 16). Cabe preguntarse: ¿quiénes eran estos hombres?, ¿por qué abandonaron su lugar de origen para establecerse en la sierra de Coalcomán?

En primer lugar, cabe señalar que en su mayoria, los migrantes no tenían propiedades antes de llegar a Coalcomán. No eran terratenientes. Mientras unos trabajaban de peones o arrendatarios en las haciendas de Tamazula, otros eran arrieros o traían algún negocio de la sierras de Cotija. Entre las razones que los incitaron a irse, encontramos el crecimiento poblacional que se manifestaba en el occidente de México durante el siglo XIX pues la presión sobre la tierra aumenta en las zonas altamente pobladas del Bajío. ${ }^{32}$ Era mas fácil y mas barato hacerse ranchero en la frontera agrícola de la Sierra Madre del Sur, que comprar una fracción de hacienda en el Bajío. Por otro lado,

la arrierfa michoacana empezó a decaer (en la década de los ochentas del siglo XIX), debido al tendido de las primeras vías férreas; muchos arrieros cotijeños empezaron a quedar sin chamba y no les quedó otro camino que vender sus mulas para dedicarse a otras actividades. Muchos enfilaron para la Tierra Caliente a meterse de ganaderos y comerciantes, de esa forma, los pueblos de Buenavista, Tepalcatepec, Aguililla y Coalcomán se vieron invadidos por los Morfín, los Mendoza, los Guízar, los González, los Valencia, los Ochoa, etc.. ${ }^{33}$

Así que muchos migrantes ya conocían Coalcomán cuando llegaron a establecerse allí. Habían encaminado hatajos de mulas por estas comarcas cuando iban a comerciar con las comunidades indígenas de la costa. Tenían sus contactos, conocían a las autoridades. ${ }^{34}$ Cabe destacar que el movimiento

31 Véase los trabajos de J. N. Guzmán Avila, Michoacán y la inversión extranjera 1880-1911. UMSNH, Departamento de Investigaciones Históricas, Morelia, 1982 p. 125 a 131 y G. Sánchez D., El suroeste de Michoacán 1852-1910, pp. 168 a 178.

32. Hipótesis formulada para la región de Aguililla por R. Rouse, op. cit., p. 9.

33. G. Sánchez Días "Mulas, hatajos y arrieros en el Michoacán del siglo XIX" en Relaciones, Estudios de Historiay Sociedad, No. 17, El Colegio de Michoacán, invierno 1984. pp. 50-51.

34. Aguililla era también un lugar conocido de los arrieros de Cotija: "A small entrepot in the trade that was developing between the Indians on the coast and the muleteers from Cotija". R. Rouse insiste sobre los lazos preexistentes que habia entre la zona de Aguililla y las regiones de origen de los migrantes, en Population Mouvements, p. 10. 
de colonización de la Sierra Madre del Sur por los mestizos seguiría durante el siglo XX hacia la costa, hasta la comunidad indígena de Pómaro. Allá, muchos de los mestizos recien "fincados" - segunda mitad del siglo XXtambién fueron arrieros. El acercamiento de los colonos hacia la costa, ilustrado en el mapa 17 y la invasión de la comunidad de Pómaro en los años sesentas, ${ }^{35}$ siempre estuvieron emprendidos por los "fleteros" y los negociantes.

El precio de la tierra era más bajo en las zonas de colonización agrícola de la sierra de Coalcomán que en el Bajío. Así que un arriero fácilmente podía comprar desde varios centenares de hectáreas hasta mil con las utilidades que sacaba de su trabajo en un año. El informe de Mr. A. de Harivel, dueño de la hacienda de Bellavista de Achotan en 1877 (Estadística de la República Mexicana 1880 citada por Arreola Cortés en: Coalcomán, pp. 208 a 215), nos permite hacer el cálculo siguiente. El flete de Coahuayana a Colima valía 2.50 pesos/carga (p. 210) para un viaje de 22 leguas. Consideremos un arriero con un hatajo de 10 mulas haciendo el viaje en 5 días. Saca un producto de 25 pesos por viaje. Si se le substrae 2 pesos de jornales ( 5 jornales de 40 centavos para un mozo), 1.5 pesos de maíz para las bestias (la fanega valía 0.75 pesos - p. 210 - el arriero compra diariamente una medida por animal) y 1.5 pesos de comida y hospedaje, queda una utilidad de 20 pesos por viaje ( 40 pesos por una ida y vuelta). Considerando que el arriero puede fácilmente hacer dos idas y vueltas por mes durante los 8 meses de la estación seca, obtenemos una utilidad de 640 pesos/año de puro flete sin tomar en cuenta las utilidades de los negocios adicionales. En aquella época la tierra valía entre 5 y 20 pesos la fanega según Mr. de Harivel -aproximadamente entre 1 y 5 pesos por hectárea, (p. 209)-, en el municipio de Coahuayana. En los terrenos de montaña de la sierra de Coalcomán, pensamos que el terreno valía todavía menos de 1 peso por hectárea (este precio corresponde al precio promedio pagado 30 años después por la Pacific Timber Company).

Asimismo, muchos de los migrantes que trabajaban antes como peones o arrendatarios, no llegaron totalmente desprovistos de dinero. Con la venta de los treinta animales que habían logrado tener con su trabajo "por contrato" en la hacienda de Tamazula, Pascual Moreno alcanzó a comprar 3,000 Has, cerca de Coalcomán en asociación con un amigo. ${ }^{36}$

No hubo tierra para todos. Los que llegaron al último, o sin tener nada, encontraron un terreno ya demasiado ca ro para sus recursos. Empezaron de medieros en los ranchos recién formados. Mientras que los últimos indios

35. Véase Capítulo V: Campesinos y ganaderos de la comunidad de Pómaro. Historia de un enfrentamiento.

36. Entrevista a Manuel Moreno, Coalcomán, Mich. 
huían hacia la costa, ${ }^{37}$ ellos sembraban maíz para engordar las piaras de puercos del dueño de la tierra.

Conclusión

La desamortización de las tierras comunales y el fraccionamiento de los latifundios empezaron muy pronto en el occidente de México, mucho antes de la época liberal. Jean Meyer demostró que la pequeña propiedad nació en el Bajío a partir del siglo XVIII ${ }^{38}$ para independizarse durante el siglo XIX ${ }^{39}$

Esta población de rancheros sigue creciendo (...) durante el curso del siglo XIX. Se expande principalmente desde los Altos de Jalisco, Cotija, etc.. hacia las tierras pobres, vacías, mal defendidas y menos pobladas del Sur, del oeste y quizá, también del norte y noreste. 40

Las tierras "pobres, vacías, mal defendidas y menos pobladas" de Coalcomán se llenaron de rancheros a fines del siglo XIX. La colonización de la Sierra Madre del Sur por los mestizos del occidente de México a fines del siglo XIX y la continuación del movimiento hacia la costa durante el siglo $\mathrm{XX}^{41}$ transformaron definitivamente el sistema agrario de la región. Instituyeron la pequeña propiedad: el rancho, su dueño y sus medieros.

\section{UN SISTEMA AGRARIO NUEVO (1900-1950)}

Cuando surge el rancho, a fines del siglo XIX, el bosque domina todavía, casi exclusivamente, el paisaje agrario. Fuera del valle de Coalcomán ya desmontado y destroncado varias decenas antes, las encineras y las pineras cubrían la mayoría de los cerros circunvecinos mientras que el bosque tropical cubría las barrancas calientes rumbo al sur. A los cincuenta años, salvo las zonas altas, toda vía cubiertas de pinos y encinos y la costa árida del Pacífico, el paisaje estaba humanizado, transformado. No quedaba práctica-

37. Entrevistas a Juan Trelles, Rafael Niño, Vicente Mendoza, Socorro Moreno y Jesús Mejía.

38. Jean Meyer, Esperando a Lozada, El Colegio de Michoacán-CONACYTs, 1984, p. 32.

39. François Chevalier y Luis González, Acerca de los origenes... op. cit., p. 5 y 10.

40. Ibid. p. 4-5.

41. Véase la invasión paulatina de la Comunidad de Pómaro, Capitulo V. 
mente ningún área que no hubiera sido desmontada recientemente. ${ }^{42} \mathrm{La}$ densidad de población, bajísima en los siglos anteriores - menos de un habitante por $\mathrm{Km}^{2}$ - subió a dos habitantes por $\mathrm{Km}^{2}$ en 1890 y a cuatro en 1920. Sin embargo, una familia de seis personas disponía de 150 hectáreas en promedio: mucho más de lo que permitían las densidades de población de las regiones de origen de los migrantes. En realidad, los propietarios poseían mucho más que esta superficie mientras que la mayoría de los campesinos eran aparceros.

\section{El rancho}

Suele considerarse que Coalcomán renació con la llegada de los migrantes: ${ }^{43}$ "los de Cotija", traían el progreso. impedido hasta entonces por los "inditos de la costa". ¿De cuál progreso se trataba? Veamos el nuevo modo de aprovechamiento del medio que se establece.

Las tierras de yunta

Con la instalación de los ranchos, se destroncan muchos montes para volverlos tierra de labranza. Estos terrenos y el sistema de cultivo que se les aplica se vuelven tan importantes como los desmontes en los sistemas de producción. Por lo general, están ubicados en los lugares menos accidentados: terrazas, rellanos, cimas redondeadas o vertientes de poca inclinación. La superficie trabajada con yunta en cada rancho dependía de la mano de obra disponible, lo que quiere decir del número de medieros "asociados" con el patrón. Un rancho en el cual tres medieros sembraban "de yunta", mientras que los demás se dedicaban al desmonte, contaba con 15 hectáreas aradas cada año más lo que podía arar el patrón o sus hijos ( 465 Has. más). Pese a la extensión de las "yuntas" y a su papel en el sistema de producción, los terrenos barbechados no representaban más que el $263 \%$ de la superficie municipal. ${ }^{4}$ Se sembraba el maíz, muchas veces asociado con la calabaza durante el primer año y se dejaba descansar la tierra todo el año siguiente -16 meses entre la cosecha en enero y el barbecho del año siguiente en

42. Testimonio de D. D. Brand, op. cit., p. 175. "outside of the areas of pine and oak forests in the highlands and a strip of coastal granities, the evidence is that recurrent shitts in location of cleared fields and of settlements sites through the centuries have left practically no areas of virgin vegetation uncleared nor any 'natural' habitation sites without the marks of human occupation" Los Indios del Sur no habian huido todavia hacia las playas de la costa que quedaba vacia de habitantes.

43. "Aguililla y Coalcomán, casi destruidas, renacieron de nuevo al establecerse en ellas familias de Cotija", G. Sánchez D., El suroeste de Michoacán 1852-1910, p. 535.

44. El censo agrícola de 1930 da la cifra de 8,795 Has. de temporal para el municipio de Coalcomán $(300,000$ Has. $)$. 
mayo-, después de que los animales hubiesen comido el rastrojo. Así que el terreno sometido a este sistema de cultivo era, en el ejemplo citado, de 30 hectáreas. En algunos ranchos, el garbanzo se sembraba después del maíz como segundo cultivo en octubre, 8 meses después de la pizca del maíz y cosechado en marzo poco antes de volver a sembrar la milpa.

El barbecho, el aporque ${ }^{45}$ y la escarda se hacían con el arado de palo (hecho de tepehuaje, encino o amoles) reforzado con una reja de fierro ${ }^{46}$ y la yunta de bueyes. Este arado no permitía llevar a cabo un verdadero barbecho. Sólo rascaba la tierra con la punta, haciendo una raya poco profunda en el suelo sin voltearlo. En lo más parejo, se podía "cruzar" para remover mejor la tierra, pero en las faldas, los bueyes no lo podían hacer. Iban siguiendo las curvas de nivel y dejaban así sucesiones de escalones - parte no tocada del terreno-y micro-terrazas (raya). El arado "extranjero" de vertedera se generaliza tardíamente en la región de Coalcomán. Los rancheros adquirieron esta herramienta a partir de los años cuarenta cuando la mayoría de los campesinos colimotes tenían la suya en $1930^{47}$ y las haciendas de tierra caliente desde mucho antes.

El año de descanso o el garbanzo sembrado después del maíz, la presencia del ganado después de la cosecha y la recolección del guano de murciélago como abono en las numerosas grutas de la sierra, permitían esperar un rendimiento de 60 a 100 cargas de maíz por anega de siembra, aproximadamente de 1 a 1.5 toneladas por hectárea. ${ }^{48}$

El desmonte

El cultivo bajo el sistema de roza, tumba y quema, casi exclusivo en los siglos anteriores sigue siendo de primera importancia. En cada rancho, dos o tres medieros se dedicaban a desmontar y sembrar en los cerros. Con el aumento demográfico la demanda de maíz se multiplicó y la superficie de monte tumbada cada año se incrementó. En el sur del municipio, toda la selva tropical caducifolia se consideraba apta para ser tumbada salvo en las barrancas más húmedas donde los árboles forrajeros - uje (Brosinum alicastrum), parota (Enterobium cyclocarpum) - de la selva subcaducifolia servían para engordar puercos; (estudiamos la lógica de este sistema de cultivo en el capítulo 5). En cambio, en la zona templada del municipio —entre 1,000 y 2,000 m.s.n.m-, el patrón de cultivo y la rotación forestal se

45. Aporque: acción de aporcar, arrimar tierra a la base de las plantas para lograr mayor sostén y eliminar las pequeñas malezas. Diccionario Agropecuario de México. INCARURAL, 1982.

46. En 1883 en el rancho de Las Ferrerías, 4 a 6 personas se dedicaban a hacer rejas y fierros extrayendo ellos mismos el fierro. G. Sánchez D., op. cit., p. 349.

47. Hubert Cochet, Historia agraria del municipio de Coquimatlin, Colima. Universidad de Colima, 1987. En prensa.

48. Entrevista con Juan Trelles (Coalcomán) y Socorro Moreno (Los Tepehuajes). 
diferenciaban un poco. Se tumbaron las encineras para sembrar maíz y a veces frijol pero las pineras no servían por la acidez del suelo. Además, cuando se derribaba un bosque de pino para sembrar, a pesar de la acidez, rara vez volvían a crecer pinos. Lo que crecía más bien era un bosquecillo a base de jalilla china. Al bosque de pino le sustituyó un monte caducifolio que ofrecía mejores condiciones de cultivo cuando se volvía a tumbar, por la hojarasca, que podía quitar al suelo una parte de su acidez. Además, la altura impedía un desarrollo del renuevo forestal tan rápido como sucedía cerca de la costa. Según la orientación de las vertientes y la calidad del subsuelo calcáreo o esquistoso, la gente derribó las encineras pero dejó las cuchillas de pinera expuestas al norte y por lo tanto más frías. Esta discriminación se nota en el paisaje actual donde el monte bajo corresponde mucho más a antiguas encineras que a antiguas pineras. Los bosques hojosos fueron siempre los preferidos para cortars; sólo se conservaron los árboles útiles para levantar cercas como el tepehuaje, Lysiloma acapulcensis o para engordar el ganado como el güizalacate, el ucach, el chaparrillo, el guajillo, el abrojo (Xanthium Strumarium). Cabe destacar que el tamaño del rancho era suficiente para que siguiera la rotación forestal sin disminuir el período de descanso y el renuevo forestal. Un rancho en el cual tres medieros desmontaban anualmente una anega cada uno contaba ${ }^{49}$ con 18 hectáreas de milpa sembrada bajo tumba, roza y quema. 360 hectáreas bastaban para que la rotación forestal fuese de 20 años correspondiendo a un año de cultivo y 19 de renuevo forestal y que la biomasa acumulada fuera suficiente para el próximo ciclo de cultivo.

La caña de azúcar

En el siglo XIX la región de Coalcomán se encontraba bordeada de haciendas cañeras (Nuevo Urecho y Apatzingán al noreste, Hihuitlán, Trojes, Pihuamo y Tecalitlán al noroeste, pero la producción local de caña era muy débil "en tan pequeña escala que apenas cubría el consumo local". 50 En 1889, todo el distrito de Coalcomán ( 4 municipios actuales: Coalcomán, Coahuayana, Aquila y Chinicuila) contaba con 8 molinos de caña.51 A principios del siglo, la producción de caña aumentó bastante. Muchos ranchos tenfan su molino o utilizaban el del vecino para moler su caña. Según don Manuel Moreno, en 1907, el valle de Coalcomán estaba totalmente plantado de caña y contaba con 20 molinos. La caña perduraba

49. Una anega equivale a $6 \mathrm{Has}$. (considerando que la anega corresponde a 24 medidas y que se siembran cuatro medidas por hectárea).

50. En 1883 según R. Arreola C., op. cit., p. 221. Se refiere al informe de Manuel de Anda reproducido en el Boletín de la Sociedad Michoacana de Geografía y Estadística (1905-1906) No. 23. p. 181.

51. G. Sánchez, El suroeste de Michoacán 1852-1910, p. 460. 
hasta ocho años. Después de este tiempo se arrancaba y se sembraban maíz y frijol algunos años para volver a plantar caña después. Si consideramos que un molino tenía capacidad para moler seis hectáreas de caña durante el invierno y la primavera, la superficie plantada con caña llegaba a 120 hectáreas en el valle de Coalcomán sin tomar en cuenta los numerosos cañaverales diseminados en la sierra según los ojos de agua existentes y las posibilidades de riego. Pero la región nunca llegó a vender fuera de ella azúcar, piloncillo o aguardiente. La productividad del trabajo era superior en los cañaverales del sur de Jalisco o de tierra caliente. Allá tenían carreteras para llevar la caña al molino cuando eso se hacía a lomo de bestia en Coalcomán; y los molinos de hierro, aunque más productivos que los de madera, no alcanzaban a moler más caña que la que producían cinco o seis hectáreas. Sin embargo, no oímos tampoco que los arrieros tuviesen que traer piloncillo de fuera para venderlo en Coalcomán. Se producía lo que se consumía o un poco más.

Es probable que de esa época daten las zanjas de riego que todavía son utilizadas ahora y cuyos rastros se dejan ver en algunas partes. En muchos lugares se podía así regar una pequeña parte del terreno para cultivar además de la caña, el frijol, la papa, el camote, algunos vástagos y árboles frutales. Eran superficies muy reducidas que juntas no representaban el $0.2 \%$ del terruño ${ }^{52}$ pero aseguraban parte del autoconsumo de la gente (véase gráfica 22).

\section{Las cercas}

Cuando se formaron los ranchos en la sierra de Coalcomán, las propiedades de cada uno se conocían gracias a las mojoneras pero no había cercas. Los medieros tenían que cercar su labor o desmonte con madera para protegerlo del ganado del patrón y éste se pasaba muchas veces de los límites del rancho. Poco a poco, la gente empezó a traer alambre de púas de Colima para cercar el rancho. Los vecinos se ponían de acuerdo para que cada uno mandara hacer la mitad de la cerca colindante salvo si el límite fuese camino real. En 1940 es probable que todas las propiedades se encontraban cercadas, hasta los límites del municipio de Aquila (en 1905, al formarse la "hacienda" de Coahuayula, se levantó la primera cerca de alambre de púas). ${ }^{53} \mathrm{Mas}$ allá, el terreno seguía "libre" hasta las playas del Pacífico.

La ganadería

El ganado que se multiplicaba en los ranchos era de "raza" criolla y de doble propósito. Se ordeñaban algunas vacas durante las aguas para elaborar un

52. El censo agrícola de 1930 da la cifra de 354 Has. para el municipio, o sea aproximadamente el $0.1 \%$ de la superficie.

53. Entrevista con Esteban Valdovinos, Colima, Col. 

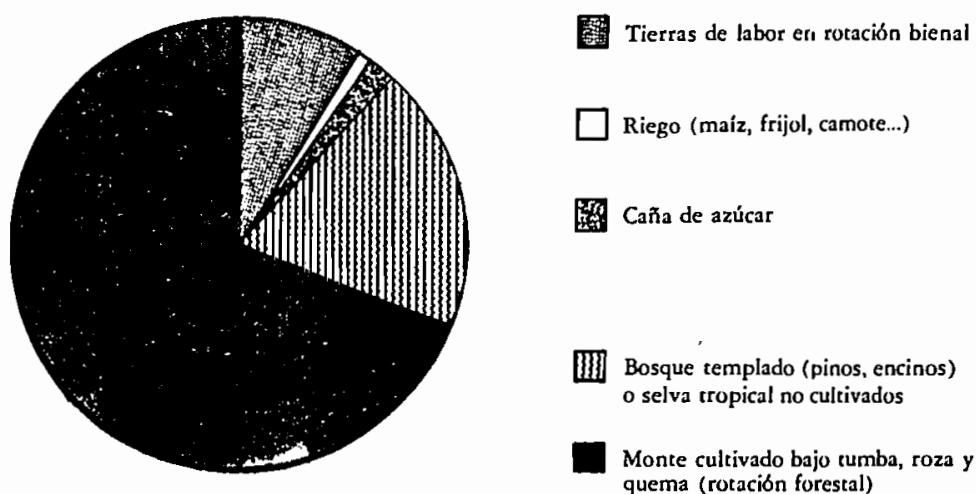
quema (rotación forestal)

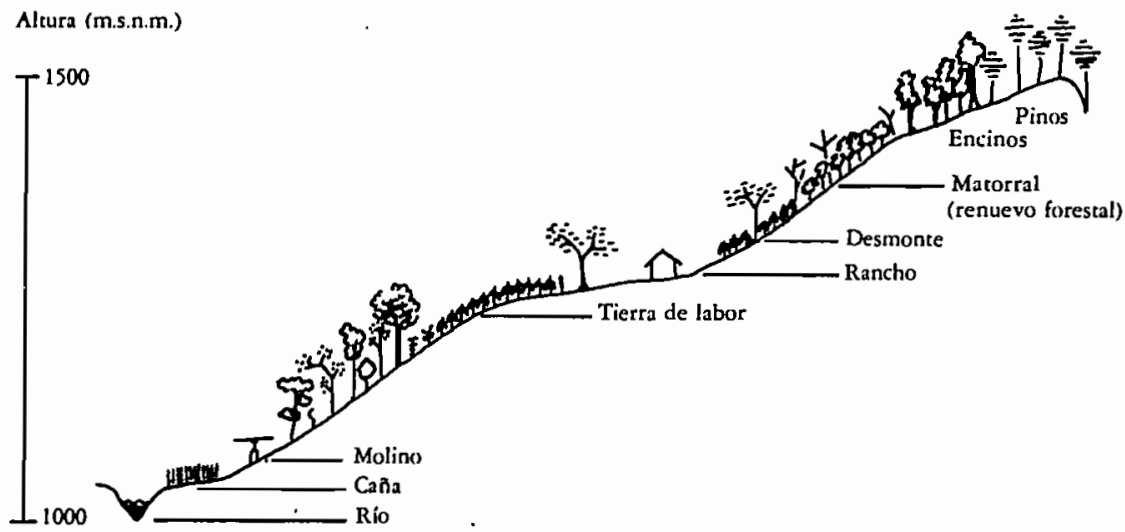

queso parecido al queso Cotija (posiblemente hayan traído la experiencia de allá). Con la ordeña de 20 vacas, y dejando leche a los becerros, se confeccionaba una pieza de 10612 kilogramos juntando la leche de dos días. Casi no se ordeñaba durante la estación seca. Las vacas se juntaban con los demás animales y se mantenían "solas" en el rancho hasta que se abrieran las labores después de la pizca. De febrero en adelante, comían el rastrojo y sólo a fines de las secas se les daba maíz rallado a los animales más débiles 
que no encontraban con que mantenerse debajo de los árboles forrajeros del monte.

En aquel tiempo no se vendían los animales jóvenes como ahora, sino más bien los novillos de 3 a 5 años listos para ser capados y amansados. Cada año los ganaderos juntaban los animales mas cornudos para llevarlos a la feria de Peribán. Los agricultores de Cotija, Zamora y Guanajuato los compraban para amansarlos y hacerlos bueyes. La feria de Peribán, que era una vez al año, el Domingo de Ramos, representaba el principal canal de comercialización de los bovinos de Coalcomán. Los demás animales se vendían directamente a las haciendas cañeras (novillos) o eran sacrificados en Coalcomán. Los cueros curtidos en el pueblo se vendían a los artesanos o se expedían a Sahuayo para la industria huarachera. ${ }^{54}$ Algunos de los recién llegados de Cotija o Tamazula se dedicaban a comprar animales a los ganaderos de las comunidades indígenas del municipio de Aquila o a los pocos indios que tenían ganado, para venderlos a Peribán o en la Cañada de los once pueblos ${ }^{5}$ (véase mapa 18). Cabe destacar los numerosos lazos que entretejía la economía agropecuaria de Coalcomán con las regiones de origen de los migrantes. Trajeron con ellos la caña y el queso, pero volvían muy seguido a sus regiones a vender animales. ¡Era gran negocio el vender novillos!

El otro negocio era el de engordar puercos con el maíz. Las crisis sucesivas en las cuales se encontraba la producción de maíz a fines del siglo XIX en el suroeste de Michoacán ${ }^{56}$ y las alzas de precios, favorecían su venta a las haciendas circunvecinas. Pero era más costeable venderlo bajo una forma condensada y movible por sí misma como los cerdos. Tres o cuatro veces al año (de noviembre a mayo) las piaras de puercos iban a venderse a Colima o Ciudad Guzmán. El viaje duraba un mes puesto que era conveniente andar "al pasito" para que los puercos engordaran en camino con las bolas caídas de los númerosos árboles forrajeros que se encontraban en las barrancas. Además, 10 o 12 bestias acompañaban la piara (de 50 a 200 cerdos) para cargar el maíz que se les daba. En 1883 un cerdo gordo valía el precio de 7 anegas de maíz. ${ }^{57}$ En 1950, valía como 20 anegas de maíz $z^{58}$ cuando 3 ó 4 bastaban para que se pusiera gordo. Cuando las avionetas

54. Entrevista con Hermelinda Garibay, Coalcomán.

55. Según don Manuel Moreno M., la cañada de los once pueblos funcionaba como centro de acopio para el ganado. Los indigenas de la región purépecha se abastecian allá de animales de todo tipo (salvo los novillos que iban a Peribán).

56. G. Sánchez D., op. cit., p. 423.

57. Cálculo realizado a partir de Memorias del Estado de Michoacán, citadas por R. Arreola C., op. cit. p. 226.

58. Según entrevista con Esteban Valdovinos, Colima: un puerco de $100 \mathrm{Kg}$. valía 250 pesos y la anega de maíz estaba a 12 pesos. 
Mapa No 18 . Destino de las ventas de ganado del municipio de Coalcoman DURANTE L.A PRIMERA MITAD DEL SIGIO XX

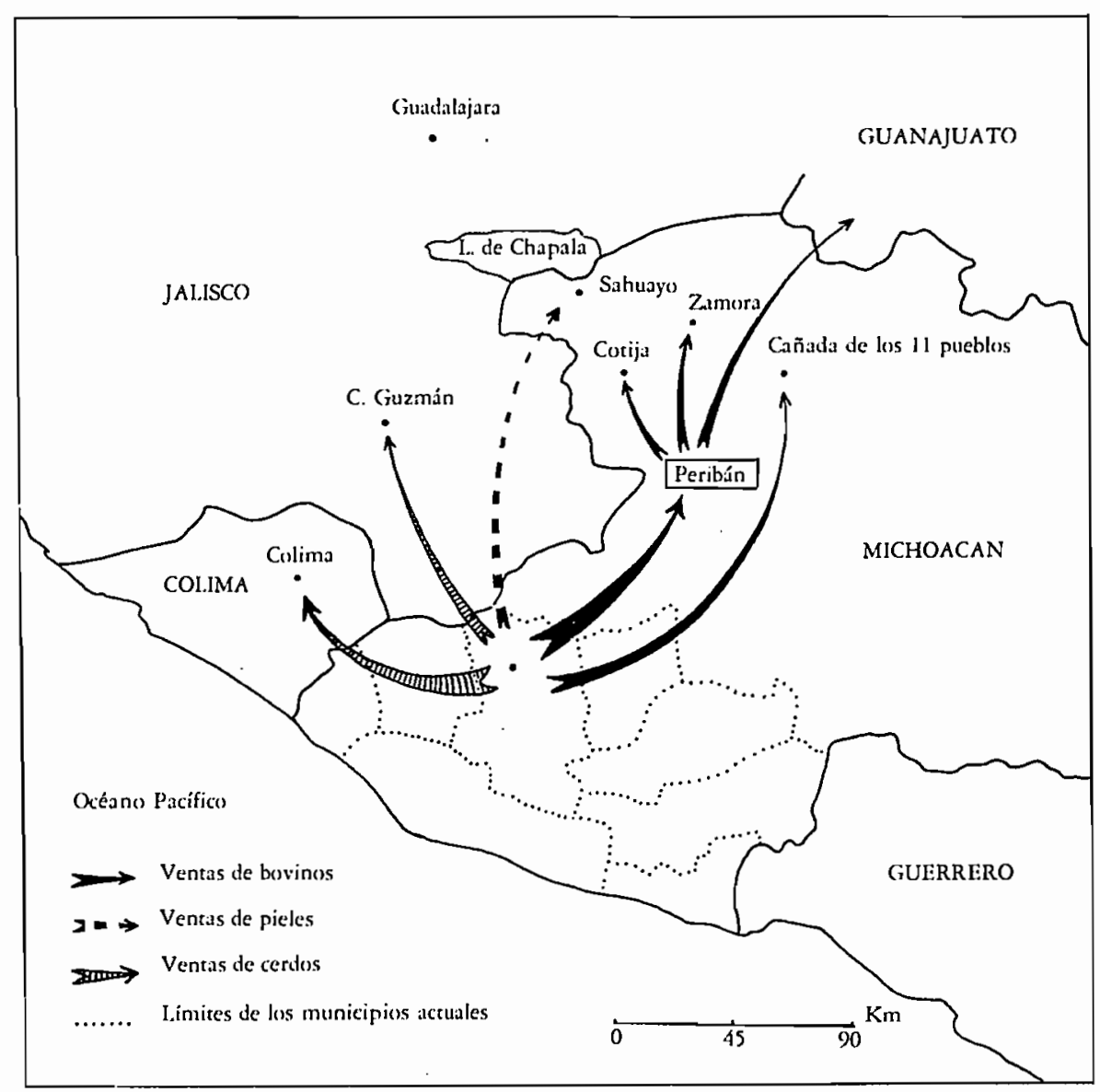

pudieron llegar a Coalcomán en los años cincuentas, los negociantes las llenaban de puercos para llevarlos a Guadalajara.

\section{Las relaciones sociales de producción}

El tamaño del rancho no se medía con la superficie que poseía, sino más bien con el número de aparceros con los cuales contaba. Del número de ellos 
dependía la cantidad de yuntas sembradas y de anegas desmontadas y al final, la cosecha de maíz y las engordas de puercos. Un rancho regular tenía cuatro o cinco medieros, unos de yunta, otros de desmonte, pero muchos propietarios contaban con más "asociados". Don Trinidad Contreras trabajaba con once medieros, de los cuales diez sembraban tierras de labor en el rancho de los Tepehuajes. ${ }^{99}$ En la Barranca del Zacasihuite, de veinte a treinta familias andaban de medieros con Isidoro Valencia ${ }^{60}$ (el rancho medía unas cinco mil hectáreas).

El contrato de mediería

Cuando hablamos de contrato, no se trata de algo escrito, firmado y conservado por ambas partes sino de un acuerdo oral que era variable según los lugares y la forma de trabajo. En todo caso, el patrón daba la tierra, el mediero su fuerza de trabajo.

-A los medieros que sembraban con yunta, les tocaba suministrar el arado de palo (ellos lo hacían o lo mandaban hacer). El dueño "ayudaba" (proporcionaba) con la vunta de bueyes, la semilla y la habilitación, prestando tres anegas de maíz por anega de siembra para que el trabajador y su familia se pudieran mantener hasta la cosecha. ${ }^{61}$ Cuando los propietarios compraron arados de vertedera, también los prestaron a sus medieros.

-A los que desmontaban, les tocaba tumbar y cercar la parcela con madera para que no se introdujera el ganado en la milpa. A veces el patrón pagaba una parte de este trabajo aparte de ayudar con habilitación.

En ambos casos, la cosecha se repartía en partes iguales entre el mediero y el propietario. Este cobraba el rastrojo para sus animales mientras aquel sólo gozaba de un permiso de pastura para "dos o tres vaquillas" nada más.

"Plus" trabajo y consolidación del rancho

De las cinco toneladas que cosechaba un mediero, ${ }^{62}$ la mitad se la entregaba al dueño, más las tres anegas de habilitación (250 kilogramos). Le quedaba un poco más de dos toneladas para mantener a su familia (750 Kgs.), engordar a tres puercos ( $750 \mathrm{Kgs}$.) y dar de comer a unas gallinas, al burro, si

59. Entrevista a Socorro Moreno y Raquel Contreras en los Tepehuajes.

60. Entrevistas a Jesús Mejía (El Crustel), Isabel Gómez (El Zacasihuite), Elvira Hernández (El Terrero de los Ocotes), Antonio Díaz (La Guadalupe) y María Spíndola (Coalcomán).

61. Aproximadamente $250 \mathrm{Kgs}$., lo que puede asegurar el consumo de una familia durante tres meses para 24 medidas de siembra, sea 4 o 5 hectáreas en tierra de yunta.

62. El caso de un año regular durante el cual el mediero cosecha una anega de siembra. Podía sembrar más si contaba con hijos en edad de trabajar. 
tenía, y a la vaca cuando se agotaba el pasto. En pocas palabras, le alcanzaba para vivir pero sus posibilidades de venta de maíz o de cerdos estaban sumamente limitadas. Al contrario, el patrón fácilmente juntaba sus cuatrocientas cargas de maíz con lo que le tocaba del trabajo de los medieros (véase gráfica 23). Con eso aseguraba el autoconsumo de su familia, mantenía sus bestias y aves de corral y guardaba la semilla necesaria para sembrar de nuevo. Le quedaba maíz a montones para engordar puercos y mandarlos a Colima, lo que le proporcionaba ingresos monetarios muy altos en comparación con lo que podía esperar el mediero. Con el dinero de la venta de diez puercos, un ranchero podía comprar cien o ciento cincuenta rollos de alambre de púas para seguir cercando su propiedad. ${ }^{63}$

El ganado a medias: ¿autonomía o dependencia?

Muchos aparceros tenían dos o tres vacas, crías de los animales que el patrón les había confiado "a medias". Así con un gasto muy limitado el pobre llegaba a tener una o dos vacas para la leche. Pero esta acumulación de capital era muy lenta pues había que esperar hasta el segundo parto de la vaca para tener un becerrito propio suponiendo que todo saliera bien y, sobre todo, limitada por el derecho de pastura: "los dueños no dejaban que tuviera uno ganado". ${ }^{64}$ Cada hoja de maíz que la vaca del mediero se comía le hacía falta al hato del patrón. La ganadería extensiva que se practicaba y la productividad del trabajo relativamente alta, aún a medias dejaban teóricamente una alternativa de enriquecimiento al mediero. Los más listos y los que gozaban de buenas relaciones con el patrón (relaciones familiares o de compradazgo) lograron al fin comprar tierras y volverse pequeños propietarios.

Otros se hicieron minifundistas. Con uno que otro puerco vendido o la cría de sus animales tomados "a medias", uno podía adquirir un pedazo de terreno, al precio que proponía el patrón.65 Se volvía todavía más dependiente del propietario puesto que se veía forzado a seguir trabajando con él pues el terrenito no le alcanzaba. Los demás, se la pasaban "brincando cerros" buscando con quién trabajar y viviendo siempre en casas prestadas

63. El rollo de alambre valía 14 pesos en 1948 según Rogelio Mendoza, agricultor en San Miguel (rollo de 100 metros).

64. Entrevista con Juan Trelles, Coalcomán. Durante toda su vida de mediero lo más que tuvo fueron seis animales.

65. En 1945, Isabel Gómez compró así cuatro anegas de monte (unas 20 Has.) con 6,000 pesos (un precio prohibitivo) que había juntado con los puercos que engordaba y lo que le tocaba de la cría de las cabras que el propietario le daba a medias. Entrevista realizada en El Zacasihuite, municipio de Coalcomán. 
GRAFICA No 23: REPARTICION DE I.A COSECHA IDE MAIZ, EN UN RANCHO DE I.A SIERRA DE CoaI.COMAN DURANTE LA PRIMERA MITAD DEL SIGIO XX (EJEMPIO DE UNA PROPIEDAD CON SEIS MFDIEROS)

\section{COSECHA MEDIEROS}

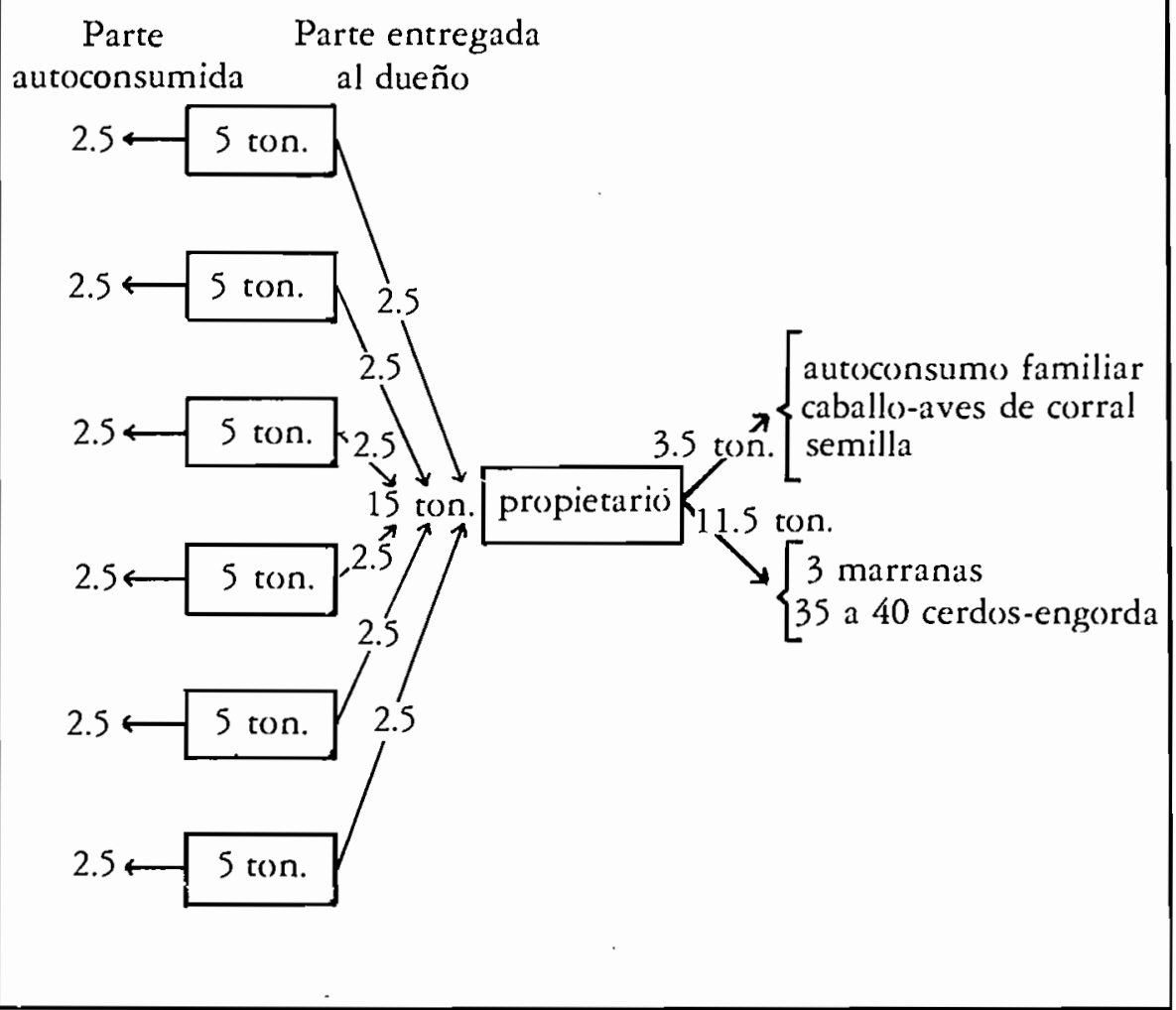

Notu: El esquema no toma en cuenta la habilitación (maiz prestado por el dueño y pagado por el mediero después de la cosecha). 
por el dueño. ${ }^{66}$ Para él, era preciso conceder algunas ventajas o "ayuditas" al mediero para que no se fuese a buscar donde trabajar en otras partes. Pero eso, pocas veces lo intentaba el mediero si no lo echaba antes el patrón, puesto que las relaciones de trabajo eran difíciles de romper: antes de la cosecha no podía irse sin abandonar la cosecha: después de ella, perdía todo el trabajo ya hecho en la tumba para el ciclo agrícola siguiente. El mediero no era un "peón acasillado" reducido a "la servidumbre por deudas" por la particularidad del "contrato" de aparcería y la especificidad de los sistemas de producción de la sierra, pero la aparcería no era tampoco la "verdadera concesión de autonomía mediante canon anual" descrita por Jean Meyer para el centrooeste de México. ${ }^{67}$

\section{Arrendatarios y peones}

Si la aparcería era la forma principal de las relaciones de producción, cabe destacar que también se trabajaba mediante el pago de una renta proporcional a la superficie sembrada. En la hacienda de Trojes, era barato ya que valía de dos a cuatro cargas de maíz para 15 medidas de desmonte. ${ }^{68}$ En San José de la Montaña, Angel Blanco cobraba ocho cargas a cada sembrador. ${ }^{69}$ Lo más común era cobrar doce anegas por anega de siembra. ${ }^{70}$ No sabemos porque en algunas partes se trabajaba así, en otras en aparcería, ni tampoco las transiciones que hubo entre ambas formas. Lo cierto es que pagar una renta era más barato pero más riesgoso. Para el pobre, era conveniente trabajar en aparcería por las facilidades que daba el propietario. En los latifundios norteamericanos - Balsas Hardwood Company y Pacific Timber Company - los que querían sembrar tenían que pagar un tributo en dinero al encargado.

El peonaje era muy limitado salvo para ayudar en las épocas de mayor trabajo (zafra, cosecha, tumba). Hacia 1930, el jornal se pagaba con un cuarterón de maíz - medida de cinco litros-, lo que era mucho menos de lo que se pagaba a fines del siglo XIX en las haciendas de Coahuayana (37

66. Esta movilidad de los aparceros está confirmada por R. Rouse para el municipio de Aguililla en op. cit., p. 11: "the oral histories suggest that it was mainly the landless day laborers and sharecroppers who moved frequently. The temporary moves involved going off to a ranch to work for a short period".

67. J. Meyer, La cristiada III: Los Cristeros. México, Siglo XXI, 1985, p. 12. Meyer agrega (p. 76): "Los aparceros y arrendatarios se hallaban exactamente en la misma situación que los pequeños propietarios, de los cuales los separaba poca cosa: un contrato de venta, un poco de dinero que entregar, un juego de escrituras. Por lo general, la aparcería conduce a la pequeña propiedad".

68. 170 a $340 \mathrm{Kgs}$. para cuatro hectáreas.

69. Entrevista a Emiliano Blanco, San José de la Montaña.

70. Una tonelada de maíz para cinco o seis hectáreas de siembra. 
centavos diarios, lo que equivale a media anega de maíz en 1877)..$^{71}$

Por último, algunos pequeños propietarios trabajaban ellos mismos su rancho sin hacerse ayudar por medieros. Eran los que tenían poca tierra o muchos hijos para ayudarlos.

\section{Revoluciones y Reforma Agraria}

La revolución mexicana no se hizo sentir en Coalcomán. No hubo lucha alguna y la vida económica no sufrió ningún desorden. Solo se notó la llegada de una que otra familia que venía huyendo de sus regiones, perturbadas por las destrucciones de la guerra, el hambre o el bandolerismo. ${ }^{72}$ El sistema agrario recién establecido en la sierra de Coalcomán no era un medio propicio a las luchas revolucionarias. La densidad de población era baja. La dispersión de las casas y la aparcería, como forma dominante de explotación, eran estructuras muy poco favorables a los levantamientos populares. Además, la proximidad de la "frontera agrícola" dejaba a los descontentos la posibilidad de ir a fincarse más "para dentro" entre los cerros de San José de la Montaña donde había poca gente.

En cambio, la "Revolución" Cristera queda muy viva en la memoria colectiva. Las peripecias de esta guerra de tres años (sitio de Coalcomán, matanza de Pinolapa, destrucción de San José de la Montaña "la segunda" cristiada) fueron contadas por Jean Meyer. ${ }^{73}$ Es interesante notar que Peribán, centro de comercialización de los bovinos donde se juntaban numerosos rancheros de Coalcomán (véase mapa 18) sirvió de foco de propagación de la rebelión a la región. ${ }^{74}$ Las actividades comerciales se encontraron interrumpidas y parece que hubo mucha destrucción de ganado y cosechas. ${ }^{75}$ Mucha gente dejaba el pueblo o sus ranchos para andar "de

71. Según informe de Mr. Le Harivel para la hacienda de Bellavista de Achotán, citado por R. Arreola C., op. cit., p. 211.

72. Luis González, Pueblo en vilo, México, El Colegio de México, 1979, p. 169.

73. Jean Meyer, La Cristiada I: La guerra de los Cristeros, 1985, $9^{\circ}$ ed., pp. 191, 229 y 230:

"Toda la región iba a ser durante tres años una verdadera república autónoma, en la cual el gobierno no se atrevería a aventurarse sino en grandes expediciones de varios millares de hombres obligados siempre a batirse en retirada y condenados a perder la mitad cuando no las dos terceras partes de sus efectivos". p. 191.

74. "En Peribán se hace la ya dicha feria una semana antes de la semana santa. Allí se reúne gente de todos los estados vecinos, unos a vender sus ganados, otros a comprarlos, otros a hacer sus luchas en otras formas, hasta a robar; alli nos dimos cuenta de que ya era mucho lo que peleaban los cristeros con el mal gobierno y que ya era tiempo de que todos los verdaderos cristianos se unieran en todas partes y hacer un sólo frente a los enemigos de Dios y de la patria". Meyer/Ezequiel Mendoza, 1968-69 citado por J. Meyer en La Cristiada, p. 190.

75. Según P. Barragán citado por R. Arreola C., op. cit., p. 248. 
venado" en el monte huyendo de la represión federal. Estos movimientos dieron lugar a una nueva fase de progresión del frente de colonización más hacia la costa. Algunas familias se establecieron primero en San José de la Montaña y luego sobre terrenos comunales de Pómaro, en el municipio de Aquila (San Antonio, San Juan de la Palmera). ${ }^{76}$ Los Guillén, líderes de la "Cristera" en toda la región y establecidos en San José de la Montaña invadieron después gran parte de la comunidad de Pómaro, de la cual se volverán caciques.

El reparto de las tierras, después de la revolución, no se dio en el municipio de Coalcomán sino hasta que Lázaro Cárdenas estuvo en el poder. En 1939 y 1940 se formaron los ejidos de El Guayabillo, el Guayabo, Mesa Bonita y Trojes; en 1943 y 1945 los ejidos de Rancho Viejo, Pantla y El Sauz de Trojes. Fueron 10,800 hectáreas repartidas entre 694 beneficiarios según los archivos de la Secretaría de la Reforma Agraria. ${ }^{77}$ Solamente se negaron las solicitudes de "La Limita", por inexistencia del poblado solicitante, y de la "Hacienda de Trojes" por incapacidad jurídica. Todos estos ejidos se ubican en la parte noroeste del municipio ${ }^{78}$ que pertenecía antiguamente a la hacienda de Trojes (véase mapa 17). En cambio, la región central del municipio - la cuenca del río Cachán, alrededor del pueblo de Coalcománno fue afectada por ninguna solicitud de tierra. El tamaño "reducido" de los ranchos, en comparación con las haciendas, y el poder de los nuevos rancheros impedían que se formara un grupo de solicitantes suficientemente poderoso para que se otorgara la dotación. Un propietario cuenta que se le presentó un grupo de agraristas que querían invadir su terreno. Les explicó que una parte de su rancho la ocupaba para mantenerse y la otra para mantener a sus animales y que así no le sobraba nada para ellos. "Con eso se fueron y nunca volvieron"; en Coalcomán no hubo revolución ni reforma agraria. La única consecuencia que tuvo el reparto de tierra en las zonas bajas del municipio fue quizás la salida de algunos medieros o arrendatarios hacia estos ejidos. Aunque no conozcamos el origen de las 694 familias beneficiarias, es probable que varios pobres de Coalcomán se hayan metido en las filas de los solicitantes mediante amistades o relaciones familiares con los líderes agraristas. Este movimiento de emigración -el primero que se manifiesta en la región- rebasó los límites del municipio puesto que unos se fueron hasta el estado de Colima en vía de "colonización" para conseguir un derecho ejidal o quedarse allá como jornalero.

A partir de los años cincuentas, el rancho descrito en este capítulo empieza a modificarse. La ganadería bovina - la cría de becerros - tiende a

76. Testimonios de Emiliano Blanco y Antonio Betancourt en San José de la Montaña.

77. Archivo del Municipio de Coalcomán. SRA. Uruapan

78. La superficie repartida no representa más que el $3 \%$ del municipio. 
volverse piedra angular de los sistemas de producción. En los apartados siguientes $(4,5$ y 6$)$, analizamos esta especialización regional hacia la ganadería de cría para carne y sus consecuencias sobre las producciones agrícolas. Explicamos también que los aparceros, trabajadores del rancho establecidos a principio de siglo, empezaron a migrar dejando el rancho sin brazos para trabajar y obligando a los dueños a modificar los contratos de mediería.

\section{CAMBIOS Y TRANSFORMACIONES EN LA GANADERIA}

A partir de los años sesentas surge en Coalcomán un nuevo tipo de ganadería cuyo propósito viene a ser la producción de becerros de 1 a 2 años para engorda.

\section{El mercado de Peribán se cierra}

En las regiones circunvecinas donde los ejidos explotaban tierras de labranza (Colima, Tierra Caliente, Bajío) los troncos de bestias sustituyeron paulatinamente a las yuntas de bueyes. ${ }^{79}$ Después, al mecanizarse la agricultura en el Bajío, disminuyó la demanda de novillos para amansar. Ambos fenómenos precipitaron la merma de la comercialización de los novillos. A pesar de que la fiebre aftosa (1948) no ocasionó pérdidas de ganado en el municipio de Coalcomán, la destrucción del ganado en el Bajío fomentó la sustitución de los bueyes por las bestias en las labores agrícolas y luego la mecanización. Así que se cerró el canal de venta de los animales de Coalcomán; la feria de Peribán se acabó a fines de los cuarentas.

El crecimiento de la demanda de carne y el mejoramiento genético a base de ganado cebú hicieron posible una reconversión de la ganadería.

\section{Los sementales de raza cebú y el mejoramiento sanitario}

El presidente Lázaro Cárdenas fue el que repartió los primeros toros mejorados en el municipio. La Unión Ganadera Local, recién fundada en 1953, se encargó de conseguir más animales finos en otros estados del país,

79. En el estado de Colima, este cambio se llevó a cabo desde los años veintes, gracias a las dotaciones de tierras y a la ayuda del Banco Nacional de Crédito Agricola en 1926. H. Cocher, op. cit. 
principalmente en Veracruz. La cruza con los sementales cebú (Gyr, Indobrasil, Brahman) se volvió sistemática a partir de los años sesentas en los hatos más importante de la región, pero los ranchos más alejados del valle de Coalcomán se beneficiaron más tardíamente del mejoramiento genético. Con esta sangre nueva, el ganado aumentó de peso y tomó una conformación más adaptada al negocio de la carne. Parece también que la sangre cebú daba al ganado criollo más resistencia a la sequía por su mayor disposición para buscar con qué mantenerse en el monte. Además, la Unión Ganadera y las campañas nacionales de higiene animal lograron mejorar notablemente el estado del ganado. Empezaron a vacunar contra el carbón, la septicemia y el derriengue. Las campañas mexico-americanas erradicaron la fiebre aftosa y el gusano barrenador. En cambio la campaña antigarrapata no tuvo los resultados esperados a pesar de los cincuenta baños garrapaticidas que se instalaron en el municipio, puesto que el precio del insecticida estaba más allá de las posibilidades de los medieros o minifundistas.

\section{Vender animales jóvenes}

En el contexto de la especialización regional, Coalcomán no podía competir -en cuanto a engorda de animales - con los trópicos húmedos de México donde el pasto crece todo el año. En la región de Coalcomán, la escasez de forraje durante la larga estación seca limitaba las posibilidades de engorda. Lo que los animales ganan en peso durante "las aguas", lo vuelven a perder en invierno si no se les da una suplementación costosa. La región se especializó entonces en la producción de animales jóvenes de 200 a 250 kilógramos que se vendían a compradores que los llevaban a esas zonas del país cuyas disponibilidades forrajeras son importantes: sorgo (Tierra Caliente, Guanajuato) ${ }^{80}$ o pastos naturales (Huasteca) (véase mapa 19). Al establecerse nuevas relaciones comerciales con estas regiones, se rompieron los viejos lazos que se mantenían entre Coalcomán y las comarcas de origen

80. El rancho El Tajo (Salamanca, Gto.) por ejemplo, compraba la totalidad de sus becerros en Coalcomán en 1986 (lo que representaba el 15\% de las ventas totales del municipio). Un ganadero del pueblo se encargaba de juntar los animales y de llevarlos hasta El Tajo en un viaje semanal. Cabe destacar que la empresa de tipo capitalista se encarga exclusivamente de la engorda de los animales hasta que pesen 400 kilogramos (la matanza interviene tan pronto como empieza a bajar el crecimiento cotidiano promedio). No asegura ninguno de los riesgos importantes de la producción (parto, desarrollo, viaje) los cuales quedan a cargo de los productores o comerciantes de Coalcomán. Sin embargo, para aumentar el valor agregado, se lleva a cabo una integración vertical hasta el detallista (entrevista realizada en El Tajo, Salamanca, Gto.). 
MaPa No 19. Destino de las ventas de Ganado del municipio de Coalcoman Y REGIONES DE ENGORDA

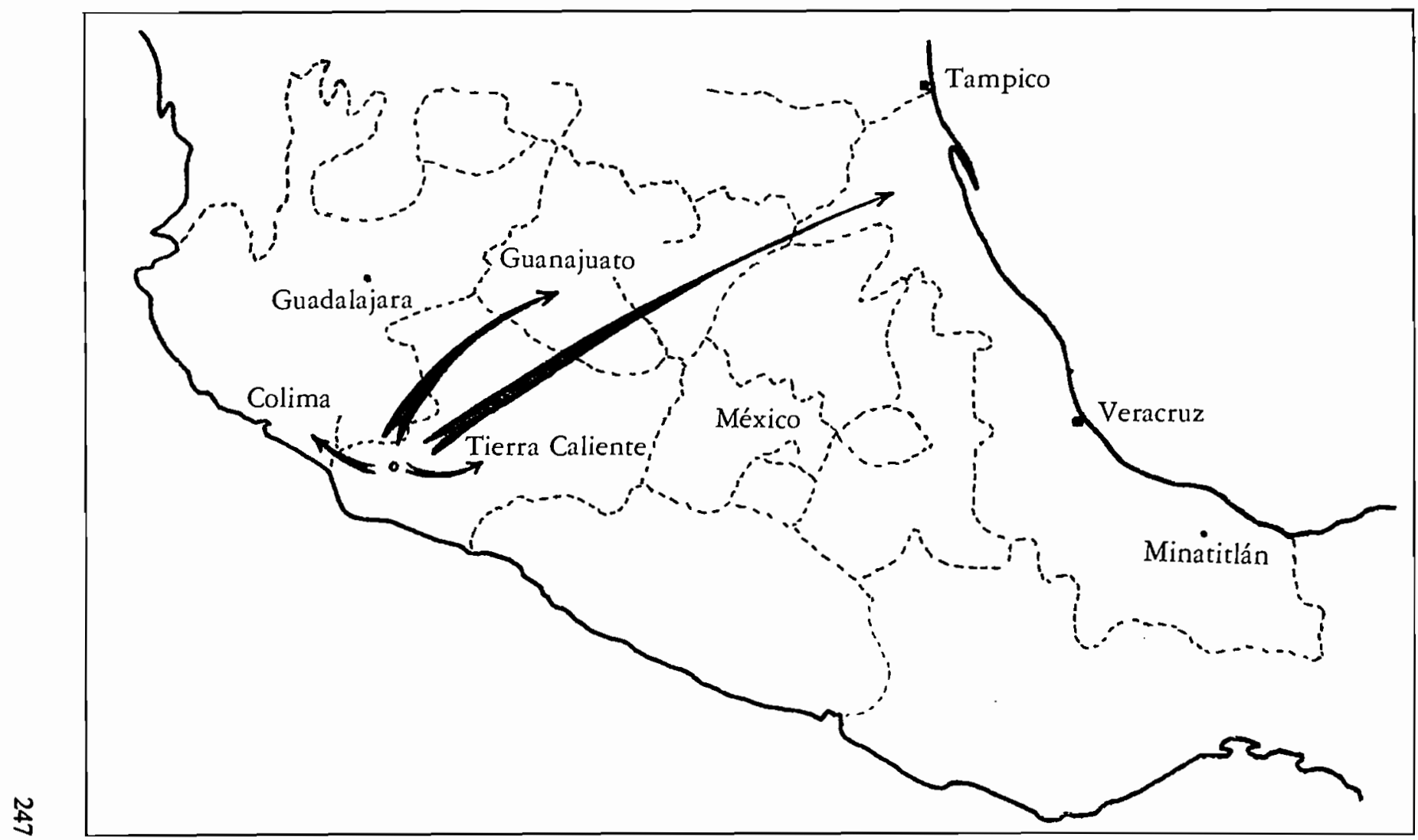


de los migrantes. ${ }^{81}$ Vender animales jóvenes de uno a dos años de edad economizaba todo el pasto que se comían los novillos de tres a cuatro años y dejaba lugar para el mantenimiento de más vacas reproductoras. Además, cabe destacar que las ventas principales (el $50 \%$ del total) se llevaban a cabo a fines de la estación lluviosa — septiembre, octubre y noviembre- (véase la gráfica 24) lo que rebajaba la carga animal para la estación seca.

El precio alentador del ganado, históricamente sobre-evaluado en comparación con el maíz hasta los años ochentas ${ }^{\mathbf{2 2}}$ y la alta productividad del trabajo de esta actividad, fomentaron el desar rollo casi exclusivo de este tipo de ganadería. La producción actual de leche queda estrictamente limitada al consumo local (pueblo de Coalcomán) y se encuentra concentrada en las unidades de producción cercanas al pueblo cuya producción puede llevarse diariamente a caballo; sólo los productores más alejados del pueblo tienen que hacer queso. Cabe destacar que esta actividad aún limitada queda relativamente protegida de la competencia externa por la lejanía de las regiones altamente productoras como Uruapan, Colima y Jiquilpan y por los costos de transporte. La escasez de leche en invierno duplica su precio. La venta de 25 litros cada día proporciona al productor ingresos monetarios altos y regulares equivalentes al doble de lo que gana el jornalero. Con la estabilización del precio del ganado en 1984 y 1985, lo que equivale a una baja neta en precios constantes, este negocio cobra más interés. Sin embargo, la cruza con la raza Suiza, recién introducida en el municipio que interesa cada vez más a los ganaderos no parece responder a una nueva "estrategia lechera", - salvo en algunas unidades de producción del valle de Coalcomán con terrenos de riego-, sino que responde más bien al deseo de mejorar la conformación de los becerros mediante la mezcla de sangre. ${ }^{83}$

\section{La división de los potreros}

Cuando las propiedades se encontraron totalmente cercadas, los ganaderos empezaron a hacer divisiones para apartar potreros para la estación seca. Hasta entonces sólo la labor y los desmontes se cercaban, pero esta técnica

81. Algunos de los ganaderos más acomodados de Coalcomán lograron comprar extensiones de terreno en zonas húmedas del país para llevar allá sus becerros y encargarse ellos mismos de la engorda de los animales, en zonas de frontera agrícola donde el terreno no-desmontado estaba muy barato. Las ganancias realizadas en condiciones de alta productividad compensan fácilmente el costo de transporte (y el riesgo) de los animales de Coalcomán hasta la Huasteca o el sur del estado de Veracruz.

82. En 1985, el precio de un becerro de $300 \mathrm{Kg}$. equivalia al precio de 20 a 25 anegas de maíz, el doble de lo que equivalía en los años treintas.

83. Efecto beterosis: superioridad fenotípica de los individuos provenientes de cruzamiento en comparación con el valor medio de las poblaciones parentales. 


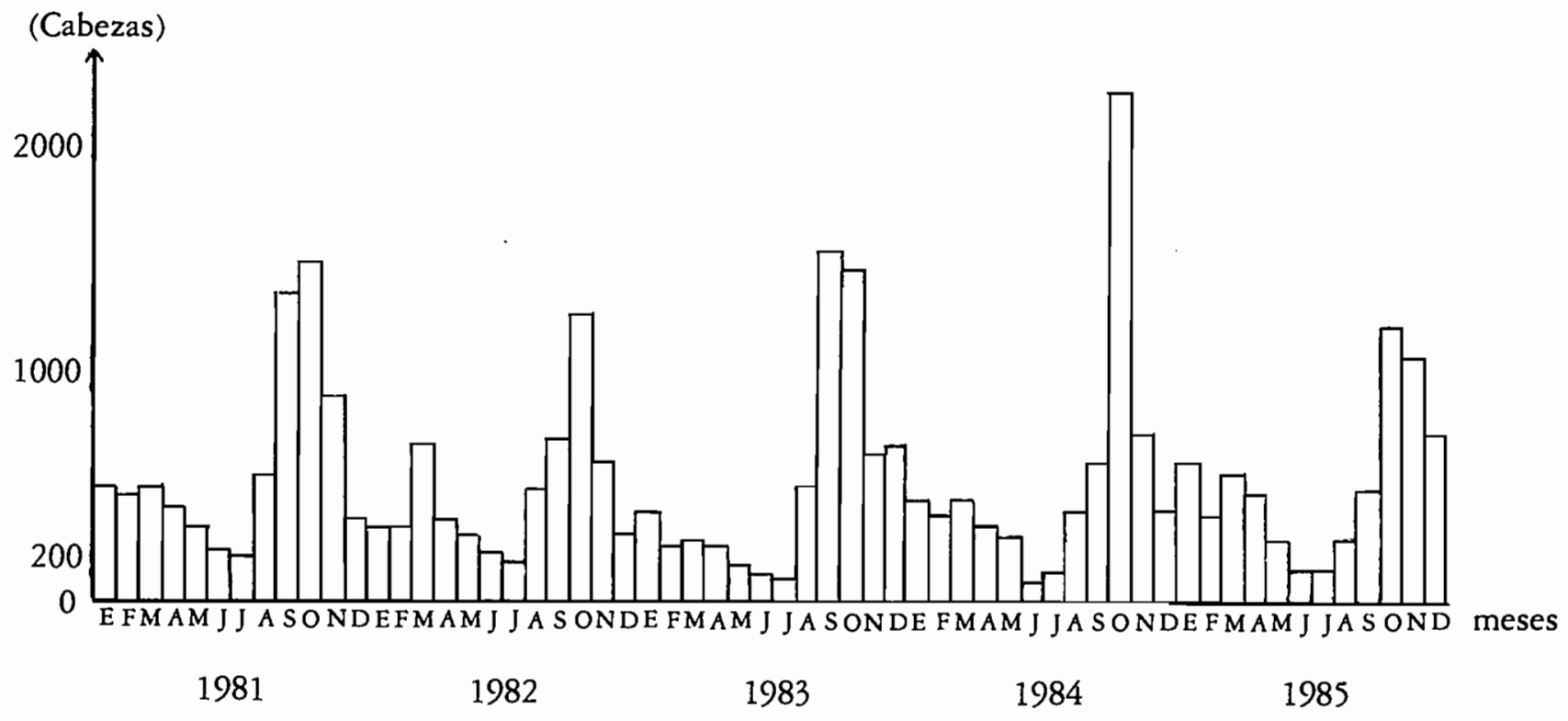


respondía a la necesidad de proteger las milpas del ganado. Ahora se trataba de aprovechar mejor el pasto disponible y a veces de separar los animales en dos grupos: las vacas paridas (ordeña) y los becerros de una parte; las vaquillas, vacas preñadas y sementales de otra. Antes se cambiaba la cerca anualmente en la medida en que iba trasladándose la milpa de un año al otro y se cercaba solamente la milpa. Los potreros que se hacían ahora eran fijos y no dependían de la milpa. Eran más amplios y rara vez se desmontaban en su totalidad para sembrar. La milpa ocupa entonces una "Cuchilla" del potrero quedandose lo demás con matorral. La división de la propiedad en potreros implica que se adapte la rotación forestal (maíz bajo roza, tumba y quema) a nuevas limitaciones (la elección del lugar para desmontar obedece mucho más a criterios zootécnicos, rotación de pastoreo, que a criterios agronómicos). El número de potreros que se hacen depende sobre todo de la topografía del rancho, de la ubicación de los ojos de agua o ríos, de la proporción de terreno cultivable bajo roza, tumba y quema, de la capacidad financiera del campesino (el ala mbre de púas resulta caro) y de su voluntad de apartar las vacas paridas para ordeñar. Poco depende del tamaño del rancho o del número de animales. Refleja más bien distintas estrategias de manejo del hato: algunas muy extensivas (no se ordeña, no hay complementación ni cultivo de maíz) otras que tratan de aprovechar al máximo los recursos forrajeros disponibles (unidades de producción con poca superficie). La mayoría de las propiedades cuentan con tres a seis potreros pero la superficie mediana de cada uno varía de 6 a 150 hectáreas, según las unidades de producción que hemos visitado. Muchas veces el potrero donde se sembró la milpa está reservado para las secas (rastrojo en febrero y marzo). Un segundo potrero donde se desmontó el año anterior cuenta con el pasto natural desarrollado en el cañizal del maíz o con pastura sembrada: asegura el pastoreo de primavera. Al final de las secas se juntan los animales, o parte de ellos, en un potrero bien abastecido en agua y cerca de la casa para que se pueda distribuir un complemento a base de manojos de hojas de maíz, maíz molido, punta de caña, paja de garbanzo o forrajes comprados (alfalfa y sorgo). ${ }^{84}$ Los potreros de bosque o matorral más lejanos del rancho sirven durante la temporada de lluvia mientras que se reservan la milpa y el potrero sembrado el año anterior.

A menudo, los potreros tienen forma de bandas largas y verticales que abarcan desde la parte más alta de un cerro hasta su base para que cada uno disponga de un acceso al río, si no hay manantiales y quede fácilmente accesible a partir del corral del rancho. Los propietarios que poseen varias fincas pueden aprovechar las particularidades ecológicas de cada una poniendo el ganado en la más fresca (2,000 m.s.n.m.) durante la estación

84. Unos cuantos ganaderos urilizan alimentos balanceados. 


\section{GRAFICA No 25: Division de POTREROS, ROTACION FORESTAL. Y PASTOREO EN DOS RANCHOS DE LA SIERRA DE COALCOMAN}

Caso l: propiediad de 500 Hass: 5 potreros

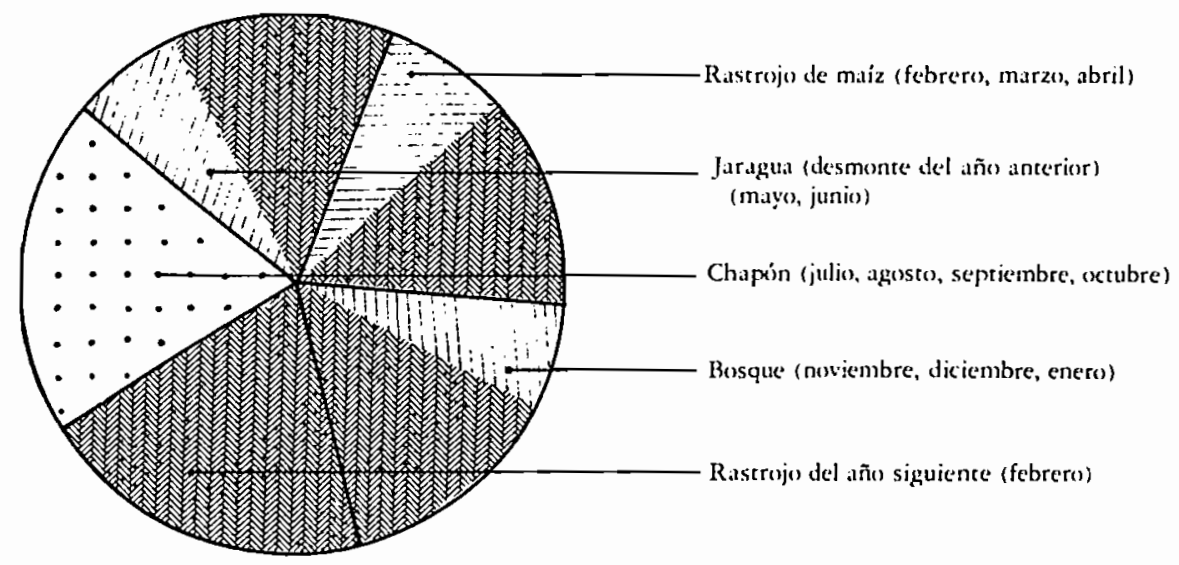

Caso II: propiediad de 50 Has : 2 potreros

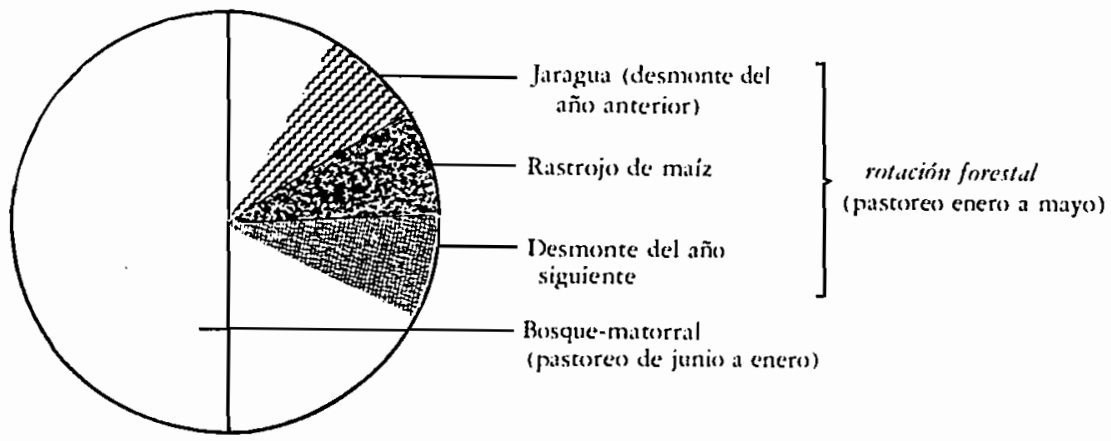


seca y bajándolo en fincas más cálidas durante las aguas. En todo caso la rotación de potreros que se establece depende de la pastura sembrada con la cual cuenta la propiedad (ver gráfica 25)

\section{La siembra de pasturas}

Ahora, la mayoría de las unidades de producción cuenta con pasturas cultivadas. Sembraron la pastura "gordura" (Melinis minutiflora) a partir de los años sesentas pero no logró evadir el ecosistema puesto que se queda actualmente limitada a una franja de terrenos frescos (1,500 m.s.n.m.). El frio impide su extensión más arriba y el Jaragua ocupa el espacio más abajo. Esta gramínea (Hyparrbenia rufa) recién introducida en la región - a fines de los años sesentas - se ha vuelto elemento importante del paisaje. Sembrada con frecuencia en los desmontes desde hace 5 ó 10 años y asociada con la milpa el primer año, invadió paulatinamente el ecosistema transformando el bosque o matorral en una formación vegetal parecida a una sabana cuyos últimos árboles son los tepehuajes (Lysiloma acapulcensis) salvados del corte para su uso como postes para las cercas y los pinos últimamente protegidos por la administración forestal.

Ambas gramíneas perduran varios años. La pastura "gordura" aguanta hasta 5 años de pastoreo; luego el monte vuelve a cubrirlo. El pasto jaragua "nunca se acaba" si se quema anualmente en mayo y si una fracción se aparta del pastoreo hasta la espigación. ¿Permite el cultivo de gramíneas forrajeras intensificar los sistemas de pastoreo y elevar la carga-animal ${ }^{85}$ de los agostaderos? En las unidades de producción estudiadas la carga animal varía de 0.15 a 0.7 animales por hectárea ${ }^{86}$ pero resultó imposible por encuestas obtener datos precisos en cuanto al pastoreo de estas praderas sembradas. En todo caso la carga-animal puede ser mayor que en los matorrales o bosques del monte cuyo coeficiente de agostadero rara vez es menor que cuatro (cuatro hectáreas por animal), salvo en las barrancas tropicales de la costa del Pacífico ricas en árboles forrajeros. ${ }^{87} \mathrm{Sin}$ embargo, el jaragua

85. Carga-animal: capacidad que tiene una hectárea de terreno para alimentar con sus pastos a un determinado número de animales, Diccionario Agropecuario de México, INCA RURAL, México, 1982.

86. Resulta imposible obtener cifras precisas dado que nunca se conoce a ciencia cierta la superficie exacta del rancho, la superficie sembrada con pastura, el número de animales y el tamaño de los potreros. Hemos calculado la carga animal haciendo la división del número total de bovinos en el rancho por la superficie total de éste (en hectáreas).

87. Para la selva mediana subperennifolia (barrancas calientes y húmedas) se da un coeficiente de agostadero de 1.4 a 5 según las condiciones en las cuales se encuentra. Para la selva mediana subcaducifolia el coeficiente dado es de 6 en el municipio de Coalcomán y de 6.16 para la selva baja caducifolia. Coeficientes calculados por el gobierno de Michoacán y citados por R. Arrela C., op. cit., pp. 322 a 330. 
muchas veces no alcanza la productividad forrajera de la milpa (bajo roza, tumba y quema) que siempre queda por encima de aquel. Una hectárea de jaragua puede asegurar el consumo de un animal de $300 \mathrm{~kg}$. durante 500 días mientras que la misma superficie de maíz, - grano, rastrojo y arvensespuede mantenerla un animal durante 600 días. [Consideramos que una hectárea de Jaragua (Myparrbenia rufa) puede producir 13 toneladas de materia seca al año y que la tercera parte es consumida por los animales, lo que equivale a 2,500 unidades forrajeras (U.F. Sistema Leroy. France). Un animal de $300 \mathrm{Kg}$. que necesita 5 U.F. por día (mantenimiento y crecimiento) puede mantenerse con eso durante 500 días (Mémento de l'agronome République Française, Ministere des Relations Extérieures. Coopération et Développement, 1984, Pp. 912, 927 y 963).

Una hectárea de maíz puede producir:

-2 toneladas de grano, o sea aproximadamente 2,000 U.F.

-2 toneladas de rastrojo, o sea aproximadamente 800 U.F.

Las dos terceras partes son consumidas (o más si se cortan las hojas para el ganado en el corral), o sea, 533 U.F.

-arvenses, unas 500 U.F. para una parcela sucia.

En total más de 3,000 U.F., lo que alcanza a mantener al animal durante 600 días].

Veremos más adelante que al irse los medieros, la siembra de pastura tiende a sustituir paulatinamente al maíz de desmonte en los sistemas de producción. Así que si el jaragua aumenta la capacidad forrajera de los agostaderos, su expansión a costa de la milpa no representa ninguna intensificación, sino más bien un sustituto menos productivo del maíz. En fin, el desarrollo de las gramíneas en el ecosistema margina a los medierosagricultores y refuerza el poder de los ganaderos. Durante la primera mitad del siglo XX, el tamaño de un rancho dependía del número de sus medieros. Ahora, se mide con el número de cabezas de ganado del propietario.

\section{Los cerdos: de la manteca a la carne}

Aunque la mayoría de los productores, propietarios o medieros sigan engordando uno o dos pares de puercos para su autoconsumo, la cría de cerdos dejó de ser la forma principal de valoración del maíz y una fuente de ingresos altos. Las grasas vegetales sustituyeron a la manteca de puerco en los mercados urbanos que ahora necesitan grandes cantidades de carne, pero sin grasa. Los criadores industriales de cerdos en Jalisco y Guanajuato, instalados en medio de inmensas superficies sembradas con sorgo, abastecen las ciudades sin dejar ninguna oportunidad de reconversión (de la manteca a la carne) a la porcicultura campesina de las sierras alejadas. En los años cincuentas un puerco gordo vendido en Colima representaba el dinero 
necesario para comprar 20 anegas de maíz. Hoy en día, el mismo puerco sólo tiene un valor equivalente a seis o siete anegas de maíz o un poco más si es de raza mejorada. Además, el maíz ya no basta para criar puercos puesto que sólo es energía, y ahora se requiere de una ración más equilibrada para producir carne. Hay que comprar alimentos balanceados, lo que ocasiona gastos monetarios elevados, y reproductores "finos" (Durok, Yorkshire) para tener crías capaces de aprovechar mejor estos alimentos.

Sin embargo, la porcicultura no ha desaparecido y los cerdos que se consumen en Coalcomán no vienen de La Piedad, Mich., sino de los alrededores de Coalcomán. La producción actual del municipio cubre el consumo local, mercado protegido hasta que se establezcan en Coalcomán canales de venta de puercos "industriales". Además, no cabe duda que la manteca tiene todavía sus adeptos. Ambos factores favorecen el mantenimiento de esta actividad en la mayoría de las unidades de producción.

Sin embargo, es interesante destacar que los campesinos, para los cuales la porcicultura conserva todavía importancia, no son los grandes propietarios que hemos descrito en páginas anteriores. Ellos se dedican a la ganadería, sus medieros se han ido parcialmente y no tienen tanto maíz como hace cincuenta años; también ha bajado la producción de calabaza que se sembraba asociada con el maíz de yunta. Han dejado de criar puercos salvo para el autoconsumo. En cambio los minifundistas, algunos medieros y gente del pueblo de Coalcomán, que no tienen tierras, tratan de seguir con el negocio de los puercos aunque tengan que gastar en alimentos balanceados. La cría de puercos sirve de "compensación" a los productores cuyo acceso a los recursos forrajeros para ganadería bovina, está limitada. Rebajan los gastos monetarios cuando siembran garbanzo o alfalfa para completar la ración de maíz. Muchos puercos se mantienen amarrados en la temporada de lluvias, pero un número creciente de agricultores les construye chiqueros rústicos para facilitar la alimentación.

Actualmente, la cría de cerdos corresponde a una estrategia de intensificación característica de los productores minifundistas, ubicados cerca del pueblo y que desean aumentar sus ingresos monetarios aún cuando les dé mucho trabajo. También siguen engordando puercos los agricultores que viven en ranchos muy apartados y que no tienen oportunidad de venta para sus excedentes de maíz.

\section{ESPECIALIZACION REGIONAL Y PRODUCCION AGRICOLA}

Cuando la sierra de Coalcomán se especializó en la producción de becerros 
para engorda, entraba en la división regional del trabajo. Mientras tanto, el algodón invadía el plan de tierra caliente, el limón mexicano, la llanura costera del estado de Colima. Los cultivos se mecanizaban en el Bajío, se modernizaban los ingenios de azúcar y se industrializaba la cría de cerdos. El tren había llegado a Apatzingán en 1941 y la carretera en $1958 .^{88}$ En 1947, una terracería hizo posible la llegada hasta Coalcomán de un vehículo durante la estación seca. La apertura a los intercambios mercantiles puso a la región de Coalcomán en competencia con las demás regiones del país, provocando la merma de las producciones vegetales poco mecanizables en la sierra. Solo la mariguana y la industria maderera encontraron condiciones favorables para su desarrollo.

\section{Las tierras de labor en rotación}

Fuera del valle de Coalcomán, los terrenos barbechados se habían vuelto muy escasos. La mayoría de las tierras de yunta se habían dejado de sembrar. Pero las terrazas, los rellanos, las vertientes de poca inclinación que se araban antes, no por eso se cubrieron de monte. Solo había crecido el huizache (Acacia schnaffneri) en estos suelos lavados, endurecidos y pisoteados por los animales, llegándose a formar una especie de estepa espinosa sólo recorrida por las vacas en busca de vainas.

"Las tierras de labor están cansadas", dicen algunos agricultores; el uso del arado de vertedera, generalizado a partir de los años cuarentas, había arruinado los suelos. Cuando sólo se utilizaba el arado de palo, la mitad de la superficie "arada" no se tocaba puesto que las rayas alternaban con camellones sin mover. Las micro-terrazas así realizadas protegían el suelo de la erosión. Al contrario, el arado de vertedera removía la totalidad de la superficie y trabajaba más profundo rascando el suelo hasta la roca dura. Se había pulverizado la tierra que en pocos años se lavó quedando "la pura piedra". Dejó terrenos endurecidos por el pisoteo de los animales en los cuales sólo nacieron las semillas de huizache concentradas y activadas en los excrementos del ganado. Este deterioro se nota con más claridad en los terrenos esquistosos o graníticos, desde luego más pobres.

También se abandonaron numerosas tierras de yunta en los pocos lugares parejos de la Sierra y la erosión difícilmente ofrece una interpretación satisfactoria. Veremos más adelante que al emigrar los medieros, se volvieran escasos los brazos para arar. La disminución de las tierras de labor en rotación, así como la invasión del ecosistema por las gramíneas sembradas, corresponde a una "adaptación" del rancho a la ida de los

88. Luis González, La Querencia. SEP, Morelia, Michoacán, México, 1982. 
medieros. Además "sembrar de yunta no sirve para hacer pastura" (sólo la vaina del huizache sirve para el ganado) "hay que tumbar para que haya pastura". A hora que la lógica forrajera tiende a imponerse en numerosas unidades de producción incluso hasta las más reducidas, el desmonte cobra más interés, siempre y cuando el Jaragua suceda a la milpa, que cualquier sistema de cultivo permanente que no incluyera cultivos forrajeros. Este caso se dió en los terrenos de riego con la alfalfa o el sorgo.

Las plagas y la sequía de los años setentas (1971-1974) acabaron con el garbanzo y el frijol a pesar de su valoración posible en ganadería. Ahora se cultivan poco excepto en las parcelas donde hay riego. ${ }^{89}$

De las cuarenta unidades de producción estudiadas, solamente catorce cuentan con maíz sembrado en terrenos laborables. La superficie total sembrada en estas unidades de producción representa la quinta parte (22\%) del maíz sembrado en las cuarenta explotaciones agrícolas ( 470 medidas de las 2,050 que hemos censado) y la mitad - 240 medidas - se han sembrado en parcelas barbechadas con el tractor. Donde la mecanización resultó posible, gracias a que el tractor sustituyó a los medieros para el trabajo del suelo, se mantuvo el sistema de cultivo permanente especialmente en los lugares donde el riego permitía dos ciclos de cultivo al año y exigía bastante rapidez al momento del barbecho intermedio. ${ }^{90}$ Aún asi, muchas tierras se han dejado de cultivar en el valle de Coalcomán, antiguamente plantado con caña pero abandonado después e invadido por la huizachera.

En los ranchos que cuentan todavía con numerosos aparceros, el maíz de yunta se ha mantenido también: las relaciones de producción no han cambiado mucho en estos ranchos lejanos del pueblo y mal comunicados y el sistema de producción conserva los rasgos del rancho descrito para el principio del siglo.

El cultivo, año con año cobraría más interés para los productores minifundistas. Para ellos se trata de aprovechar mejor el terrenito que tienen en propiedad para no ir a desmontar a medias en tierra ajena. Además, el maíz "Tablio", sembrado de yunta, da elotes más pronto, "cuando lo necesita uno". Arar la tierra en los lugares parejos permitía mejorar las condiciones de uso del agua y limitaba los riesgos en caso de

89. Es interesante comparar la merma actual de los sistemas de cultivo con barbecho en la sierra de Coalcomán con su desarrollo opuesto cerca de la costa. Allá, en algunas porciones comunales indígenas, donde la presión sobre la tierra está muy fuerte (frontera entre las comunidades de Pómaro y Coire) la transformación de la rotación forestal en un sistema de cultivo con el arado de palo año con año puede ser interpretada como una tentativa de apropiación de un pedazo de monte por un comunero así fincado definitivamente (véase Capitulo V).

90. Dejaron de utilizar el guano de murciélago pero ocupan el sulfato de amonio. 
sequía ya que se reseca menos. ${ }^{91}$ Es por eso que al fraccionarse las propiedades, por motivos de herencia, algunos campesinos tumbaron los huizaches y trataron de volver a arar las antiguas tierras de yunta. Pero los que no tenían la yunta de bueyes necesaria prefirieron seguir sembrando bajo roza, tumba y quema aunque tuvieron que rociar con gramoxone ${ }^{92}$ para acabar con el pasto: el costo de oportunidad ${ }^{93}$ de su trabajo, para tumbar el monte puede ser muy bajo o nulo ${ }^{94}$ cuando el precio de una yunta $-600,000$ pesos en 1986 - o de la renta que cobra su propietario - 12 anegas de maíz por yunta - son demasiado altos.

\section{Terrenos de riego y cañaverales}

De las 40 unidades de producción estudiadas, ${ }^{95}$ trece cuentan con terrenos de riego cuya superficie varía de 0.2 hectáreas sobre pequeñas terrazas a la orilla de los ríos a 12 hectáreas en el valle de Coalcomán. Aunque muy limitadas ${ }^{96}$ éstas extensiones de regadío juegan un papel decisivo en los sistemas de producción. Con ellas, la diversificación de las producciones -autoconsumo y venta - se vuelve posible, así como los cultivos forrajeros de invierno. Una vez más, observamos que el uso que se da del regadío depende de la situación económica del productor y de su sistema de producción.

Los parvifundistas que lograron arreglar el bordo de un río ("playa") o un ojo de agua, tratan de completar la dieta básica de la familia cultivando maíz y frijol, legumbres, tubérculos y "un pedacito de caña para los niños". Si les sobra espacio, siembran alfalfa para los puercos o la vaca.

Los productores que cuentan con más superficie de regadío también siembran maíz puesto que su precio de venta durante el verano puede ser muy alto. El frijol se cultiva asociado con el maíz, ambos sembrados en enero. Arrancan el frijol en abril y pizcan el maíz en mayo (maíz "Tablio"

91. El barbecho permite también controlar mejor las malezas. No hay obligación de rociar, lo que rebaja los gastos monetarios.

92. Gramoxone: herbicida no selectivo, destruye todas las malezas de una parcela.

93. Costo de oportunidad: costo equivalente a lo que pierde el campesino al no aprovechar una oportunidad de trabajo asalariado fuera de la unidad de producción. (Si no hay ninguna oportunidad de trabajo remunerado fuera de la unidad de producción, el costo de oportunidad del trabajo que el campesino realiza en su propia parcela es nulo).

94. Para un propietario que manda hacer el trabajo pagando la mano de obra, sembrar de yunta resulta más barato (en términos de gastos monetarios) aunque tenga que alquilar la yunta (desmontar necesita el pago de numerosos jornaleros).

95. Encuestas realizadas en el municipio de Coalcomán: octubre de 1985 a mayo de 1986.

96. 140 hectáreas en total para las explotaciones estudiadas (sin tomar en cuenta los cañaverales). 
precoz) para volver a sembrar en junio. Cuando los demás recursos se agotan en mayo, el rastrojo ofrece un forraje oportuno, y de muy buena calidad cuando está molido y mezclado con la paja de frijol o de garbanzo, asi como el sorgo cortado diariamente y distribuido a los animales en el corral.

Por último, los cultivos comerciales de riego proporcionan a sus beneficiarios ingresos altísimos. La sandía por ejemplo, puede dar mas de dos millones de pesos por hectárea en 1986 siempre y cuando la parcela se ubique al borde de una brecha frecuentada por los consumidores para evitar un gas to enorme de transporte y esté cuidada día y noche por un miembro de la familia. Resulta igual para algunos productores de frutales como naranja, limón, aguacate, aunque el transporte sea menos costoso.

Al crear una demanda relativamente importante y estable, el crecimiento demográfico y el desarrollo urbano del pueblo de Coalcomán fomentaron un mercado local relativamente protegido por el aislamiento de la región. ${ }^{97}$ Queda claro que estas producciones no pueden rebasar los límites de este mercado por la competencia de Tierra Caliente y Colima. Son contados los productores que pudieron o supieron "meterse" a estos negocios.

Al contrario, la competencia de las regiones cañeras como Los Reyes y Tamazula, provocó una baja de precios en los años cincuenta y la desaparición de decenas de molinos de caña en el valle de Coalcomán que ahora no cuenta con ningún trapiche. Además, era una actividad exigente en mano de obra que se volvió costosa cuando se fueron los medieros ya que se tenía que pagar a mozos para llevar a cabo el trabajo. Sin embargo, se observan todavía numerosos cañaverales aunque de tamaño reducido y diseminados en la sierra. El azúcar consumida en Coalcomán viene de otras regiones pero el piloncillo local sigue cobrando interés para el mercado micrọregional puesto que se ha vuelto un producto "de lujo" cuyo precio es el doble del precio del azúcar, mientras que en los años cuarentas era lo contrario. La recuperación de los esquilmos para la alimentación del ganado fomenta también el mantenimiento de los cañaverales y su explotación, siempre y cuando el productor disponga de numerosos ayudantes familiares (no-remunerados) para la zafra y la confección del piloncillo.

\section{El maíz de desmonte}

Al disminuir las tierras laborables en los ranchos de la sierra de Coalcomán, la milpa sembrada bajo roza, tumba y quema vuelve a cobrar más importancia en los sistema de producción. El $77 \%$ del maiz sembrado en las unidades de producción estudiadas se sembró en desmonte durante 1985, y

97. Véase el caso de la leche y del queso. 
sólo una no contaba con este sistema de cultivo. Pese al aumento demográfico, la superficie incluida en la rotación forestal no ha logrado crecer. Las pineras y las últimas encineras están protegidas por la administración forestal que no las deja cortar y constituyen el límite superior de lo que uno puede quemar. Así que solamente se pueden desmontar los matorrales que ya se han cultivado. Además, al extenderse las praderas mejoradas de "gordura" y Jaragua se perjudicó el renuevo forestal debido a que los ganaderos machetean el montecillo para mantener el pasto más tiempo.

Por último, la división de los ranchos en potreros cuyas cercas son fijas introdujo cada vez más nuevas limitaciones, en la medida en que se iba fraccionando la propiedad por herencia. Ahora el renuevo forestal dura menos. En lugar de tumbar un monte grueso, los agricultores desmontan "chapones" de dos a cinco años de edad, todavía empastados en parte (sólo un período largo de renuevo forestal interrumpe la invasión de la parcela por las hierbas) y cuya quemazón no alcanza a abastecer el suelo de los elementos minerales necesarios. Por lo que tuvieron que conseguir nuevos medios de producción.

\section{Herbicidas y fertilizantes}

Desde los años sesentas, la milpa se rocía con el esterón, herbicida que destruye la mayoría de las malezas de "hoja ancha". No perjudica al maíz y se echa un mes después de la siembra para que las malezas no "tapen el maíz". De la misma manera, se introdujo en los años setentas el fertilizante sulfato de amonio 20.5-0-0 y ahora todos los agricultores lo utilizan ${ }^{98}$ aunque en cantidades muy variables (de 10 a 100 kilogramos por medida de siembra, o sea aproximadamente de $10 \mathrm{a} 100 \mathrm{~kg}$. de nitrógeno por hectárea). A pesar de que la utilización de estas nuevas técnicas haya permitido aumentar o mantener los rendimientos cabe destacar que las gramíneas y pastos sembrados no destruidos por el Esterón selectivo, siguen perjudicando al maíz y que el echar sulfato de amonio de manera sistemática no abastece al suelo de fósforo y potasio como lo hacía la incineración de un monte alto.

Al introducir estos medios de producción, se plantea el problema de quién los va a pagar en los ranchos donde la aparcería domina las relaciones de producción: ¿el dueño o el mediero? Por lo general, se considera que el Esterón reemplaza el trabajo de limpia y que por eso le toca al mediero aunque el propietario le preste la bomba de fumigar. Al contrario, el fertilizante no suplanta ningún trabajo del mediero y compensa la pobreza

98. Echando un puñado al pie de cada mata en dos aplicaciones: cuando las plantas miden unos 40 centímetros de altura ( 30 días después de la siembra y una vez rociado con el Esterón) y luego cuando "quiere espigar". A pesar del fraccionamiento en dos aportaciones, las pérdidas por lixiviación han de ser fuertes. 
del suelo; por tanto le toca al propietario. 99 Veremos más adelante que, en realidad, los "contratos" de aparcería son de todo tipo y han cambiado bastante. (El crédito que se otorga a veces al propietario no ayuda al mediero más que la "habilitación del patrón").

Competencia maíz-jaragua

El desarrollo de la ganadería y de las pasturas sembradas sustituye la milpa por una asociación maíz-pastura. El Jaragua o el "gordura" se siembran al voleo poco después de la milpa o el mismo día. Rociar con Esterón no afecta el Jaragua recién nacido. Sólo se corta un poco con guadaña hasta que la milpa se desarrolle suficientemente. Después se deja crecer para que pronto haya pastura cuando se acabe la estación lluviosa. Aunque en algunos ranchos no se vuelva a sembrar cada año, siempre quedan "manchitas" de pasto, rasgos de siembras anteriores o resultado de la expansión natural del jaragua en el ecosistema.

Por falta de estudios agronómicos precisos, resulta difícil saber si la pastura causa perjuicio a la milpa o no, y de qué manera. En caso de sequía, es probable que la competencia por el agua haga daño a la milpa y si llueve demasiado puede pudrirse más pronto. En todo caso, la competencia por los elementos minerales y el fertilizante que se aplica ha de ser muy fuerte. En realidad, se observa que la conciencia que se tiene de los daños ocasionados al maíz por el jaragua depende del productor y de sus intereses: para el ganadero "no le hace nada". La pastura cobra más importancia que el grano y olvida sus efectos eventuales sobre el rendimiento de la milpa. La cantidad total de pastura cuenta más que el grano, mas aún cuando el mediero coge la totalidad del grano. Para este último, que muchas veces tiene un permiso de pastoreo limitado a dos o tres animales, la pastura es todo un perjuicio. El propietario le da la semilla con la condición de que la riegue en el desmonte pero no le da por eso la posibilidad de aprovechar esa pastura. Sólo le da más trabajo. La asociación maíz-jaragua refleja perfectamente los conflictos que pueden suceder entre mediero y ganadero cuyos intereses son antagónicos a pesar de la apariencia. En el pueblo de Coalcomán, no se vende ningún herbicida capaz de luchar contra las gramíneas arvenses, sin hacer daño al maíz. Estos productos existen y se conocen en varias regiones del país. Su ausencia en Coalcomán nos parece altamente significativo del poder de los ganaderos y de la debilidad de los medieros.

Los pequeños y medianos productores que trabajan por su cuenta tratan de mantener un equilibrio entre la pastura y el maíz de autoconsumo. A veces tienen que rociar con Gramoxone antes de sembrar para acabar con

99. En los terrenos mecanizables, se considera que el tractor sustituye por una parte a la yunta y al arado y por otra el trabajo del mediero. Cada quien paga la mitad de los gastos. 
el pasto que queda. Donde el jaragua invadió la totalidad de los terrenos disponibles, unos agricultores se "refugian" debajo de las pineras, cuyo suelo queda libre de jaragua, para sembrar maíz a pesar de la acidez del suelo ${ }^{100}$ (la gráfica 26 ilustra este caso particular).

Rentabilidad del cultivo

A pesar de estas dificultades nuevas, todos los campesinos siguen desmontando para volver a sembrar milpa. El clima, mucho más favorable que en el municipio vecino de Aquila, favorece el mantenimiento del cultivo y la CONASUPO no distribuye tanto maíz como en los pueblos de la costa. Es probable que el municipio permanezca autosuficiente o logre exportar una parte de su producción. La superficie sembrada (gráfica 26) es variable según los ranchos - de 8 a 250 medidas - pero la siembra más común es de 20 a 30 medidas lo que corresponde a la capacidad de trabajo de una persona - 120 a 180 días de trabajo- y a las necesidades de una familia en caso de mala cosecha.

Para los medieros que han logrado más ventajas en el contrato de aparcería y se quedan con el $100 \%$ del grano cosechado, sembrar milpa sigue siendo la mejor manera de asegurar el autoconsumo de la familia mientras esperan que les sobre algo para vender. Los propietarios ganaderos también quieren que sus medieros desmonten para sembrar pastura en la milpa de ellos.

Sin embargo, la productividad del trabajo no ha aumentado mucho, ni los precios de venta. El productor que quisiera mandar hacer el trabajo con jornaleros - unos 30 días por hectárea de milpa- no sacaría ningún beneficio del cultivo. Sólo los productores que trabajan por ellos mismos y cuyo trabajo tiene un costo de oportunidad bajo o nulo, pueden lograr ingresos monetarios regulares siempre y cuando no estén ubicados demasiado lejos de las terracerías y tengan vehículo. En San José de la Montaña, al sur del municipio, el flete aumenta el precio del fertilizante un $50 \%$ y rebaja el precio del maíz o de los puercos pagado al productor.

\section{Amapola y marihuana}

El único cultivo que se ha desarrollado últimamente con mucho éxito en la sierra de Coalcomán ha sido la marihuana y en menor escala la amapola. Esta, aunque cultivada desde mucho tiempo como planta medicinal se queda muy limitada cuando aquella se cultiva en numerosos lugares. Desde hace unos diez años los sembradíos se han multiplicado a pesar de la campaña

100. No tumban los pinos y echan fertilizante. 


\section{Grafica No 26: El. MAIZ DE DESMONTE EN LOS SISTEMAS DE PRODUCCION}

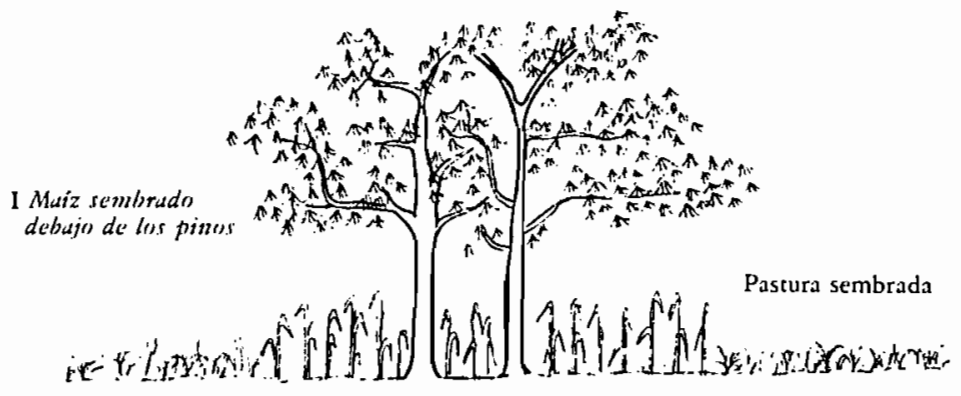

Agricultores .

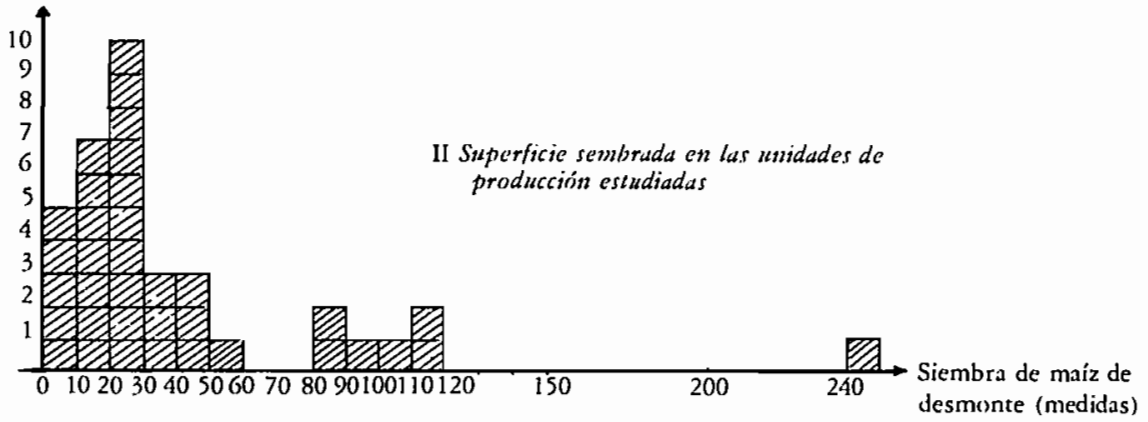

Fuente: entrevistas (oct.'85-mayo'86)

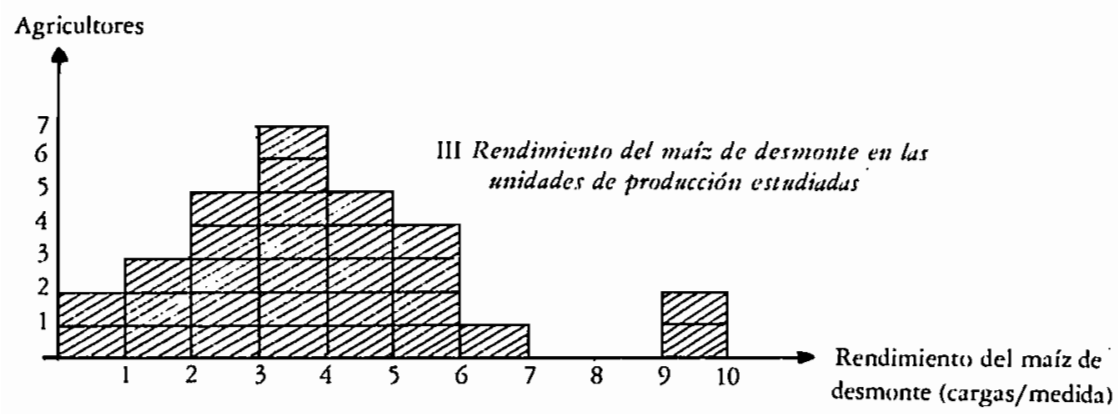

Fuente: entrevistas (oct.'85-mayo'86). 
mexico-norteamericana por combatirlos y de la apertura de numerosas brechas para comunicar los ranchos más alejados. El aislamiento de la región y su topografía accidentada se vuelven ventajas comparativas en el contexto de la especialización regional y fomentan el desarrollo del narcotráfico.

No cabe duda de que este negocio sea el más costeable de todos. Con la venta de cincuenta kilogramos de marihuana, el productor gana lo que hubiera ahorrado durante 10 meses de trabajo en California o el sueldo acumulado de un jornalero durante 10 años. Además, este cultivo requiere poco trabajo. Se trata de regar la semilla en un lugar apartado y de cosechar lo que queda del plantío después de las destrucciones operadas por el ejército y/o la policía judicial. En tales condiciones, la productividad del trabajo es elevadísima.

Sin embargo, estos cultivos prohibidos no constituyen un elemento estable de los sistemas de producción. A menudo, el campesino siembra una vez la planta como si estuviera jugando cartas siendo el riesgo la apuesta. Si le sale bien, tiene una oportunidad de acumular sin precedentes. Puede comprar terrenos, casas, carros o ganado. Una vez hechas estas inversiones deja el negocio y sigue de agricultor-ganadero con un capital multiplicado. Sin duda alguna, el narcotráfico fue y sigue siendo la única fuente de acumulación para numerosos minifundistas, medieros o peones. De la noche a la mañana, se vuelven "pequeños propietarios" y alcanzan su "independencia económica": dejan de trabajar en terrenos de otro. Unos vuelven a sembrar cinco o diez años después para mantener el nivel de vida alcanzado. Los productores sin suerte, descubiertos o denunciados están encarcelados. Sus familiares no tienen más alternativa que seguir con el negocio para pagar los "gastos" de su liberación. En todo caso, el riesgo es inmenso para el productor que no esté protegido por una red de relaciones familiares y de compadrazgo capaz de neutralizar los elementos represivos. Aunque unos cuantos parvifundistas, campesinos sin tierra o medieros hayan sacado provecho del narcotráfico, no cabe duda de que éste ha fomentado la concentración del poder y de la propiedad en pocas manos.

\section{La industria maderera}

Bosque y reforma agraria

Después de que los latifundios norteamerica nos ${ }^{101}$ habían sido afectados por la reforma agraria, los inmensos terrenos boscosos de la sierra calcárea al este del municipio pertenecieron a otras compañías. En 1954, la "Michoacana

101. Pacific Timber Company y Balsas Hardwood Company. 
de Occidente" 102 obtuvo una concesión de explotación por 25 años, con el compromiso de realizar obras de beneficio social, ${ }^{103}$ en los nueve municipios de la Sierra Madre del Sur. Compraba la madera a los propietarios y la llevaba a sus aserraderos de Varaloso y Dos Aguas. Como no cumplía sus compromisos, los trabajadores de la empresa y los campesinos vecinos hicieron la lucha para que se formaran ejidos. Al iniciarse los trámites de solicitud, se reunieron en estos dos lugares numerosas gentes "puros medieros de los ranchos circunvecinos" 104 que querían beneficiarse de la dotación de tierra. También vinieron de Dos Aguas, pueblo importante recién formado alrededor del aserradero de la compañía.

\section{CUADRO No 22}

CRECIMIENTO DE LOS NUEVOS CENTROS DE POBLACION:

\begin{tabular}{|c|c|c|c|c|}
\hline Pueblos & 1940 & 1960 & 1970 & 1985 \\
\hline El Varaloso & 16 & 287 & 327 & $1,535(?)$ \\
\hline Barranca seca & 13 & 50 & 247 & 911 \\
\hline
\end{tabular}

Fuente: 1940, 1960, 1970: Censos Nacionales de Población y Vivienda. 1985: Censo Escolar (SEP).

La resolución presidencial de 1959 concedió 7,000 hectáreas de bosques -un $5 \%$ de la superficie maderable del municipio-a 2 ejidos nuevos: El Varaloso (2,715 Has. para 155 ejidatarios) y Barranca Seca (4,215 Has. para 280 ejidatarios). ${ }^{105}$

Aserraderos y silvicultura intensiva

Al inicio, estos ejidos no contaban con ninguna infraestructura productiva. Los primeros años vendieron la madera a La Michoacana (1965-1967) pero la empresa se llevó las máquinas en 1973. A partir de 1979, los ejidos consiguieron sus propios aserraderos con crédito gubernamental. El Varaloso compró su aserradero en 1979 y Barranca Seca empezó a trabajar

102. Compañia privada: los principales socios eran extranjeros (norteamericanos).

103. Una carretera hasta la costa, casas para los obreros, centros de salud y escuela. Véase Arreola C., op. cit., p. 268.

104. Entrevistas en El Varaloso.

105. Datos de SRA-Uruapan, Michoacán. Como se acostumbra en tales casos, el número real de eịidatarios no alcanza las cifras oficiales de la SRA. Son 48 ejidatarios efectivos en El Varaloso y 120 en Barranca Seca, los demás se han ido por causa de conflictos o no han nacido todavía.. 
con el suyo en 1981. También se fomentaron el desarrollo de industrias privadas: aserradero del Resumidero y de Coalcomán. ${ }^{106} \mathrm{Al}$ formarse la Unidad de Administración Forestal, ejidatarios y pequeños propietarios estuvieron asesorados por los técnicos forestales. En la Sierra Madre del Sur, siendo una de las zonas forestales más importantes del estado y muy poco explotada, ${ }^{107}$ se hizo hincapié en el desarrollo de nuevas técnicas de explotación del bosque más productivas y que tomaran en cuenta la regeneración del bosque: La silvicultura intensiva o método de desarrollo silvícola (MDS) sucedió al método mexica no de corte cuyo propósito sólo era cortar un porcentaje de los árboles ( 35 ó $40 \%$ del total) cada doce años. Para imponer el método de silvicultura intensiva, se divide cada predio en áreas de corte de aproximadamente $100 \mathrm{Has}$. divididas ellas mismas en 6 zonas más o menos homogéneas cuyo tratamiento resulta distinto: Preaclareo (P-A), primer aclareo $(1 A)$, segundo aclareo (2A), tercer aclareo $(3 A)$, corte de regeneración (CR) y corte de liberación (CL). Cada zona lleva su propio tratamiento aunque no tenga, al empezar el método, las características necesarias (árboles de la mis ma edad). Este método refleja la voluntad de los técnicos de obtener en algunos decenios seis zonas homogéneas en cada área de corte. ${ }^{108}$

Todos los propietarios tienen que conformarse con estas técnicas puesto que el personal de la forestal dirige los cortes y controla la producción de los aserraderos. A la inversa de lo que se da en la parte norte del estado, el corte clandestino casi no existe en la décima Unidad Administrativa Forestal en la Sierra Madre del Sur, por la bajísima densidad de población. El aislamiento de la zona y la ausencia de mercados no-oficiales no fomentan la "tala de luna". Solamente los agricultores llegan a tumbar algunos árboles para levantar una casa o ampliar un poco su área de desmonte sin pedir para eso un permiso especial ya que los trámites duran mucho. A pesar de la reducción drástica del bosque consecutiva al aumento demográfico expansión de los desmontes y desarrollo de las praderas sembradas- la situación actual del bosque de pino parece estabilizada. Al contrario, las encineras ya bastante taladas para sembrar milpa desde principios del siglo se estan agutando. ${ }^{109}$

106. La empresa del Resumidero (Madeco) cuenta con 25 socios y tiene el aserradero más importante de la región; emplea 250 personas. El aserradero de Coalcomán (22 socios) es más reducido y emplea unas cincuenta personas.

107. Con un potencial de corte de un millón de metros cúbicos de madera de pino o sea el $30 \%$ de la capacidad estatal (información: PROFORMICH de la Unidad Administrativa Forestal No. 10).

108. Entrevista al Ing. José Antonio Padua, Unidad Administrativa Forestal No. 10.

109. Los encinos no están tan protegidos como los pinos por la administración forestal puesto que no tienen el mismo valor comercial. 
Bosque y acumulación

Desde que se desarrollo la industria forestal, el poseer pineras pudo proporcionar utilidades importantes. Este capital que poco "rendia" se ha vuelto disponible para los 569 propietarios privados y ejidos forestales. 110 De 100 hectáreas de pinera explotadas en silvicultura intensiva se puede sacar $4,000 \mathrm{~m}^{3}$ rollo, pagados a 8 y 10 millones de pesos (el precio era, a principios de 1986 de 2,000 a 2,500 pesos $/ \mathrm{m}^{3} \mathrm{r}$ ). De las 40 unidades de producción estudiadas, cinco se beneficiaron de esta fuente de ingresos. Los recursos forestales se consideran en general como caja de ahorros para cuando se presenta un gasto excepcional: compromisos, compra de una casa en la cabecera municipal, adquisición de terrenos, etc. Las utilidades generadas por estos recursos sin duda fomentaron la concentración de la propiedad puesto que solamente los predios forestales importantes pueden justificar la construcción de una brecha y la explotación maderera. Sólo los grandes propietarios forestales consideran al bosque como un capital productivo que tiene que ser explotado con criterios típica mente capitalistas. Los 25 socios de la empresa Madeco en el Resumidero controlan unas setenta mil hectáreas de bosque maderable en el municipio de Coalcomán. El "metro cúbico tabla" (producto de los aserraderos) se vende diez veces más caro que los dos "metros cúbicos rollo" necesarios para su elaboración comprados a los propietarios: un negocio jugoso que deja utilidades considerables. ${ }^{111}$

Los ejidatarios del Varaloso también sacan sus utilidades aunque en menor escala. En 1985, la empresa ejidal entregó un millón de pesos de utilidad a cada uno de los 48 ejidatarios lo que fomenta una acumulación de capital impresionante y poco común en los ejidos; además de la madera ejidal, el ejido compra el $80 \%$ de los árboles a propietarios privados. ${ }^{112}$ En 1974 compraron 330 hectáreas de terreno laborable en el plan de Tierra Caliente (Huisto, municipio de Aguililla) con el producto de una temporada de madera. Durante muchos años los ejidatarios pidieron una ampliación. Como no se las daban, todos empezaron a comprar con las utilidades que les quedaron terrenos colindantes con el ejido. Se volvieron pequeños propieta-

110. 567 predios particulares y 2 ejidos según datos de la presidencia municipal. Primer Informe, Gobierno Municipal. Coalcomán, 14 de diciembre de 1984 (en realidad el bosque maderable se encuentra concentrado en pocas manos).

111. Para la empresa Madeco, la tasa de ganancia se acerca al $50 \%$. Las empresas tienen que abrir brechas largas para sacar la madera de las zonas incomunicadas, pero las facilidades de explotación, la importancia de los recursos disponibles, así como el precio pagado al propietario (más barato que en la parte norte del estado) compensan estos gastos.

112. En Barranca Seca, sólo se repartieron 43,000 pesos a cada socio por problemas internos. 
rios con presta-nombres, y ganaderos. El hecho de que ahora nadie pida ampliación, por temor a que se afecten los propios terrenos de ellos evidencia la rapidez de esta acumulación.

$\mathrm{La}$ industria forestal ha creado en la región una fuente de empleos sin precedente. Actualmente, los cuatro aserraderos del municipio dan trabajo a unas 550 gentes - primera fuente de trabajo no-agrícola - principalmente agrupados en tres nuevos centros de población: Dos Aguas, El Varaloso y Barranca Seca. Aunque muchos obreros contratados hace 20 años por la Compañía Michoacana de Occidente venían de otras regiones del estado como Zitácuaro, Uruapan, Tepalcatepec o de los estados de Durango, Zacatecas y México, el desarrollo reciente de esta industria ha quitado al sector agropecuario de Coalcomán una parte de sus trabajadores (medieros). Los que no lograron hacerse ejidatarios emigran a Estados Unidos en verano y regresan a Coalcomán para la temporada de corte de madera que es de noviembre a mayo. Pese a condiciones de trabajo muy difíciles y peligrosas, su nivel de vida se ha mejorado. De hecho, nunca han regresado a desmontar.

\section{LA APARCERIA EN CRISIS}

\section{Los medieros escasean}

La división de la propiedad

Desde que se formaron los ranchos a principios del siglo, muchas propiedades se han fraccionado por herencia a medida que crecía la población y la presión sobre la tierra. La población rural, fuera del pueblo de Coalcomán, creció un $53 \%$ entre 1930 y 1950 (véase gráfica 27). Al disminuir el tamaño de las propiedades, varios medieros se tuvieron que ir cuando los hijos del antiguo propietario quisieron posesionarse de su parte. Las fracciones que heredaron eran de un tamaño más reducido y no podían dar trabajo a muchas personas: dos o tres medieros, a parte del dueño cuando éste no se quedaba solo. A la tercera generación resultaba imposible, salvo para las propiedades más grandes que cada nieto se quedara con una finca de dimensiones aceptables para vivir a gusto como el abuelo. Unos se volvieron minifundistas pero la mayoría dejaron la propiedad encargada con un mediero mientras se iban a vivir en el pueblo de Coalcomán o en Estados Unidos.

De 1950 a 1960, la población "urbana" del pueblo de Coalcomán se duplica (crece un 111\%; gráfica 27) cuando la población rural se queda estable. Numerosos propietarios o medieros abandonaron el campo y se 
Grafica No 27: Evolucion demografica EN El. MUNICIPIO de CoAICOMAN ENTRE 1930 Y 1980 (URBANIZACION DEL PUEBIO Y EMIGRACION)

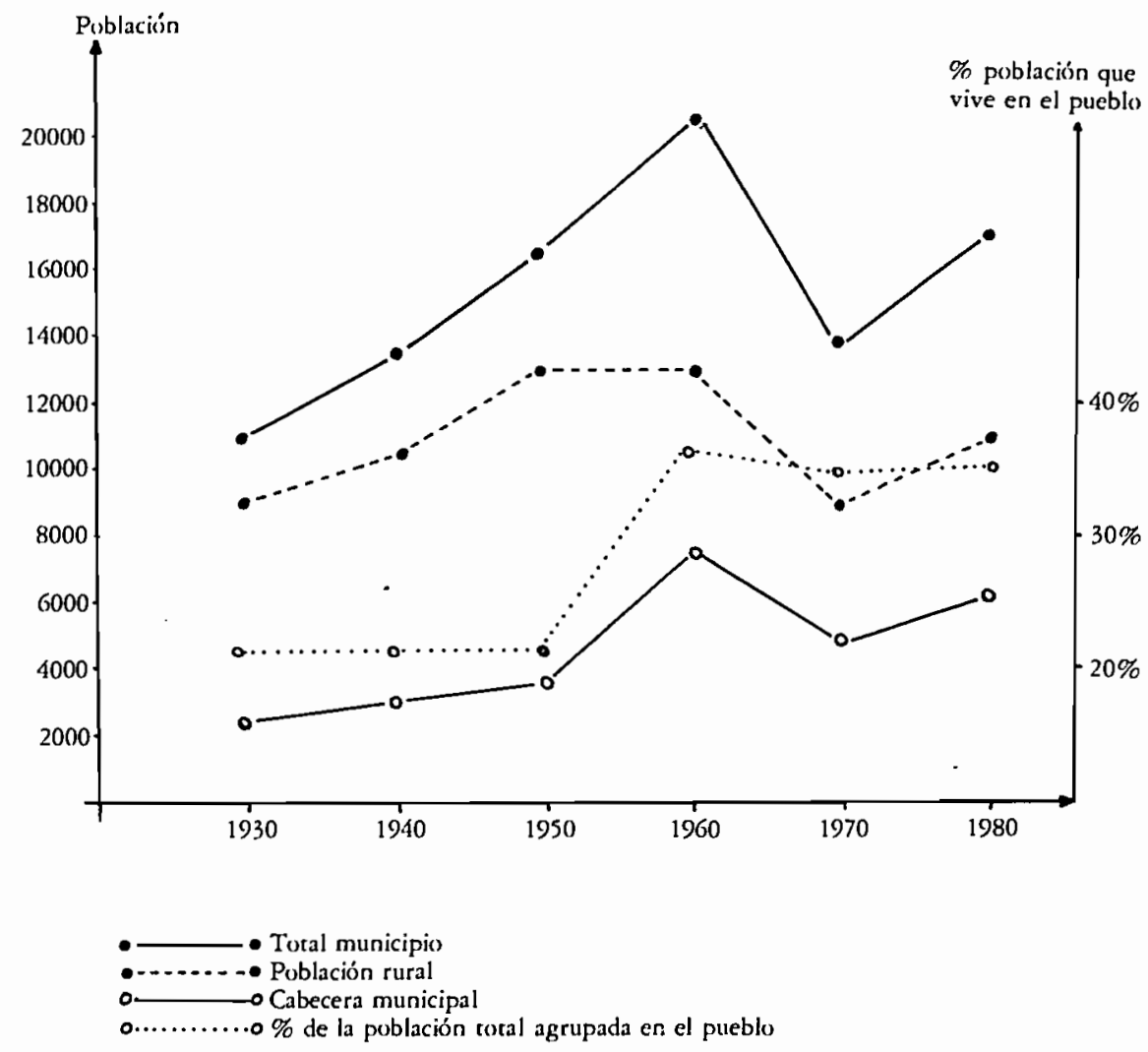

Frente: Censos de población.

juntaron en la cabecera municipal para buscar trabajo o hacer negocio. No duraron muchos años en el pueblo. De 1960 a 1970 y según los censos demográficos, se observa una baja impresionante de las estadísticas demográficas: $-33 \%$ para el municipio, $-32 \%$ para el campo y $-36 \%$ para el pueblo cuando la población del país crece de un $3.4 \%$ al año. ${ }^{113}$ Después de 1970 , la población se recupera un poco sin alcanzar todavía los niveles de 1960. Esta evolución espectacular y poco común se debe a los fenómenos de

113. Thierry Linck, Le paysan dépossédé, pouvoir, technique et décision au Mexique. These de doctorat d'état. Centre de recherche en développement comparé. El Colegio de Michoacán-CEDEC, 1985 , p. 85. 
emigración que se dieron a partir de los años cuarentas para acelerarse después.

\section{Las migraciones}

Hemos visto en capítulos anteriores que al formarse los ejidos de la parte noroeste del municipio bajo la presidencia de Lázaro Cárdenas, gentes de la Sierra bajaron para integrarse a los ejidos o ir a buscar trabajo en el distrito de riego de Colima. A medida que se desarrollaba la fruticultura de regadío en Colima y que se repartían más tierras, crecía el flujo de migrantes. El municipio de Coquimatlán, Col. contaba con un 20\% de inmigrados de 1940 a $1970^{114}$ y muchos de ellos venían de Villa Victoria y Coalcomán en el suroeste de Michoacán. A falta de estadísticas, resulta difícil evaluar la cantidad de hombres que salieron así del municipio de Coalcomán y las condiciones económicas en las cuales se encontraban cuando se animaron a irse. Sin embargo, parece probable que muchos emigrantes eran pobres, medieros, parvifundistas o peones. En efecto, tuvieron dificultades para conseguir tierra. Hoy en día la mayoría de ellos no tienen acceso al riego. Unos se benefician de una parcela ejidal de temporal; los demás, vecinos de los ejidos, trabajan de jornaleros. Nunca volvieron a la sierra de Coalcomán.

El segundo movimiento de emigración que se observa en el municipio de Coalcomán cobra más importancia. El bracerismo se ha vuelto un rasgo esencial de la vida rural. De los cuarenta jefes de explotaciones entrevistados quince han ido por lo menos una vez a Estados Unidos o siguen emigrando cada temporada. Doce nunca se han ido al norte pero tienen allá parientes cercanos. A menudo los jóvenes salen a Estados Unidos antes de casarse para volver con algo de dinero. Cuando regresan en diciembre, para las posadas, forman colas muy largas en el ed ificio de Bancomer para depositar el dinero que les sobra y cobrar intereses. El trabajo asalariado en los ranchos de California "rinde" más que todos los negocios que se puedan tener en Coalcomán, salvo el narcotráfico, en 1985, se ganaban de quinientos a mil dolares mensualmente. Ello representa una fuente de acumulación de capital exógena de primera importancia para numerosas unidades de producción aunque no sea siempre un capital productivo: compran un solar en el pueblo y levantan una casa para acomodar a sus padres o mandar a los hijos a la secundaria. Ellos siguen trabajando en sus ranchos de la sierra

114. 2,076 personas de las 10,722 que cuenta el municipio en 1970. De las 37 personas que hemos visitado allá (de abril a junio de 1984) 18 eran inmigrados. H. Cochet, op. cit., pp. 128 y 140.

Nicolás Fornage confirma el fenómeno para el ejido de Cruz de Piedra (municipio de Coquimatlán, Col. 29 ejidatarios) donde ha encontrado 11 campesinos originarios de Villa Victoria y Coalcomán que Jlegaron durante los tres últimos decenios (CUIDA, Escuela de Agricultura de Tecomán, Col.). 
aunque tengan que "aventarse" viajes largos en brechas pésimas dos o tres veces a la semana. ${ }^{115}$ Por eso compraron también camionetas.

Para otros emigrantes, el dinero ahorrado sirvió para comprar tierra. De los quince productores emigrantes que hemos encontrado, cuatro exmedieros o hijos de mediero lograron comprar una fracción de terreno para volverse pequeños propietarios (minifundistas). Sólo uno, hijo de pequeño propietario, alcanzó a comprar un rancho regular. Sin embargo, no hay que olvidar que "irse para el norte" sigue siendo un viaje riesgoso y muy costoso ya que la mayoría no tiene documentos. A principios de 1986, los "coyotes" cobraban quinientos dólares por persona. Los migrantes que son detenidos por el servicio estadounidense de migraciones pierden este dinero y se quedan endeudados por muchos años, excepto si intentan otra vez cruzar la línea (endeudándose más). Así que no a todos les sale bien. Cuatro jefes de familia, entre los quince migrantes entrevistados no han logrado ningún mejoramiento de su nivel de vida por haberse enfermado, accidentado o haber sido detenidos por los servicios migratorios. Al presentarse al coyote o al contratista norteamericano, no todos los migrantes son iguales. Los que tienen familiares al otro lado, conocen al coyote o cuentan con un padrino mayordomo, tienen una probabilidad mayor de llegar a su destino y de encontrar trabajo. Entre todos los campesinos que salieron a Estados Unidos, es probable que los hijos de pequeños propietarios que han sacado provecho de su emigración sean más numerosos que los hijos de medieros. Nietos o bisnietos de los primeros rancheros que se apoderaron de la tierra a fines del siglo XIX toman el relevo de la larga tradición de migración de la familia. ${ }^{116}$

Una de las migraciones menos conocida ha sido siempre la continuación del movimiento de colonización de la sierra hacia las playas del Pacífico y la enajenación consecutiva de los terrenos comunales del municipio de Aquila. Con la rebelión cristera, se formó en San José de la Montaña un "foco" avanzado de mestizos, a media hora de camino del municipio de Aquila. Sirvió de retaguardia cuando la gente de razón invadió la comunidad indígena de Pómaro y se volvió dueña del pueblo de San Pedro Naranjestil

115. Numerosos productores tienen así dos casas: una en el rancho y otra en el pueblo. Fomentaron el crecimiento urbano de Coalcomán. Sin embargo los censos demográficos y la repartición de la población entre ciudad y campo son difíciles de interpretar porque nunca se sabe si la familia fue censada en su rancho o en el pueblo.

116. Hipótesis planteada por $\mathrm{R}$. Rouse en su estudio sobre las migraciones en el municipio de Aguililla: "The northward migration has brougth many changes to guilillan'slives. However, for many families, migration itself was not a novelty. Many of the people who left in the early years had already been involved in migration within west-central Mexico and, more importantly perhaps, most of them were members of families with migratory traditions stretching back into the nineteenth century", op. cit., p. 1. 
(1965-1985). ${ }^{117}$ Los invasores son antiguos medieros, minifundistas o arrieros. Vendieron los pocas vacas adquiridas a medias que tenían en el municipio de Coalcomán para establecerse en los terrenos comunales donde la renta de la tierra todavía no existía. Compraron solares en los pueblos indígenas y alambre de púas. A pesar de la disminución de la arriería, con la apertura de las vías de comunicación, los arrieros seguían haciendo negocio entre Coalcomán y las comunidades de la costa: "vendían la ropa allá al doble de su precio de Coalcomán", "Mi hermano se quedó allá. Se metió hace 20 años cuando ya tenía cuñados y compadres. Ahora tiene una tienda de abarrotes. ${ }^{118}$

Conviene destacar que los migrantes que invadieron las comunidades de la costa eran los más humildes de Coalcomán, pero sus bienes acumulados aunque modestos representaban mucho más que el capital de los indígenas. Un siglo antes, los rancheros que venían de Cotija o Tamazula no eran tampoco terratenientes. Se volvieron poderosos al llegar a una región cuyo terreno era casi gratuito.

\section{Conclusión}

Antiguamente, la región de Coalcomán atraía los migrantes. A partir de 1940, empezó a despedirse de ellos. Hijos de Pequeños propietarios o de medieros, se han ido a buscar condiciones económicas mejores en los distritos de riego de Colima, en las comunidades indígenas de la costa o en Estados Unidos. Solamente los braceros regresan a veces para volverse pequeños propietarios. La formación de los ejidos forestales y la reapertura de las minas de Guadalupe del Cobre, Mich. al noroeste del municipio y de Los encinos, Jal., han ofrecido también más oportunidades de trabajo. Así que han escaseado mucho los medieros en los ranchos del municipio. Basta recorrer las principales terracerías de la sierra para observar las casas abandonadas y arruinadas. La barranca del Sacasihuite, por ejemplo, contaba con más de 30 casas antes de 1940 (112 habitantes en 1940). Ahora todas se encuentran "solas" o recubiertas por la vegetación (49 habitantes en 1960, 28 en 1970 y cero en 1985). .19 $^{19}$

Actualmente, la aparcería sigue siendo una forma de relaciones de producción esencial a pesar de la multiplicación de las pequeñas propiedades agrícolas explotadas por el dueño mismo. Las propiedades que no se han fraccionado o que resultan de una reconcentración de la tierra, así como las propiedades medianas cuyo dueño se ha ido a vivir al pueblo o a Estados Unidos, cuentan todavía con tres o cuatro medieros nada más. En todo caso,

117. La invasión de la Comunidad Indígena de Pómaro por los ganaderos mestizos está descrita en el Capitulo V: Campesinos y ganaderos de la comunidad de Pómaro.

118. Entrevista con Guadalupe Valencia, Ixtala.

119. Censos de población, 1940-1960-1970 y Censo escolar (SEP), 1985. 
los "contratos" de mediería se han modificado bastante.

\section{Diversidad y evolución de los contratos de mediería}

Diversificación de los "contratos" de mediería

En el rancho de principios del siglo, el patrón prestaba la tierra y el mediero su fuerza de trabajo. No había más medios de producción que la semilla, el machete y, para las tierras laborables, la yunta y el arado. Cuando se generalizó el uso de nuevos medios de producción en los sistemas de cultivo como fertilizante, herbicidas, tractor en los terrenos parejos, etc., las relaciones de trabajo entre propietario y mediero empezaron a modificarse de manera variable según los ranchos. Al principio, parecía normal que ambas partes gastaran lo que supuestamente se refería a sus aportes respectivos. El mediero compraba el herbicida si no quería limpiar a mano. El gasto para el fertilizante se repartía entre ambos o le tocaba al propietario, según los casos. En los terrenos mecanizables, el dueño pagaba la mitad de los gastos ocasionados por el alquiler del tractor que sustituía a la yunta de bueyes y el mediero la otra mitad que sustituía también al arado de palo y al trabajo.

El caso más común sigue siendo cuando cada uno paga la mitad de los medios de producción pero muchos medieros lograron que el propietario se encargue de una proporción mayor de los gastos: $100 \%$ del sulfato de amonio por ejemplo y a veces del Esterón. Como contrapartida, el mediero tiene que regar en el desmonte la semilla de jaragua que le ha dado el propietario. Así una parte del fertilizante aplicado lo aprovecha la pastura del dueño.

En cuanto a la remuneración del trabajo, los contratos también se han modificado. En un caso sobre dos el propietario participa en la cosecha del maíz. Trabaja él mismo junto con el mediero, o contrata mozos para que le ayuden. Si el mediero trabaja con sus dos hijos o dos mozos pagados por él, el patrón contrata tres mozos más o dos si participa él mismo. Cada quien pizca su parte. En algunos casos el dueño del terreno ayuda también para el trabajo de la tumba pagando al mediero una parte del trabajo necesario - de la misma manera que para la cosecha- o por contrato. Las diferencias de un caso a otro son muy importantes. En 1985 un mediero cobro 6,000 pesos para desmontar 27 medidas mientras que otro obtuvo 320,000 pesos (contrato) para tumbar 30 medidas de monte alto (encinera). A veces el mediero así ayudado queda comprometido a trabajar gratuitamente para el dueño en el mantenimiento del rancho. Siempre tiene que sembrar jaragua para el ganado del propietario.

Ultimamente, el reparto de la cosecha por mitad de volvió a discutir en algunas explotaciones ganaderas de la sierra. El 100\% del grano cosechado 
queda en manos del mediero. El dueño cobra el rastrojo, la pastura que tiene que sembrar el mediero, $\mathrm{y}$, a veces, algunas ayudas del mismo mediero como una renta en trabajo para arreglar cercas, etc. Este último paga entonces todos los insumos. Siendo ganadero el propietario, sólo llaman su atención el rastrojo y la pastura.

En las propiedades confiadas a los medieros para que las cuiden, mientras el dueño vive en el pueblo o en otras partes, se ha desarrollado un nuevo tipo de "ganadería a medias" (ahora muy pocas personas tienen ganado a medias como se hacía a principios de siglo). En verano, el mediero ordeña y hace el queso que se reparte después en cantidades iguales entre él y el dueño. En los ranchos ubicados cerca de Coalcomán, el mediero tiene que llevar la mitad de la leche diariamente al pueblo para entregarla al dueño, salvo si este último viene cada día a su rancho para llevarsela. En invierno, el mediero tiene que cuidar el ganado y arreglar las cercas, aunque todas las crías se queden en propiedad del dueño. En contrapartida, tiene la siembra "dada" ( $100 \%$ de la cosecha de grano) y/o cobra un sueldo mensual de 10,000 a 30,000 pesos (1986).

Las "asociaciones" posibles entre propietarios y medieros son pues múltiples. En el mismo rancho, entre el dueño y su mediero, pueden existir varias formas de relaciones de producción según el tipo de terreno o de actividad. Así, en cada rancho, se lleva a cabo una "combinación" de contratos de mediería distintos para el desmonte, el riego, el ganado, las colmenas, la caña de azúcar, etc...

Las nuevas relaciones de producción

Los medieros lograron mejorar sus condiciones de trabajo. A medida que disminuía el número de medieros disponibles y los brazos para trabajar, los propietarios tuvieron que conceder más ventajas a sus medieros para que no se fueran al norte. Así la proporción de trabajo no remunerada por el dueño de la tierra, bajó cuando se emanciparon los medieros. Sin embargo, es interesante observar que las ventajas conseguidas por los medieros abarcan la cosecha de maíz, el financiamiento de los insumos y la remuneración del trabajo. De ninguna manera se le permitieron ventajas al mediero en asuntos de ganadería o de pastos. El derecho de pastoreo quedó limitado a 4 ó 5 animales salvo excepciones, aunque los medieros tengan que conformarse con el jaragua. Ahora, lo que se espera del mediero es que siembre todo lo que pueda desmontar para que haya más pastura. Si resulta necesario, se le paga un sueldo o se le da la siembra. Cuando la ganadería se volvió el único negocio costeable de la región, los ganaderos dejaron a sus medieros los demás negocios poco interesantes, entre ellos el cultivo de maíz, pero no les dieron oportunidad de acumular ganado.

Los latifundistas ausentistas encargan su rancho a un conocido de ellos para que cuide el ganado, cambie los animales de potrero de vez en cuando y 
arregle las cercas. A cambio, le dan permiso de desmontar lo que quiera en la propiedad y de mantener hasta 20 ó 30 animales suyos. Se trata de un caso muy particular de relaciones de producción hasta ahora poco conocido en la región pero que tiende a desarrollarse, sustituyendo a la aparcería.

Parece que los medieros que viven y trabajan cerca del pueblo principal han logrado más fácilmente mejorar el contrato de mediería a su favor que los medieros ubicados en ranchos incomunicados. Bastante lejos de Coalcomán, hemos encontrado relaciones de aparcería muy similares a las que hemos descrito en el tercer apartado. Es posible que la evolución de las relaciones de producción haya sido tanto más rápida cuanto más cercano del pueblo estuviera ubicado el rancho. ${ }^{120}$

\section{¿Perspectivas de acumulación?}

A pesar del mejoramiento aparente de su situación, los medieros no han logrado elevar su capacidad de acumulación de capital. Ahora algunos se quedan con la totalidad de su cosecha de grano pero no les sirve para "hacer negocio": el precio del maíz pagado al productor por la CONASUPO es bajo y la manteca de puerco dejó de tener mercado. Mientras no tengan acceso a los recursos forrajeros, los medieros no podrán desarrollar sus actividades ganaderas y elevar su nivel de vida. Además, siguen siendo muy dependientes de su contrato con el dueño de la tierra. Como lo hemos explicado anteriormente no pueden romper el contrato sin perder la parte de la cosecha que les toca o su trabajo acumulado en la tumba para el próximo ciclo agrícola. Son contados los medieros que superaron su dependencia económica y se volvieron pequeños propietarios sin casarse con una hija de terrateniente o salir a Estados Unidos algún tiempo. Estos últimos tuvieron la oportunidad de comprar un terreno con un capital acumulado fuera de la región, salvo para los sembradores de marihuana. De los cuarenta productores entrevistados, nueve propietarios habían sido medieros o eran hijos de mediero.

Los pocos medieros que se han vuelto "encargados" están en condiciones más favorables. Además de la siembra "dada" tienen un acceso más amplio a los pastos de la propiedad. Pariente o ahijado del dueño, se benefician del estatuto privilegiado de "encargado" del rancho.

Al disminuir el número de medieros en la sierra de Coalcomán, se

120. En la región de San José de la Montaña, al sur del municipio, el arrendamiento sigue siendo la forma principal de las relaciones de producción, pero las rentas han subido. Anteriormente se cobraba quince anegas. Quedará por investigar el porqué tales relaciones de producción se establecieron en este pueblo del municipio en lugar de la aparcería clásica. 
extensificaron los sistemas de producción de las medianas y grandes propiedades. Se abandonaron muchos terrenos laborables y de riego. AI final, la especialización ganadera y el desarrollo de las pasturas sembradas pueden interpretarse como una adaptación de los sistemas de producción al enrarecimiento de la mano de obra. Por otra parte la pastura sembrada en los desmontes condena el cultivo de maíz a largo plazo, transformando los cerros en praderas que no se pueden cultivar sin arar. Al condenar al maíz, se condena a los medieros puesto que sembrar maíz es la única actividad que les queda. Finalmente, todo sucede como si el nuevo sistema agrario que se diferencia no ocupara medieros o tendiera a arreglarse sin la participación de ellos.

\section{CONCLUSIONES}

\section{Repartición de los medios de producción}

Las divisiones sucesivas de las propiedades y las compras realizadas por algunos medieros fomentaron la multiplicación de las pequeñas propiedades (menos de 100 hectáreas) y la formación de un minifundio importante. ${ }^{121}$ Sin embargo, quedaron propiedades muy grandes que no se fraccionaron o se volvieron a concentrar. Gracias a una acumulación rápida permitida por la ganadería, uno de los herederos puede comprar a sus hermanos y hermanas las fracciones correspondientes para reconstruir el rancho de origen. Ultimamente, las ganancias realizadas en la industria maderera facilitaron la formación de neolatifundios forestales. Por falta de catastro rural, resulta imposible conocer con precisión la situación actual de la tenencia de la tierra. La gráfica 28 fue realizada a partir de los datos disponibles en la oficina de Administración de Rentas de Coalcomán donde 1,947 propiedades están registradas. La superficie total registrada es de 93,817 hectáreas, más 9,621 hectáreas que pertenecen a ocho ejidos. La suma de estas dos cantidades representa el $34 \%$ de la superficie total del municipio, lo que quiere decir que las dos terceras partes de la propiedad no están registradas, no tienen existencia legal ni están sujetas a impuestos. Queda claro que estos orillan a los propietarios a no registrar la superficie real de su rancho. En realidad existen numerosas propiedades cuya superficie rebasa los límites amparados por la Ley de Reforma Agraria. La

121. Predio rural de pequeña extensión (inferior a 20 o 30 hectáreas de agostadero), el minifundio no alcanza a satisfacer las necesidades económicas de la familia. El jefe de familia tiene que trabajar a medias con los vecinos. 
Grafica Ne 28: Reparticion de la propiedad en el. municipio de Coalcoman

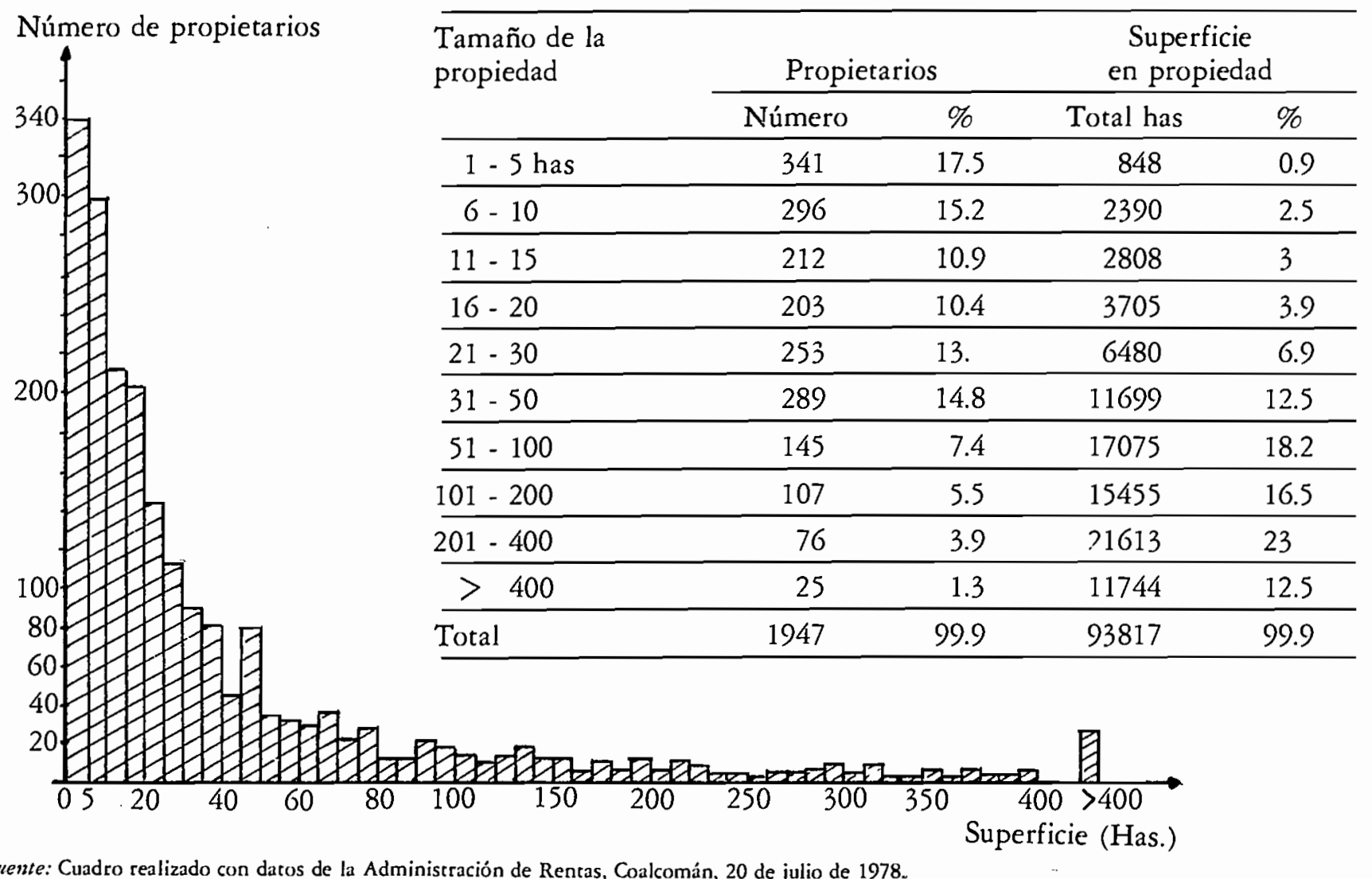


propiedad registrada más grande tiene oficialmente 516 hectáreas cuando en la realidad hemos visitado varios ranchos de miles de hectáreas. Aun así, la gráfica 28 nos da una idea significativa de la tenencia de la tierra en el municipio. Refleja la repartición desigual de este medio de producción: el $50 \%$ de los propietarios, (sin tomar en cuenta los campesinos sin tierra ni los ocho ejidos poseen el $10 \%$ de las tierras y sólo un $10 \%$ de todos los propietarios acaparan el $50 \%$ de las tierras.

Los grupos agraristas que se formaron a partir de los años cincuenta no lograron ningún resultado: se rechazaron solicitudes para las tierras de Coalcomán y El Terreno (1957), de Marvata y La Pájara (1971), de La Zanja (1974), de La Cofradía y Los Chapiles (1979) y de El Salitre, Las Tabernas, Tupitina, Corral de Piedra y Monte Verde (1980); ${ }^{122}$ se declararon improcedentes las solicitudes de tierra por incapacidad jurídica o por falta de predios afectables dentro del radio legal de $7 \mathrm{Km}$. En efecto, la ley ampara las propiedades cuyo tamaño alcanza a mantener quinientos animales. Con un coeficiente de agostadero de 5,123 la superficie amparada es de 2,500 hectáreas. Además, la división artificial de las propiedades con prestanombres, sociedades, régimen legal de separación de bienes entre los cónyuges casados, etc., disimula propiedades más grandes pero inafectables.

La repartición del ganado entre los productores de Coalcomán también ilustra la diferenciación campesina (gráfica 29). El problema de las estadísticas se plantea de la misma manera que para la propiedad territorial. La Unión Ganadera local tiene registradas 31,175 cabezas de ganado repartidas entre 1,028 ganaderos, pero el informe de gobierno municipal en diciembre de 1985, reconoce la existencia de ochenta mil cabezas de ganado vacuno en el municipio. Si se da fe a esta estimación, el $60 \%$ del ganado no estaría registrado. ${ }^{124}$ Por temor a las afectaciones de tierra, los ganaderos que tienen más de quinientas cabezas de ganado no registran todos sus animales. Por otra parte, muchos productores de los más pobres no registran su ganado. Los que tienen dos o tres animales no hacen los trámites necesarios para registrar su ganado aunque sea obligatorio para poder venderlo. Así que el número de productores que tienen entre una y diez cabezas de ganado está muy subestimado en la gráfica 29. Sin embargo, se observa que el $50 \%$ de los productores se reparten el $20 \%$ del ganado registrado cuando $20 \%$ de los ganaderos posee el $50 \%$ del ganado.

122. La única solicitud que tuvo éxito fue la de El Cuartón, cerca de Trojes en el noroeste del municipio, donde se dieron 1,442 hectáreas a 24 solicitantes (S.R.A.).

123. Fijado por la Comisión Agraria Mixta.

124. Las cuarenta unidades de producción estudiadas cuentan con un total de 2,854 cabezas de ganado vacuno (según las entrevistas) pero solamente 1,351 (el 47\%) están registradas. 
Número de productores

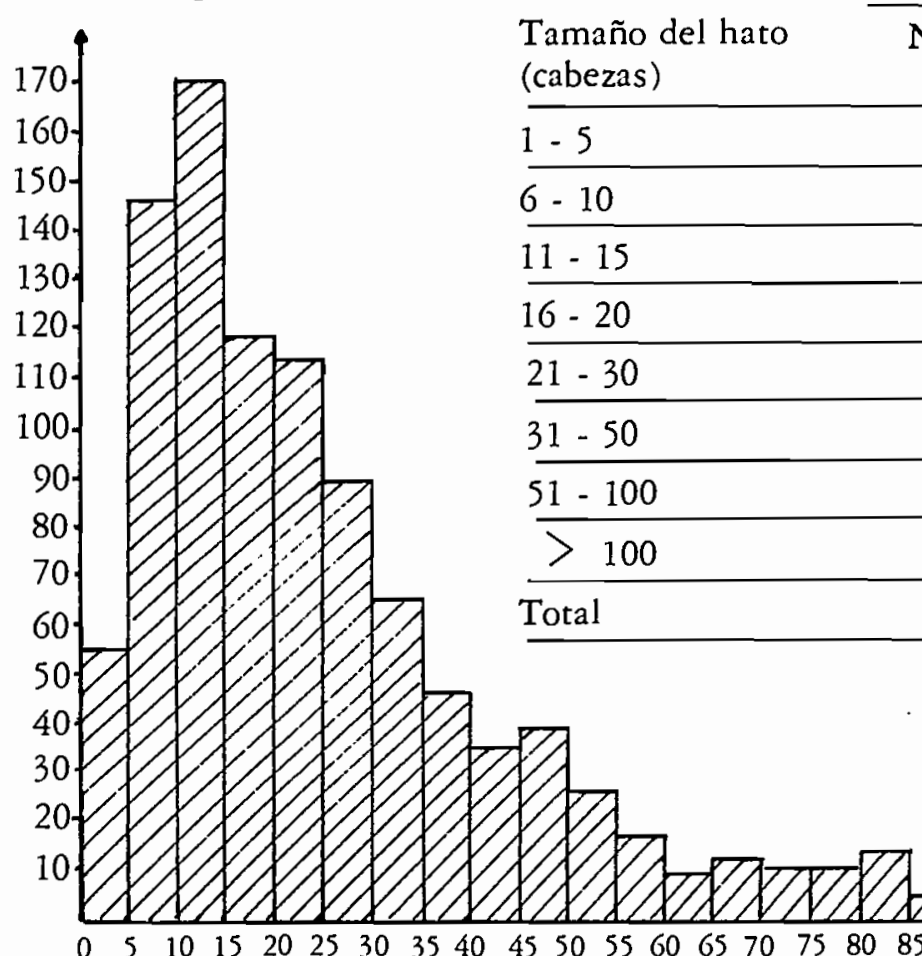

Productores

\begin{tabular}{cccc} 
Número & $\%$ & $\begin{array}{c}\text { Número } \\
\text { (cabezas) }\end{array}$ & $\%$ \\
\hline 55 & 5.3 & 204 & 0.7 \\
\hline 147 & 14.3 & 1205 & 3.9 \\
\hline 170 & 16.5 & 2178 & 7. \\
\hline 119 & 11.6 & 2166 & 6.9 \\
\hline 202 & 19.6 & 5073 & 16.3 \\
\hline 186 & 18.1 & 7285 & 23.4 \\
\hline 112 & 10.9 & 7872 & 25.3 \\
\hline 37 & 3.6 & 5192 & 16.7 \\
\hline 1028 & 99.9 & 31175 & 100.1 \\
\hline
\end{tabular}

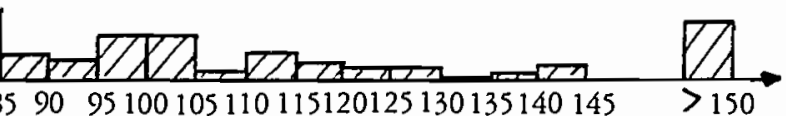

Número de animales 


\section{Intensificación o extensificación}

La repartición de los medios de producción aparece así bastante desigual. Fomenta una evolución diferenciada de los sistemas de producción.

En las unidades de producción de recursos limitados, se observa una intensificación general que responde a la necesidad de aprovechar mejor la superficie disponible. A pesar de que el maíz siga siendo la piedra angular del sistema de producción, el campesino trata de mejorar la capacidad forrajera de su terreno y siembra pasturas mejoradas como jaragua y "gordura" con mucho cuidado para no perjudicar la milpa. Mantiene siempre un equilibrio entre el maíz y la pastura. A veces vuelve a arar las tierras de yunta transformadas en huizachera. Si está ubicado al margen de un río, arregla una playita para sembrar granos básicos, legumbres, caña, o cultivos forrajeros (maicillo, sorgo, alfalfa). La asociación entre agricultura y ganadería se hace más íntima. Se cortan manojos de hojas a montones, se encaraman en un árbol fuera del alcance del burro y se reparten a fines de la estación seca. A veces se junta el abono de corral para esparcirlo en el terreno barbechado. Cuidan al máximo su ganado puesto que la muerte de un animal representa una pérdida inmensa.

En las unidades de producción más grandes - de 100 a 300 hectáreas en la sierra o menos en el valle de Coalcomán-, la intensificación de los sistemas de producción ha encontrado sus límites cuando escasean los brazos para trabajar pues los hijos se van a Estados Unidos y los medieros ya "no quieren trabajar". Las actividades que llevan una productividad del trabajo demasiado baja se han abandonado al presentarse una oportunidad de viaje "al norte". Si el rancho está confiado a un mediero, los intereses antagónicos de ambas partes - competencia maíz-jaragua, derecho de pastoreo- también limitan las posibilidades de intensificación puesto que una parte del trabajo invertido por el mediero se le escapa. El mediero corta hojas de maíz para sus vacas si puede apartarlas del ganado del patrón. Los trabajos de mejoramiento se aplazan hasta que el dueño se anime a participar.

En los ranchos de quinientas hectáreas o más, la evolución del sistema de producción está caracterizada por una extensificación cada vez mayor. Los medieros se han ido, dejando la propiedad sin fuerza de trabajo salvo en algunos ranchos donde perdura el sistema de producción tradicional descrito en el tercer apartado. La ganadería extensiva representa la actividad principal del rancho. El número de cabezas se regula con las ventas de octubre para rebajar la carga-animal pero no se da ningun complemento al ganado. El "encargado" es la última persona que sigue sembrando maíz en la propiedad.

El desarrollo diferenciado y contradictorio de los sistemas de producción 
que aquí hemos analizado, ha pretendido ilustrar la diversidad de los intereses en juego. Enseña también el papel decisivo de la repartición de los medios de producción y de las relaciónes de producción en la evolución general del sistema social de producción. 


\title{
CAPITULO V \\ CAMPESINOS Y GANADEROS DE LA COMUNIDAD DE POMARO, MUNICIPIO DE AQUILA
}

\author{
Hubert Cochet \\ Irene Felix \\ Rocín Martínez K.
}

\section{RESUMEN HISTORICO}

\section{Origen del poblamiento y toponimia}

Los restos arqueológicos de Maruata viejo y las relaciones del siglo XVI son testigos de la antigüedad del poblamiento indígena de la zona costera de Michoacán. Cuando llegaron los españoles, esta sierra estaba ocupada por núcleos pequeños de población más o menos aislados unos de otros. Se cultivaban las orillas de los ríos y la gente sembraba el maíz bajo el sistema de roza, tumba y quema. ${ }^{1}$

Era una ocupación "difusa" del espacio: "Sólo el pueblo de Pómaro, en esta comarca tendría cien vecinos, y el de Tlatictla, de este río, casi otros tantos; y aún dudo que lleguen a ciento; los demás serían como de a veinte o a treinta y de cuarenta y de cincuenta, y dos o tres que hay, de a cinco indios". ${ }^{2}$

A pesar de la cercanía de las minas de oro y plata de la provincia de Motín de Oro que, "antes de que llegaran los españoles eran trabajadas intensamente por los naturales de la región", ${ }^{3}$ parece que la población de Pómaro no trabajaba el metal: "ni tenían oro ni plata aunque la tierra es de oro en algunas partes de esta provincia, y bien cercano y vecino de este río, no lo sabían sacar ni aprovechar".4

1. La gente no vivia en la costa por calurosa e insalubre, pero bajaba al mar para aprovechar sus recursos.

2. "Relaciones de la provincia de Motines" en: Alvaro Ochoa S. y GerardoSánchez D., op. cit., pp. 98-99.

3. Ignacio M. del Castillo y Raúl G. Guerrero, En los Motines del Oro. Expedición etnográfica y lingüística, 1946, p. 6.

4. "Relaciones de la provincia de Morines", Ibid., p. 102. 


\section{Colonización tardía y superficial}

Pocas cosas se saben de la conquista de estas comarcas alejadas. Esta no fue con "guerra sino por halagos y buenas razones.".s Como lo hemos mencionado en el capítulo IV, parece que la conquista y la colonia no modificaron las actividades agropecuarias de la comunidad tanto como en la región vecina de Coahuayana y Colima donde las tierras de riego de los indigenas fueron plantadas de cacao, lo que modificó totalmente el sistema agrario y coadyuvó al descenso demográfico.

Por lo menos es probable que la organización social no se haya modificado de manera clara y nunca se cobró tributo según las relaciones. ${ }^{6}$

Muy alejada, de acceso muy difícil y sin recursos agrícolas, la región nunca llamó la atención de los españoles y en 1533, Hernán Cortés firmó el acto que reconocía la comunidad indígena de Pómaro (Título original).

Curiosamente, el acontecimiento que tuvo más consecuencias en el siglo XVI fue la llegada a la comunidad de Pómaro de una etnia indígena diferente procedente del estado de Guerrero y que andaba huyendo de "la crueldad desarrollada por los españoles". Después de muchas migraciones, se instalaron definitivamente a principios del siglo XVII en el pueblo de Coire (véase mapa 20) donde formaron su comunidad gracias a concesiones de tierras otorgadas por las comunidades vecinas de Pómaro y Ostula. Como veremos más adelante, estos acontecimientos, consecuencia indirecta de la conquista, tuvieron más efectos, en cuanto a la tenencia de la tierra, que la conquista misma, puesto que los conflictos entre ambas comunidades todavía no se acaban.

\section{Liberalismo y saqueo mercantil}

Durante la primera mitad del siglo XIX, la zona costera todavía no presentaba muchos casos de venta o arrendamiento de tierras. ${ }^{7}$ En 1871, después de que fueron adoptadas las leyes liberales, y mientras que "el gobierno del Estado trataba de que a toda costa fueran repartidas las propiedades comunales del Distrito de Coalcomán, Pómaro fue una de las

5. Ignacio M. del Castillo y Raúl G. Guerrero, op. cit., p. 102. "Los pueblos que tengo referidos en este dicho río y aún los demás de motín y Pómaro que tengo por decir cuando adoraban a sus ídolos en tiempo de su gentilidad se averigua que nunca fueron sujetos a ningún señor natural, ni unos a otros se sujetaban, y así se halló en ellos cuando los conquistadores los sujetaban, que fue sin guer ra sino por halagos y buenas razones".

6. "Nunca supieron dar tributo porque, como eran pobres no tenían ropas". Relaciones en op. cit., p. 102.

7. Gerardo Sánchez, El suroeste de Michoacán: estructura económico-social 1821-1851. UMSNH, 1979, Mapa 4. "Despojo de tierras comunales 1828-1851", p. 53. 


\section{MAPA № 20: MAPA topografico de l.A COMUNidAd DE Pomaro}

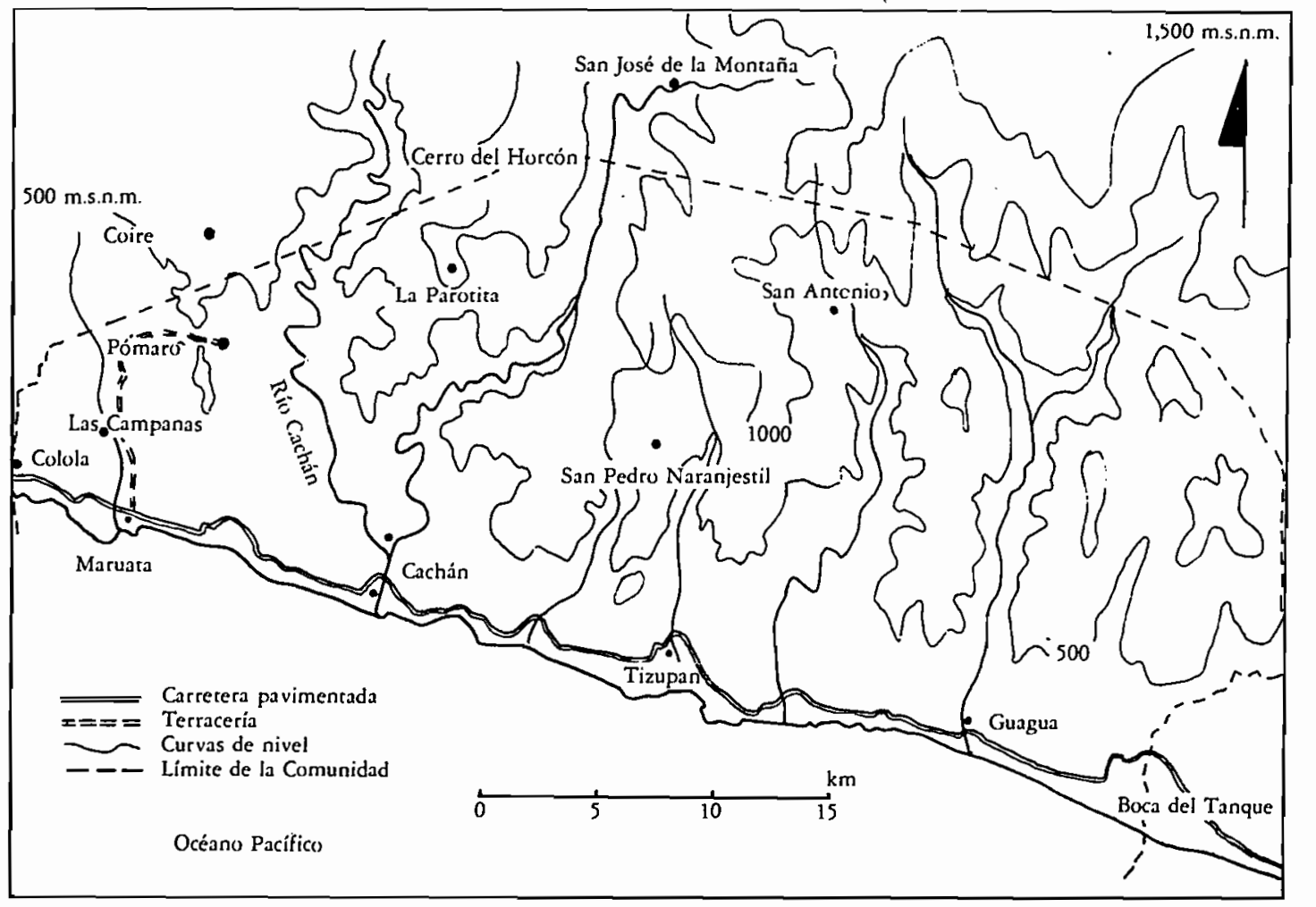


comunidades que más resistencia presentó a que sus tierras fueran fraccionadas". 8

Sin embargo y según don Camilo Chávez, comunero de Pómaro, algunos jóvenes de la comunidad que se habían ido a vivir cerca de la "frontera" norte de la comunidad, empezaron a vender pedazos de tierra a los mestizos circunvecinos. En 1892 se vendió un terreno cerca de San Pedro por $\$ 9,000.00$ y en 1896 vendieron otro en La Cavalilla (más arriba de San Antonio: véase mapa 20). ${ }^{9}$ El gobierno siguió presionando a la comunidad para que repartiera sus tierras y pagara sus contribuciones. A pesar de la resistencia de la comunidad, "a mediados de agosto de 1906 se informó que los indígenas de Pómaro tenían arrendados los ranchos de La Parota, Las Trojillas, Agua Fría, Siete Ocotes, Santiaguillo, Guagua y el Cerro Ve. Je". ${ }^{10}$

Así entraron definitivamente los primeros mestizos en la parte norte de la comunidad, volviéndose dueños efectivos del terreno. Estas enajenaciones de tierras comunales corresponden al flujo de migrantes mestizos que poblaron la Sierra de Coalcomán a fines del siglo XIX como lo hemos analizado en el capítulo anterior (véase mapa 17).

Mientras que se iban rentando tierras de la comunidad, se desarrollaron intercambios comerciales, mejor dicho un saqueo de los recursos naturales de la región mediante la venta de madera fina a compañías privadas norteamericanas. La Pacific Timber Company compró así varias barrancas de la desembocadura del río Guagua en los primeros años del siglo XX (véase el mapa 17 del capítulo IV). Pero este tráfico, la tala de madera fina, había empezado mucho antes puesto que en 1863 se trajeron unas campanas de Nueva York para la iglesia de Pómaro con trueque de madera bracífera (árbol de donde se sacaba una tinta para escribir). Otro contrato se llevó a cabo de la misma manera en 1886. La comunidad mandaba gente para cortar los troncos y llevarlos hasta Maruata con carretón de ruedas de madera arrastrado por bueyes. ${ }^{11}$

Del embarcadero de Maruata se llevaban la madera con canoas hasta los barcos norteamericanus que venían de San Francisco, California. Así había empezado un comercio tan próspero que se hizo un proyecto de puerto internacional en la bahía de Maruata, proyecto muy ambicioso que iba a cambiar la vida de todos los michoacanos. Se planteó la construcción de una vía de ferrocarril de Morelia a Maruata, ${ }^{12}$ las actividades mercantiles estaban

8. Gerardo Sánchez, Ill suroeste de Michoucán: estructura económico-social 1852-1910. UNAM, 1982, p. 341.

9. Camilo Chávez, Diurio de bistoriu de lu comunidud de Pómaro. Pómaro, municipio de Aquila, Mich. (manuscrito). Agradecemos a don Camilo por su apoyo y ayuda durante todo nuestro trabajo de campo.

10. G. Sánchez, op. cit., p. 344.

11. Camilo Chávez, Ibid.

12. G. Sánchez, op. cit., p. 508. 
por desarrollarse en Maruata y llegaron más barcos a llevar madera. Pero se dejó este proyecto por razones que no conocemos y nunca llegaron más que canoas al "puerto" de Maruata.

Mas allá de las anécdotas, el proyecto del puerto de Maruata pone de relieve el hecho de que las únicas relaciones mercantiles que tenía la comunidad de Pómaro hacia fines del siglo pasado, eran muy parecidas a las de la colonia: un saqueo de los recursos naturales (madera-minas) por parte del capital nacional e internacional.

\section{La tenencia de la tierra a principios de los años cincuentas}

Desde fines del siglo XIX, familias mestizas en número creciente habían ocupado rancherías en la parte norte de la sierra, llegando de la región de Coalcomán. La comunidad de Coire reconocida oficialmente desde 1704, seguía tomando tierras cerca de Pómaro. Ya se había vendido buena parte de la comunidad que se reducía con cada reconocimiento oficial de los linderos (1901-1945-1961).

A partir de los años cincuentas, una segunda ola de invasión se desarrolla por parte de ganaderos "de razón". Desde entonces la historia y la evolución de la comunidad de Pómaro y de sus actividades agropecuarias se relacionan directamente con el problema de la tenencia de la tierra. Actualmente 600 comuneros censados comparten 80,000 hectáreas de sierra pero parte de esta superficie está ya en manos ajenas. Los comuneros están a la defensiva y los acontecimientos violentos se vuelven cotidianos. El textö a continuación, escrito en 1946,13 cuenta la situación de choque entre mestizos e indígenas en Aquila, Mich. Da una idea, aunque poco distinta, de lo que iba a pasar en la Comunidad de Pómaro a partir de los años cincuentas,

Por lo que toca a la posesión legal de la tierra en la actualidad, se ha tomado un nuevo cariz, que es la situación de choque en la que se han colocado mestizos e indígenas. En Aquila, por ejemplo, es donde más claramente se ve este problema, pues, como ya se dijo, la población mestiza es la que predomina en número. Los mestizos reconocen que los indígenas son los propietarios legales de la tierra, pero en vista de que desde hace varias generaciones ellos han vivido allí y trabajado esas tierras, consideran ya tener derecho a la propiedad rústica y urbana y no pagar más la renta anual que les cobran los indígenas.

Por otra parte, los indígenas se han retirado de la población dejándola en completo dominio de los mestizos, y se han ido a vivir a pequeñas rancherías en los alrededores de Aquila, pero considerándose y sabiéndose propietarios, no dejan de cobrar la renta anual de $\$ 6.00$ (seis pesos) por el terreno que ocupen los mestizos, ya sea como predio urbano para la construcción de sus

13. Ignacio M. del Castillo y Raúl G. Guerrero, op. cit., pp. 31 y 32. 
habitaciones, o como predio rural para labores agrícolas.

Cualquiera supondría, que en estas circunstancias, la situación de los indígenas es privilegiada, pues aparentemente tienen una ganancia sin trabajar la tierra. Pero el caso real es que se ven obligados a trabajar como peones de los mestizos, pues el monto de esas rentas nunca llega a manos de los aborigenes, ya que los dineros se filtran entre los "líderes", quienes se escudan con el pretexto de sostener una costosa of icina en Coalcomán para el arreglo de esos asuntos.

En Ostula, Coyre y Pómaro no se nota este problema porque no tienen población mestiza y los indigenas en cada uno de estos lugares, están constituidos en comunidad.

Es lamentable el hecho de que exista ese conflicto de la propiedad de la tierra, pues al mismo tiempo se presenta una discriminación racial entre mestizos e indígenas, que puede degenerar en sucesos sangrientos, como ya ocurrió hace algunos años en Coyre, donde los mestizos fueron arrojados mediante la violencia.

\section{CUANDO TODAVIA HABIA POCA GENTE "DE RAZON" (1940-1950)}

\section{Terruño y organización comunitaria}

Organización del espacio

Antes de los años sesentas, cuando todavía había muy poca gente de fuera de la comunidad, la organización del terruño, espacio todavía dominado por el bosque y las plantas leñosas, era la siguiente (véase gráfica 30):

La mayor parte del terruño, cubierta por la selva baja caducifolia, estaba incluída en la rotación de cultivos y sometida al cultivo de maíz bajo roza, tumba y quema y al pastoreo libre.

Una parte distinta del bosque, más húmeda - las barrancas-, estaba cubierta por la selva mediana subperennifolia - "breña" o "monte grueso"-no incluida en la rotación de cultivos. Los animales aprovechaban los árboles forrajeros de estas breñas con el pastoreo libre. Era también zona de recolección (leña-frutas).

El pueblo estaba constituido por un número reducido de casas donde se criaban los animales domésticos. Cada casa tenía su montón de rastrojo seco y unos árboles frutales.

Terrenos planos, cuya superficie era muy reducida, cerca del pueblo y cultivados año con año.

Por lo general, la milpa estaba protegida por una cerca de madera tanto en las parcelas cultivadas año con año, como en las de desmonte ubicadas cerca del pueblo, (solamente las parcelas muy alejadas del pueblo y del 
Grafica No 30: Organizacion del espacio en la comunidad de Pomaro (1950)

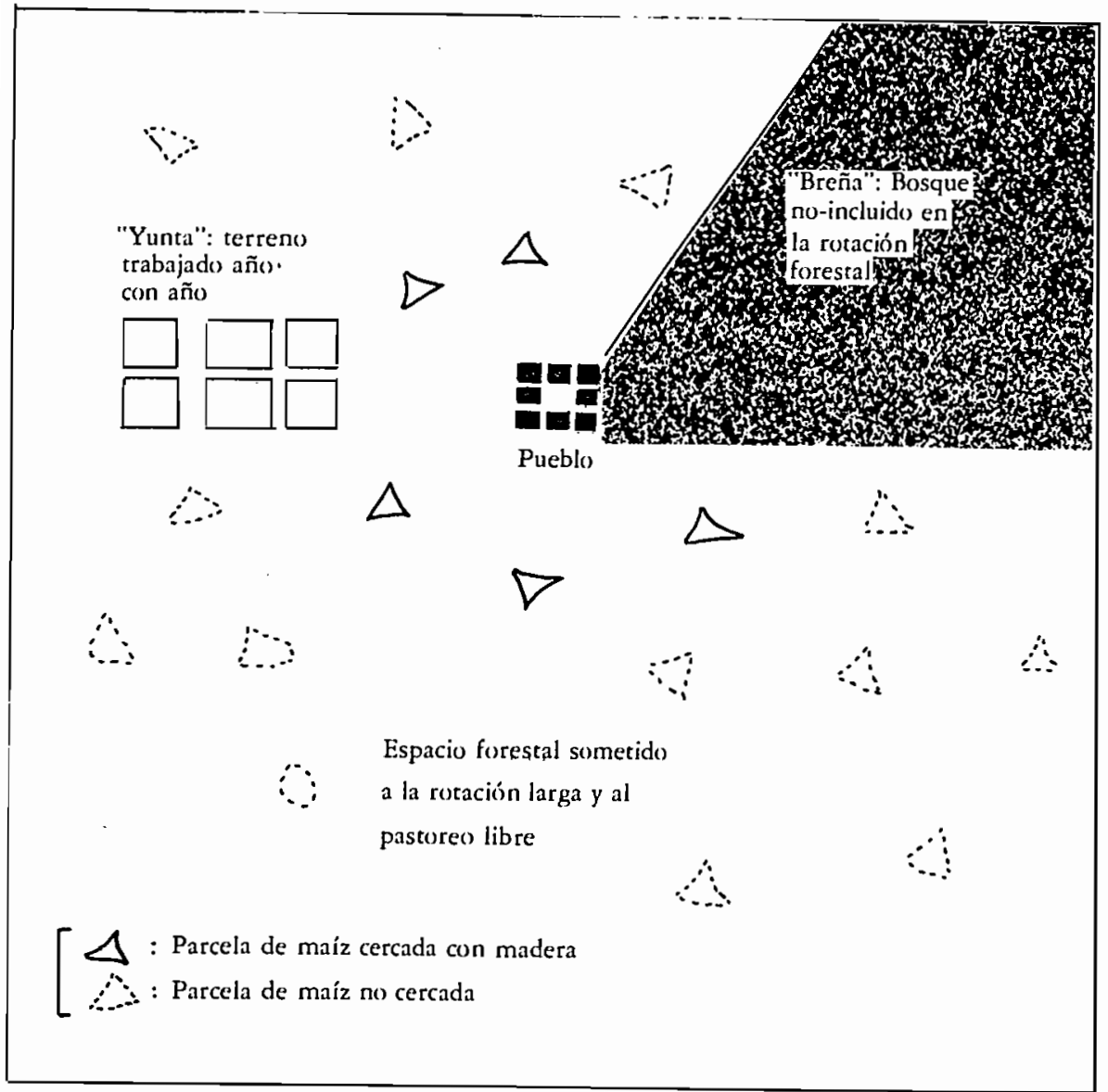

movimiento del ganado se dejaban sin protección alguna). Esta protección se debía a la organización del pas toreo libre en el territorio de la comunidad: los animales de cada comunero andaban sueltos todo el año en los terrenos comunales. Una vez levantada la cosecha, se abrían todas las cercas para que los animales de cada quien pudieran aprovechar la pastura de todas las parcelas.

A este papel básico de la cerca (protección de la milpa) se puede sumar otro que era el de almacenamiento de la leña. En efecto, para cercar las parcelas ubicadas cerca del pueblo, se juntaba madera. A los dos o tres años, cuando los palos empezaban a pudrirse, la gente se los llevaba paulatinamente 
a la casa donde se utilizaban como leña mientras que se volvía a traer madera para volver a cercar.

Tenencia de la tierra

La tierra era comunal. Cada comunero, reconocido como tal, tenía derecho a trabajar estas tierras libremente y podía desmontar donde quisiera para sembrar, siempre y cuando las autoridades elegidas de la comunidad estuvieran de acuerdo y no hubiera pleitos entre diferentes comuneros. Mientras que el usufructo era individual, la propiedad permanecía colectiva. Además del permiso para tumbar y sembrar, cada uno tenía derecho a tener animales, en número limitado, en los terrenos comunales, a recolectar leña o frutas, a cazar y pescar.

La tierra era inalienable. Se prohibían renta y compra-venta de terrenos. Sin embargo, y de acuerdo con varias entrevistas, la venta de terrenos entre dos comuneros - no se trata de las ventas a los "de razón" llevadas a cabo a fines del siglo XIX - era cosa bastante común en la comunidad de Pómaro mucho antes de que fueran invadidas las tierras comunales. Pero a pesar de que se enajenaba una parcela, en este caso de venta, no se trataba verdaderamente de una propiedad privada, en el sentido jurídico romano del término por las siguientes razones:

Al comprar una parcela, un comunero no compraba más que el trabajo acumulado y reconocido en la parcela. No se compraba la tierra en sí misma sino el trabajo que se había invertido en ella. Así una parcela de monte nunca se vendía ni se compraba. Pero uno podía comprar una parcela desmontada (compraba entonces el trabajo hecho para la tumba), una parcela desmontada y cercada (pagaba el trabajo efectuado para tumbar y cercar esta parcela), o una parcela destroncada (pagaba en este caso el trabajo llevado a cabo para destroncar).

En estas condiciones, la renta de la tierra no existía. El terreno en sí mismo no era mercancía.

Además el sistema de cultivo forestal bajo roza, tumba y quema hace que a los dos años de cultivo, el trabajo invertido se recupere y la parcela dejada por varios años, con el fin de que vuelva a crecer el monte, se queda sin valor alguno. A largo plazo, el trabajo hecho en la parcela no se reconocía puesto que ya no representaba nada para el siguiente ciclo de cultivo. Y el reconocimiento por la Comunidad del derecho de un comunero para tumbar no planteaba a largo plazo ningún derecho para este comunero. Al tumbar una parcela en el año no se apartaba el lugar hasta que se volviera a tumbar diez o veinte años después. En una carta mandada al Palacio Federal, el presidente del Comisariado de Bienes Comunales escribía: "todos los comuneros trabajamos las tierras en libertad respetando parcelas circuladas y chapones señalados con anterioridad para tumbarlos, la cual nos sirve para 
saber que se va a ocupar". ${ }^{14}$ Esta anterioridad nunca rebasaba el año de la tumba o el año siguiente. Cuando uno dejaba su parcela, al segundo año de cultivo, abandonaba todo derecho sobre ella. Se ilustra eso citando el caso de un comunero que queriendo apartarse un lugar "le pone cada año una señal para que nadie se meta así que no lo trabajaba ni lo dejaba trabajar". Otro comunero se metió a trabajar la parcela en cuestión y las autoridades comunales le dieron la razón.

Así, la ausencia de la renta de la tierra y el no-reconocimiento a largo plazo, del derecho de apartarse una parcela sembrada, impedía el desarrollo de la propiedad privada.

En el caso de las parcelas destroncadas, cultivadas año con año, el trabajo acumulado perduraba y su reconocimiento tendría consiguientemente que convertir el usufructo ocasional en un usufructo indefinido, luego privado. Pero las parcelas así privatizadas eran muy pocas, debido a la topografía de la región.

\section{Policultivo, ganadería y valoración de varios ecosistemas}

Bajando a un nivel de observación más reducido, el del sistema de producción (nivel de la familia), cabe señalar que el funcionamiento de las unidades de producción descansaba generalmente sobre la multi-producción (vegetal y animal) y el aprovechamiento de varios niveles ecológicos.

Era un sistema de policultivo y multicría de animales. A pesar del hecho de que el maíz dominaba, y de muy lejos las actividades agropecuarias, se notaba una gran variabilidad de producciones.

En cuanto a los cultivos, el maíz ("Reventador", "Tampique", "Tepite", "delgado", "roquero" y "negro") llevaba muy seguido otros cultivos asociados o sembrados aparte, como la calabaza, la sandía, el frijol. La dieta básica estaba complementada por:

-Oleaginosas y proteaginosas: frijol bayo (Vigna sinensis), cacahuates.

-Tubérculos: jícama, camote.

-Condimentos: chile, jamaica.

-Tabaco.

-Planta textil: algodón blanco.

En cuanto a la cría de animales, tambiên se notaba una gran variabilidad de producciones aunque en pequeña cantidad. La producción más importante era posiblemente la de puercos. Era uno de los escasos productos que uno lograba vender. Andaban sueltos bajo el sistema de pastoreo libre ya mencionado. Además, se engordaban con calabazas y maiz,

14. Carta del Presidente del Comisariado de Bienes Comunales al Delegado del Departamento de Asuntos Agrarios y Colonización, Morelia, 20 de marzo de 1971, SRA. 
cuando sobraba, y aprovechaban los árboles forrajeros de las breñas y la bellota de los encinos en las partes altas de la comunidad. También se criaban vacas, cabras, borregos, y gallinas, pero en cantidad reducida.

Cabe señalar que la cría de animales era probablemente el sector de la producción donde se manifestaba más claramente la diferenciación campesina entre los comuneros. No todos eran iguales. Algunas familias ya contaban con bastante ganado ( 10 a 50 bovinos) mientras que la mayoría no tenían vacas. Parece que las reglas comunitarias que limitaban el número de cabezas que cada uno podía mantener en los terrenos comunales no funcionaba realmente o había dejado de hacerlo por razones poco claras.

La caza del venado, jabalí, iguanas, tigrillo y la recolección, participaban en la economía familiar aumentando la variabilidad de los productos disponibles.

Aunque no aparezca en la gráfica 30 , hay que tomar en cuenta la valoración que cada familia hacía de varios ecosistemas o niveles ecológicos, cada uno caracterizado por su altura, sus condiciones climáticas, su vegetación, etc. En efecto, si la mayoría de la gente tenía su casa en la sierra, a los 500-800 m.s.n.m. uno bajaba a la costa para aprovechar sus recursos y condiciones ecológicas distintas. Se sembraban milpas en las tierras de humedad de la costa (orilla de ríos, desembocadura). Se levantaban cosechas de cocos y plátanos y otros frutales. La gente de la sierra bajaba así a la costa para trabajar esas tierras cuando las tareas agrícolas de la estación seca lo necesitaban. Luego se regresaban a la sierra puesto que la costa era insalubre para vivir.

Ignacio M. Castillo contaba en 1946:15

Por lo que toca a Pómaro, su salida al mar es por el llamado puerto de Maruata, lugar que, a pesar de ser intensamente palúdico por los esteros que hay cerca de la playa, tiene grandes terrenos cultivables, que han aprovechado con palmas de coco y siembra de ajonjolí y maíz.

Uno podía así aprovecharse de las zonas costeras para llevarse frutas tropicales, cacao (mencionado todavía en 1944 en lugares sombríos y húmedos), plátanos, limón. Bajar a la playa permitía también el aprovechamiento de los recursos del mar mediante la pesca y la recolección de cangrejos y huevos de tortuga.

De la misma manera, se ocupaban las regiones altas de la sierra para completar la producción. Las mayores precipitaciones y la temperatura más templada, permitían el cultivo de otras variedades de maíz - lo que disminuía el riesgo del cultivo mediante un mayor reparto de la fechas de siembra y la variabilidad de la duración del ciclo de cada variedad-, de la caña de azúcar, la recolección por los puercos de la bola de los encinos, etc.

15. Ignacio M. del Castillo y Raúl G. Guerrero, op. cit., p. 4. 
La combinación de varios pisos ecológicos plantea una organización vertical del trabajo (desde la costa hasta las partes altas de la comunidad), organización ya conocida en varias partes montañosas del mundo.

Cabe señalar que la organización social de la comunidad —ausencia de renta de la tierra, posibilidad para cada miembro de cultivar la tierra que le convenía y aprovechamiento global de los recursos-estaba perfectamente adaptada a este tipo de organización productiva.

Veremos más adelante que a pesar de la destructuración social y agropecuaria de la comunidad (migraciones, cambio de ubicación de los pueblos, especialización) esta valoración combinada de varios pisos ecológicos sigue siendo importante para varias unidades de producción, mediante las relaciones familiares y de compradrazgo.

El cultivo forestal: el maíz bajo roza, tumba y quema

Para entender con precisión el funcionamiento y la organización productiva de la comunidad, bajamos una vez más al nivel de análisis más reducido todavía que el sistema de producción: el sistema de cultivo. ${ }^{16}$ No se trata, en esta parte, de analisar detalladamente todos los sistemas de cultivo que se encontraban en esta época (años 40-50), sino de presentar la lógica del sistema de cultivo predominante: el cultivo del maíz bajo roza, tumba y quema.

Descripción somera de las técnicas agrícolas

Este sistema de cultivo se desarrollaba en un medio ambiente básicamente forestal. Se trataba primero de tumbar una parcela de monte con hacha o machete y de cortar los árboles así tumbados para que la biomasa se secara rápidamente. Este trabajo se hacía en invierno y a fines de las secas se amontonaban y se prendían. Se quemaba la parcela mientras que una guardarraya protegía el bosque vecino. Se construía luego una cerca de madera que protegía la milpa. A principios de las aguas, después de las primeras tormentas cargadas, se sembraba el maíz con una lanza ("espeque" o bastón plantador o coa) tirando tres o cuatro granos en cada pozo, andando al paso. Luego la parcela se limpiaba con machete hasta la cosecha en noviembre.

Rotación de cultivo

Después de dos años de siembra en la mis ma parcela, se dejaba el lugar hasta que el monte se volviera "grueso", bueno para tumbar. Este tiempo de "descanso" podía durar de 15 a 20 años. El bosque obtenido al término de

16. Sistema de cultivo: véase la definición en la introducción general. 
este periodo era una selva baja caducifolia secundaria, más o menos degradada según el tiempo de "descanso"; de todos modos, el bosque no se destruía. Nunca se destroncaba y el medio a mbiente permanecía forestado, aunque no fuera una selva primaria. La superficie tumbada durante un año determinado, no rebasa el $10 \%$ del territorio forestal (una hectárea de maíz primero, una hectárea de maíz segundo y 18 hectáreas de "barbecho" en el ejemplo de un ciclo de 20 años). La erosión quedaba entonces muy limitada y este agrosistema era perfectamente reproducible.

Sentido de este sistema

El periodo de descanso, - renuevo forestal- interrumpía la invasión de la parcela por las hierbas.'A partir del segundo año de cultivo, la limpieza de la parcela se volvía un trabajo pesadísimo. En efecto, las semillas de gramíneas y hierba cualquiera tiradas al suelo durante el primer año de cultivo empezaban a crecer invadiendo rápidamente la parcela que se convertía en una pradera imposible de cultivar. Este sistema de cultivo no incluía un trabajo del suelo o uso de herbicidas. El campesino tenía entonces que dejar esta parcela. A los 5 ó 6 años de renuevo forestal, los estratos arbóreo y arbustivo dominaban el estrato herbáceo, limpiando totalmente el suelo de las malezas y de sus semillas por la competencia para la luz y la quemazón de la superficie. Mientras más duraba el renuevo forestal, más eficiente era esta limpia y más fácil el control de las malezas cuando se volviera a sembrar.

El renuevo forestal reconstituía el potencial de fertilidad de los suelos: durante el primer año de cultivo, la ceniza de la quema abastecía al suelo de buena cantidad de elementos minerales (fosfato y potasio) incorporados al suelo al empezar la temporada de lluvias. Además, la mineralización ${ }^{17}$ era muy importante durante las primeras semanas de lluvias, que entregaba nitrógeno al suelo. Pero éso se acababa pronto y los recursos minerales se agotaban a los dos años. El campesino tenía entonces que dejar su parcela (segunda razón). Durante el renuevo, los árboles extraían elementos del subsuelo y llevaban a cabo una concentración de minerales y materia orgánica en la superficie del suelo. Mientras más duraba el renuevo forestal más importante era la cantidad de elementos nutritivos acumulados.

En conclusión, con estos dos aspectos, entendemos que este sistema de cultivo tenía una gran coherencia interna. La rotación forestal, mediante un período largo de no-cultivo, alcanzaba a resolver los dos problemas fundamentales que habían surgido al segundo año de cultivo: la invasión del estrato herbáceo y la baja de fertilidad de los suelos.

17. Mineralización: transfurmación bioquímica de la materia orgánica que suelta los elementos constitutivos, por ejemplo el nitrógeno. 
Excedentes e intercambios: una débil integración al mercado regional

Sabiendo como se llevaba a cabo la producción de maíz en la sierra de la comunidad, cabe preguntarse si las unidades de producción que descansaban sobre este. sistema de cultivo eran capaces de producir más de lo que era necesario para la familia y si la comunidad de Pómaro llevaba a cabo intercambios de productos fuera de la comunidad.

Productividad del sistema de cultivo forestal

Si ponemos como ejemplo un rendimiento de una tonelada por hectárea de monte sembrado el primer año y media tonelada por hectárea al segundo año de cultivo, la superficie total necesaria para producir esta cantidad de maíz ( 1.5 ton.), será de 20 hectáreas tomando en cuenta los terrenos dejados para el renuevo forestal (digamos 18 años para facilitar los cálculos).

- El rendimiento global será de $\frac{15}{20}=0.075$ toneladas por hectárea o sea 75 kilogramos por hectárea, una productividad del terreno muy baja (aunque la productividad del trabajo pueda ser bastante alta).

Si consideramos que una unidad de producción consume tres toneladas de maíz al año, ${ }^{18}$ tiene que ocupar una superficie mínima de 40 hectáreas, tumbando cada año dos hectáreas de monte nuevo y volviendo a sembrar la tumba del año anterior, lo que implicaba mucho trabajo. Este hecho traía consigo dos consecuencias:

La densidad de población en la comunidad indígena de Pómaro era necesariamente baja.

-Por la baja productividad del terreno del sistema de cultivo.

-Por el hecho de que no todo el terruño podía ser sometido a este sistema de cultivo (breñas y zona costera menos favorable véase gráfica 30).

No podía rebasar a los 10 habitantes por kilómetro cuadrado. De hecho y según los censos de población, el municipio de Aquila tenia una densidad cerca de tres habitantes por kilómetro cuadrado.

Aunque el poblamiento de la comunidad tenía varios siglos, (Pómaro es pueblo prehispánico), la densidad se quedó en la de una sociedad de colonización agraria ocupando el espacio de una manera difusa y extensiva.

La segunda consecuencia es que el excedente de producción de una familia no podía llegar a grandes cantidades de maíz para vender.

De todos modos, la falta de vías de comunicación ter restres, impedía el transporte de grandes cantidades de maíz (producto pesado) y por tanto, lo que sobraba, no podía ser intercambiado o llevado fuera de la comunidad, sino bajo una forma concentrada que se desplazaba por sí misma: los puercos.

18. Pongamos para el cálculo: consumo humano de maiz: 1.5 ton. ( 5 personas-250 Kg.): 
Autosuficiencia e intercambios regionales

Aparece claramente que los sistemas de producción correspondían a una lógica de autoconsumo y de autosuficiencia en todos los aspectos de la economía familiar caracterizada por la diversidad de las producciones y la valoración de un máximo número de ecosistemas así como cierto autoabastecimiento en cuanto a la ropa (algodón, cueros para huaraches), en cuanto al material de las casas (paredes de vara y enjarradas o de adobe, techo de palma, paja o teja), en cuanto al equipo (muebles, sudadero, sillas, desgranadoras, almacén), etc.

De acuerdo con Ignacio $M$. del Castillo, ${ }^{19}$ parece que la región, bastante aislada desde el punto de vista geográfico por falta de vías de comunicación, tenía muy pocos intercambios comerciales fuera de la comunidad.

Los productos que se obtienen en la región son consumidos allí mismo, o vendidos en las distintas plazas que visitan. De diversos lugares, aún los más lejanos, como Pómaro y San Pedro, vienen hasta La Placita a comprar sal que se produce en gran cantidad en las salinas de este pueblo.

La jamaica, el ajonjolí, el coco, el coyol y otros productos son enviados fuera de la región, a Manzanillo, Colima y Guadalajara, llevándolos en animales de carga hasta Cerro de Ortega en donde hay compradores en gran escala.

En Coyre ${ }^{20}$ el aspecto económico comercial es sumamente pobre, pues tuvimos oportunidad de darnos cuenta del monto total de compras que encargó un comerciante para su tienda con motivo de las fiestas que se acercaban, y la suma total de compras ascendió a la suma de $\$ 15.00$ (quince pesos); lo que da idea de la pobreza comercial de ese lugar, pues aún tratándose de días de fiesta, durante las cuales siempre el comercio en todos los pueblos crece un poco, el monto de la compra fue sumamente pequeño y deficiente.

Por lo general todas las transacciones comerciales las llevan a cabo con Colima, Manzanillo, Tecomán y Guadalajra, más que con Coalcomán, Villa Victoria u otros sitios de su estado natal.

En realidad, hasta donde sabemos de esta época, pensamos que los intercambios ya no eran tan escasos.

Además de los productos mencionados por Ignacio M. del Castillo, la gente iba a Colima y/o a Coalcomán a llevar manteca de puerco, puercos en pié, cabras y cocos. No había arrieros - gente que cobrara el flete nada más-, pero los que tenían bestias y que podían salir llevaban productos de los demás a vender.

gallinas y puercos 1.5 ton., total 3 toneladas.

19. Op. cit., 1946, p. 87.

20. Véase mapa 20. 
Regresando, se traían la sal de La Placita, jabón, azúcar, refrescos y ropa lo que pronto acabó con los tejidos locales de algodón.

Antiguamente en esta región, desde el valle, se cultivaba el algodón, pero ahora se ha descuidado su cultivo y sólo tienen el necesario para su uso personal, aparte de que ya son muy pocas las personas que tejen telas, pues la mayoría las compran hechas. ${ }^{21}$

A pesar del aislamiento de esta comunidad, compañías extranjeras habían llegado en el siglo XIX a sacar maderas preciosas por mar. De la misma manera en los años cuarentas llegaban

por lo menos dos veces al año pescadores de tiburón 22 que venían a instalar su campamento en esas playas vírgenes para permanecer allí por un término aproximado de dos meses en cada ccasión, y entonces cuando los de Pómaro hacen algún comercio con los pescadores les venden huevos, gallinas, maíz, coco de agua, y algunas veces también sal para la conservación en latas de los hígados de riburón que extraen los pescadores de los grandes animales que logran diariamente. ${ }^{23}$

Así se explotaban desde afuera los recursos naturales de la comunidad como se habían explotado en aquel tiempo las minas y la madera fina. Este negocio no dejaba utilidades a la mayoría de las comunidades. Era una forma de seguir con la economía extractiva en detrimento de la comunidad.

Así supimos de algunos intercambios, ventas de productos y compras de mercancías que se llevaban a cabo entre la comunidad y las ciudades circunvecinas, pero estos intercambios eran limitados y no rebasaban a la región costera de Michoacán y de Colima.

En los años cincuentas el estado de Colima, con el riego se estaba convirtiendo, en una de las principales regiones de exportación de frutales. Tierra Caliente exportaba su arroz y la produccción de algodón se iba desarrollando. Por el contrario, la sierra costera de la comunidad de Pómaro, se iba quedando aislada, sin vías de comunicación, muy poco integrada al mercado nacional y a la división regional del trabajo.

Era casi autosuficiente. En cambio, en la sierra de Coalcomán, la ganadería ya estaba desarrollándose y llegaba a la parte norte de la comunidad. Veremos en los apartados siguientes como esta especialización se extendió a la comunidad de Pómaro, llevando a cabo una verdadera revolución agrícola.

21. Op. cit., p. 102.

22. Ibid., p. 4.

23. Ibid., p. S. 


\section{SE REVOLUCIONA EL MODO DE APROVECHAR EL MEDIO} (1960-1985)

A partir de los años sesentas y hasta la fecha, se observa un cambio profundo radical de las actividades agrícolas y pecuarias, de los sistemas de producción, de la organización productiva de la comunidad y del paisaje agrario. Se trata de una revolución agropecuaria que puede ser ilustrada, por la instalación de los ganaderos mestizos llegando de la sierra de Coalcomán para invadir las tierras de la comunidad. Pero la invasión de tierra no es más que el choque frontal entre dos formas distintas de ocupación del territorio. Aunque fue brutal y rápida esta evolución tuvo varias modalidades; se manifestó bajo muchas formas según el espacio geográfico e histórico. Se trata de un proceso continuo que empezó en los sesentas y sigue desarrollándose en la actualidad, expresándose a través de distintas manifestaciones.

\section{Características básicas de este cambio}

Las invasiones de tierras

En los últimos años, las invasiones de tierra y el cercado del monte, modificaron definitiva y fundamentalmente la tenencia de la tierra.

Cabe recordar que desde fines del siglo XIX ya habían entrado varias familias mestizas provenientes del municipio de Coalcomán. En 1950, la parte norte de la comunidad (La Parotita, La Parota, San Juan de la Palmera, San Antonio) ya estaba ocupada por la "gente de razón". Pero esta gente desarrollaba un sistema de producción similar al de los comunes, ocupando pocas cercas. En algunas partes, habían ocupado terrenos muy poco poblados. Ni siquiera se puede hablar de invasión sino de colonización ya que estas familias estaban "integradas" o adoptadas por la comunidad. Tenían sus derechos de comuneros. ${ }^{24}$ Por el contrario, la llegada de la gente de razón al terruño de San Pedro Naranjestil a partir de los años sesentas puede ser interpretada como invasión de tierra. El cercado del monte y el desarrollo de la ganadería fueron instrumento y consecuencia a la vez de tales invasiones.

Al comienzo llegaron a San Pedro unas pocas familias que levantaron sus casas, gracias a la complícidad interesada de las autoridades comunales (Jefatura de San Pedro N.).

La diferenciación campesina en el seno de la comunidad manifestada en la desigual repartición del ganado entre los comuneros, por ejemplo, la

24. Censo de 1960. Secretaría de la Reforma Agraria. Caso de las familias Cisneros, Zambrano, Guillén). 
desagregación probable de las reglas comunitarias (limitación de ganado, cercado de parcela) y la dispersión de los ranchos en la sierra, facilitaron la instalación de estas primeras familias y la corrupción de algunas autoridades.

En realidad, como veremos más adelante, las invasiones de tierras han de ser interpretadas como manifestación del desarrollo de un sistema de producción más eficiente, más poderoso, y de una nueva organización del espacio impuesta por la población mestiza.

Vinieron tantas familias, que aún en 1974 " 63 individuos mestizos con sus respectivas familias se encuentran invadiendo terrerios pertenecientes a la comunidad de San Pedro Naranjestil". ${ }^{25}$ A pesar de que estas familias ocupan ahora la mitad de la superficie de la comunidad, no están censadas por la SRA, al çontrario de las primeras familias llegadas desde fines del siglo XIX. El último censo (1976) daba derechos comunales a 600 comuneros (indígenas y mestizos "integrados").

Pero en San Pedro Naranjestil 16 familias de las 23 entrevistadas en este pueblo no tienen derechos comunales. En 1984, se estimaba que las dos terceras partes de la población de este pueblo eran mestizos, lo que ilustra el grado de invasión que sufrió el pueblo. ${ }^{26}$

El cercado del monte

El surgimiento de las cercas de alambre de púas representa la manifestación más visible y más impresionante de esta revolución agropecuaria. Cuando uno camina en la parte norte de la comunidad (San Pedro Naranjestil, véase gráfica 31), no se puede salir del camino por los alambres de púas que lo bordean de ambos lados. El monte está totalmente cerrado y se vuelve mosaico de potreros cuyo tamaño es variable y con frecuencia alcanza las 20 o 30 hectáreas.

A falta de estadísticas sobre las ventas de alambre, las entrevistas realizadas ${ }^{27}$ nos dan ideas cualitativas y cuantitativas de la importancia que tienen actualmente las cercas en la comunidad.

De los 60 campesinos entrevistados, 41 tienen potreros cerrados con madera o alambre de púas. Hasta donde sabemos, sólo cuatro campesinos entrevistados no ocupaban la cerca, aparte de los que no tienen tierra propia para trabajar.

Claro que la cerca por sí misma no es cosa nueva en la comunidad de Pómaro. Hemos visto que el antiguo sistema ya incluía la cerca de madera como protección de la milpa. Además, el alambre de púas se conocía desde hace más de 30 años en la región.

25. S.R.A. Carta mandada al delegado del departamento de Asuntos Agrarios y Colonización, en fecha $11 / 11 / 74$.

26. Población indígena 33\%, población mestiza 67\%. Según el censo escolar. SEP. 1984.

27. Febrero a junio de 1985 . 


\begin{tabular}{|c|c|c|c|c|c|}
\hline Pueblo & $\begin{array}{l}\text { No ocupan } \\
\text { cercas }\end{array}$ & $\begin{array}{l}\text { ocupan } \\
\text { cercas }\end{array}$ & $\begin{array}{l}\text { no hay } \\
\text { información }\end{array}$ & $\begin{array}{l}\text { no tienen } \\
\text { tierra }\end{array}$ & Total \\
\hline Pómaro & 2 & 6 & 0 & 0 & 8 \\
\hline Maruata & 0 & 10 & 2 & 1 & 13 \\
\hline Cachán & 0 & 10 & 0 & 0 & 10 \\
\hline S. Pedro & 1 & 12 & 1 & 9 & 23 \\
\hline La parotita & 1 & 1 & 2 & 0 & 4 \\
\hline Las campanas & 0 & 2 & 0 & 0 & 2 \\
\hline Total & 4 & 41 & 5 & 10 & 60 \\
\hline
\end{tabular}


Sin embargo, el desarrollo del cercado del monte a gran escala es un fenómeno reciente. Empezó de repente con la llegada de los ganaderos mestizos en los años sesentas y sigue hasta la fecha cada día con más intensidad. La gráfica 31 da una idea de la nueva organización territorial ya establecida completamente en el pueblo de San Pedro Naranjestil (véase en comparación la gráfica 30).

Grafica No 31: El. CERCADO DEI. MONTE: TERRUÑo DE $S_{\text {AN }}$ PEdro Naranjestil. (ESQuima SIMPI.IFICAdo)

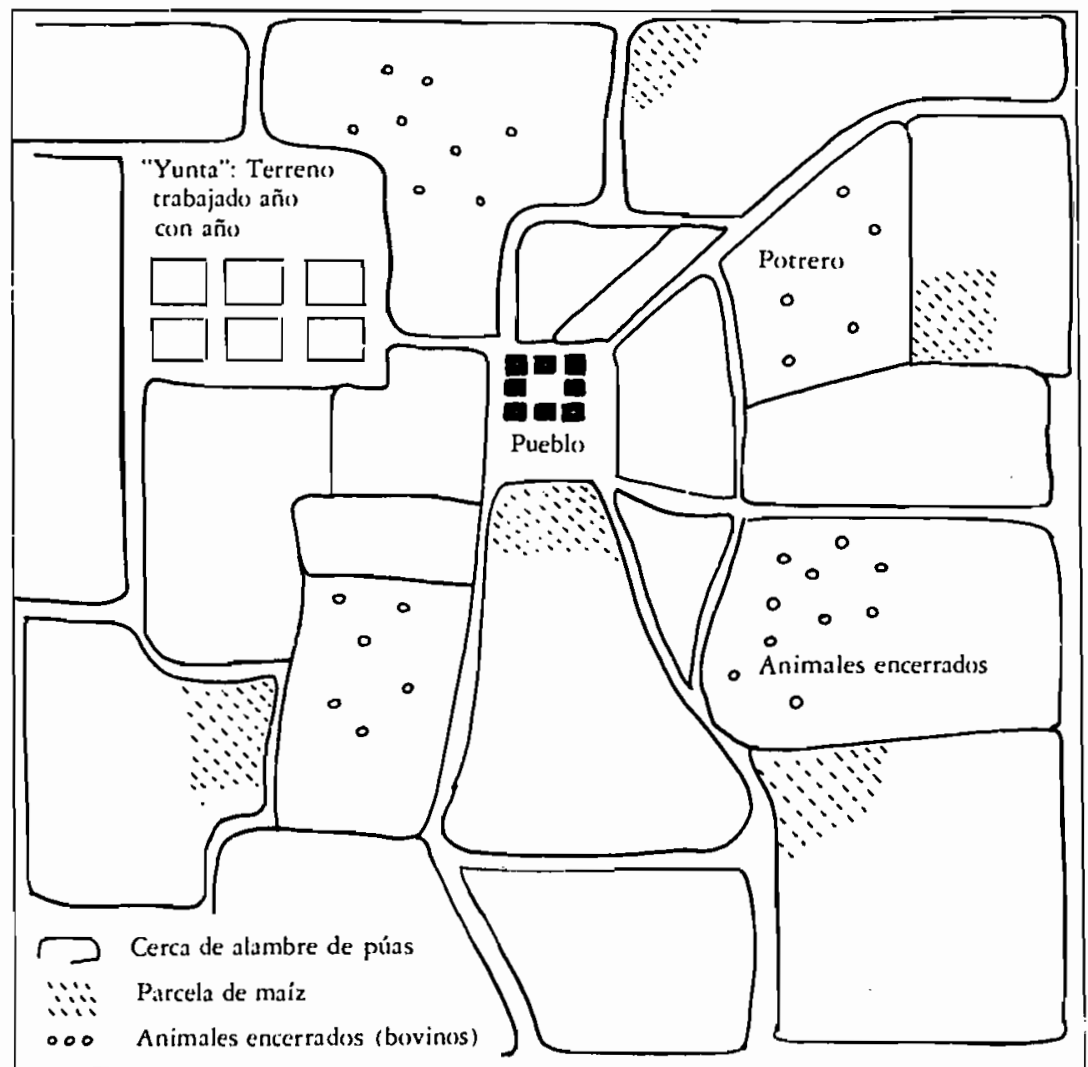


De acuerdo con la organización territorial que prevalecía antes de 1950, la cerca de madera era una protección de la milpa ante los animales que andaban en pastoreo libre en los terrenos comunales y servía también como almacén de leña. La cerca de púas que se desarrolla después no tiene el mismo papel: no protege la milpa sino encierra el ganado en los potreros del dueño reforzando la ganadería. A pesar de la semejanza existente entre la cerca de los años cincuentas y la de los años ochentas, se trata de dos medios de producción distintos. Se refieren a dos lógicas diferentes, opuestas e incompatibles.

El alambre de púas que sustituye a la madera y que resulta más rápido de instalar, es comprado en Tecomán, Col. y llevado a todas partes de la sierra con mulas. Sin embargo, una cerca con cuatro alambres no alcanza a encerrar a las cabras. Así, en los pueblos donde se crían chivos encontramos ot ro tipo de cerca más adaptado, tal y como lo muestra la gráfica 32. En estos casos, por el costo elevado del ala mbre se favorece más bien la instalación de un tipo de cerca mixta (alambre y madera).

Desarrollo de la ganadería

Con el cercado del monte, se desarrolló la ga nadería bovina en la mayoría de las unidades de producción estudiadas. Aunque ya estaba presente en los años cincuentas, la ganadería no tenía en aquel tiempo el desarrollo que ahora tiene. Unas familias indígenas tenían algo de ganado y los mestizos de Coalcomán ya tenían ganado en la zona norte de la comunidad de Pómaro (La Parota...) y en la comunidad vecina de Coire. A partir de los años sesentas, se incrementa el ganado vacuno, así como el caprino. Estas actividades tienden a volverse predominantes en muchas unidades de producción. Este desarrollo fue lento, irregular y variable (sufrió los años de sequía de 1973 y 1974) pero determinante para la evolución del sistema social de producción.

A hora, de las 60 unidades de producción estudiadas, la mitad cuenta con ganado vacuno - un promedio de 13 cabezas por hato- y solo un $25 \%$ no posee ni vacas ni cabras.

Analizando la información por pueblos, aparece que la mayoría de las unidades de producción (u.p.) que no cuentan con vacas ni cabras ( 10 de las 14 u.p. estudiadas que no tienen ganado), se ubican en San Pedro Naranjestil, pueblo totalmente invadido por los ganaderos y en el cual precisamente está más desarrollada la ganadería (20 cabezas en promedio en las u.p. que tienen ganado, estudiadas en este pueblo). Eso saca a relucir el carácter al tamente contradictorio y desigual de este desarrollo. Mientras que se forman hatos grandes - 50 cabezas para arriba-, una proporción cada vez más importante de gente no tiene acceso a los recursos forrajeros necesarios y tiene que dejar esta actividad. 
Grafica No 32: Cercas y alambre de puas en ia comunidad de Pomaro

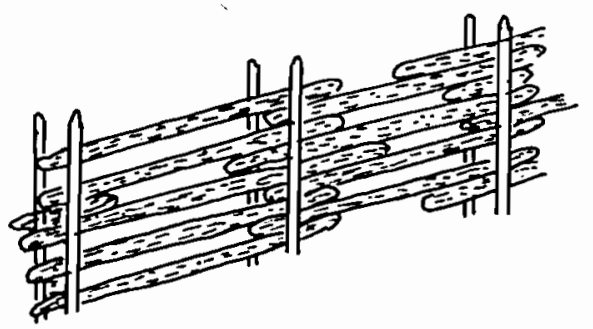

I Cerca de madera

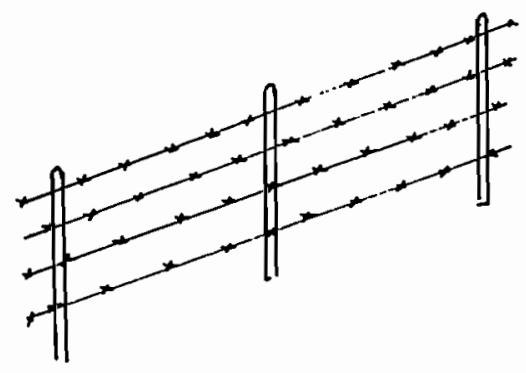

II Cerca de alambre de púas

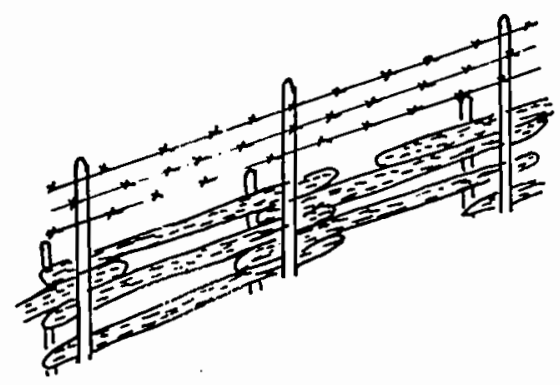

III Cerca mixta: madera/púas (para cabras)

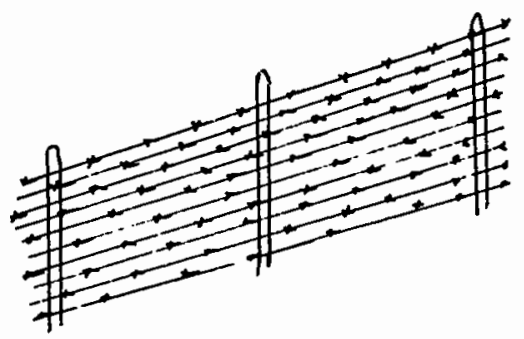

IV Cerca de alambre de púas (para cabras) 
Cabe señalar también que este desarrollo de la ganadería se llevó a cabo de acuerdo con una especialización regional. Mientras que crece la cría de bovinos y en segundo lugar la de cabras, disminuye la población de puercos y desaparece la cría de borregos.

La producción agrícola: abandono de cultivos.

En cuanto a la producción agrícola, los últimos treinta años se caracterizan por las evoluciones siguientes:

El maíz siguió siendo el cultivo dominante de la región pero veremos más adelante que los patrones de cultivo cambiaron mucho a lo largo de los años (disminución del número de variedades sembradas, modificación de las técnicas, etc...).

Las praderas artificiales - sembradas por el hombre-se desarrollaron y se volvieron elementos dominantes del paisaje en unas partes ya completamente especializadas.

Se abandonó el cultivo de un gran número de plantas, como ajonjolí, frijol bayo, jícama, camote, jamaica, tabaco, algodón, caña, y sólo se siembran en algunas partes en forma muy reducida.

Se inició y se desarrolló el cultivo de marihuana y amapola a gran escala, fenómeno generalizado en toda la Sierra Madre del Sur.

\section{Significación y consecuencias}

Desorganización del sistema de producción anterior

El hecho de cercar el monte, es decir, de dividirlo en potreros cuyo uso es estrictamente personal, individual, privado, acaba con la coherencia interna de los procesos de producción y lleva una lógica totalmente opuesta e incompatible.

Al nivel del sistema de cultivo de maíz bajo roza, tumba y quema, el surgimiento de las cercas introduce una limitación fuerte en la rotación forestal larga. Vimos anteriormente que la elección por el campesino, de una parcela de monte "grueso", después de un renuevo forestal largo, determinaba la posibilidad de cultivar después de haber tumbado y quemado.

Las cercas perjudican esta elección, y no se puede planear esta rotación larga en un potrero privado chico, tal y como lo veremos más adelante. Veremos también por qué y cómo el sistema de cultivo de la milpa bajo roza, tumba y quema tuvo que adaptarse y diversificarse de acuerdo con las limitaciones introducidas por el desarrollo de la ganadería.

Al nivel de sistema de producción, el cercado del monte proporciona las modificaciones siguientes:

No permite el pastoreo libre. Los recursos forrajeros se vuelven de hecho privados. La posesión individual de potrero cercado aparece desde 
luego como condición necesaria para criar animales. El desarrollo de las cercas acaba con la cría libre de animales.

Al volver individual y privado el uso de buena parte de los terrenos de la comunidad, el cercado del monte dificulta la utilización, por parte de una misma familia, de varios ecosistemas. Reduce entonces la variabilidad de los recursos disponibles para una familia. El sistema de producción ya no cuenta con varios niveles ecológicos y se tiene que concentrar espacialmente. Veremos más adelante que las migraciones observadas en la comunidad y la diferenciación de los sistemas de producción pueden estar interpretados como respuestas a estas limitaciones nuevas.

\section{La privatización de la tierra}

Levantando cercas de alambre de púas y formando grandes potreros, los mestizos hicieron del usufructo comunal ocasional un derecho a largo plazo que se vuelve privado sin que otro comunero lo pueda disfrutar de ninguna manera. El terreno cuyo valor se medía con el trabajo acumulado en él, se vuelve un capital acaparado por estas familias.

El usufructo antiguo se vuelve uso definitivo, exclusivo, individual. En el informe de la asamblea de la comunidad del 25 de febrero de 1979 se pide a los mestizos que levanten sus alambres para que pueda seguir el "libre usufructo de los auténticos comuneros del lugar". ${ }^{28}$

Abuso de los recursos naturales: al acabar con el usufructo de los terrenos comunales, el dueño deja de tener interés en el mantenimiento de los recursos productivos fuera de su potrero privado. "Talan nuestros montes a diestra y siniestra sin ninguna consideración". ${ }^{29}$

Los mestizos [...] han estado explotando los montes a tal grado que en varias partes ya no es costeable sembrar porque ya no se encuentran montes nuevos y se puede observar que en forma despiadada los mestizos tumban las maderas finas que se encuentran en este lugar con tal de sembrar en tierras primerizas. ${ }^{30}$

La tierra adquiere un precio en sí misma, aparte del precio del trabajo acumulado en la parcela. Es un capital que se compra, se vende y se renta. Nace así la renta de la tierra: cercar el monte, establece de hecho la propiedad privada (usar, gozar y disponer) y la forma predominante de tenencia de la tierra de las próximas generaciones. Esta acumulación de

28. Informe. Asamblea del 25 de febrero de 1979 mandado a Dirección General de Inspección, Procuración y Quejas, SRA.

29. Carta al presidente constitucional de la República Mexicana, del 19 de marzo de 1972, enviada por los comuneros, SRA.

30. Informe de la Liga de Comunidades Agraria y Sindicatos Campesinos del Estado de Michoacán para el gobernador constitucional del estado Lic. Carlos Gálvez Betancourt (fecha desconocida) SRA. 
capital determina desde entonces la diferenciación campesina que se desarrollará en los próximos años.

De la misma manera, se privatiza el uso del agua, concentrando las posibilidades de riego en pocas manos reforzando así los mecanismos de la diferenciación campesina del porvenir.

Migración hacia la costa

La evolución reciente de la comunidad está marcada por una migración generalizada de la población de la sierra hacia la costa. En el mapa 21 viene el lugar donde viven las familias con las cuales se llevaron a cabo las entrevistas, y el lugar de origen de la familia. El movimiento general de bajada a la costa está muy marcado y solamente unas pocas familias viven donde siempre han vivido.

En realidad, se puede dividir esta migración en dos etapas o más bien dos realidades, dos movimientos de la gente que se llevan a cabo uno tras otro o simultáneamente.

Por una parte, la concentración de la gente en los pueblos de Pómaro y San Pedro Naranjestil, los más importantes de la sierra, se hace para disfrutar de los servicios de tienda, escuela, aeropista, iglesia. En el caso de San Pedro Naranjestil se trata de la reorganización del pueblo de acuerdo con la población mestiza y sus intereses. Así se observa un traslado del centro del pueblo hacia el barrio nuevo de los mestizos (casas de ladrillo, techos de lamina, cuadras). El centro antiguo del pueblo, donde está la jefatura de tenencia y la iglesia se vuelve barrio periférico alejado del nuevo centro de la actividad económica.

Por otra, la migración trae como consecuencia la formación de pueblos nuevos en la costa, zona que no estaba poblada por ser insalubre. ${ }^{31}$ Cabe señalar que la organización de estos pueblos, sigue siendo conforme a las exigencias del proceso de producción "indígena": casas dispersas, sin organización en calles y cuadras, pastoreo libre y marcha errante de los animales de cada quien en el pueblo (bestias, puercos, vacas, chivas, aves en el caso típico de Maruata). El pueblo de Maruata que apenas tiene unos 15 años no se parece en nada al nuevo pueblo mestizo de San Pedro Naranjestil.

31. A fines de los años cincuentas se inició la Campaña Nacional de Lucha contra el Paludismo y se mejoraron las condiciones sanitarias de la costa. 


\section{Mapa № 21: Movimientos migratorios en la comunidad de Pomaro}

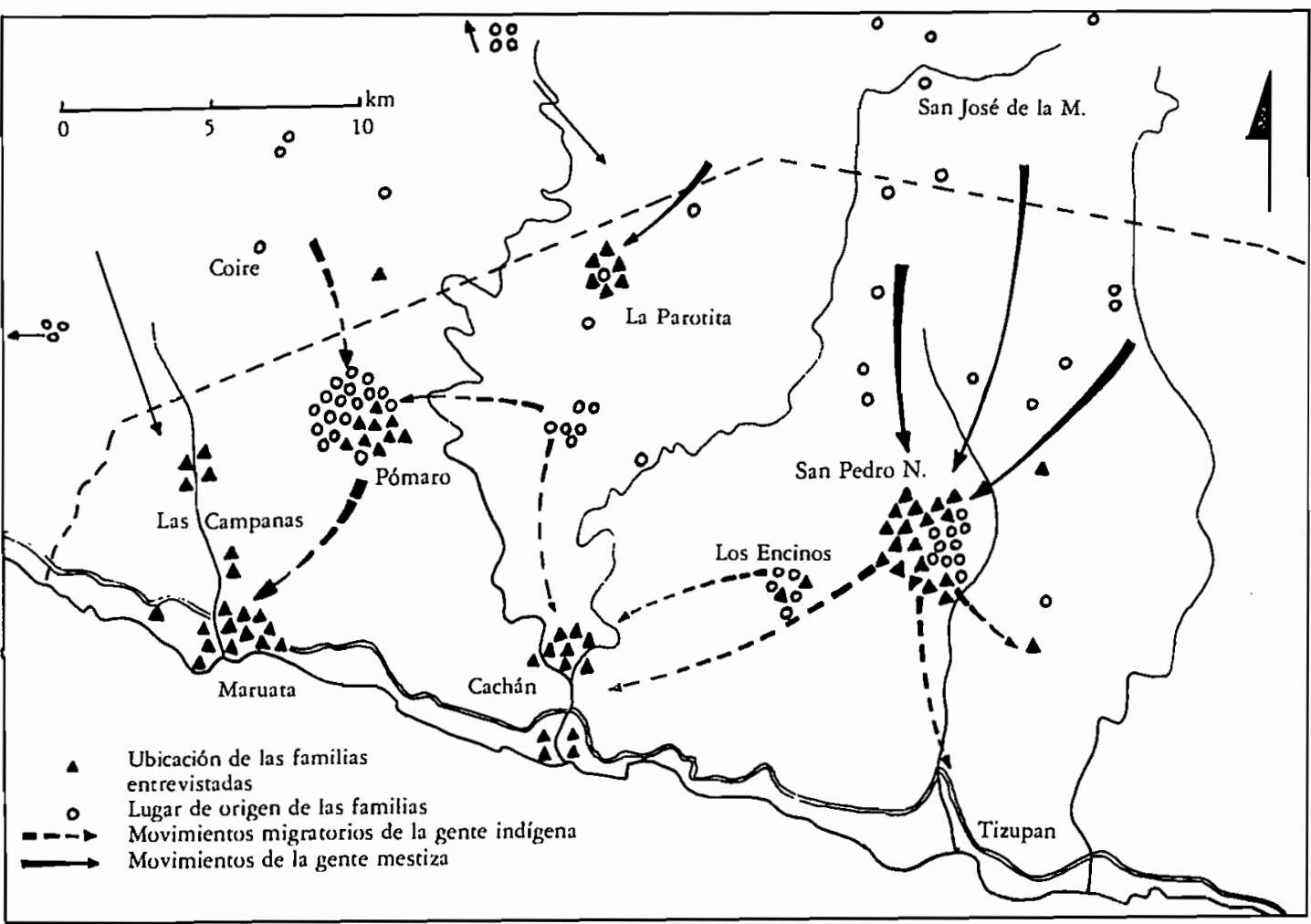


Estas dos etapas de la migración pueden ser ilustradas de la manera siguiente:

\section{Grafica No 33: Formacion de los PUeBLos De LA COSTA}

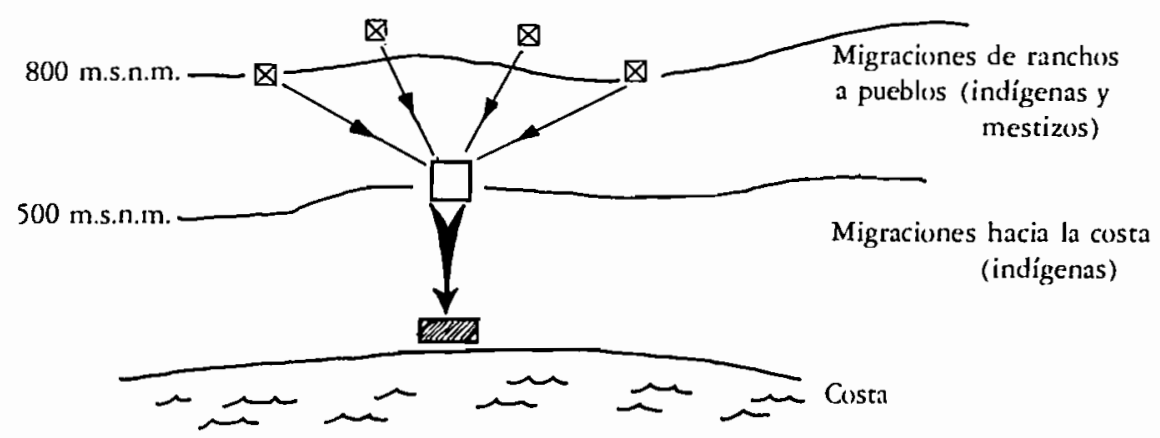

Este movimiento general puede ser entendido como huída de la población indígena ante la invasión mestiza, y la presión sobre la tierra manifestada por parte de la comunidad de Coire. Esta simplificación no nos hace olvidar que se trata más bien de una huída ante la expansión del nuevo sistema de producción ganadero que impone su hegemonía. La población así trasladada hacia la costa, tiene que llevar a cabo una reorganización productiva adaptada a un nuevo ecosistema costeño cuyas condiciones de producción son menos favorables debido a la baja precipitación, al calor, a los suelos poco desarrollados y a la vegetación muy escasa. Por ello mismo, tendrán que buscar otras actividades complementarias como la pesca, el trabajo en la carretera costera y el aprovechamiento de las actividades basadas en ella.

Acerca de la carretera costera, cabe hacer notar que su construcción no puede ser interpretada como la fuente y la causa principal de la migración a la costa y de esta revolución agrícola, ya que dicha evolución se inició mucho antes de que se construyera. Asimismo la carretera amplió el fenómeno, dando muchas oportunidades de trabajo en la costa y desde luego, facilitando las migraciones, incluída la migración dirigida hacia Tecomán, donde el riego proporcionó mucho trabajo. La carretera, así fue un elemento de la red de comunicaciones que favoreció la especialización regional (véase el caso del maíz Conasupo más adelante).

Las migraciones, la valoración de otros ecosistemas y la diversificación de las actividades, sirvieron como base a la diferenciación de los sistemas de producción. 
Las familias indígenas que no bajaron a la costa y que no pudieron adoptar el nuevo sistema de producción desarrollaron formas de resistencia propias ante el cercado del monte. Varias familias huyeron a los ranchos más aislados para seguir con la rotación forestal larga y el pastoreo libre (El Mirador, Cuirla, Los Encinos). Otros hicieron un potrero colectivo entre siete familias (antes de que se metieran los mestizos). que servía como reserva de tierra en la que seguía desarrollándose la rotación forestal larga y el libre pastoreo. Vale la pena mencionar el caso particular del rancho de Los Encinos en el cual los comuneros levantaron una muralla de alambre de púas como protección ante el cercado del monte, a fin de que se mantuviera el mismo sistema de producción, tal y como se ilustra en la gráfica 34:

\section{GRAFICA No 34: FORMAS DE RESISTENCIA AL CERCADO DEL MONTE (CASO DEL RANCHO DE LOS ENCINOS)}

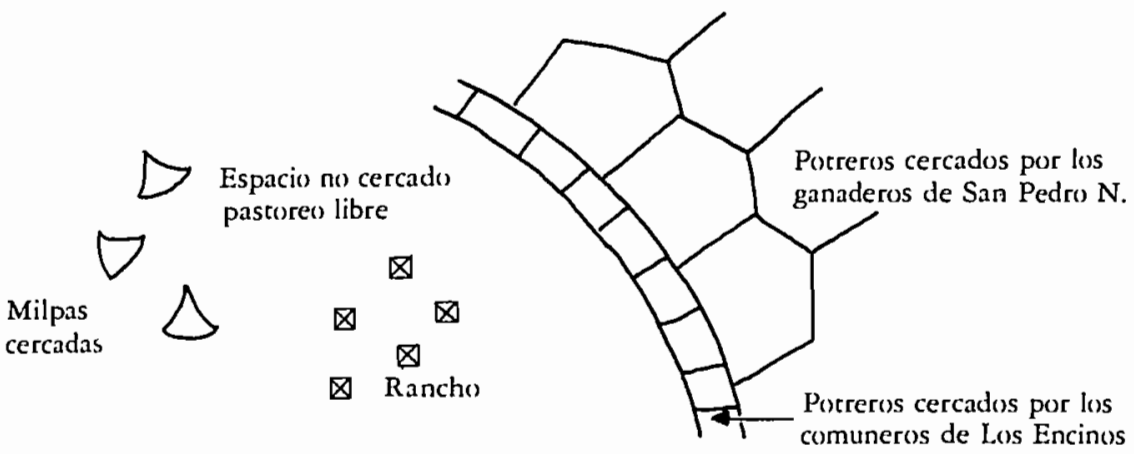

El ambiente social de la comunidad está muy marcado por la estrategia defensiva de los comuneros ante la hegemonía mestiza. La comunidad se mantiene a la defensiva. Ya en 1963 el peligro de invasión completa se agudizó a tal punto que en la asamblea del día 20 de marzo se toma un acuerdo: "queda estrictamente prohibido aceptar en ningún poblado de éstos una sola persona más de fuera porque no se dará un metro de tierra más a ninguna otra persona nueva o que no esté censada". ${ }^{32}$ Ahora bien, siendo efectiva la invasión de la parte norte de la comunidad, ésta prohibió el acceso a la costa, último bastón de los "naturales", a toda persona "de razón". La conciencia indígena se desarrolló mucho durante estos últimos años en el

32. Archivo SRA. Uruapan, Mich. 
"núcleo duro" de la comunidad que ante la dominación económica de los mestizos desarrolla cada vez más su estrategia defensiva, incluso violenta, aunque de una manera poco realista y desesperada. Por ejemplo, se está construyendo por faenas un mercado en el centro indígena de San Pedro Naranjestil. Será exclusivamente reservado a la mercancía de los indígenas y demuestra una voluntad de volver a dar a este barrio, su papel de centro económico del pueblo. Sin embargo, el dinero y la riqueza están en el nuevo centro mestizo del pueblo. Allá se quedará el centro de gravedad de la economía local.

En síntesis, la invasión de tierra, el cercado del monte y la huída nos permiten sugerir una analogía con el momento de la conquista española, no en cuanto a la llegada de los primeros blancos, sino por la revolución socioeconómica que se da a través de un choque frontal entre dos formas de utilización del espacio, con la consiguiente hegemonía de una y el aplastamiento de la otra.

A continuación se analiza este enfrentamiento a partir de las técnicas agropecuarias que se impusieron.

\section{SURGIMIENTO Y DESARROLLO DE LOS SISTEMAS DE GANADO}

El desarrollo de sistemas de ganado descansando sobre la apropiación privada de los recursos forrajeros introdujo nuevas técnicas de ganadería y modificó las prácticas campesinas tradicionales en toda la comunidad aunque de manera distinta según los ranchos, el medio natural y el tipo de animales de que se tratara.

\section{La ganadería bovina}

Con el pastoreo libre que prevalecía en la comunidad antes de que se empezara a cercar, cada animal podía desplazarse en el terruño para buscar su alimentación. Según las épocas del año, aprovechaba los diferentes recursos forrajeros de la sierra, en distintos pisos ecológicos: en el monte, de julio a diciembre; el rastrojo de maíz de diciembre a febrero para el maíz de temporal, y de mayo a junio para el maíz de humedad o de riego; árboles for rajeros como la "parota", la "higuera", el "uje" de marzo a mayo; ${ }^{33}$ y pasto natural en la temporada de lluvias y primeros meses de secas. Cada tipo de

33. Parota (Enterolobium cyclocarpum), higuera (Ficus segoviae), uje (Brosinum alicastium). 
forraje era limitado y disponible sólo durante una estación precisa. El aprovechamiento sucesivo y combinado de estos recursos forrajeros caracterizaba la alimentación del ganado.

Al multiplicarse las cercas de alambre de púas, los animales no podían andar libremente para buscar su alimentación; la lógica del sistema de ganado bajo pastoreo libre fue sustituida por una lógica diferente y antagónica: el aprovechamiento privado e individual de los recursos forrajeros. Del nuevo sistema de tenencia de la tierra dependía el acceso de cada uno a los recursos forrajeros; acceso por supuesto desigual, diferenciado, del que dependían los nuevos sistemas de ganado que se establecían: los ganaderos más poderosos son los que lograron cercar una superficie importante de monte. Además de contar con todos los tipos de recursos en sus potreros, sembraron pastura. Los pastos guinea y $b u f f e l^{34}$ han sustituido paulatinamente desde hace unos 15 años al monte en varias unidades de producción. El calendario forrajero puede ser esquematizado de la siguiente manera:

GRAFica No 35

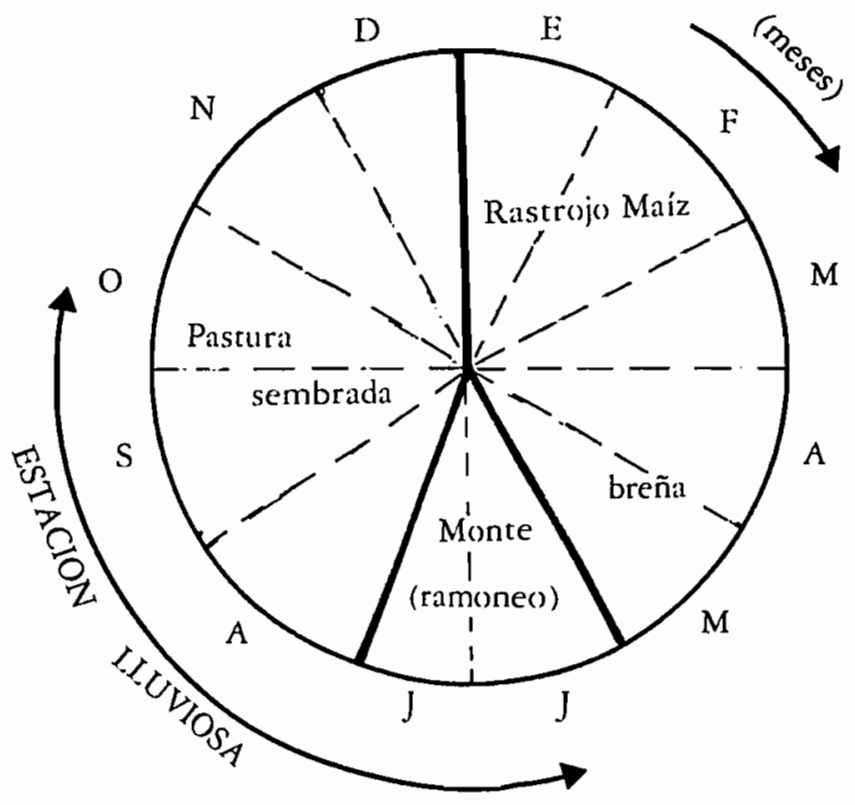

34. Pasto guinea (Panicum maximum), buffel (Cenchrus ciliaris). 
Siguiendo el movimiento general de especialización ganadera observado en la sierra de Coalcomán, los ganaderos mestizos instalados en la comunidad de Pómaro adaptaron sus sistemas de ganado a la cría de animales para carne gracias a la introducción de las razas Cebú, al mejoramiento sanitario (erradicación del gusano barrenador, baños garrapaticidas, vacunas, etc.), a la rotación de potreros y a la venta de animales jóvenes (becerros de 1 a 2 años).

Sin embargo, las ventas de ganado no se han concentrado en los meses de septiembre y octubre como ocurrió en el municipio de Coalcomán, sino que siguen llevándose a cabo a fines de la temporada seca. El ganado engorda en abril y mayo gracias a los frutos y hojas de los árboles forrajeros, o también en diciembre y enero para las unidades de producción que cuentan con pastura sembrada. Los ganaderos más poderosos venden directamente sus animales a los comisionistas de los rastros de Guadalajara y Ciudad Lázaro Cárdenas.

Los pequeños hatos en la zona ocupada por los ganaderos

En esa zona, todas las tierras están cercadas, lo que impide el pastoreo libre. Los campesinos que no tienen un potrero con acceso al agua tuvieron que vender sus vacas. Para los demás campesinos no hubo más alternativa que adoptar la misma lógica forrajera que los ganaderos, pero en potreros chicos, donde los recursos son poco diversificados y hay una gran degradación del monte por la disminución del descanso en la rotación forestal. El calendario forrajero se esquematiza así:

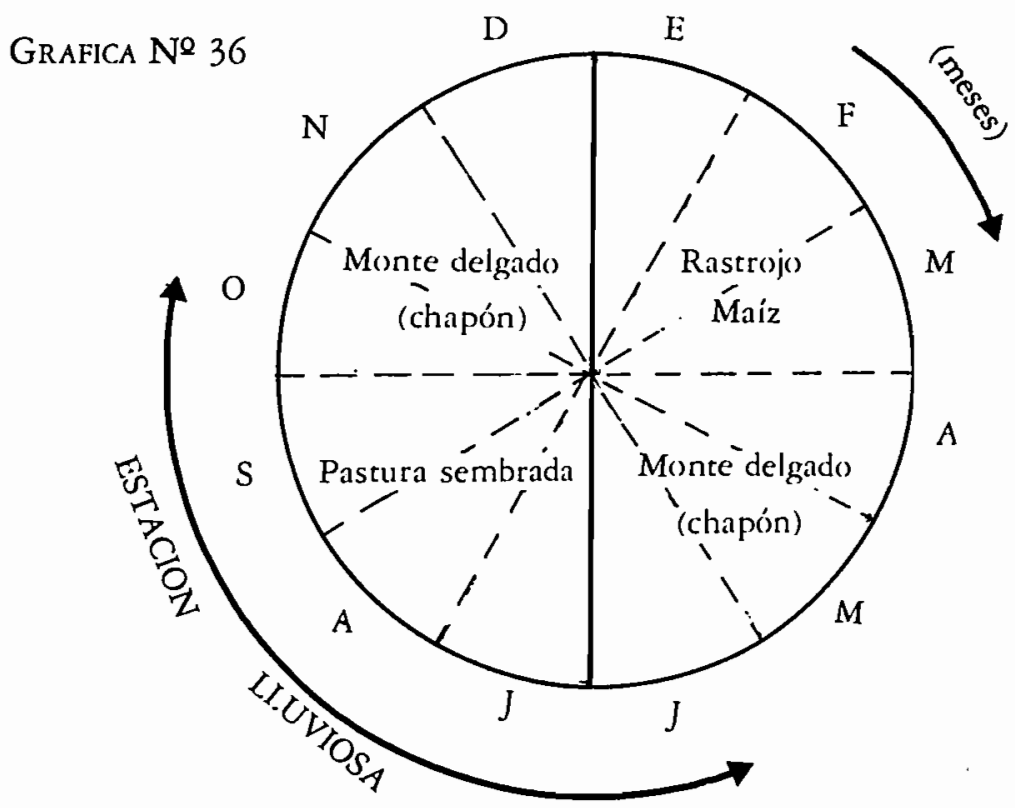


El forraje a veces hace falta en las secas. El tamaño del hato queda limitado por el del potrero.

Con 5 ó 15 cabezas no se puede tener un semental, pues el capital invertido es demasiado elevado, por lo que los campesinos lo piden prestado a los ganaderos durante unos meses. A veces, los mismos becerros se utilizan como sementales y la sangre cebú es escasa en esos hatos. Las vacas no están fecundadas en esos meses y el intervalo promedio entre dos partos es con frecuencia de dos años.

Los comisionistas de los rastros no tratan con los campesinos que tienen que vender a los ganaderos o a otros comerciantes. Venden cuando necesitan dinero y no según los precios del mercado, por eso los compradores se aprovechan imponiendo sus precios.

El manejo no permite que el hato sea muy eficiente, por lo que las ventas son escasas y el hato tiene, en parte, función de ahorro.

El sistema con pastoreo libre y su evolución

El sistema de ganadería que existía antes de que llegaran los mestizos, sigue presente en donde queda espacio libre.

En los pueblos más preservados como Pómaro, los ranchos indígenas y La Parotita, los animales andan sueltos todo el año y se mezclan los hatos en los cerros y en las barrancas. Se mantienen en el monte todo el año, y el rastrojo de maíz solo completa la alimentación en las secas (gráfica 37) haciendo que su uso sea cada vez mạ́s privado.

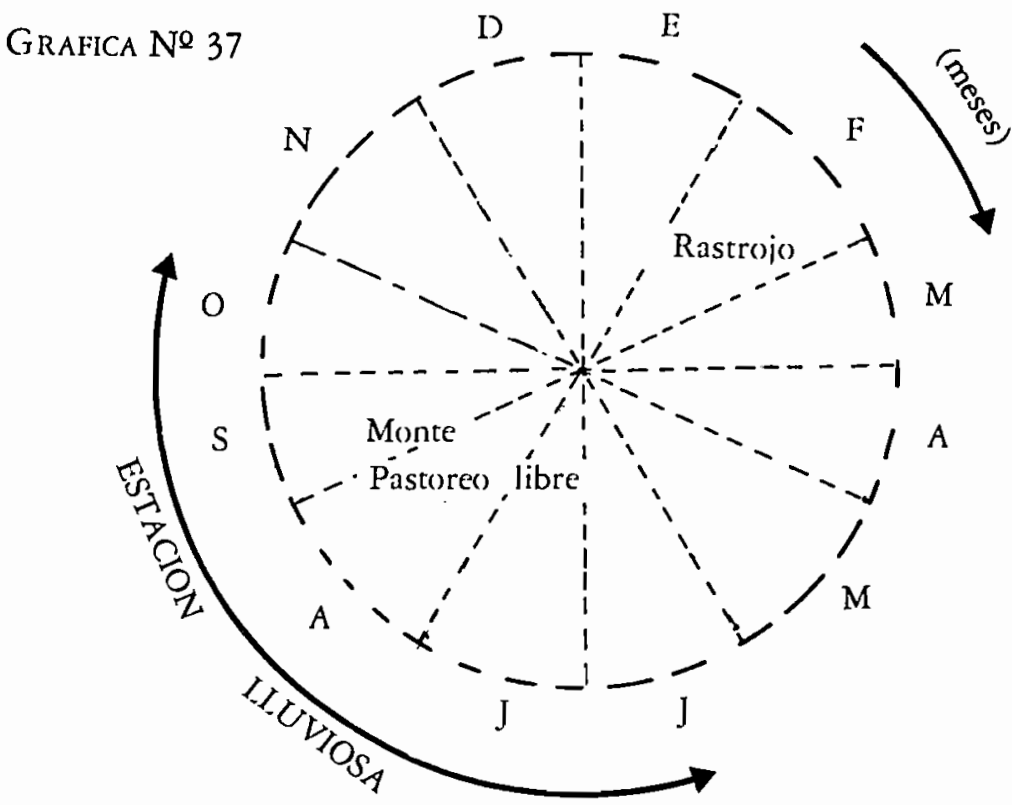


Hay que destacar que ese sistema no impide que haya hatos grandes; por el contrario, cada quien puede aprovechar las tierras de la comunidad. Se encuentran tanto hatos de dos o tres cabezas, frecuentes en Pómaro, como de 30 a 50 cabezas como en La Parotita.

Existen distintas formas de transición entre la explotación comunitaria y privada del forraje. En unos pueblos, como Los Encinos, los indígenas cercaron juntos las tierras del pueblo, para protegerlas contra los ganaderos (véase gráfica 34). Los hatos se mezclan dentro del potrero común, al interior del cual se manejan del mismo modo que en Pómaro. A pesar de las cercas, no se trata de una apropiación del forraje, sino de una protección de los bienes comunales.

En Las Campanas, y a veces en Cachán y Maruata, las vacas andan sueltas en las barrancas de junio a diciembre, desde la siembra a la cosecha de maíz. En las secas, se quedan encerradas pastando el rastrojo de maíz, la pastura sembrada y el monte. Parte del forraje está apropiado, pero no se aprovecha tanto como cuando hay potreros empastados y cerrados aparte del maíz, que pueden ser pastados en las lluvias.

En la costa, los animales con frecuencia carecen de forraje hacia finales de las secas, por la misma sequía, la falta de ojos de agua y la pobreza del monte en árboles forrajeros. Como las vacas están fecundadas desde que vuelven a entrar en celo - en los primeros meses de lluvias - por disponer de mucho más forraje que en las secas, paren en abril o mayo, nueve meses después a fines de las secas cuando escasean los recursos forrajeros. Es muy común que vacas o becerros mueran de hambre o de sed, lo que ocurre mucho menos en la sierra, por la diversidad y riqueza de los recursos forrajeros que son menores en la costa haciéndose más difícil el mantenimiento del ganado.

\section{La ganadería caprina}

Desarrollo de la producción

La ganadería caprina tuvo un desarrollo reciente en la Comunidad de Pómaro. Las primeras cabras llegaron hace 25 ó 30 años de la sierra de Coalcomán. A hora, la cría de cabras está generalizada en la parte poniente de la comunidad que no sufrió tanto las invasiones de tierra y el desarrollo de la ganadería bovina (Pómaro, Maruata, Cachán, La Parotita).

En la zona de Pómaro, tres "chiveros" se reparten el negocio de compra-venta de cabras. Sus actividades nos dan una idea cuantitativa de la importancia de la producción. Uno de ellos puede juntar hasta 70 cabezas cada 8 días en las épocas de mayor venta (mayo-julio) y cada 15 o 20 días en las demás épocas. Varios miles de animales salen así de la comunidad cada año. Sin embargo, el número y el tamaño de los hatos, es muy desigual según 
las unidades de producción. De las 60 unidades de producción estudiadas, 30 contaban con esta actividad, a menudo 5 o 15 cabezas por familia, pero solamente seis jefes de familia la tenían como actividad principal en hatos grandes y/o compra-venta. Cabe señalar que el crecimiento del hato puede ser rápido en una misma unidad de producción por la prolificidad de la raza que da hasta dos crías por cabra cada año según los campesinos entrevistados. El gobierno quiso apoyar el desarrollo de esta actividad, proporcionando créditos, pero los animales así entregados - "las chivas del gobierno"venían de zonas más frescas y no se adaptaron a las condiciones difíciles de la zona costera, provocándose fuertes pérdidas que superaron el $50 \%$ del total.

\section{Manejo del hato}

La producción de cabras descansa básicamente sobre el pastoreo libre. Los animales andan sueltos en el monte todo el año, regresando por la tarde al corral de la casa y saliendo por la madrugada. El manejo está sometido a reglas colectivas con el fin de proteger los cultivos durante el ciclo vegetativo (junio-noviembre) en el cual, el hato debe estar cuidado por un pastor que generalmente es un niño de la familia. Aunque se junten los animales cada noche en un corral, cabe señalar que no se usan las deyecciones como abono sino sólo en casos aislados.

La mayoría de los animales son "criollos", rústicos y adaptados a la recolección de alimentos en el monte seco de la costa, lo que no era el caso con "las chivas del gobierno". Se observa con frecuencia, una repartición del terruño entre vacas y cabras según las exigencias de cada tipo de animal y para que éstas no "acaben" con el pasto de aquéllas (en las zonas cercadas por los ganaderos, estos dos tipos de producciones son incompatibles). Las vacas se quedan en las barrancas más húmedas y con árboles forrajeros, mientras que las cabras andan en el monte.

La producción se vende en pie a los "chiveros" locales que venden ellos mismos a compradores de afuera. La mayoría de las ventas se llevan a cabo antes de sembrar en mayo y junio para que el manejo del hato no se vuelva demasiado pesado en tiempo de lluvias. Los productores que pueden contar con la mano de obra familiar - niños-y gozan de condiciones geográficas particulares - aislamiento del rancho, por ejemplo, que permite un cuidado más fácil del hato- pueden vender en enero cuando los animales están en mejor condición.

Cría de cabras y sistema de producción

Es obvio que la producción de cabras parece adaptada al sistema de ganado que descansaba sobre el libre pastoreo, a tal punto, que esta producción se volvió característica de las zonas poco cercadas en las cuales la ganadería bovina no alcanzó un desarrollo fuerte. En las zonas invadidas, el cercado del monte y el desarrollo de la ganadería bovina impidieron la cría de caprinos a 
pesar de que las cercas para vacas (4 hilos) no lograban encerrar a las cabras. Incompatibilidad que refleja el poder político y económico de los ganaderos recién llegados a la comunidad. El desarrollo de la cría de cabras en las zonas bajo control indígena de la comunidad —desarrollo que se llevó a cabo en la misma época de las invasiones de tierras y del cercado del monte en la parte norte de la comunidad- parece contradictorio y difícil de interpretar. ¿Será considerado como forma de defensa indigena ante el cercado del monte?, ¿o lo consideraremos como adaptado a la zona costera más difícil, con clima menos favorable a la ganadería bovina y todavía poco cercada? De todos modos, no puede ser interpretado aparte del movimiento general analizado más arriba, sino al contrario como elemento constitutivo de la evolución general del sistema social de producción.

\section{EVOLUCION DE LOS SISTEMAS DE CULTIVO}

El cultivo del maíz bajo roza, tumba y quema, sobre el cual descansaba el sistema de producción de los años cuarentas, sufrió muchas modificaciones. El cercado del monte, las migraciones de la población y el desarrollo de la ganadería lo hicieron cambiar. Siendo el clima uno de los factores más determinantes para el cultivo del maíz, presentamos a continuación una breve descripción de sus características antes de analizar la evolución de los sistemas de cultivo en la parte alta de la comunidad y luego en la costa.

\section{El clima: una agricultura aleatoria}

En la costa, las lluvias son débiles e irregulares. Se concentran en verano, de junio a octubre (véase gráfica 38 ). El cuadro siguiente expone el total de las lluvias durante 5 años de observación.

Este cuadro muestra la variabilidad interanual de las precipitaciones, 1982: 286 milímetros; 1984: 1,222 mm. o sea de 1 a 4 en tan sólo seis ciclos. Una sequía como la de 1982 no es excepcional. En 1973 y 1974, tampoco se cosecharon ni un kilogramo de maíz a causa de la sequía. ${ }^{35}$

De la duración de la estación de lluvias depende, la del ciclo de las plantas que se pueden sembrar sin riego y la del crecimiento del bosque.

La duración de la temporada de lluvias es también muy variable como lo enseña el siguiente cuadro:

Trataremos ahora de ver cómo se reparten las lluvias durante la

35. En 1974, el gobierno mandó un barco de maíz a Maruata como ayuda alimenticia. 
GraficA No 38: DIAGRAMA DEL UMBRAL TERMICO (ESTACION PLUUIOMETRICA DE CaChan. Promedio 1979-1984)

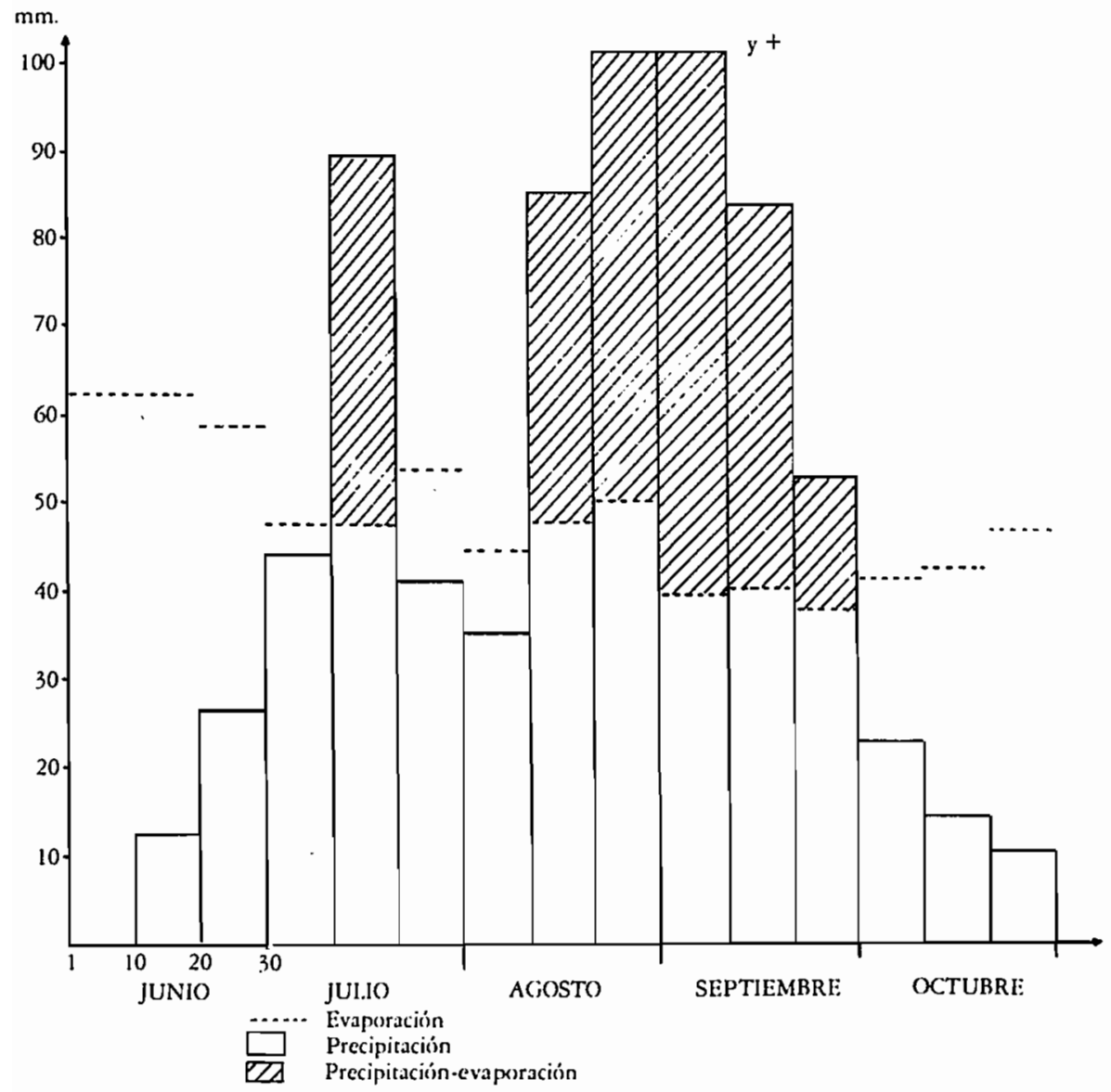

temporada tal y cómo se aprecia en la gráfica 39.

Casi siempre, al principio de las aguas caen unas lluvias escasas y la evaporación todavía es muy fuerte, la tierra se seca pronto. Una planta que estuviera sembrada en la primera lluvia no podría aguantar la sequía. La duración de las lluvias "útiles" para el cultivo está entonces aún más reducida que lo que presentamos antes.

Cada año caen pocas aguas a fines de julio o principios de agosto. Ese fenómeno llamado "canícula", está muy bien marcado en la gráfica de los promedios de los 6 años. Durante unas semanas, la evaporación es más fuerte que la precipitación (gráfica 38). Puesto que en el monte los suelos 
CuAdro № 24

\begin{tabular}{|c|c|c|c|c|c|}
\hline Año & $1980^{1}$ & 1981 & 1982 & 1983 & 1984 \\
\hline $\begin{array}{c}\text { Total de Iluvias } \\
\text { de junio } \\
\text { a octubre }\end{array}$ & $(450)$ & 1091 & 286 & 916 & 1222 \\
\hline Evaporación & 800 & 696 & 739 & 719 & 545 \\
\hline
\end{tabular}

Fuente: Estación climatológica de Cachán. Esta ubicada a $2 \mathrm{Km}$. del mar y a unos 10 metros sobre el nivel del mar.

\section{CuAdRo № 25}

\begin{tabular}{|c|c|c|c|c|c|c|}
\hline Año & 1979 & 1980 & 1981 & 1982 & 1983 & 1984 \\
\hline Primera lluvia que moja & 13 julio & 26 jun. & 15 jun. & 1 jul. & 30 jun. & 5 jun. \\
\hline Ultima lluvia & $?$ & 3 oct. & 30 oct. & 6 oct. & 19 oct. & 12 oct. \\
\hline $\begin{array}{l}\text { Número de días entre la } \\
\text { la. y la última lluvia }\end{array}$ & $?$ & 100 & 137 & 98 & 112 & 129 \\
\hline
\end{tabular}

Fuente: Idem.

1. Faltan los datos del 21 al 31 de agosto.

son a menudo delgados, no hay reservas grandes de agua en el suelo para las plantas. Por tanto, hay riesgo de stress hídrico, afectando el rendimiento del cultivo de maíz.

Aunque falta seguido el agua, hay tormentas muy cargadas de más de 100 milímetros en 5 días. Esas lluvias pueden acabar con el cultivo, sobre todo en septiembre cuando la milpa está alta y se cae. Además, corriendo en las pendientes, el agua arrastra los nitratos y si se abona antes de una tormenta, el fertilizante no se aprovecha debidamente. Así, las precipitaciones escasas e irregulares aparecen, desde luego, como obstáculos mayores a la producción agrícola de la costa. Además el clima costeño es muy caluroso. 
Grafica No 39: DistribuCION DE LAS PRECIPITACIONES DURANTE LA ESTACION DE LLUVIAS. (1980 A 1984).

(Estacion Climatologica de $\mathrm{C}_{\text {ACHAN) }}$
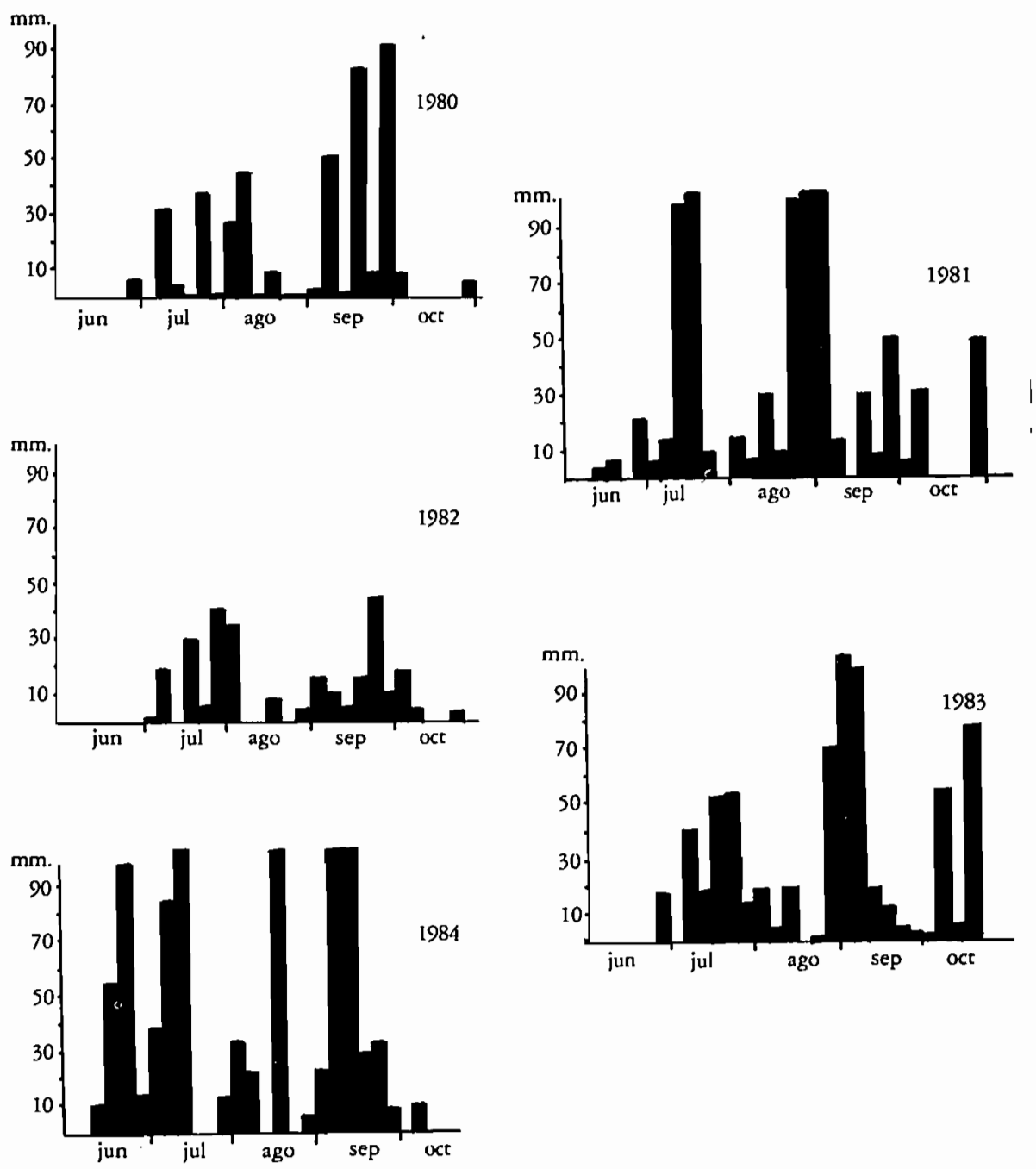
Los mínimos no bajan a menos de $15^{\circ} \mathrm{C}$. En verano, fluctuando entre $20 \mathrm{y}$ $25^{\circ} \mathrm{C}$ de noche y 28 a $35^{\circ} \mathrm{C}$ durante el día. La humedad relativa, por la alta temperatura, es muy alta favoreciendo el desarrollo de las plagas.

En la sierra, el clima cambia paulatinamente en la medida en que se asciende. En Pómaro, a los 500 m.s.n.m., todavía llueve poco, pero más arriba, las lluvias son más abundantes y más regulares que en la costa. En La Parotita, parte alta de la comunidad, "el maíz pega cada año, si no lo cortan los vientos". No le falta el agua ya que las lluvias suelen empezar a mediados de junio y siguen hasta fines de octubre. Se pueden sembrar variedades de ciclo más largo que en la costa y el monte alcanza a crecer más cada año. El descanso de agosto es débil. El exceso de agua impide el cultivo de ajonjolí que se sembraba mucho en la costa, pero favorece el de café y de caña de azúcar. Las temperaturas más bajas permiten el cultivo del frijol.

\section{Evolución de la milpa en la sierra}

El sistema de cultivo bajo roza, tumba y quema descansaba sobre el bosque: era un sistema forestal cuya coherencia y reproductibilidad dependian del renuevo forestal. Solo un monte alto podía acabar con el estrato herbáceo (malezas), y devolver la fertilidad al suelo. Ahora ya no es posible tumbar un monte asi por las siguientes razones:

-Por el desarrollo de las cercas, pues solo los dueños de potreros grandes pueden escoger el lugar bueno para tumbar. Los dueños de terrenos chicos y los que no tienen tierras están condenados a tumbar matorral o monte delgado ("chapón").

-El desarrollo de la ganadería introdujo nuevas rotaciones de cultivos incluyendo las especies forrajeras. Las parcelas así sembradas de pastura salen del sistema forestal (rotación larga) disminuyendo el espacio dedicado a la milpa.

-La concentración de la población en los pueblos más importantes impone una presión más fuerte sobre la tierra en los alrededores; el caso de San Pedro Naranjestil es el más desarrollado por el crecimiento de la población mestiza. Ya no se encuentran montes altos sino a varias horas de camino del pueblo.

Así, el periodo de renuevo forestal fué disminuyendo en las zonas donde se desarrollaba la ganadería, y no es suficiente para que los árboles cubran el estrato herbáceo; tampoco alcanza a renovar la fertilidad del suelo, con lo que el sistema de cultivo pierde su coherencia interna imponiendo cambios de técnicas. La lucha contra las malezas se lleva a cabo con dos técnicas nuevas: el adelanto de la fecha de siembra y el uso de herbicidas. En relación a la primera los campesinos siembran "en seco", a fines de mayo y a principios de junio en lugar de esperar que se moje bien la tierra para 
sembrar, para que la milpa aproveche las primeras lluvias y así crezca más pronto que las malezas. ${ }^{36} \mathrm{Al}$ caer las primeras tormentas germinan y brotan las plantas. Pero si sigue un tiempo sin lluvias, la tierra se reseca pronto faltando agua a las plantas. A veces, el campesino tendrá que reșembrar. Ese riesgo no es tan alto arriba de los 500 m.s.n.m. como para que impida a los campesinos sembrar antes de las lluvias, pero siempre hay que tomarlo en consideración.

El cuadro que ofrecemos a continuación pone a la vista el desarrollo de esta nueva técnica en el pueblo de San Pedro Naranjestil, cuyo terruño estuvo cercado por los ganaderos. Se hace la comparación con el pueblo de Pómaro.

\section{CUADRO No 26}

\begin{tabular}{|l|c|c|c|c|c|}
\cline { 2 - 6 } \multicolumn{1}{c|}{} & \multicolumn{5}{c|}{ Fecha de siembra } \\
\cline { 2 - 6 } & $\begin{array}{c}\text { Antes de las } \\
\text { 1as. lluvias }\end{array}$ & $\begin{array}{c}\text { Después de } \\
\text { las } \\
\text { 1as. lluvias }\end{array}$ & $\begin{array}{c}\text { No siem- } \\
\text { maíz }\end{array}$ & $\begin{array}{c}\text { Falta la } \\
\text { información }\end{array}$ & $\begin{array}{c}\text { Total } \\
\text { entrevistas }\end{array}$ \\
\hline $\begin{array}{l}\text { San Pedro } \\
\text { Naranjestil }\end{array}$ & 8 & 2 & 3 & 10 & 23 \\
\hline Pómaro & 1 & 5 & 2 & 1 & 9 \\
\hline
\end{tabular}

Por lo que se refiere al uso de herbicidas, esta técnica se desarrolló desde hace tres o cuatro años. Se trata de un producto específico (Esterón) que destruye todas las malezas de "hoja ancha". Al contrario, la pastura a veces sembrada asociada con el maíz no padece por la aplicación del producto.

En tales condiciones, el uso de herbicidas aparece como una técnica muy bien adaptada a los sistemas de producción descansando sobre la ganadería.

36. Eso no se podia hacer tumbando un monte alto: después de la quema, la tierra estaba demasiado caliente para que se pudiera mantener la semilla hasta las primeras lluvias. Además, según los campesinos, una milpa así sembrada crecía demasiado una vez mojada la tierra, pero no aguantaba las demás tormentas ni el viento. Es probable que, por la alta tasa de materia orgánica en el suelo (raíces...) y por la temperatura del suelo (favorable a la actividad de los microorganismos), la mineralización fuera excesiva (y el nitrógeno disponible para las plantas) al caer las primeras lluvias. 
El cuadro 27 da una idea del desarrollo desigual de esta técnica en dos pueblos de la comunidad.

CuAdro № 27

\begin{tabular}{|c|c|c|c|c|c|}
\cline { 2 - 6 } \multicolumn{1}{c|}{} & $\begin{array}{c}\text { utilizan } \\
\text { herbicidas }\end{array}$ & $\begin{array}{c}\text { No utilizan } \\
\text { herbicidas }\end{array}$ & $\begin{array}{c}\text { No siem- } \\
\text { bran maiz }\end{array}$ & $\begin{array}{c}\text { Falta la } \\
\text { inform. }\end{array}$ & $\begin{array}{c}\text { Total } \\
\text { entrev. }\end{array}$ \\
\hline $\begin{array}{c}\text { San Pedro } \\
\text { Naranjestil }\end{array}$ & 9 & 5 & 3 & 6 & 23 \\
\hline Pómaro & 0 & 7 & 2 & 0 & 9 \\
\hline
\end{tabular}

La aplicación del Esterón lleva como consecuencias la imposibilidad de sembrar calabazas o pepino asociado con el maíz. La calabaza, por ejemplo era un elemento importante del sistema de producción que servía de alimento para la familia y los animales. Muchos productores dejaron este cultivo mient ras que unos lo siguen sembrando aparte del maíz o limpiando a mano la milpa asociada; éstas opciones exigen más trabajo. Es obvio que la disminución de la producción de puercos en la sierra está ligada al abandono de este cultivo en numerosas unidades de producción.

A manera de conclusión puede decirse que ante la invasión rápida de la milpa por las malezas, los campesinos cambiaron sus técnicas con el fin de proteger su milpa por lo que adelantaron la fecha de siembra, usaron fertilizante y limpiaron con guadaña su milpa varias veces.

En realidad, esta respuesta técnica - más trabajo y más gastos monetarios para seguir con el sistema de cultivo forestal- está en contradicción con la nueva lógica forrajera que maneja los sistemas de producción ganadera.

En efecto, el cultivo bajo roza, tumba y quema descansaba sobre el bosque, elemento fundamental y central del sistema. Las hierbas -el estrato herbáceo- era el enemigo que había que combatir mediante el renuevo forestal. Ahora los ganaderos quieren producir hierbas, pastura para su ganado. Siembran gramíneas en lugar de combatirlas, mientras que el bosque se vuelve enemigo del cultivo; impiden su crecimiento porque perjudica el desarrollo del pasto. Esta lógica distinta impone la transformación del paisaje agrario: el bosque se transforma en pradera.

La introducción de los fertilizantes

Para los campesinos, la evolución de los rendimientos se debe a la baja de 
fertilidad del suelo. De acuerdo a las personas entrevistadas, al tumbar monte alto un "año bueno", desde el punto de vista climático, se puede esperar un rendimiento de ocho cargas por medida de siembra, aproximadamente tres toneladas por hectárea. Pero ahora, el renuevo forestal no rebasa siete u ocho años. Tumbando un monte bajo ("chapón"), no se alcanzan las cinco o seis cargas por medida (aproximadamente dos toneladas por hectárea). Pero aplicando fertilizante, el rendimiento vuelve a alcanzar, si llueve bien, las ocho cargas por medida de siembra. Así, desde hace seis y echo años, los productores utilizan el sulfato de amonio, aplicándolo una vez cuando las plantas tienen $30 \circ 40 \mathrm{~cm}$. de alto. La cantidad utilizada es de 500 kilogramos por hectárea, aproximadamente 100 kilogramos de nitrógeno por hectárea, lo que permite aumentar el rendimiento de una tonelada por hectárea si los factores climáticos no son limitantes. Si hace falta el agua, o si llueve demasiado, ${ }^{37}$ no hay ningún beneficio para el cultivo. Es probable que haya muchas pérdidas de nitrógeno por lixiviación; si no hubiera, el alza potencial del rendimiento una vez aplicada la cantidad de 100 kilogramos por hectárea, sería de mucho más que una tonelada por hectárea.

En realidad, cabe señalar que el uso de fertilizante está lejos de ser generalizado en la comunidad. Solamente 13 personas, de las 60 entrevistas, ocupan este insumo de las cuales 7 viven en la zona de San Pedro Naranjestil, muy desmontada y sin bosque alto. En la zona costera, recién poblada y poco desmontada, el uso de fertilizante es excepcional aunque la carretera costera facilita el transporte del producto.

Para tener una idea de la rentabilidad del sulfato de amonio, hemos estudiado dos unidades de producción en San Pedro Naranjestil. Una en la que el campesino es dueño del terreno y otra en la que es mediero.

Las hipótesis previas son las siguientes:

-La aplicación de 100 kilogramos de nitrógeno permite esperar un aumento de producción de una tonelada, en el caso favorable para el cual no hay otros factores limitantes.

-El dueño del terreno contrata mano de obra para aplicar fertilizantes y para la cosecha. El mediero mismo hace el trabajo. Hemos escogido un costo de oportunidad de su trabajo igual al salario de un peón, costo que puede ser inferior en las épocas de subempleo e igual o superior durante la cosecha.

-El costo del fertilizante es el precio comercial más el costo de flete: 5 viajes de una mula, o sea, 5 días a $\$ 1,000.00$ el día. Para el dueño del terreno, si es dueño de las mulas, será un costo de oportunidad. Para el mediero que no tiene bestias, es costo monetario.

37. Censo de 1984. Los rendimientos no alcanzaron la tonelada por hectárea (con o sin fertilizante). 
-Se toman en cuenta los productos y gastos que cambian con la aplicación del fertilizante, los demás no aparecen en el cálculo.

\section{Cuadro No 28}

RENTABILIDAD COMPARADA DE LA APLICACION DE FERTILIZANTES en dos Unidades de PRoduccion de San Pedro Naranjestil.

\begin{tabular}{|c|c|c|c|c|c|c|}
\hline \multirow{3}{*}{ Para $1 \mathrm{Ha}$} & \multicolumn{3}{|c|}{ Dueño del terreno } & \multicolumn{3}{|c|}{ Mediero } \\
\hline & \multirow{2}{*}{ producto } & \multicolumn{2}{|c|}{ gastos } & \multirow{2}{*}{ producto } & \multicolumn{2}{|c|}{ gastos } \\
\hline & & monet. & de oport. & & monet. & de oport. \\
\hline $\begin{array}{l}\text { cosecha maiz: } 1 \text { ton. } \\
\$ / \mathrm{Kg}: 35\end{array}$ & 35,000 & 一 & 一 & 17,500 & - & - \\
\hline $\begin{array}{c}\text { Fertilizante } \\
100 \mathrm{Kg} \text {. nitrógeno }\end{array}$ & - & 10,000 & 一 & 一 & 10,000 & - \\
\hline Fertilizante: flete & - & 一 & 5,000 & - & 5,000 & - \\
\hline Mano de obra & - & 4,000 & - & - & - & 4,000 \\
\hline Total & 35,000 & 14,000 & 5,000 & 17,500 & 15,000 & 4,000 \\
\hline $\begin{array}{l}\text { Margen bruto debido a la } \\
\text { aplicación del producto }\end{array}$ & \multicolumn{3}{|c|}{$+\$ 16,000.00 / \mathrm{Ha}$} & \multicolumn{3}{|c|}{$-\$ 1,500 / \mathrm{Ha}$} \\
\hline
\end{tabular}

Así, la aplicación de fertilizante puede ser rentable para las unidades de producción que cuentan con terrenos propios siempre y cuando el clima permita la valoración del producto. Pero es probable que el riesgo climático fuerte impida el desarrollo de esta técnica. El crédito del banco, por falta de seguro, no logra difundir mucho el empleo del sulfato de amonio.

Para el mediero, la aplicación de fertilizante no tiene sentido excepto en aquellos casos de contrato en el que encuentra mayor ventaja, por ejemplo cuando todo el grano es para él y el rastrojo para el dueño del terreno.

Las variedades del maíz

No se sembraban las mismas variedades de maíz en toda la sierra. Entre 500 y 800 m.s.n.m. los productores sembraban variedades precoces (Tampique, Tepite) mientras que el maíz delgado y el roquero que son variedades menos precoces se sembraban más arriba.

Hace 10 o 15 años, empezaron a traer una variedad nueva: el 507 
llamado el bíbrido por los campesinos. El desarrollo rápido de su utilización se explica de la siguiente manera:

-Es una variedad de doble propósito da grano y rastrojo abundante, que se adapta bien al reciente desarrollo de la ganadería.

-Aunque sea híbrido, este maíz degenera lentamente 38 y se puede sembrar varios años sin comprar cada vez la semilla.

-Este maíz puade ser sembrado en la costa hasta los 800 m.s.n.m., en una parte amplia de la comunidad. Sustituyó paulatinamente al maíz Tepite y Tampique pero el delgado y el roquero se siembran más en las partes altas por tener un ciclo más largo y una mejor resistencia al acame. ${ }^{39}$

Resumiendo lo dicho sobre la evolución del sistema de cultivo bajo roza, tumba y quema el cuadro 29 presenta las modificaciones que se llevaron a cabo a medida que se iba acabando el monte alto.

Las condiciones de producción de la milpa en los cerros de la comunidad se volvieron muy difíciles: tumbar un monte bajo parece más arriesgado que tumbar un monte alto. Sembrar antes cie las lluvias para controlar las malezas aumenta el riesgo de la sequía; comprar fertilizantes y herbicidas representa una inversión sometida al riesgo climático. Disminuye la diversidad de las producciones impidiendo la asociación de cultivos.

Tumbando un monte bajo, el sistema de cultivo se vuelve más exigente en trabajo. No se tarda tanto para la tumba (menos trabajo en invierno) pero aumenta el número de jornadas necesarias para la siembra en seco (suelo más duro) las limpias a mano, la aplicación de fertilizantes y herbicidas.

Ante las presiones ejercidas por el desarrollo de la ganadería se modificó el patrón de cultivo del sistema de cultivo forestal. También se diferenciaron otros sistemas de cultivo como el descrito a continuación

La adopción del cultivo año con año

Dejando definitivamente la lógica de la rotación forestal larga, los campesinos destroncaron parcelas reducidas. No sólo tumbaron los árboles sino que también extrajeron troncos y raíces empezando por lo más parejo en las partes altas de los cerros y siguiendo en los declives. Una vez destroncada la tierra, se trabaja con arado de palo y yunta de bueyes. El arado raspa la capa superficial de la tierra pasando dos veces cruzadas en las partes

38. A los 3 o 4 años, se observa la degeneración:

-la mazorca disminuye;

-la mazorca no esta llena hasta la punta;

39. Acame: acción y efecto de doblarse el tallo de las plantas debido a la acción del viento.

Diccionario Agropecuario, INCA RURAL, México, 1982. 
Cundro Ne 29

\begin{tabular}{|c|c|c|c|}
\hline & & \multicolumn{2}{|c|}{ Monte tumbado: } \\
\hline & peración & "grueso" & delgado ("chapón") \\
\hline \multicolumn{2}{|c|}{ fecha de siembra } & $\begin{array}{l}\text { después de las } \\
\text { primeras lluvias }\end{array}$ & $\begin{array}{c}\text { antes de las } \\
\text { primeras lluvias }\end{array}$ \\
\hline \multirow{2}{*}{ 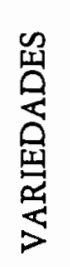 } & 500 a 800 m.s.n. & Tampique-Tepite & $\begin{array}{c}\text { H 507-Tampique- } \\
\text { Tepite }\end{array}$ \\
\hline & 800 m.s.n.m. & Roquero-Delgado & Roquero-Delgado \\
\hline \multicolumn{2}{|c|}{ cultivos asociados } & calabaza-pepino & pastura \\
\hline \multicolumn{2}{|c|}{ herbicidas } & no & sí \\
\hline \multicolumn{2}{|c|}{ fertilizantes } & no & sí \\
\hline \multicolumn{2}{|c|}{$\begin{array}{l}\text { Limpias manuales } \\
\text { (escarda) }\end{array}$} & $0 \circ 1$ & $1 \circ 2$ \\
\hline
\end{tabular}


planas y una vez en los declives siguiendo las curvas de nivel. Las vertientes de los cerros parecen así sucesiones de escalones y micro-terrazas que el arado vuelve a hacer y consolidar cada año, pasando por los mismos surcos del año anterior. La semilla se siembra con espeque en el surco.

En este caso, el trabajo del suelo con el arado tendría como objetivos: suavizar la superficie de la tierra para que no haya terrones impidiendo la germinación y el brote de las semillas, y limitar la erosión, que tiende a desarrollarse después de haber destroncado la parcela, mediante las microterrazas. El agua corre en los surcos perpendicularmente al sentido de la pendiente, lo que permite aplicar fertilizante sin que lo lave la lluvia.

Sin embargo, el arado de palo no voltea la tierra ya que no tiene aleta lo que no permite una lucha eficiente contra las malezas. Este sistema de cultivo tiene que incluir el uso de herbicidas y la limpia manual. Tampoco se resuelve el problema de la fertilidad del suelo y el uso de fertilizante pronto se vuelve indispensable.

Trabajando así una parcela en un año dado, la combinación de la especie cultivada, de la sucesión de técnicas y del clima condiciona el medio en el cual estará sembrado el cultivo del año sigu iente, poniendo así en parte, las bases del éxito de dicho cultivo. El trabajo de un año dado se invierte para los años siguientes. Esta memoria de un trabajo acumulado favorece el uso privado de la parcela y luego su apropiación.

Esta apropiación privada se lleva a cabo con mucho trabajo y con pocos gastos monetarios, en comparación del gasto que se requiere para cercar potreros grandes y desarrollar la ganadería. Aunque este sistema esté todavía poco desarrollado, veremos más adelante cómo tiende a extenderse.

\section{El cultivo de maíz en la costa}

La invasión de la comunidad y la extensión de las cercas tuvieron como consecuencias migraciones de población hacia la costa. Al llegar a la costa, los indígenas desarrollaron varios sistemas de cultivo de acuerdo a la variabilidad de los recursos disponibles: desmonte, tierras planas, tierras de humedad y riego.

El cultivo bajo roza, tumba y quema

En la parte costera de la comunidad no se trataba de resolver los problemas derivados de una disminución del tiempo de renuevo forestal: nunca se había desmontado mucho esta parte de la comunidad pues las aerofotos de un vuelo realizado en 1971 lo demuestran claramente y las tierras no ocupaban todavía fertilizante ni herbicida. Las técnicas tuvieron que adaptarse a un medio mucho más seco siendo el problema agronómico básico la ubicación del ciclo vegetativo de la milpa respecto a la estación de 
lluvias y la selección de variedades adaptadas.

Apenas alcanza a madurar el maíz de ciclo semi-corto ( 120 días) como el H. 507 sembrado por casi todos los productores. Con respecto al clima, una variedad precoz (90 días) sería mejor pero siendo de porte bajo, este tipo de variedades produce poco rastrojo, por lo que no conviene a los campesinos que tratan de alimentar su ganado.

No se puede alargar el ciclo de la planta mediante una siembra precoz antes de las primeras lluvias por el riesgo que tiene esta técnica, ya que es muy frecuente que suceda una pequeña sequía después de las primeras tormentas. Hay que sembrar cuando la tierra está bien mojada.

Si tardan las primeras lluvias, la floración del maíz que es la fase crítica para las plantas, se presenta en la suspensión de lluvias de agosto ("canícula"). Un stress hídrico en esta fase afecta definitivamente el rendimiento de grano. Según los campesinos el "año bueno" es cuando las lluvias empiezan a mitad de junio para sembrar a fines de junio ("el día de San Juan"). En los últimos siete años, sólo ocurrió una vez.

Así, aunque haya todavía monte "virgen" para desmontar, el sistema de cultivo bajo roza, tumba y quema en la costa es muy arriesgado y los rendimientos son bajos. Desde que se formaron nuevos pueblos en la costa, se pueden ver zonas en las cuales el renuevo forestal disminuye por la aceleración de la rotación forestal. Por tanto, se suman todos los factores limitantes observados en la sierra pero agudizados en este caso. Finalmente cabe señalar el fenómeno del desarrollo de pastizales también presente en la zona costera.

Las tierras planas de temporal

Aunque una parte de estas tierras ya se sembraban antes de que se formaran los pueblos, la mayoría fue destroncada en la medida que bajaron las familias a la costa.

a)Descripción del sistema

Trabajo de suelo: aunque todavía se encuentran arados de palo, el arado de hierro con vertedera lo sustituyó a partir de 1970 cuando el Banco empezó a trabajar en la zona. A partir de los años ochentas, mientras que se terminaba de construir la carretera costera, llegaron los primeros tractores. Ahora, la mayoría de las tierras planas de la costa están barbechadas con el tractor ( $y$ "los discos"). Los demás trabajos son manuales o con energía animal (escarda).

Fertilizantes: el uso de este insumo es todavía muy limitado. Veremos más adelante los problemas ligados a la fertilidad del suelo.

Lucha contra las malezas: aunque el arado de vertedera y los discos del tractor permitan un control más eficiente de las malezas que el arado de palo, se generalizó el uso de herbicidas: el Esterón y también el Gramoxone antes de arar la tierra. Cuando la milpa alcanza una altura de 70 a 80 
centímetros, se limpia a mano.

b) Problemas y reproductibilidad

Aparte de que permite un trabajo del suelo más profundo, el tractor reduce mucho el tiempo de trabajo necesario, lo que conviene a las unidades de producción para las cuales el costo de oportunidad del trabajo de la milpa es elevado. Además, el trabajo se lleva a cabo rápidamente, lo que permite una mejor elección de la fecha de siembra. En realidad, el hecho de que haya un solo tractor disponible y rentado para todos y de que haya que esperar las primeras lluvias para poder arar, no les permite a los campesinos escoger la época de siembra. Al contrario, la mayoría tienen que esperar mucho tiempo al tractor. El manejo de este medio de producción obedece más a criterios políticos - relaciones de poder, compadrazgo- que agronómicos y no ha provocado ningún mejoramiento del sistema de cultivo.

Otro de los problemas del cultivo año con año es la pérdida de fertilidad. Ahora bien, los fertilizantes no se utilizan mucho y los campesinos entrevistados siguen diciendo que todavía no se "cansan" esas tierras planas. Sin embargo, es de esperarse que la cantidad de humus en el suelo esté bajando de año en año. Con un trabajo de suelo menos profundo - arado y yunta-, la dis minución de esa tasa no sería tan rápida.

Sin embargo, es posible que la baja de fertilidad no sea tan fuerte, ya que si así fuera, los campesinos ya hubieran dejado de sembrar. En efecto, podemos suponer que haya aportaciones de materia orgánica por las aguas que bajan de los cerros, por lo que la ubicación de la parcela sigue siendo el factor más determinante.

Por otra parte, los problemas fitosa nitarios aparecen; con el cultivo año con año de la misma planta, se desarrollan las enfermedades y las plagas: gusanos, royas ("chahuistle"). El cultivo necesita así más productos químicos ("Foley", "Parathion") lo cual incrementa los gastos monetarios asociados.

Tomando en consideración estas limitaciones, es obvio que este sistema de cultivo necesita cada vez más medios de producción como tractor, fertilizante, herbicida, productos fitosanitarios con lo que se vuelve más y más costoso. Sin embargo, veremos más adelante que en estas tierras se está concentrando la producción residual de maíz de la comunidad. El tractor, que disminuye el tiempo de trabajo, y las posibilidades locales de venta de granos en los pueblos, crean condiciones de productividad menos desfavorables que en otras partes.

Las tierras de humedad

Son tierras ubicadas cerca de los ríos, principalmente en Cachán, que guardan humedad en toda la estación seca, permitiendo su cultivo. Ya estaban trabajadas desde antes por la gente que bajaba de vez en cuando de los ranchos de la sierra. Así, cada familia tenía unos surcos de humedad. 
Ahora, ya no quedan para los recién llegados.

En Cachán, la mayoría de esas tierras están cubiertas por el agua casi todos los años dejando arcilla y materia orgánica, que sirve de abono. En los demás casos, el problema de la fertilidad se plantea de la misma manera que en las tierras planas. Aunque estas tierras de humedad y riego sean muy limitadas, tienen bastante importancia por la variabilidad de cultivos que producen en la temporada seca.

Una parte está plantada con plátanos. Lo demás se siembra en enero o febrero con maíz y cultivos asociados. En invierno entra el tractor a arar y todavía no se ocupan fertilizantes ni herbicidas. En Cachán, cuando "pega bien", los rendimientos alcanzan 15 cargas/medida ( 5 toneladas por hectárea).

Esa cosecha llega a fines de las secas, cuando empieza a hacer falta el maíz del año pasado. Las hortalizas (sandía, pepino) son muy escasas en mayo y junio y se venden caros. Son importante fuente de ganancia, por su extemporalidad respecto a los cultivos de desmonte. Del mismo modo, el rastrojo ayuda cuando falta forraje al principio de las lluvias.

\section{ORIGEN DEL DESARROLLO TENDENCIAL DE LA GANADERIA Y ESPECIALIZACION REGIONAL}

\section{Ganadería y productividad diferencial. Estudio comparativo}

A lo largo de los apartados anteriores, se explicó que el sistema de producción que descansaba sobre la ganadería bovina de carne, tendía a desarrollarse en toda la comunidad a expensas del sistema de producción basado en el cultivo forestal y el pastoreo libre. Planteamos como hipótesis que era el sistema más eficiente económicamente el que sustituía paulatinamente a los demás sistemas. Ahora cabe preguntarse: ¿es realmente más eficiente el proceso de producción de los ganaderos?, ¿por qué?, ¿cuáles son los criterios y conceptos capaces de ayudarnos en la comprensión de tal fenómeno?

Desarrollaremos nuestro estudio a partir de dos ejemplos: trataremos de cuantificar las situaciones estudiadas de acuerdo con la información que tenemos. Nos limitaremos a ciertas aproximaciones, resultado de las comparaciones del producto bruto, de la remuneración del capital constante, del valor agregado y de la productividad del trabajo y del terreno. El cuadro 30 nos da el resumen de estos criterios económicos para los dos ejemplos estudiados (el detalle de los cálculos está en el anexo). 
Cundro No 30 RESUmen GenERAL

\begin{tabular}{|c|c|c|}
\hline Concepto & ejemplo 1* & ejemplo 2** \\
\hline PB & 230,000 & $2^{\prime} 420,000$ \\
\hline CP & 0 & 160,000 \\
\hline Cf & 20,000 & 630,000 \\
\hline CP + Cf $=$ CC & 20,000 & 790,000 \\
\hline VA & 210,000 & $1 ' 630,000$ \\
\hline $\begin{array}{c}\text { Productividad } \\
\text { del trabajo }\end{array}$ & 210,000 & 545,000 \\
\hline $\begin{array}{c}\text { Productividad } \\
\text { del terreno }\end{array}$ & 7,700 & 16,300 \\
\hline
\end{tabular}

- Caso de un sistema de policultivo y poliganadería. Descansa sobre el cultivo forestal y el pastoreo libre.

* Caso de un ganadero de San Pedro Naranjestil. Producción de animales jóvenes (1-2 años). Uso de cercas y cultivos forrajeros.

Producto bruto y valor agregado

La diferencia entre el producto bruto de las dos unidades de producción es muy importante (de 1 a 10) y da una primera idea acerca del contraste entre los dos sistemas de producción. En el caso del productor de maíz bajo roza, tumba y quema, la parte del autoconsumo representa la mitad del producto bruto, lo que significa que la diferencia entre el ingreso monetario es mucho más grande (de 1 a 20).

La relación de los valores agregados ilustra con más precisión los resultados económicos de las dos unidades de producción. Aunque en el primer ejemplo los gastos sean débiles, el valor agregado es ocho veces menor al del segundo ejemplo.

Productividad del trabajo y productividad del terreno

Estos criterios nos permiten entender la eficiencia económica de cada unidad de producción. No se trata de ingresos, de riqueza, sino de la eficiencia del trabajo hecho y la del terreno ocupado. Consideramos estos dos criterios como básicos para entender la dinámica general de los sistemas de producción.

La productividad del trabajo del segundo ejemplo es 2.5 veces más elevada que la del primero. Quiere decir que cuando un trabajador de la u.p. 1 produce una unidad de producto, uno de la u.p. 2 produce 2.5 unidades de 
producto en el mismo tiempo (cálculo en pesos). La misma cantidad de trabajo invertida en estas dos diferentes u.p. produce dos cantidades de producto distintas.

La productividad del terreno de la u.p. 2 es dos veces mayor a la de la u.p. 1. Quiere decir que una hectárea de la u.p. 2 produce dos veces más que una hectárea de la u.p. 1.

Pese a la imprecisión de los cálculos, se puede afirmar que más allá de la diferencia de producto bruto o valor agregado - diferencia de riqueza-, la relación de productividad del trabajo entre un ganadero y un agricultor "forestal" es obvia y caracteriza la mayor eficiencia del nuevo sistema de producción.

Al terminar la exposición de estos ejemplos, nos parece que el cercado del monte, las invasiones de tierra, el desarrollo de la ganadería tienen que analizarse en términos de productividad diferencial.

Además, hemos visto que la diferencia entre las productividades del trabajo - de 1 a 2.5 - es mayor que la diferencia entre las productividades del terreno -1 a 2 . Pensamos que la revolución agrícola que se está llevando a cabo en la comunidad no es fundamentalmente ni una intensificación ni una búsqueda de productividad del terreno (o por unidad de superficie), sino más bien, para muchas unidades de producción un aumento de la productividad del trabajo, en el seno de un sistema de producción que sigue siendo básicamente extensivo.

El cultivo de marihuana puede ser parte integrante del sistema y lleva una productividad del trabajo elevadísima. Entre la siembra y la cosecha, es poco el trabajo que hay, aparte de la vigilancia de la parcela y la relación de productividad del trabajo, con el ejemplo 1 antes citado, puede ser de 100 a 1 o de 1000 a 1.

\section{Inversión de capital y fuentes de acumulación}

Para tener una idea del capital necesario al desarrollo de un nuevo sistema de producción que descansa sobre la cría de animales, se propone volver a los dos casos ya mencionados en el párrafo anterior.

La inversión para la ganadería representa una inmovilización de capital muy elevada que no tiene nada que ver con el capital manejado en una unidad de producción descansando sobre el cultivo del maíz bajo roza, tumba y quema y el pastoreo libre (cabras). La relación entre estas inversiones es de 50 por 1.

En cuanto a las cercas, cabe hacer hincapié en el cambio de material utilizado (cerca de madera y cerca de púas), y su significación en términos de capital inmovilizado. El cuadro 32 da los gastos de construcción de las cercas, según el tipo del material utilizado (nos referimos a las cercas ilustradas en 
Cundro No 31

\begin{tabular}{|c|c|c|}
\cline { 2 - 3 } \multicolumn{1}{c|}{} & ejemplo 1 & ejemplo 2 \\
\hline $\begin{array}{c}\text { capital vivo inmo- } \\
\text { vilizado (ganado...) }\end{array}$ & 50,000 & $2^{\prime} 500,000$ \\
\hline $\begin{array}{l}\text { capital muerto inmo- } \\
\text { vilizado (cercas...) }\end{array}$ & 100,000 & 800,000 \\
\hline Total & 150,000 & $3^{\prime} 300,000$ \\
\hline
\end{tabular}

la gráfica 32).

El costo monetario de una cerca de alambre de púas es bastante elevadc (en 1985, 100 pesos por metro en el caso I). Cercar un potrero de 25 hectáreas representa un desembolso de alrededor de 200,000 pesos. Contando con 3 vacas a medias, la u. p. 1 alcanzaría a juntar este dinero en seis u ocho años con una acumulación en base a estas 3 vacas (en el caso de las hembras nacidas que se quedan en la unidad de producción. Ver anexo).

Así, la modificación del sistema de producción y la generalización de cercas muy largas y muy costosas, necesitaron inversiones bastante importantes, difíciles de alcanzar en el sistema de producción tradicional.

Para hacer esta inversión, las fuentes locales -endógenas- de acumulación no estaban adaptadas. La milpa forestal no permitía la producción de excedentes importantes. Casarse y recibir un becerro como regalo o conseguir unas vacas a medias, no permitían tampoco una acumulación rápida. Las fuentes de acumulación fueron más bien exteriores, exógenas y detentadas por la gente de razón originaria de Coalcomán. Allí la ganadería ya se había desarrollado en una sociedad agraria mestiza muy distinta, descansando sobre el régimen de la propiedad privada. Es probable que estas familias llegaran a la comunidad de Pómaro con un capital ya establecido, pre-acumulado

-sea como pequeño propietario, vendiendo sus tierras para ir a la comunidad de Pómaro donde la renta de la tierra era nula,

-sea con un capital acumulado a lo largo de los años con el trabajo a medias en la ganadería extensiva de Coalcomán. (Aunque a medias, la productividad del trabajo sigue siendo superior), 
CuAdro Ne 32

\begin{tabular}{|l|c|c|c|c|c|}
\hline \multicolumn{1}{|c|}{ Tipo de cerca } & & I & II & III & IV \\
\hline \multirow{2}{*}{$\begin{array}{l}\text { Costo monetario } \\
\text { por metro \$/m. } \\
(1985)\end{array}$} & $\begin{array}{c}\text { Mano de } \\
\text { obra }\end{array}$ & - & 87.5 & 87.5 & 175 \\
\cline { 2 - 6 } & Total & - & 100 & 87.5 & 190 \\
\hline $\begin{array}{l}\text { Costo de oportunidad del } \\
\text { crabajo \$/m. (1985) }\end{array}$ & $0-100$ & - & $0-50$ & 15 \\
\hline
\end{tabular}

-sea con un capital acumulado en Estados Unidos. El movimiento migratorio de los mestizos de Coalcomán "al norte" era muy importante desde los años cuarentas.

Así, los arquitectos de esta revolución agropecuaria fueron los mestizos, no por tener "la razón" sino por gozar de mejores condiciones para llevar a cabo inversiones e inmovilización de capital. Esta superioridad económica se volvió hegemónica en la comunidad de Pómaro en la cual los conflictos, las desigualdades, y una organización comunitaria a lo mejor debilitada coadyuvaron a la pérdida del poder de la sociedad indígena.

\section{Especialización regional}

Cambiando de nivel de observación, y pasando a un nivel más global o más regional, entendemos que la selección de dos actividades - cría de animales y cultivo de marihuana-, fue el resultado de una confrontación en el mercado entre las producciones de la sierra y las del resto del país traídas con el comercio y la red de comunicaciones. Así, una tras otra se abandonaron y se están abandonando muchas actividades por no hacer competencia con los productos recién llegados a la sierra.

En cuanto a la mercancía ligera - textiles, abarrotes...-

Los intercambios con el mercado regional y, por lo mismo fuera de la comunidad se ampliaron con el desarrollo de las pistas aéreas a partir de los años sesentas. Hay que decir que a fines de los años setentas y mucho antes de que se terminara la carretera costera, cada pueblo contaba con su campo 
de aviación lo que permitía a la gente viajar de vez en cuando a las ciudades circunvecinas, llevar enfermos o heridos y traer mercancía mediante el pago de un flete todavía barato.

Así, la producción local de algodón y de ropa no soportó la competencia de la ropa traída de Colima, hecha bajo condiciones de productividad mucho mejores.

De la misma manera, se disminuyó o desapareció la producción de tabaco, de dulces (piloncillos...), de bebidas alcohólicas (tuba), etc.

Los transportes terrestres y la especialización regional

Es demasidado pronto para percibir con precisión los cambios derivados de la carretera costera recién terminada. Sin embargo, es probable que sus efectos directos o indirectos sean múltiples y determinantes para la evolución socioeconómica de la comunidad.

Antes de que pongamos atención en estos efectos, cabe repetir que esta región estaba integrada al mercado regional y nacional mucho antes de que se abriera la carretera y que el movimiento migratorio hacia la costa no tuvo nada que ver, al principio, con la construcción de la carretera.

En realidad, la llegada de esta vía de comunicación a la comunidad permitió que se hiciera más fácilmente la bajada a la costa de los indigenas desposeídos. Proporcionó empleos y favoreció una cierta diversificación de las actividades alternativas a las actividades campesinas. Al final, permitió salidas a Tecomán o a Lázaro Cárdenas, polos de atracción de la mano de obra.

Al nivel de la unidad de producción y con la construcción de la carretera costera, llegaron los granos básicos de fuera. La producción de maíz entró en competencia directa con la producción del estado de Colima y del resto del país, cuyo precio depende del nivel del precio de los excedentes mundiales, el cual es muy bajo por estar producido en condiciones de productividad altisima en comparación con las de la Sierra Madre del Sur. A pesar del aumento reciente al precio del maíz, su cultivo tiende a disminuir en la comunidad de Pómaro.

-El costo de oportunidad del trabajo de la milpa se vuelve muy elevado en comparación con el precio de venta de Conasupo recién instalada en la costa.

- Aunque la producción de maíz sigue en las partes más favorables de la comunidad como son las partes más altas y las llanuras costeras semi-mecanizadas, la región se ha vuelto importadora neta de maíz en los dos últimos años.

-El único caso anterior de importación de maíz había sido durante la sequía de 1973-74 cuando el gobierno mandó al puerto de Maruata un barco con maíz.

En la gráfica 40 aparecen las ventas mensuales de maíz en las 
岧

Grafica No 40: Ventas mensuales de maiz en unas tiendas Conasupo de la comunidad de Pomaro

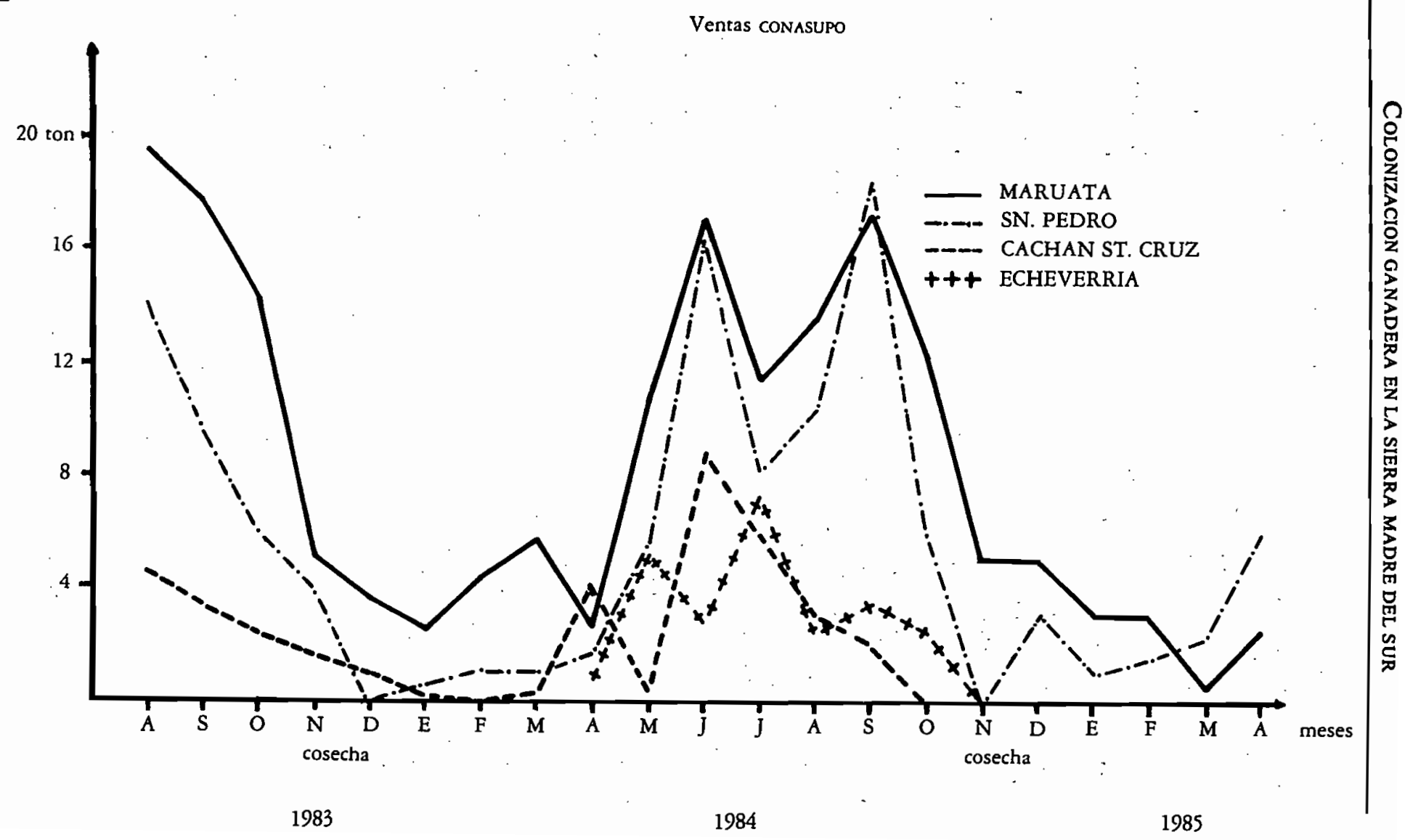


principales tiendas Conasupo de la comunidad. Ilustran el hecho de que ahora la producción local de maíz no alcanza para más que cinco meses, siendo muy espectacular el crecimiento de las ventas a fines de las secas. En 1984, se vendieron 73 toneladas de maíz, proveniente del estado de Colima, en la tienda de San Pedro Naranjestil lo que representó unos $130 \mathrm{Kgs}$. por persona o sea, como la mitad de su consumo anual. En Maruata se vendieron 110 toneladas, o sea $300 \mathrm{Kgs}$. por persona: una cantidad muy importante que pone de relieve dos fenómenos:

-muchas familias dejaron de sembrar el maíz;

-familias de Pómaro bajaron a Maruata para comprar maíz.

Siendo así de desiguales las condiciones de productividad del trabajo para el maíz entre la sierra y las tierras de Colima, es obvio que la milpa no puede ser de las actividades que se están desarrollando en la comunidad.

\section{Frutas y verduras}

Los campesinos de las comunidades siempre han tenido algunos frutales en su solar o alguna palma de la costa. La formación de los pueblos de la costa y la valoración de las pocas tierras de humedad y de la orilla de los ríos, ocasionaron un cierto desarrollo de los frutales y de las hortalizas. Pero la configuración del terreno no permite que estos cultivos alcancen un desarrollo significativo. Pueden proporcionar buenas utilidades, tomando en cuenta los precios elevados que cobran los vendedores provenientes de Colima. Pero los productores no lograron vender sus productos muy lejos puesto que al precio del mercado de Colima, trabajan en condiciones de productividad muy desventajosas.

\section{SISTEMAS DE PRODUCCION Y ESTRATEGIAS CAMPESINAS}

Los cambios en la manera de aprovechar los recursos del medio tuvieron efectos inmediatos en toda la comunidad de Pómaro, aunque se trate de procesos que aún no han concluido. Una nueva forma de ocupación del territorio impuso movimientos migratorios, "colonización" de la costa y formación de nuevos pueblos. Cada familia tuvo que adaptarse y participar en estos cambios. Desarrollaron así sistemas de producción nuevos en relación con las nuevas condiciones de producción. Identificamos 9 tipos de sistemas de producción, bastante distintos, siendo cada uno de ellos la expresión de una estrategia campesina de producción. Con esta clasificación de los sistemas de producción, no queremos decir que no haya cierta diversidad al interiur de un mismo tipo, sino más bien que todos los productores ahí agrupados, tienen una misma estrategia de producción. El cuadro 33 expresa el número de entrevistas realizadas en cada pueblo 
correspondientes a los diversos tipos de sistema de producción. Es obvio que este cuadro no da resultados estadísticos en cuanto a la importancia relativa de cada tipo de sistema de producción, puesto que la muestra no es representativa cuantitativamente. Sin embargo, la repartición geográfica desigual de los distintos sistemas de producción nos permitirá realizar un mapa de los mismos lo que da una idea de su importancia respectiva.

\section{CuADro No 33}

EnTRevistas Realizadas en los pUeblos de la COMUNidad de Pomaro, SEGUN LOS SISTEMAS DE PRODUCCION

\begin{tabular}{|c|c|c|c|c|c|c|c|c|c|c|c|}
\hline $\begin{array}{c}\text { Sistemas de producción } \\
\text { Pueblos/Ranchos }\end{array}$ & Ia & Ib & Ic & IIa & Ilb & IIc & IId & Ile & IIf & Total \\
\hline $\begin{array}{c}\text { San Pedro } \\
\text { Naranjestil }\end{array}$ & - & 4 & 4 & 8 & 6 & - & 1 & - & - & - & 23 \\
\hline La Parotita & - & - & - & - & - & 2 & - & 2 & - & - & 4 \\
\hline Pómaro & - & - & - & - & 4 & 3 & - & 1 & - & 1 & 9 \\
\hline Las Campanas & - & 2 & - & - & 1 & - & - & - & - & - & 3 \\
\hline Cachán & - & - & - & - & 3 & 1 & 2 & 4 & - & - & 10 \\
\hline Maruata & - & - & - & - & - & - & 2 & 4 & 5 & - & 11 \\
\hline Total & - & 6 & 4 & 8 & 14 & 6 & 5 & 11 & 5 & 1 & 60 \\
\hline
\end{tabular}




\section{Comentarios a CUADro № 33}

Nota: Ia.- Ganaderos. Hatos importantes. Giandes superficies divididas en potreros cercados.

Ib.- Sistema de producción ganadera con limitación fuerte de superficie.El maíz todavía juega un papel importante.

Ic.- Medieros. Actividades diversificadas (artesanía/asalariada).

Ila.- Sistema de policultivo y poliganadería. Este sistema descansa todavía sobre elcultivo del maíz forestal (bajo tumba rosa y quema) y el libre pastoreo.

Ilb.- Sistema desarrollando la cría de cabras. Especialización ganadera en terruño poco cercado.

IIc.- Sistema de producción vegetal. Utilización de las Jlanuras costeras y orillas de río, con sistema de cultivos mecanizados (uso del tractor para el trabajo del suelo). Asociación posible con la ganadería.

IId.- Evolución del tipo IIc hacia una especialización ganadera. La pastura sembrada tiende a sustituir a la milpa.

Ile.- Combinación de actividades no-agrícolas: Pesca; negocio, cuadrillas de carretera. La agricultura y la ganadería pueden tener un papel complementario pero residual.

IIf.- Sistema de producción descansando sobre una intensificación del cultivo de maíz en la sierra mediante la introducción del trabajo del suelo en las vertientes de los cerros. Transición del sistema de cultivo forestal a un cultivo continuo. Asociación posible con la ganadería a pequeña escala, limitación fuerte de superficie.

El mapa 22 da una idea de la repartición de los sistemas de producción en la comunidad, al registrar cinco zonas distintas. Cada zona corresponde a una forma de valorización del espacio, a un sistema social de producción que es la expresión de una combinación de varios sistemas de producción.

\section{Zona noroeste. El terruño de San Pedro Naranjestil}

Representa más de la mitad de la comunidad. Es la zona invadida por los ganaderos mestizos que vinieron de los municipios de la sierra (Coalcomán). Las transformaciones descritas anteriormente se llevaron a cabo totalmente. El espacio está privatizado, cercado y dominado por el sistema de producción Ia. Estos ganaderos cuentan con la mano de obra constituida por 
MAPA № 22: REPARTICION DE LOS SISTEMAS DE PRODUCCION eN LA COMUNidad DE Pomaro

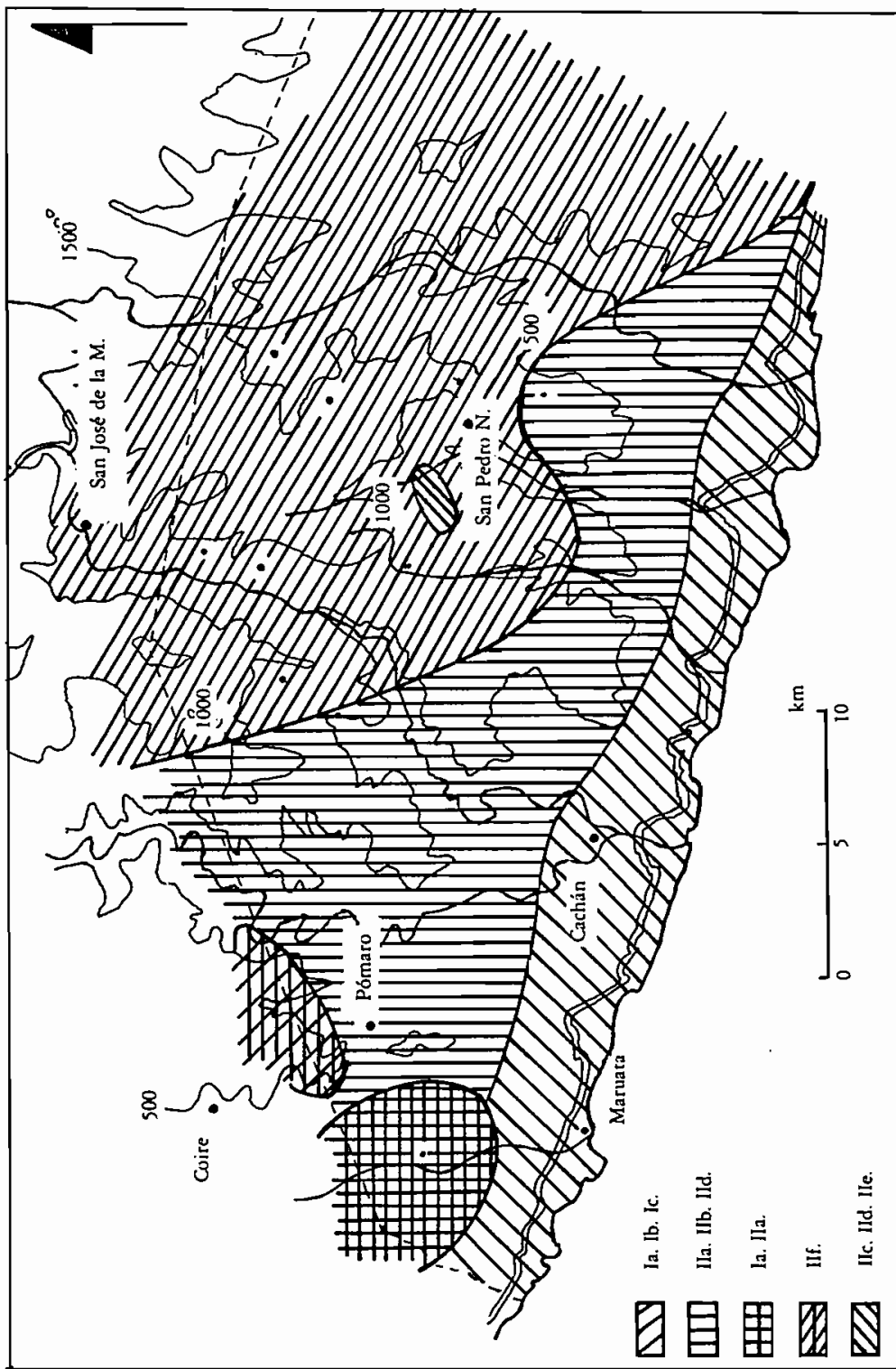


las familias sin tierra (medieros, peones, tipo Ic). Unas cuantas familias controlan el terruño y el pueblo de San Pedro Naranjestil. Las demás familias, principalmente mestizos que llegaron hace pocos años cuando ya no había grandes espacios para cercar o indígenas desposeidos, tratan de mantener algunas vacas en potreros chicos en los que siguen sembrando el maíz bajo roza, tumba y quema con fines de autoconsumo y, de obtener rastrojo. La limitación de la superficie agudiza el problema de la degradación del monte ${ }^{40}$ lo que impone un aumento de los costos monetarios del cultivo del maíz. Unos tienen a veces que desmontar a medias con otro dueño para dejar crecer el monte, en su propio potrero. Este sistema de producción (Ib) no alcanza a diversificarse mucho por las limitaciones impuestas por el sistema Ia; el encercamiento del monte no permite la cría de cabras o puercos fuera del solar de la casa.

En esta zona, muchas familias no tienen acceso al espacio. No tienen tierra. La mayoría son familias indígenas que fueron desposeidas de sus recursos cuando se cercó el monte. No alcanzaron a volverse dueños de potreros. Son medieros (tipo Ic) o prones. Trabajan en los potreros privatizados de los ganaderos (Ia). Muchas veces, la artesanía se vuelve para ellos la actividad principal (adobe, sudadero, etc...). Tampoco pueden tener ganado puesto que se acabó el pastoreo libre.

Muchos indígenas prefirieron irse a lugares todavía no cercados hacia la costa (véanse las migraciones al interior de la comunidad).

Solamente una pequeña zona cerca de San Pedro queda bajo el control de unas familias indígenas desarrollando el sistema de producción, Ila (ver las formas de resistencia al cercarse el monte).

\section{Terruño de Pómaro y sierra occidental de la comunidad}

Esta zona puede ser considerada como centro histórico de la comunidad. El espacio no está todavía totalmente cercado y privatizado. El maíz forestal y el pastoreo libre siguen siendo dos elementos básicos de los sistemas de producción. El tipo IIa domina todavía las formas de valoración del espacio. Viene del sistema de producción que prevalecía en la comunidad en los años cuarentas aunque sufrió modificaciones. El cercado de algunas partes con alambre de púas no significa siempre una privatización del espacio, aunque exprese una tendencia obvia, sino también una forma de resistencia ante el expansionismo de los sistemas de producción ganaderos (Ia) como en Los Encinos. Aquí ha disminuído fuertemente la diversidad de las producciones que caracterizaba al antiguo sistema. Sin embargo, la valorización por una

40. Sustitución del monte alto ("breña") en monte bajo ("chapón"). 
misma familia de varios pisos ecológicos sigue siendo muy importante gracias a las relaciones familiares y de compadrazgo. Estas relaciones se desarrollan con las unidades de producción de la costa. Una familia recién llegada a Maruata, tendría sus padres en Pómaro y sus abuelos en un rancho más arriba, en la sierra. A parte de los intercambios de productos que se pueden así realizar, aumentan las posibilidades de diversificación de la ganadería: se pueden llevar cabras a medias con un familiar a una zona de la sierra todavía no cercada, mientras que las vacas se quedan en un potrero cercado de la costa. Estas relaciones sociales de producción entre familiares o compadres no tienen mucho que ver con las que se encuentran en la zona 1 (San Pedro Naranjestil) aunque parezcan a veces similares.

Hemos visto que la cría de cabras se había desarrollado ampliamente desde hace algunos años. Así, algunas unidades de producción se especializaron en ello olvidando las demás actividades (sistema de cultivo IIb). Formaron hatos importantes de 20 a 80 cabezas y por lo que la ganadería caprina pudo desarrollarse en las zonas no-cercadas puesto que mantener cabras dentro de un potrero era muy difícil y necesitaba grandes inversiones (cercas de madera con 8 hilos de púas). En la zona de San Pedro Naranjestil, los ganaderos no permiten la cría libre de cabras y matan a las que ven en sus potreros. La cría de cabras se presenta entonces como una actividad típicamente "indígena" puesto que no es compatible con el desarrollo de la ganadería bovina a gran escala. Esta actividad tuvo éxito en las partes no invadidas de la comunidad debido a que el ganado caprino es menos costoso que el ganado bovino además de que se adapta al libre pastoreo. Aunque unos pocos se dediquen exclusivamente a la cría/compra-venta de cabras, esa actividad queda por lo general asociada con otras actividades, como la ganadería bovina a escala reducida.

\section{Zona costera. Terruños de Maruata y Cachán}

Las pequeñas llanuras costeras y las orillas de los ríos ya estaban cultivadas mucho antes de que se fundaran los pueblos de la costa. Pero, cuando las primeras familias indígenas bajaron a establecerse a la costa, ante la presión que imponía la situación de la tenencia de la tierra en el norte de la comunidad, tuvieron que adaptarse a un medio distinto, más difícil que la sierra en cuanto a las condiciones climatólogicas.

Se diferenciaron sistemas de producción básicamente "costeños". Estas pocas familias tomaron las tierras más favorables y planas de la costa: llanuras y orilla de ríos. Destroncaron más tierras, entraron con el arado, luego con el tractor. Estas unidades de producción (tipo IIc) descansan todavía sobre el cultivo de maíz a "gran escala" ( $5-20 \mathrm{Has}$.) que tiene condiciones de productividad menos desfavorables aunque sea riesgoso el 
clima. También se desarrolló un poco el riego y las plantaciones de frutales.

Siendo muy limitada la superficie de estos terrenos planos, este tipo de sistema de producción cuenta con un número muy limitado de unidades de producción. Por la misma razón, no podía desarrollarse mucho. Además, la pastura (zacatón) tiende a sustituir al maíz en estas tierras planas de la costa. Al sembrar pastura se cambia la lógica del sistema de producción que se vuelve ganadero (tipo IId). El cultivo del maíz disminuye y se reduce a lo necesario para el gasto de la familia o desaparece siendo más económico -en término de costo de oportunidad del trabajo de la milpa-comprarlo en la tienda Conasupo.

El desarrollo de este nuevo sistema de producción en la costa no tiene más que unos 10 años, a partir de que el Banco apoyó a la comunidad, aportando capital para que fundaran grupos colectivos de ganadería en Maruata y Cachán. El proyecto colectivo fracasó debido a que el ganado no estaba adaptado, a la sequía de 1974 , a la falta de organización, etc. y se repartieron las vacas que quedaron después del pago. Así se están desarrollando otra vez pequeños hatos individuales. Los que tienen acceso a las tierras planas, pueden mantener más animales cuando siembran zacatón. Se observa que los hatos más grandes pertenecen a las familias que tenían antes un sistema de producción vegetal (IIc) descansando sobre las mejores tierras de la costa.

Muchas familias de esta zona costera no son ni agricultores ni ganaderos. Las pocas tierras favorables no están repartidas en forma pareja y pocas familias gozan de este privilegio. Hay peones y medieros, pero no de igual forma que en la zona invadida de San Pedro. Cabe señalar que la zona costera fue favorable a la diversificación de las actividades no agropecuarias. En 1973 se fundó la cooperativa pesquera de Maruata y muchos hijos de comuneros dejaron el campo para volverse pescadores. La pesca ha podido proporcionar altos ingresos a los miembros de la cooperativa por lo menos durante la temporada de invierno. Podían ganar hasta 10,000 pesos diarios en 1985 mientras que un peón ganaba solo 1,000 pesos.

A hora que se acaba de terminar la carretera costera (Tecomán-Lázaro Cárdenas) se multiplicaron las oportunidades de trabajo asalariado debido a la construcción misma de la carretera, fuente importante de trabajo que hizo bajar a la costa a muchas familias. Para éstas la carretera constituyó una fuente importante de acumulación que hizo posible la formación de pequeños hatos. Otras oportunidades de trabajo fueron el mantenimiento de la carretera, las tiendas y las facilidades para salir a buscar trabajo en el distrito de riego del Ranchito o de Tecomán. Agrupamos estas familias en el grupo Ile aunque muchas de estas familias dejaron de ser unidades de producción agropecuarias. 


\section{Zona frontera con la Comunidad de Coire. Sistema de producción IIf}

Este sistema de producción descansa sobre un sistema de cultivo nuevo: el cultivo de los cerros año con año mediante el trabajo del suelo.

Cabe hacer énfasis en el significado de tal evolución.

Un trabajo del suelo con yunta de bueyes y arado de palo, siempre se ha llevado a cabo en las parcelas planas cerca de los pueblos. Pero el caso estudiado aquí tiene otro significado. Se trata de la transformación del sistema de cultivo forestal en las vertientes de los cerros, es decir una intensificación del cultivo de maíz en la sierra. Se observa, sobre todo en una zona fronteriza entre las dos comunidades de Pómaro y Coire en donde la presión sobre la tierra es muy fuerte. Este fenómeno puede ser interpretado como una tentativa de apropiación de un pedazo de monte cercado con alambre de púas de unas 10 ó 15 Has., que no tiene nada que ver con los grandes potreros de San Pedro Naranjestil. La ganadería puede estar asociada al sistema de cultivo con el aprovechamiento del rastrojo. La diferenciación de este sistema de producción tiene muy pocos años (5-6) pero es probable que se vaya a desarrollar más en ciertas zonas conflictivas de la comunidad. El caso estudiado puede ser considerado como precursor de una nueva estrategia.

\section{Zona de Las Campanas}

Aunque esté ubicada en la parte poniente de la comunidad todavía no cercada en su totalidad, este rancho tiene poblamiento mestizo y se encuentra dentro de la clasificación de sistemas de producción Ia, aunque con sistemas diversificados (IIa). Aunque parezca otro foco de la expansión del sistema de producción Ia, nos parece que pueda haber un convenio tácito de no-agresión entre este rancho y el resto de la comunidad.

En síntesis, el estudio de la diferenciación de los sistemas de producción nos presenta una aparente contradicción: la especialización regional -cría de becerros- se está llevando a cabo mediante una diversificación de los sistemas de producción. Las invasiones de tierra y los movimientos de población hicieron surgir muchas formas nuevas de explotación y aprovechamiento del medio, cada una adaptándose a un medio físico reducido y a condiciones agroecológicas y socio-económicas distintas. Pero en realidad, en cada forma de explotación, se identifica una preocupación cada vez mayor por la ganadería, como si cada una de ellas fuera un medio de adaptación y de participación en la especialización regional. 


\section{CONCLUSIONES}

El conjunto de los cambios que se llevaron a cabo en los últimos 30 años caracterizan una verdadera revolución agropecuaria. Una colectividad campesina se ha vuelto sociedad de ganaderos. Esta revolución fue lenta, contradictoria y todavía está lejos de acabar con el sistema de producción que descansaba sobre el cultivo de maíz bajo roza, tumba y quema y pastoreo libre. Más aún, es parcial e incompleta en la parte costera de la comunidad cuyas condiciones naturales son más difíciles.

Sin embargo, se detectó una preocupación cada vez mayor por la ganadería en la mayoría de los sistemas de producción. $Y$ las estrategias campesinas de producción descansan, por lo general, sobre la búsqueda de una major productividad del trabajo.

Por tanto, es poco probable que una política agrícola que no tome en cuenta esta preocupación, tenga éxito: intensificación del cultivo de maíz o desarrollo de micro-obras de riego en la sierra como terrazas, canales, desempiedre, etc. De la misma manera, es obvio que, el sistema de producción tradicional — rotación forestal larga, pastoreo libre - no logró y no logrará dar a los comuneros el poder ecorómico necesario para impedir la invasión de la comunidad por parte de los ganaderos mestizos. Al contrario, el cercar el monte y desarrollar la ganadería permite duplicar la productividad del trabajo. Para los comuneros preocupados por la invasión de sus tierras, podría ser el último medio de conservar su terruño. La cría de cabras, en pastoreo libre, no logrará acabar con las invasiones de tierra mientras que haya ganaderos más poderosos para cercar. Pero ¿con qué capital se puede cercar y comprar ganado? El retraso en la acumulación de capital y las condiciones de productividad desfavorables en la costa no lo permitirían excepto si hubiera políticas agrícolas capaces de invertir las fuentes de acumulación: como el crédito refaccionario para cercas y ganado.

Otra alternativa sería la reorientación hacia otras actividades no agropecuarias como la pesca, actividad ya desarrollada con bastante éxito, o el turismo. Pero el desarrollo probable de grandes proyectos turísticos no controlados por la Comunidad le quitarían lo poco que queda en sus manos: la franja costera. 


\section{CONCLUSIONES}

Las técnicas de cultivo y de manejo del ganado no son neutrales. Cuando el ganadero de Coalcomán facilita una siembra a su mediero, éste tiene que regar semilla de jaragua en su milpa a fin de que haya más pastura para los animales. Allí, a nivel del sistema de cultivo, es donde aparece con más claridad el enfrentamiento entre dos lógicas productivas distintas, opuestas, dos formas antagónicas de aprovechamiento del medio: sembrar maíz para alimentar a la familia o aumentar la capacidad forrajera de un potrero. De la misma manera, el cercar los terrenos comunales de la costa acaba con la coherencia de un sistema de producción basado en el cultivo forestal y el pastoreo libre; así de un lado, tenemos el bosque, principal "medio de producción" puesto que la reproductibilidad del sistema "tradicional" descansa sobre él, y, del otro, la pastura, fundamento de la ganadería y sembrada a expensas del bosque.

En ambos casos, la confrontación entre dos conjuntos de prácticas cuyos objetivos son antagónicos llega a la dominación absoluta de una sola forma de aprovechamiento del medio: la ganadería de cría para carne.

En ambos casos, la reproductibilidad de las unidades de producción así dominadas, se vuelve cada día más difícil. Los productores tienen que gastar más dinero y trabajar más para mantener a flote un sistema de producción basado en la milpa y que cada vez produce menos. Al final, los medieros se salen del rancho, los indígenas "huyen" hacia la costa. Desaparecen del paisaje agrario como productores agrícolas, cuando no logran volverse ganaderos ellos mismos. No se trata de consecuencias de la expansión ganadera sino de elementos constitutivos de un mismo desarrollo multifacético.

Los dos casos estudiados representan dos aspectos de un solo y único movimiento histórico de especialización regional hacia formas de ganadería poco intensificadas. Dicho movimiento está basado en una extensión horizontal de las superficies dedicadas al ganado, por lo que el aumento de la productividad del trabajo tiende en realidad a fomentar una extensificación 
de los sistemas de producción. El movimiento tiene raíces históricas en el fenómeno de "colonización" de las tierras tropicales, iniciada a fines del siglo XIX.

En aquella época, con lo poco que tenían los primeros arrieros de Cotija o los peones o arrendatarios de las haciendas del sur de Jalisco, al llegar a la sierra de Coalcomán, alcanzaron a comprar terrenos muy extensos. Años después, el fenómeno observado es muy similar; con la venta de un pedazo de tierra o de alguna vaca, el minifundista o mediero de Coalcomán alcanzaba, en 1960, a comprar un solar en los pueblos indígenas del municipio de Aquila y una decena de rollos de alambre de púas. Ambos casos corresponden a la confrontación entre dos niveles diferentes de acumulación de capital. La diferencia, aún muy reducida, basta para que el sistema de producción que cuente con más capital se expanda a costa del otro. Además, las condiciones de acumulación diferencial, generadas por esta diferencia inicial y por la productividad diferencial del trabajo entre ambos sistemas, acentúan el desnivel entre los que logran aumentar su capital productivo, que son los ganaderos, y los que "consumen" sus medios de producción. Estos últimos, que son los medieros y los indígenas no logran incorporarse a la dinámica de acumulación (ganaderización), y viven un proceso de pauperización progresiva.

Podemos afirmar, que las migraciones representan un elemento estructural del sistema agrario y de su evolución. El migrante que menos oportunidad tenía en su región de origen, puede al llegar a una región menos poblada, volverse más poderoso e imponer un nuevo modo de aprovechamiento del medio, gracias a que la renta de la tierra y el nivel de capitalización de los sistemas de producción son allí más baios. 

TERCERA PARTE

DIFERENCIACION CAMPESINA EN AREAS FRUTICOLAS 
. 


\section{INTRODUCCION}

Los capítulos VI y VII abarcan el problema de la "respuesta" de los sistemas de producción a la introducción y al desarrollo de un cultivo específico: en el primer caso, el aguacate en la parte occidental de Michoacán, objeto de una especulación muy fuerte por parte de los productores, y en el segundo, el mango en las vertientes de la tierra caliente, promovido por el Estado.

En ambos casos hay una difusión muy exitosa del nuevo cultivo. Pero cabe preguntarse: ¿Cuáles son las condiciones que permiten a los sistemas de producción incorporar al nuevo cultivo? ¿Cómo cambian las estrategias campesinas en tal forma que adoptar un cultivo nuevo se convierta en un objetivo para determinados productores?

En ambos casos, se trata de plantaciones, que requieren una inversión tanto más importante, cuanto que se necesita esperar varios años hasta la primera cosecha. En estas condiciones, ¿Qué tipo de productores podían realmente beneficiarse del nuevo cultivo? ¿Cómo se había hecho la acumulación previa necesaria para la inversión? Consecuentemente, ¿ habrá de frenar una aceleración de la acumulación diferencial, muy previsible con la introducción de una actividad remuneradora?

En ambos casos, la acumulación previa se logra mediante las mismas actividades: ganadería y cultivo de la caña de azúcar. Pero en cada lugar la especificidad del proceso de producción y transformación de la caña, y luego la especificidad del nuevo cultivo en cuanto a organización del trabajo y características económicas llevan a una evolución totalmente diferente de los sistemas de producción. En un caso hay una transformación acelerada, en el otro la existencia de sistemas de producción muy estables matiza y contiene el desarrollo del cultivo con consecuencias muy distintas sobre la acumulación diferencial. 


\section{CAPITULO VI \\ EL AUGE DEL AGUACATE \\ ¿HACIA QUE TIPO DE DESARROLLO? (MUNICIPIO DE ATAPAN)}

Jean Damien de Surgy

Rocío Martínez $\mathrm{K}$.

Thierry Linck $\mathbf{M}$.

\section{INTRODUCCION}

El cultivo del aguacate se ha calificado como "oro verde" de Michoacán. Tal riqueza puede significar mucho en los lugares donde se produce el aguacate: impulso al empleo en el medio rural, repercusión sobre las fuerzas productivas de la agricultura, incremento del ingreso de los campesinos y por lo tanto de la demanda solvente, aumento de excedente agrícola disponible para nuevas inversiones, factores que contribuyen a fomentar nuevas actividades, etc., en una palabra, un desenvolvimiento económico, un "desarrollo" que puede beneficiar a todos.

Sin embargo, a escala más detallada se observa que el cultivo del aguacate se introduce en lugares donde existía cierta organización del trabajo en la agricultura, con una distribución del esfuerzo entre productores a veces compleja y una diferenciación social marcada ya que, unos carecen de tierras y otros, de agua o de recursos financieros. Así, se puede prever que en Atapan el aguacate benefició de igual manera a los diferentes grupos que, participando en la valorización del terruño, componen su campesinado.

El cultivo del aguacate puede identificarse fácilmente como actividad rectora del sistema social de producción en Atapan. Nos importará entonces evaluar la amplitud de su impacto y su poder transformador en las relaciones de producción sea en el acceso a los recursos, en la repartición de la riqueza, en el papel que desempeña en la difusión del cambio tecnológico, o en la importación de insumos y tecnología,...etc. En fin, nos interesa porque el desarrollo local no sólo se evalúa por el incremento global del ingreso rural sino también por su repartición entre los agentes económicos, por la naturaleza de las nuevas expectativas que se abren y por la evolución del grado de autonomía de los campesinos, así como su capacidad de "autodeterminación" de las actividades que desempeñan. 
Atapan: aguacate entre bosque y caña

Atapan, tenencia del municipio de Los Reyes, Michoacán, es un pueblo de más de 2,000 habitantes, ubicado en la vertiente occidental de la Sierra Tarasca, que domina el Valle de Los Reyes (véase mapa 23). En la Sierra

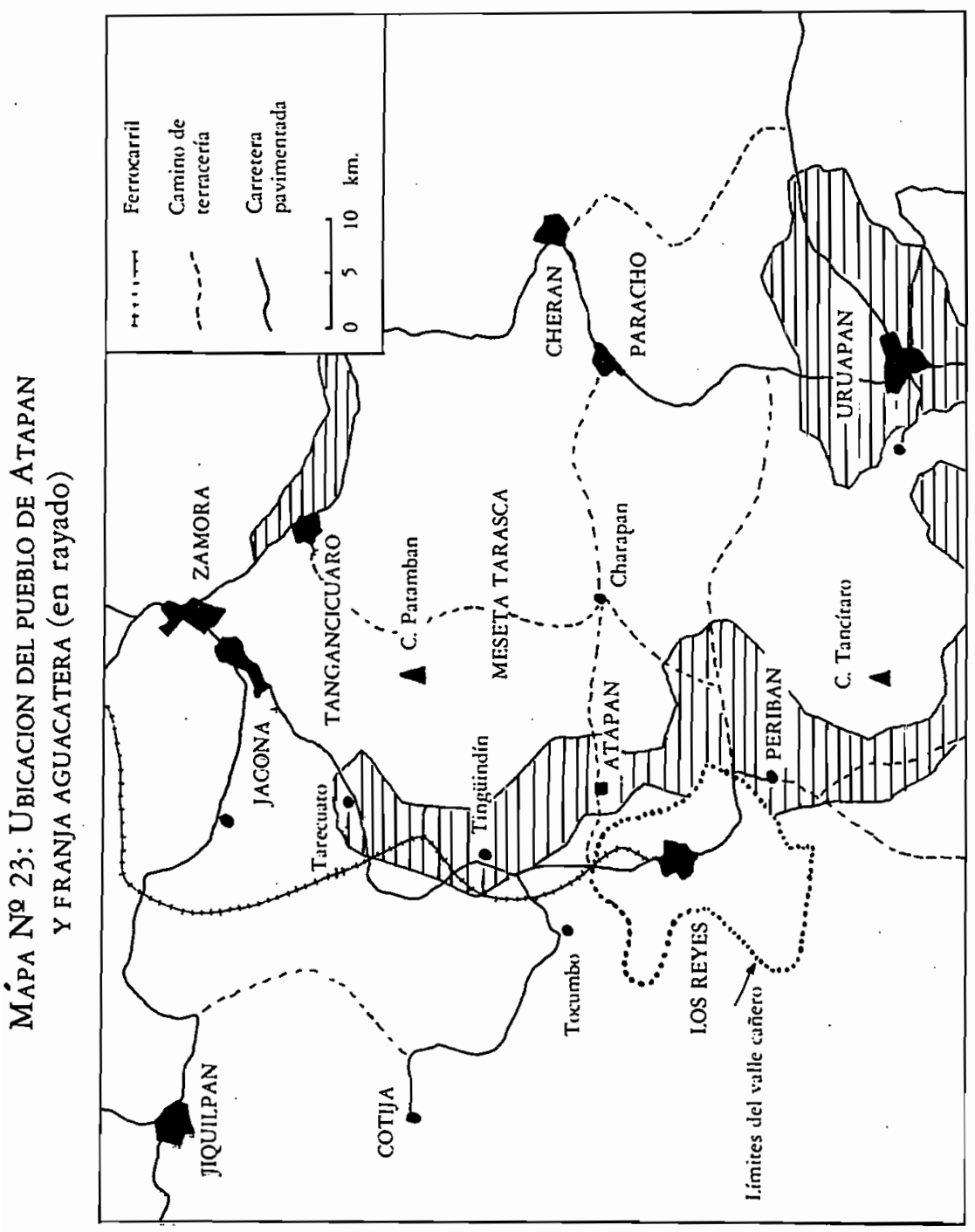


Tarasca $(2,200 \mathrm{~m}$ de altura promedio) se encuentran antiguos conos volcánicos cubiertos de bosques, de pino en su mayor parte, entre los cuales las comunidades indígenas, recolectoras de madera, practican la agricultura de humedad residual (maíz) en llanos formados por la acumulación de cenizas volcánicas.

En el valle de Los Reyes (1,300 m de altura) se practica desde la colonización española el cultivo de la caña para la industria azucarera -antes en las haciendas y hoy, como cultivo de riego casi exclusivo-en una mayoría de ejidos que abastecen a dos ingenios azucareros paraestatales.

Atapan se encuentra en un lugar de transición, donde los suelos tienen su origen en los escurrimientos de material volcánico, con un menor grado de cenizas que en la Sierra. Por otro lado, estos suelos tuvieron un proceso de formación diferente por la vegetación y el clima; Atapan se beneficia de la humedad y de la frescura de la Sierra en la primavera y el verano, mientras en invierno recibe vientos tibios provenientes de Tierra Caliente. Si añadimos una amplitud térmica diaria muy reducida, es un clima ideal para el desarrollo del aguacate.

El aguacate se cultiva principalmente en una pequeña "meseta" situada entre los 1,500 y los 1,700 metros de altura, y donde se encuentra el pueblo (véase mapa 24), por la existencia de suelos profundos, bien drenados y con riego; sin embargo, el aguacate aguanta temperaturas más bajas que las de ahí y su cultivo tiende a extenderse hacia arriba, en el monte. La caña, porsu parte, se destaca en la parte central (parcelas aisladas) y sobre todo en las barrancas y en la prolongación del valle, más baja y cálida, donde los suelos son mucho más arcillosos y compactos.

En conjunto el aguacate aparece así como el elemento dominante del paisaje, y además de su "irrupción" en las milpas se nota de repente su dinámica agresiva contra el bosque de pinos, que es un recurso muy relevante del terruño pues existen ahí muchos desmontes plantados con aguacate joven. Esto evidencia que el aguacate es mucho más que un cultivo de "zona de transición marginal", porque se expande muy rápidamente; ahora Atapan cuenta con unas 650 hectáreas de aguacate, y esta superficie aumenta en casi 50 hectáreas cada año, aunque últimamente dicho crecimiento se ha venido frenando. Una tercera parte de la superficie actual, está plantada con árboles en desarrollo que todavía no producen, lo que prefigura un gran incremento de la producción local para los años entrantes.

\section{Atapan: tres grupos, una sola organización económica}

En las laderas de la Sierra, dada la ausencia de llanos aptos para la agricultura, las comunidades indígenas no han prosperado igual que en la Sierra. En Atapan, por ejemplo, gracias a la comunicación que tiene hacia los 
MAPA № 24: El teRritorio APROVECHADO POR LOS A tAPENSES

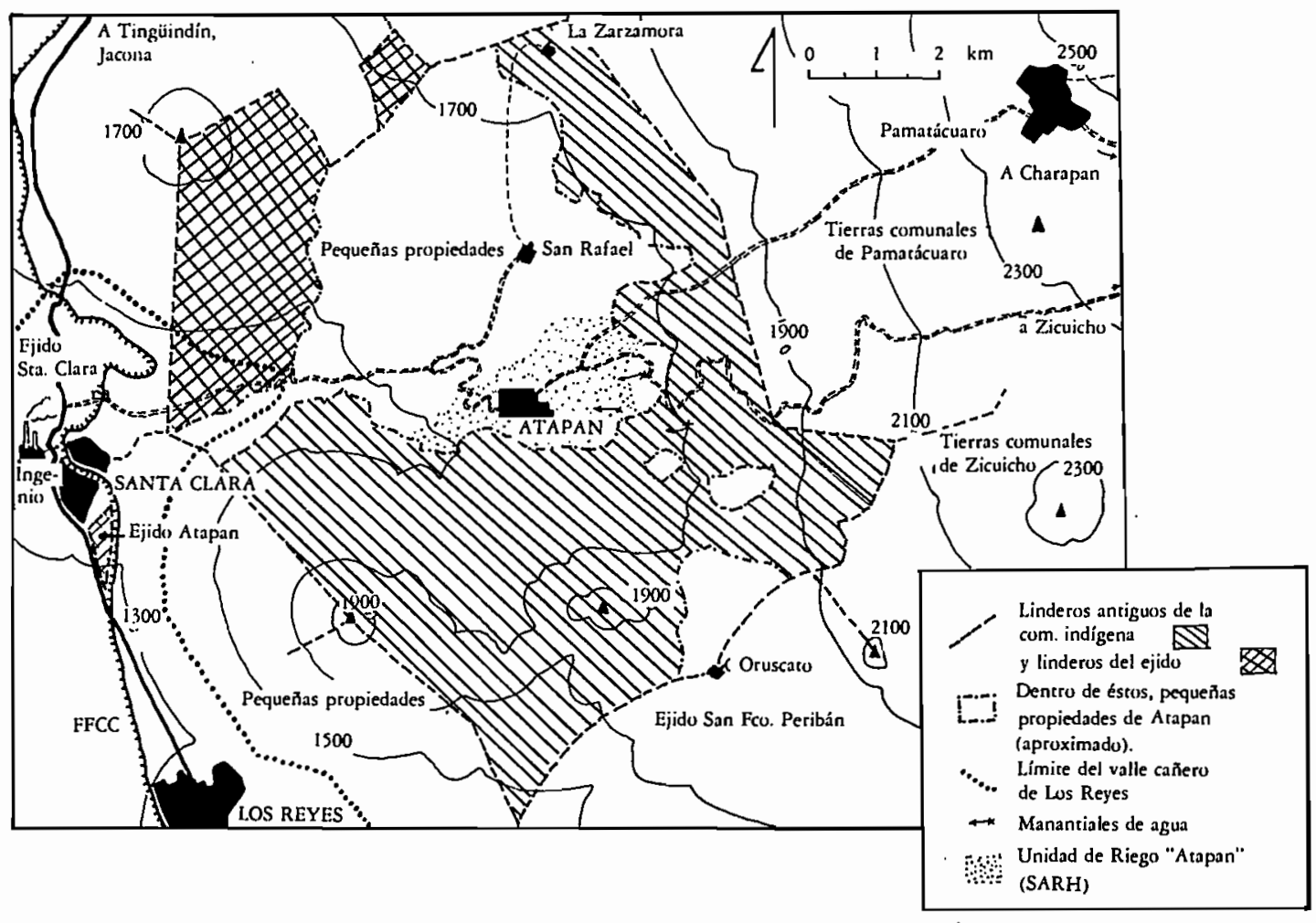


valles donde además hay oferta de trabajo se observa un cierto grado de desarrollo sometido a una influencia mestiza mucho más marcada.

En Atapan existe una numerosa comunidad indígena, que efectivamente se caracteriza por sistemas de producción y una organización del trabajo distintos de los que prevalecen en las comunidades serranas tanto por razones físicas - aprovechamiento de un bosque más diversificado, patrones de cultivo del maíz regidos por un clima y suelos diferentes,...- como por condiciones socioeconómicas: importancia histórica del trabajo asalariado en el valle cañero, existencia de una "presión mestiza" reciente sobre la tierra, ligada al cultivo de la caña y del aguacate. De hecho existe ahora un importante grupo mestizo ${ }^{1}$ en Atapan, en el cual se concentra la mayoría de los aguacateros. Estos "pequeños propietarios" (pP) han logrado ocupar una posición dominante en el pueblo, como lo evidencia la apariencia de sus casas ubicadas en el centro, mientras los indígenas viven aglutinados en la orilla de una barranca, a lo largo de una sola calle.

\section{GRAFICA No 41}

UBICACION DE LA VIVIENDA EN EL PUEBLO DE ATAPAN

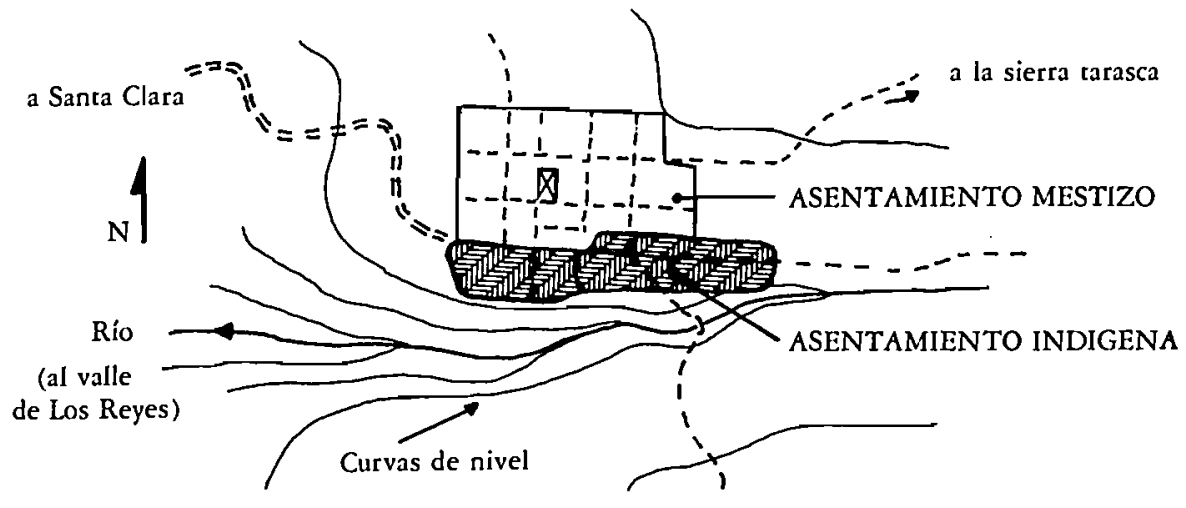

1. La diferencia que se hace aquí entre mestizos $e$ indígenas no se fundamenta estrictamente en la raza - pues hubo mucha asimilación de ambos lados- sino en la existencia de dos grupos con diferencias muy marcadas en la organización de las actividades productivas, y divididos por un conflicto latente en torno al cual cada grupo se define como "mestizo" o "indígena". 
Existe, además, un tercer grupo de campesinos en Atapan cuyo origen data desde que se repartieron las tierras de las haciendas azucarecas del valle: un pequeño ejido cañero, integrado por miembros o ex-miembros de la comunidad indígena. Por otro lado, la caña de Atapan se produce tanto en terrenos de propiedad privada como en predios ejidales.

Observando la participación de cada grupo en el esfuerzo productivo se destaca en primer lugar la importancia del aguacate: unos 170 jefes de familia (un 68\%) trabajan allí de manera directa, y además participan productores de los 3 grupos, aunque cada uno tiene al parecer un papel específico en la repartición de las tareas. Las actividades que siguen en importancia son el trabajo de la caña (cultivo o corte: $44 \%$ de los jefes de familia) y la recolección de la resina (44\%).

Esto evidencia que ningún grupo social en Atapan puede completar el ciclo agrícola sin la intervención de los demás; plantea la existencia de un sistema social de producción coherente e indivisible que involucra a toda la población de Atapan. Nuestra área de estudio (ver mapa 24), determinado por esta observación, será entonces el "te' ruño" del pueblo de Atapan, o sea una unidad espacial congruente de valorización agrícola en la cual la coordinación de los esfuerzos productivos cobra su máxima expresión.

Como lo enseña la misma encuesta, la comunidad indígena - que era en tiempos remotos dueña exclusiva del terruño- proporciona una parte muy importante de la fuerza de trabajo asalariada. Esta situación evidencia, con el despojo progresivo del patrimonio indígena, la existencia de una profunda modificación en las relaciones de producción. Sin embargo, en Atapan, al igual que en toda la región intermedia entre el valle mestizo de Los Reyes y la sierra o meseta indígena, esta modificación es muy anterior al auge aguacatero. No podría entenderse sin remitirnos a una compleja evolución del sistema agrario que culmina con la introducción del aguacate privilegiado por la expansión de las haciendas y luego por el desarrollo cañero.

La naturaleza de la participación de la comunidad indígena en el esfuerzo productivo - las modalidades de su integración en la organización de la producción-plantea nuevos interrogantes sobre las demás actividades en las cuales se ha ido especializando: ¿Cuál es el sentido del peonaje, de la recolección de la resina y de la disminución de los cultivos tradicionales? ¿Cómo se relacionan con las actividades rectoras - aguacate y, luego, cañadel sistema social de producción? ¿en qué medida logran asegurar el sustento de la comunidad indígena?

En el barrio donde ésta se asienta, predominan las casas de adobe con piso de tierra, carentes a menudo de los servicios más elementales. Esta pobreza relativa - a veces también absoluta- demuestra que no todos se han beneficiado de igual manera de las riquezas derivadas del auge 
aguacatero. Por otro lado, son cada vez menores las manifestaciones de coherencia entre miembros de la comunidad indígena dentro del territorio que ésta aprovecha directamente:

-ya no se habla tarasco en Atapan (con excepción del apartado rancho de La Zarzamora);

-gran parte de los comuneros son peones agrícolas;

- pocos son los campesinos que todavía se autoabastecen;

-el bosque se va desmontando y la erosión se incrementa.

Así, a pesar de haber traído una prosperidad notable, el auge aguacatero refuerza un desarrollo selectivo que no permite el mantenimiento de una población creciente en todos los grupos sociales. Nos proponemos analizar aquí la dinámica que llevó a un desgaste de sus propios recursos a la comunidad indígena, mientras surgió un grupo de aguacateros -el $15 \%$ que detenta el $63 \%$ de la superficie plantada - que consolidaba su posición mediante la penetración de insumos externos, tecnología importada, así como por su integración al mercado nacional.

\section{EVOLUCION DEL ACCESO DE LOS DIFERENTES GRUPOS A LOS RECURSOS DEL AREA}

En primer lugar llama la atención en Atapan el hecho de que los "mestizos" sean dueños al menos desde la reforma agraria de una parte importante de los mejores predios agrícolas, antes detentados por los indígenas. El control de la tierra aparece así como un factor determinante de la evolución en las relaciones de producción. Por otro lado, este proceso cobra en Atapan rasgos muy particulares, que probablemente no pueden generalizarse a toda la región aguacatera de Michoacán

\section{Sistemas de producción antes de los años cuarentas}

En Atapan se practicaba un sistema de producción que involucraba muchos cultivos y actividades. La base era el cultivo del maíz, complementado por el trabajo de muchos comuneros en las haciendas cañeras del valle, sobre todo durante la zafra.

El maíz se asociaba con frijol, a veces calabaza y en las parcelas de riego se cultivaba trigo en el ciclo de otoño-invierno, para autoconsumo y venta a las panificadoras de Tingüindín. Había una gran diversidad de ciclos de cultivo según la ubicación de los terrenos (barranca, pequeña meseta, sierra), la existencia o no del riego y las variedades de maíz. 
El rastrojo de maíz y trigo - variedades criollas de paja alta- se aprovechaba para alimentar a una numerosa población ganadera "criolla' que se utilizaba para el tiro, la venta de carne y la ordeña durante seis meses de estación lluviosa. La comunidad indígena contaba con unos cuantos ganaderos que tenían más de 50 reses; éstos utilizaban el monte y el forraje colectivos, y a menudo rentaban a los demás campesinos sus bueyes o caballos como animales de trabajo. En fin, la ganadería era una actividad prioritaria que determinaba la evolución del sistema social de producción.

Los sistemas de producción se completaban con la utilización del bosque para la recolección, el autoabasto y el cultivo del maguey para hacer aguamiel y pulque. Se tenían huertas sembradas con café, plátano y aguacate criollo que se daba a los puercos, algunos naranjos y limones y varios cultivos de riego para autoabasto local (camote, jitomate). Los principales productos vendidos eran el plátano y el aguamiel; varios comuneros vivían en el cerro donde había cercas de maguey entre los lotes individuales de bosque, y bajaban el aguamiel directamente a Los Reyes a cambio de arroz para mantenerse. Así producía el pueblo todo lo necesario para abastecerse, y además tenía ingresos monetarios, produciendo parte de las necesidades del Valle mientras las haciendas se limitaban al cultivo del arroz y de la caña.

Pero esta organización no reflejaba ninguna "prosperidad" especial para los campesinos de Atapan, al contrario, permitía que las haciendas cañeras dieran remuneraciones muy bajas a los peones, que de alguna forma podían asegurar su propia subsistencia. En muchos casos, las haciendas se habían apropiado territorios comunales con el fin de que las comunidades, privadas de una parte de sus recursos, se vieran obligadas a proporcionarles la mano de obra necesaria. En Atapan la reforma agraria redujo estas obligaciones, pues la comunidad solamente quedó despojada de una parte de sus bosques, que no era la base del sustento de los campesinos, y de una fracción menor de sus tierras de labor ( $20 \%$ como máximo, entre los cuales se encuentran probablemente los predios entregados a los pequeños propietarios durante la "desamortización" del siglo pasado - posiblemente en San Rafael). Resultó que entre los que iban a trabajar de peones en la caña, muchos lo hacían de manera eventual. Así, la comunidad indigena de A tapan tenía cierto grado de independencia en los años treintas mientras los ingenios conocían fuertes dificultades para conseguir mano de obra.

Lo primero en disminuir fue la producción de aguamiel cuando la cerveza reemplazó al pulque en las ciudades, mientras el arroz desapareció de los sistemas de cultivo del Valle. Luego el café se redujo a lo necesario para los habitantes del pueblo porque estaba muy mal pagado; solo se podía trabajar con mano de obra familiar. Por su lado, el trigo, a partir de los años sesentas, empezó a sufrir la competencia de los trigos del Bajío y de Sonora, producidos con maquinaria, y poco a poco se acabó, dejando libre una numerosa mano de obra. Mientras tanto, la progresiva desaparición del 
plátano y del aguacate criollo tuvieron su causa principal en la competencia directa con el aguacate mejorado. Pero la merma en la diversidad de las actividades, no constituyó lo más importante del proceso de cambio en las relaciones productivas.

\section{El ejido y los cambios consecuentes}

En Atapan, la caña empezó a incorporarse a los sistemas de producción del pueblo en 1938, cuando se repartieron las haciendas cañeras y algunas tierras de cultivo, propiedades de dueños de trapiches - pues los ingenios y los molinos permanecieron como propiedad privada-, promoviendo como ejidatarios a 24 campesinos de la comunidad indígena. Por falta de recursos financieros y de animales, los ejidatarios no pudieron seguir sembrando caña en todas partes hasta que el ingenio Santa $\mathrm{Clara}^{2}$ empezó a ayudarles con crédito en los años cuarentas produciendo, al principio, básicamente maíz de temporal y leña para las calderas del ingenio antes de que éste utilizara petróleo.

Los "capacitados" para ser ejidatarios eran casi todos comuneros (150), pero por falta de tierras resultó que solamente los más influyentes lograron obtener dotaciones ejidales ( 24 en total). Esto dio origen a un conflicto perdurable, pues varios ejidatarios se quedaron con las tierras comunales, que además trabajaban, a pesar de las protestas emitidas por otros comuneros. Una familia, posiblemente de los anteriores caciques de la comunidad, logró acaparar el ejido, conservando miembros en la comunidad, como usufructuarios de terrenos comunales. Su poder económico, debido a nuevos ingresos de la caña, participación en los ingresos "colectivos" de la comunidad indígena, a veces por la fuerza, etc., le permitió incrementar una clientela política importante entre los indígenas. Este dominio, absoluto sobre el ejido y parcial sobre la comunidad indígena, fue la base del control del pueblo por dicha familia, de la cual salieron siempre el comisario ejidal y el jefe de tenencia. El representante de bienes comunales y sus asesores casi siempre eran de otros bandos - de los que después iban a controlar el aprovechamiento del bosque - produciéndose pleitos violentos entre ejido y comunidad indígena, así como entre comuneros, hasta mediados de los años sesentas. Esta fecha parece corresponder al auge económico y político de los mestizos y de los aguacateros ya que desde 1964 el jefe de tenencia casi siempre ha sido un mestizo y la merma de este conflicto tal vez puede interpretarse como índice de un cambio profundo en las relaciones de producción locales, expresado en una nueva polarización - hacia el

2. El área de Atapan no abastece al ingenio San Sebastian. 
aguacate- de los intereses particulares en los diversos grupos, y una evolución de los conflictos hacia un antagonismoentre mestizos e indígenas.

\section{El auge de los mestizos}

En el área ya había una pequeña colonia mestiza desde hace 200 años, en el rancho vecino de San Rafael. Tenían sistemas de cultivo muy parecidos a los de Atapan, excepto que había muy poco maguey y, sobre todo, muy pocas' tierras de riego. Esta pequeña colonia se amplió con la llegada de algunos rancheros de Tocumbo, de Tingüindín y del distrito de Jiquilpan. Los últimos en llegar, venían huyendo de las zonas afectadas por la guerra durante la revolución, y en los años treintas de las regiones devastadas por la cristiada.

Estos mestizos se instalaban en tierras comunales poco explotadas, para aprovechar madera y leña. Uno de ellos se adueño de la mayor parte del bosque que está al lado noroeste del pueblo de Atapan, y puso aserraderos que funcionaron hasta fines de los años setentas.

Pero lo más relevante fue la expansión ganadera de los mestizos, pues se apropiaban tierras comunales donde sembraban maíz y trigo de riego, para criar con el rastrojo a sus animales que se exportaban hasta las Huastecas para engorda.

A partir de los años cuarentas, el aprovechamiento de tierras indígenas por los mestizos se acelera y se modifica. Primero, a consecuencia de la erupción del Paricutín (1943). La tierra, recubierta con cenizas, se "esterilizó"; las mismas cenizas dificultaron la fecundación del maíz, sobre todo hacia San Rafael; se enrareció el follaje, y los mestizos intensificaron sus presiones para que se les vendiera tierras de riego. Las consecuencias no se redujeron a un simple cambio de dueño de la tierra: poco a poco, el ganado mestizo empezó a rentarse para el tiro en la comunidad indígena, desplazando a los caciques en este papel y provocando una transferencia de ingresos hacia los ganaderos mestizos. La riqueza acumulada con el bosque y la ganadería permitió además que algunos mestizos se convirtieran en nuevos prestamistas usureros para la comunidad indígena. En segundo lugar, porque los cambios más importantes fueron relacionados con las profundas transformaciones en el proceso productivo de la caña. Los ingenios del Valle eran afectados por la baja producción de caña después del reparto agrario (1921 a 1939 en el valle de Los Reyes), debido a la falta de recursos de los ejidatarios y a la preferencia de éstos por el cultivo del arroz, para el cual los molinos daban crédito. ${ }^{3}$ En 1942 el ingenio Santa Clara

3. Ver Emilia Velázquez, Las haciendas en el valle de Los Reyes, El Colegio de Michoacán, Zamora, 1983 
asentó las bases de un extenso control del proceso de producción gracias al crédito y a la asistencia técnica. En esa época, la introducción de fertilizantes químicos permitió elevar los rendimientos y realizar un corte de caña al año.

Así, las tierras irrigadas del valle se beneficiaron de un incremento apreciable de su "renta diferencial". En Atapan el poder de los ejidatarios creció mientras los comuneros se vieron marginados: la situación jurídica de sus tierras no les permitía el acceso al crédito y por lo tanto al cultivo de la caña. En tales condiciones mejor era rentarlas o venderlas a los mestizos que convertirse en peones, pues siendo los "sujetos de crédito" más confiables, los mestizos se apresuraron para tener dónde sembrar caña. La expansión territorial del cultivo de la caña y el incremento de los rendimientos exigían brazos en Atapan mismo. Esta necesidad se hizo todavía más apremiante cuando el cultivo del aguacate empezó a cobrar importancia. Resultó que muchos peones de Atapan dejaron de ir a trabajar al Valle, y en la actualidad los ingenios están en la obligación de contratar mayormente a trabajadores de fuera del área (Tierra Caliente y Pajacuaran principalmente) para la zafra.

Entonces el proceso de asentamiento mestizo en Atapan se hizo a la vez en cañaverales y en tierras maiceras. Fue el resultado de una desigualdad económica creciente entre mestizos e indígenas, a la cual se aunaba la imposibilidad de entrar al cultivo de la caña la mayoría de los comuneros.

La forma que adquirió este movimiento fue principalmente la venta definitiva de tierras comunales, acompañada de una lenta "proletarización" de los indígenas. Estas ventas se autentificaban mediante "mordidas" al representante de bienes comunales ${ }^{4}$ y la secretaría de la Reforma Agraria.s Parte de las ventas se hacían como resolución de algunas deudas contraídas por los indígenas y, cuando menos, el comunero salía en desventaja en la misma venta por no conocer el valor de una parcela en la cual se podía sembrar caña o del animal que le daban a cambio de su tierra o, simplemente por haber perdido una apuesta. En la mayoría de los casos el dinero que los comuneros sacaban de estas ventas no les permitía hacer inversiones competitivas con la caña y luego con el aguacate; a lo más podrían comprarse una bestia. Además no pocas veces se ha gastado en alcohol, en una época en que la cerveza y los nuevos aguardientes de fabricación industrial empezaron a llegar al mercado local.

El éxito del aguacate mejorado, injertado sobre las plantas criollas e introducido en 1960 por una familia bien relacionada con los primeros

4. Hay manifestaciones de cierta alianza entre algunos mestizos y gente poderosa de la comunidad: compadrazgos - que también pueden existir por simple amistad-, entrada de algunos comuneros a la Unión de Productores de caña, etc.

5. Esta dependencia aceptaba hacer confirmaciones de linderos solamente cuando se trataba de conflictos con las comunidades indigenas vecinas. 
centros de producción de Peribán, tuvo como consecuencia una aceleración de la compra de tierras, que esta vez se enfocó de manera muy precisa hacia la pequeña "meseta central" (véase mapas 25 y 26). Esta meseta se encontraba provista de suelos adecuados (tierra " $t$ 'upuri") 6 profundos, bien drenados y de textura franca. Estos suelos tienen una importancia estratégica porque son los únicos que permiten una alta productividad de los árboles: además del espacio requerido por las raíces y de la sensibilidad de éstas al exceso de humedad, solamente en estos suelos penetra el fertilizante químico hasta las raíces más profundas. A estas exigencias se aunaba el deseo de los aguacateros de tener riego, y desde este punto de vista las tierras que rodean el pueblo de Atapan siempe han sido las mejores.

Con sus primeras adquisiciones, los mestizos eran ya dueños de una parte de estas tierras. Pero de hecho eran casi los únicos que, gracias a la acumulación realizada con la caña, podía n enfrentar los gastos de plantación de aguacatales en gran escala, esta vez con apoyo de la banca privada, que no discriminó sus créditos en caso de algún ejidatario o comunero provisto de tierras privadas. Así se reanudó la compra-venta de tierras comunales en formas similares a las anteriores, a lo largo de los años sesentas y setentas; a veces los futuros aguacateros ocupaban tierras de pastal-cerril o de monte con su ganado, hasta que la comunidad aceptara el compromiso.

Cuando tenían los recursos suficientes, los aguacateros ponían energía eléctrica o diesel para con bombeo incrementar la superficie irrigable:

\section{Grafica No 42: INFRAESTRUCTURA HIDRAULICA EN ATAPAN}

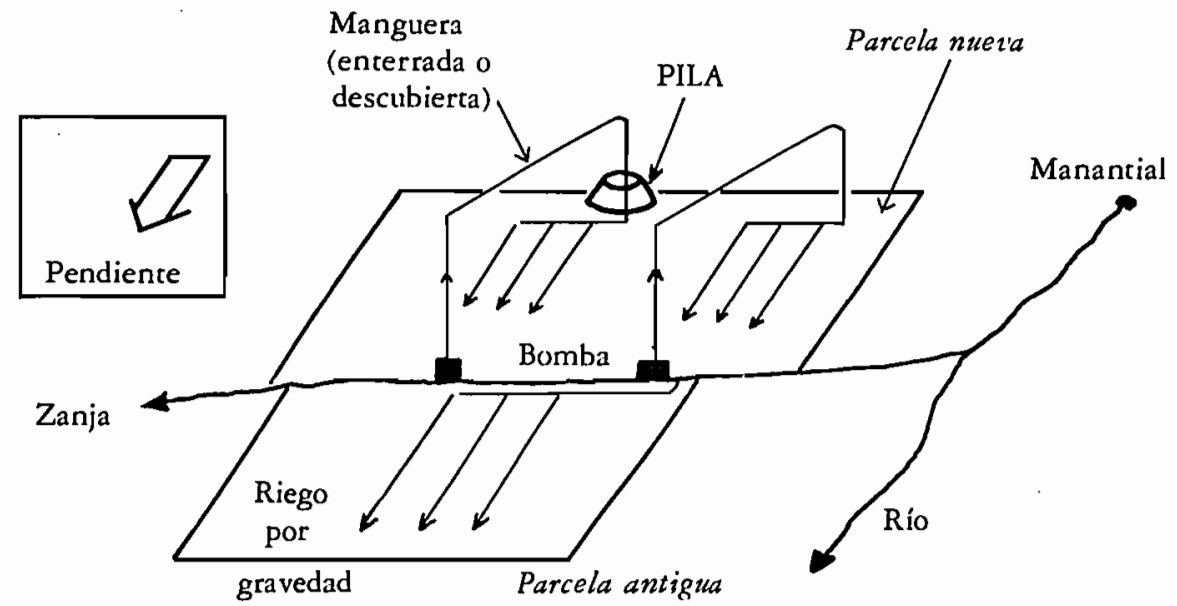

6. T"upúri: se trata del "más productivo de los suelos de humedad de las tierras altas", explica R. West, (1948) quiẹn lo describe "como semejante a los suelos calés y cuya textura es extremadamente fina, debido a su composición: $55 \%$ de arena fina, $23 \%$ de limo, $21 \%$ de arcilla y $1 \%$ de grava gruesa". 
Así, los aguacateros se comportaron como "inversionistas capitalistas", consiguiendo tierras donde más les iba a redituar y gastando en infraestructuras; los mestizos realizaron un desplazamiento de San Rafael a Atapan, ${ }^{7}$ comprando también casas y solares, ${ }^{8}$ y poco a poco el poder económico en Atapan se estuvo ligando al aguacate, mientras las ganancias en la caña se encontraban estancadas frente a las nuevas posibilidades. ${ }^{9}$

\section{Integración de la comunidad indígena al proceso de cambio}

En esta evolución se nota la facilidad con la cual los comuneros, por la venta de tierras, abandonaban parte de sus milpas y de sus animales, suprimiéndose ingresos y fuentes de autoabasto. El proceso de despojo se llevó a cabo tanto más fácilmente cuanto que coincidió con un notable incremento de la demanda de trabajo en la caña y en el aguacate. Pero una oportunidad la proporcionó el incremento de la demanda de resina, ligada al desarrollo de la industria química internacional a partir de los años treintas. En Atapan la extracción pudo empezar en 1942, y tuvo un crecimiento muy fuerte en los años sesentas por dos razones principales:

-atractivo incremento de los precios pagados al productor en gran parte de la región, por la creación de plantas resineras ejidales en la Sierra Tarasca; ${ }^{10} \mathrm{e}$

-incremento de las necesidades monetarias de los comuneros como consecuencia de las primeras ventas de tierra.

En la resina, los precios están dictados por el mercado internacional de subproductos, pues las plantas de Michoacán solamente fabrican productos brutos como la brea, el aguarrás y otros derivados. Para conservar sus beneficios estas plantas presionan mucho a los productores: renta del bosque privado a tarifas muy bajas ( $\$ 6,000$ anuales/millar de caras), falta de pago de los aguinaldos, "despidos" de los productores como ocurrió en

7. Se nota la debilidad del proceso en San Rafael (también comunicado con Atapan), donae todavía se encuentran huertas importantes de plátanos y café, potreros grandes para el ganado y pocos cultivos de riego. Ahí viven apenas unas 20 familias.

8. La génesis del barrio mestizo es, de hecho, un poco más complicada: hubo también un mestizaje reciente entre indigenas y algunos ladinos de San Rafael o los escasos ladinos de Atapan. Además, son propietarios de grandes casas y solares del centro algunas personas de ascendencia indígena, ahora aguacateros, que se "aculturaron" totalmente y forman parte integrante del grupo mestizo.

9. Estimamos hoy en día que un cañero, con la superficie promedio que se cultiva en Atapan ( 3 Has.), no gana mucho más que el salario mínimo con sus utilidades netas. Tal ingreso puede ser alcanzado con media hectárea de aguacate.

10. El estado las apoyó frente a los abusos de algunas empresas privadas; luego el mismo estado tuvo interés en controlar más estrechamente el proceso productivo, y ahora todas las plantas resineras de la regiún son paraestatales. 


\section{Atapan en 1983.11}

A pesar de estas dificultades, la "penetración capitalista" en el campo de Atapan mediante el aprovechamiento de la resina fue la que, -dando ingresos monetarios a los comuneros-permitió, con el cultivo de la caña y del aguacate, la integración de los campesinos a los mercados nacional e internacional mediante la compra de tierras comunales por los cañeros y los aguacateros.

Esto solamente podía funcionar con el acuerdo y el apoyo de algunos miembros de la comunidad indígena, particularmente de los que ocupaban los puestos de responsabilidad; fue el caso de:

-la gente ligada a las familias de ejidatarios. Estos, teniendo mucho poder y poca oportunidad de verse obligados a vender sus tierras, participaron en el reparto de las "mordidas".

- la gente que solamente tenía parcelas en el monte para sacar resina tampoco iban a ser afectados, y a menudo tenían que aliarse al montero y al rayador de la resinera; éstos podían rechazar la resina de cualquier campesino inconforme.

De hecho, el acaparamiento de tierras por aguacateros y cañeros se acompañó del surgimiento de los que controlan el proceso resinero como principales caciques en la comunidad indígena. ${ }^{12}$ Hoy en día, hay una identidad pronunciada entre autoridades de la comunidad y empleados locales de la Resinera o montero, ${ }^{13}$ lo que evidentemente tiende a favorecer un acceso desigual al bosque (ver cuadro 34 ).

Este proceso de enajenación de las tierras comunales se acabó hacia 1977-78, no tanto porque no quedaran tierras buenas que comprar sino porque ante el éxito que habían tenido los aguacateros, los comuneros empezaron a buscar el modo de poner sus propias huertas con toda clase de esfuerzo.

Para las autoridades comunales y otros campesinos interesados, esto representó, en cierto modo, el fin de un negocio y hubo que buscar otras fuentes de ingresos comparables. Así empezó el aprovechamiento en gran escala de los bosques comunales para sacar madera; una vez más, gracias a la corrupción de la administración del ramo (SRA y Forestal), 10,000 $\mathrm{m}^{3}$

11. La Resinera de Zacapu quiso aumentar el precio de tres pesos en cada kilogramo pero suprimiendo los "pases" del seguro social, de los cuales los campesinos abusaban, so pena de no llevarse la resina; los comuneros tuvieron que cambiarse con la de Uruapan, con nuevo montero, nuevo rayador y nuevo depósito.

12. Los antiguos caciques ganaderos de la comunidad perdieron mucho poder en estas transformaciones. Lo mejor que pudieron hacer fue vender ganado para comprar tierra (a veces su propia parcela) y plantar aguacate.

13. Montero: encargado de checar el respeto de los lotes asignados y la conformidad de las técnicas aplicadas con las normas definidas por el estado. 
autorizados por año, (equivalentes a 100 hectáreas de una sola pieza), rebasan por mucho el potencial productivo de los bosques de Atapan. Además se tumban árboles resinables, perjudicando a algunos comuneros, y sin embargo a un precio muy bajo (vendidos a $\$ 600 / \mathrm{m}^{3}$ en rollo a los aserraderos de Tingüindín en la primavera de 1984). Los pequeños propietarios también aprovecharon la madera comunal, pero mucho antes, y los lotes que pillaron están ahora desforestados totalmente, al igual que en Tingüindín; sus aserraderos ya cerraron, mientras la inversión se trasladó a plantas de importancia regional.

De hecho la resina no genera muchos ingresos para las autoridades comunales: el monte se aprovecha en lotes individuales, y luego el fondo comunal constituido por los "derechos de monte" que pagan las resineras a la comunidad ( $\$ 685$ tonelada en 1984) queda depositado en Morelia (NAFINSA) y sólo se puede utilizar para obras de interés colectivo en las cuales participan el gobierno estatal y el gobierno federal. Lo único en la resina que se puede repartir de manera desigual es el aguinaldo pagado anualmente a los productores a través de las autoridades comunales.

Asimismo se entiende la amplitud que cobró el negocio de la madera. Este fue utilizado a veces para otras inversiones (camión de pasajeros), pero fueron casos aislados y nunca en beneficio de toda la comunidad indígena.

\section{Consecuencias}

El cuadro 34 resume, como resultado actual de las transformaciones descritas, las características de los tres grupos, con su acceso diferenciado a los recursos. Como se observó previamente, el ejido y la comunidad indígena están muy ligados y sometidos internamente a procesos similares de acaparamiento desigual de los recursos. Pero sobre todo se evidencia cómo los mestizos detentan una mayor parte de los recursos estratégicos actuales: las principales plantaciones de aguacate y la infraestructura de comercialización y de transporte.

Estas transformaciones han fomentado nuevos patrones de ocupación y uso del suelo: en la zona más afectada - la pequeña "meseta central"irrumpieron las huertas de aguacate (véanse mapas 25 y 26) con un proceso simultáneo de privatización de la tierra. En la Unidad de Riego Atapan por ejemplo se observa que la totalidad de las huertas de aguacate son de pequeña propiedad; la ocupan 67 mestizos con 4.5 hectáreas cada uno, 4 ejidatarios con 3.2 hectáreas cada uno y 16 comuneros con 3.2 hectá reas cada uno en promedio.

Pero sobre todo se nota en estos lugares una nueva estructuración del paisaje, debido a la ocupación selectiva del terreno por el aguacate: los suelos con capa suficiente de tierra (t'upúri) solamente se encuentran en las partes 
CUADRo No 34

ACCESO A LOS RECURSOS EN ATAPAN

\begin{tabular}{|c|c|c|c|}
\hline & $\begin{array}{l}\text { Pequeños propietarios } \\
100 \text { familias }\end{array}$ & $\begin{array}{l}\text { Ejido } \\
24 \text { familias }\end{array}$ & $\begin{array}{l}\text { Comunidad indígena } \\
120 \text { familias }\end{array}$ \\
\hline Superficie total & 2500 ha & 800 ha & 5500 ha \\
\hline $\begin{array}{l}\text { Repartición de } \\
\text { las tierras }\end{array}$ & 3 a 50 ha de propiedad privada $c / u$ & $\begin{array}{l}\text { Unidad de dotación: } \\
3 \text { ha caña } \\
3 \text { ha temporal } \\
25 \text { ha bosque }\end{array}$ & 35 no tienen tierras $(30 \%)$ \\
\hline $\begin{array}{l}\text { Cultivos } \\
\text { (muy aproximado) }\end{array}$ & $\begin{array}{l}\text { Aguacate } 600 \text { ha. } \\
\text { Caña } 140 \text { ha. } \\
\text { Maíz } 70 \text { ha. } \\
\text { Solares } 15 \text { ha. } \\
\text { Agostaderos } 300 \text { ha. } \\
\text { Otras huertas } 100 \text { ha. } \\
\text { Bosque } 1000 \text { ha. }\end{array}$ & $\begin{array}{l}\text { Aguacate } 15 \text { ha. } \\
\text { Caña } 70 \text { ha. } \\
\text { Maiz } 50 \text { ha. } \\
\text { Solares } 2 \text { ha. } \\
\text { Agostaderos = monte + parcelas } \\
\text { en descanso } \\
\text { Otras huertas } 10 \text { ha. } \\
\text { Bosque } 650 \text { ha. }\end{array}$ & $\begin{array}{l}\text { Aguacate } 70 \text { ha. entre } 8 \\
\text { Caña } 40 \text { ha. entre } 12 \\
\text { Maíz } 70 \text { ha. } \\
\text { Solares } 5 \text { ha. } \\
\text { Agostaderos = monte + parcelas } \\
\quad \text { en descanso } \\
\text { Otras huertas } 50 \text { ha. } \\
\text { Bosque } 4800 \text { ha. entre } 87 \\
\text { (100,000 árboles resinables) }\end{array}$ \\
\hline $\begin{array}{l}\text { Repartición de } \\
\text { los cultıvos de mayor } \\
\text { importancia }\end{array}$ & $\begin{array}{l}52 \% \text { tienen abajo de } 200 \text { árboles } \\
\text { de aguacate y totalizan un } 12 \% \text { de } \\
\text { la superficie plantada. } \\
15 \% \text { tienen arriba de } 1000 \text { árboles } \\
\text { y toralizan un } 63 \% \text { de la superficie } \\
\text { plantada. }\end{array}$ & $\begin{array}{l}1 \text { familia controla la mayor parte } \\
\text { de la superficie plantada con caña. }\end{array}$ & $\begin{array}{l}\text { Resina } \\
60 \% \text { tienen alrededro de } \\
1000 \text { árboles } \mathrm{c} / \mathrm{u} \\
7 \text { comuneros tienen arriba } \\
\text { de } 4000 \text { pinos } \\
\text { Madera } \\
\text { De uso colectivo pero sólo beneficia } \\
\text { a las autoridades }\end{array}$ \\
\hline
\end{tabular}




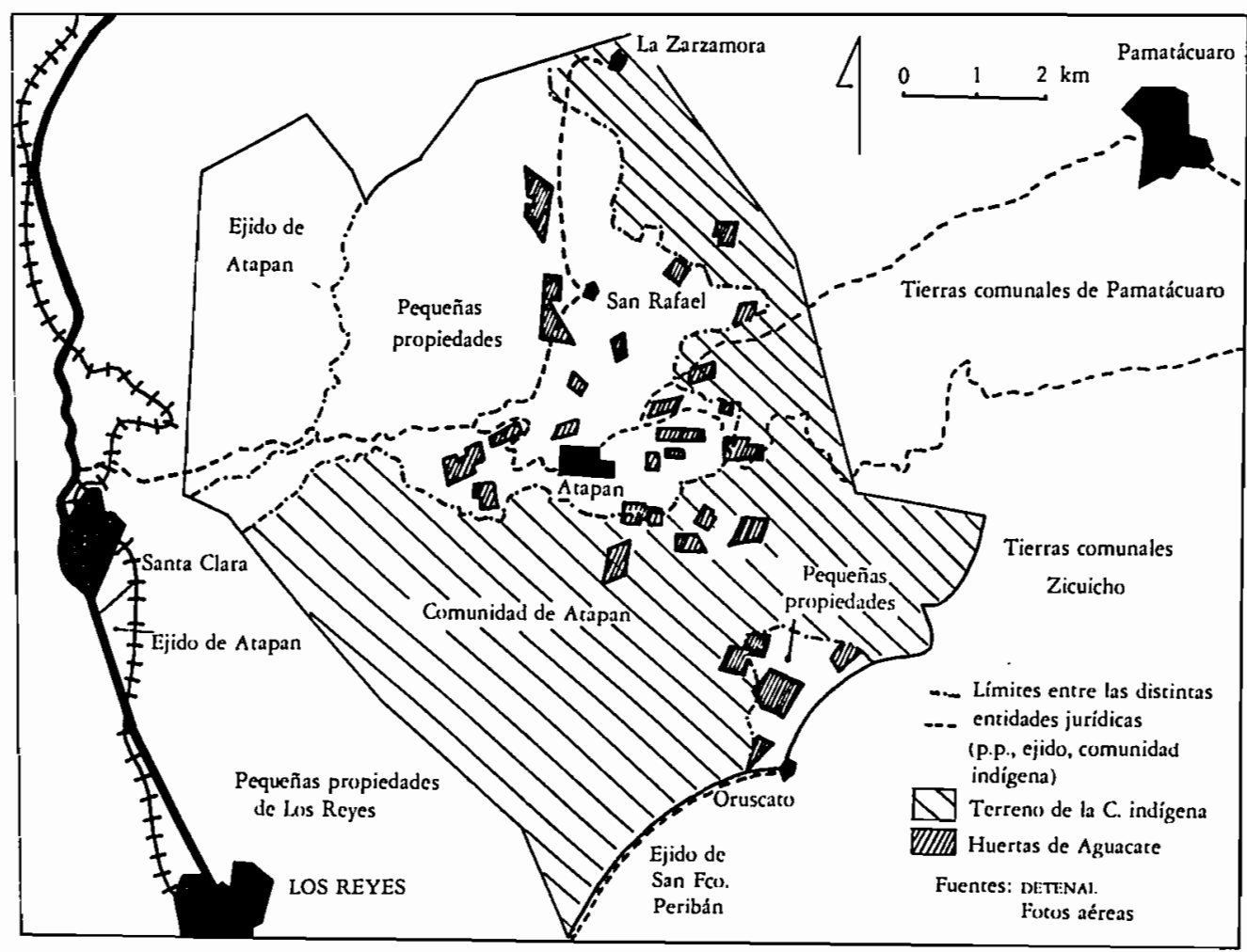




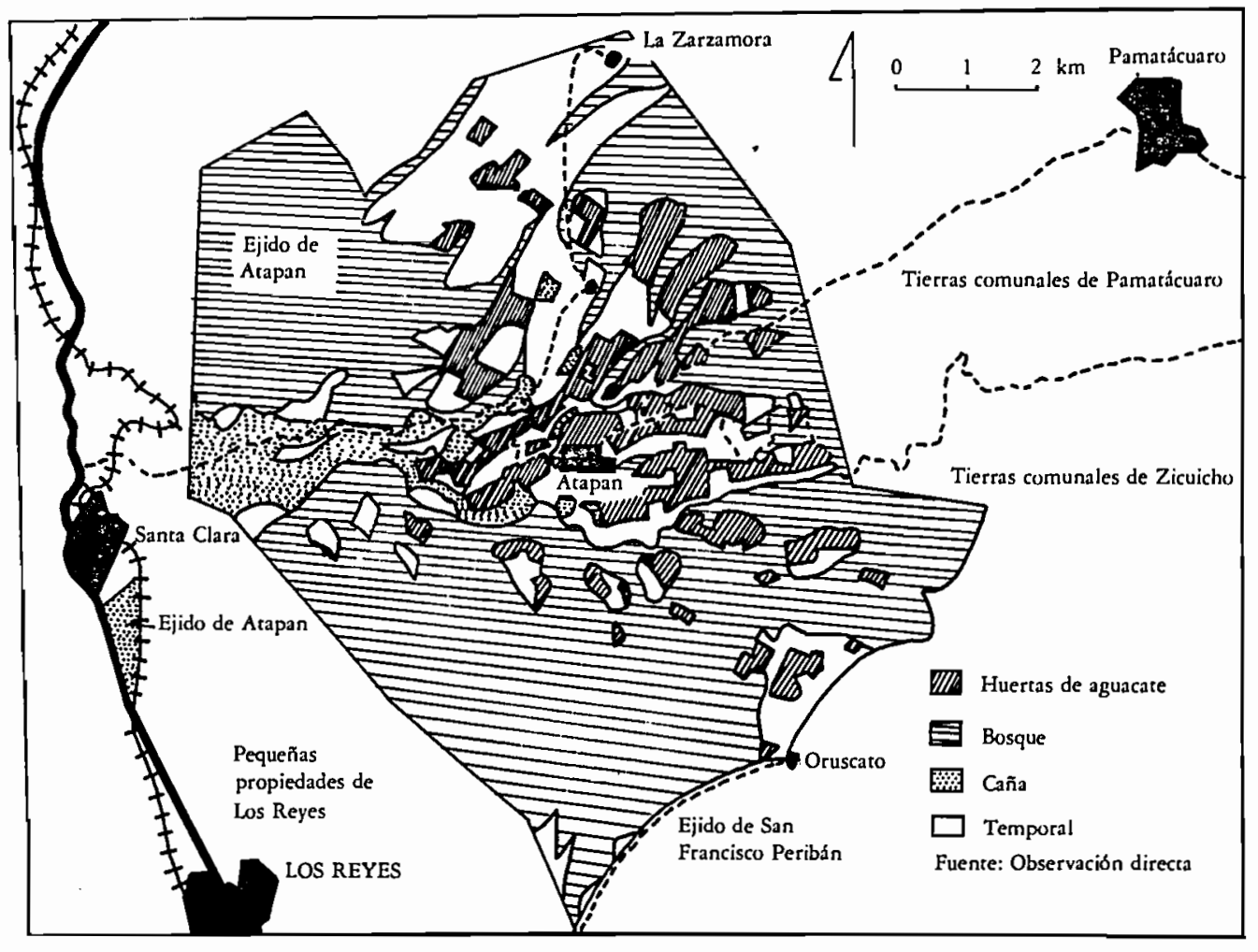




\section{Grafica No 43: Uso del SUELo en A TAPAN}

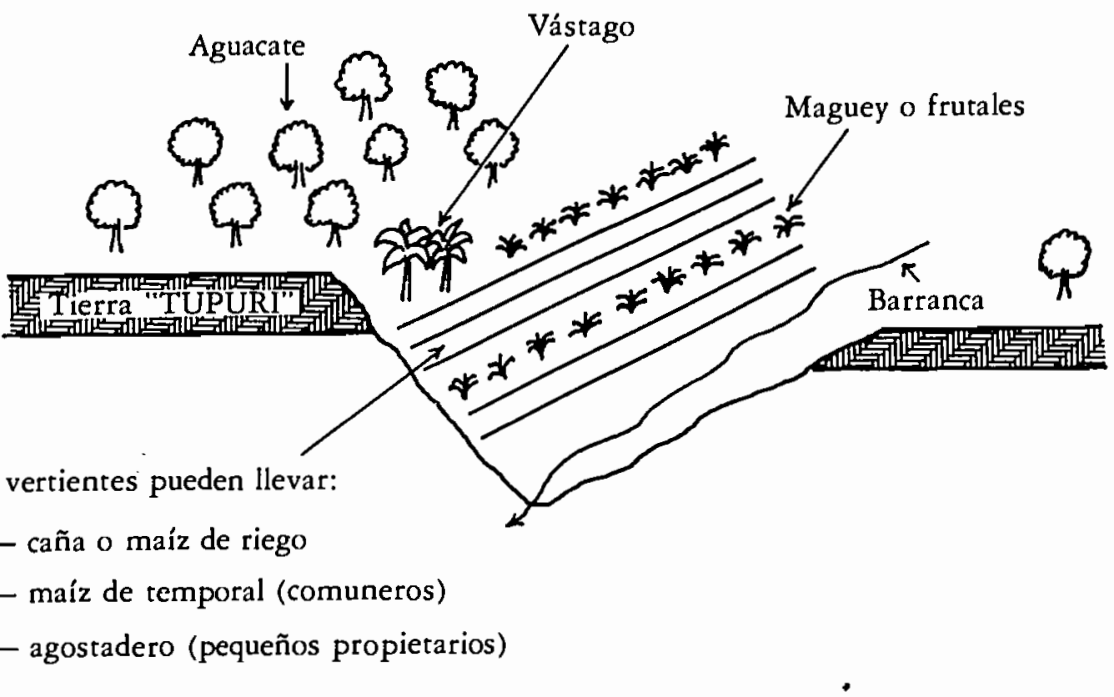

que no han sido excavadas por los arroyos.

Esta micro-diferenciación territorial explica, por un lado, la permanencia del cultivo de la caña en esta parte del terruño pues las vertientes de las barrancas cuentan a menudo con riego, y por otro lado la existencia de una pequeña base de sustento para los trabajadores agrícolas, que cultivan el maíz en estas barrancas con una organización similar a la que prevalece en el Valle cañero, donde muchos peones tienen ecuaros en las laderas. Otras partes del paisaje han cambiado menos, como la zona cañera que conserva su fisonomía de hace 30 años, y el bosque, que sin embargo va mermando con los desmontes para plantar aguacate y el saqueo de la madera.

\section{Conclusiones}

45 años de transformaciones han llevado entonces a la situación siguiente: -La comunidad indígena ha enajenado cerca de la mitad del territorio recuperado, correspondiente a la parte más fértil y cultivable, mientras muchos de sus miembros iniciaron nuevas actividades: jornal agrícola en el aguacate, recolección de la resina, etc.

-Su bosque se está saqueando, antes por mestizos foráneos y ahora por los propios miembros de la comunidad.

-El cultivo del maíz y la ganadería se redujeron en proporciones importantes, así como otros cultivos y actividades; se ha perdido mucha diversidad, y ahora solamente quedan tres recursos relevantes 
en el terruño: aguacate, caña y bosque.

Lo más relevante en este proceso histórico es la ubicación del auge aguacatero dentro de una evolución más larga de las fuerzas productivas: el aguacate siendo en primera aproximación un cultivo exclusivo de campesinos que tienen recursos financieros, su irrupción, sin embargo sólo refuerza y acelera la diferenciación social ya existente por los ganaderos y la implementación de la caña. Así, es principalmente la exclusión de los comuneros indígenas del comercio ganadero y, luego, del cultivo de la caña, la que promovió a una mayoría mestiza como "élite" económica que aprovecha la riqueza aguacatera en Atapan. El surgimiento de este grupo de agricultores - pequeños propietarios mestizos y ejidatarios- es, desde luego, muy anterior al auge aguacatero.

\section{COMO EL AGUACATE AFECTA LAS DEMAS PRODUCCIONES}

Queda claro entonces que en el área ya habían sucedido trans̀formaciones importantes cuando llegaron los años sesentas. Pero la introducción de la caña había preservado, en cierta medida, el cultivo del maíz, ya que ambos cultivos no competían realmente las mis mas tierras. En cambio, el aguacate lo desplazó de una manera mucho más sistemática, relegándolo a las orillas, las barrancas y el "cerro", en las peores tierras. A hora, el desplazamiento del maíz tiene consecuencias muy profundas. Equivale a cuestionar en su totalidad el sistema social de producción estructurado alrededor de este cultivo. Implica la transformación profunda de los modos de vida y, como lo vimos, de la estructura social a través de la organización del trabajo.

\section{Disminución de la superficie dedicada al maíz}

Como lo hemos subrayado, este fenómeno sucedió principalmente por un cambio de dueño de la tierra y, sólo más tarde, los comuneros y los pequeños propietarios más pobres empezaron a plantar aguacate ahí donde ellos mismos habían cultivado maíz.

Para la comunidad indígena, abandonar las tierras maiceras, fuente de abasto alimenticio, podía representar un trastorno muy importante; sin embargo hay factores que facilitaron mucho la venta de estas tierras como la ausencia desde siempre de pastoreo comunitario de las tierras en descanso o de labores colectivas en la comunidad indígena de Atapan. La causa de este fenómeno se debe a la ausencia de áreas de cultivo compactas y extensas, a que los sistemas de cultivo más comunes son de año con año y también a que 
se cultivan muchas variedades que tienen períodos de siembra y cosecha diferentes:

-maíz de riego (pinto), sembrado de febrero a abril, cosechado en elote de mayo a julio.

-maíz de "chucandirán" (amarillo). Se cultiva en las tierras de temporal más cálidas y arcillosas del área. Su ciclo muy corto (3 meses) permite sembrarlo de junio a agosto y cosecharlo de septiembre a diciembre. -maíz de "temporal" (azul) de ciclo largo. Se siembra en junio y se cosecha en enero.

Además, el ciclo de cultivo, en épocas anteriores, incluía muchas veces el trigo de invierno de humedad residual o de riego, cosechado en marzoabril, y hoy incluye el garbanzo como cultivo de temporal de invierno después del maíz. Por la existencia de rotaciones a veces sofisticadas, resulta que los periodos en los cuales la tierra queda libre son cortos y variados, y no se pueden determinar momentos en que el "ganado comunal" invada todas las tierras en descanso. ${ }^{14}$

Por otro lado, una familia, combinando las diversas variedades, puede sembrar de febrero a agosto y cosechar de mayo a enero, procurando una repartición muy adecuada del trabajo a lo largo del año sin necesidad de recurrir a mano de obra externa y abundante en momentos claves, y con un aprovechamiento óptimo de los animales de trabajo.

Cada uno manejaba entonces sus parcelas de maíz con mucha independencia, lo que facilitó de manera apreciable la enajenación de estas tierras. Este era el paso clave; luego se conseguía con facilidad la mano de obra necesaria al cultivo del aguacate:

-Los maiceros desplazados eran disponibles

-El trigo, muy exigente en fuerza de trabajo, (siembra y cosecha manuales) desaparecía poco a poco

-Los peones de Atapan que trabajaban en el valle cañero tenían mucha ventaja en regresarse al área, con mejores condiciones de trabajo.

Como lo vimos, la extracción de la resina fue un elemento que permitió la restricción de la superficie destinada al maíz. Además, tuvo un crecimiento muy importante en las dos últimas décadas, hasta convertirse en la actividad principal de la comunidad indígena.

Normalmente un pino se tiene que rebanar ${ }^{15}$ una vez a la semana, y así

14. Esto siempre ha limitado las posibilidades de acumulación para los ganaderos importantes en la comunidad: para conseguir forraje tenían a veces que comprarlo o, con mayor frecuencia, rentar las tierras donde quedaban rastrojo y pasto. A principios de 1984 se rentaba aproximadamente en $\$ 2,000$ una hectárea para pastoreo en la temporada de secas.

15. Rebanar: hacer una raya en la corteza del árbol, por la necesidad de mantener una superficie viva, de lo contrario, la hendidura se cicatriza y la resina ya no puede gotear. 
se saca en promedio $1 \mathrm{Kg}$. de resina al mes para cada cara. ${ }^{16}$ Pagada a $\$ 20$ el $\mathrm{Kg},{ }^{17}$ son unos 20,000 pesos mensuales los que se pueden sacar de 1,000 caras cantidad mínima dotada a un resinero. La mayoría de los lotes son de este tamaño.

Pero esto implica que el trabajo sea realizado lo mejor posible: rebane y recolección de todos los pinos una vez a la semana, engrape ${ }^{18}$ para las caras que ya se volvieron demasiado largas...etc. Este trabajo requiere 3-4 horas diarias en el bosque para 1,000 caras semanales, a las cuales hay que agregar el tiempo de recorrido con los burros que transportan las latas de resina. Se puede ahorrar parte de este tiempo concentrando el trabajo sobre 2 o 3 días de la semana; de este modo se sacan al máximo 2 o 3 latas de $23 \mathrm{Kg}$. por día trabajado, lo que con un solo burro se trae al depósito del pueblo.

Sin embargo, las cosas rara vez suceden así: si el trabajo se efectuara como se ha descrito, habría, en promedio anual, unas 10 toneladas de resina cada semana en el depósito de los comuneros, y unas 4 en el de los ejidatarios y particulares, mientras que en la estación más productiva -abril, mayoapenas se alcanzan en realidad las 8 y 3 toneladas respectivamente; en invierno el abasto no rebasaba las 3 y 1 toneladas en ios respectivos depósitos. Además, la dotación de cada uno le permitía sacar 6 latas de 23 $\mathrm{Kg}$. a la semana durante una buena parte del año, lo cual otorga el acceso al "pase" del seguro social; pero ni la mitad de los resineros entregan esa cantidad, y se les paga la resina a $\$ 25 / \mathrm{Kg}$., más aguinaldo, pero sin seguro; no obstante, esta situación no impide que varios consigan un pase cuando lo necesitan.

Esto comprueba que muy poca gente resina sus árboles de manera completa; se lo pueden permitir porque al no rebanar, lo único que arriesga uno es una baja de la producción; si solamente se rebana y recolecta una vez al mes, no hay desgaste del producto ni daño de los árboles; tampoco disminuye eso la capacidad productiva de los pinos. Por el contrario, en el cultivo del maíz, todos los trabajos deben realizarse en estricta conformidad con el calendario agrícola, si no, la cosecha se echa a perder. ${ }^{19}$

Esta "flexibilidad" de la actividad resinera ha tenido consecuencias

16. Nombre que se da la herida abierta sobre el tronco del pino. Sobre los árboles de mayor diámetro se pueden abrir varias.

17. Más $\$ 2.50$ de aguinaldo precio de 1984 .

18. Consiste en la colocación de un pedazo de lámina para formar el pico por donde la resina gotea en el bote.

19. Así, hay mucha gente que practica la extracción de la resina como actividad importante, pero dedicándose el tiempo que dejan libre las demás actividades. Siembran maíz en verano, se contratan en las huertas de aguacate en invierno y van a resinar en los dias que les quedan. Sin embargo, como la producción veraniega de los pinos es importante, es frecuente que durante ese periodo la esposa y los hijos aseguren gran parte de los trabajos en el maíz con azadón. 
importantes: los que dejaron el cultivo del maíz para dedicarse a recolectar la resina nunca darán marcha atrás, por lo cómodo que es ir a trabajar cuando uno quiera y poder percibir en esos momentos unos 20,000 pesos mensuales (1984) trabajando sólo de medio tiempo. Esto también les permite ocuparse en otras actividades; los ejidatarios, por ejemplo, se dedican a su caña y algunos negocios (molinos de nixtamal), y sacan muy poca resina; muchos comuneros trabajan de peones en el aguacate o la caña, y van al bosque en sus momentos libres.

Esta particularidad de la actividad resinera es sumamente interesante para los aguacateros: les permite aprovechar una mano de obra muy disponible en momentos claves, sin tener que mantenerla todo el año. En efecto existe una muy buena complementariedad en el tiempo entre la actividad resinera y el cultivo del aguacate, desde el punto de vista de la competencia por el trabajo ya que la mano de obra es disponible en cualquier época del año, -especialmente en invierno que es la estación más intensa de cosecha del aguacate-, excepto en los meses de abril y mayo en los cuales, por la sequedad y el calor, los pinos producen mucha resina. Precisamente este periodo es el de menor trabajo en el aguacate: solamente cajeteo y riegos; ${ }^{20}$ la cosecha ya para entonces está realizada.

Con las ventajas que proporciona esta organización, la resina hubiera podido permitir un buen mantenimiento de la comunidad indígena. Sin embargo, lo que más se ha aprovechado es la posibilidad de ir a trabajar cuando uno quiera o pueda; esto ha permitido el incremento de los niveles de alcoholismo de la comunidad. Además los rayadores de las compañías resineras que tienen cada semana un fondo para pagar a los productores, pueden prestar dinero a corto plazo y sin intereses a los comuneros en apuros. Muchos campesinos recurren a este sistema para aplazar el día que iran al monte, cuando se les acaba el dinero.

En este conjunto de condiciones, la extracción de la resina es un trabajo a destajo bastante seguro y muy poco exigente en cuanto a la organización del tiempo. Pero los bosques beneficiaron principalmente a unos campesinos que en el momento del "auge resinero" lograron reunir un gran número de árboles: más de los 4,000 que alcanzaría a trabajar un solo hombre. Estos contrataron a 2 o 3 peones para sacar provecho de la "trementina", lo que permitió un acceso parcialmente desigual a los recursos forestales en el seno mismo de la comunidad indígena.

Por otra parte, los indígenas son peones "poco confiables" que no necesitan trabajar todos los días y, consecuentemente, se les paga poco y se les contrata de manera ocasional; sólo el aguacate les da fuentes de empleo

20. El cajeteo consiste en conformar o reparar el "cajete", hoyo alrededor del árbol, donde queda encerrada el agua de riego y donde se hecha el fertilizante. 
pero en condiciones permanentemente precarias. En fin, esta situación fomenta un incremento de la diferencia de nivel social entre mestizos e indígenas que tiene su origen en mecanismos diferentes de un simple despojo territorial o de una "explotación" directa de unos por otros ya que muchos mestizos que partieron de las mismas condiciones que cualquier comunero han logrado, con un trabajo intensivo, acumular un poco, y luego plantar y cuidar una huerta de aguacate. Eso no fue la lógica de un comunero que no tuviera seguridad alguna en la tenencia de su tierra y tampoco con que a fianzar préstamos refaccionarios pues no pudo hacer otro uso de su ingreso monetario que gastarlo diariamente.

A pesar de estas complejas transformaciones, el maíz se sigue cultivando por varias razones: hay pequeños propietarios que no pueden plantar aguacate en sus tierras por falta de agua. Allí cultivan maíz de temporal barbechado con tractor; los que no tienen aguacate consiguen tractores rentados con los aguacateros $(\$ 2,200 / \mathrm{Ha}$. en 1984).

En los desmontes para plantar aguacate se cultiva maíz de temporal con azadón o animales, esperando a que los árboles entren en producción. Estas milpas sirven a menudo para adueñarse del terreno.

El maíz de "chucandirán" se sigue cultivando por su alta flexibilidad: por su ciclo muy corto se tienen más de dos meses para sembrarlo, y se logra sacar buena cosecha poniéndole lo mínimo de insumos y trabajo. Sobre todo para los que todavía tienen un tronco propio de caballos, estas parcelas representan un ahorro apreciable en la compra de maíz para el gasto.

El maíz de riego se cultiva todavía para sacar elotes, que permiten valorar cada kilo de grano al doble. Con siembra durante tres meses y cosecha escalonada de mayo a julio, se emplea un mínimo de mano de obra pues una persona alcanza a trabajar hectárea y media; muchas veces los que se dedican a esto son medieros, como algunos comuneros viejos que ya no quieren iniciar la experiencia del aguacate. En este sistema el maíz se riega de noche $y$, desde el mes de abril que es el mes más seco, antes de las lluvias fuertes - $1,000 \mathrm{~mm}$ anuales-de mayo a octubre se tiene rastrojo verde que completa adecuadamente la alimentación de algunas vacas lecheras. Muchas veces los "ecuareros" - campesinos que a veces tienen extensiones bastante grandes-, asocian a este cultivo verduras altamente redituables a pequeña escala: jitomate, frijol ejotero ("jicote")...etc. Todo el producto se vende en Atapan.

En sistemas de cultivo tan especiales, el Banco de Crédito Rural fracasó en tratar de implementar crédito para insumos al igual que en la Sierra Tarasca. Sólo en sistemas de temporal con tractor se hizo rentable, pero aún ahí, por el fraude perpetrado, dicha institución tuvo que retirarse a los dos años. Los campesinos que querían crédito para maíz lo consiguieron de otra 
manera, hasta utilizando los subsidios del FIOSCER. ${ }^{21}$ De todos modos la estrategia bancaria no contempla la vertiente aguacatera como zona propicia al financiamiento de un incremento en la producción maicera, lo que además no sería suficiente para mantener el cultivo en Atapan.

En fin, la superficie que dejan al maíz los sistemas de producción actuales, está lejos de asegurar la autonomía alimentaria en el área. Se estima que en los años cuarentas se lograba esta autonomía, pero sin que jamás se haya exportado maíz de Atapan.

Esto quiere decir que ahora, casi todos los habitantes tienen que abastecerse afuera. Afortunadamente prevalecen las relaciones familiares, y cada atapense trae maíz por su cuenta de la Sierra - Pamatácuaro, Zicuicho-o de lugares como Tocumbo y Tacátzcuaro. ${ }^{22}$ Pero en las tiendas, el cuarterón (1.5 Kg.) se pagaba hasta $\$ 72$ en marzo de 1984 , -o sea 3 o 4 veces el precio de garantía de la cosecha 1983-, bajo la presión especulativa en Atapan. La gente más acomodada - aguacateros- traen a menudo tortillas hechas en Los Reyes.

Esto nos lleva a concluir que: 1) el aguacate y la resina no lograron incrementar el nivel de vida de la mayoría de los comuneros; 2) a esa misma gente se les quitaron las fuentes de autoabasto, es decir se les empobreció y como consecuencia ahora se puede ver a varias familias ayudándose en su manutención; 3) es mucho el dinero prestado que nunca se devuelve, y las prácticas usureras alcanzaron los más altos niveles entre los abarroteros.

Así, desde que entró el aguacate, los campesinos tienen que comprar su maíz, y se les acabó el frijol y la calabaza, así como la posibilidad de mantener puercos con el grano. Con ello, se observa un empobrecimiento apreciable en la dieta campesina, sobre todo en cuanto a proteínas.

En síntesis, para muchos comuneros y sus familias las transformaciones recientes significaron un retroceso que contradice el "desarrollo" esperado del aguacate y de la resina.

\section{El aguacate elimina ciertas actividades}

El maíz no fue el único cultivo afectado por la introducción del aguacate; los campesinos acabaron con todo lo que se encontraba en tierra apta al cultivo del aguacate.

La fuerza que impuso al aguacate como cultivo principal con tanta rapidez fue en primer lugar su atractivo económico: con las técnicas

21. FIOSCER: Fideicomiso de Obras Sociales a Campesinos Cañeros de Escasos Recursos.

22. La Sierra Tarasca tiene que sostener el abastecimiento de varias zonas aguacateras en expansión como la de Atapan, lo que contrarresta el esfuerzo que el Estado desempeña ahí en tratar de incrementar la producción de maíz para el mercado nacional. 
utilizadas se recupera la inversión de la plantación a los seis años cosechados, y luego se puede sacar una utilidad promedio de $\$ 600,000$ por hectárea (1984) -más de 5 veces la de la caña-que se va incrementando con la edad del árbol (a los 7 años se sacan $80 \mathrm{Kg}$. de aguacate por árbol, y a los 15 años, $200 \mathrm{Kg}$. con costos apenas superiores).

Esta naturaleza de "producto de lujo" le permitió entonces eliminar todas las demás huertas: la utilidad por unidad de superficie es hasta 10 veces mayor que la del plátano, del café, del limón, del naranjo, y también muy por encima de las que generan los cultivos de riego como el ca mote y el jitomate. Sin embargo, estos tipos de frutales y verduras, se quedaron principalmente en los solares para asegurar el autoabasto de los atapenses que además, no modificaron su gusto por el aguacate criollo tan rápido como sus cultivos.

En las condiciones económicas vigentes se observa que la mayor redituabilidad del aguacate "Hass" (variedad mejorada que se encuentra en más del $95 \%$ de las huertas) se obtiene con dosis máximas de fertilizante y control total de plagas. Todo cultivo asociado está entonces prohibido ya que consume el fertilizante y almacena plagas que perjudican al aguacate. Estos cultivos - maíz, avena forrajera, caña - tradicionalmente asociados con los frutales, desaparecen rápidamente de las huertas, excepto cuando los árboles jóvenes todavía no entran en producción. Pero se estima que pronto se llegará a una desaparición total de las asociaciones con el aguacate en vista de que se están agotando las tierras donde todavía se podrían plantar nuevos arbolitos.

Y si bien no hay cultivos bajo los árboles, crece en ca mbio mucho pasto aprovechable para la ganadería. Esto, que es posible con el aguacate criollo, no lo es con las variedades mejoradas, que tienen ramas hasta el suelo y raíces que afloran: es por eso que no es posible la presencia del ganado en la parcela.

Si acaso algunos quieren seguir alimentando vacas prefieren cortar el zacate y llevárselo a los animales a los corrales y potreros. Esto representa un importante derroche de recursos debido a que:

- Hace falta mano de obra para cortar y cargar el zacate;

- Ahora las huertas se tienen que abonar con estiércol comprado afuera, -en los establos porcícolas de La Piedad o lecheros y avícolas de Jalisco- con todas las dificultades de manejo que esto implica. El costo elevado de esta operación la hace exclusiva de los productores más importantes, con lo que se acrecienta aún más la diferenciación.

-Los rastreos que se hacen en las huertas jóvenes ya no se aprovechan "gratuitamente" para los cultivos asociados.

De manera general resultó que el aguacate ha suprimido enormes superficies forrajeras: maíz y trigo utilizados por su rastrojo, y cultivos asociados a las huertas. Fuera de los potreros grandes que todavía tienen cuatro o cinco familias en San Rafael, esos cultivos eran el único recurso de 
muchos campesinos para alimentar su ganado de trabajo y de abasto. Sin embargo, la presión ga nadera disminuyó en los años cincuentas con la fiebre aftosa, que entonces facilitó la liberación de apreciables superficies de maíz y trigo; la ganadería nunca volvió a cobrar la importancia que tenía, y ahora solamente unas 15 personas tienen más de 10 reses.

Para mantener su ganado mucha gente introdujo cultivos forrajeros en lugares donde no se planta el aguacate: sorgo y avena, a menudo en tierras de riego; esto les permitía intensificar por la producción de leche el aprovechamiento de algunas vacas poco numerosas. A veces estos cultivos forrajeros se trabajaban en superficies apreciables y se vendían a los ganaderos que carecían de forraje.

A fines de los años sesentas los campesinos que tenían contactos afuera de la comunidad, los mismos que introdujeron el aguacate mejorado, empezaron a traer a Atapan ganado lechero de alto registro (Holstein), haciendo negocio en el pueblo con los sementales y encabezando un desarrollo lechero en pequeña escala. Potencialmente había posibilidades de comercialización gracias a la apertura de la terracería a Santa Clara que permitió el transporte de la leche a Los Reyes, ciudad en rápida expansión, en camionetas, pero nunca se exportaron del pueblo más de 150 litros diarios, entre seis productores.

Lo que sucedió mucho más fue la "holsteinización" de las pocas vacas lecheras que se tienen para "el gasto". El ganado lechero sacaba mejor provecho del escaso forraje, en cuanto que éste se presenta sobre todo en forma fresca: pasto en el monte durante las lluvias, rastrojo verde de maíz, sorgo y avena de riego, garbanzo y puntas de caña durante la zafra (los cañeros vendían el manojo a $\$ 50$ en mayo de 1984 , cuando el rastrojo no se quedaba a medias entre el dueño de la parcela y el cortador). De esta manera, el ganado mejorado ha permitido sacar el mejor provecho de la pequeña producción forrajera todavía existente. La leche no se exporta pero permite el autoabasto en Atapan, de tal forma que en el pueblo se venden leche, crema y jocoque por parte de los que tienen leche de sobra, siendo éstos principalmente miembros de familias mestizas.

La ganadería mixta se practica todavía en los grandes potreros de San Rafael y permite que sigan ejerciendo algunos matadores, pues el ganado ya no se vende a la Huasteca para el mercado nacional. Pero el "retroceso forrajero" vinculado al cultivo del aguacate ha entrañado que se "subaprovechen" mucho los agostaderos comunales constituidos por los bosques. Ahora estos agostaderos se encuentran en una situación de desperdicio total por parte de la comunidad indígena, y se "regalan" a ganaderos de Los Reyes u otras comunidades, que pueden introducir sus animales al bosque de Atapan solamente a cambio de una cooperación para la fiesta del pueblo.

Finalmente, además de esta "enajenación" de los recursos en la comunidad indígena, el decaimiento ganadero tiene otras consecuencias 
nefastas:

- Baja de la fertilidad orgánica en las parcelas de aguacate de todos los que no se pueden permitir la compra de estiércol; precisamente los comuneros que solamente pudieron plantar unos cuantos árboles en pendientes fuertes, ahí donde la erosión cobra su máximo efecto.

-Escasez de las bestias de tiro pues los bueyes no se usan desde muchos años y solamente quedan algunos caballos lo que todavía hace más utópico volver a cultivar maíz en sistemas que no incluyan muchos insumos ajenos.

En pocas palabras, la comunidad indígena es la que más se encuentra afectada por el decaimiento ganadero vinculado con la expansión del aguacate.

\section{Aguacate y caña}

Con mucha certeza se puede afirmar que la mayoría de los aguacateros importantes sacaron de la actividad cañera los recursos para plantar el aguacate. ${ }^{23}$ Después de pocos años, éste rinde bastante como para poder dejar la caña y plantar aguacate en su lugar. Pero no ha sucedido así, porque de los dos cultivos, cada uno se acomoda a un suelo muy diferente. Se estima en menos de un $10 \%$ la superficie cultivada en caña en 1960 , que se convirtió en huertas de aguacate. Esta pequeña disminución fue contrarrestada por los desmontes que hicieron algunos ejidatarios para plantar caña; resulta que la superficie de caña cultivada en la "zona 18" (Atapan) siempre se ha mantenido alrededor de 240 hectáreas desde hace 25 años, de los cuales 12 a $15 \%$ se cortan a los 2 años por estar en lugares más frescos.

Se supone entonces que muchos campesinos tienen sistemas de producción que involucran de manera estable el aguacate y la caña. En el cuadro 35 está un resumen simplificado de los conceptos que constituyen el proceso de trabajo más frecuente para los dos cultivos; se evidencia que el aguacate y la caña tienen un calendario de trabajo bastante parecido, aunque el aguacate es más intensivo: requiere más mano de obra por hectárea.

En la estación seca la mano de obra para las cosechas es muy diferenciada. Los cortadores de caña son exclusivamente comuneros - los mestizos desprecian este trabajo-mientras los cortadores de aguacate son en mayor parte jóvenes de todo el pueblo, que se pueden trepar a los árboles sin lastimarlos. En cuanto a la zafra, la mayor parte del corte en el área de

23. Actualmente las utilidades netas alcanzan $\$ 80,000$ a 120,000 cada año por hectárea en la caña, y estaban mucho mayores en valor real hace 10 años. Después de algunos años de depresión están subiendo de nuevo, mientras que las del maíz, cuando existen no rebasan los 15,000 pesos por hectárea (precios de 1984). 
Procesos PRoductivos DEL AGUACATE Y DE LA CAÑA

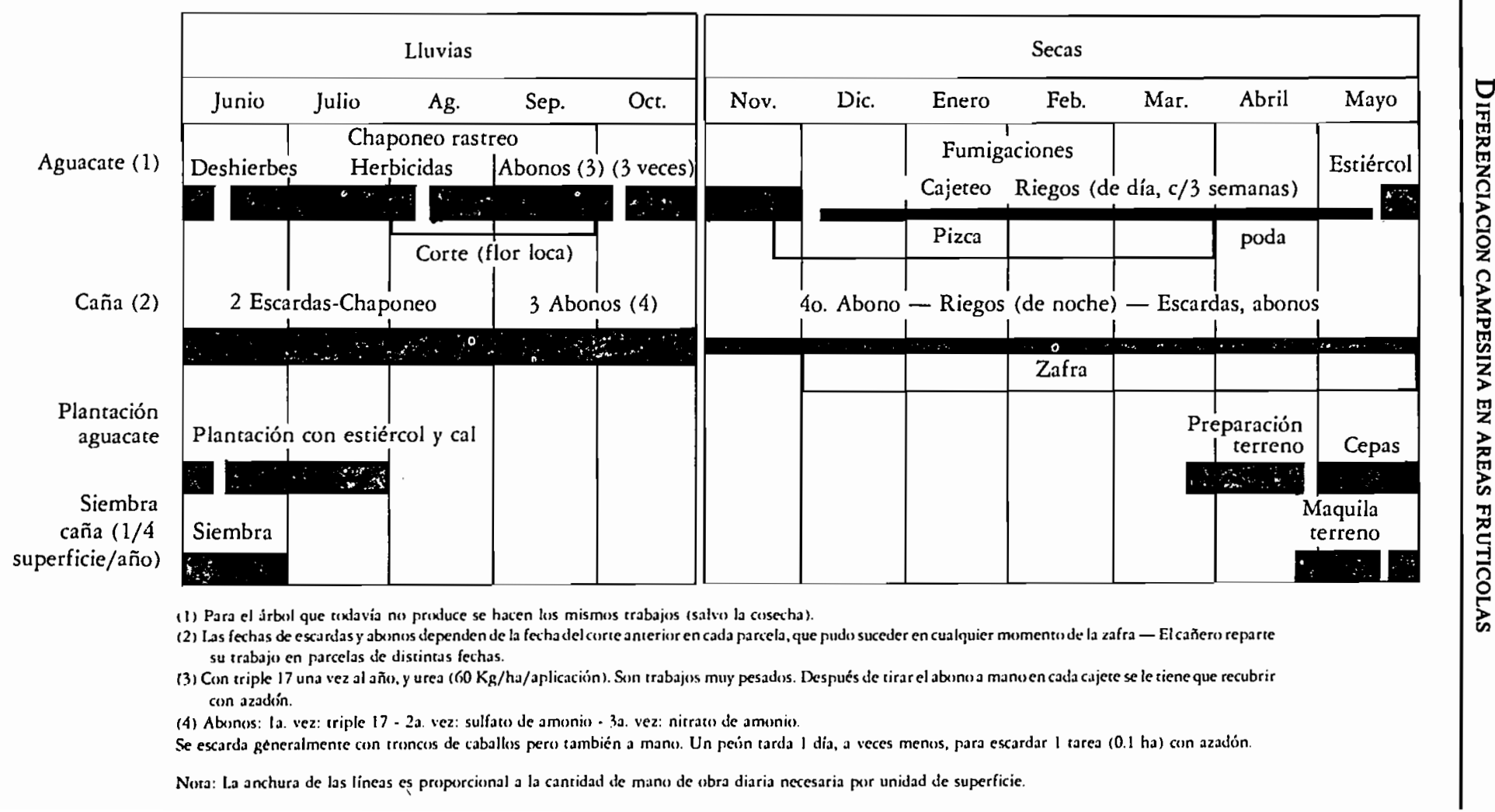


estudio lo realizan campesinos de Atapan. Estos cortadores, a diferencia de los foráneos que trabajan en el Valle, tienen la oportunidad de cenar y dormir en sus casas. Sin embargo esto les quita bastante poder de organización colectiva y además, sus condiciones de trabajo son de las más difíciles: pendientes húmedas donde la caña no se quema bien y donde no entran los camiones ni las máquinas cargadoras, por ello hay que cargar mucha caña a lomo, mientras los amarradores acaparan una mayor parte de los sobrecargos correspondientes. Esto ha hecho que en Atapan los cortadores de caña sean los que no se han podido contratar en el cajeteo del aguacate. Si llegan a faltar cortadores en la zafra, el ingenio siempre puede traer cuadrillas de afuera.

En cambio el problema de la competencia entre los dos cultivos por la mano de obra se hace más agudo en la estación de lluvias, y siempre se resuelve a favor del aguacate porque el atractivo del peonaje en el aguacate rebasa en mucho el de las demás actividades; por ejemplo, en mayo de 1984 una jornada de chaponeo en las huertas, trabajando en la sombra se pagaba - cuando no era a destajo- a $\$ 400$ por un horario de las 7 a las 12 o 13 horas conseguido por los peones para comer en casa y no estar bajo las tormentas eléctricas. Esto rebasaría al salario mínimo oficial $(\$ 550)$ por una jornada completa. En cambio no se alcanzaba el 80 o 90\% de este "mínimo" en las demás actividades: $\$ 400$ a $\$ 500$ por tarea ${ }^{24}$ de caña chaponeada, y $\$ 300$ al día en la resina. ${ }^{25}$ La ventaja del aguacate se hace todavía más evidente cuando se trabaja a destajo: en el cajeteo se pagó el cajete a $\$ 50$ en 1984, cuando se podían hacer 20 al día.

Se comprueba entonces que la actividad aguacatera, por las buenas utilidades que deja, se ha reservado la posibilidad de un uso óptimo de la mano de obra con el pago de sueldos apenas superiores. Las consecuencias más importantes se encuentran en una deficiencia de trabajadores para las labores de plantación y mantenimiento de la caña. En efecto, los escasos campesinos que no trabajan en el aguacate se ocupan con los animales de tiro en la siembra del maíz de temporal. Esto lo resuelve el ingenio introduciendo cada vez más maquinaria, contratando a tractoristas de Los Reyes para hacer los trabajos de preparación del terreno, primera escarda y a veces abonos, lo que reduce en un tercio el número de peones y animales necesarios en la temporada de lluvias. Esta práctica no es absoluta en Atapan, pues existen muchas parcelas en las cuales los tractores no entran; sin embargo de este modo campesinos foráneos sustituyen a los atapenses, quienes requieren

24. Una tarea (22 surcos de $50 \mathrm{~m}$. de largo) es lo que en promedio se chaponea en una jornada completa.

25. De dos latas que se pueden sacar diariamente $(45 \mathrm{Kg}$. a $\$ 20$ ) el dueño de los árboles conserva entonces $\$ 550$ por día, lo que le asegura el salario mínimo mientras se puede dedicar a otras actividades. 
entonces que se mantenga el nivel de empleo en el aguacate.

Con todo, sería equivocado ver a la caña y al aguacate como dos cultivos que se hacen una competencia destructiva: hay muchas razones por las cuales se encuentran en el seno de los mismos sistemas de producción. De hecho, los aguacateros aprovechan las ventajas financieras ligadas al cultivo de la caña:

-El ingenio da crédito de avío hasta el fin de la zafra para casi todos los gastos de la producción, entre ellos el fertilizante: a menudo se echa parte de este fertilizante en las huertas de aguacate;

-Este crédito de avío cuesta al campesino solamente un $12 \%$ anual lo que representa un subsidio bastante importante; además permite que en las lluvias solamente queden por hacer los gastos del aguacate. Estos se hacen con las utilidades netas de la zafra (tras descuento de los insumos a precio del año anterior más un $12 \%$ ), lo que sale mucho más ventajoso que el tener que pagar los insumos a precios del año siguiente; -El ingenio (FIMAIA) ${ }^{26}$ vende camiones de carga con un crédito muy interesante, que supuestamente se paga trabajando cinco años en el transporte de la caña durante la zafra. Muchos aguacateros aprovechan estos camiones para cargar aguacate: es un elemento apreciable para comercializarlo individualmente.

También existen casos en los cuales los campesinos mantienen una parcela de caña para beneficiarse del seguro social: el seguro de los cañeros es interesante porque da derecho a una jubilación (el cañero o la viuda perciben entonces el salario mínimo).

En Atapan no se da tanto este caso porque gran parte de los resineros tienen seguro, y quizá los aguacateros lo van a tener proximamente. En fin, los que son marginados por la falta de seguro social son los que solamente cultivan maíz, que por lo menos tienden a ser cada vez más escasos.

La existencia de un buen seguro no quedará entonces como primera motivación para seguir cultivando caña. Esta actividad tiene más bien interesantes ventajas financieras, además de ser la más redituable en las tierras arcillosas donde no se da el aguacate.

En síntesis, los fenómenos descritos en este capítulo evidencian que al aguacate, se le otorga el uso óptimo, y a veces exclusivo, de los factores de producción, provocando ajustes o desequilibrios en las demás actividades. En efecto, el cultivo del aguacate ejerce presiones selectivas sobre aquellas que no compiten directamente con él: caña, resina, madera y, en menor medida, ganadería, al mismo tiempo que somete a todos los demás a un proceso de eliminación más o menos rápido. De esta manera, al convertirse en un cultivo prioritario, ha contribuido a consolidar el proceso de 
diferenciación social, sin que esto signifique la eliminación de los productores maiceros, que en adelante serán el estrato inferior del sistema social de producción.

\section{EVOLUCION SOCIO-ECONOMICA INDUCIDA POR LA EXPANSION DEL AGUACATE}

Las transformaciones producidas por el aguacate han ido mucho más allá de los efectos inducidos por el desplazamiento de varias actividades: por una parte, su cultivo requiere mano de obra con características especiales y por otra, su manejo involucra grandes cantidades de dinero.

\section{El aguacate como generador de empleo}

En efecto, en lo que a mano de obra se refiere, se trata de un cultivo más intensivo que las demás producciones del área: se estima que en la estación más cargada se necesita un hombre para cada dos hectáreas, mientras el mismo trabajaría 4 o 5 hectáreas en el maíz o la caña y 80 hectáreas en la resina. Excepto en los meses de abril y mayo, el aguacate ocupa entonces casi 300 personas de Atapan, entre las cuales 170 son jefes de familia.

Sin embargo los efectos locales sobre la oferta de trabajo se limitan a la producción misma. En efecto los empleos indirectos que se generan abarcan principalmente los sectores lejanos de la comercialización, quizá la industrialización, y sobre todo de los insumos de fabricación industrial para el cultivo. En los sitios de producción, los empleos industriales se limitan a los que proporcionan las empacadoras de aguacate ( 20 en Atapan), y a nivel regional la producción de tablitas para hacer las cajas. ${ }^{27}$

A pesar de esta última observación, es indudable que desde los años sesentas el desarrollo aguacatero ha fijado a la población; eso se confirma en el hecho de que la emigración definitiva parece ser mucho mejor en Atapan que en lugares donde no hay aguacate, tal y como puede apreciarse en el cuadro 36.

Resulta que el aguacate no ha alcanzado a atraer población; pero sí redujo mucho la emigración y permitió que los atapenses se quedaran a trabajar en su pueblo, especialmente los jóvenes, cuya presencia se hace

27. Estas provienen de la Sierra Tarasca. Es una de las formas relevantes de aprovechamiento clandestino y depredador de la madera, pero mantiene a numerosos campesinos desocupados de las comunidades indígenas. 
CuAdro No 36

\begin{tabular}{|c|c|c|c|}
\hline Población de Atapan* & $\begin{array}{c}\text { Tasa anual } \\
\text { de crecimiento } \\
\text { real }\end{array}$ & $\begin{array}{c}\text { Tasa anual } \\
\text { de crecimiento } \\
\text { natural }\end{array}$ & $\begin{array}{l}\text { Saldo } \\
\text { migratorio } \\
\text { a nual }\end{array}$ \\
\hline Censo 1950: 1385 hab. & \multirow{2}{*}{$-0.8 \%$} & \multirow{2}{*}{$+3.5 \%$} & $-4.3 \%$ \\
\hline Censo 1960: 1296 hab. & & & \multirow{2}{*}{$-1.3 \%$} \\
\hline Censo 1970: 1560 hab. & $+2.4 \%$ & $+3.7 \%$ & \\
\hline & $+3.3 \%$ & $+3.5 \%$ & $-0.2 \%$ \\
\hline
\end{tabular}

- Según los censos de población y vivienda de la S.P.P. Los datos de 1950 y 1960 son exactos; los de 1970 y 1980 son aproximaciones a partir de los datos de población por tamaño de localidad y su evolución.

notar, en fuerte contraste con el éxodo de los pueblos de la Sierra en Pamatácuaro y Zicuicho; la gente recuerda que hasta los años sesentas hubo desempleo en la región, y éste ha desaparecido.

Ciertamente, hay mucha emigración temporal a los Estados Unidos; aunque ésta es menor que antes, los que van ahora son jóvenes solteros, - comuneros sobre todo-, que traen dinero para que su familia plante aguacate. Antes, los ingresos de la emigración se utilizaban mucho más para mantenerse en la comunidad indígena, mientras los mestizos poco afortunados iban a Estados Unidos para poder plantar aguacate o comprarse una camioneta al volver. Ahora, se estima que en Atapan hay un equilibrio entre la oferta y la demanda de trabajo, tanto permanente, como lo evidencia la debilidad del saldo migratorio actual, como temporal. Este equilibrio existe a nivel de la producción de aguacate y caña. Durante la zafra, los cortadores del pueblo cubren en forma aproximada los requerimientos de fuerza de trabajo de la "zona 18" (según la nomenclatura del ingenio), perteneciente a los cañeros de Atapan. Así, a nivel del terruño, se desenvuelve un sistema social de producción bien delimitado, pues casi ningún atapense trabaja fuera y pocos foráneos - albañiles, tractoristas - trabajan en Atapan. Y cuando alguien sale a trabajar fuera, deja de vivir en Atapan.

Por otro lado, se supone que con el número de campesinos que ahora cobran un salario u otros ingresos monetarios provenientes del aguacate, se incrementaría la demanda solvente, lo que podría ayudar a crear otras actividades en la región y ampliar los mercados regionales.

En cuanto a otras actividades, en el pueblo solamente han surgido como empresas las cinco empacadoras de aguacate. Pero la actividad más relevante ha sido la construcción de casas nuevas o sus ampliaciones por parte de los aguacateros. El jefe de tenencia registra unas 200 construcciones 
nuevas entre 1965 y 1982, que han reducido la superficie de lós solares plantados con frutales. Hoy en día la actividad constructora sigue siendo muy importante en Atapan y por medio de la contratación de albañiles y de la compra de materiales se da un fuerte impulso a la economía de la ciudad de Los Reyes, cabecera del municipio.

Por otro lado, para traer los materiales de construcción la gente de Atapan utiliza los camiones de carga destinados al transporte de aguacate o de caña. Los propietarios de estos camiones venden sus servicios a los demás, transportando grava, cemento, arena, ladrillo y tabique. Así, varios camiones que supuestamente se tienen que pagar al ingenio con trabajo en la zafra, sirven durante la misma zafra para cargar materiales de construcción (temporada seca). Si se les reclama a los dueños, aguacateros en su mayoría, aseguran poder pagar el camión al contado. Varios campesinos se volvieron "camioneros": cargan caña en la zafra —pagado \$140 a \$210 el viaje en 1984 más las propinas, por 5 o 6 viajes diarios- y materiales de construcción durante todo el año; durante las lluvias la demanda es menor, lo que les permite cuidar su huerta de aguacate o transportar madera hasta Tingüindín para la comunidad indígena. ${ }^{28}$ Cuando tienen tiempo, estos camioneros contratan peones para llevarlos a las familias que los requieren.

Esta dinámica ha generado que los ingresos del aguacate se inviertan mucho en camiones o camionetas, éstas últimas teniendo una doble utilidad: transporte del aguacate y mejoramiento del nivel de vida, que ansían muchos mestizos con el "poder de consumo" que les otorgan las utilidades del aguacate. De este modo, las zonas aguacateras constituyen un buen mercado para la industria automotriz nacional e internacional.

La otra cara del "desarrollo" es que, con el empleo que of rece el aguacate, muchos comuneros que eran campesinos en el sentido de que cultivaban la tierra, se han convertido en peones temporaleros con otra fuente variable de ingresos como es la resina. Resulta así un empobrecimiento progresivo en la comunidad indígena, por la reducción paulatina a estos dos tipos de actividades. En fin, la misma comunidad indígena ha llegado a ser poco a poco una reserva de mano de obra para las resineras y los aguacateros. La forma de las relaciones productivas se ha simplificado y radicalizado en comparación con la que existía entre los caciques y los campesinos pobres; unos agricultores se han consolidado como aguacateros, dueños de la tierra y patrones, mientras la situación de muchos va siendo cada día más precaria (peones a destajo) a pesar de su participación en el incremento global de los ingresos.

28. Cobran $\$ 6,000$ el viaje, unos $\$ 300$ por $\mathrm{m}^{3}$, acaparando así una tercera parte de la ganancia total que se realiza en Atapan con la madera. Por otra parte, se desmonta el bosque que tiene el acceso más directo a los caminos transitables: los de la parte oriental del territorio. 


\section{El aguacate como inversión fuerte de lenta recuperación}

Para plantar aguacate en una parcela hace falta instalar cierta infraestructura de riego; a veces comprar bombas de agua y mangueras y, a menudo, construir un almacén de agua (pila). Además de estos gastos y de los que se hacen en el mismo proceso de plantación, hay que esperar 3 o 4 años a que los árboles empiecen a producir para percibir ingresos. Mientras tanto, los costos anuales de mantenimiento alcanzan $\$ 200,000 /$ ha. anuales, ${ }^{29}$ y se estima que estos gastos iniciales se pagan con la cosecha de los tres primeros años productivos, es decir, se amortizan a los seis años de haber sido cosechados. Por tanto, antes de ese momento es necesario tener otras fuentes de ingresos.

Cuando los árboles ya están produciendo, los costos se elevan a $\$ 300,000$ al año o más, repartiéndose de la siguiente manera: ${ }^{30}$

-mano de obra: $27 \%$

-fertilizante, insecticidas, herbicidas y fungicidas, mantenimiento de la maquinaria: $56 \%$

-otros gastos: $17 \%$

Para realizar todo esto se necesita disponer de mucho dinero de antemano. Es la razón por la cual en varios lugares muchas huertas son de profesionistas de fuera. Pero cuando se instalaron los primeros aguacateros en Atapan los bancos privados ya empezaban a dar crédito a los de Peribán, y los atapenses supieron aprovechar la oportunidad.

Actualmente estos bancos, dan créditos refaccionarios y de avío para la plantación y el mantenimiento del aguacate. El Banco de México, a través del FIRA, es el que aporta del 50 al $90 \%$ del capital necesario. Las tasas de crédito dependen de los ingresos globales del productor, generados por el conjunto de sus actividades:

Cunadro Ne 37

\begin{tabular}{|c|c|c|}
\hline Clase & Ingreso neto anual (pesos, 1984) & Tasa promedia \\
\hline 1 & 0 a 550,000 & $28 \%$ \\
2 & 550 a $1^{\prime} 750,000$ & $37 \%$ \\
OTP* & más de 1'750,000 & $52 \%$ \\
\hline
\end{tabular}

- = Otro tipo de productores.

29. Una hectárea lleva de 100 a 150 árboles. Precios de 1984.

30. Fuente SARH-INIA, Pátzcuaro. 
Resulta que como $\$ 550,000$ anuales (45,000 mensuales) -y más todavía $\$ 1750,000$ - son ya ingresos netos muy importantes, la mayoría de los aguacateros no alcanza este nivel, teniendo que recibir el máximo subsidio. Así, en las clases uno y dos se encuentran muchos aguacateros ya "acomodados".

Los bancos tienen criterios bastante selectivos —además de un estudio muy detallado de las disponibilidades anuales previsibles de cada productorpara otorgar el crédito. En efecto, el valor de la tierra y de la huerta misma están lejos de poder constituir una garantía para las cantidades de dinero que se manejan, además de que no les interesa a los bancos encargarse de las huertas. Entonces influyen mucho las recomendaciones de otros aguacateros respecto al solicitante, sobre todo cuando se trata de la primera huerta, para la toma de decisiones del banco. Esto favorece la concentración de las huer tas en torno a ciertos grupos teniendo acceso más fácil al crédito los que ya han probado su eficiencia y pudiendo incluso, impedir a través de ciertos aguacateros, el acceso de otros grupos al crédito refaccionario. Por tanto, para el aguacate en tierra comunal o ejidal casi no se otorgan créditos porque la "responsabilidad colectiva" que respalda el crédito llega a menudo a ser un fracaso, sobre todo en un lugar como Atapan donde hay divergencias de interés entre los comuneros. Cuando ha ocurrido que se otorga crédito a una comunidad indígena, el banco toma como garantía el fondo comunal de la resinera.

Muchos campesinos no tienen acceso al crédito para el aguacate, sobre todo los ejidatarios y los comuneros. Ellos recurren entonces a diversas fuentes de dinero. A veces utilizan algunos ahorros que pudieron acumular. A continuación registramos las posibilidades de que disponen los campesinos:

- Venta de ganado (ya son pocos los que aún tienen);

-Uso de ingresos del trabajo en los Estados Unidos;

-Injerto sobre aguacate criollo (evita comprar la planta pero ya son escasos los que disponen de matas de criollo);

-Utilización de los créditos otorgados por Banrural para el maíz (a veces da este banco crédito de avío para aguacate a los ejidatarios);

- Venta de la cosecha al tiempo a los empacadores-comerciantes. El precio pagado está más bajo $(\$ 60-80 / \mathrm{Kg}$.) que el precio vigente en la estación de mayor saturación del mercado (invierno del 83-84: \$100$120 / \mathrm{Kg}$.). Sin embargo muchos tienen que recurrir a eso, que además no resuelve el problema de la plantación.

-Sistema de plantación a medias: uno pone el trabajo y los insumos, otro la tierra. Precisamente son casi siempre los comuneros los que ponen la tierra, y los pequeños propietarios los que pueden pagar la mano de obra y los insumos. Cuando los árboles entren en producción, 
se comparte la huerta en dos mitades iguales para cada quien. Supuestamente, el total regresará al comunero cuando los árboles se agoten ( 25 años después) pero de hecho es una nueva forma de acaparamiento de las tierras por parte de los pequeños propietarios, ya que muchos comuneros recurren a este sistema para poner su primera huerta.

La elevada frecuencia de los campesinos que pusieron su huerta sin crédito bancario, recurriendo así a la plantación a medias y a la venta al tiempo, hace resaltar la existencia de una diferenciación marcada entre los sistemas agrícolas de producción que cuentan con aguacate. A continuación describimos lo que se puede considerar como los dos casos "extremos" que, sin embargo, se presentan con una frecuencia elevada:

a) Unos, en su mayoría comuneros tuvieron que recurrir a alguna de las estrategias mencionadas anteriormente porque no conseguían crédito. Como se trata de plantaciones recientes, y en la mayoría de los casos ya no quedaba tierra hubo que ir al monte donde los comuneros saben ubicar la tierra "T"upúri" o la tierra "de encino". Así se encuentran pequeñas plantaciones, que por no rebasar los cien árboles no les darán derecho al seguro aguacatero, en sitios que se apropiaron y procuraron poner riego, a través de la captación del agua de algún pequeño manantial. En la mayoría de los casos estas plantaciones se ubican en pendientes fuertes.

Como no tienen mucho dinero, no traen estiércol, y como abono químico solamente compran sulfato de amonio, que es el más barato. Resulta así una fertilización inadecuada y una baja en la fertilidad orgánica -lo que facilita la erosión ya de por sí pronunciada en las pendientes.

La venta al tiempo limita mucho los gastos que pueden hacer al año siguiente; lo cual significa un uso casi nulo de insecticidas y fungicidas y muchas veces una realización diferida de los trabajos en comparación con la fecha ideal: así, estos campesinos se ocupan en otras actividades, y al contrario de ciertos aguacateros, no pueden contratar a los peones el día que quieran para que efectivamente se realice el trabajo a tiempo.

Varios han tenido que plantar aguacate de puro temporal porque no tenían agua disponible; de este modo la fruta sale más chica, perjudicándose mucho el productor ya que se paga según el calibre y el árbol tarda más en desarrollarse; para recuperar la inversión de la plantación hay que esperar dos años más, aunque con costos un poco menores.

b) Otros instalaban huertas más grandes, que les dieron la posibilidad de "acumular" los recursos: con los ingresos de las primeras huertas se gastó en infraestructuras hidráulicas para poder plantar más arriba. ${ }^{31}$ También se

31. Si a éstas se les agrega las plantaciones de los comuneros en el cerro, son muchas hectáreas de aguacate de riego fuera de las "Unidades de Riego" de la SARH. 
pudo gastar entonces en almacenes de agua ya guardada en pilas, cuya función es doble: utilizar agua en las huertas fuera de los días autorizados a cada uno para tomar en la zanja, y asegurarse contra la falta de agua, por ejemplo tomándola de noche.

Estos aguacateros tienen una productividad del trabajo más alta: con tractor, comprado al contado hace 10 años o rentado, ${ }^{32}$ para rastreo, con discos y herbicidas, se prescinde de los peones necesarios para chaponear y cargar el zacate; el mismo tractor permite realizar hasta 12 fumigaciones al año con un sólo hombre en 5 Has., o más. Así, tienen bajo control el mayor factor de inseguridad del cultivo.

Aplican una fertilización calculada con mucha precisión, lo que aumenta su eficiencia, y cada día ajustan la mano de obra a las necesidades del cultivo, contratando peones a destajo.

Algunos tienen pensado aumentar todavía la productividad del trabajo con una inversión importante que es el riego por aspersión que permite regar de noche follaje y suelo con sistema automático y gastar un mínimo de agua, a la cual se pueden incorporar abono e insecticida para limitar el gasto de energía. El único obstáculo es actualmente la carencia de energía eléctrica.

Estos aguacateros procuran vender su cosecha cuando el precio sube; sólo hace falta cierta reserva de dinero para esperar, pues la fruta de todos modos se conserva varios meses en el mismo árbol, lo que es una de las grandes ventajas de la variedad Hass. Estos productores son generalmente de los que ya habían plantado en los años sesentas o a principios de los setentas, gozando de una fuerte "renta diferencial" porque tuvieron las mejores tierras a los precios más baratos, la planta costaba muy poco y la fruca se vendía más cara. El precio de la planta, que viene de los viveros de Peribán, ha subido mucho desde hace cinco años (\$200 la pieza en 1984) y a veces se tiene que abandonar la mitad del terreno para poder plantar.

Así, Atapan se caracteriza por una fuerte diferenciación entre los aguacateros, sobresaliendo los que plantaron más temprano y en gran escala, únicos que realmente tienen una posibilidad de control sobre el proceso productivo y la comercialización. En este sentido, la "riqueza" de muchos dueños de huerta es bastante precaria y relativa.

El aguacate rinde mucho.

En general cualquier persona quiere tener una huerta, aún pequeña, por los beneficios que se logran alcanzar; en 1984 una hectárea - 130 árboles de 9

32. Se estima que unas 50 personas aprovechan con frecuencia variable los 15 tractores que hay en Atapan. 
años de edad- puede dar una utilidad de $\$ 700,000$ contra $\$ 100,000$ por hectárea en la caña; estas cifras son muy ilusorias en ciertos sistemas de producción, pero suficientes para generar una verdadera "carrera ciega" de todos los campesinos para plantar aguacate y un esfuerzo sostenido para lograrlo, originando una competencia desmedida por el control de los recursos indispensables.

En la comunidad indígena los que carecían de tierra tomaron por la fuerza tierras del cerro, donde han desmontado y sembrado maíz para adueñarse del terreno mientras el aguacate va creciendo. Así se perjudicó a algunos resineros, y se expandió una tendencia al cercado de parcelas en el bosque. Por otro lado, la madera que resultó de estos desmontes no se pudo aprovechar legalmente para el bien del campesino que la tumbó, y se quedó tirada con el derroche que esto implicaba.

Con el aumento de las necesidades para el riego, el agua empezó a faltar con frecuencia en las secas (esto se debe también a los desmontes que se hicieron en la Meseta Tarasca). Las pilas y el riego de noche son estrategias para no carecer de agua, y ha resultado que en las partes donde ésta es más abundante - tierras con los aguacatales más antiguos- los campesinos se oponen a la instalación de obras repartidoras por la SARH. Pero los que todavía padecen más son los ejidatarios y todos los cañeros de la cuenca regada por el río Atapan en la parte baja.

Plantar aguacate se ha vuelto, en cierto modo, un objeto de competencia entre los campesinos por lo que la asistencia técnica es algo que buscan desesperadamente, al contrario de lo que sucede con muchos otros cultivos. Los bancos no necesitan encargarse de proporcionarla y los aguacateros más experimentados en el pueblo pueden canalizar sus consejos hacia las personas que quieren, controlando así el desarrollo aguacatero en todo el terruño.

Por supuesto los agricultores no son los únicos en beneficiarse de las buenas utilidades del aguacate. La mayor parte vende su producto a cinco comerciantes, - tres son de la misma familia- que tienen empacadoras con algunos obreros en Atapan y bodegas en el mercado de Guadalajara, vendiendo para exportación o para el mercado nacional. Tres comerciantes forasteros - de Peribán y Tocumbo-vienen también a comprar aguacate en Atapan. Estos empacadores traen a menudo cuadrillas de pizcadores, que se utilizan, sobre todo, en las huertas de los campesinos que venden al tiempo y no pueden contratar cortadores. El precio de venta al tiempo incluye el "descuento" correspondiente, a menudo más importante que el costo real del corte. En estos casos el comerciante espera hasta que los precios suban en el mercado nacional para cosechar y realizar un beneficio máximo. Por ejemplo, en abril de 1984 , vendían $1 \mathrm{Kg}$ a $\$ 270$, cuando ellos lo compraban a $\$ 70$, con solamente $\$ 25$ adicionales de costos: corte, empaque y transporte. Se entiende entonces la alianza entre comerciantes y bancos para 
lograr que no todos los productores consigan crédito de avío.

En los demás casos los comerciantes realizaban en promedio una utilidad de $\$ 30$ por kilogramo de aguacate en 1984 , mientras el transporte con sus propios camiones les costaba $\$ 10$. Para recuperar esta utilidad del comerciante, algunos aguacateros han tratado de conseguir una salida directa al mercado, en caso de tener camiones como es el caso de varios mestizos y de un comunero. Otros tienen algunos parientes en situaciones estratégicas y abastecen varios tianguis de Guadalajara o México, realizando así la venta directa. Aquí se nota otra vez la importancia de tener una camioneta o un camión. Los aguacateros de Atapan han logrado cierta independencia en la comercialización, y casi no sufren del dominio del centro regional que es Peribán, aunque como lo hemos visto, ya solamente una parte de los aguacateros aprovecha esta situación.

Otros sectores foráneos luchan por compartir las ganancias. Así, en Atapan mismo hay tres o cuatro bancos que compiten para conseguir clientes, para el provecho de muchos aguacateros que consiguen facilidades. Además el cultivo del aguacate utiliza muchos insumos industrializados; "ahora la tierra 'necesita' el fertilizante", es una reflexión común porque ha incrementado mucho las exigencias de los campesinos en cuanto a la productividad por árbol y esto se entiende perfectamente porque su precio como producto de lujo hace más rentable la utilización de dosis muy altas de fertilizantes, insecticida o fungicida; el costo marginal del insumo es muy inferior al valor de la producción adicional de aguacate.

Así, con la superfície que cubre el aguacate en la región se ha impulsado un fuerte desarrollo local de FERTIMICH y del comercio privado de insumos agrícolas en Los Reyes y Peribán. Detrás de todo eso se nota el impacto de la industria internacional -especialmente estadounidense - de maquinaria (tractores Ford, Massey Ferguson y sus implementos), químicos (insecticidas y herbicidas) y sistemas de riego, que tiene con el cultivo del aguacate fuertes posibilidades de expansión.

Dicha expansión tiene ciertos límites: es tal la cantidad de árboles de aguacate joven que todavía no están en producción, que existe la posibilidad de que se rebase la capacidad del mercado actual cuando estos árboles entren en producción.

Frente a esta eventualidad, los que están más protegidos, aparte de los cañeros, son los productores que reducirán el uso de mano de obra por medio de tractores, riego por aspersión, etc. Estos podrían aguantar bajas importantes en los precios. La generación de productores innovadores que ha introducido el aguacate en Atapan, es la misma que sigue anticipando las modificaciones en las técnicas empleadas 10 años después. Los que son 
ingenieros ${ }^{33}$ tuvieron oportunidad de informarse sobre otros cultivos y sus mercados, y podrán introducir nuez "de macadamia", papa o soya si el aguacate deja de ser rentable. Muchos aguacateros "chicos", menos relacionados e informados, no podrán aprovechar los nuevos cultivos; porque no tienen tierras en las restringidas áreas que serían favorables a estas nuevas producciones, o porque no tienen ingresos suficientes para hacer nuevas inversiones con anticipación.

La eventualidad de un retroceso aguacatero es lo que, de manera muy concreta, da la medida de la inseguridad en la cual están la mayoría de los campesinos de Atapan. Así, es muy probable que dentro de 10 o 20 años vuelva a hacerse imperante de una u otra forma la necesidad de la emigración para completar los ingresos monetarios muy eventuales del trabajo asalariado en las huertas y los decrecientes beneficios de una parte apreciable de los aguacateros.

\section{CONCLUSIONES}

Integración campesina y dinámica de los sistemas de producción Al final se confirma la existencia de un sistema social de producción muy coherente en Atapan, pues la organización del trabajo se enmarca en un terruño muy bien delimitado, inscrito dentro de los antiguos linderos de la comunidad indígena y de los del ejido de Atapan. Con el desarrollo aguacatero se reforzó esta "individualidad" del sistema, pues muchos trabajadores regresaron al área de estudio.

Dentro de este marco las diversas actividades están estrechamente relacionadas entre sí, de tal manera que la irrupción del aguacate ha fomentado o acelerado cambios muy profundos:

-Eliminación progresiva de todos los cultivos que competían directamente por la tierra, con el aguacate, principalmente el del maíz de autoabasto, y gran parte de la base forrajera para la ganadería;

-Auge de la extracción de resina por la mano de obra empleada en el aguacate: primero como sustituto al cultivo del maíz para conseguir ingresos y luego como la actividad que tiene la mejor complementariedad con el trabajo asalariado en el aguacate en cuanto a organización del trabajo;

-Permanencia del cultivo de la caña que se combina territorialmente con el aprovechamiento de las huertas y participa en el financiamiento del aguacate.

Desde un punto de vista socio-económico, este proceso de simplificación

33. Entre los mestizos hay mucha preocupación para que los hijos puedan estudiar agronomía, mientras en la comunidad indígena una mayoría de niños deja la escuela temprano para trabajar de peón o ayudar a la familia. 
en los sistemas de producción se ha acompañado de la emergencia de los mestizos, como productores con las mayores posibilidades de acumulación y de una paulatina proletarización en la comunidad indígena.

En resumen presenciamos una dinámica por la cual en el transcurso de 15 años, un cultivo ha logrado extenderse borrando en los sistemas de producción todas las características que no permitían su introducción. Aquí, nos damos cuenta de que la principal limitante, es decir, la necesidad de abastecimiento de granos básicos para los peones, pudo ser rebasada por la apertura de la actividad resinera.

Ahora bien, esta "coincidencia" es suficiente para que todos se beneficien del auge económico generado. Así nos lo enseña una breve tipología de los productores con las distintas racionalidades socioeconómicas de sus sistemas.

-Aguacateros exclusivos: tienen una estrategia de inversionistas buscando las mejores ganancias y el mejor uso de la mano de obra asalariada. -Aguacateros "de complemento": son cañeros, resineros "grandes", o ganaderos que tienen una superficie limitada y que han buscado plantar una máxima cantidad de aguacate en relación con los recursos monetarios y la tierra disponible. Buscan una maximización del ingreso por unidad de superficie. Son los que cuentan con huertas de mayores riesgos por su alta densidad de plantación e infraestructura mínima.

-Jornaleros-resineros: su estrategia básica es la adecuación del ingreso monetario a las necesidades diarias. Trabajan a destajo, los más pobres se emplean en la zafra, mientras otros han logrado tener una pequeña huerta en condiciones muy precarias (a medias). Casi todos pertenecen a la comunidad indigena. No tienen posibilidad de acumulación.

El desarrollo del aguacate ha logrado, en pocos años una diferenciación extrema entre los productores, a tal grado que las estrategias posibles se asemejan progresivamente a las que tendrían patrones por un lado y obreros por otro.

Se observa también, que los campesinos de Atapan están ahora integrados en varios mercados nacionales e internacionales tal y como lo expresa el cuadro 38.

Pero a nivel regional la presencia de las zonas aguacateras ya no fomenta mucho dinamismo en el desarrollo económico e industrial: en los ingenios cañeros y en las plantas resineras ya no se crean empleos desde hace más de 15 años. Pero en relación directa con el aguacate, los principales flujos que concretizan la integración de Atapan a la región son:

-El consumo de tablas de la Sierra para hacer las cajas de aguacate;

-El consumo de químicos y maquinaria, sobre todo para el transporte, que hace prosperar el comercio en Los Reyes;

-El consumo de nuevos bienes (muebles, aparatos) y de alcohol, ligado 


\section{Cuadro No 38}

\begin{tabular}{l|l|l|}
\multicolumn{1}{c}{ Compra } & \multicolumn{2}{c|}{ Venta } \\
\cline { 2 - 3 } $\begin{array}{l}\text { Mercado } \\
\text { nacional }\end{array}$ & $\begin{array}{l}\text { - estiércol (La Piedad, Jalisco) } \\
\bullet \text { fertilizantes } \\
\bullet \text { alcohol }\end{array}$ & $\begin{array}{l}\bullet \text { azúcar } \\
\bullet \text { aguacate (Guadalajara) }\end{array}$ \\
\cline { 2 - 3 } $\begin{array}{l}\text { Mercado } \\
\text { inter- } \\
\text { nacional }\end{array}$ & $\begin{array}{l}\bullet \text { químicos (EEUU) } \\
\bullet \text { maquinaria (-C) }\end{array}$ & $\begin{array}{l}\bullet \text { aguacate } \\
\bullet \text { resina (por Zacapu, Urua- } \\
\text { pan hacia EEUU, RFA) }\end{array}$ \\
\hline
\end{tabular}

al incremento de los ingresos y del nivel de vida, también elemento del dinamismo comercial en Los Reyes;

- La construcción en los pueblos aguacateros, que impulsa la fabricación de materiales y el empleo en Los Reyes.

Esta última parece ser la única actividad realmente productiva, estimulada indirectamente por el cultivo del aguacate en esta región constituida por la ciudad de Los Reyes y su entorno inmediato. En fin, como lo enseña el cuadro, el aguacate sólo ha hecho que se refuercen en el área las ganancias de sectores ajenos a la comunidad por el uso o el consumo de bienes producidos en empresas concentradas y con alta productividad del trabajo.

El desarrollo del aguacate tiene otros inconvenientes: en el caso de Atapan. En los años recientes ha sido acompañado de un despilfarro de los recursos locales y de uso inmoderado o por la imposibilidad de usarlos nuevamente para el provecho de los habitantes:

-desperdicio del agostadero abajo del bosque y de los árboles de aguacate, vinculado con el decaimiento de la ganadería;

-desperdicio paulatino de los terrenos que servían para huertas de aguacate criollo, y de toda la tierra de temporal donde no se da el aguacate;

-tiradero de madera en los desmontes hechos para plantar aguacate; -saqueo del bosque y aprovechamiento desenfrenado de la madera; -desperdicio de energía fósil y humana en los patrones actuales del cultivo del aguacate;

-mantenimiento de los campesinos con un maíz comprado, después de pasar por manos de varios intermediarios;

-sustitución de la mano de obra cañera por forasteros.

Obviamente, el grupo que más padece de este derroche es la comunidad indígena. Además, con la aparición de nuevas relaciones productivas se incrementó la desigualdad en la repartición efectiva de los recursos:

-La comunidad indígena alienó casi la mitad de sus mejores tierras; 
-La comunidad casi no tiene cultivos de autoconsumo,

-Muchos comuneros tienen una inseguridad total en el trabajo (pocos son empleados permanentes en el aguacate, y los contratos con las resineras son anuales);

-Sus huertas, por lo general, son las de peor rentabilidad y no están subsidiadas a través del crédito público. ${ }^{34}$ Lo mismo que muchas huertas de mestizos pobres, plantadas en los años recientes, muy amenazadas por la caída paulatina de los precios.

Lo grave para la comunidad es que esta situación goza de una buena estabilidad, porque plantar aguacate se ha convertido en la estrategia campesina. Escasos son los campesinos que no quieren tener su huerta, a pesar de los sacrificios que eso puede implicar. De tal suerte que ya no hay estrategias campesinas que se encaminen hacia la renovación de los recursos naturales.

En esta situación la SRA y la Forestal tienen una responsabilidad sumamente importante, que no es solamente del pasado pues ahora desprotegen los recursos por los permisos que se dan de aprovechar la madera. En otros términos, cabe preguntarse si no habrá cierta complicidad y "no-intervención" del Estado al amparo de un desarrollo aguacatero a todo precio.

Quizá podrían existir estrategias de "defensa" y de preservación de los recursos en la comunidad indígena si ésta no estuviera saqueada por parte de sus propios miembros. Esto la mantiene en estado de división y limita en proporciones considerables el poder de los que quisieran unirse para reclamar sus recursos así como justos ingresos repartidos de manera igualitaria. Esta situación beneficia a los aguacateros, lo que a veces, indirectamente, ha reforzado un divisionismo entre mestizos e indígenas ya latente desde el surgimiento de nuevas relaciones productivas.

\section{Generalización a otras zonas aguacateras}

En las márgenes de la Meseta Tarasca donde no hay caña (Tarecuato,

34. Se evidencia aquí el problema de un financiamiento sectorial, por producto, de parte del Estado: los aguacateros importantes, a la vez cañeros, acumulan la mayor parte de los subsidios gubernamentales otorgados localmente a través del crédito; de hecho el Estado promueve a los "empresarios" en el cultivo del aguacate.

Por otro lado tenemos con la situación de la comunidad indígena un ejemplo de lo que sucede con el fomento de una "especialización regional" hacia una sola actividad determinada por las "aptitudes diferenciales" de cada terruño: el desarrollo de la producción elegida crea el surgimiento de un grupo de agricultores reconocidos oficialmente, mientras se aceleran sensiblemente la diferenciación social y la marginación de una parte creciente del campesinado local. 
Tingüindín, Nuevo Zirosto, Zacán) hubo probablemente un "corte" en el proceso histórico: se empezaron a comprar las tierras directamente para plantar aguacate. Ya no podía darse el hecho de campesinos locales enriquecidos por la caña resultando que en esos lugares la tierra fue acaparada - de manera mucho más brutal-por inversionistas ${ }^{35}$ que lo hicieron en gran escala a partir de ganancias que eran las de profesionistas. Resulta entonces que en esos rumbos las huertas tienen un tamaño promedio superior a las de Atapan o San Francisco Peribán ${ }^{36}$ y, probablemente, están más tecnificadas por lo general. Ahora bien, puede ser un poco excepcional el proceso de apropiación de la tierra en Atapan por un gran número de particulares, permitido por una reorientación masiva de las actividades en la comunidad indígena ya que pasaron de la agricultura a la recolección de la resina. En otras zonas cañeras, se supone que es más frecuente el caso de un desarrollo aguacatero en manos de ejidatarios cañeros, con menores consecuencias agrarias sobre las comunidades indígenas. Pero de todos modos parece entonces que en Atapan, como en toda la región de Los Reyes, la caña fue un factor que, elevando la capacidad económica de todos los que la sembraban, permitió un acceso un poco más democrático al cultivo del aguacate.

Con todo, hay probablemente rasgos comunes en todas las zonas aguacateras en cuanto a algunas transformaciones provocadas por la expansión de las huertas:

-Desplazamiento de campesinos "tradicionales", muchas veces pertenecientes a comunidades indígenas, pero con menores consecuencias sobre desocupación en el campo que en el caso de muchos cultivos comerciales;

- Acaparamiento del poder político y económico por parte de los aguacateros, independientemente de donde sea su origen;

-Desgaste de los recursos locales y decaimiento de la ganadería;

-Falta de agua y erosión del suelo;

- Auge del trabajo asalariado en el campo e incremento de la precariedad para los campesinos que se convierten en peones; ${ }^{37}$

- Auge de las actividades de construcción y reforzamiento de una posición estratégica para los dueños de camiones de carga.

35. En el caso de un fracaso aguacatero, estos empresarios serían de los primeros en sacar su capital vendiendo las huertas para invertirlo en otros sectores.

36. Este pueblo tiene una estructura socio-económica muy parecida a la de Atapan, excepto que el ejido, aguacatero y cañero, es mucho más importante. Por otro lado, el control de los pequeños propietarios sobre los bosques comunales es mucho más relevante.

37. En lugares donde poco se aprovecha la resina (Tingüindín, Tarecuato y otros) puede ser que sigan con milpas, lo que les proporcionaría menores ingresos pero teniendo con qué comer a un precio más bajo. 
En fin, el aguacate hubiera sido más positivo para el desarrollo regional si no hubiera sido por la necesidad que tiene este cultivo de invadir zonas maiceras importantes. $Y$ si bien gracias al aguacate se ofreció trabajo a campesinos desplazados, no se han creado muchos empleos para trabajadores que no fueran oriundos de las mismas áreas de producción. En síntesis, el espectacular desarrollo socio-económico de la región, ha ido acompañado de la pérdida de la identificación de los campesinos con los recursos de su terruño. 


\section{CAPITULO VII \\ TRAPICHES Y HUERTAS. EL EJIDO TEPENAHUA, MUNICIPIO DE NUEVO URECHO}

Jean Damien de Surgy

\section{INTRODUCCION}

La principal motivación para este estudio de caso está en el interés hacia las "zonas de transición", que ocupan vastas superficies del territorio michoacano, tal vez más de la quinta parte. Esta denominación pretende apoyarse sobre varios aspectos:

1. El fisiográfico, referido a áreas intermedias según varios criterios como la altura, la temperatura, las precipitaciones y la accesibilidad. Se ubicarán esencialmente entre la tierra "templada" y la tierra "caliente", o también al margen de unidades geofísicas más pequeñas, por ejemplo, entre la Meseta Tarasca y el Bajío o los valles cañeros.

2. El socio-económico, relacionado a áreas donde el sistema social de producción cobra rasgos intermedios desde el punto de vista del grado de organización colectiva en la producción, y también el de la finalidad de las actividades productivas: del autoconsumo hasta las diferentes modalidades de comercialización.

3. El político, que se refiere al interés estratégico de una zona y al grado de intervención del Estado en la toma de decisiones y el control de la producción agropecuaria.

Respecto a estas zonas de transición, queremos entender de qué manera están participando o influyendo en el desarrollo de zonas vecinas que ya han sido bien caracterizadas por estudios socio-económicos o antropológicos. En algunos casos pueden incluir sistemas de producción propios y originales, encarrilados en una dinámica propia muy fuerte coma en el caso de la franja aguacatera en Michoacán. Pero puede ser también que bajo la infiuencia de la evolución en las zonas vecinas, los rasgos originales de estos sistemas se hayan ido borrando con el tiempo.

Escogimos aquí un lugar donde se manifiestan conjuntamente ambas tendencias. La preocupación inicial era conocer, constatando las importantes transformaciones ocurridas en el Plan de Tierra Caliente de Michoacán tras 
40 años de ininterrumpida intervención del Estado, cuáles podían ser las consecuencias de este movimiento sobre los tipos de sistema de producción que existen en las laderas de Tierra Caliente. Ahí encontramos varios escenarios de los que se desprenden diversas preguntas:

1. Puesto que en el Plan de Tierra Caliente se hicieron grandes inversiones en infraestructuras hidráulicas, que debieron redituar mediante los cultivos comerciales de exportación, se puede pensar que las laderas fueron colocadas en el papel de productoras de granos básicos. Esto no resulta cierto, pues el Plan de Tierra Caliente sigue produciendo grandes cantidades de maíz y frijol mientras el cultivo de maíz de temporal no es tan relevante en los márgenes.

2. Al contrario, en la medida en que muchos ejidos y pequeñas propiedades de Tierra Caliente tienen a la vez tierras de riego y tierras de temporal o matorrales en la vertiente, hay una fuerte tendencia a la "ganaderización" de las laderas, mientras la agricultura se concentra en las parcelas de riego. En esas laderas hay presencia de medieros para desmontar, hacer milpa y dejar potreros de buena calidad para el ganado. Esto sí resulta cierto en todas las vertientes áridas de Tierra Caliente, que son la mayoría, dada la escasez de precipitaciones por debajo de los 1,200 metros de altura.

3. Pero en las laderas, en torno a las corrientes de agua que bajan del cerro, existen numerosas zonas de pequeño riego que tienen una función muy antigua: la de suministrar, en pequeña escala, productos tropicales para la tierra fría. También sirven como proveedoras de granos durante temporadas en las cuales éstos escasean en la tierra templada. Esto queda claramente ilustrado, a manera de ejemplo, por las actuales relaciones entre Nuevo Urecho y Ario de Rosales (ver mapa 27).

Estas zonas de pequeño riego fueron integradas al Distrito de Riego del Plan de Tierra Caliente. Esto implicaba el control total del Estado sobre la repartición del agua, pero además la planificación de las actividades en los ejidos por parte del Banco Ejidal (luego Banrural) a través del financiamiento selectivo de los cultivos, primero el algodón, luego los cítricos y el melón, acompañados por algunos granos básicos como arroz y frijol. De esta manera, aunque con una renta diferencial supuestamente desfavorable, se introdujeron en las vertientes algunos de los cultivos comerciales practicados en el Plan, posiblemente con los mismos efectos de sumisión a la aleatoriedad de los mercados nacional e internacional, de hegemonía de empacadoras e industrias agroalimenticias en el proceso de producción y de renta de tierras ejidales a las plantas. Uno de nuestos objetivos será medir la importancia de estos mismos fenómenos en lugares que, sin embargo, quedan un poco al margen del proceso de "modernización agrícola" que sigue transformando la Tierra Caliente. 


\section{MAPA No 27: U BICACION DEL MUNICIPIO DE NUEvo U RECHO}

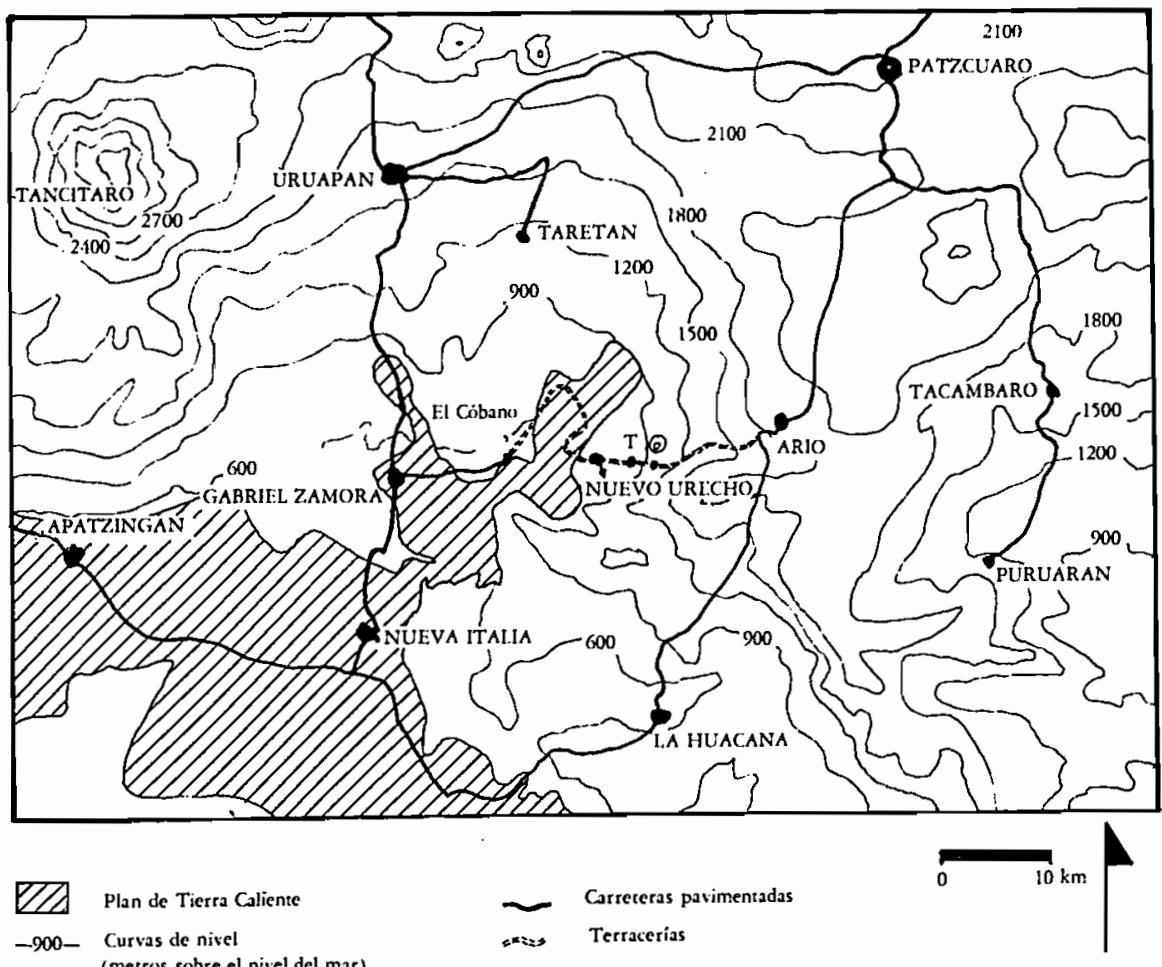

La parte oriental del municipio de Nuevo Urecho (ver mapa 28) incluye precisamente en la vertiente una de esas áreas de pequeño riego, que además, presenta la ventaja de ser igualmente abierta sobre el Plan de Tierra Caliente y sobre la tierra templada hacia Ario de Rosales, comunicado a Nuevo Urecho por un camino de terracería transitable en la estación seca. El poblamiento de esta área tiene una dinámica propia (ver mapa 28 y comentario), en claro contraste con el resto de la ladera cuya vegetación oscila entre el matorral muy seco y el bosque de encino que está dedicado casi exclusivamente a la ganadería, o más bien al pastoreo de hatos ganaderos cuyos dueños - que emplean algunos vaqueros y medieros- no radican ahí. Estos lugares áridos obviamente no merecen un estudio como "zonas de transición" pero sus características son importantes en el análisis del área que nos interesa. Está presente además una estratificación muy completa de los cultivos y de las actividades a lo largo de 500 metros de desnivel, que 
Mapa No 28: DinamiCa de La POBI.ACION en el. MUNicipio de Nuevo Urecho

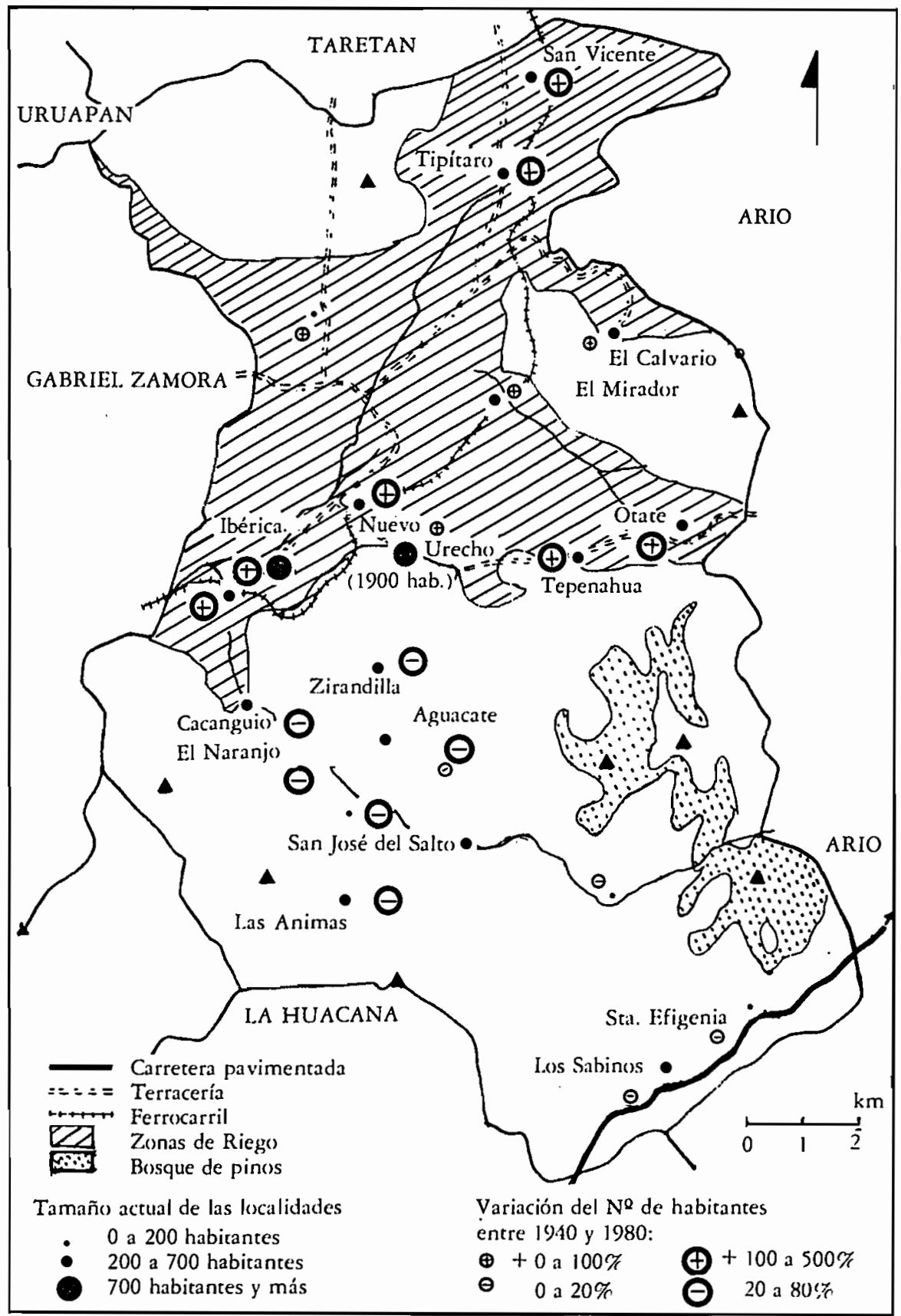




\section{Comentarios al M APA No 28}

Este mapa refleja los movimientos de población que tuvieron lugar entre los años cuarentas y ochentas en el municipio de Nuevo Urecho (8,140 hab. en 1980). En todo el periodo el crecimiento real de la población del municipio nunca ha rebasado un $3 \%$ al año (promedio $1.5 \%$ ), lo que indica que siempre hubo una fuerte emigracion hacia otras zonas (Taretan, valle de Apatzingán, Uruapan). Sólo en la década de los cuarentas bajó por un tiempo el saldo migratorio negativo, cuando las infraestructuras de riego y la modernización agrícola empezaron a ocupar a muchos jornaleros en el valle de Lombardía. Desde ese momento los jornaleros del Valle representan un $30 \%$ de la población económicamente activa del municipio, igual que los ejidatarios.

En realidad, lo que cambió entre 1940 y 1955 sólo fue el punto de llegada de los emigrantes que siempre han salido de las laderas secas del municipio: por un tiempo se cambiaron a lugares que quedaban dentro de los límites del municipio. Pero en esas partes áridas la población de todos los ranchos que tenían menos de 150 habitantes en 1940 nunca ha dejado de bajar. Los únicos asentamientos que tuvieron un crecimiento absoluto entre 1940 y 1980 se ubican en las zonas de riego (crecimiento importante en los principales ejidos) ${ }^{*}$ y en los lugares bien comunicados. Así, lo más relevante fue la migración al interior del mismo municipio, de las zonas secas hacia las de riego, vinculada con una autosuficiencia alimentaria cada vez más reducida y el surgimiento de un control total de las zonas áridas por los ganaderos grandes.

- Con inmigración sólo en Titíparo, San Vicente (cercanos al ingenio azucarerode Taretan) y Los Otates (por el piloncillo). Estos pueblos, y sólo ellos, quintuplicaron su población a lo largo de 40 años, a pesar de la existencia en el valle de una pequeña emigración a EEUU. desde 1960. En el pueblo de Tepenahua el crecimienro real fue regular (entre $1.5 \%$ anual durante todo el periodo). 
corresponde a la vez a todos los grados posibles de control por parte del Estado: muy marcado en el valle de Lombardía; éste se reduce a su mínima expresión en el lugar llamado Otates, donde se produce caña para hacer piloncillo. La presencia en el área de este complejo caña/piloncillo restringe en enormes proporciones la representatividad del estudio en cuanto a lo que sucede en las laderas de Tierra Caliente; pero por su misma capacidad de frenar la evolución de los sistemas de producción específicos de las laderas, confiere al área de estudio verdaderas características de zona intermedia, que no depende exclusivamente de lo que sucede en el Plan de Tierra Caliente, y donde la organización socio-económica no está totalmente trastornada por la "modernización".

Más precisamente, enfocamos nuestro estudio sobre dos núcleos del ejido Tepenahua: los asentamientos llamados respectivamente Tepenahua y Los Otates, que son los más poblados y mejor comunicados de los cuatro (con El Mirador y El Calvario) que conforman el ejido ${ }^{1}$ cuyo dominio abarca la mayor parte de las tierras de riego que existen en la vertiente oriental del municipio de Nuevo Urecho. En efecto los campesinos de esas dos localidades cultivan parcelas en todos los niveles, desde el Plan, en el lugar llamado San Juan, hasta el manantial que permite regar la cuenca. También cultivan importantes superficies de temporal, una cuarta parte del total, y tienen monte y bosque. Pero más que todo, llama la atención la diversidad de los cultivos y la importante proporción de maíz y frijol en los sistemas de producción, que es mucho menor en los ejidos de Nuevo Urecho, dedicado al mango e Ibérica, dedicado al arroz y melón principalmente.

Además de esta diversidad, existen comunicaciones directas hacia arriba y hacia abajo y, más que eso, se nota una "doble polarización" que cobra una importante dimensión geográfica, a tal punto que las dos localidades no parecen pertenecer al mismo ejido, como lo observamos en la primera parte del estudio. En efecto, las dos localidades no solamente tienen producciones y actividades diferentes, sino también una dinámica de la fuerza de trabajo muy distinta en la agricultura. Además, esta observación nos lleva a admitir que, si existió un sistema social de producción coherente a nivel de todo el ejido, éste se ha desagregado, o bien se encuentra ahora en otro nivel; antes sí había una coherencia que se fundamentaba sobre el procesamiento de la caña de azúcar. Pero hoy en día, la base territorial de la industria azucarera en la vertiente se ha restringido a un área mucho más

1. Las cuatro rancherías se juntaron en los años treintas para formar un ejido cañero. Eran pocos campesinos en cada una pero esto no basta para explicar por qué se juntaron así. Tepenahua siempre ha quedado como "cabecera del ejido", tal vez porque de ahí eran los propietarios de un anciguo pequeño ingenio destruido durante la revolución: supuestamente fueron ellos quienes fomentaron el ejido para controlar una zona importante del abastecimiento de caña al ingenio de Taretan y varios trapiches. 
pequeña, mientras la otra parte del ejido se ha transformado mucho. Trataremos de explicar por qué el proceso de modernización sólo afectó a una parte del ejido; y veremos que en la parte cañera se ha reforzado curiosamente un sistema social de producción que descansa sobre una fuerte organización colectiva del trabjo: el complejo caña/piloncillo en Otates. Entonces podremos entender cómo la coherencia de este sistema modifica la evolución de la parte más controlada por el Estado y de toda la cuenca alrededor del ejido. Así, el interés de esta zona de transición es porque ahí interfieren dos tipos totalmente distintos de evolución de las relaciones entre productores.

A estas observaciones debemos agregar un nuevo hecho: si la intervención del Estado se había enfocado sólo hacia el Plan de Tierra Caliente durante mucho tiempo, los años setentas marcaron el principio de un interés hacia las zonas de temporal y hacia las laderas, sectores olvidados donde pareció que se pudieran rentabilizar nuevas inversiones y abrir nuevas perspectivas en la agricultura. Concretamente, así como la finalidad de la producción en el Plan de Tierra Caliente es alcanzar los mejores rendimientos en cultivos de exportación, las laderas de Nuevo Urecho han sido elegidas para el monocultivo del mango, comercializable a nivel nacional e internacional. Este proyecto refleja la búsqueda de una máxima "eficientización" de cada hectárea regada en base al planteamiento siguiente: "en las laderas, donde no se puede meter maquinaria, hay que dinamizar la fruticultura y dejar las tierras planas únicamente para los cultivos mecanizados". Resulta que en el ejido Tepenahua se da una intervención del Estado sumamente orientada: sólo se financia el mango, y toda la asistencia técnica está enfocada hacia este único cultivo. Observaremos cómo este proyecto se integra en un conjunto sumamente diversificado de sistemas de producción donde al parecer, los campesinos están frenados por limitantes fuertes que ahí se oponen a las ambiciones del Estado: un auge del mango limitado por las características originales de la organización campesina podría ser un auténtico factor de desarrollo para todos los productores del área.

\section{TIPOLOGIA DE LOS SISTEMAS DE PRODUCCION}

A fin de jerarquizar las diferentes actividades y ver de qué manera los campesinos de Tepenahua y Otates integran en sus sitemas de producción la diversidad de los cultivos y su distribución en el espacio, aplicamos una encuesta que nos permitió evidenciar diferencias marcadas entre los campesinos de los dos pueblos. 


\section{La encuesta}

Dado el tamaño muy reducido de las poblaciones que nos interesan (alrededor de 270 y 400 habitantes respectivamente), se han podido obtener datos respecto a un $60 \%$ de los jefes de familia en cada pueblo, y de esta manera reconstituir con apreciable confiabilidad la repartición de los cultivos a nivel de los dos pueblos que representan, además, un $70 \%$ de la población del ejido.

Unos 200 ejidatarios se reparten, según los datos oficiales, 3,195 hectáreas de monte, 402 de temporal y 1,375 de riego. En cuanto a los agostaderos colectivos, resultó que menos de un $5 \%$ de los campesinos encuestados tienen más de tres reses. Es decir que en realidad estos predios son controlados por miembros del ejido que radican en la cabecera de Nuevo Urecho, Lombardía o Uruapan, dueños de hatos muy grandes. Así, la encuesta nos precisa sobre todo cómo se reparten los diferentes cultivos en las superficies de labor (ver cuadro 39 ). ${ }^{2}$

\section{CuADro No 39}

\begin{tabular}{|l|c|c|l|}
\cline { 2 - 4 } \multicolumn{1}{c|}{} & Tepenahua & Otates & \multicolumn{1}{|c|}{} \\
\hline Maíz & $\begin{array}{l}48 \% \\
\text { Arroz }\end{array}$ & $\begin{array}{c}48 \% \\
-\end{array}$ & $\begin{array}{l}\text { Primavera-verano } \\
\text { Primavera-verano }\end{array}$ \\
\hline Frijol & $39 \%$ & $2 \%$ & $\begin{array}{l}\text { Otoño-invierno } \\
\text { Otoño invierno } \\
\text { Otoño-invierno }\end{array}$ \\
$\begin{array}{l}\text { Melón } \\
\text { Pepino }\end{array}$ & $5 \%$ & - & \\
\hline Caña & $2 \%$ & - & $\begin{array}{l}\text { Ambas temporadas } \\
\text { Ambas temporadas }\end{array}$ \\
Mango & $33 \%$ & $10 \%$ & \\
\hline
\end{tabular}

2. En el cuadro los porcentajes se refieren a la superficie ocupada durante la temporada indicada (en la estación seca hay tierras en descanso: $23 \%$ en Tepenahua, $46 \%$ en Otates).

En Tierra Caliente el frijol casi nunca se cultiva asociado con el maíz en primaveraverano: con el calor y la humedad ambiental se pudre.

Hay muy poco arroz de otoño-invierno: casi siempre faltaría el agua de riego para alcanzar las necesidades de los meses de marzo y abril. 
En realidad, ningún campesino de Tepenahua u Otates tiene esta repartición de cultivos, y más que eso, a una profunda diferenciación en la agricultura de riego se agregan diversos grados de participación en otras actividades: agricultura de temporal, ganadería, extracción de la resina y aprovechamiento de otros recursos del bosque, comercio, etc.

Se nota en primer lugar que el área estudiada no constituye de ninguna manera una reserva de mano de obra para los cultivos comerciales del Plan de Tierra Caliente. En efecto, los que se pusieron a trabajar de peones en el valle ya han emigrado hacia pueblos (Ibérica) o ciudades (Lombardía) del Plan de Tierra Caliente. En la zona que nos interesa, parece que ya no hay participación de los campesinos de las laderas en los trabajos que se hacen en el valle.

Varios datos de la encuesta confirman la existencia de una dinámica diferente entre Tepenahua y Otates: a la especialización marcada -fruticultura en Tepenahua, caña en Otates- que se nota en la repartición de la P.E.A., se añade una serie de diferencias, relacionadas con el uso del suelo:

-en Otates se cultiva sobre todo el maíz de temporal con azadón oyunta de bueyes alquilada, mientras en Tepenahua alternan maíz y frijol de riego, cultivados a menudo con tronco propio de caballos;

-hay una polarización de los jornaleros: en Otates todos trabajan en la caña o en los trapiches, y pocos en otros cultivos. Muchos de Tepenahua van a Otates para la zafra, aunque ahí casi no hay caña; -en Otates se acostumbra mucho el trabajo después de comer, hasta el anochecer. Además se registra una importante proporción de campesinos inmigrantes; todo indica que ahí la mano de obra está ocupada al máximo.

-ahí trabajan tres hijos por cada dos jefes de familia, mientras en Tepenahua, son dos hijos por cada tres jefes de familia;

-en Otates las plantaciones de mango son más recientes;

- la parte intransitable de la terracería durante las lluvias está entre Tepenahua y Otates; el primero queda entonces comunicado con Nuevo Urecho, mientras el segundo solamente lo está con Ario de Rosales.

No cabe duda alguna de la importante diferenciación socio-económica existente entre las dos localidades. Pero esto sugiere también que los respectivos sistemas de cultivo se reparten el espacio de manera polarizada, y quisimos ver cómo se reflejaba esta organización en el paisaje.

\section{Uso del suelo}

Observando este paisaje, aparece efectivamente un escalonamiento de la 
vegetación y de los cultivos. Para conocer su repartición en el área de estudio, hicimos recorridos y para las zonas donde no hubo muchos cambios (matorrales, bosques y cañaverales) y que no fueron visitadas, usamos fotografías aéreas de 1975 y 1976 (DETENAL) como marco de referencia. Así, aparece (ver mapa 29) una zonificación del área en unidades de paisaje, al interior de las cuales se observa cierta homogeneidad en la combinación de cultivos y actividades y, quizá, vegetación natural. Como lo veremos más adelante, varias de estas unidades de paisaje corresponden a un tipo de sistema de producción practicado por una parte de los campesinos, es decir que en esta zona hay un escalonamiento espacial de los sistemas de producción que se nota sobre todo cuando se hace un recorrido transversal en las zonas de riego, desde el valle hasta la parte más alta de la cuenca regada, arriba de Otates.

En el mapa 29, primero aparecen las zonas que no son aprovechadas por campesinos de Tepenahua u Otates:

En la orilla del valle de Lombardía, los ejidatarios de Ibérica practican sistemas basados sobre cultivos comerciales de riego (arroz/frijol, melón, pepino, sandía).

Rodeando los pueblos pero sobre todo el de Nuevo Urecho, hay una "cintura" de huertas de mango, pertenecientes a propietarios de la cabecera y son las más antiguas que se plantaron -antes de los años setentas-, si no se toman en cuenta los solares. Las de mayor tamaño - hasta 7 hectáreasson, sobre todo, de ganaderos importantes.

Luego hay extensas zonas sin riego, ${ }^{3}$ dedicadas a la ganadería. Los ganaderos, algunos de los cuales son ejidatarios de Tépenahua, viven en la cabecera municipal o fuera del municipio. Según la asociación ganadera local, cada uno tiene en promedio 40 cabezas de ganado corriente, cebú o cruzado cebú-suizo. Ocupan una posición fuerte en el mercado regional de crías y carne. Siempre tienen por otro lado una proporción apreciable de vacas lecheras, alimentadas en la estación seca con pastura comprada en Uruapan. Los medieros que cultivan maíz en sistemas de barbecho largo para desmontarles potreros a los ganaderos, así como los agricultores que les dejan pastorear el rastrojo, son de los ranchos más apartados del municipio, en plena zona árida (La Zirandilla, El Aguacate, San José del Salto, etc.).

Luego, al interior del área estudiada se observa una polarización muy clara. En la zona llamada de "maíz-frijol-mango-potreros" se desenvuelven esencialmente sistemas de cultivo practicados por campesinos del poblado Tepenahua (como lo veremos en la tipología de los sistemas). Los más diversificados cultivan además tierras del valle. Arriba (zona caña/maíz) dominan los sistemas de cultivo de los campesinos de Otates (ver Cuadro

3. Matorrales o bosques. 
MAPA No 29: USO DEL SUEI.o EN El AREA (UNIDADES DE PAISAJE)

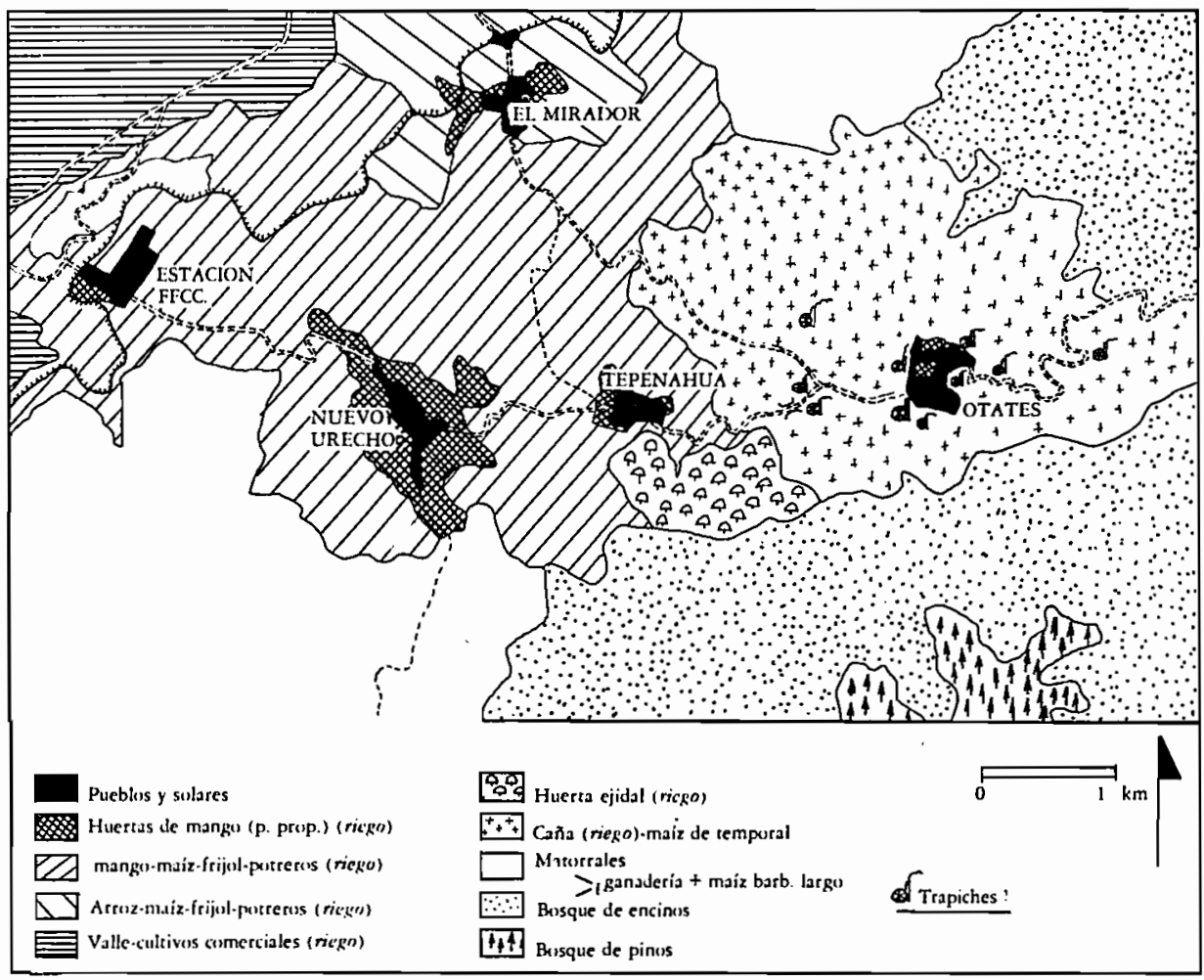

40), donde las huertas de mango son más chicas y más recientes. En realidad hay una transición progresiva entre las dos zonas, pero ésta no ocupa un espacio muy ancho y pusimos el límite en la parte inferior del territorio delimitado por la caña. Los ejidatarios ganaderos aprovechan sobre todo la parte de abajo, donde se notan más potreros en tierras de riego.

Así, esta estricta separación geográfica de los sistemas de cultivo y de ganado no deja de llamar la atención. También evidencia que los campesinos de cada pueblo cultivan las tierras que rodean el asentamiento, y comprobamos que igual sucede en las localidades de El Calvario y El Mirador que están mucho más incomunicadas. No hay entonces ninguna distribución de las parcelas de cada uno en todo el territorio ejidal. Al contrario, este ejido parece abarcar a varios terruños, que son el resultado de una evolución diferenciada del ejido. Obviamente, la creación de este ejido obedeció a la necesidad política del momento y no a la existencia de un solo grupo 
campesino. El único elemento de coherencia a nivel de todo el ejido sería la migración a Otates común a la mayoría de los jornaleros agrícolas durante la zafra.

Tipología de los sistemas de producción (cuadro 40)

Las primeras impresiones llevan a concluir que existiría cierto "atraso" en la agricultura de Otates en realidad la diferencia está en que se usa mucha más mano de obra por unidad de superficie en este pueblo, tomando en cuenta la actividad de transformación en los trapiches. Así, como lo vamos a ver, puede ser que en Otates no sea interesante aumentar la productividad del trabajo en el cultivo del maíz, y que la introducción del mango no represente una intensificación tan provechosa en cuanto al ingreso generado.

Este sólo es uno de los aspectos de la diferenciación en la agricultura local: tenemos que hacer un análisis más fino de los sistemas de producción, que también son variados en cada localidad, para ver qué tipos de racionalidad socioeconómica se pueden encontrar.

Aparecieron ocho tipos claramente delimitados, entre los cuales se reparten las 56 familias campesinas encuestadas. Algunos tipos de sistema son característicos de campesinos de Otates, mientras otros lo son de campesinos de Tepenahua.

Primero se eliminó a tres de los encuestados, que por ser inactivos, no fueron considerados sustentadores de un sistema de producción propio. Luego, la diferenciación se hizo en base al cruzamiento de 2 criterios simples:

-actividad principal: agricultura, fruticultura, o cultivo y procesamiento de la caña.

-acceso a los recursos: campesinos con tierra o jornaleros.

Teniendo en cuenta que fueron encuestadas un $60 \%$ de las familias que viven en los 2 pueblos, es bastante confiable la repartición númerica de los campesinos en cada tipo. (Solamente el tipo 2 esta bastante sobrerepresentado en la encuesta).

\section{1 y 2: cañeros}

A todos los cañeros les absorbe la caña más del $80 \%$ de su tiempo de trabajo (incluida la molienda en los trapiches). Aquí se nos hizo fundamental separar a los que poseían o no su "taller" para la transformación (molinos). 3 y 8: jornaleros

Muchos, sobre todo en Otates, tienen su parcela de maíz y a veces unos mangos. Pero se les consideró como jornaleros cuando dedicaban a este tipo de actividad más de tres meses de tiempo completo excepto el caso de un campesino que es peón en la zafra pero también importante fruticultor, 
Cuadro No. 40

Tipologia de los sistemas de produccion en Tepenahua- Otates

\begin{tabular}{|c|c|c|c|c|c|c|c|c|c|}
\hline \multicolumn{2}{|l|}{ Características generales } & \multicolumn{2}{|c|}{$\begin{array}{c}\text { No.de } \\
\text { encuestas }\end{array}$} & \multicolumn{2}{|c|}{ Otates } & Tepehanua & \multicolumn{2}{|c|}{$\begin{array}{c}\% \text { de } \\
\text { ejidatarios }\end{array}$} & \multirow{2}{*}{$\begin{array}{c}\% \text { de } \\
\text { medieros }\end{array}$} \\
\hline 1. Dueño de trapiche & & & 8 & $100 \%$ & & - & & $87 \%$ & \\
\hline 2. Cañero sin trapiche & & & 1 & $100 \%$ & & - & & $100 \%$ & - \\
\hline 3. Jornalero - caña & & & 11 & $100 \%$ & & - & & $55 \%$ & $9 \%$ \\
\hline 4. Agricultor - Maiz & & & 4 & $75 \%$ & & $25 \%$ & & $50 \%$ & $50 \%$ \\
\hline 5. Agricultor diversificado & & & 8 & $50 \%$ & & $50 \%$ & & $88 \%$ & $25 \%$ \\
\hline 6. Fruticultor - agricultor & & & 12 & - & & $100 \%$ & & $83 \%$ & - \\
\hline 7. Agricultor - maíz/frijol & & & 6 & - & & $100 \%$ & & $83 \%$ & $17 \%$ \\
\hline 8. Jornalero diversificado & & & 3 & - & & $100 \%$ & & - & $33 \%$ \\
\hline $\begin{array}{l}\text { Sistemas de cultivo } \\
\text { y ganado }\end{array}$ & $\begin{array}{l}\text { No. de } \\
\text { mangos }\end{array}$ & caña & $\begin{array}{l}\text { No } \\
\text { arroz }\end{array}$ & $\begin{array}{l}\text { e hectár } \\
\text { frijol }\end{array}$ & $\begin{array}{l}\text { reas pro } \\
\text { melón } \\
\text { sandía } \\
\text { pepino }\end{array}$ & maíz & $\begin{array}{l}\text { des- } \\
\text { canso }\end{array}$ & $\begin{array}{l}\text { Animales } \\
\text { de trabajo }\end{array}$ & $\begin{array}{c}\text { Vacas } \\
\text { lecheras }\end{array}$ \\
\hline 1. Dueño de trapiche & 40 & 3 & - & - & - & 1.5 & 0.5 & 8 & 3 \\
\hline 2. Cañero sin trapiche & 0 & 2 & - & - & - & 2 & - & - & - \\
\hline 3. Jornalero - caña & 8 & - & - & - & - & 1.3 & 0.5 & 1 & 1 \\
\hline 4. Agricultor - maíz & 0 & - & - & - & - & 2.2 & 0.5 & 1 & - \\
\hline 5. Agricultor diversificado & 10 & - & 2 & 3 & 0.5 & 3.2 & 1 & 2 & 3 \\
\hline 6. Fruticultor - agricultor & 110 & - & 1.3 & 1.5 & 0.3 & 1.8 & - & 2 & 1 \\
\hline 7. Agricultor - maiz/frijol & 4 & - & - & 2.5 & - & 2 & 0.3 & 1 & 1 \\
\hline 8. Jornalero diversificado & 0 & - & - & - & - & 0.7 & - & - & - \\
\hline
\end{tabular}


clasificado en el tipo 6.

4 y 7: agricultores "maiz" $y$ "maiz-frijol"

Estos ca mpesinos no tienen otros cultivos; por otro lado la separación entre los dos tipos es muy clara porque los primeros cultivan sólo maíz de temporal, mientras los segundos lo cultivan en parcelas donde siembran frijol de riego en otoño-invierno.

5: agricultores "diversificados"

Estos tienen cultivos adicionales como arroz, melón, pepino o sandía y, a veces, algunos frutales. La ganadería es ta mbién un elemento importante de la "diversificación" (el 50\% de ellos tienen ganado).

6: fruticultores-agricultores

Consideramos que un campesino entraba en esta categoría cuando la fruticultura, mango sobre todo, era la actividad principal. Esto corresponde más o menos a una huerta de tamaño superior a los 45 árboles - bajo la condición de que no se tenga caña. En efecto 45 mangos (1/2 Ha.) corresponden aprximadamente:

-al trabajo necesario para 3 hectáreas de maíz;

-a la necesidad de una persona de tiempo completo cuando menos durante la mitad del año;

-a un ingreso neto que rebasa los 150,000 pesos -invierno 84-85- (el de dos hectáreas de frijol, o una hectárea de arroz "encharquinado" — con trasplante- o tres hectáreas de arroz al voleo, o de cuatro hectáreas de maíz de riego).

Para tener un panorama completo de lo que existe en el área, habría que agregar dos tipos de sistema que son complementarios entre sí en el aprovechamiento de un espacio común (matorrales y bosques): el de los grandes ganaderos, y el de los medieros que cultivan maíz con ciclo de barbecho largo. Estos dos tipos no están representados entre los habitantes de Tepenahua y Otates. Sin embargo, son importantes para entender la dinámica general.

En cuanto a características generales, se pueden precisar ciertas diferencias entre los dos pueblos: en Tepenahua los jornaleros son jóvenes, mientras en Otates se puede hablar de una verdadera clase de peones. Esto se confirma por el hecho de que un $55 \%$ de ellos son ejidatarios, es decir que ahí la estructura de la organización colectiva determina que muchos campesinos con tierra trabajen de jornaleros durante la zafra.

En cambio los cañeros que no tienen trapiche son jóvenes que pertenecen a una organización familiar en la cual un miembro de más edad tiene un trapiche y muele la caña de sus parientes más jóvenes.

Al parecer, hay dos tipos de campesinos sin tierra: los jornales que a diario toman el trabajo que se les of rezca y los "medieros" que cultivan pequeñas superficies de maíz en tierras muchas veces prestadas en forma 
gratuita por fruticultores o cañeros que no siembran maíz. Estos últimos (tipos 1 y 6), junto con los agricultores que tienen tierras en el Valle y con los ganaderos (tipo 5) son los campesinos con el mejor nivel de vida en el área estudiada. El usufructuario de la parcela no cobra, aunque no es gratuita esta relación en el sentido de que requiere de peones que, fuera de las épocas de cosecha, tengan con qué mantenerse.

Se analizará más adelante la repartición de los cultivos, que expresa fuertes divergencias entre los tipos de sistema. Pero ya sorprende la existencia de un importante grupo de campesinos que no cultivan más que maíz y frijol, y por lo tanto se destaca aquí que la especialización en mango o caña es bastante selectiva.

En cuanto a sistemas de ganado, los animales de trabajo incluyen burros, mulas, caballos y bueyes propios. No aparecen aquí los animales rentados a ganaderos grandes. El elevado número de burros concentrados por los dueños de trapiches se explica por la necesidad de acarrear la caña.

Los bovinos de abasto son poco representados y el tamaño de los rebaños es muy variable; son campesinos de fuera los que practican esta ganadería. En Tepenahua y Otates predomina la ganadería lechera - con ganado cebú, suizo o Holstein-, con pocas vacas pero con 6 meses de ordeña permitida por la alimentación con bagazo, puntas de caña y pastura de riego. Muy frecuentemente se observan en plena zona de riego tierras en descanso para tener potreros con abundante pasto. Así se satisface la demanda de leche en Nuevo Urecho, Tepenahua, Otates y las rancherías vecinas.

El interés de hacer una tipología de los sistemas de producción está en poder comparar luego, las posibilidades de expansión de los diferentes grupos de campesinos, y ver de qué manera la lógica socio-económica de unos es decisiva sobre los limitantes del sistema de producción de otros.

En Tepenahua y Otates el principal problema se basa en las posibilidades de combinación de las actividades en el tiempo. En el cuadro 41 damos un calendario de trabajo simplificado para las principales actividades, de manera que se puedan comparar las necesidades de fuerza de trabajo en cada periodo.

Registramos así cinco puntos claves en los cuales, por la excesiva necesidad conjunta de mano de obra, aparecen problemas cuando se trabajan dos cultivos en el seno de un mismo sistema de producción:

1. La siembra del frijol interviene en plena zafra - de enero a marzo-, la cual exige que todos los brazos disponibles estén en los trapiches. Así resulta que los campesinos de los grupos 1, 2 y 3 en la tipología (cañeros y jornaleros de Otates) casi no cultivan frijol como se ve en el cuadro 40 , a pesar de tener las tierras adecuadas. Estas tierras de riego se destacan en el paisaje que rodea a Otates en noviembre-diciembre: ahí queda en pie el 


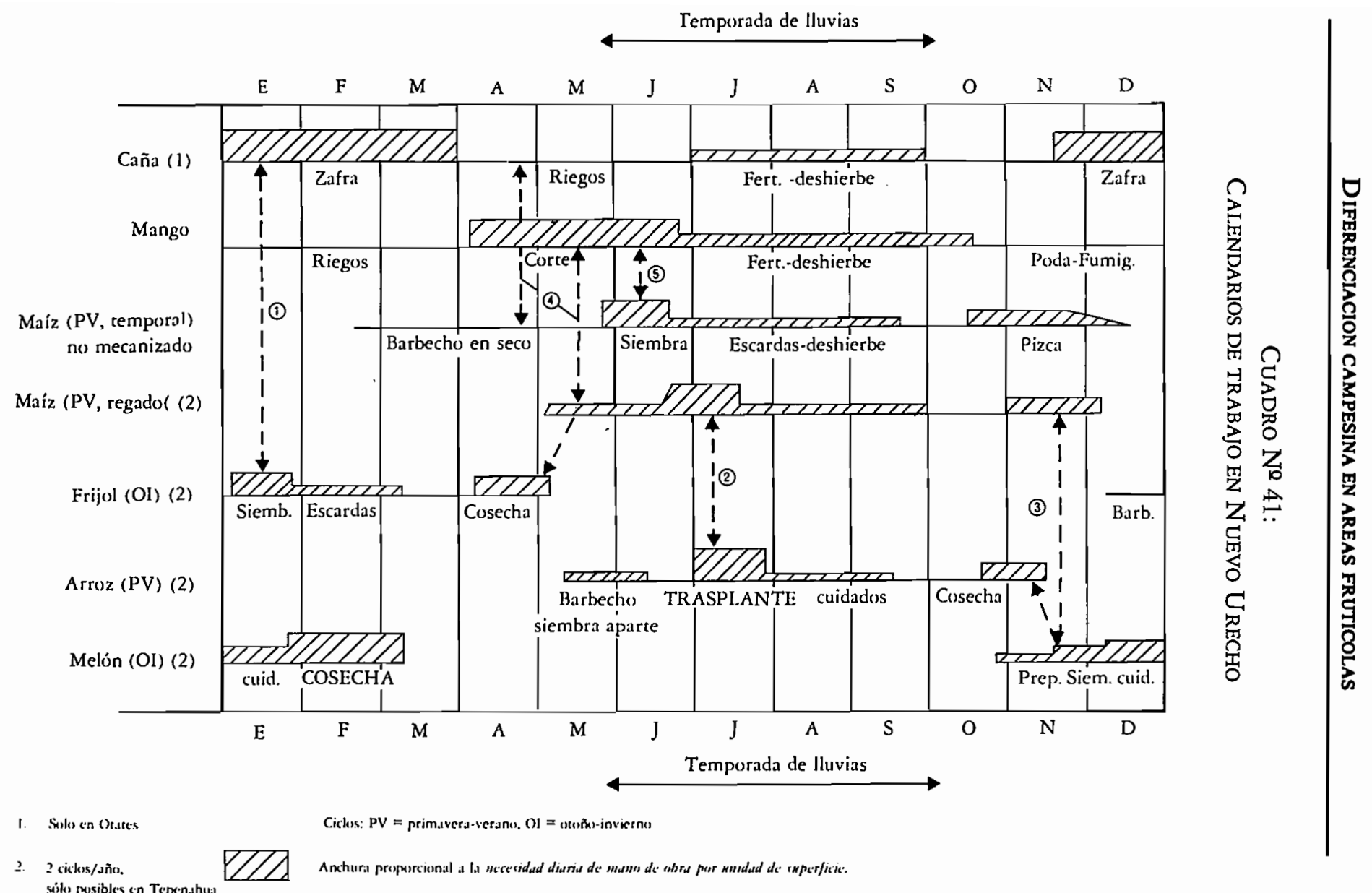

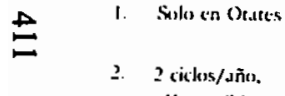
silu posibles en Tenendhu 
rastrojo del maíz entre las parcelas de caña, mientras las tierras de los agricultores de Tepenahua ya están en barbecho para sembrar el frijol.

2. El trasplante del arroz viene en el momento más o menos preciso de la siembra del maíz, cuando éste último alterna con el frijol para hacer dos ciclos de cultivo al año. Los empresarios agrícolas usan entonces la siembra mecanizada para el maíz. Sin embargo, existen medieros (en el grupo 5 de la tipología) que sólo cuentan con sus animales y su propia fuerza de trabajo para hacerlo todo. Estos resuelven el problema evitando la operación del trasplante. Es decir, siembran el arroz al voleo aunque técnicamente sea "una aberración" ya que se despilfarra el agua y se alcanzan rendimientos de 2 a 3 toneladas por hectáreas contra 8 toneladas en promedio para el arroz "encharquinado", es decir, con trasplante. La otra solución sería suprimir el maíz, que "reditua poco y por eso no vale la pena rentar una tierra para él". Pero para un mediero es imprescindible cultivar maíz para tener con qué comer; el objetivo no es venderlo. Así es perfectamente lógico e imprescindible que en Tepenahua se cultive el arroz al voleo, que corresponde también para el mediero gastos mínimos en efectivo y una máxima valoración de su parte de la cosecha. Así el comportamiento de algunos ejidatarios que prefieren dar su tierra en aparcería es uno de los factores de fracaso para la divulgación de técnicas de cultivo con trasplante. Esto explica por qué la SARH tiene pocos resultados "positivos" respecto a este problema en Tepenahua.

Los cañeros no siembran arroz por la falta de tierras planas adecuadas.

3. Los agricultores que siembran melón -escaso en el área de estudio- después del maíz o del arroz, tienen un plazo muy reducido para preparar el terreno. El melón sufre a menudo asfixia e inundaciones en la región, lo que lleva a los técnicos a criticarles por inadecuadas técnicas de preparación del suelo e insuficiente número de pasadas con el tractor; para poder hacerlo correctamente necesitarían suprimir el cultivo de primavera, verano, o bien retrasar la fecha de la cosecha del melón, con la imprescindible pérdida de ingreso que se debería a la caída de los precios en plena estación de cosecha. El problema de la saturación del mercado es, en realidad, el que más conduce a los agricultores a apresurarse para preparar el terreno, lo que para ellos es preferible a la obtención de rendimientos óptimos. Así resulta que en esta problemática, los más favorecidos son los agricultores que están estrictamente especializados en el melón, es decir las empresas que lo cultivan en tierras ejidales rentadas.

4. Los fruticultores (grupo 6) y los agricultores que siembran frijol (grupos 5 y 7 en la tipología) tienen poco tiempo para barbechar y sembrar su maíz, mientras los cañeros y los jornaleros que trabajan en la zafra (grupos 1,2 y 3) están totalmente libres desde abril hasta julio para hacer los trabajos de barbecho y siembra. Estos pueden trabajar sin problemas con 
yuntas de bueyes rentadas o prestadas, que además se mantienen con un cuidado mínimo y que están a cargo del dueño cuando no se les ocupa, mientras aquellos tuvieron que comprar sus caballos o mulas para trabajar rápido y tener los animales listos el día y a la hora que se necesiten. Así, no es ninguna prueba de atraso que en Otates se sigan usando bueyes: más bien, ahí les conviene mejor a los campesinos que necesitan la tracción animal sólo en el periodo de menores apuros. ${ }^{4}$

5. Pero el problema que más nos interesa para determinar la evolución de toda el área es la incompatibilidad entre la cosecha del mango y la siembra del maíz de temporal. Esta situación tiene numerosas repercusiones sobre la evolución de los sistemas de producción en Tepenahua y Otates:

a) los grupos de campesinos (No. 3, 4, 8 en la tipología) que no cuentan con los recursos suficientes para mecanizarse, contratar peones o comprar sus alimentos, están forzados a seguir cultivando su maíz con azadón o animales, y a sembrarlo temprano porque la mayoría de ellos tiene solo tierras de temporal. Esta necesidad les impide el acceso al mango, porque no lo podrían cosechar ni por medio de la contratación de algunos peones (además, nadie estaría disponible). El umbral infranqueable es el de los 30 o 40 primeros árboles, porque luego, con una huerta más grande, podrían dejar de sembrar una parte del maíz. En pocas palabras, estos campesinos no pueden enriquecerse con el mango.

b) el sembrar menos maíz es precisamente lo que hacen los fruticultores (grupo 6), que tienen según el cuadro 40 , escasas superficies de maíz propio ( 1.8 hectáreas en promedio). Estos rentan o dan a medias sus tierras de temporal a campesinos que por cultivar maiz en condiciones precarias no tendrán oportunidad de plantar más que un pequeño solar con mangos. Así se incrementa rápidamente la diferenciación social entre los campesinos del área.

c) un fenómeno paralelo sucede en Otates, donde los dueños de trapiches plantaron mucho mango últimamente. En efecto se nota en el cuadro 41 una buena complementariedad en el tiempo entre la zafra y el corte del mango; éste, menos exigente, viene en un periodo en el cual las numerosas familias cañeras están disponibles, así como algunos peones que no ocupan tres meses barbechando tierra y sembrando maíz. Hay también algunos dueños de trapiche que han preferido la opción de no cultivar mango y sembrar superficies apreciables de maíz, que se vende a los demás "trapicheros" y a comerciantes de fuera. Los que no pueden escoger son los jornaleros de la caña, que siembran maíz para su autoconsumo y no plantarán mangos con lo

4. En Otates es tal la disponibilidad de mano de obra familiar en las lluvias que se hacen hasta cuatro escardas en la caña y el maíz (la última con azadón), aumentándose así el rendimiento $\sin$ gastos suplementarios. 
que se incrementará la diferenciación social. Estos jornaleros son mucho más afectados que los agricultores de Tepenahua, quienes alternan su maíz con frijol y pueden sembrarlo más tarde en tierras de riego.

d) una expansión del cultivo del mango necesitará numerosos peones. Pero si éstos no tienen huertas por no poder cosecharlas, menos podrán ir a cosechar las de los patrones. Una consecuencia del auge del mango podría ser el separar a los jornaleros de sus cultivos de autoconsumo, en otras palabras acelerar su proletarización o hacerla más completa. Se puede imaginar una situación en la cual los peones de Tepenahua/Otates cortarían la caña en otoño-invierno y cosecharían el mango en la primavera.

En realidad, no sucede así por razones que serán detalladas más adelante. En efecto la gran mayoría de los jornaleros son los que trabajan actualmente en la zafra (incluso los de Tepenahua, aunque de manera más eventual), y éstos están involucrados en un sistema de producción colectivo en el cual están muy arraigados en su terruño; participar en el procesamiento de la caña como asalariado en Otates no es peonaje sino cooperación, y la siembra del maíz en el terruño marca la pertenencia a la comunidad. Los únicos peones de tiempo completo que se pueden concebir, son los que cortarían el mango por ejemplo, y luego harían otros trabajos en el valle. Pero de hecho, los salarios son mejores en los trapiches y la mayoría de los jornaleros siguen alternando el corte de la caña/molienda y siembra del maíz.

Esta situación - la existencia de un sistema social de producción, casi intocable en torno a los trapiches- da su máxima relevancia a la incompatibilidad mango/maíz de temporal en los sistemas individuales y por la escasez de jornaleros disponibles, limita de este modo la expansión del mango. Así, hay poderosos factores que frenan el impulso a la diferenciación social generada por la fruticultura. Esto llama la atención sobre la organización del trabajo en torno a los trapiches, lo cual será analizado a continuación.

\section{FALTAN BRAZOS EN EL CAMPO: LA PRODUCCION DE PILONCILLO}

La industria "panochera" sorprende al principio por lo atrasado y obsoleto de los procesos que maneja: usa molinos de agua o bestias, los cortadores no queman la caña, ésta se transporta a lomo de burro, el bagazo se seca a mano, no se emplea luz eléctrica para mover los jugos ni una gota de petróleo para calentar las calderas..., en pocas palabras, los trapiches emplean una cantidad enorme de mano de obra respecto al volumen de la producción 
obtenida, y tienen una bajísima productividad del trabajo.

Pero también se pueden hacer las tres observaciones siguientes, como primera justificación de la "viabilidad" del sistema:

-los trapiches no están en competencia con los ingenios porque no sacan el mismo producto, ya que en las condiciones regionales, los dos productos tienen un mercado totalmente distinto.

-los trapiches son un ejemplo perfecto de integración local de la producción, porque los campesinos son dueños de sus medios de transformación y no hay intermediarios en este primer nivel.

-en todo el occidente de México hay pocos lugares con tanta concentración de trapiches (permitido por el aislamiento de esta pequeña cuenca cañera): los campesinos de Otates tienen una posición oligopólica en el mercado regional del piloncillo. ${ }^{5}$

\section{La infraestructura productiva}

En Los Otates existen once trapiches en actividad (en el cuadro 42 se registran las características de ocho de ellos): ocho movidos por fuerza hidráulica, dos por animales y uno por máquina diesel. Para tener un panorama más completo registramos en los alrededores un trapiche en Chachalacas (poblado de El Calvario) y otro en Los Negros (municipio de Ario de Rosales) donde más bien se produce caña para venderla fresca en Pátzcuaro.

Esta concentración es probablemente igual a la que había en antiguas zonas cañeras en donde ahora trabajan los ingenios, y la permanencia de los trapiches en Otates se debe a un conjunto de factores. Los principales son que ahora esta zona está fuera del alcance del ingenio y que en un pasado reciente tampoco interesaba a los ingenios el cultivo en las pendientes pedregosas de Otates por no poder mecanizarse. En efecto, desde los años sesentas, la caña no es rentable para un ingenio si éste tiene que pagar por medio de los cañeros a numerosos peones para los procesos de cultivo y siembra. Además, Otates no tiene acceso transitable hasta las parcelas para los camiones y las máquinas cargadoras de caña, aparte de todas las dificultades que saldrían en la zafra para quemar y cortar en dichas parcelas. Esta "incomunicabilidad" hacia Tierra Caliente ha preservado en medida importante la producción del piloncillo.

Cada trapiche se abastece con determinada superficie de caña, cultivada

5. Existen puntos de venta muy lejanos en el norte: para un distribuidor de mayoreo guanajuatense, por ejemplo, tiene que poder llevar en un solo viaje grandes cantidades de piloncillo, las cuales se encontrarán en un mismo lugar de producción, solamente si existen ahí más de 2 o 3 trapiches de agua. 
CARACTERISTICAS DE LOS TRAPICHES (ZAFRA 1983-84)

\begin{tabular}{|c|c|c|c|c|c|c|c|c|}
\hline Trapiche No. & 1 & 2 & 3 & 4 & 5 & 6 & 7 & 8 \\
\hline Fuente de energía & Diesel & $\begin{array}{l}\text { Bestias } \\
(2 \times 2)\end{array}$ & $\begin{array}{l}\text { Bestias } \\
(2 \times 2)\end{array}$ & Agua & Agua & Agua & Agua & Agua \\
\hline $\begin{array}{l}\text { Capacidad (ron. pilonc./día) } \\
\text { Productividad }\end{array}$ & 0.07 & 0.18 & 0.20 & 1 & 2.2 & 1 & 0.7 & 0.8 \\
\hline $\begin{array}{l}\text { (kg. piloncillo/ton. caña) } \\
\text { Temporada de molienda } \\
\text { Tons anuales de piloncillo } \\
\text { No. de trabajadores }\end{array}$ & $\begin{array}{c}60 \\
\text { ene-mar } \\
7\end{array}$ & $\begin{array}{l}70 \\
\text { nov-mar } \\
30\end{array}$ & $\begin{array}{c}70 \\
\text { ene-mar } \\
18\end{array}$ & $\begin{array}{c}100 \\
\text { dic-mar } \\
110\end{array}$ & $\begin{array}{c}100 \\
\text { nov-abril } \\
190\end{array}$ & $\begin{array}{c}100 \\
\text { nov-mar } \\
125\end{array}$ & $\begin{array}{l}90 \\
\text { dic-marzo } \\
60\end{array}$ & $\begin{array}{c}95 \\
\text { dic-abril } \\
70\end{array}$ \\
\hline (familia y peones) & 5 & 7 & 7 & 12 & 22 & 12 & 10 & 11 \\
\hline No. de burros & 3 & 8 & 6 & $6+5$ & 17 & 13 & del arriero & 9 \\
\hline Superficie de caña propia & $1.5 \mathrm{ha}$. & $2.5 \mathrm{ha}$. & 1 ha. & $3 \mathrm{ha.}$ & $10 \mathrm{ha}$. & 5 ha. & 4 ha. & 5 ha. \\
\hline $\begin{array}{l}\text { Superficie total molida } \\
\text { Muelen 1. caña propia }\end{array}$ & 1.5 ha. & 3 ha. & 2 ha. & 10 ha. & 15 ha. & 10 ha. & 7 ha. & 8 ha. \\
\hline $\begin{array}{l}\text { 2. de los parientes } \\
\text { 3. de los peones } \\
\text { 4. de otros (maq) }\end{array}$ & 1 & 1,4 & 1,3 & 1,2 & $1,3,4$ & 1,4 & $1,2,4$ & $1,2,3$ \\
\hline $\begin{array}{l}\text { Precio de venta mayoreo } \\
\text { (promedio/kg. abril ' } 84 \text { ) }\end{array}$ & $\$ 25$ & $\$ 40$ & $\$ 45$ & $\$ 45$ & $\$ 45$ & $\$ 45$ & $\$ 40$ & $\$ 45$ \\
\hline No. de reses & 1 & 7 & 3 & 2 & 4 & 5 & 3 & - \\
\hline No. de mangos & - & 20 & - & 4 & $\begin{array}{l}100 \\
\text { rentados }\end{array}$ & 30 & 25 & 50 \\
\hline
\end{tabular}

Nota: el trapiche no. 5 ("la hacienda") tiene dos calderas. 
en las inmediaciones. Faltan datos históricos, pero hoy en día el dueño de un trapiche o "molino" muele su producción y la de sus familiares que no tienẹn molino y, con menor frecuencia, la de otros ejidatarios y de sus peones cuando éstos tienen una parcela. Así nos encontramos frente a un hecho poco común: un ejido en el cual los ejidatarios poseen sus plantas procesadoras. Esto no quiere decir que tengan un nivel de vida de "patrones". De hecho, por la falta de peones, tienen que participar en el trabajo igual que cualquiera de sus obreros. $Y$ probablemente es así desde que los dueños de los trapiches son en su mayoría ejidatarios.

\section{Procesos de trabajo}

Cada trapiche cuenta con un molino movido por agua o bestias, una infraestructura para cocer los jugos y un juego de moldes para conformar el piloncillo.

El molino se abastece con caña que traen los arrieros de las parcelas, y desspués de ser pesada esta caña pasa entre un juego de cinco cilindros movidos por el molino. El residuo sólido, o bagazo, es inmediatamente puesto bajo el sol para que se seque. El jugo de la caña ("guarapo") es almacenado en una pila donde se le agrega cal para evitar las fermentaciones. El poder almacenar el guarapo es importante porque hay días en que no se usa el molino, sobre todo cuando la capacidad de cocimiento o la disponibilidad de los trabajadores no son suficientes. De la pila se saca el guarapo para cocerlo en unos estanques de hierro, abajo de los cuales está una caldera. Estọs estanques están divididos en yariọ compartimiẹtos, unos de pre-evaporacíon y otros de cocímiento, colocados en posición diferente arriba de la caldera según la temperatura que se quiere usar. Abajo un "atizador" abastece la caldera con bagazo según las indicaciones precisas del "panochero" para obtener un fuego de determinada intensidad.

En la construcción de la mayoría de los trapiches de agua, los molinos están concebidos para abastecer dos calderas. Estas, para la comodidad de la manipulación del piloncillo y de los juegos, están abajo del plan de trabajo y abiertas hacia el occidente para ser atizadas por los vientos dominantes del invierno. Esta disposición corresponde precisamente al sentido de la pendiente en Otates (así, este lugar goza de una máxima productividad de la quema del bagazo).

En casi todos los molinos (ver cuadro 42), no existe la mano de obra suficiente para trabajar las dos calderas y, generalmente, sólo se usa una, trabajando el molino solamente tres o cuatro días a la semana ( $y$ los hombres siete días). La necesidad de mano de obra no está solamente en la fabricación del piloncillo sino también el secado y la manipulación del bagazo que es el 


\section{GRAFICA No 44: EsTRUCTURA DE UN TRAPICHE DE AGUA}

Occidente

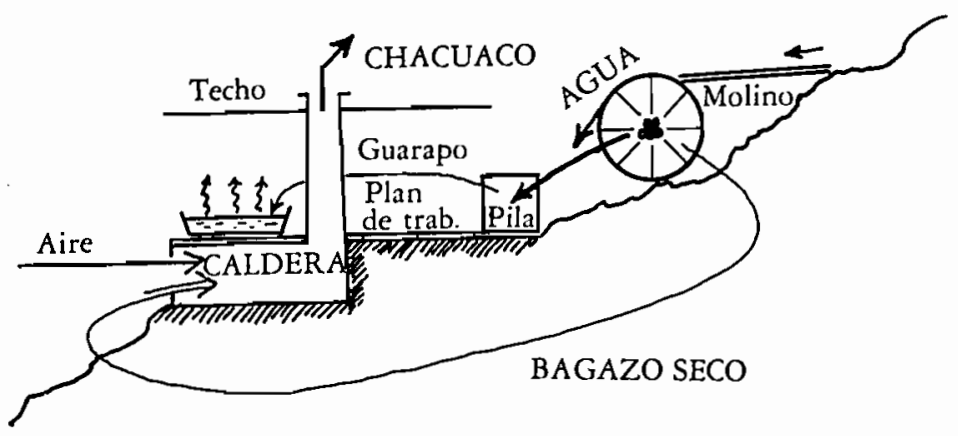

único combustible utilizado en los trapiches, aunque también se emplea un poco de leña al empezar la temporada. De hecho se requiere un atizador permanente en la caldera y tres o cuatro hombres en el área de secado del bagazo que siempre está a un lado del trapiche.

Cuando el "panochero" juzga que el cocimiento del "guarapo" llegó al punto, lo saca y lo vierte en un recipiente de madera largo y angosto, donde se bate y se refrigera el piloncillo. Luego se llenan los moldes de madera (de 200 a 500 moldes de a 10 conos en un trapiche) y cuando está todo bien enfriado, se corta el piloncillo, listo para ser empacado. En el momento de llenar los moldes y cortar, vienen los "bagaceros" a ayudar, lo que no debería ocurrir en un trapiche funcionando con un número suficiente de obreros. De hecho se estima que en un trapiche de agua de tamaño regular se necesitan doce personas en el molino y doce personas en el campo (corte y acarreo de la caña). Pero según nuestras observaciones (ver cuadro 42) se llega en realidad al promedio siguiente: cinco familiares directos, dos parientes lejanos, cinco o seis jornaleros de Otates y tres jornaleros de Tepenahua, quince personas en total; faltarían seis o siete para una correcta cobertura de las tareas y es por eso que en muchos de los trapiches sólo se usa una de las dos calderas.

A la vez, esta repartición promedio de la mano de obra nos da una idea de la importante participación de las familias extensas de los dueños de los trapiches, y nos explica que en Otates se encuentran familias enteras de peones de la caña. Estas trabajan más bien en el corte de la caña, mientras los parientes del dueño casi siempre están todos en el molino. También ahí en las parcelas se emplea mucha mano de obra, ya que la caña no se quema. De hacerlo cambiaría el color y el sabor del piloncillo. Este problema no existe en los ingenios ya que las impurezas salen en la melaza. Uno o dos trabajadores aseguran el acarreo con una tanda de burros que casi siempre 
pertenecen al dueño del trapiche. Cada viaje corresponde a la caña cosechada por un cortador, para que en el trapiche la pesen y remuneren al peón según la cantidad cortada. De hecho todos los trabajadores del trapiche son remunerados por tarea; en el molino ésta se mide por "cuarto", correspondiente al trabajo común necesario para sacar $250 \mathrm{Kg}$. de piloncillo y a la cantidad de guarapo que llena un estanque de cocimiento. En los molinos de agua de tamaño regular se sacan cuatro cuartos al día en plena estación productiva. Así, en la zafra de 83-84 se pagó la tonelada de caña cortada a $\$ 400$ (también $\$ 100$ al arriero por tonelada cargada y acarreada) y el cuarto a $\$ 200$, o sea aproximadamente $\$ 800$ diarios para la mayoría de los jornaleros, cuando el salario mínimo estaba a $\$ 550$ diarios. En la zafra $84-85$ el sueldo diario promedio oscilaba entre 1,200 y 1,500 pesos diarios: de $\$ 300$ a $\$ 450$ el cuarto, y de $\$ 500$ a $\$ 800$ la tonelada de caña cortada (de manera muy original, el jornal aumenta durante la temporada de molienda). Pero por la importante participación familiar y por la circunstancia de que, aunque no aparezca en la encuesta, muchos peones tienen sembradas pequeñas parcelas de caña, los arreglos son múltiples y variados. Así, cuando en un trapiche se muele la caña de uno de los peones, se acostumbra no pagarle su sueldo y cobrarle de 15 a $30 \%$ del piloncillo que se saca. El peón se queda con 70 a $85 \%$ del piloncillo, lo que es sumamente ventajoso si se considera que 80 a $85 \%$ del costo del piloncillo está absorbido por la transformación siendo los gastos del cultivo de la caña muy bajos.

Así se acostumbra que cuando el dueño de un trapiche muele la caña de sus familiares, se cobra con la mitad del piloncillo, y con las dos terceras partes cuando se maquila para una persona ajena a la familia.

Cuando se calcula la repartición del ingreso, en todos los casos, sobre todo cuando se trata de la caña de un peón, hay entonces un acto de solidaridad del dueño del trapiche hacia su cliente. La reciprocidad está en la participación indispensable de estas personas en la molienda.

\section{Comercialización y ganancias}

La situación oligopólica de los productores permite que el piloncillo les sea bien pagado: en 1984 , el promedio de pago en Otates era de $\$ 40 / \mathrm{Kg}$. y en 1985 oscilaba entre $\$ 80$ y $\$ 85$ lo que representó más de un $100 \%$ de aumento. Sin embargo, los productores, por falta de mano de obra, no están disponibles para llevar a cabo la comercialización, y por eso es frecuente, sobre todo para los productores importantes, que recurran a contratos de venta en los cuales aseguran a un comerciante determinado tonelaje para la temporada. Muchas veces estos contratos están asociados con préstamos del comerciante para financiar el cultivo de la caña y pagos adelantados para financiar el principio de la zafra; muchas veces los comerciantes ponen una 
condición para estos préstamos ya que tienen bajas ganancias relativas (del 40 al $80 \%$ sobre el $\mathrm{Kg}$. de piloncillo) y quieren tener la posibilidad de provocar una calda eventual de los precios del mercado sobre el productor. Pero obviamente el mercado no está saturado en las condiciones actuales. $Y$ estos contratos son muy diferentes de cualquiera "venta al tiempo"; aquí el comprador paga el producto a medida que se lo lleva y al precio normal de la temporada. Los que sufren bajos precios son los productores de muy pequeñas cantidades, que no encuentran comprador a menos que bajen sus precios o que vayan directamente a vender el piloncillo a Pátzcuaro y a lugares aún más lejanos.

En estas condiciones, hemos hecho una aproximación a las ganancias de un dueño de trapiche, tomando como referencia el promedio de los trapiches de agua, es decir moliendo diariamente diez toneladas de caña durante una temporada de $\mathbf{8 0}$ días trabajados a plena capacidad.

Haciendo el balance de estas tres formas de compartir las ganancias según su frecuencia respectiva, estimamos que moliendo cuatro cuartos al día, el dueño ganaba aproximadamente $\$ 12,000$ diarios en promedio durante la zafra de 1984 , que representaba de $\$ 800,000$ a 900,000 para todo el año ( $\$ 75,000$ mensuales). Aunque esta ganancia parece buena, en realidad hay que relativizarla porque en primer lugar corresponde a un trabajo muy duro (de sol a sol) durante cuatro meses, y porque el beneficio se ve recortado por los intereses de los créditos particulares pues se cobran las tasas de interés usuales en el comercio, y el Estado no tendría níngún interés en subsidiar la producción de piloncíllo. Sencillamente, no existen créditos públicos para la caña en Otates.

En el cuadro 43 se observa una marcada solidaridad; un cañero puede sacar casi el mismo beneficio que su pariente dueño del trapiche, cuya ganancia es baja cuando muele la cana familiar. Esto expresa un derecho muy importante que tienen los hermanos, hijos y peones del dueño sobre el trapiche; sin ellos, el molino no funcionaria, y de hecho en Otates la verdadera unidad de producción ligada a un trapiche es la familia extensa. Los trapiches que mejor funcionan tienen generalmente una diyisión del trabajo muy bien establecida entre un padre y varios hijos o sobrinos que aportan parte de los medios de producción o de los cañaverales, y que tienen cada uno un puesto clave en la zafra. Como lo enseña el cuadro 43, esta solidaridad recíproca es permitida por los altos precios pagados por el piloncillo. Más aứn, el margen bruto elevado que permite sacar la venta del piloncillo es una garantía para la sobrevivencia del sistema. En efecto, éste se ve muy amenazado por la falta de peones, y esto exige que las ganancias del piloncillo permitạn dejarles un sueldo más elevado que el salario mínimo. La participación de un campesino como peón en un trapiche siempre le es agradecida de alguna manera, por ejemplo, solamente se le cobra su ayuda al momento de molerle su caña. $O$ bien, cuando se trata de 
Cundro No 43

Utilidad de un cuarto de piloncillo en 1984

$(250 \mathrm{Kg}$. a $\$ 40 / \mathrm{Kg}$. $=\$ 10,000)$

\begin{tabular}{|l|c|r|c|} 
& $\begin{array}{r}\text { Caña del } \\
\text { dueño }\end{array}$ & $\begin{array}{r}\text { Caña de un } \\
\text { pariente (1/2) }\end{array}$ & $\begin{array}{r}\text { Caña de un } \\
\text { tercero (2/3) }\end{array}$ \\
\hline Piloncillo para el dueño & $\$ 10,000$ & $\$ 5,000$ & $\$ 6,670$ \\
\hline $\begin{array}{l}\text { Mano de obra } \\
\text { Cultivo de caña }\end{array}$ & $-3,600$ & $-3,400$ & $-3,600$ \\
Diversos & $\begin{array}{l}-900 \\
-500\end{array}$ & $-250^{3}$ & -500 \\
\hline $\begin{array}{l}\text { Ganancia del dueño } \\
\text { Ganancia del cañero }\end{array}$ & $\$ 5,000$ & $\$ 1,350$ & $\$ 2,570$ \\
\hline
\end{tabular}

1. 18 peones a $\$ 200$ (contando el trabajo de mantenimiento del molino).

2. $2.5 \%$ de los gastos para sacer 100 Ton. (1 Ha.), que equivalen a $\$ 36,000$.

3. Los hermanos o hijos participan en ciertos gastos, como el mantenimiento de los animales.

4. Trabaja de obrero en el trapiche sin cobrar sueldo.

campesinos muy desprovistos, el dueño del trapiche les presta con frecuencia un terreno "gratuito" para sembrar maíz y alimentar a su familia. Así hay varios inmigrantes en Otates, que vienen de ranchos aislados o de las tierras frías. Ahí encuentran un trabajo eventual y una parcela por la cual no se les cobra renta. Así, por ese mecanismo de solidaridad recíproca, las buenas ganancias de los dueños de los trapiches sirven, además de mantener a una numerosa familia, para fijar una numerosa población en Otates, sin lo cual todo el sistema se vendría para abajo. Es tanto más indispensable en cuanto que siempre ha existido un "tabú" respecto a los trapiches, en los cuales el trabajo no sólo es muy duro sino que es el mismo que desempeñaban en tiempos remotos los esclavos indios o negros. De hecho hay muchos jornaleros que prefieren trabajar en otros culiivos aunque ganen mucho menos, y resulta que los trapiches no solamente están 
obligados a trabajar abajo de su capacidad, sino que los dueños limitan la superficie de caña sembrada para estar seguros de poder molerla toda.

No pueden tampoco alargar la temporada de la zafra porque en abril y mayo el cauce de las zanjas que abastecen los molinos se reduce mucho. Además, habría un problema por la falta total de disponibilidad de la mano de obra para ir al campo durante el inicio de la zafra para proporcionar los cuidados a una caña que sería cortada en abril y mayo. Todo esto explica la fuerte limitación de la superficie sembrada y el desaprovechamiento de los trapiches en la primavera (ver cuadro 42). Además, hay ahora una fuerte tendencia, a que en esos dos meses, una parte de los jornaleros se vayan al corte del mango cuando no siembran maíz.

\section{Consecuencias sobre los sistemas de producción en el área}

A pesar de estas fuertes limitantes, asistimos a un fenómeno casi paradójico, permitido por el alto valor del piloncillo. ${ }^{6}$ Este valor es el que permite el mantenimiento de una actividad muy intensiva en mano de obra (una hectárea de caña necesita diez días de molienda —o sea 150 jornadas en un trapiche de agua de tamaño regular, lo que significa que una hectárea de caña mantiene a mucho más de una persona -7 mejor que el mango) y muy poco productiva (ver cuadro 44): por ejemplo en la zafra un cortador saca dos toneladas al día contra seis cuando queman la caña; el transporte de la caña no es mecanizado; la molienda permite sacar de 70 a 100 kilogramos de piloncillo por tonelada de caña mientras en los ingenios se sacan de 100 a 120 kilogramos de azúcar por tonelada; todo el cultivo de la caña es a mano con azadón...etc. (Véase el cuadro 44).

Pero esto es solamente una parte, ya que la producción de piloncillo es también muy redituable por unidad de superficie para el campesino, como lo demuestra a continuación el cuadro 45 .

Ya sabemos que según las circunstancias, esta utilidad se puede repartir de distintas maneras entre el dueño del trapiche y el dueño de la caña. Pero de todos modos es más elevada en promedio que la de cualquier otro cultivo, incluso la del mango que se situaba entre $\$ 150,000$ y $\$ 200,000$ por hectárea en 1984 .

6. Si considera mos que el piloncillo contiene un $60 \%$ de azúcar, ésto pone el valor del kilo de azúcar que sale de los trapiches a $\$ 70$ sin gastos de refinación, mientras el costo de producción del azúcar en los ingenios oscilaba en 1984 entre $\$ 20$ y 30 por kilo; esto demuestra que en el mercado se le atribuye un valor específico al piloncillo como tal.

7. Supongamos un trapiche que muele ocho hectáreas de caña con 16 personas en la temporada: se mantienen dos activos por hectárea de caña, es decir seis personas en caso de que cada activo tenga además media hectárea de maíz. 
CUADRO No 44

Comparacion del procesamiento de la CAÑa

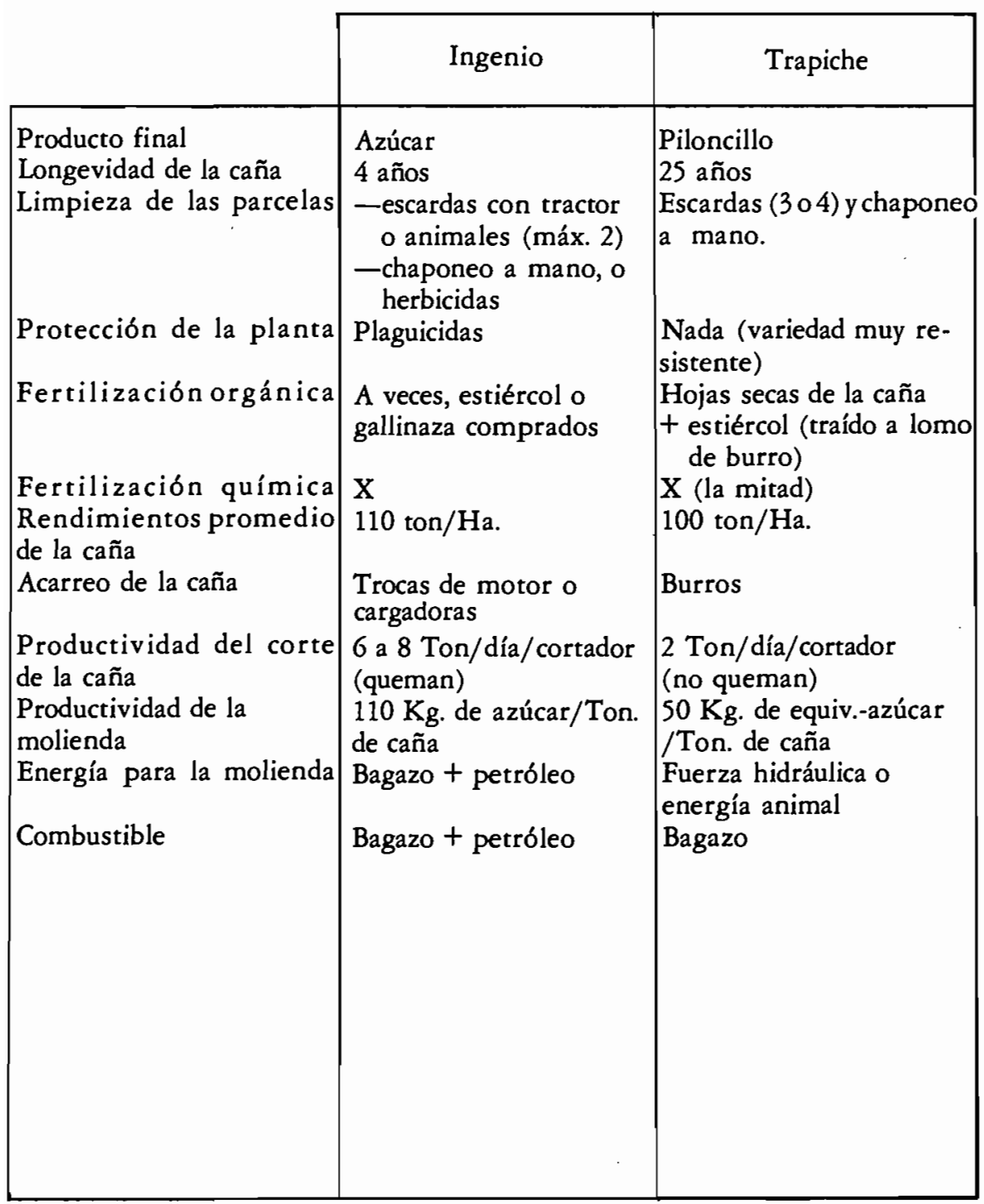

Nota: Las calderas sirven para evaporar el agua del "guarapo" después de algunos tratamientos químicos (entre ellos, agregación de cal para evitar las fermentaciones que gastan el azúcar), y sale una miel que en los trapiches sólo se enfría (se obtiene el piloncillo) y en los ingenios se centrifuga después de salir de los "tachos", para separar el azúcar de las "mieles no cristalizables" (melaza). 


\section{Cuadro No 45}

UTILIDAD DE UNA HECTAREA DE CAÑA (abril 1984)

(1 Ha. representa 100 Ton. de caña $=10$ Ton. de piloncillo $=10$ días de molienda en un trapiche de agua)

Valor del piloncillo (ingreso)

Costos del cultivo

- Lluvias: 1 peón/30 días

- Fertilizante 1 ton.

- Riegos y diversos

Total

Costos de la molienda

- 160 jornadas a $\$ 800$ en prom.

- Mantenimiento del molino (mucho trabajo familiar no pagado en las secas)

y diversos (cal, leña, bultos, mantenimiento de los burros... etc.)

Esta relación es clave para entender la dinámica de los sistemas de producción en el área: la fruticultura en esta parte de la ladera, no tomará el lugar de la caña en un futuro inmediato a pesar de los planes del Estado. En efecto los dueños (usufructuarios) de las parcelas tienen mejores utilidades así, y sobre todo hay una enorme cantidad de peones que está presionando para que los trapiches queden como fuente de empleo, mucho más interesante que las huertas de mango porque éstas no les permiten sembrar su maíz de autoconsumo en buenas condiciones. Con el piloncillo se 
desenvuelve un sistema social de producción muy bien integrado en el cual pocos campesinos podrían abandonar su papel. Más aún, los productores de maíz en Otates tienen su fuente de subsistencia en parcelas prestadas y por eso están ligados de manera imprescindible al proceso de producción del piloncillo. Pocos están dispuestos a convertirse en jornaleros permanentes y así participar en el auge del mango. Además, las estrategias campesinas de los patrones consisten en fomentar una organización que retenga a sus jornaleros. En efecto, la disponibilidad de la mano de obra es su principal limitante, mientras la cantidad de trabajo les es impuesta por la estructura de sus medios de producción. No están en la misma situación que los antiguos dueños de los trapiches, que eran capitalistas y aprovechaban la mano de obra más barata que había ya que ésta representaba el gasto más importante. Al contrario, los de ahora tienen que mantener sueldos bastante elevados, mientras sus peones, por la naturaleza polifacética de las relaciones que tienen con su patrón (que es un trabajador como ellos), están lejos de constituir un verdadero proletariado. Un síntoma muy claro de estas relaciones de producción es que ahí no hay amarradores para "encuadrillar" el corte de la caña. En casos de emergencia, sólo hay personas que se encargan de buscar peones fuera del área.

Así, el desarrollo del cultivo del mango se enfrenta a una cohesión sumamente fuerte de todos los campesinos que participan en el procesamiento de la caña. En realidad la diferenciación entre los terruños de Otates y Tepenahua se va reforzando, y si efectivamente los dueños de trapiches plantan algunos mangos en Otates, esto se verá muy limitado por el papel de actividad complementaria permitida por la menor ocupación de los cañeros que no siembran maíz, entre los meses de abril y noviembre.

Además, las posibilidades de intervención indirecta del Estado son muy limitadas: este casi no controla la producción de maíz en Otates, lo cual se expresa por el bajo porcentaje de campesinos que recurren a créditos del Banrural. En efecto, cultivar el maíz en las condiciones normales del mercado -en tierra rentada y con insumos comprados con un crédito que hay que devolver - es totalmente irredituable. En cambio, el sembrar maíz cobra sentido cuando los cañeros financian el cultivo a los campesinos pobres y prestan los trapiches para moler el maiz destinado a abastecer a todo el pueblo (con algunos problemas de combinación de tiempo el maíz a veces tiene que ser molido de noche). Pero resulta que ni el Estado ni intermediario alguno pueden comprar ahí cantidades apreciables de maíz para comercializarlo; el mismo Estado no tiene posibilidad alguna de romper el sistema, más bien, lo refuerza cerrando bodegas locales de la Conasupo en Ibérica.

Cabe señalar también las importantes ventajas de la producción de piloncillo a nivel ecológico: 
-los trapiches no queman ni una gota de petróleo;

-su sobrevivencia implica, por parte de los cañeros, una máxima preocupación por la preservación de los recursos naturales; en efecto un aprovechamiento desmedido del bosque de encino y del bosque de pinos de la parte alta del territorio tendría consecuencias irremediables sobre el cauce de las zanjas de agua que abastecen los trapiches, con el riesgo de ver los molinos atorados a cada rato por el exceso relativo de caña introducida entre los cilindros cuando la fuerza del agua disminuyera y no habría suficientes hombres para moler siete días a la semana. Actualmente, el aprovechamiento del bosque ejidal por parte de los habitantes locales se limita a la extracción de la resina; sobre los $\$ 25$ a $\$ 26 \mathrm{Kg}$. que paga la resinera de Ario a los seis o siete resineros de Otates en $1984, \$ 10$ son detenidos para "obras de interés colectivo", lo que hace de este trabajo algo poco atractivo.

-el cultivo de la caña es sumamente economizador de energía e insumos. En efecto, se planta una variedad especial (carrisilla) que no alcanza rendimientos altos pero tiene mucha resistencia a las plagas y una máxima longevidad: como no entran "trocas" y máquinas en las parcelas que opriman y asfixien el suelo, una misma plantación de caña puede durar de 25 a 30 años. Así, los gastos de cultivo, excepto la fertilización química, se reducen a algunas escardas con azadón y un chaponeo. Las hojas secas, que no se queman ahí, permanecen en el suelo después del corte de la caña y permiten así una máxima renovación de la fertilidad orgánica. Esta, a su vez, mejorando la estabilidad estructural del suelo, disminuye las necesidades de trabajo del mismo. Así se limitan al máximo el uso de energía e insumos (fertilizantes y plaguicidas), lo que es un importantísimo factor entre los que limitan las consecuencias de una baja productividad del trabajo.

Así, la producción de piloncillo tiene todos los elementos para una mínima integración del campesino en los mercados de energía, insumos y tecnología. Por eso es bajísima la intervención real del Estado en este proceso de producción, y en todo caso sólo podría tender a destruirlo. Se siente la completa originalidad de las prácticas campesinas en el sentido de que ahí cuando los campesinos hablan de la actividad cañera y de sus sistemas de producción, lo hacen con total control de su organización y una claridad rara vez alcanzada por campesinos en sus explicaciones respecto a las técnicas que utilizan, a las cantidades manejadas, al modo de combinar los recursos y a sus estrategias. Esto es la prueba de que manejan perfectamente bien su sistema de producción. En fin, hay un alto grado de "autodeterminación campesina". 


\section{EVOLUCION DEL EJIDO}

Los habitantes de Tepenahua y Otates no son representativos de todos los miembros del ejido. Ha habido fuertes procesos de diferenciación social que, acompañados o provocados por la modernización de la Tierra Caliente, han hecho "estallar" el ejido en la medida en que hoy son numerosos los ejidatarios que no radican en alguno de los cuatro pueblos. Muchas veces ya no son campesinos, como lo evidencia la frecuencia de las rentas de tierras ejidales en todo el Plan de Tierra Caliente y las características de la ganadería en Nuevo Urecho.

\section{El "ausentismo" de los ejidatarios}

Es lo primero en llamar la atención. Esto se ilustra en los resultados de nuestra encuesta; si se considera que ésta abarca un $60 \%$ de los campesinos de Tepenahua y Otates que representan a su vez un $70 \%$ de la población total del ejido, llegamos a lo siguiente.

En la encuesta resultaron 38 ejidatarios es decir un $67 \%$ de los campesinos encuestados. Serían entonces 63 entre Tepenahua y Otates y 90 en todo el ejido, mientras éste cuenta oficialmente con cerca de 200 ejidatarios. Muchos viven en la cabecera municipal, y otros viven fuera. Esto es muestra de una racionalidad socio-económica que no es solamente la de los campesinos que radican en los pueblos del área. Para esos ejidatarios, sus tierras son como un capital que les deja ganancias más o menos buenas y a menudo las rentan para emplear sus recursos en actividades más lucrativas. Así, por lo menos una tercera parte de las huertas de mango de Tepenahua están rentadas a parientes que no tienen derecho ejidal.

El otro sector en el cual invierten mucho los ejidatarios "ausentistas" es la ganadería. Por un lado, algunos ganaderos que se instalaron sobre todo en la cabecera municipal, tienen "potreros de riego" y poseen vacas lecheras. Por otro lado, los ejidatarios-ganaderos que viven en la cabecera, en Lombardía o en Uruapan se aseguraron, con su capacidad de acumular ganado, el acaparamiento de los agostaderos ejidales. Ahí hay una diferenciación muy pronunciada: estos ganaderos también se han hecho dueños de matorrales y bosques privados; poseen de 30 a 150 reses y algunos hasta 400 , mientras la mayoría de los habitantes de Tepenahua y Otates sólo tienen sus animales de trabajo. Este monopolio está, a veces, mantenido por la fuerza y son muchos los campesinos del área que solamente tienen sus parcelas en descanso para mantener su ganado; además, no pueden pagar vaqueros para cuidar hatos muy pequeños en lugares retirados.

Se puede también cuantificar el ausentismo de los ejidatarios por la 
CuAdRo No 46

Datos COMPARADOS DE LA PARTICIPACION DE CULTIVOS

EN EL EJIDO TEPENAHUA

\begin{tabular}{|c|c|c|c|c|}
\hline Cultivo & Oficial & Encuesta & $\begin{array}{l}\text { N2 de socios } \\
\text { en las nóminas } \\
\text { del Banco }\end{array}$ & $\begin{array}{c}\quad \mathrm{N} 2 \mathrm{de} \\
\text { campesinos } \\
\text { (encuesta) }\end{array}$ \\
\hline Maíz & 17 Has. & 220 Has. & 3 & 65 \\
\hline Frijol & 120 & 100 & 40 & 35 \\
\hline Arroz & 5 & 45 & 1 & 22 \\
\hline Melón & 43 & 12 & 30 & 4 \\
\hline Caña & 120 & 120 & 17 & 17 \\
\hline Mango & 210 & 60 & 70 & 40 \\
\hline
\end{tabular}

comparación entre los datos oficiales de la repartición de cultivos en el ejido (SARH) y los datos obtenidos de la encuesta. Para tener cifras comparables hicimos una extrapolación de la encuesta cuya muestra representa un $42 \%$ del total del ejido (cuadro 46).

Este cuadro nos proporciona dos informaciones: primero, cuando la cifra oficial es superior, hay cultivos como el melón, mango y frijol que en importantes proporciones son manejados por ejidatarios que no radican en ninguno de los pueblos del ejido. Así, de diez miembros del ejido Tepenahua que siembran o "hacen cultivar" melón, sólo dos viven en Tepenahua.

En segundo lugar, cuando la cifra of icial es inferior, hay cultivos que a menudo son manejados por no-ejidatarios como el arroz, el maíz y también el mango; se les rentan las huertas con importante provecho para los ejidatarios. Eșta observación es en parte sesgada por el hecho de que para estos dos cultivos los campesinos prescinden a menudo de la intervención del Banco. Pero no cabe duda, sobre todo para el maíz - que abarca grandes superficies- de que estos cultivos son trabajados sobre todo por medieros o arrendatarios, lo que se vio claramente en la encuesta.

Estamos ante una situación en la cual los ejidatarios "ausentistas" no solamente detentan los factores de producción importantes (huertas de mango, agostaderos y ganado), sino que ademas dejan a los campesinos sin tierra todas las producciones "no rentables" (maíz, arroz al voleo). Una vez más el cultivo del maíz está en pésimas condiciones como para generar 
excedentes para el mercado nacional. ${ }^{\mathrm{s}}$

En fin, las laderas de Tierra Caliente se ven como zonas pobres. En el caso del ejido Tepenahua, los habitantes están, en su mayoría, cerca de la marginación pues no hay más que ejidatarios pobres, medieros, arrendatarios de huertas, jornaleros agrícolas y cañeros que sí tienen mejores ingresos pero con una carga de trabajo que es la más elevada de todos los sectores de la producción campesina.

Estos productores, que son la parte más pobre pero todavía importante del ejido, están muy determinados por el modelo de desarrollo vigente en el Plan de Tierra Caliente; así, el mercado de semillas y las exígencias de la Conasupo les obligan a sembrar muchas variedades híbridas de maíz aunque no sea siempre lo más adecuado; solamente queda una variedad criolla de temporal: el "molonco". Pero a la vez hay poderosos factores de "resistencia" pues los maiceros casi nunca trabajan con el banco, y aprovechan al máximo la producción diversificada de frutas de solar en la cual no hay ninguna injerencia del Estado. Para estos productos los campesinos tienen un mercado tradicional (Ario de Rosales, Pátzcuaro) mucho más desarrollado que el que tendrían los habitantes del Valle. En resumen, la vertiente no tiene las mismas posibilidades que el Plan. Por ejemplo, la tierra de las laderas no conviene para sacar altos rendimientos en melón aunque en ciertos aspectos los campesinos de las laderas conservan más autonomía.

\section{Origen histórico de la integración de Tepenahua}

Pero el control más o menos estrecho del Estado sobre los cultivos comerciales y de autoçonsumo no puede explicar por sí solo la enorme diferenciación social entre los ejidatarios, ni la división del espacio en dos terruños, ni la penetración diferenciada de la fruticultura y otros cultivos comerciales, mucho más presentes en los sistemas de producçiọn del pueblo de Tepenahua.

En effecto Tepenahua fue desde muy temprano, un lugar elegido para el desenvolvimiento de la iniciativa privada a través de la industria azucarera y, por algunas casualidades, Otates fue una excepción en el proceso conținuo de concentración de la industria azucarera.

Parece cierto que en el pueblo de Tepenahua hubo trapiches igual que

8. El dueño çapitalista de la parcela puede "jinetear" el crédito de avío que le da el banco para mano de obra, en cuanto que tener a un mediero es como si se pagara a un peón toda la temporada al momento de la cosecha. Esto es interesante para el dueño si el sueldo no es excesivo, es decir con un mediero si la cosecha no rebasa las dos toneladas por hectárea. Por afa no es el inteŕ́s del dueño (ni dẹl mediero, que lo tendíla que pagar con el riesgo de una mala cosecha) echar mucho fertilizante: los ejidatarios desvían el fertilizante del banco "para maíz" hacia sus huertas. 
en Otates. Pero a principios del siglo XX ya existía en Tepenahua una hacienda azucarera que procesaba la caña en un pequeño ingenio; en ese periodo, supuestamente había una competencia entre el azúcar y el piloncillo, y por su alta productividad, el ingenio se enriqueció mucho más que los trapiches, eliminando primero los trapiches de Tepenahua.

Pero el ingenio fue más afectado por la revolución dejando de funcionar en 1915 y sus dueños no pudieron echar a andar de nuevo la producción de azúcar. Les fue mejor entregar la caña al ingenio más moderno de Taretan,? mientras acumulaban ganado en sus propiedades de las partes áridas.

Al momento del reparto de tierras (1935) se juntaron los demás campesinos de los cuatro pueblos - al lado de los diez ejidatarios que aprovecharon las nuevas infraestructuras de riego en el Valle después de los años cuarentas- para pedir cañaverales y beneficiarse de los agostaderos colectivos y así, pudieron acumular ganado rápidamente, rentando bueyes cada año a los cañeros más pequeños. Estas personas llegaron a controlar los animales de trabajo de todo el ejido, y tal vez por eso quedó Tepenahua como "cabecera" del ejido.

Es probable que muchos trapiches de Otates habían sido del mismo dueño que el del ingenio, ya que los cañaverales que los abastecían fueron expropiados - hoy, un $90 \%$ de la caña cultivada en Otates es ejidal-, y sin base territorial controlada, el dueño ya no podía procesar el piloncillo, por eso tuvo que vender los trapiches muy baratos; éstos cambiaron de manos muchas veces y fueron comprados por ejidatarios que lograban con su familia organizar la producción.

En realidad todo esto sucedió porque la caña de Otates nunca fue a abastecer al ingenio de Taretan, por la incomunicación de esta zona con el valle en una época en que se empezó a motorizar el acarreo de la caña; así se crearon las condiciones para que una parte del ejido produjera caña para el ingenio, mientras la otra molía la suya y lograba comercializar el piloncillo siendo comunicada con las zonas de arriba (Ario, Pátzcuaro).

En este punto empiezan a cobrar influencia los dos procesos de concentración de los ingenios y de "modernización" de la Tierra Caliente; a medida en que las inmediaciones de Taretan se cultivaban con caña de manera cada vez más exclusiva, el costo del transporte de la caña de Tepenahua a Taretan ${ }^{10}$ empezó a cobrar una importancia relativa, y frente a los constantes aumentos de productividad con disminución del costo de procesamiento por tonelada, esta caña - antes muy cotizada por tener la mejor concentración de azúcar en la región- se volvió muy poco competitiva por el hecho de que el costo del flete no se pudo reducir. Por

9. Al de Ibérica primero, hasta que éste úlrimo también cerró.

10. $30 \mathrm{Km}$. 
supuesto este flete se cobraba a los campesinos como descuento sobre el valor de la producción, por lo que cada día les resultaba menos rentable.

Al mismo tiempo, esto modificó el marco de la agricultura en Tepenahua: no fue tanto la promoción por el Estado de nuevas infraestructuras de riego, pues en Tepenahua todo ya estaba regado, por lo menos en la vertiente y en los caña verales del Plan, sino la apertura de un mercado local y regional con infraestructuras de procesamiento, comercialización y suministro de insumos para producciones como el frijol y el arroz entre otros. Estos cultivos tenían la enorme ventaja de poder combinarse -entre ellos o con el maíz - para hacer dos ciclos de cultivo al año sin ocupar más mano de obra que la caña, y así podían generar utilidades mucho mayores que las de la caña en decaimiento. Resultó que de 1965 en adelante toda la ladera regada en las inmediaciones del pueblo de Tepenahua dejó la caña y pasó a ser productora de maíz, frijol y arroz, mientras había sido sede de los más ricos cañaverales. Hoy en día la única parte del ejido que todavía manda caña a Taretan es la zona situada al noroeste del rancho El Mirador. Poco a poco la mano de obra liberada por la desaparición de la caña se fue empleando en el mango, que empezó a cobrar importancia en el área a partir de los años setentas.

En toda la zona afectada por esta intensificación, que acompañó el abandono de la caña, cambió el comportamiento de los ejidatarios, sobre todo frente a los cultivos que exigen muchos gastos por unidad de superficie. En el melón la productividad del trabajo es mejor cuando lo cultiva un "empresario" que agrupa cantidades importantes para venderlo a los exportadores, y esto permite al ejidatario cobrar hasta $\$ 100,000$ por hectárea rentada en 1984; también se pueden cobrar importantes rentas sobre huertas de mango trabajadas por campesinos del pueblo de Tepenahua.

Así, les resultó mejor a estos ejidatarios salir del área y vivir de sus rentas y de su ganado, desinteresándose de los asuntos del ejido. Resultaron por lo mismo transformaciones en la ganadería, la cual se ha especializado en la producción extensiva de carne para un $90 \%$ de los hatos. Para el ganado, hacen milpa los medieros de las rancherías aisladas en terreno ejidal o privado, igual que antaño, a fin de desmontar el bosque y los matorrales y dejar a los dueños potreros que tendrán buen pasto durante tres o cuatro años. A veces, los habitantes más pobres de Tepenahua, teniendo conciencia de que algunas tierras del valle pertenecen a todo el ejido cuando sus usufructuarios nunca vienen, se posesionan como "paracaidistas" de algunas tierras sembradas de melón, y se les saca con violencia. Estas relaciones dentro del ejido son la prueba de una desintegración total de las relaciones de cooperación. Estas solamente son preservadas en la zona que sigue siendo cañera (Otates) tal como lo vimos anteriormente, y también entre los habitantes de Tepenahua, solidarios alrededor del comisario ejidal para hacer una huerta colectiva. 


\section{EL AUGE DEL MANGO}

Hasta la fecha, el ejido de Ibérica - y de manera más general el valle, prolongación del plan de Tierra Caliente de Lombardía - han sido considerados como la zona más dinámica del municipio. Sin embargo, desde los años setentas hay planes del Estado para convertir toda el área regable de las laderas en zona frutícola. No es solamente el deseo del Estado sino también de numerosos agricultores de la ladera -empezando por los de la cabecera y el mismo presidente municipal - que no ven alternativa de desarrollo en la ganadería, por la presencia de un fuerte abigeato en toda la región. Este proyecto, en términos oficiales, esta siendo llevado a cabo por las dependencias agropecuarias federales (SARH y BANRURAL) y, por otra parte, por el gobierno del estado de Michoacán, que tomó a su cargo el mejoramiento de la terracería Nuevo Urecho-Ario de Rosales y tal vez su pavimentación. El acceso a las huertas no es el último objetivo de la carretera, por supuesto, pero la importancia de ésta en la agilización de la comercialización del mango es obvia.

\section{Desarrollo actual del cultivo}

En el ejido Tepenahua existen alrededor de 230 hectáreas plantadas con mango, de las cuales unas 170 están en producción. Las 230 hectáreas se pueden dividir entre:

- unas 30 hectáreaş de propiedades privadas, correspondieñtes a los solares de los campesinos donde el mango está muchas veces revuelto con otros frutales.

-unas 150 hectáreas de tierras ejidales. " Por lo menos un $40 \%$ de estas huertas están rentadas por ejidatarios "ausentistas" a campesinos de Tepenahua. Lạs rentas, cuando no se vende el derecho ejidal, giraban en la temporada 1984-1985 alrededor de $\$ 1,500$ por árbol en plena producción, o sea de $\$ 140,000$ a $\$ 180,000$ por hectárea, ${ }^{12}$ mientras las tierras del Plan se cotizaban a unos $\$ 100,000$ por hectárea en promedio, se aprecia la rapidez con la cual los ejidatarios "capitalistas" -que fomentan el cambio de producción según sus intereses- están plantando huertas de mango para rentarlas. Para enfrentar el gasto, es

11. Tamaño promedio: 80 árboles en Otates, 100 en Tepenahua.

12. Por un ingreso neto de $\$ 200,000$ a $\$ 300,000$ por hectárea antes de pagar la renta. 
muy frecuente que los arrendatarios se asocien. ${ }^{13}$

-unas 46 hectáreas constituyen una "huerta ejidal" que funciona con una cooperativa de 16 socios, financiada por el Banrural.

Esta descripción tiene que ser matizada por un panorama a nivel del municipio en su totalidad, en el cual el ejido Tepenahua solamente es un "pequeño productor" de mango. En efecto el ejido Nuevo Urecho se dedica esencialmente a este cultivo. Además, el mango existe en Nuevo Urecho desde mucho antes de que interviniera el Estado, y las huertas más antiguas se concentran alrededor de la cabecera municipal en pequeñas propiedades. El total de la superficie plantada en Nuevo Urecho-cabecera, propiedad privada y ejido, rebasa las 600 hectáreas.

Estos productores ya tenían sus redes de comercialización, que constaban por una parte de los comerciantes locales de la tierra templada (Ario, Pátzcuaro) y por otra parte de comerciantes operando a nivel nacional, de Irapuato principalmente. En 1984 se les vendió un millón de piezas provenientes de Nuevo Urecho. Con el desarrollo del cultivo llegaron otros exportadores mexicanos, que vienen de Zamora, Morelia, Irapuato y de la frontera con los Estados Unidos. Así desde 1972-73, hay 3 regiones en el occidente de México que participan en la exportación del mango: ColimaCoahuayana, Petacalco-Lázaro Cárdenas y Nuevo Urecho. La llegada de los exportadores ha transformado la repartición de las variedades cultivadas. La variedad mejorada $H e i d i$, en plantación directa o injertada, es la que tiene el mejor valor comercial y la mejor precocidad (4-5 años). Pero como es menos resistente a plagas y enfermedades que las variedades criollas (corriente, oro, manila), las cuales son más frondosas y además tienen un mejor rendimiento a dosis igual de fertilizante $(400 \mathrm{Kg}$. de fruta por árbol contra 250), el Heidi no ha logrado desplazar a todos los árboles criollos, cuya fruta es también muy apreciada en el mercado interior mexicano. De hecho, la intervención del Estado en el mango sólo se ha manifestado en aspectos de comercialización por la promoción de la variedad Heidi, destinada sobre todo a exportadores de Monterrey instalados en Lombardía.

Pero la comercialización autónoma tiene aspectos muy interesantes; en pocas palabras, la mayoría de los comerciantes vienen a Nuevo Urecho o Tepenahua con "trocas", resolviéndoles a los campesinos el difícil problema del empaque. Se llenan las "trocas" con fruta madura suelta, vendida a \$4 la pieza de diversos tamaños en 1984. Los que tienen huertas en ranchos apartados traen la fruta en costales a lomo de burro. La mayor parte de los comerciantes se llevan el mango sazón en los primeros meses de cosecha

13. Estamos en una situación opuesta a lo que pasa con otros cultivos de Tierra Caliente: ahí los ejidatarios que no pueden financiar el cultivo rentan su tierra a empresarios, los cuales se encargan del cultivo. Aquí la situación se invierte por ser el mango un cultivo muy exigente en mano de obra. 
-fines de marzo, abril y mayo-; en 1984 el precio era de $\$ 800$ la caja de 30 $\mathrm{Kg}$., lo que para el productor no representaba mucha diferencia en comparación con el otro sistema de venta.

En Nuevo Urecho el mercado del mango tiene los siguientes rasgos: primero se hacen las ventas según la oferta y la demanda, con decisiones tomadas entre comerciante y productor en el lugar mismo de la producción. Son escasos los productores que siempre tratan con el mismo comprador: si tienen tiempo, los campesinos esperan al que dará el mejor precio, mientras cada comerciante que llega al pueblo busca a los fruticultores que más están en apuros para vender su cosecha. Esta situación es muestra de que el mercado no está saturado ni siquiera en algunas semanas del año. El más seguro indicador es la indiferencia de los fruticultores cuando se les propone hacer una Unión de Productores para defender el precio, como lo hacen el presidente municipal y algunos compañeros que quieren tener una estrategia a largo plazo. Casi todos están seguros de conseguir individualmente precios más remuneradores y las ventas al tiempo de huertas en pie casi no existen.

Estas constataciones nos enseñan que de todos modos y a pesar de la intervención del Estado, el cultivo del mango tiene una dinámica de expansión muy segura en la comarca. Por las razones que hemos subrayado, esta expansión se siente más en Tepenahua que en Otates. En Tepenahua existían huertas antes de 1970 mientras en esa época sólo el dueño del trapiche La Hacienda tenía mango en Otates. De hecho lo grueso de la expansión no se hizo con el principio de la intervención estatal (1970-72) sino con el desarrollo de la exportación a partir de 1975.14 En Otates empezaron los dueños de trapiches a plantar una vez que la situación estaba bien establecida, y con las limitaciones que hemos subrayado (parte 3 ).

Lo interesante para los campesinos de Tepenahua es que el mango tiene un auge rápido pero no es un cultivo tan remunerador como para desplazar sistemáticamente a todos los frutales de solar. Al contrario, los campesinos pobres todavía tienen las ventajas de un mercado diversificado en el cual los interlocutores son gentes de igual peso económico - muchas veces parientes instalados en Ario de Rosales y Pátzcuaro- mientras que los habitantes de Tepenahua y Otates no van ellos mismos a llevar sus productos a los mercados de esas poblaciones; tales productos son guanábana, tamarindo, papaya, mamey, zapote y en menor medida plátano, guamúchil, limón, naranja y algunas frutas de tierra templada como chayote, durazno, guayaba. Además se aprovechan cultivos de riego muy intensivo en mano de obra, sobre muy pequeñas superficies: jícama y cacahuate. Cada

14. Las fechas más comunes de plantaciones recientes en Tepenabua son de 1976 a 1978 y de 1981 a 1983, según la encuesta. 
familia en Tepenahua y Otates tiene por lo menos 5 frutales en producción, que les sirven par abastecer la casa, el mercado local y el mercado regional en Ario y Pátzcuaro. El hecho de ser la parte de Tierra Caliente más accesible desde Pátzcuaro, ha permitido a Tepenahua igual que a Otates, conservar sus relaciones tradicionales con la tierra templada. A su vez estas relaciones son fuente de diversificación y seguridad para los campesinos.

\section{La huerta ejidal}

Esta huerta "colectiva" de 46 hectáreas, es el resultado local de una política que, en el sexenio de Luis Echeverría (1970-1976) buscaba aumentar la productividad del campo mediante la asociación de ejidatarios para conformar empresas agrícolas de tamaño tal que ahí se pudiera concentrar el capital en máquinas y grandes instalaciones aumentando la productividad campesina. En el ejido Tepenahua las incidencias de esta política fueron las siguientes:

-en 1971 y 1973, dos créditos para una huerta colectiva de mango con 16 socios ejidatarios, entre ellos las autoridades ejidales. ${ }^{15}$

-en 1973, un crédito refaccionario para ganado en Cháchico (noroeste del ejido). Los ejidatarios aportaron medio establo y las superficies forrajeras.

En Tepenahua, esa primera inversión constituye lo más grueso de la intervención del Estado para dinamizar el mango. Pero a la vez, esto correspondía a una preocupación real del comisario ejidal y de muchos campesinos de Tepenahua para incrementar sus ingresos, bajísimos en comparación con los de los agricultores del valle. A la vez esta huerta debía permitir un aprovechamiento más justo de los recursos locales, sacando ingresos para los campesinos que efectivamente viven y trabajan en Tepenahua, y no para los "ejidatarios ausentistas". Por esta razón, la huerta ha podido sacar ganancias gracias a la dedicación de los socios, a pesar de los siguientes problemas:

-Los socios de la huerta son de los ejidatarios que pueden financiar el cultivo pero solo del pueblo de Tepenahua. Esto se explica por qué en Otates no participaron en el proyecto en vista de que tenían otras necesidades. Sin embargo, esta situación es considerada como injusta por los campesinos de El Mirador, El Calvario y Otates, para quienes los créditos del Estado no deberían concentrarse exclusivamente en el pueblo y en el terruño de Tepenahua.

15. En la encuesta aparecieron seis socios de la huerta ejidal. Todos son ejidatarios y radican en el pueblo de Tepenahua. Casi todos tienen aparte una huerta propia. Todos hacen tareas en la huerta ejidal. 
-Supuestamente la huerta tiene la finalidad de incrementar el nivel de empleo para los campesinos de las cuatro localidades. En la práctica hay serias dificultades por los bajos salarios autorizados por el Banco hasta que se recupere la inversión en dos años más: $\$ 500$ la jornada, contra $\$ 700$ en promedio en los predios privados de mango. ${ }^{16}$ Esto es un poco humillante para ejidatarios no pertenecientes a la sociedad o jornaleros de Tepenahua, quienes supuestamente iban a sacar beneficio de la inversión. Resulta que los campesinos del ejido Tepenahua prefieren sembrar maíz y emplearse de jornaleros en la zafra, frente al trabajo en la huerta ejidal. En la encuesta sólo resultaron cinco campesinos que trabajaron ahí de jornaleros en 1984 (4 de Tepenahua y 1 de Otates), y dos de ellos iban a dejar de hacerlo en 1985, mandando mejor a sus hijos chicos por lo bajo de los sueldos. Según otros informantes, no pasaban de 12 los campesinos del ejido que iban con frecuencia a hacer tarea ahí. Esto implica para los socios tener que ir a buscar fuera la ma no de obra. De hecho, vienen a menudo jornaleros de la cabecera municipal. Sin embargo, en el periodo más cargado -agosto y septiembre, para el chaponeo- es cuando llegan sin problema los campesinos del ejido para unos días o algunas semanas, porque es cuando tienen tiempo libre después de escardar el maíz. Así, se salvaguarda el funcionamiento de la huerta por lo menos en cuanto a los cuidados que se le deben aportar.

-Los problemas más serios son los del corte ${ }^{17}$ y de la comercialización. Para sacar utilidades de la huerta, se debe tener la seguridad de que se podrá absorber la producción de 6,000 árboles Heidi y 2,000 criollos. Además faltan los cortadores en Tepenahua y el Banco ha resuel to el problema de la manera más radical: se vende toda la producción al tiempo (en pie) a un exportador de Lombardía que trae cajas y cortadores. La idea inicial del proyecto era formar junto con la huerta un centro de acopio manejado por los ejidatarios pero, por la escasa disponibilidad de la mano de obra, un poco provocada, se ha llegado a una pésima valoración del producto. Sin duda, en las condiciones actuales de escasa saturación del mercado, la comercialización hubiera sido más eficiente si se hubiera apoyado con créditos refaccionarios a campesinos individuales.

De hecho el fomento de esta huerta ha querido responder a dos problemas inexistentes en la actualidad: la organización de los productores frente al mercado y la falta de empleo para los campesinos de Tepenahua. la falta de ingresos en efectivo sí es un problema real, pero la huerta, en los términos en que está manejada actualmente, no aporta una solución

16. De hecho se paga por tarea en el corte: en $1984, \$ 200$ por millar de mangos sazones. En las huertas chicas, los jornaleros negocian el precio.

17. En la temporada del corte (abril a junio) se ocupa una persona por 15 o 20 árboles adultos o por 30 o 40 árboles jóvenes. 
adecuada. En cuanto a la comercialización la intervención del Estado no responde ahora a necesidad alguna de los campesinos. Pero es muy probable que en el futuro las estructuras que se están instalando ayuden a los campesinos a colocarse en el mercado cuando éste se vuelva más cerrado. Esto explica en gran parte la dedicación desempeñada por los socios de la huerta ejidal, con esperanzas de que aquí a dos años se puedan aumentar los ingresos. La huerta ejidal es también para los campesinos una manera de beneficiarse de una asistencia técnica muy regular y eficiente (una visita cada 15 días del técnico del Banco, coordinada con el ingeniero de la SARH).

Ahora los planes del Estado siguen en la misma línea. Se proyecta duplicar la superficie plantada con mango en las laderas de Nuevo Urecho, y el próximo financiamiento va a ser para un ejido vecino, una huerta integrada por 17 socios en el lugar llamado Santa Clara. Esta vez existirán lotes individuales de 1 a 7 hectáreas y cada campesino tendrá autonomía para la comercialización; sólo el crédito será colectivo, lo que al parecer representa una mejor adaptación de los planes del Estado a la realidad de los sistemas de producción. A la vez, se espera que con el aumento de las superficies plantadas se pueda en un futuro abastecer a una enlatadora ejidal, lo que permitiría controlar un proceso de transformación que actualmente se lleva a cabo en los Estados Unidos. Actualmente no se piensa en una obligación de abastecimiento de la enlatadora por parte de los campesinos, pero si la gestión está bien planeada esto podría conducir a una importante ventaja - cuando haya más competencia entre los campesinos en el mercado nacional - para los ejidatarios de todo el municipio.

\section{Mango y sistemas de producción}

A pesar de todo esto, el desarrollo de este cultivo tiene consecuencias sobre la diferenciación social en Tepenahua. En efecto, los ejidatarios son los únicos beneficiarios de créditos del Estado, dejando de lado a los jornaleros y pequeños propietarios. Resulta que muchos de estos últimos autofinancian su huerta, o lo hacen con la ayuda de comerciantes. Pero el acceso a las huertas se restringe así a los que tienen otros ingresos: cultivos de melón en el valle, ganado...etc.; los comerciantes sólo financian a los que por otro lado ya ofrecen garantías por la existencia de una primera huerta; en otros términos se favorecen más las a mpliaciones que las creaciones de huertas. Afortunadamente, se ha evitado con la huerta ejidal el dar créditos para mango a ejidatarios ganaderos "ausentes".

De hecho las huertas de mango no son todavía tan inaccesibles: así se nota en la encuesta que la posesión de una huerta de tamaño apreciable, arriba de 150 árboles no está necesariamente vinculada con la de otros recursos remuneradores (solo $2 / 3$ de los casos). Hasta hay jornaleros que 
con sus ganancias en los molinos han logrado plantar mango. Lo que más se podría cuestionar es lo relativo a la repartición de los recursos del Estado. En efecto, aparte de los créditos se gasta una buena parte en asistencia técnica por parte del Distrito. Obviamente las orientaciones recientes han hecho que ésta se enfoque ahora esencialmente sobre la fruticultura, y los que más se benefician son, por supuesto, los campesinos del pueblo de Tepenahua. Sin embargo, hay que matizar esta observación:

La asistencia técnica para la caña en Otates sería una aberración, ya que el proceso productivo es el mejor controlado por parte de los campesinos, y las obligaciones del técnico de Distrito lo conducen a hacer una selección dentro de los cultivos que pueden recibir asistencia; en efecto todo el verano está ocupado por los trámites y asambleas de organización del riego (en este caso entre todos los ejidos y propiedades que usan agua del mismo río en la ladera), y le queda poco tiempo para el arroz. ${ }^{18}$ En invierno se ocupa principalmente de la asistencia para el mango y el melón -que siempre tiene graves problemas de plagas y asfixia, y requiere muchas aplicaciones de químicos--, y en menor medida, del frijol. Así que el cultivo más excluido es el maíz, sobre todo el de temporal que no cumple exigencias de comercialización. En el de riego es más frecuente el uso de herbicidas y pesticidas, y son más importantes las cantidades entregadas a la Conasupo, lo que justifica un poco más la intervención del técnico. Desde este punto de vista, se puede concluir que el campesinado de Otates es el más marginado en cuanto al aporte de recursos públicos para la siembra del maíz. La reorganización de los Distritos Agropecuarios (fusión local de Programa de Incremento de la Producción Maicera, PIPMA, Distrito de Riego y Sanidad Vegetal) no cambiará mucho esta situación, que solamente mejorará para los maiceros de riego con una intervención más coordinada del Estado

En general, hay poca diferenciación entre los agricultores que han integrado el mango en sus sistemas. Todos, pequeños o grandes tienen más o menos las mismas carencias en el manejo técnico del cultivo: exceso de abono con nitrógeno más barato, lo que hace que los árboles sean más frondosos y menos fértiles, mal manejo de los insecticidas "sistemáticos", aplicados demasiado tarde y en cantidades excesivas que dañan la floración, mala absorción del fertilizante en huertas mal cajeteadas (en pendientes), etc.

Todo esto hace de la asistencia técnica una intervención no muy desigual y adaptada en este caso a las posibilidades de la agricultura local. Con la apertura de la carretera Nuevo Urecho-Dr. Silva se abrió paso no a un monopolio comercial, sino que se multiplicó el contacto de los productores con varios comerciantes en competencia. En resumen, estas intervenciones

18. Desde 1978 el Estado hace un gran esfuerzo para difundir las técnicas con trasplante. 
del Estado están fomentando al parecer un desarrollo lo más integral posible para los productores de mango. La única limitante fuerte es la falta de acceso al crédito para los campesinos más pobres y los jornaleros.

Pero no se debe olvidar que la introducción del mango genera el desplazamiento de otros cultivos. En primer lugar las huertas han tomado el lugar de los antiguos cañaverales, pero también han desplazado muchas milpas, además de perjudicar al cultivo del frijol debido a la competencia por el agua. En efecto, el mango consume en las secas mucho más agua que el frijol. Sin embargo este desplazamiento no cobra tanta importancia, por lo que todavía no cuestiona el autoabasto de los productores en granos básicos; la única consecuencia es una reducción de las ventas a la Conasupo, la cual ya cerró su bodega de Ibérica, poniendo a los productores que todavía le entregaban, en una situación peor, por el aumento del flete que ahora se les cobra. Pero esto es compatible con los planes del Estado, que busca una "especialización micro-regional" y la concentración del cultivo de los granos básicos - frijol de otoño-invierno mecanizado- en el valle.

Además, hay limitantes fuertes al desarrollo perpetuo del mango: la disponibilidad de agua en la vertiente de Tepenahua-Nuevo Urecho permite el riego de 1,300 hectáreas de mango al máximo, por 800 ya plantadas; en el valle, el Estado ha congelado las plantaciones que dan fruta de calidad muy inferior, para dejar posibilidades de expansión a los cultivos anuales. Así, las superficies plantadas solamente podrán aumentar de un 60 a $70 \%$ en total.

Habría una oportunidad de incrementar las posibilidades de expansión de las huertas: suprimir parte del cultivo de la caña. En efecto, la cantidad de agua que se usa para regar una hectárea de caña podría abastecer dos hectáreas de mango. Pero aquí el Estado se enfrenta a una cohesión total de los campesinos de Otates, frente a los cuales no tiene argumentos y no puede proponer alternativas para la numerosa mano de obra que resultaría excedente. De hecho, el Estado solamente interviene ahí para repartir los turnos del riego.

Así vemos que la cohesión que conlleva el proceso de producción que existe en torno al piloncillo tiene un doble papel en la limitación de la expansión de las huertas: controla la cantidad de agua y también la mano de obra disponible.

La existencia en la comarca de este importante factor de control y regulación espontánea impone asimismo al proyecto del Estado el no rebasar ciertos límites: por el aumento controlado de la producción regional, mantiene a los campesinos en condiciones favorables sobre el mercado (las otras regiones productoras no tienen tampoco grandes posibilidades de expansión). Además, esto permite la conservación de una densidad importante de variedades criollas de mango, e impide que éste se vuelva un monocultivo. Son condiciones necesarias para mantener un buen equilibrio 
fitosanitario, aunque esto no sea lo más interesante para hacer prosperar la industria química como pasa con el melón. La SARH quisiera difundir el uso exclusivo de variedades mejoradas y pesticidas sobre grandes superficies para realizar economías de escala, ${ }^{19}$ pero no sería ventajoso para los campesinos con pequeñas superficies y afortunadamente hay factores que lo impiden.

Por no poder encontrar suficiente agua ni suficientes peones, se limita antes que todo el crecimiento de las huertas grandes. Hay por lo mismo un freno a una diferenciación social acelerada, que ha conducido en otros sectores de la fruticultura como el aguacate, por ejemplo, a una proletarización excesiva del campesinado en los ranchos.

En fin, hay un dinamismo propio de la fruticultura en Nuevo Urecho, capaz de satisfacer las expectativas del Estado sin necesidad de que éste intervenga demasiado. $Y$ a la vez, existen por la presencia de la actividad piloncillera en la comarca, fuertes factores que limitan las ambiciones del Estado --valorizándose sobre todo la asistencia técnica promovida, más que las grandes operaciones de financiamiento- y que mantienen el auge frutícola en la forma más adecuada posible a las necesidades del conjunto de los campesinos.

19. Reducción de los costos por hectárea en una explotación por el hecho de realizar el mismo cultivo a gran escala. 


\section{CONCLUSIONES}

Contrariamente a lo que se podía esperar, la fuerte intervención del Estado en la Tierra Caliente michoacana desde hace muchos años, no ha llevado a una destrucción sistemática de los rasgos originales de los sistemas de producción existentes en las laderas de esta unidad geográfica. Si el trastorno ha sido total en las laderas secas e incomunicadas, con Nuevo Urecho, por el contrario, tenemos un ejemplo de "resistencia" de las cuencas de riego periféricas a la "modernización acelerada" promovida por el Estado que genera una diferenciación social marcada en los ejidos, en una difusión indiscriminada del cultivo del mango siguiendo ciertas normas.

El primer factor de estabilidad se encuentra en la integración regional de Nuevo Urecho y los ejidos vecinos; ahí los productos tropicales tradicionales - frutales muy diversificados - se benefician de una buena renta diferencial - accesibilidad-en la competencia que se ejerce en los mercados de Ario de Rosales y Pátzcuaro. Esta parte de la ladera no está dependiendo exclusivamente de Banrural y exportadores de Lombardía y Uruapan para su comercio, como es el caso para muchos otros lugares de Tierra Caliente. Lo es para los cultivos de exportación del Plan, pero no para el mango que tiene canales muy variados de comercialización. De Uruapan dependen la comercialización de los puercos y la obtención de pastura, pero es poca cosa, lo que permite una inserción armoniosa de los ejidos de la vertiente entre varios "polos" regionales. La pérdida de importantes superficies de caña ha desvinculado el ejido Tepenahua de otro polo regional que es Taretan pero sin precipitarlo en la dependencia de algún otro centro exclusivo. De manera más abstracta, este equilibrio se observa también en el balance de las fuentes de financiamiento para la agricultura local: las públicas se han ido para abajo; las privadas se han incrementado. En el campo esto se expresa por una diferenciación social bastante limitada entre los que se quedaron, excluyendo los procesos previos que seleccionaron a los ejidatarios "rentistas" y a los ganaderos.

Lo que ha permitido esta situación favorable a una limitación de la diferenciación en el campesinado en una a nomalía: los precios excepcionalmente altos del piloncillo que permiten la sobrevivencia de una actividad cuya productividad del trabajo es especialmente baja, y que no podría existir a la vez en muchos lugares de Michoacán. Esta situación permite el mantenimiento de una densidad de población rural excepcionalmente alta - 100 hectáreas de caña y 100 de maíz mantienen a 400 personas en Otates, o sea a 200 habitantes por $\mathrm{Km}^{2}$-, que paradójicamente están muy lejos de constituir un proletariado. En realidad los jornaleros de la caña son en primer lugar campesinos de su terruño y trabajadores muy ligados a su 
"herramienta de producción", teniendo por lo mismo estrategias de preservación de sus recursos, casi tanto como sus patrones. Ahí la visión del Estado choca, sobre todo, con la agricultura practicada por los medieros del arroz y por los campesinos que siembran exclusivamente maíz de temporal. $Y$ se puede pensar que en zonas desprovistas de caña se ejerce una marginación mucho más acelerada de este tipo de campesinos, que entonces constituyen lo grueso de los jornaleros que participan en los trabajos de los cultivos comerciales en el Plan de Tierra Caliente. Excepto en épocas restringidas de cosecha, hay en el valle una regresión de la oferta de trabajo que muy seguramente llevará a un incremento de la emigración, fenómeno reciente en Tierra Caliente, excepto en sus laderas. Las vertientes de Nuevo Urecho están todavía muy preservadas; incluso hemos observado que Otates es un sitio de inmigración. Paradójicamente, la situación es así en un lugar en el cual se registran con absoluta certeza las mínimas manifestaciones de modernización de toda la Tierra Caliente. Hecho que, si lo pensamos bien no es tan contradictorio. 


\section{ANEXO 2}

Estudio económico de dos unidades de producción en la Comunidad de Pómaro.

\section{UNIDAD DE PRODUCCION NUMERO 1}

Producto bruto

Venta de maíz + autoconsumo $3000 \mathrm{Kg} .+2580$

$$
\$ 40 / \mathrm{u}
$$

Venta cacahuates $84 \mathrm{Kg}$. \$50/u

Venta lechón para engorda $7.5 \$ 4500 / \mathrm{u}$

Venta puerco gordo 1

Venta becerros

tiene 3 vacas a medias 1.5 becerros/año

-0.75 para el dueño

-0.75 para él 0.375 becerro vendido

$0.375 \times 300 \times 200$

$\$ 120,000$

4,200

33,750

30,000

0.375 hembras vendidas o guardadas

Producto bruto (cifras redondas)

$\$ 232,000$

Capital variable

Costo monetario

Capital proporcional

Capital fijo (consumo anual de capital fijo)

Herramientas (aproximación)

Ganado (regeneración del hato, bovinos y puercos)

Capital constante

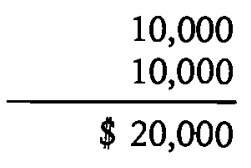

Valor agregado $=\mathrm{PB}-\mathrm{CC}$

Productividad del trabajo VA/trabajador

$\$ 212,000$

Productividad del terreno VA/Ha (27 Ha. ocupadas) 


\section{UNIDAD DE PRODUCCION NUMERO 2}

Producto bruto

Ventas maíz $10,000 \mathrm{kgs}$. $\$ 40 / \mathrm{kg}$.

$\$ 400,000$

Ventas becerros $25 \times 60,000$

1/año-vaca

$1^{\prime} 500,000$

Venta leche

aproximación 100 días $\times 351$. $\times 60$ pesos

210,000

Venta flete 1 viaje/semana

6 bestias $\$ 1000 /$ día-bestia

$52 \times 6 \times 1000$

312,000

Total $=$ producto bruto

$\$ 2 ' 422,000$

Capital variable. Mano de obra

Gasto monetario 800 jornadas x 1000 pesos

800,000

Capital constante

Capital proporcional gasto para: maíz

110,000

ganado

Total

$\begin{array}{r}50,000 \\ \hline 160,000\end{array}$

Capital fijo

$$
\begin{array}{r}
\text { cercas 10\%) } \\
\text { vacas (regeneración 20\%) } \\
\text { herramientas }
\end{array}
$$

80,000

500,000

50,000

Total

$\$ 630,000$

Valor agregado PB-CC

Productividad del trabajo VA/no trabajadores

$\$$ W 54,400

Productividad del terreno VA/ha (100 ha.)

$\$ /$ ha 16,320 


\section{CONCLUSION}

Cabe resumir ahora cuáles son las diferencias relevantes entre el desarrollo del aguacate y la expansión del mango en las condiciones descritas, abordando las características previas de los sistemas de producción y el papel de éstas dentro de los cambios analizados.

En Atapan, el aguacate no se combina con la permanencia de un autoabastecimiento en granos básicos; tampoco se combina con el calendario de trabajo de la caña. Sin embargo, logra imponerse por las extremas ganancias generadas. Sólo la existencia de otra fuente de ingresos como la recolección de la resina, permite que todavía se logre el mantenimiento de una numerosa comunidad indígena. La introducción de este cultivo tiene por lo tanto un efecto muy transformante sobre los sistemas de producción y genera una aceleración extrema de la diferenciación campesina. Los productores que quedan al margen del proceso de acumulación son quienes no tenían ganado ni caña como base de acumulación y quienes no tienen una forma de tenencia de la tierra susceptible de respaldar créditos.

Es decir, se trata básicamente de la comunidad indígena en su sentido jurídico. Aquí la capacidad de respuesta financiera es una traba al desarrollo de las fuerzas productivas en el seno de comunidades y ejidos.

En Nuevo Urecho, la evolución es muy diferente; el mango se introduce en algunos de los sistemas de producción pero en otros casi no logra penetrar por dos razones básicas: a) porque el calendario de trabajo no combina con el del maíz ya que la cosecha de mango coincide con la época de siembra del maíz, (aunque éste cultivo no ha sido eliminado tal y como sucedió en las zonas aguacateras) b) porque el mango no ha logrado desplazar al cultivo de la caña para hacer piloncillo; a pesar de que no hay competencia directa por la mano de obra sino, quizá, por el riego, la estabilidad tiene razones muy precisas: ahí el cultivo de la caña, a pesar de la bajisima productividad del trabajo en los trapiches, es el que genera el mejor ingreso por unidad de superficie y el más intensivo en términos de uso y mantenimiento de mano de obra.

Es precisamente esta mano de obra la que necesita cultivar maíz para mantenerse fuera de las épocas de zafra y, por lo mismo, no puede participar en los trabajos del mango.

Así, se observa que la elección de los cultivos en un sistema de producción responde a objetivos muy precisos que necesitan ser esclarecidos antes de elaborar proyectos; aquí, lo que cuenta es la maximización de la mano de obra mantenida por unidad de superficie. Aquí, el desarrollo no se consigue con un incremento de la productividad del trabajo.

Pero el mango se introduce en sistemas de producción que no están ligados a los trapiches; ahí sí hay una expansión fuerte por lo que este cultivo 
es a la vez el que da el mejor ingreso neto por hectárea y la mayor tasa de ganancia para el capital invertido. Sólo está frenado por la escasez de mano de obra, ocupada en la caña y es así como la presencia de los trapiches permite frenar la acumulación diferencial en la comarca en cuanto que obliga a los fruticultores a pagar salarios elevados y limita el tamaño de las huertas. Asistimos en este caso a la expansión de un cultivo exigente en capital invertido, pero con consecuencias mucho menores en términos de diferenciación campesina.

En estas cuencas frutícolas se observa que el ejido rara vez puede constituir un nivel de análisis pertinente para el entendimiento de la evolución de los sistemas de producción. En el primer caso el ejido, muy pequeño, está incluido en una red de relaciones productivas que sólo se entienden abarcando a decenas de pequeños propietarios y una comunidad indígena; en el segundo caso el ejido no tiene ninguna dinámica coherente y parece formado por varios grupos sociales, casi independientes en cuanto a la organización colectiva del trabajo; ahí por ejemplo la coherencia está en el sistema social de producción conformado alrededor de los trapiches, que constituyen dentro del ejido un nivel de organización sumamente estable. En este tipo de ejidos toda la información que salga de manera global e indiferenciada, especialmente la estadística, llevará a una incomprensión total de los procesos de evolución actuales.

Así, el ejido Tepenahua aparecerá sumamente estancado en cuanto al uso de maquinaria, insumos químicos y crédito de avío.

Sin embargo se desarrolla el mango, se incrementan los ingresos de los ejidatarios así como de los peones y se dan numerosos casos de inmigración a Otates, lugar donde las técnicas usadas son antiquísimas y la productividad del trabajo bajísima. Así se demuestra que un "desarrollo" en términos de oferta de trabajo y mejoramiento del nivel de vida, no está necesariamente ligado a una "modernización" en términos de técnicas más productivas, mayor capital invertido, etc. No parece poder lograrse un desarrollo equilibrado sin un cuidadoso detenimiento sobre cómo se ha llegado a la situación que se quiere modificar. 


\section{BIBLIOGRAFIA}

\section{OBRAS CONSULTADAS}

ANDA, Manuel de. Informe relativo a la exploración del distrito de Coalcomán, México, Secretaría de Fomento. 1983.

ARREOLAC., Raúl. Coalcomán. Monografias municipales del estadode Michoacán, Gobierno del estado de Michoacán 1980.

BARRAGAN, Esteban. Más allá de los caminos, los rancheros de la sierra, tesis de maestría, El Colegio de Michoacán, (no publicado aún). 1986.

BASALENQUE, Diego. Historia de la provincia de San Nicolás Tolentino de Michoacán del orden NPS, Agustin. Edit. Jus, México. 1963.

BELSHAW, M. La tierra y la gente de Huecario, Fondo de Cultura Económica, México. 1976.

BONNAMOUR, Jaqueline. Geographie rurale, méthodes et perspectives, Masson, Paris. 1973.

BRAND, Donald D. Coalcomán and Motines de Oro an ex-distrito of Michoacán, Mexico, The Institute of Latin American Studies, The University of Texas, Austin, Texas. 1960.

CARDENAS DE LA PEÑA, E. Tierra Caliente, porción Sureste de Michoacán, SAHOP, México. 1980.

CHEVALIER, François. "Acerca de los orígenes de la pequeña propiedad en el Occidente de México. Historia comparada", en Después de los latifundios, III Coloquio de Antropología e Historia Regionales, El Colegio de Michoacán, Zamora. 1981.

COCHET, Hubert. Historia agraria del municipio de Coquimatlán, Colima. DAAINA.PG, Universidad de Colima, 1988.

DEL CASTILLO, Ignacio M. y GUERRERO, Raúl G. En los Motines del Oro, Expedición etnográfica y lingüística, Informe. Archivo del INAH, (no publicado). 1946.

DUFUMIER, Marc. Sistema de producción y desarrollo agricola en el tercer mundo, Institut National Agronomique, Paris-Grignon, Paris. 1984. (Conferencia presentada en el Encuentro Latinoamericano de Investigación y Desarrollo Agropecuario, Estado Falcon, Venezuela).

DURAN JUAREZ, J. M., BUSTIN, A. Revolución agrícola en Tierra Caliente de Michoacán. El Colegio de Michoacán. 1983.

FIGUEROA DOMENECH, J. Guia General descriptiva de la República Mexicana. Historia, Geografía, Estadística, T. 2, Estados y Territorio Federal. 1899. 
GONZALEZ, Luis. La Querencia, SEP, Michoacán, México. 1982.

Pueblo en vilo, Tercera edición, El Colegio de México. 1979.

GUZMAN AVILA, J. N. Michoacán y la inversión extranjera 1880-1911, UMSNH, Departamento de Investigaciones Históricas, Morelia, Michoacán. 1982.

GUZMAN, E. El clima en la región de Tierra Caliente, CAETICA, INIA, SARH. 1984.

INCA RURAL. Diccionario agropecuario de México, México. 1982.

LAZAGA, Diego. Descripción del partido de Motines, Archivo General de la Nación, Ramo de Padrones (octubre 23 de 1792).

LINCK, Thierry. Le paysan dépossédé. Pouvoir technique et décision au Mexique, These de doctorat d'Etat, Centre de recherches en Développement comparé, CEDEC, (3 tomos). 1985.

"Estrategias campesinas y agropolíticas. Un caso en la Meseta Tarasca" en Relaciones. No. 9, El Colegio de Michoacán, Zamora. invierno 1981-1982.

"La mecanización de la agricultura de temporal en México. ¿Cuál sociedad elegir?" en Comercio Exterior, vol. 35, núm.2. febrero 1985.

LOPEZ LARA, Ramón. El Obispado de Michoacán en el siglo XVII. Fimax, Morelia. 1973.

MEYER, Jean. Esperando a Lozada, El Colegio de Michoacán, CONACYT. 1984.

La Cristiada 3: Los Cristeros, $7^{\circ}$ edición, Siglo XXI, México. 1985.

La Cristiada 1: La guerra de los Cristeros, $9^{\circ}$ edición, Siglo XXI, México. 1985. "Los 'Kulaki' del ejido (los años 30)" en Relaciones, No. 29, El Colegio de Michoacán, Zamora. 1987.

"La fiebre aftosa y la Unión Nacional Sinarquista (1947)" en Relaciones, No. 16, El Colegio de Michoacán, Zamora. 1983.

MORENO G., H. Después de los latifundios, El Colegio de Michoacán, Fonapas. 1982.

OCHOA S., Alvaro y SANCHEZ D., Gerardo. Relaciones $y$ memorias de la provincia de Michoacán. 1579-1581, UMSNH, Ayuntamiento de Morelia. 1985.

PEREZ ESCUTIA, Ramón A. El distrito de Maravatío. Economía y Sociedad 1910-1940. UMSNH, (en prensa), Morelia. 1987.

RAMIREZ, Santiago. Bibliografía de D. Andrés Manuel del Río, Colegio de Minería, México. 1891.

République Française: ministere des Relations Exterieures. Coopération et Développement. Memento de l'agronome, collection "Techniques rurales en Afrique". 1984.

ROMERO, José Guadalupe. El Partido de Coalcomán en 1863. Cuadernos Quahucomecos, No. 1, Testimonios S. XIX.

ROUSE, Roger. Population movements in the municipio of Aguililla Soutbwest Michoacan, from the middle of the nineteenth century to the revolution. Ponencia, Coloquio sobre Migraciones, CEMCA, Stanford University, julio 1986.

SANCHEZ DIAZ, Gerardo. El Suroeste de Michoacán. Estructura económicosocial 1821-1851, UMSNH, 1979, (tesis de licenciatura). 
El Suroeste de Michoacán. Estructura económico social 1852-1910, UNAM, 1984, (tesis de maestría).

"Movimientos campesinos en la Tierra Caliente de Michoacán. 1869-1900" en Jornadas de Historia de Occidente, No. 4, Centro de Estudios de la Revolución Mexicana "Lázaro Cárdenas", A.C., Jiquilpan, Mich. 1980, (p. 31-45).

"Reparto y resistencia en las comunidades Nahuas de la Costa de Michoacán 1869-1909" en Boletin, Centro de Estudios de la Revolución Mexicana "Lázaro Cárdenas", A.C., Jiquilpan, Mich., mayo 1982, pp. 3-11.

"Mulas, hatajos y arrieros en el Michoacán del siglo XIX" en Relaciones. No. 17, El Colegio de Michoacán, invierno 1984.

SEBILLOTE, M. Journées du Départament d'Agronomie de l'INRA, Vichy, 1982. TAVERA CASTRO, J.Huetamo, historia y geografía, Talleres Gráficos del Estado, Morelia. 1968.

VELAZQUEZ M., Emilia. Las haciendas en el Valle de los Reyes, Centro de Estudios Rurales, El Colegio de Michoacán, 1983, (no publicado).

\section{DOCUMENTOS CONSULTADOS}

Censos de Población 1921, 1930, 1940, 1950, 1960, 1970 y 1980.

Censos agrícolas y ganaderos 1930, 1940, 1950, 1960, 1970 y 1980.

SEP, Censo escolar, 1985.

Gobierno municipal de Coalcomán, Michoacán. Primer informe diciembre 14 de 1984. Segundo informe diciembre 7 de 1985.

Secretaría de Reforma Agraria. Documentos consultados en Uruapan y Morelia, Michoacán.

Administración de rentas. Propiedades registradas del municipio de Coalcomán, 20 de julio de 1978.

Asociación ganadera regional de Morelia, Michoacán, ventas de ganado del municipio de Coalcomán, Mich.

Unión Ganadera de Coalcomán: ganado registrado en el municipio de Coalcomán, Mich.

PROFORMICH. Informaciones para la unidad administrativa forestal No. 10.

Secretaría de Programación y Presupuesto: Cartas topográficas 1:250,000 y $1: 50,000$.

SPP. Representación en Huetamo. Censos Económicos Turitzio, Zicuirán, Huetamo 1983; Comunicación personal con el señor Montes de Oca, 1987.

INEGI, Anuario de estadisticas de los Estados Unidos Mexicanos 1984-1985. Anuario de Estadísticas Estatales, 1984-1985.

La Voz de Michoacán. 5 de julio de 1987.

SARH: Dirección General de Obras Hidráulicas e Ingeniería Agrícola para el Desarrollo Rural. Estudio de realización de un proyecto de irrigación en Charácuaro, Mpio. de Huetamo, Mich.

SARH: Dirección General de Estudio. Subdirección de Agrología. Datos climatólogicos.

SARH: Distrito de Temporal No. IX. Huetamo, Mich. Comunicación directa, 1987.

SARH: Representación en Cd. Altamirano, Gro. Comunicación directa, 1987. 


\section{INDICE}

INTRODUCCION

4PUNTES TEORICOS 14

jistema de cultivo y sistema de ganado $\quad 16$

$\begin{array}{ll}\text { il sistema de producción } & 17\end{array}$

iistema social de producción $\quad 20$

istema agrario 23

1 estudio dinámico de los procesos de producción 25

lerramientas metodológicas 28

NTECEDENTES Y PUNTO DE PARTIDA 29

$\begin{array}{ll}\text { as áreas estudiadas } & 31\end{array}$

RIMERA PARTE. GANADERIA Y

IFERENCIACION CAMPESINA EN EJIDOS

EMPORALEROS 35

VTRODUCCION

1 APITULO I. EMERGENCIA Y DESARROLLO EN

I N CACIQUISMO GANADERO EN EL EJIDO DE

- URITZIO 39

I ITRODUCCION: MARCOS DE ESTUDIO 39

1 "fondillo del mundo" 39

( Indiciones de la actividad humana 41

I. ISTEMA DE PRODUCCION ANTES DEL AGRARISMO 44

R Tcherías y "condueñazgo" 44

L. organización del trabajo: arrendatarios y peones 46

Bi es técnicas de los sistemas de producción 49

Ci nercio e intercambios $\quad 55$

$\begin{array}{ll}\text { Ci } \text { iclusiones } & 57\end{array}$ 
2. GANADEROS Y AGRICULTORES: DIFERENCIACION Y ACUMULACION EN EL EJIDO DE TURITZIO (1936-1960)

Creación del ejido y diferenciación social

Apertura de la economía campesina

Ganaderos - comerciantes y agricultores- braceros:

acumulación y diferenciación

La ocupación del espacio agropecuario

\section{CRECIMIENTO GANADERO Y SATURACION}

DEL SISTEMA AGRARIO (1960-1980)

Crecimiento demográfico y saturación del espacio agrario

Modificación de las condiciones macro-económicas

Evolución de los sistemas de producción

Un sistema saturado

4. ACUMULACION FORANEA Y APERTURA A UNA NUEVA DINAMICA GANADERA (1980-1987)

Se acelera el proceso de acumulación: migraciones

a EE.UU. y cultivo de la marihuana

Expresiones de la acumulación: avances en la ganaderización

del sistema agrario

¿Hacia qué tipos de estrategias?

90

Elementos de una tipología evolutiva

CONCLUSIONES: PROYECTO DE DESARROLLO Y

94

TRANSNACIONALES: ¿CUALES SON LAS ALTERNATIVAS

ANTE LA SATURACION DEL SISTEMA AGRARIO?

El Plan Ganadero del sur y la perspectiva de la apropiación definitiva de los agostaderos

Irrigación y expansión capitalista: el proyecto de Charácuaro

CAPITULO II. LA VIA LECHERA:

UNA ALTERNATIVA AL MAL DESARROLLO EN EL VALLE DE MARAVATIO

INTRODUCCION

1. EL AREA DE ESTUDIO

Ubicación

El clima

Los suelos

Población y poblamiento 
Sistemas de producción en el valle de Maravatío

a principios del siglo (1900-1935)

2. Creación de los ejidos y nueva dinámica de diferenciación (1935-1947)

3. Tecnificación de la agricultura y acentuación del fenómeno de diferenciación (1947-1970)

4. Hacia una especialización de los sistemas de producción (1970-85)

3. SISTEMAS ACTUALES DE CULTIVO Y GANADO

Sistemas de cultivo

Sistemas de ganado

4. TIPOLOGIA DE LOS SISTEMAS DE PRODUCCION

CRISTEROS

DESCRIPCION

CONCLUSIONES

Dos vías de evolución

Qué tipo de apoyo se puede dar al desarrollo lechero

CAPITULO III. FRACASA LA VIA MAICERA EN EL BAJIO SECO. AGUANUATO.

1. EVOLUCION Y DIFERENCIACION DE

LA COLECTIVIDAD AGUANUATENSE

Origen

Emigración

2. CARACTERIZACION DE LOS SISTEMAS DE PRODUCCION 170

Organización colectiva de trabajo

Sistemas de ganado

Sistemas de cultivo

Reproducción de la fertilidad

Ingresos. Papel económico de cada actividad en los

sistemas de producción

Diferenciación socio-económica

Tipología de los productores

3. MAIZ Y GANADO PARA LA PEQUEÑA PROPIEDAD 188

Especialización del terruño y factores de evolución

Tractorización

Producción de los sistemas y concentración de los recursos: una visión prospectiva

El cambio tecnológico y el crédito: intervención del Estado y "autodeterminación" campesina 
CONCLUESIONES

ANEXO 1. DATOS ESENCIALES SOBRE AGUANUATO

Y SU EJIDO

CONCLUSIONES

SEGUNDA PARTE. COLONIZACION GANADERA EN LA SIERRA MADRE DEL SUR

INTRODUCCION

CAPITULO IV. GANADERIA Y APARCERIA EN LA SIERRA DE COALCOMAN

1. ORIGEN DE POBLAMIENTO: DE LA COLONIA A 1870

2. LA FORMACION DE LOS RANCHOS EN LA SIERRA

DE COALCOMAN (1870-1920)

La colonización de la sierra

Nace la pequeña propiedad

Origen de los migrantes y acumulación

Conclusión

3. UN SISTEMA AGRARIO NUEVO (1900-1950)

El ranchà

Las relaciones sociales de producción

Revoluciones y Reforma Agraria

4. CAMBIOS Y TRANSFORMACIONES EN LA GANADERIA 245

El mercado de Pexibán se clerra

Los sementales de raza cebú y el mejoramiento sanitario

Vender animales jóvenes

La división de los potreros

La slembra de pasturas

Los cerdos: de la manteca a la carne

5. ESPECIALIZACION REGIONAL $Y$

PRODUCCION AGRICOLA

Las tierras de labor en rotación

Terrenos de riego y cañaverales

El maíz de desmonte

Amapola y marihuana

$\mathrm{La}$ industria maderera

6. LA APARCERIA EN CRISIS $\quad 267$

Los medieros escasean

Diversidad y evolución de los contratos de mediería 272 ¿Perspectivas de acumulación? 


\section{CONCLUSIONES}

Repartición de los medios de producción 275

Intensificación o extensificación

CAPITULO V. CAMPESINOS Y GANADEROS DE LA COMUNIDAD DE POMARO, MUNICIPIO DE AQUILA 281

1. RESUMEN HISTORICO 281

Origen del poblamiento y toponimia $\quad 281$

Colonización tardía y superficial $\quad 282$

Liberalismo y saqueo mercantil 282

La tenencia de la tierra a principios de los años cincuenta 285

\section{CUANDO TODAVIA HABIA POCA GENTE}

"DE RAZON" (1940-1950) 286

Terruño y organización comunitaria 286

Policultivo, ganadería y valoración de varios ecosistemas 289

El cultivo forestal: el maíz bajo raza, tumba y quema 291

Excedentes e intercambios: una débil integración al mercado

al mercado regional

3. SE REVOLUCIONA EL MODO DE APROVECHAR

BL MEDIO (1960-1985)

Caracteristicas básicas de eate cambio $\quad 296$

Significación y consecuencias

302

\section{4, SURGIMIENTO Y DESARROLLO DE LOS SISTEMAS}

DE GANADO

La ganadería bovina

La ganadería caprina

El clima: una agricultura aleatoria

Evolución de la milpa en la sierra

6. ORIGEN DEL DESARROLLO TENDENCIAL DE

Ganadería y productividad diferencial:' Estudio comparativo 
7. SISTEMAS DE PRODUCCION Y ESTRATEGIAS CAMPESINAS

Zona noroeste. El terruño de San Pedro Naranjestil

Terruño de Pómaro y sierra occidental de la comunidad

Zona costera. Terruños de Maruata y Cachán

Zona frontera con la comunidad de Coire. Sistema de producción II

Zona de los campesinos

CONCLUSIONES

CONCLUSIONES

TERCERA PARTE. DIFERENCIACION CAMPESINA

EN AREAS FRUTICOLAS

INTRODUCCION

CAPITULO VI. EL AUGE DEL AGUACATE ¿HACIA

QUE TIPO DE DESARROLLO? MUNICIPIO

DE TAPAN

INTRODUCCION

Atapan: aguacate entre bosque y caña

Atapan: tres grupos, una sola organización económica

1. EVOLUCION DEL ACCESO DE LOS DIFERENTES GRUPOS

A LOS RECURSOS DEL AREA

Sistemas de producción antes de los años cuarentas $\quad 356$

El ejido y los cambios consecuentes $\quad 358$

El auge de los mestizos

Integración de la comunidad indígena al proceso de cambio $\quad 362$

Consecuencias

Conclusiones

2. COMO EL AGUACATE AFECTA A

LAS DEMAS PRODUCCIONES

Disminución de la superficie dedicada al maíz $\quad 369$

El aguacate elimina ciertas actividades $\quad 374$

Aguacate y caña

3. EVOLUCION SOCIO-ECONOMICA INDUCIDA POR

LA EXPANSION DEL AGUACATE

El aguacate como generador de empleo

El aguacate como inversión fuerte de lenta recuperación

El aguacate rinde mucho

CONCLUSIONES

Generalización a otras zonas aguacateras 
CAPITULO VII. TRAPICHES Y HUERTAS.

EL EJIDO TEPENAHUA, MUNICIPIO

DE NUEVO URECHO

1. TIPOLOGIA DE LOS SISTEMAS DE PRODUCCION 402

La encuesta

Uso del suelo

Tipología de los sistemas de producción

2. FALTAN BRAZOS EN EL CAMPO: LA PRODUCCION

DE PILONCILLO

La infraestructura productiva

Procesos de trabajo

Comercialización y ganancias

Consecuencias sobre los sistemas de producción en el área

3. EVOLUCION DEL EJIDO

El "ausentismo" de los ejidatarios

Origen histórico de la integración de Tepenahua

4. EL AUGE DEL MANGO

Desarrollo actual del cultivo

La huerta ejidal

Mango y sistemas de producción 


\section{INDICE DE CUADROS}

Cuadro No 1 Estudio dinámico de los procesos de producción:

caso de la zona costera de Michoacán

Cuadro $N^{\circ} 2$ Calendario de trabajo agrícola y de abastecimiento en forrajes: la ocupación complementaria del espacio cultivado

Cuadro $N^{\circ} 3$ Sin título

Cuadro No 4 Trayectorias simplificadas de los diferentes grupso campesinos

Cuadro No 5 Datos climatológicos de los 10 últimos af́os (Laguna del Fresno) Medias mensuales

Cuadro No 6 Sin titulo

Cuadro No 7 Extensión de las haciendas de Casa Blanca, Sta. Elena y La Huerta 1889

Cuadro No 8 Producciones de las Haciendas de Casa Blanca, Sta. Elena y La Huerta 1889

Cuadro $N^{\circ} 9$ Rendimientos de los cultivos básicos en Maravatlo 1924-33

Cuadro $N^{0} 10$ Constitución y extensión de tierras de los ejidos de Casa Blanca, Santa Elena, Pomaro y Campo Hermoso en 1937122

Cuadro No 11 (Sin nombre)

Cuadro $N^{0} 12$ Evolución de la potencia y el número de máquinas agricolas automotrices en el ejido de Campo Hermoso

Cuadro $N^{\circ} 13$ Calendarios de trabajo y de cultivos en

el valle de Maravatio

Cuadro $N^{0} 14$ Número de bovinos registrados en el área

Cuadro $N^{0} 15$ Tipología general de las unidades de producción

Cuadro $N^{\circ} 16$ Migración estacional de la población residente en Aguanuato

Cuadro $N^{\circ} 17$ Procesos de trabajo agrícola en Aguanuato: maíz-frijol-calabaza

Cuadro $N^{o} 18$ Ingresos monetarios de una familia promedio de Aguanuato 
Cundro $N^{Q} 19$ Costo comparado por 4 hectáreas

Cuaaro \&y ?n Costo monetario/Ha. supuesto en Aguanuato en 1983196

Cuadro No $21 \mathrm{Mi}$ iz TCF análisis de costo integral de cultivo/Ha. 197

Cuadro N.2 22 Cre 'miento de los nuevos centros de poblaciór. 264

Cuadro No 23 Sín' lo 298

Cuadru $\mathrm{N}^{\circ} 24$ Sin títu, $\quad 316$

Cuadro $N^{2} 25$ Sin títul. . $\quad 316$

Cuadro $N^{\circ} 25$ Sin títulc $\quad 319$

Cuadro No 27 Sin título $\quad 320$

Cuadro $N^{2} 28$ Rentabilidad comparada de 1 a ,iil ac un de fertilizantes en dos unidades de producción de San Yedro Naranjestil 322

Cuadro $N^{2} 29$ Sin título $\quad 324$

Cuadro $N^{0} 30$ Resumen general 329

Cuadro No 31 Sin título 331

Cuadro $N^{0} 32$ Sin título $\quad 332$

Cuadro No 33 Sin título $\quad 336$

Cuadro No 34 Acceso a los recursos en Atapan 365

Cuadro $N^{2} 35$ Procesos productivos del aguacate y de la caña 378

Cuadro $N^{\circ} 36$ Sin título $\quad 382$

Cuadro No 37 Sin título $\quad 384$

Cradro No 38 Sin titulo $\quad 392$

Cuadro Ne 39 Sin tltulo $\quad 403$

Cuadro Ne 40 Tipologla de los sistemas de producción en Tepenahua-Otaces 408

Cuadro No 41 Calendarios de trabajo en Nuevo Urecho 411

Cwadro No 42 Caracterlsticas de los trapiches $\quad 416$

Cuadro No 43 Utilidad de un cuarto de piloncillo en 1984

Cuadro No 44 Comparación del procesamiento de la cafla 423

Cuadro No 45 Utilidad de una hectírea de cafa 424

Cuadro $N^{\circ} 46$ Datos comparados de la participación de cultivos en el ejido de Tepenahua 
Mapa No 1 Ubicación de los 7 estudios de caso en el estado de Michoacán

Mapa No 2 Ubicación del ejido de Turitzio

Mapa $N^{o} 3$ Ocupación del espacio agropecuario en el área de estudio antes del agrarismo

Mapa $N^{o} 4$ Comercio e intercambio en la cuenca del Balsas en los años 1930

Mapa $N^{0} 5$ El ejido de Turitztio en el marco de los antiguos latifundios

Mapa $N^{o} 6$ Ocupación del espacio agropecuario a fines de los años ' 50

Mapa $N^{Q} 7$ Actual ocupación del espacio físico en el ejido de Turitzio Mapa No 8 Ubicación del valle de Maravatío

Mapa No 9 El valle meridional de Maravatío, tierras y poblamiento Mapa No 10 Ocupación de los suelos en el ejido de Campo Hermoso Mapa $N^{0} 11$ Entorno regional de Aguanuato

Mapa $N^{0} 12 \mathrm{El}$ espacio micro regional

Mapa No 13 Ubicación de los municipios de Coalcomán y Aquila en el estado de Michoacán

Mapa $N^{Q} 14$ Carta topográfica del municipio de Coalcomán

Mapa $N^{Q} 15$ Ubicación de las haciendas, ranchos y comunidades indígenas a fines del siglo xvill en el distrito de Coalcomán

Mapa $N^{o} 16$ Origen geográfico de algunas familias de Coalcomán. Inmigración 1870-1970

Mapa $N^{o} 17$ Tenencia de la tierra y formación de los ranchos en la sierra de Coalcomán 1870-1920

Mapa $N^{o} 18$ Destino de las ventas de ganado del municipio de Coalcomán durante la primera mitad del siglo $\mathrm{xx}$

Mapa $N^{o} 19$ Destino de las ventas de ganado del municipio de Coalcomán y regiones de engorda 
Mapa $N^{2} 20$ Mapa topográfico de la comunidad de Pómaro

Mapa $N^{0} 21$ Movimientos migratorios en la comunidad de Pómaro 305

Mapa No 22 Repartición de los sistemas de producción en

la comunidad de Pómaro

Mapa No 23 Ubicación del pueblo de Atapan y franja, aguacatera 351

Mapa No $24 \mathrm{El}$ territorio aprovechado por los atapenses

353

Mapa $N^{2} 25$ Extensión del aguacate en Atapan en 1974

366

Mapa $N^{2} 26$ Uso del suelo en Atapan en 1984

367

Mapa $N^{Q} 27$ Ubicación del municipio de Nuevo Urecho

398

Mapa $N^{o} 28$ Dinámica de la población en el municipio

de Nuevo Urecho

399

Mapa $N^{o} 29$ Uso del suelo en el área

406 
Gráfica No 1 Diagramas climatológicos correspondientes a la zona de estudio

Gráfica $N^{0} 2$ Precipitaciones-evaporación en el periodo de mayores riesgos (agosto-septiembre)

Gráfica No 3 Sin título

Gráfíca No 4 Sin título

Gráfica No 5 Sin título

Gráfica $N^{0} 6$ Diagramas climatológicos

Gráfica $N^{0} 7$ Evolución de la potencia en las máquinas agrícolas en el ejido de Campo Hermoso

Gráfica No 8 Sin título

Gráfica No 9 Sin título

Gráfica $N^{0} 10$ Sin título

Gráfica $N^{0} 11$ Sin título

Gráfica $N^{0} 12$ Esquema simplificado de ocupación del espacio

Gráfica No 13 Sin título

Gráfica $N^{0} 14$ Repartición del trabajo familiar en Aguanuato

Gráfica $N^{0} 165$ hectáreas de labor bajo diversos tipos de tenencia

Gráfica No 17 La gráfica abarca unas 700 has. ejidales y los pedazos de propiedad privada...

Gráfica $N^{0} 18$ Repartición del número de vacas entre los aguanuatenses, que refleja la distribución del agostadero ejidal

Gráfica $N^{o} 19$ Repartición acumulada del ganado mayor y del aprovechamiento del agostadero ejidal

Gráfica $N^{0} 20$ Evolución de la población en los municipios de Aquila y Coalcomán (1532-1822)

Gráfica $N^{o} 21$ Evolución de la población en los municipios costeros (Coahuayana y Aquila) y templados (Coalcomán y Chinicuila) $1822-1930$ 
Gráfica $N^{2} 22$ Uso de la tierra, rotaciones y perfil topográfico de un rancho de la sierra de Coalcomán durante la primera mitad del siglo $\mathrm{XX}$

Gráfica $N^{0} 23$ Repartición de la cosecha de maíz en un rancho de la sierra de Coalcomán durante la primera mitad del siglo $\mathrm{xx}$

Gráfica $N^{0} 24$ Ventas mensuales de ganado del municipio de Coalcomán de 1981 a 1985

Gráfica $N^{0} 25$ División de potreros, rotación forestal y pastoreo en dos ranchos de la sierra de Coalcomán

Gráfica $N^{0} 26 \mathrm{El}$ maíz de desmonte en los sistemas de producción 262

Gráfica $N^{0} 27$ Evolución demográfica en el municipio

de Coalcomán entre 1930 y 1980

Gráfica $N^{o} 28$ Repartición de la propiedad en el municipio de Coalcomán

276

Gráfica $N^{\circ} 29$ Repartición del ganado en el municipio de Coalcomán 278

Gráfica $N^{0} 30$ Organización del espacio en la comunidad de Pómaro (1950)

Gráfica $N^{e} 31 \mathrm{El}$ cercado del monte: terruño de San Pedro Naranjestil

Gráfica No 32 Cercas y alambre de púas en la comunidad de Pómaro 301

Gráfica $N^{0} 33$ Formación de los pueblos de la costa 306

Gráfica $N^{2} 34$ Formas de resistencia al cercado del monte 307

Gráfica $N^{0} 35$ Sin título

309

Gráfica $N^{0} 36$ Sin título

310

Gráfica $N^{0} 37$ Sin título

311

Gráfica $N^{0} 38$ Diagrama del umbral térmico

Gráfica $N^{0} 39$ Distribución de las precipitaciones durante la estación de lluvias

Gráfica $N^{0} 40$ Ventas mensuales de maíz

en tiendas Conasupo. Pómaro

Gráfica $N^{\circ} 41$ Ubicación de la vivienda en el pueblo de Atapan 354

Gráfica $N^{0} 42$ Infraestructura hidráulica en Atapan

361

Gráfica $N^{o} 43$ Uso del suelo en Atapan

368 
Paisajes agrarios de Michoacán se terminó de imprimir el 16 de diciembre de 1989 . Se tiraron 2000 ejemplares.

\author{
Interlínea \\ diseño y fotocomposición \\ pipila 612 s.h. \\ tels. 14-92-96 \\ 14-55-99 \\ gráflca nueva \\ impresión y encuadernación \\ pipila 638 s.h. \\ tel. 13-29-74 \\ guadalàjara, jalisco, méxico
}


lo largo de sus diez abriles El Colegio de Michoacán - foco importante de la política descentralizadora de Méxicoha propiciado los estudios agrícolas regionales. Una de sus primeras publicaciones fue el libro pionero de Thierry Linck sobre la usura rural en la región potosina. Ahora vuelve el mismo autor, acompañado de una pléyade de jóvenes franceses tan entusiastas como bien provistos de herramientas intelectuales, para estudiar a fondo las transformaciones recientes de la agricultura campesina en cinco regiones de la heterogénea geografía michoacana: el Bajío, la Meseta Tarasca, los Balcones, la Tierra Caliente y la Sierra Madre del Sur. Han agrupado los frutos de su minuciosa investigación en tres partes. En la primera, se exhiben tres ejidos donde ha empezado a cundir la desigualdad. En la segunda, se enfatiza la invasión de los ganados en algunos lugares de la Sierra del Sur, y en la tercera, se dice cómo han entrado en la moda de los cultivos del aguacate y el mango las gentes de la franja meridional de la Meseia Tarasca. A todos los estudios los unifica la lucha dramática de rancheros contra campesinos. Mientras en el cine los buenos son los hombres de a caballo y pantalón ceñido, en esta obra la bondad recae en el obscuro campesinado y la villanía en los ganaderos bigotones y descoloridos. 